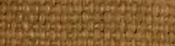

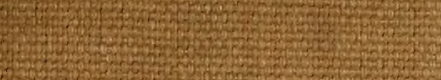

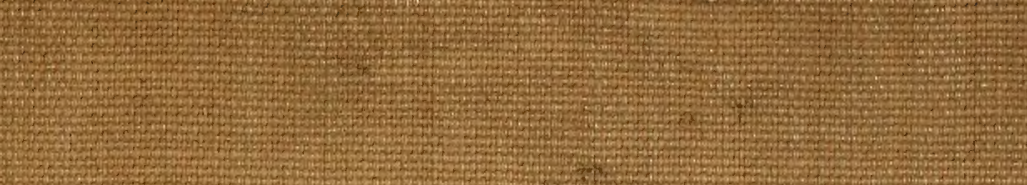

(1)

W.

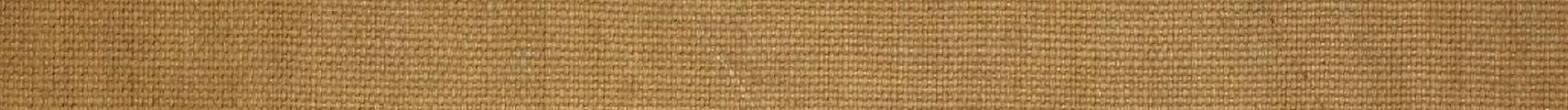

W.

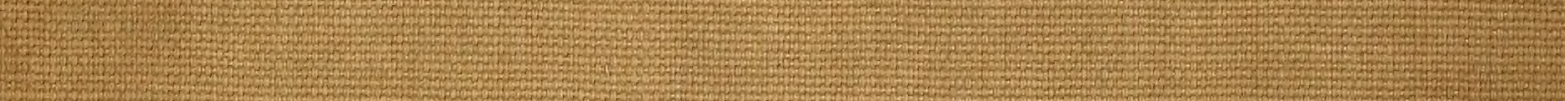

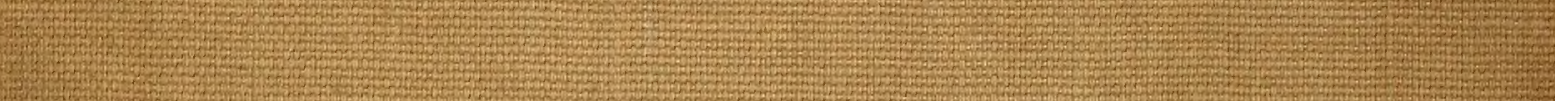

$\frac{2+2}{2+2}$

5ive

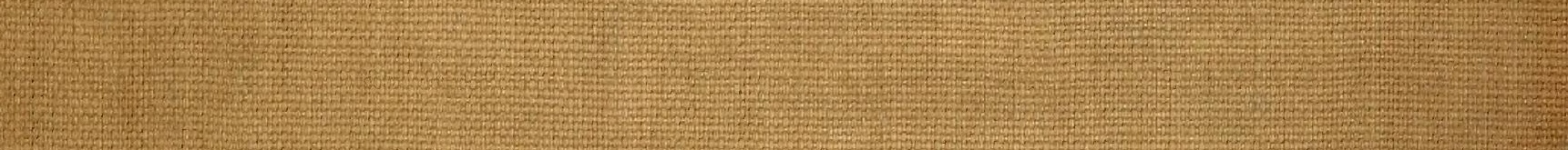

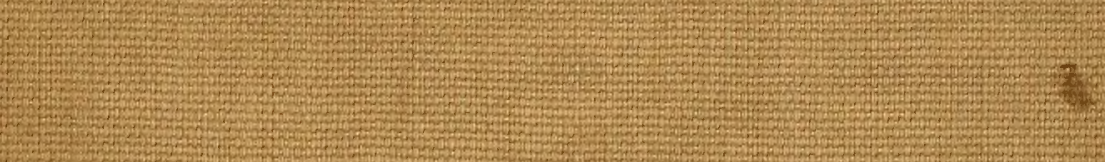

in

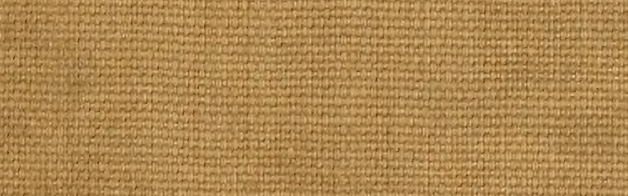

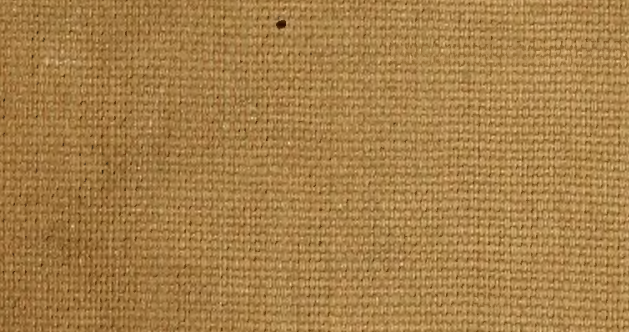

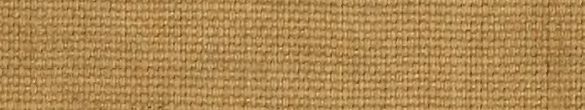

$\frac{1}{4+x+5}$

(3).

7

$\frac{4+4}{4}$

$5+25$

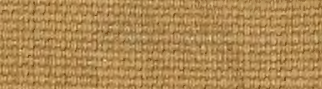

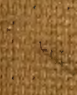

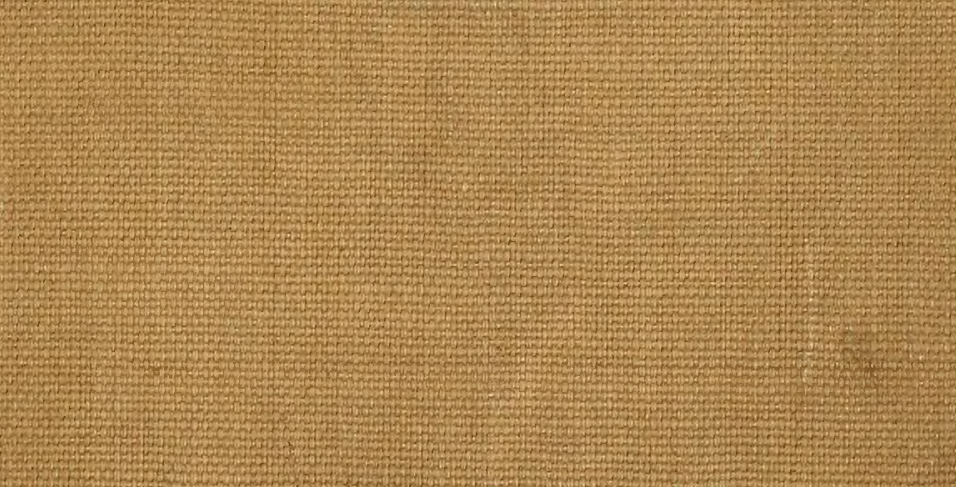

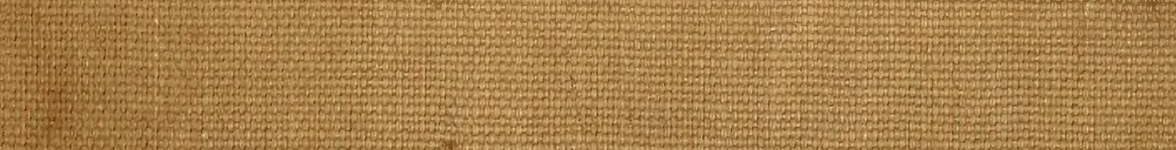

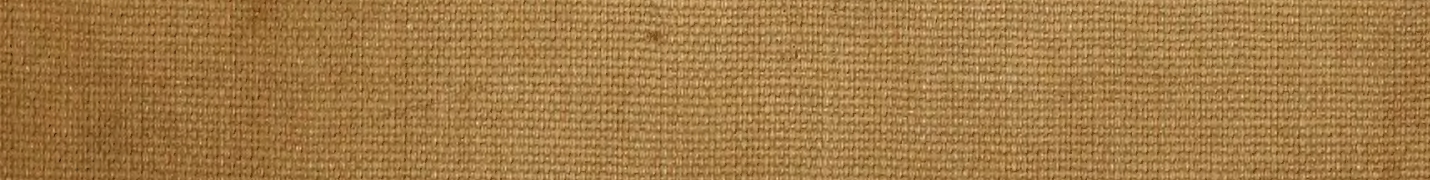

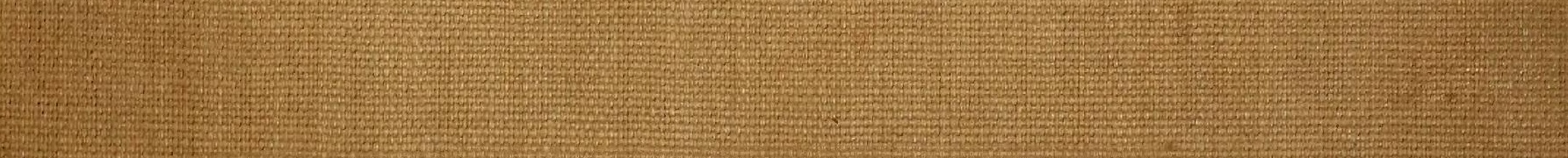

$\frac{15}{3+4}=$ 


WILSON COPEPOD LIBRARY

Smithsonian Instíution

Invertebrate Zoology

(Crustacea) 



\section{DIE MARINEN COPEPODEN:}

DER

\section{DEUTSCHEN SÜDPOLAR-EXPEDITION 1901-1903/}

II. DIE PELAGISCHEN COPEPODEN DER WESTWINDDRIFT

UND DES SÜDLICHEN EISMEERS,

MIT BESCHREIBUNG MEHRERER NEUER ARTEN AUS DEM ATLANTISCHEN OZEAN

VON

\section{Dr. R. NORRIS WOLFENDEN \\ (LONDON) *)}

MIT TAFEL XXII-XLI

UND 82 ABBILDUNGEN IM TEXT.

*) Aus dem Englischen übersetzt von E. VANHÖFFEN.

Deutsche Sudpolar-Expedition. xII. Zoologie IV., heft 4 ,

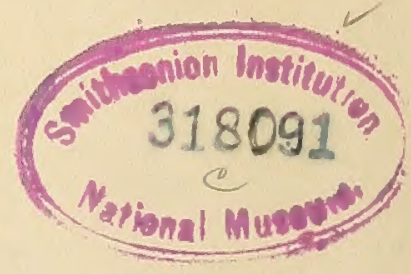

WILSON COLLSCTON

WILSON COPEPOD LIBRARY Smithsonian Institution Invertebrate Zoology. (Crustacea)

26 



\subsection{4 \\ $\cdot 1085$

Die Untersuchung der von der Deutschen Südpolar-Expedition erbeuteten Copepoden, soweit dieselben nicht bereits von Professor G. S. Brady bearbeitet sind, ergab zu diesen noch 276 Arten, von denen etwa $25 \%$ neu sind. Die letzteren wurden ausführlich beschrieben, ebenso wie einige noch nicht genügend bekannte Arten aus der Antarktis und der Atlantischen Tiefsee, während die gewöhnlichen Oberflächenformen nur mit Datum und Tiefe des Fanges erwähnt sind. Zum Vergleich wurden auch vier nicht vom „Gauss" erbeutete Arten herangezogen und eingehend beschrieben. Abgesehen von diesen vier, welche in der folgenden Liste in Klammern ( ) aufgeführt werden, bestand die Ausbeute des „Gauss" aus folgenden Arten:

1. Calanus propinquus BRADY ................. Antarktis.

2. Calanus acutus, Giesbrecht ............... Antarktis.

3. Calanus simillimus GIE SBRECHT ............. Antarktis.

4. Calanus gracilis DANA.................. Atlantischer Ozean.

5. Calanus robustior GIESBReCHT .............. Atlantischer Ozean.

6. Calanus vulgaris DANA ................. Atlantischer Ozean.

7. Calanus darwini LuвbоcK .................. Atlantischer Ozean.

8. Calanus minor Claus .................... Atlantischer Ozean.

9. Calanus pauper GIE SBRECHT ............... Atlantischer Ozean.

10. Calanus brevicornis LuBBock ............... Atlantischer Ozean.

11. Rhincalanus grandis GIE SBRECHT ............. Antarktis.

12. Rhincalanus nasutus GiesbRecht ............ Atlantischer Ozean.

13. Rhincalanus cornutus DANA ................ Atlantischer Ozean.

14. Megacalanus princeps n. g. n. sp.............. Atlantischer Ozean und Antarktis.

15. Bathycalanus maximus n. sp................ Atlantischer Ozean.

16. Bathycalanus richardi SARS................ Atlantischer Ozean.

17. Heterocalanus medius n. g. n. sp. ............ Atlantischer Ozean.

18. Mecynocera clausi J. С. Тномрsоn ............ Atlantischer Ozean.

19. Paracalanus aculeatus GIESBRecht ............. Atlantischer Ozean.

20. Clausocalanus arcuicornis DANA .............. Atlantischer Ozean und Antarktis.

21. Clausocalanus furcatus G. S. Brady ............ Atlantischer Ozean.

22. Ctenocalanus vanus GIESBRECHT ............. Atlantischer Ozean und Antarktis.

23. Calocalanus plumulosus CALUS .............. Atlantischer Ozean.

24. Calocalanus pavo DaNA ................... Atlantischer Ozean.

25. Eucalanus attenuatus DANA ................. Atlantischer Ozean. 
26. Eucalanus elongatus DANA ........ Atlantischer Ozean.

27. Eucalanus mucronatus GIESBRECHT . A Atlantischer Ozean.

28. Eucalanus monachus GIESBREcHT ... Atlantischer Ozean.

29. Eucalanus pileatus GiesBREсHт ..... Atlantischer Ozean.

30. Eucalanus subtenuis GIESBRECHT.... Atlantischer Ozean.

31. Eucalanus subcrassus ............ Atlantischer Ozean.

32. Acrocalanus gracilis GIESBRECHT .... Indischer Ozean.

33. Stephus longipes GIESBRecht ...... Antarktis.

34. Stephus antarcticum WoLFENDEN .... Antarktis.

35. Stephus neptuni Cheve........... Antarktis.

36. Aetidius armatus BoEck .......... Atlantischer Ozean.

37. Aetidius giesbrechti Cleve ......... Atlantischer, Indischer Ozean, Westwinddrift.

38. Bradyidius armatus GIESBRECHT .... Antarktis.

39. Chiridius polaris n. sp. .......... Antarktis.

40. Chiridius poppei Giesbrecht....... Atlantischer Ozean.

41. Faroella antarctica WoLFENDEN .... Antarktis.

42. Faroélla minor n. sp. . . . . . . A Antarktis.

43. Spinocalanus horridus n. sp........ Atlantischer Ozean.

44. Spinocalanus magnus WoLFENDEN . Antarktis.

45. Spinocalanus antarcticus n. sp...... Antarktis.

46. Spinocalanus abyssalis GIESBRECHT . Antarktis.

47. Hypsicalanus gracilis n. g. n. sp..... Atlantischer Ozean.

48. Oxycalanus gracitis n. sp.......... Atlantischer Ozean.

49. Gaidius tenuispinus SARS ......... Atlantischer Ozean und Antarktis.

50. Mesogaidius intermedius n. g. n. sp. . Atlantischer Ozean und Antarktis.

51. Mesogaidius maximus n. sp........ Atlantischer Ozean.

52. Gaetanus divergens n. sp.......... Atlantischer Ozean.

53. Gaetanus brevicaudatus n., sp. ....... Atlantischer Ozean.

54. Gaetanus recticornis n. sp......... Atlantischer Ozean.

55. Gaetanus antarcticus WoLFENDEN.... Antarktis.

56. Gaetanus pileatus FARraN......... Atlantischer Ozean.

57. Gaetanus major WoLFENDEN........ Atlantischer Ozean.

58. Gaetanus miles GresbrechT ........ Atlantischer Ozean.

59. Gaetanus rectus n. sp. .......... Atlantischer Ozean.

60. Gaetanus holti FARRAN .......... Atlantischer Ozean.

61. Gaetanus minor FARRAN .......... Atlantischer Ozean.

62. Euchirella spinosa n. sp........... Atlantischer Ozean.

63. Euchirella rostrata CLAUs ......... Atlantischer Ozean.

64. Euchirella rostromagna n. sp. ....... Antarktis.

65. Euchirella carinata WoLFENDEN .... Atlantischer Ozean.

66. Euchirella curticauda GIEsBREснт... Atlantischer Ozean. 


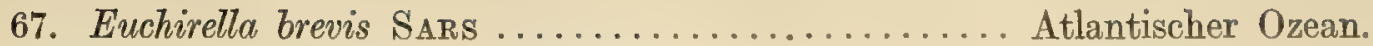

68. Euchirella messinensis GIESBRECHT ............ Atlantischer Ozean.

69. Euchirella gracilis n. sp. ................. Atlantischer Ozean.

70. Euchirella simitis n. sp. ......................

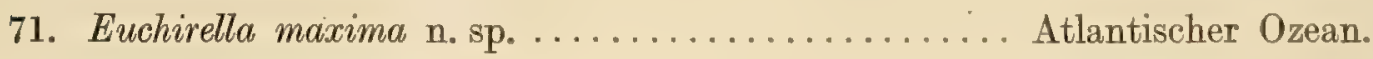

72. Euchirella elongata n. sp................. Antarktis.

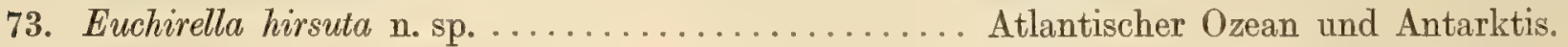

74. Euchirella pulchra LuBBock ................ Atlantischer Ozean.

75. Euchirella galatea GIESBRECHT ............. Atlantischer Ozean.

76. Chirundina streetsi GIESBRECHT .............. Atlantischer Ozean.

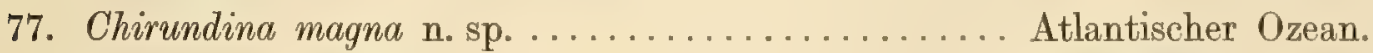

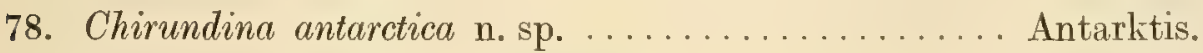

79. Undeuchaeta major GiesBrecht ............ Atlantischer Ozean.

80. Undeuchaeta minor GIESBRECHT ............. Atlantischer Ozean.

81. Mesundeuchaeta asymmetrica n. g. n. sp.......... Atlantischer Ozean.

82. Drepanopsis frigidus n. g. n. sp.,.............. Atlantischer Ozean und Antarktis.

83. Valdiviella oligarthra STEUER .............. Atlantischer Ozean.

84. Valdiviella insignis FARRAN.............. Atlantischer Ozean.

85. Valdiviella brevicornis SARS .................. Atlantischer Ozean.

86. Valdiviella minor $\mathrm{n} . \mathrm{sp} . . . \ldots \ldots \ldots \ldots$ Atlantischer Ozean.

87. Scolecithrix abyssalis GIESBRECHT ............ Atlantischer und Indischer Ozean.

88. Scolecithrix scotti GIESBRECHT .............. Atlantischer Ozean.

89. Scolecithrix danae LuBBock ................ Atlantischer und Indischer Ozean.

90. Scolecithrix bradyi GIESBRECHT ............. Atlantischer Ozean.

91. Scolecithrix persecans GIESBRECHT............. Atlantischer Ozean.

92. Scolecithrix glacialis GIESBRECHT............. Antarktis.

93. Scolecithrix polaris n. sp. ................ Antarktis.

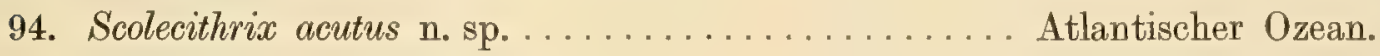

95. Scolecithrix aequalis n. sp..................... Atlantischer Ozean.

96. Scolecithrix medius n. sp. ................ Atlantischer Ozean.

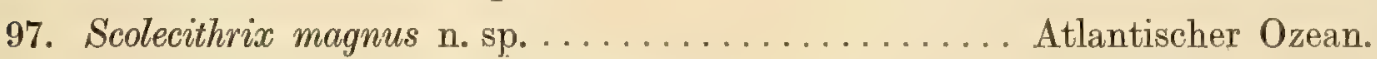

98. Racovitzanus antarcticus GIESBRECHT ........... Antarktis.

99. Amallophora magna Scotт ................. Atlantischer Ozean und Antarktis.

100. Amallophora subbrevicornis n. sp............. Antarktis.

101. Amallophora impar n. sp. ................. Antarktis.

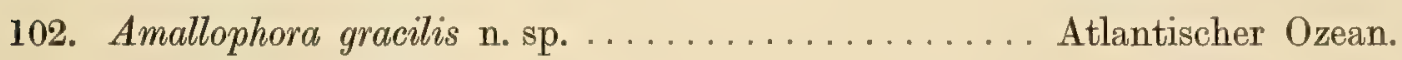

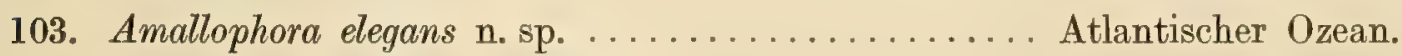

104. Lophothrix frontalis GIESBRECHT .............. Atlantischer Ozean.

105. Lophothrix securitrons M. Sсотт .............. Atlantischer Ozean.

106. Lophothrix simplex n. sp................... Atlantischer Ozean.

107. Lophothrix similis $\mathrm{n} . \mathrm{sp} . \ldots \ldots \ldots \ldots \ldots \ldots$ Atlantischer Ozean. 
108. Lophothrix quadrispinosa n. sp............... Atlantischer Ozean.

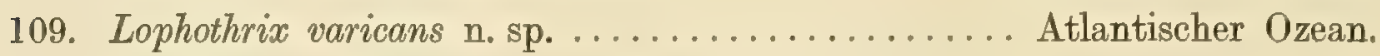

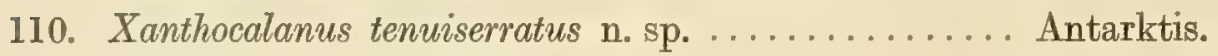

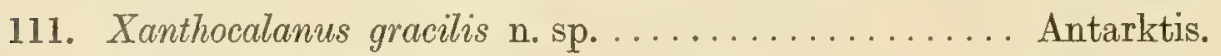

112. Onchocalanus magnus WoLFENDEN ............. Antarktis.

113. Onchocalanus frigidus n. sp.................. Antarktis.

(114. Onchocalanus cristatus WoLfENDEN ............ Atlantischer Ozean.)

115. Onchocalanus subcristatus n. sp.............. Atlantischer Ozean.

(116. Talacalanus calaminus WoLfEnden ............ Atlantischer Ozean.)

117. Cornucalanus magnus n. sp................ Atlantischer Ozean.

118. Cornucalanus chelifer I. C. Тномеsом ........... Atlantischer Ozean und Antarktis.

119. Cephalophanes frigidus n. sp............... Antarktis.

120. Phaenna spinifera Claus ................. Atlantischer und Indischer Ozean.

121. Microcalanus pusillus SARS .................. Antarktis.

122. Metridia gerlachei GIESBRECHT ............. Antarktis.

123. Metridia curticauda GIESBRecht.............. Atlantischer Ozean und Antarktis.

124. Metridia normani GIESBRECHT ............ Atlantischer Ozean.

125. Metridia princeps GIESBRECHT ............... Atlantischer Ozean und Antarktis.

126. Pleuromamma abdominalis LuBbock............ Atlantischer Ozean.

127. Pleuromamma gracilis Claus ............. Atlantischer Ozean.

128. Pleuromamma xiphias GIESBRECHT ............. Atlantischer Ozean.

129. Pleuromamma quadrangulata $\mathrm{D}_{\mathrm{AHL}} \ldots \ldots \ldots \ldots$........ Atlantischer Ozean.

130. Gaussia scotti WoLFENDEN ................. Atlantischer Ozean.

131. Chiridiella atlantica n. sp................. Atlantischer Ozean.

132. Euchata antarctica GIESBRECHT .............. Antarktis.

133. Euchaeta austrina GIESBRECHT . . . . . . . . . . Antarktis.

134. Euchaeta similis WoLFENDEN ............... Antarktis.

135. Euchaeta quadrata FARRAN ............... Atlantischer Ozean.

136. Euchaeta tonsa GIESBRECHT .............. Atlantischer Ozean.

137. Euchaeta spinosa GiesBrecht.............. Atlantischer Ozean.

138. Euchaeta marina Prestandrea.............. Atlantischer und Indischer Ozean.

139. Euchaeta acuta GIESBReCHT ................ Atlantischer Ozean.

140. Euchaeta concinna DANA ................... Atlantischer und Indischer Ozean.

141. Euchaeta grandiremis GIESBREcHT ............ Atlantischer Ozean.

142. Euchaeta robusta n. sp.................. Atlantischer Ozean.

143. Euchata exigua n. sp.................... Atlantischer Ozean.

144. Euchaeta scotti FARRAN .................... Atlantischer Ozean.

145. Heterorhabdus longicornis GIESBRECHT .......... Atlantischer Ozean.

146. Heterorhabdus spinifrons CLAUS ............. Atlantischer Ozean.

147. Heterorhabdus papilliger Claus ............... Atlantischer Ozean.

148. Heterorhabdus brevicornis DAHL.............. Atlantischer Ozean. 
149. Heterorhabdus clausi GIESBRecht...... Atlantischer Ozean.

150. Heterorhabdus tropicus $\mathrm{DAHL}_{\mathrm{AH}} . . . . .$. Atlantischer Ozean.

151. Heterorhabdus vipera GIESBRECHT ...... Atlantischer Ozean.

152. Heterorhabdus abyssalis GIESBRE'HT .... Atlantischer und Indischer Ozean.

153. Alloiorhabdus austrinus GIESBRECHT .... Antarktis.

154. Alloiorhabdus medius n. sp. .......... Antarktis und Indischer Ozean.

(155. Hemirhabdus grimaldii RicHARD ........ Atlantischer Ozean.)

156. Hemirhabdus falciformis $\mathrm{n} . \mathrm{sp} . . . . .$. Atlantischer Ozean.

(157. Mesorhabdus brevicaudatus WoLFENDEN . Atlantischer Ozean.)

158. Disseta atlantica n. sp............ Atlantischer Ozean.

159. Lucicutia grandis WoLFENDEN ......... Atlantischer Ozean und Antarktis.

160. Lucicutia magna n. sp. ............ Atlantischer Ozean und Antarktis.

161. Lucicutia major $\mathrm{n} . \mathrm{sp} . \ldots \ldots \ldots \ldots$ Atlantischer Ozean.

162. Lucicutia maxima SteUeR .......... Atlantischer Ozean.

163. Lucicutia ovalis n. sp. ............. Atlantischer Ozean.

164. Lucicutia frigida n. sp. ............ Antarktis.

165. Lucicutia bicornuta n. sp. .......... Atlantischer Ozean.

166. Lucicutia flavicornis GIESBRECHT....... Atlantischer und Indischer Ozean.

167. Lucicutia longiserrata GIE SBRECHT...... Atlantischer Ozean.

168. Lucicutia longicornis GIESBRECHT ...... Atlantischer Ozean.

169. Haloptilus longicornis CLAUS,......... Atlantischer, Indischer Ozean, Antarktis.

170. Haloptilus ornatus GIESBRECHT ........ Atlantischer Ozean.

171. Haloptilus plumosus CuAUs ......... Atlantischer Ozean.

172. Haloptilus spinipes GIESBRECHT....... Atlantischer Ozean.

173. Haloptilus chierchiae GIESBRECHT ...... Atlantischer Ozean.

174. Haloptilus oxycephalus GIEsBrecht .... Indischer Ozean.

175. Haloptilus ocellatus WoLfENDEN ....... Antarktis.

176. Haloptilus major n. sp............. Atlantischer Ozean.

177. Pseudhaloptilus longimanus n. sp...... Atlantischer Ozean.

178. Phyllopus helgae Farran .......... Atlantischer Ozean.

179. Phyllopus impar FARRAN .......... Atlantischer Ozean.

180. Arietellus setosus Gie SBRECHT ........ Atlantischer Ozean.

181. Arietellus armatus.n. sp............ Atlantischer Ozean.

182. Arietellus minor $\mathrm{n} . \mathrm{sp} . . . \ldots \ldots \ldots$ Atlantischer Ozean.

183. Arietellus simplex SARS ........... Atlantischer Ozean.

184. Augaptilus cornutus n. sp............ Antarktis.

185. Augaptilus antarcticus $\mathrm{n}$. sp........... Antarktis.

186. Augaptilus fungiferus (?) STEUER...... Atlantischer Ozean.

187. Augaptilus gibbus WolFENDEN ........ Atlantischer Ozean.

188. Augaptilus cucullatus SARS.......... Atlantischer Ozean.

189. Augaptilus megalurus GiesBrecHT ..... Atlantischer Ozean. 
190. Augaptilus hecticus GIESBRECHT ............. Atlantischer Ozean.

191. Augaptilus palumboi GIESBRECHT ............ Atlantischer Ozean.

192. Augaptitus longimanus SARS ............... Atlantischer Ozean.

193. Augaptilus squamatus GIESBRECHT ............. Atlantischer Ozean.

194. Augaptilus rattrayi ScoTT................. Atlantischer Ozean.

195. Augaptilus filigerus Claus ..................Atlantischer Ozean.

196. Augaptilus longicaudatus GiesBRechT........... Atlantischer Ozean.

197. Augaptilus magnus WoLFENDEN .............. Atlantischer Ozean.

198. Augaptilus subfiligerus $\mathrm{n} . \mathrm{sp} . \ldots \ldots \ldots \ldots \ldots$ Atlantischer Ozean.

199. Augaptilus facilis FARRAN ................ Atlantischer Ozean.

200. Augaptilus simplex FarRan ............... Atlantischer Ozean.

201. Isocalanus major n. sp. .................. Atlantischer Ozean.

202. Isocalanus minor n. sp. ................. Atlantischer Ozean.

203. Autanepsius major n. sp.................. Atlantischer Ozean.

204. Autanepsius minor n. sp. ................. Atlantischer Ozean.

205. Paraugaptilus meridionalis n. sp.............. Atlantischer Ozean.

206. Temoropsis simplex n. sp................ Antarktis.

207. Centropages violaceus Brady ............... Atlantischer Ozean.

208. Centropages gracilis Gie SBRecht ............. Atlantischer Ozean.

209. Centropages chierchiae GIESBRECHT ............ Indischer Ozean.

210. Centropages furcatus BradY ............... Indischer Ozean.

211. Candacia longimana Claus ................ Atlantischer Ozean.

212. Candacia simplex GIesBrecht .............. Atlantischer Ozean.

213. Candacia varicans GIESBRECHT .............. Atlantischer Ozean.

214. Candacia aethiopica DANA ................... Atlantischer Ozean.

215. Candacia pachydactyla Dana ............... Atlantischer Ozean.

216. Candacia curta DaNA ....................... Atlantischer Ozean.

217. Candacia bispinosa Claus ................. Atlantischer und Indischer Ozean.

218. Acartia negligens DANA ................... Atlantischer und Indischer Ozean.

219. Acartia danae GIESBRECHT .................. Atlantischer Ozean.

220. Acartia centrura, GIESBRECHT ............. Atlantischer Ozean.

221. Temora stylifera GIESBReCHT .............. Atlantischer Ozean.

222. Temora kerguelensis $\mathrm{n}$. sp. ............... Kerguelen.

223. Copilia quadrata DANA ......................

224. Copilia vitrea GIESBRECHT ................ Atlantischer Ozean.

225. Copitia denticulata Claus.................. Atlantischer Ozean.

226. Copilia mirabilis DANA .................. Atlantischer und Indischer Ozean.

227. Copilia lata GIESBRECHT................... Atlantischer Ozean.

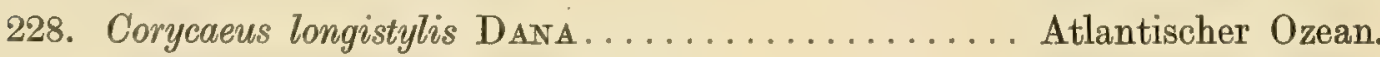

229. Corycaeus venustus DaNa .....................

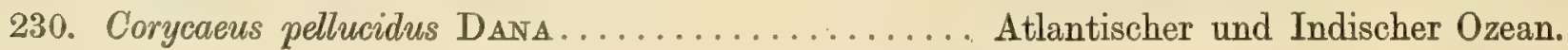


231. Corycaeus furcifer Claus ........... Atlantischer Ozean.

232. Corycaeus ovalis Claus ............ Atlantischer Ozean.

233. Corycaeus alatus GIESBRECHT ......... Atiantischer Ozean.

234. Corycaeus speciosus DanA .......... Atlantischer, Indischer Ozean, Antarktis.

235. Corycaeus robustus Giesbrecht ........ Atlantischer Ozean.

236. Corycaeus danae GIeSBrecht ..........Atlantischer und Indischer Ozean.

237. Corycaeus elongatus Claus .......... Atlantischer Ozean.

238. Corycaeus rostratus Claus .......... Atlantischer, Indischer Ozean.

239. Corycaeus flaccus Gresbrecht ......... Atlantischer Ozean.

240. Corycaeus obtusus DaNA ............ Atlantischer Ozean.

241. Corycaeus gracilicaudatus GIESBRECHT .. Atlantischer Ozean.

242. Sapphirina angusta DANA.......... Atlantischer Ozean.

243. Sapphirina gemma DaNA ........... Atlantischer Ozean.

244. Sapphirina vorax GreSBRECHT ........ Atlantischer Ozean.

245. Sapphirina metallina DANA ......... Atlantischer Ozean und Antarktis.

246. Sapphirina opalina DANA...........Atlantischer Ozean.

247. Sapphirina intestinata Giesbrecht ..... Atlantischer Ozean.

248. Sapphirina ovatolanceolata DANA....... Atlantischer Ozean.

249. Sapphirina salpae Claus .......... Atlantischer Ozean.

250. Sapphirina nigromaculata Claus...... Atlantischer Ozean.

251. Labidocera acutifrons DANA ......... Atlantischer Ozean und Antarktis.

252. Labidocera scotti Giesbrecht......... Atlantischer Ozean.

253. Labidocera nerii KRöYer ........... Atlantischer Ozean.

254. Labidocera wollastoni LuвBock........ Atlantischer Ozean.

255. Labidocera acuta DANA ............ Indischer Ozean.

256. Pontella tera DanA ............. Atlantischer Ozean.

257. Pontella atlantica M.-Edwards ........ Atlantischer und Indischer Ozean.

258. Pontella securifer Brady............ Atlantischer und Indischer Ozean.

259. Pontella spinipes Giesbrecht ........ Atlantischer Ozean.

260. Pontellina plumata DanA ........... Atlantischer und Indischer Ozean.

261. Pontellopsis regalis Dana ........... Atlantischer Ozean.

262. Oncaea conifera GiessRecht.......... Atlantischer Ozean und Antarktis.

263. Oncaea venusta PHILIPPI............ Atlantischer und Indischer Ozean.

264. Oncaea mediterranea Giesbrecht....... Atlantischer Ozean.

265. Oncaea notopus GIESBRECHT .......... Atlantischer Ozean.

266. Oncaea curvata GIESBREcht ........... Antarktis und Indischer Ozean.

267. Oncaea media Gie SBREcht .......... Atlantischer Ozean.

268. Oithona plumifera BAIRD ........... Atlantischer und Indischer Ozean.

269. Oithona similis ClaUs............. Atlantischer Ozean und Antarktis.

270. Oithona linearis GIESBRECHT ........ Atlantischer Ozean.

271. Oithona frigida Giesbrecht .......... Antarktis. 
272. Aegisthus mucronatus Giesbrecht...... Atlantischer Ozean.

273. Lubbockia squillimana Claus......... Atlantischer Oezan.

274. Lubbockia aculeata GiesBRECHT ....... Atlantischer Ozean.

275. Ectinosoma antarctica GIESBRECHT ..... Antarktis.

276. Ectinosoma atlanticum BRADY .........Atlantischer und Indischer Ozean.

277. Corynura gracilis BRADY ........... Atlantischer Ozean.

278. Setella gracilis DANA ............Atlantischer, Indischer Ozean, Antarktis.

279. Clytemnestra scutellata DANA ........ Atlantischer und Indischer Ozean.

280. Miracia efferata DANA ........... Atlantischer Ozean.

Calanus. Leach.

Vier Arten dieser Gattung gehören dem südlich kalten Gebiet an: Calanus propinquus, Calanus acutus, Calanus simillimus und Calanus tonsus; eine Anzahl anderer Arten, häufige und wohlbekannte Formen, wurde während der Aus- und Heimreise des "Gauss" gesammelt. Die beiden erstgenannten Arten sind sehr häufig in den Sammlungen des "Gauss" aus der Antarktis. Sie wurden von Giesbrecht im Belgica Report ${ }^{1}$ ) und von mir im Discovery Report ${ }^{2}$ ) ausführlich beschrieben und abgebildet und bedürfen daher hier keiner eingehenden Beschreibung. Calanus tonsus, der in der Ausbeute der Discovery vorhanden war, wurde bei der Gauss-Station trotz der großen Anzahl der von den beiden anderen Arten eingesammelten Exemplare nicht gefunden.

\section{Calanus propinquus (Brady).}

Diese Art schien eine sehr weite Verbreitung zu haben. Nach BRADY ${ }^{3}$ ) sollte sie in allen Ozeanen vorkommen, im Indischen Ozean bis $65^{\circ} \mathrm{s}$. Br., im Pazifischen bis $35^{\circ} \mathrm{n}$. Nr. und im Atlantischen Ozean bis $3^{\circ} \mathrm{n}$. Br. Giesbrecht und SchmeIL geben dann im ,Thierreich" ihr Verbreitungsgebiet von $55^{\circ} \mathrm{n}$. Br. bis $65^{\circ} \mathrm{s}$. Br.. im Atlantischen Ozean an. Aber GIesbrechit hat im Belgica Report die Frage weiter erörtert und dabei gefunden, daß die von ihm früher vom Atlantischen Ozean zwischen $37^{\circ} \mathrm{n}$. und $52^{\circ} \mathrm{s}$. Br. als Calanus propinquus beschriebene Form als eigene, obwohl nahe verwandte Art unter dem Namen Calanus simillimus unterschieden werden müsse. Ich glaube bestimmt, daß GIESBRECHT darin Recht hat und daß Calanus propinquus erheblich geringere Ausbreitung hat, als vorher angenommen wurde. Die Unterschiede zwischen dieser Art und Calanus simillimus sind auf den ersten Blick nicht gleich deutlich, abgesehen von der geringeren Größe der letzteren und gewissen guten Merkmalen im Bau des dritten, vierten und fünften Fußpaares.

In größter Häufigkeit wurde Calanus propinquus bei der Gauss-Station und im angrenzenden Eismeer angetroffen. Zusammen mit Calanus acutus ist diese Art für die Antarktis ebenso bezeichnend, wie es Calanus finmarchicus und Calanus hyperboreus für das Nordpolarbecken sind. Von $60^{\circ} \mathrm{s}$. Br. bis zur Gauss-Station und im Scholleneise erschien sie fast überall in den Fängen und in vielen Fällen in großer Zahl. Weiter nach Norden trat sie weniger häufig auf, bis sie gegen den

1) Résultats du Voyage du S. Y. „Belgica“" en 1897-1898, Rapp. Scientif. 1902.

$\left.{ }^{2}\right)$ National Antarctic Expedition Nat.-Hist. vol. IV, 1908.

$\left.{ }^{2}\right)$ Challenger Report, The Voyage of H. M. S. Challenger, Zoology Part XXIII, 1883. 
Indischen Ozean hin gänzlich verschwand. In dieser Richtung kann Kerguelen als bezeichnend für die nördliche Verbreitungsgrenze angesehen werden.

Calanus propinquus erscheint zwar in vielen Stationen von Dezember 1901 zwischen Kap und Crozet-Inseln, doch immer in geringer Zahl, und so ist es nicht wahrscheinlich, daß er in den Atlantischen Ozean eindringt, abgesehen von vereinzelten und durch Tiefseeströmungen mitgeführten Exemplaren. Aus seiner Häufigkeit im Eismeer, wo er in allen Entwicklungsstadien auftritt, und aus seiner allmählichen Abnahme an Zahl nach Norden hin bis zu eventuellem Verschwinden ergibt sich der Schluß, daß das Verbreitungszentrum desselben innerhalb des Polarkreises liegt und daß er eine typische antarktische Art repräsentiert.

Die Durchschnittsgröße von Calanus propinquus beträgt $5 \mathrm{~mm}$, während sie bei Calanus simillimus nur $3 \mathrm{~mm}$ erreicht, und der gezähnte Rand der Grundglieder des 5. Fußpaares ist eigenartig gebildet, ,nicht eingebuchtet, sondern flach konvex und schiebt sich mit seinem distalen Ende so weit auf die Hinterfläche des Gliedes, daß seine letzten Zähnchen verdeckt werden, wenn man die Gliedmaße von der Vorderfläche betrachtet; hinter dem letzten Zähnchen dieses Saumes ist die Zahnreihe durch eine Lücke unterbrochen, und hinter der Lücke stehen an der von dem inneren und dem distalen Gliedrande gebildeten Ecke noch 2 bis 3 Zähnchen " (GiesBRecht a. a. O.).

q 5 bis $5,5 \mathrm{~mm}$. Der Cephalo thor ax ist über dreimal so lang als das Abdomen, die Furkaläste zweimal so lang als breit, der Kopf gleichmäßig gerundet, ohne Spur von einem Kamm, und vom ersten Thoraxsegment getrennt. Das letzte Thorakalsegment tritt an jeder Seite mit kleiner Endspitze hervor. Die vorderen A n te n n e n sind nur so lang oder ein wenig länger als der ganze Körper, das vorletzte Glied derselben kürzer als das letzte. Wenn man quer über das letzte Glied des Außenastes der $\mathrm{S} \mathrm{chw}$ i m $\mathrm{m}$ fü $\mathrm{Be}$ eine Linie vom Außendorn gezogen denkt, so teilt diese das Glied in zwei ungleiche Teile: Die Verhältnisse derselben sind:

beim 2. Fuße proximaler Teil zum distalen $=24: 25$,

beim 3. Fuße proximaler Teil zum distalen $=20: 23$,

beim 4. Fuße proximaler Teil zum distalen $=36: 20$.

Beim 5. Fuß ist der innere Rand des Basalgliedes unten konvex, distal konkav, mit 13 bis 14 Zähnen besetzt, die distal 3 größer als proximal sind. Das letzte Glied des Außenastes trägt nur 5 Borsten.

đ. Das Männchen unterscheidet sich hauptsächlich durch den Bau des 5. Fu B pa a res und die Gestalt von $\mathrm{Kopf}$ und $\mathrm{Th}$ or ax. Der Kopf ist oval, gerundet und verlängert; das erste Thorakalsegment hat eine tiefe Auszackung, deren hinterer Rand hervortritt. Die Basalglieder der vorderen Antennen sind stark untereinander verschmolzen. Die hinteren $\mathrm{Ma}$ xilli p e d e $\mathrm{n}$ haben eine sehr lange, dicht gefiederte Dorsalborste. Der linke 5. F u B ist stark verlängert; die beiden ersten Glieder des Außenastes sind länglich, das dritte Glied sehr kurz und birnförmig mit kurzer Distalborste. Der Innenast ist nur halb so lang als der Außenast und trägt 1, 1, 6 kurze, schwache Randborsten. Beim rechten 5. Fuß ist der Innenast fast so lang als der Außenast und ebenfalls mit 1, 1, 6 schwachen Randborsten versehen. Der Außenast ist nicht viel mehr als halb so lang wie der der gegenüberliegenden Seite. Der Innenrand der ersten Basalglieder ist mit 17 bis 20 großen Zähnen bewaffnet, im oberen Teile schwach konkav, im unteren schwach konvex. 


\section{Calanus acutus (Giesbrechi).}

Diese Art, welche mit der vorigen regelmäßig zusammen gefunden wird, läßt sich leicht von derselben durch größere Transparenz, schwächeren Bau und scharf vorspringenden, fast dreieckigen Kopf unterscheiden.

o 4,5 bis 5,3 mm. Der Ce phal othorax ist nicht ganz viermal so lang wie das $\mathrm{Ab}$ domen, und der Kopf ist vom ersten Thorakalsegment abgesetzt. Bei seitlichem Anblick erscheint der Kopf vorn etwas verlängert und oval, dorsal gesehen aber deutlich dreieckig mit schwacher Andeutung einer Crista in der Mittellinie. Das letzte Thorakalsegment springt zwar auch jederseits etwas vor, ist aber gleichmäßig gerundet ohne Andeutung von Dornen. Die Furkaläste sind nur sehr wenig länger als das Analsegment und beinahe zweimal so lang als breit. Die vorderen A n te n n e n variieren bei verschiedenen Exemplaren etwas an Länge, doch überragen sie die Furka um. höchstens 1 oder 2 Glieder. Das letzte Glied (25) ist ungefähr doppelt so lang als das vorletzte.

Die Schwimmfüße zeigen im letzten Glied der Außenäste bei entsprechender Teilung wie bei der vorigen Art folgende Verhältnisse:

beim 2. Fuße proximaler Teil zum distalen $=24: 13$,

beim 3. Fuße proximaler Teil zum distalen $=29: 15$,

beim 4. Fuße proximaler Teil zum distalen $=15: 15$.

Dieses Glied trägt 8 Borsten beim 2. und 3., 7 beim 4. und nur 4 beim 5. Fußpaare. Beim 5. Pa a r e fehlt die äußere Randborste des letzten Segments vom Innenast, und außerdem fehlen Zähne oder Haare am Innenrande der ersten Basalglieder. Es ist merkwürdig, daß, ebensowenig wie es GIESBRECHT unter den Copepoden der „Belgica“ reife Männchen dieser Art zu finden gelang, solche auch trotz der großen Individuenzahl in der Ausbeute der „Discovery“ und des „Gauss" nicht nachgewiesen werden konnten.

\section{Calanus simillimus (Giesbrecht).}

Während diese Art in den Sammlungen der „Belgica“ und „Discovery" reichlich vertreten war, wurde sie bei der Gauss-Station nicht so häufig gefunden.

o $2,9 \mathrm{~mm}$. Der Cephalothorax ist dreimal so lang als das Abdomen, der Kopf ist vom ersten Thorakalsegment abgetrennt, einfach gerundet und trägt keine Crista. Die letzten Thorakalsegmente treten seitlich etwas hervor, sind gerundet und enden mit kurzen Spitzen. Die vorderen Antennen überragen die Furka nur etwa mit dem letzten Gliede. Das Genitalsegment ist ebenso lang wie die beiden folgenden Segmente, und die $\mathrm{F} \mathrm{u} \mathrm{r} \mathrm{k} \mathrm{a} \mathrm{ist} \mathrm{dreimal} \mathrm{so} \mathrm{lang} \mathrm{als} \mathrm{breit}$ und länger als das Analsegment. Die dritten Glieder der Außenäste der Schwi m m be in e lassen sich entsprechend wie bei den vorigen Arten in folgendem Verhältnis teilen:

$$
\begin{aligned}
& \text { beim 2. Fuße proximaler Teil zum distalen }=\text { (etwa) } 1: 1 \text {, } \\
& \text { beim 3. Fuße proximaler Teil zum distalen }= \\
& \text { beim 4. Fuße proximaler Teil zum distalen }= \\
& \text { r }
\end{aligned}
$$

Das 3. Segment des Innenastes trägt beim 3. Fußpaar 8, beim 4. Paare 7 und beim 5. Paare 5 Borsten. Beim 5. P a a I ist der Rand des 1. Basalgliedes mit 14 Zähnen besetzt, von denen $3 \mathrm{im}$ distalen Teile der Zahnreihe größer als die übrigen sind. 
4. Calanus gracilis (DANA).

5. Calanus robustior (Giesbrecht).

Diese beiden Arten wurden bei der Fahrt durch den Atlantischen Ozean sehr häufig vom „Gauss" angetroffen. Es ist nicht immer leicht, beide zu unterscheiden. Die Charaktere von Calanus robustior sind nach GIESBRECHT: bedeutendere Größe, kräftigerer Bau, stärkeres Hervortreten der Genitalhöcker und das Vorhandensein einer ,buckelförmigen Auftreibung am Außenrande des 1. Gliedes des Basp. der 2. Maxille“. In vielen Fällen, wo die Unterscheidung schwierig war, habe ich mich wesentlich auf die Größe (etwa 3 bis $5 \mathrm{~mm}$ statt $3 \mathrm{~mm}$ bei Calanus gracilis), die kräftigere Form und das beträchtliche Hervortreten des Genitalhöckers verlassen.

Keine der beiden Arten erschien südlich von der Agulhas Bank, und beide waren verhältnismäßig selten in der Nähe der Küsten von Natal und der Kapkolonie. Calanus gracilis breitet sich wahrscheinlich weiter nach Süden aus als Calanus robustior und könnte etwa den $40 .{ }^{\circ}$ s. $\mathrm{Br}$. erreichen.

6. Calanus vulgaris (DANA).

\%. Calanus darwini (LubBock).

8. Calanus minor (ClaUS).

9. Calanus pauper (Giesbrecht).

Diese gut bekannten und häufigen Arten wurden im Atlantischen Ozean in großer Menge gefunden, doch fehlen dieselben südlich vom Kap der guten Hoffnung und im Eismeer.

10. Calanus brevicornis (LubBock).

wurde nur an einer Station im Südatlantischen Ozean beobachtet.

\section{Rhincalanus Dana.}

Der einzige Vertreter der Gattung im südlich kalten Gebiet ist Rhincalanus grandis (GIESBRECHт). Von der nordischen Art Rhincalanus nasutus (Rhincalanus gigas s. später) und von dem tropischen und subtropischen Rhincalanus cornutus ist die südliche sicher verschieden. GIESBRECHT hat schon die Möglichkeit der Identität dieser Art mit Rhincalanus gigas erwogen, die 1883 von BRADY im Challenger Report beschrieben wurde. Die Größe des letzteren (8,5 bis $10 \mathrm{~mm}$ ) und sein Vorkommen (zwischen $36^{\circ}$ und $65^{\circ}$ s. Br.) wïrde diese Ansicht stützen. BRADYs Beschreibung der Dornen an den drei letzten Thorakalsegmenten und an dem ersten und letzten Abdominalsegment stimmt nicht mit den Merkmalen von Rhincalanus grandis überein. Wie GIESBRECHT bemerkt, handelt es sich bei BRAdys Figur im Challenger Report um ein unreifes Exemplar, was sich aus dem 5. Fußpaare des ô ergibt. Die Exemplare von Rhincalanus gigas (BRADY), welche ich aus dem British Museum untersuchen konnte, waren sicherlich unreif und können wohl junge Exemplare von Rhincalanus grandis GrESBREcht (Belgica Report) sein ${ }^{1}$ ). Wenn sich dieses so verhalten sollte, verdient es hervorgehoben zu werden, daß diese Art vom südlichen Eismeere bis zum 36. ${ }^{\circ} \mathrm{s}$. Br. im Pazifischen Ozean (zwischen Japan und Honolulu) verbreitet sein würde.

1) Bei den Exemplaren des Britischen Museums fand sich ein Paar sehr kleiner Seitendornen ventral am 3. und ein Paar größerer Dornen am 4. Thorakalsegment und ein Dorsaldorn am 1. Abdominalsegment. Am Thorax waren keine Dorsaldornen vorhanden. Das Abdomen bestand aus 4 Segmenten, der Außenast des 1. Fußes aus nur 2 Gliedern und der 5. Fuß war einästig mit 3 Gliedern. Länge etwa $6,0 \mathrm{~mm}$. 
Die Exemplare von Rhincalanus gigas, welche Scotr von Fair Island (19 ${ }^{\text {th }}$ Report Scotch Fishery Board) und MöвIUs vom Norden Schottlands beschrieben, hält GIESBREcHT, wie ich glaube mit Recht, für Rhincalanus nasutus.

Wie es bei der Gattung Calanus der Fall war, ist auch die antarktische Art von Rhincalanus völlig von der arktischen Art verschieden.

\section{Rhinealanus grandis (Giesbrecht).}

Diese Art wurde von GIESBRECHT im Belgica Report und von mir nach den Sammlungen der „Discovery“ ausführlich beschrieben. Sie fällt durch ihre bedeutende Größe auf. Das + ist 8 bis $9 \mathrm{~mm}$ lang. Das 3. Thorakalsegment trägt ein Paar ganz kleiner Seitendornen, das 4. ein Paar, die viel größer sind. Sie gehören nicht zum 5. Segment, wie es bei oberflächlicher Betrachtung scheinen könnte. Die Abwesenheit von Dorsaldornen, auch von Dornen auf den Abdominalsegmenten überhaupt, unterscheidet diese Art von Rhincalanus nasutus, ihren nächsten Verwandten. Bei Rhincalanus grandis bestehen Innen- und Außenast des 1. Beinpaares aus nur 2 Gliedern, während die Äste des 2., 3. und 4. Paares dreigliederig sind. Beim 5. F u B pa r erscheint jederseits nur 1 Ast aus 3 Gliedern bestehend, von denen das 2. eine lange innere Randborste, das 3. drei etwa gleichlange Borsten trägt. Zwei davon, die dickere außen, treten als Endborsten, die dritte distal als Innenrandborste auf. Im oberen Drittel des Außenrandes findet sich ein kurzer Dorn.

Der $K \circ \mathrm{p} f$ ist nach vorn verlängert und erscheint bei der Ansicht vom Rücken etwa dreieckig mit großen seitlichen Schwellungen an der Basis. Der $\mathrm{Ceph}$ a lothor ax ist sechsmal so lang als das dreigliederige Abdomen, und die vorderen Antennen überragen die Furka mit etwa 6 Gliedern.

Scotrs Rhincalanus? gigas gehört der Größe nach und wegen der paarigen Dorsaldornen am Thorax und dem Genitalsegment sicher zu Rhincalanus nasutus. In ihrer Verbreitung schließt sich die Gattung Rhincalanus an Calanus an. So erscheint Rhincalanus nasutus von den nördlichen Meeren bis zu den Kap Verdeschen Inseln, wo er am 9. und 13. Oktober 1903 vom „Gauss" unter $20^{\circ}$ n. Br. etwa oder etwas südlich davon noch gefunden wurde. In nördlicher Richtung wurde er häufig im Faroe-Kanal und bis zur norwegischen Küste (SARS, Crustacea of Norway) angetroffen, und endlich gehört er dem ganzen Indischen Ozean an. Rhincalanus grandis folgt der Verbreitung von Rhincalanus propinquus und Rhincalanus acutus, und auch sein Entwicklungszentrum liegt im südlichen Eismeer, wo alte und junge Exemplare zusammen in großen Mengen erscheinen. Wie aus Fängen vom Dezember 1901 hervorgeht, nimmt die Zahl der Exemplare nach Norden zu stark ab, und bei $46^{\circ} \mathrm{s}$. Br. etwa verschwindet die Art in den Sammlungen des „Gauss" bis auf einzelne Exemplare, welche gelegentlich durch die Tiefsee etwas weiter nördlich verbreitet werden können, da ein Individuum noch am 12. November 1901 in einem Vertikalfang aus $3000 \mathrm{~m}$ Tiefe noch erbeutet wurde. (Die den Daten entsprechenden Fundorte sind in der Karte Tafel XLI angegeben.)

12. Rhincalanus nasutns (Giesbrecht).

13. Rhinealanus cornutus (DANA).

Beide Arten bedürfen keiner weiteren Beschreibung. Die letztere ist ein ebenso charakteristischer Bewohner der tropischen und subtropischen Meere, wie die erstere im kalten und temperierten 
Gebiete. Während der Fahrt des „Gauss" im Atlantischen Ozean erschien Rhincalanus cornutus konstant, während Rhincalanus nasutus nur gelegentlich in Tiefenfängen, so aus $3000 \mathrm{~m}$ am 12. November 1901 und 13. Oktober 1903, auftrat.

\section{Megacalanus Wolfenden.}

Im Jahre 1904 (Journal of the Marine Biological Association vol. VII nr. 1) habe ich diese neue Gattung nach zwei in der tiefen atlantischen Rinne westlich von Irland gefangenen Exemplaren kurz beschrieben und die Art damals Megacalanus princeps benannt. Professor G. O. SARS beschrieb 1905 (Bull. Musée Océanographique de Monaco 20 Mars 1905) die Art noch einmal unter dem Gattungsnamen Macrocalanus, hat jedoch später dieses korrigiert und den Namen Megacalanus angenommen (Bull. Inst. Océan. 1907).

Die Gattung Megacalanus weicht in einigen wesentlichen Merkmalen von der folgenden Gattung Bathycalanus ( $\mathrm{SARS}_{\mathrm{A}}$ ) ab, und es fragt sich, zu welcher von beiden die von BrADY im Challenger Report als Calanus princeps beschriebene Art gehört. SARs rechnet sie zu Megacalanus, und Farran schließt sich seiner Ansicht an (Fisheries Ireland Sci. Invest. 1906 II [1908]).

BraDY's Originalbeschreibung (Challenger Report) lautet: „, the maxilla palp is made up of fewer segments than usual, having one quadrate and two ovate plates together with a small bisetose digit. The anterior footjaws are armed with strong curved setae, which are densely clothed on their inner margins with short delicate and closely set hairs except towards the base, where the setae are naked". Die Abbildungen BraDY's geben keine Aufklärung über die Gestalt des Kopfes, die für die Gattung wichtig ist, auch erwähnt der Autor nicht den großen, deutlich hakenförmigen Fortsatz am ersten Fußpaare, welcher ebenfalls charakteristisch ist und welchen er kaum übersehen haben würde. Die Darstellung einer der Borsten des vorderen Kieferfußes gleicht nicht einer solchen von Megacalanus. Um die Identität dieser Art festzustellen, untersuchte ich BRADY's Originalexemplar im British Museum. Die einzigen der Untersuchung zugänglichen Teile fanden sich seit vielen Jahren in einem mikroskopischen Präparat, und obwohl der Kopf etwas gedrückt war, ließ sich doch erkennen, daß wie bei Bathycalanus keine Andeutung von einer Crista oder von kleinen Frontaldornen vorhanden war. Das Rostrum besteht aus zwei starren, verdickten Fortsätzen, wie sie für Bathycalanus, aber nicht für Megacalanus charakteristisch sind; die Borsten der vorderen Maxillipeden sind dicht bewimpert und gleichen daher denen von Bathycalanus, und die langen Borsten der hinteren Maxillipeden zeigen die gewöhnliche Form, sind nicht dicht, sondern ziemlich schwach bewimpert. Das erste Fußpaar hat keinen Hakenfortsatz am Basalglied, und der Außenast ist dreigliederig. Der Bau des Rostrums, die dicht bewimperten Borsten der vorderen Maxillipeden und die Abwesenheit des Hakens am ersten Fußpaare sind Charaktere, welche der Zugehörigkeit dieser Art zur Gattung Megacalanus widersprechen. Sie nähert sich mehr der Gattung Bathycalanus im Bau des Rostrums und der Bewehrung der vorderen Maxillipeden, weicht jedoch durch den Mangel der charakteristischen Dornen auf der Kopfwölbung und durch den dreigliederigen Außenast des ersten Fußpaars von dieser ab ${ }^{1}$ ).

1) Bei der Gattungsdiagnose von Bathycalanus erwähnt Professor SARS, daß der Außenast des 1. Fußpaares nur zweigliederig ist (Bathycalanus richardi). 
Bradys Exemplar (Calanus princeps) ist sicher nicht mit Megacalanus princeps Wolfenden identisch, sondern scheint in den drei oben erwähnten Merkmalen den Eigentümlichkeiten der Gattung Heterocalamus zu entsprechen.

Gattungscharaktere: Die Tiere sind von sehr erheblicher Größe. Der Kopf ist vom 1. Thorakalsegment abgesetzt und die letzten beiden Thorakalsegmente sind in ähnlicher Weise separiert. Das Abdomen besteht aus 4 Segmenten. $5 \mathrm{FuBpa}$ a re sind vorhanden; das 3. Glied der Außenäste trägt 3 Außenranddornen; das 1. Fußpaar ist mit sehr großem und charakteristischem Fortsatz am 1. Basalgliede versehen, und dem 5. Fußpaare fehlt jede Zähnelung an den Basalgliedern; der Kopf ist gleichmäßig gerundet, zeigt weder Kamm noch Dornen, und das Rostrum gegabelt mit starken, schwach herabgekrümmten Zinken, die sich allmählich zuspitzen.

\section{Megacalanus princeps (WoLfenden). (Taf. XXII Fig. 1-11, Textfigur 1 a.b.)}

q etwa $10 \mathrm{~mm}$ lang; der C e pha loth o r a x ist ungefähr 31/2 mal so lang als das Abdomen und setzt sich aus 6 Segmenten zusammen. Der Kopf ist vom übrigen Thorax abgesetzt und die

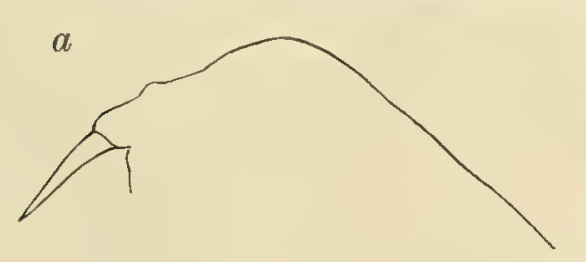
beiden letzten Segmente sind getrennt. Der Thorax ist etwa dreimal so lang als breit. (XXII I. Ia.)

Der Kopf ( $\mathrm{I}$.a) ist ein wenig nach vorn verlängert, dorsal vollkommen gerundet, ohne Spur von Kamm oder Dornen, und das Rostrum besteht aus zwei etwas nach unten gekrümmten

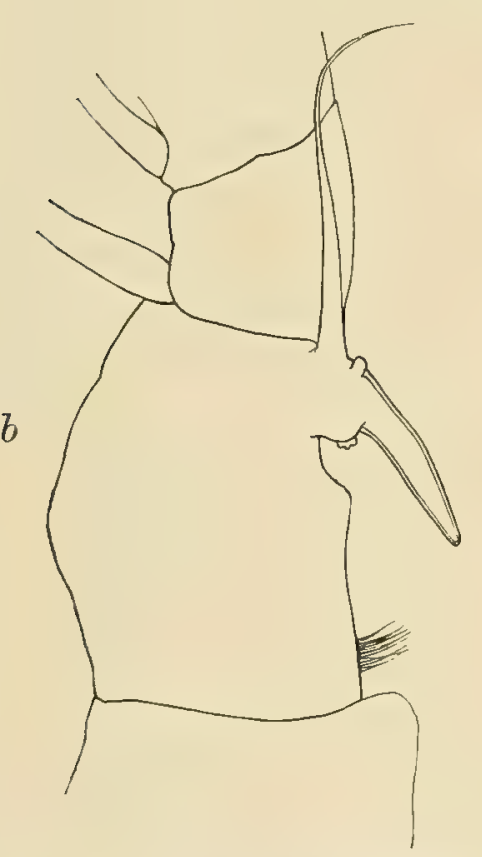

Fig. 1. Megacalanus princeps (WOLFENDEN).

$a$ Kopf von der Seite.

$b$ Zweites Basalglied vom 1. Fuß. spitzen Ästen. Am letzten Thorakalsegment treten zwei kurze, flügelartige Spitzen hervor.

Das A bdomen besteht aus 4 Segmenten, von denen das Genitalsegment sehr wenig länger als breit, das 2. Segment größer als das 3. und dieses wiederum größer als das 4 . Segment ist. Die Furkaläste sind etwa ebenso lang wie das Analsegment und nur sehr wenig länger als breit. Jeder Ast trägt 5 Schwanzborsten und eine kurze innere Nebenborste. Die 2. innerste Borste jederseits ist dicker und länger als die übrigen Borsten.

Die vorderen Antennen haben 25 Glieder und überragen den Körper etwa mit 8 Segmenten, alle Borsten derselben, abgesehen von den Endborsten, sind sehr kurz. Das 17., 18. und 19. Glied sind am längsten, die beiden letzten Glieder fast gleichlang und kürzer als das 23. Glied. Das 12. und 13. Glied haben auf der Unterseite eine Reihe feiner Zähne.

Die hinteren Antennen zeigen etwa gleichlange Äste; das 1. Basalglied trägt einen basalen Randhöcker und eine starke Borste, das 2. Basalglied 2 Borsten. Das erste Glied des Innenastes ist viermal so lang als breit.

Der Innenast der M a n i b e $\mathrm{ln}$ ist ein wenig länger als der Außenast. Die Kauplatte ist halb so breit als lang und trägt 6 starke, zweispitzige Zähne. Das 1. Glied des Innenastes weist 
(wie bei Calanus gracilis) einen starken Randhöcker auf; das 2. Basalglied ist ziemlich lang und trägt 4 starke Randborsten.

Die M a xille n (XXII. 2) haben einen Außenast von ovaler Form, der fast ebenso lang wie der Innenast ist. Der letztere ist klein und viel schmäler als das 2. Basalglied, aber deutlich dreigliederig. Am Innenaste finden sich 14 Borsten, 4 am zweiten Basalglied, 11 am Außenaste, 9 am ersten Außenlobus, 1 am zweiten Außenlobus und 4 am zweiten Innenlobus.

Die vorderen Maxillipeden sind kurz und kompakt; der 5. Lobus derselben ist viel länger als die übrigen und mit einem langen, dünnen Haken versehen. Am 4. und 6. Lobus sind keine Haken vorhanden, und alle proximalen Borsten tragen steife, weit gestellte Randhaare.

Bei den hinteren Maxillipeden ist das 1. Basalglied viel länger als das 2. Der Innenast ist kurz, die Verhältniszahlen sind $20: 14: 11$. Jedes Basalglied ist doppelt so lang als breit, und die Borsten zeigen den üblichen Charakter. Weder bei den vorderen noch bei den hinteren Maxillipeden sind die Borsten dick und bewimpert wie bei Bathycalanus.

Jeder der Schwimmfüße hat dreigliederigen Innen- und Außenast; die ersten Basalglieder des 2. und 4. Paares haben stark konvexen Innenrand. Der Innenast des 1. Fußpaares trägt an seinen 3 Gliedern 1, 2 und 6 Borsten, und das 2. Basalglied einen merkwürdigen, aus zwei starken Haken bestehenden Fortsatz auf der Hinterseite. (1. b.) Der untere Haken ist sehr dick und stark und springt nach unten, hinten und außen vor (was bei Profilansicht deutlich hervortritt), und der obere Hakenfortsatz erscheint unten breit und verschmälert sich zu peitschenartigem Ende, das gerade nach oben gerichtet ist und mehr als halb so lang als der Innenast ist. Jedes Segment des Außenastes trägt einen langen geißelartigen Randdorn. (XXII. 7.)

Das 2. Basalglied des 2. Fußpaares (XXII. 8) zeigt am Distalrande 3 Dornen (einen äußeren und zwei zentrale). Der Innenast ist nicht mehr als halb so lang wie der Außenast; die äußeren Ränder des 1. und 2. Gliedes vom Innenast endigen in Spitzen (ähnlich wie beim 3. oder 4. Paare). Das 3. Glied des Außenastes ist verhältnismäßig groß, breit an der Basis und distal schmal. Dieses Glied wird durch die Außendornen in drei Teile, einen proximalen, medialen und distalen mit den Verhältnissen von $14: 8: 14 \frac{1}{2}$ zerlegt. Die Endsäge ist nicht so lang wie der letzte Teil des Gliedes.

Das 3. und 4. Fußpaar sind einander im allgemeinen ähnlich; beim letzteren ist der Proximalteil des letzten Gliedes vom Außenaste bei weitem am längsten (proximal 19 1/2, median 11, distal 13), und die Endsäge ist etwas länger als das distale Drittel des Gliedes.

Der Innenast des 2. Paares trägt 1, 2, 8 Borsten am 1., 2. und 3. Gliede; die Außenränder des 2. Gliedes und der Proximalteil des 3. Gliedes des Außenastes vom 2. bis 5. Fuße sind dicht behaart; die Sägen sind an der Basis in allen Fällen breit, lanzettlich und blattartig, mit sehr zahlreichen Rippen; der Außenrand ist nicht gesägt. (XXII. 11.)

Am distalen Außenrande der 2. Basalglieder vom 4. Fußpaare findet sich außer dem kurzen Dorne noch eine kurze, zarte Federborste. Alle die äußeren Randdornen sind klein; es treten am Endgliede jedes Außenastes des 2. bis 4. Fußpaares 3 solche Randdornen auf.

Das 5. F u B p a a r gleicht den übrigen, abgesehen von seiner geringeren Größe und davon, daß der Außenrand des letzten Gliedes nur 2 statt 3 Dornen trägt. Am Innenrande des 1. Basalgliedes vom 5. Fußpaare sind weder Dornen noch Haare vorhanden. (XXII. 10.) Die Farbe 
der Tiere war nach frisch gefangenen Exemplaren (W. von Irland) grünlichgelb ohne jede Pigmentzeichnung.

0. Das Männchen ist dem o ähnlich, aber kleiner, und die vorderen Antennen tragen eine größere Anzahl von Aesthetasken; das Abdomen besteht aus 5 Segmenten, und das 5. Fu Bpa ar ist abweichend gebaut. (XXII. 9.) Der Fuß der einen Seite ist auch ein wenig von dem der andern Seite verschieden. Bei dem einen trägt der Innenrand des 2. Segments vom Außenast einen stumpfen Fortsatz am äußeren Distalrande, der mit einem Dorn und kräftiger Borste endet. Die inneren und äußeren Ränder sind sehr dicht behaart. Am 3. Gliede findet sich oft gerade unter seinem distalen Ende ein aufrechter Dorn, der das Ende des Gliedes ein wenig überragt, dessen Länge aber bei verschiedenen Exemplaren variiert. Beide Ränder sind im proximalen Zweidrittel dicht behaart. Der Außenrand des 3. Segments trägt nur einen Dorn distal von der Mitte. Dem Fuße der gegenüberliegenden Seite fehlt der Fortsatz am 2. Gliede des Außenastes. Die Basalglieder sind zahnlos und das erste derselben verhältnismäßig lang; der Innenast hat $0,1,6$ Randborsten.

Die Mundteile, Maxillen und Maxillipeden sind etwas rückgebildet. (XXII. 3-6.)

Diese Art hat augenscheinlich eine weite Verbreitung, da sie an mehreren der atlantischen Stationen des „Gauss" erscheint (9. Oktober 3000 m, 26. September 19033000 m, 30. September $1903800 \mathrm{~m}$, 13. Oktober $19033000 \mathrm{~m}, 22$. August $19031500 \mathrm{~m}$ ) und auch am 1. März 1903 bei einem Fang aus $2450 \mathrm{~m}$ in der Eisregion angetroffen wurde.

Ich zweifle nicht daran, daß diese Art identisch mit den später von SARS als Macrocalanus longicornis (Bull. Musée Oceanogr. 20. März 1905) beschriebenen Copepoden ist, und ich bin jetzt sicher, daß sie nicht mit BRADYs Calanus princeps übereinstimmt, so daß der Artname longicornis (SARS) dem früheren Namen princeps weichen muß.

\section{Bathycalanus (SARs).}

Diese Gattung wurde von Sars (Bull. Musée Oceanogr. Monaco 20. März 1905) von Megacalanus unterschieden wegen der Rostralanhänge, welche ,dünn und gerade sind und mit scharfen Spitzen endigen, ferner wegen der starken Entwicklung beider Maxillipedenpaare, von denen das vordere sehr dick ist und lange, hakenförmige Borsten trägt, während das hintere, ebenfalls verlängerte Paar mit 3 sehr kräftigen, gekrümmten, sichelförmigen Endborsten versehen ist, und endlich weil der Außenast des 1. Fußpaares nur zweigliederig ist".

Bei dieser Gattung ist die Gestalt des Kopfes besonders charakteristisch, und die Stirn ist mit 2 kurzen Dornen unmittelbar über der Basis des Rostrums bewehrt. Das 1. Fußpaar besitzt nicht immer einen nur zweigliederigen Außenast, da dieser bei der unten beschriebenen Art sich als dreigliederig erwies.

\section{Bathycalanus maximus n. sp. (Tafel XXIII Fig. $1-7$, Textfigur 2 a.b.)}

o 10,9 bis $12 \mathrm{~mm}$ lang; Cephalothorax mit 5 Segmenten, von denen die beiden letzten verschmolzen sind; der Kopf ist vorn beträchtlich verschmälert, die Stirn tritt schwach hervor und trägt 2 kurze Dornen, mit 2 kleinen kurzen Haaren unter ihnen. (2. b.) Die Rostralfortsätze sind lang und starr und enden stumpf ohne Filamente. Der hintere Rand des Thorax ist 
gerundet und nur wenig vorspringend. Das Abdomen besteht aus 4 Segmenten, von denen das Genitalsegment doppelt so lang als das folgende ist und im oberen Teile ventral stark angeschwollen erscheint. (2. a.)

Die vorderen $\mathrm{A} n \mathrm{t}$ e $\mathrm{n} \mathbf{n}$ e $\mathbf{n}$, aus 25 Gliedern bestehend, überragen den ganzen Körper mit wenigstens 4 Gliedern; die Basalglieder sind klein, und vom 8. bis 19. nehmen die Glieder allmählich an Länge $\mathrm{zu}$, das 20. bis 23. Glied ist kürzer, das 24 . nur halb so lang als das 23 . und das 25 nicht ganz doppelt so lang als das 24. Glied.

Die hinteren Antennen und Mandibeln sind wie bei Megacalanus gebaut. Die Maxillen (XXIII.4) haben ein ziemlich birnförmiges 2. Basalglied und birnförmigen Innenast; der letztere ist teilweise gegliedert, doch nur am Innenrande; der 2. äußere Lobus ist klein und anscheinend borstenlos.

Die vorderen Maxillipeden (XXIII. 3) tragen auf den proximalen Loben kurze, schwache Borsten. Der 5. und 6. Lobus und auch der Innenast besitzen sehr dicke und lange, bandförmige, proximal in halber Länge dicht befiederte Borsten. Diese Borsten sind für die Gattung sehr charakteristisch.

Die hinteren Maxillipeden (XXIII.5) sind mit sehr dicker, dornförmiger, dicht befiederter Borste und einer zweiten dünnen Borste versehen, welche beide von dem distalen lamellösen Vorsprunge des 1. Basalgliedes entspringen und beide so lang wie das 2. Basalglied sind. Die Borsten des letzten Gliedes vom Innenaste sind lang, breit und gleichen denen der vorderen Maxillipeden.

Die ersten 4 Schwimmfußpare haben dreigliedrige Äste und gleichen im allgemeinen denen von Megacalanus. Das letzte Glied der Außenäste trägt 3 Randdornen. Doch hat das 1. Fußpaar keine Andeutung eines Hakens, wie er so charakteristisch für Megacalanus ist, und am Innenaste fehlen auch die äußeren Randborsten des 1 . und 2. Gliedes. (XXIII. 7.)

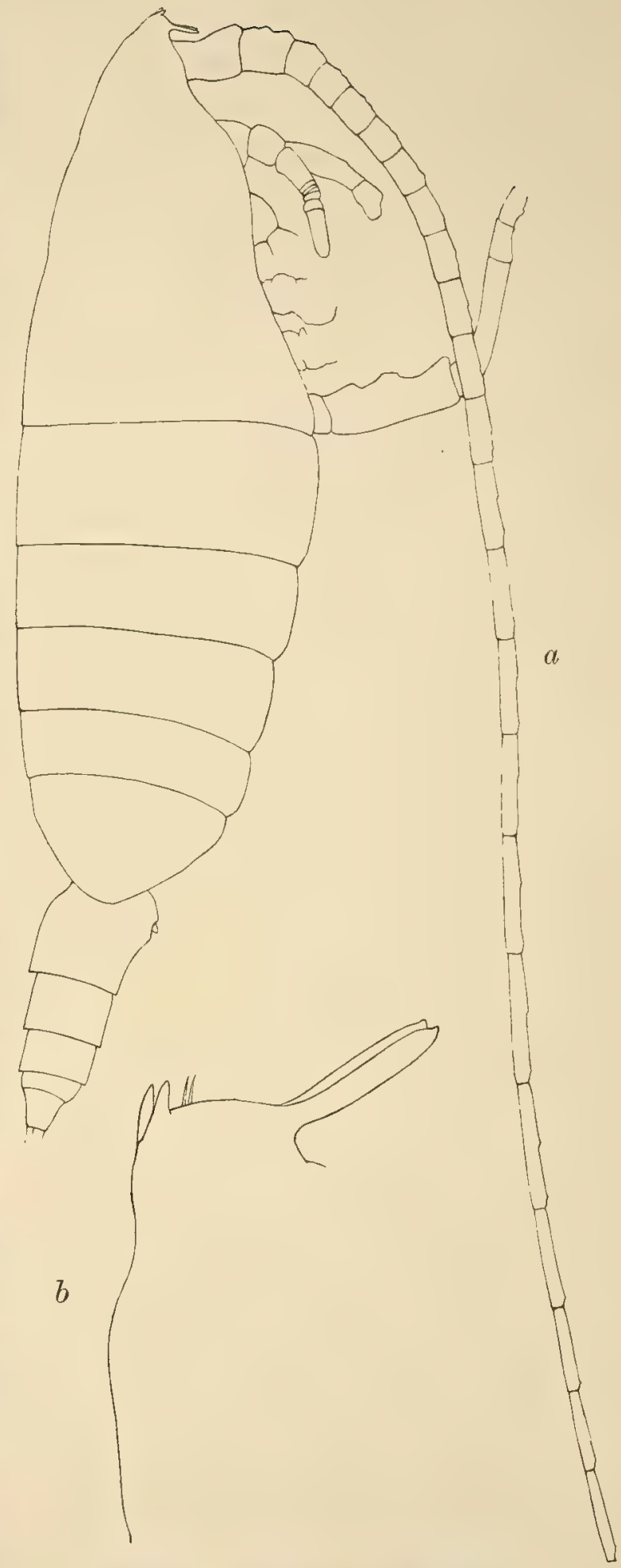

Textfig. 2. Bathycalanus maximus $f^{.}$

a Seitenansicht.

$b$ Kopf von der Seite. 
Das 5. F u ß p a a $\mathrm{r}$ hat nur 2 äußere Randdornen am letzten Gliede des Außenastes, 4 innere Randborsten und eine Endsäge, die dreiviertel der Länge des Gliedes erreicht. An den Rändern der Basalglieder sind keine Zähne vorhanden. Die Endsägen der Füße tragen zahlreiche feine, dichtgestellte Zähne.

Die Unterschiede zwischen dieser Gattung und Megacalanus sind sehr auffällig, und Tiere, die zu ihnen gehören, lassen sich leicht erkennen an der Gegenwart (Megacalanus) oder der Abwesenheit (Bathycalanus) des Hakens am 1. Fußpaare, an den dicht befiederten und bandförmigen Borsten der Maxillipeden (die bei Megacalanus fehlen) und dem normalen Rostrum (bei Megacalanus) oder dem verschmälerten Kopfe, den Kopfdornen und steifen Rostralanhängen (bei Bathycalanus). ${ }^{1}$ )

Es kann sein, daß die hier beschriebene Art mit Bathycalanus Richardi (SARS) identịsch ist, doch darf nicht übersehen werden, daß für diese Art ein zweigliederiger Außenast des letzten Fú paares festgestellt ist, wodurch dieselbe sich zweifellos von Bathycalanus maximus mit stets dreigliederigem Außenast unterscheidet.

3. Nur wenig abweichend in der Gestalt des Kopfes, doch fehlen die beiden kleinen Stirndornen; die letzten beiden Thoraxsegmente sind getrennt, das Abdomen hat 5 Segmente, vordere

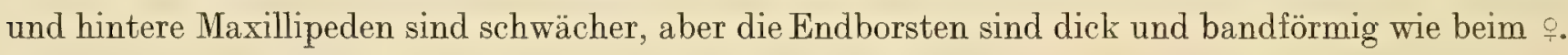
Das 5. Fußpaar (XXIII. 6) ist abweichend gebildet. Bei diesem hat das letzte Glied des Außenastes nur einen äußeren Randdorn und einen sehr kurzen Enddorn, welcher die Endsäge repräsentiert; die innere Randborste ist modifiziert, kurz, dornartig, gekrümmt und mehr oder weniger rechtwinklig zum Endgliede gestellt. Am 2. Gliede findet sich eine innere Randborste, aber der stumpfe Fortsatz, der beim ơ von Megacalanus vorhanden ist, fehlt hier. Wie bei der letzteren Art jedoch sind die beiden Füße nicht ganz symmetrisch entwickelt, da die innere Randborste des 2. Gliedes an einem Fuße fehlt. Das 1. Basalglied ist nicht so verlängert wie bei Megacalanus, und am Innenrande sind keine Zähne vorhanden. Das 2. Basalglied jedoch ist distal am Innenrande stark konvex und trägt kräftige Haarbüschel. Der Innen- und Außenrand des 2. und vom proximalen Zweidrittel des 3. Gliedes sind dicht behaart.

\section{Bathyealanus Richardi (SARS). (Tafel XXIII Fig. 8.)}

Eine Nachuntersuchung konservierter Exemplare ergab ein oder zwei Individuen mit zweigliederigem Außenaste des 1. Fußpaares. Das 2. und 3. Glied sind hier vereinigt, da eine schwache Andeutung einer Furche am inneren Rande vorhanden ist, doch reicht die Linie nicht weit quer in das Glied hinein. Im übrigen erscheint der Fuß nur kleiner, sonst nicht verschieden von Bathycalanus maximus. Das ganze Tier ist nur kleiner und zeigt den erwähnten Unterschied im Bau des

1) Die Tiere, welche ich in den Planktonstudien als Megacalanus princeps und Megacalanus Bradyi beschrieb, erwiesen sich als Megacalanus princeps und Bathycalanus maximus, und die ursprünglich von BraDY im Challenger Report als Calanus princeps beschriebene Art gehört, wie ich glaube, zu einer dritten neuen Gattung, nämlich Heterocalanus, doch ist schwer zu sagen, ob sie identisch mit Heterocalanus medius ist oder nicht.

In dem Originalexemplar BraDys ist der Kopf etwas gekielt und zeigt keine Spur der Dornen von Bathycalanus; die Rostralfortsätze sind steif und dick, nicht ähnlich denen von Megacalanus; die Borsten der vorderen Maxillipeden sind bandförmig und dicht bewimpert, die der hinteren Maxillipeden schwach; am 1. Fuße findet sich kein Hakenfortsatz; das 3. Glied des AuBenastes hat nur eine Borste in der Mitte und eine am Ende, und am 1. und 2. Gliede sind keine Dornen vorhanden. Es ist sicher nicht ein Megacalanus. 
1. Fußpaares. (XXIII. 8.) Daher nehme ich an, daß es sich um die von SARs als Bathycalanus Richardi beschriebene Form handelt.

Vorkommen: B. maximus: 10. III. 03 3000; 9. X. $03 \quad 3000 ; 13$. X. $033000 ; 4$. IX. 03 2000; 26. IX. 03 3000; 30. IX. 03 1500; 12. XI. 013000. B. Richardi: 9. X. 03.3000.

\section{Heterocalanus. n. g.}

Wie bei den beiden vorigen Gattungen, so sind auch hier die Gestalt des Kopfes, die Charaktere der Maxillipeden und Fïße für die Gattungsdiagnose wichtig. Sie genügen, um die hier beschriebene Form von jeder der beiden Gattungen Megacalanus und Bathycalanus zu unterscheiden, und ioh kann der Ansicht Farran's (a.a.O.), daß Heterocalanus und Megacalanus Synonyme seien, nicht zustimmen, obwohl ich mit ihm darin übereinstimme, daß BRADYs Calanus princeps wahrscheinlich ein Heterocalanus ist.

Die Gattung ist durch die folgenden Punkte ausgezeichnet: Der $\mathrm{K}$ opf ist vorn etwas verschmälert, wenn auch nicht so stark wie bei Bathycalanus, und die Rostralanhänge, obwohl steif und gerade, sind weniger lang. Ferner fehlen Haare oder Dornen auf der Wölbung des Kopfes, der unter spitzem Winkel mit kleinem, helmartigem Fortsatz hervortritt und dorsal sehr deutlich gekielt erscheint. Dieser Kiel erstreckt sich nur ein kleines Stück auf den Rücken. Die Endborsten der vorderen Maxillipeden sind bandförmig und dicht bewimpert (wie bei Bathycalanus), aber diejenigen der hinteren Maxillipeden sind alle zart und von gewöhnlichem Charakter. Das 1. Fußpaar hat 2 dreigliedrige Äste und entbehrt des für Megacalanus charakteristischen Hakens.

FARran hält Megacalanus (Macrocalanus longicornis (SARS), Megacalanus princeps (WoLfENDEN), Calanus princeps (BRADY) und Heterocalanus medius (WoLFENDEN) für identisch, doch sind die Gründe dafür nicht einzusehen. Es kann nicht länger zweifelhaft sein, daß Bradys Art wegen der bandförmigen, dicht bewimperten Borsten der Maxillipeden sicherlich nicht zu Megacalanus gehört.

Ob die Charaktere dieser drei Gattungen genügen, um ihre Abtrennung voneinander zu rechtfertigen, kann Ansichtssache sein, wenn aber die generische Unterscheidung von Bathycalanus und Megacalanus anerkannt wird, so erscheint auch die Abtrennung von Heterocalanus als eigene Gattung berechtigt, denn Heterocalanus unterscheidet sich von jeder der beiden andern Gattungen deutlich durch die Bewaffnung der Maxillipeden, die Form des Kopfes und den Bau des 5. Fußpaares.

\section{1\%. Heterocalanus medius n. sp. (Tafel XL Fig. $1-5$. )}

o 10,75 mm lang; der Ceph a loth o r a ist ungefähr viermal so lang als das Abdomen. Die Breite des Rumpfes ist mehr als doppelt so groß wie die des Abdomens an der breitesten Stelle. (XL. 1.) Der Kopf ist vom ersten Thorakalsegment abgesetzt und das letzte Segment ist gerundet und tritt mit den Rändern nur wenig hervor. Der Kopf (XL. 2-4) ist vorn ziemlich schmal, in Dorsalansicht dreieckig mit vorspringendem Kiel, bei Dreiviertelansicht zeigt sich ganz deutlich ein kurzer, helmförmiger Stirnfortsatz. Dornen oder Fortsätze, wie sie bei der vorigen Gattung auftreten, fehlen hier am Kopfe, und die Rostralfortsätze sind gerade, steif und kräftig und von etwas ungleicher Länge; sie haben keine Endfilamente oder Dornen und gleichen denen von Bathycalanus. Das Ge $\mathrm{n}$ it a $\mathrm{l}$ s e g m e n t erscheint vom Rücken gesehen fast kugelig und 
ist ein wenig breiter als lang und viel breiter als das nächste Segment; in seitlicher Ansicht konkav im oberen Teile, stark konvex unten auf der Bauchfläche, mit einem kleinen Spalt in der Mitte. Das Analsegment ist sehr klein und die Furkaläste sind.um ein Fünftel länger als breit und etwa so lang als das Analsegment. Die vorderen Antennen und die Schwanzborsten waren leider abgebrochen.

Der achtgliedrige Außenast der hinteren Antennen ist etwas länger als der Innenast. Am 1. Gliede desselben findet sich eine äußerst kleine Borste, und am zweiten Basalgliede treten 2 ähnliche Borsten auf.

Die Maxillen haben einen großen, ovalen Außenast; das 2. Basalglied erscheint etwas birnförmig, der Innenast ist klein und unvollkommen in 3 Glieder geteilt. Der 1. äußere Lobus hat 7, der Außenast 11, das 2. Basalglied zwei sehr kurze und zarte Borsten und der Innenast $1+2$, von denen eine sehr kurz ist. Das letzte Glied des Innenastes trägt 4 lange und eine sehr kurze Borste; der 3. Innenlobus hat 2 kurze Borsten, der 1. Innenlobus 10 Hakenborsten.

Die vorderen $\mathrm{M}$ a xilli p e d e $\mathrm{n}$ gleichen denen von Bathycalanus; die Proximalloben haben sehr lange, bandförmige und dicht bewimperte Borsten am letzten Lobus und dem Innenast die doppelt so lang als das ganze Glied sind.

Die hinteren Maxillipeden haben 2 Basalglieder von fast gleicher Größe; der Innenast ist etwa nur halb so lang. Das 1. Basalglied ist etwa dreimal so lang als breit und das 2. Basalglied nahezu fünfmal so lang als breit.

Die Borsten aller Loben sind sehr zart, kurz und dünn; die Endborsten des Innenastes sind auch schwach und nicht so lang wie der Innenast mit dem 2. Basalglied. Die Borsten dieses Gliedes gleichen daher mehr denen von Megacalanus als denen von Bathycalanus.

Alle $\mathrm{F} \ddot{u} \mathrm{~B}$ e tragen dreigliederige Äste und entsprechen dem den beiden vorigen Gattungen gemeinsamen Typus. Beim 1. Paar ist weder am 1. noch am 2. Gliede ein Randdorn vorhanden, dagegen findet sich einer am 3. Gliede des Außenastes. Ein Hakenfortsatz fehlt dem Basalgliede (XL.5).

Der Innenast des 2. Paares ist kurz und reicht nur bis zum Ende des 2. Gliedes vom Außenaste; das 3. Glied des letzteren ist größer als die beiden proximalen Glieder und mehr als doppelt so lang wie breit, hat 3 Randdornen und eine Endsäge, die halb so lang als das letzte Glied ist.

Das 3. und 4. Fußpaar gleichen dem 2. Das 5. Paar gleicht den übrigen, ist nur kleiner und nur dreiviertel so lang wie das 4. Paar. Das 3. Glied des Außenastes hat jedoch nur 2 Randdornen, die Endsäge ist dreiviertel so lang als das Glied, und von inneren Randborsten sind 1, 1, 4 vorhanden, eine weniger als bei den andern Füßen. Die Basalglieder sind nicht so konvex wie bei den andern Fußpaaren, sondern haben fast gerade Ränder.

Vorkommen: 9. X. 033000.

Mecynocera (I. C. Thompson).

18. Mecynocera Clausi (I. C. Tномpson).

Diese Art hat eine sehr weite Verbreitung durch den ganzen Atlantischen Ozean, da sie von mir an der Westküste Irlands gefunden und vom Golf von Biscaya bis zum Kap der guten Hoffnung bekannt ist. 


\section{Paracalanus BoEck.}

\section{Paracalanus aculeatus (Giesbrecht)}

ersetzt im südlichen Atlantischen Ozean den im nördlichen Teil inklusive Ostsee und Mittelmeer auch im Pazifischen Ozean weit verbreiteten Paracalanus parvus (CLAUs), welcher nach Süden nicht so weit, wie man annahm, vorzukommen scheint. Vom ,Gauss ${ }^{66}$ wurde Paracalanus aculeatus, der sich als typische Warmwasserform erweist, am 8. September 1903, 21. September 1903, 26. September 1903 und 19. Oktober 1903 in Vertikalfängen von $400 \mathrm{~m}$ Tiefe erbeutet.

\section{Clausocalanus Gigsbrecht.}

\section{Clausocalanus arenicornis (DANA).}

Von den beiden gut bekannten Arten dieser Gattung (= Drepanopus BRADx im Challenger Report) hat Clausocalanus arcuicornis erheblich weitere Verbreitung. Verschiedenheit der Temperatur und der Lokalität scheint wenig oder keine Bedeutung für sein Vorkommen zu haben. Außer in den Fängen aus dem nördlichen und südlichen Atlantischen Ozean, wo er regelmäßig gefunden wurde, erschien er auch in zwei Fängen aus dem südlichen Eismeere, nämlich am 31. Dezember 1902 aus $385 \mathrm{~m}$ und am 24. Februar 1903 aus $400 \mathrm{~m}$ Tiefe.

\section{Clausocalanus furcatus (Brady)}

ist dagegen eine ausgesprochene Warmwasserform, die nach GIESBRECHT (Das Tierreich.) zwischen $20^{\circ} \mathrm{n}$. Br. und $20^{\circ} \mathrm{s}$. Br. im Atlantischen Ozean verbreitet sein soll. Von der Deutschen Südpolar-Expedition wurde sie am 3. September 1903, 5. September 1903 und 11. Oktober 1903 in Vertikalfängen aus $400 \mathrm{~m}$ Tiefe gefunden.

\section{Ctenocalanus Giesbrecht.}

\section{Ctenocalanus vanus (Giesbrecht).}

Durch die drei Südpolar-Expeditionen der ,Belgica“", „Discovery“ ${ }^{66}$ und des ,Gauss" wurde bewiesen, daß diese Art, welche vorher auf den nördlichen Atlantischen Ozean beschränkt zu sein schien, im antarktischen Ozean eine sehr häufige Erscheinung ist. In großen Mengen fand sie sich in den Sammlungen der Discovery, und von der Deutschen Südpolar-Expedition wurde sie am 18. Dezember 1901 bei einem Fange aus $2500 \mathrm{~m}$ nördlich von den Prinz Edward-Inseln, ferner in mehreren Vertikalfängen von der Gauss-Station (19. April 1902, 5. Dezember $1902300 \mathrm{~m}, 20$. Dezember $1902100 \mathrm{~m}$ ) und aus dem Gebiete nördlich davon noch im Scholleneise (6. Februar 1903 150 m, 3. März 1903400 m, 6. März 19031200 m, 27. März 19032000 m) erbeutet. Wesentliche Differenzen im Bau konnten zwischen den im Norden und den im Süden vorkommenden Exem. plaren nicht gefunden werden.

\section{Calocalanus (Giesbrech'T).}

23. Calocalanus plumulosus (Claus).

24. Calocalanus pavo ( $\left.\mathrm{D}_{\mathrm{ANA}}\right)$.

Diese für das Warmwassergebiet charakteristischen Arten wurden in einigen der südatlantischen Fänge, z. B. 11. Oktober 1901 in $1500 \mathrm{~m}$ und 5. September 1903 in 400 m, angetroffen. 


\section{Eucalanus (Dana).}

25. Eucalanus attenuatus (DANA).

An allen Stationen des Atlantischen Ozeans zwischen $400^{\circ}$ n. Br. (am 18. November 1903) und $35 .{ }^{\circ}$ s. Br. (12. November 1901, $3000 \mathrm{~m}$ ) wurde diese Art häufig angetroffen. Südlich vom Kap wurde sie nicht mehr beobachtet, doch erschien sie wieder am 30. Oktober 1903 bei Natal und in der Nähe der Küste bei der Fahrt von Port Natal nach Simonstown.

26. Eucalanus elongatus (DANA).

Während Giesbrecht und SchmeiL den $33 .^{\circ}$ s. Br. als Grenze für die Verbreitung dieser Art im Süden angeben, wurde diese Art noch etwa unter $47^{\circ} \mathrm{s}$. Br. im Norden der Prinz EdwardsInseln am 18. Dezember 1901 bei einem Fang aus $2500 \mathrm{~m}$ gefunden. Ferner war sie im Atlantischen Ozean an verschiedenen Stationen, von denen Tiefenfänge vorlagen, vorhanden, so am 19. Oktober $1901(500 \mathrm{~m})$, 12. November 1901 (3000 m), 17., 19., 22. August 1903 (400 und $1500 \mathrm{~m}$ ), 4. September $1903(2000 \mathrm{~m})$, 13. Oktober 1903 (3000 m).

2\%. Eucalanus mucronatus (GiesBReCht).

Diese aus dem Pazifischen Ozean beschriebene Art wurde nun auch im Atlantischen Ozean unter dem Äquator àm 30. September 1903 (1500 m) und unter $20^{\circ} \mathrm{n}$. Br. am 13. Oktober 1903 $(3000 \mathrm{~m})$ nachgewiesen.

28. Eucalanus monachus (Gresbrecht)

fand sich im tropischen Atlantischen Ozean am 10. September 1903 und 26. September 1903 (3000 m) und am 4. Oktober $1903(400 \mathrm{~m})$.

\section{Eucalanus pileatus (GIEsBrechi)}

wurde südlich von St. Helena am 26. August 1903, dann zwischen St. Helena und Ascension am 3., 8. und 9. September 1903 in Fängen aus $400 \mathrm{~m}$ Tiefe erbeutet.

30. Eucalanus subtenuis (Giesbrecht)

war nur in einem Fange aus $2000 \mathrm{~m}$ am 4. September 1903 unter $10^{\circ} \mathrm{s}$. Br. im Atlantischen Ozean vorhanden.

\section{Eucalanus subcrassus (GIESBRECHT)}

wurde allein im Porto grande bei Sao Vincente, Kap Verden, gefunden.

\section{Acrocalanus (GIesbrecht).}

32. Acrocalanus gracilis (GIESBRECHT).

Diese im Indischen Ozean häufige Art wurde am 31. Mai 1903 bei Port Natal gesammelt.

Stephus (Тн. Sco'Tr).

In ozeanischen Tiefenfängen war diese Gattung nicht zu erwarten, dagegen fanden sich in der Sammlung des „,Gauss"zwei für dieAntarktis charakteristische Arten derselben. Die eine von ihnen war bereits von GIESBRECHT im Belgica Report als Stephus longipes, die andere von mir nach der 
Ausbeute der ,Discovery“ unter dem Namen Stephus antarcticum beschrieben worden. Beide wurden auch bei der Gauss-Station gefunden, von wo Exemplare von Stephus longipes vom 5. Januar 1903 und 4. April 1902 aus $100 \mathrm{~m}$ und von Stephus antarcticum vom 29. Juni 1902 vorlagen.

\section{Stephus longipes Giesbrecht.}

q $0,75-0,80 \mathrm{~mm}$ lang, mit stark gerundetem Körper und schwach gewölbtem Kopf, ohne Rostrum; der Kopf ist teilweise vom Thorax gesondert; die letzten Segmente des Rumpfes sind symmetrisch und zeigen gerundete Ränder. Das $\mathrm{Ab} \mathrm{domen}$ besteht aus 4 Segmenten, von denen das Genitalsegment so lang wie die beiden folgenden und breiter als lang ist. Die Furkaläste sind nur so lang wie das Analsegment, haben gerundete Ränder und tragen je 4 Endborsten sowie eine kurze innere Randborste. Die vorderen A n tennen sind kurz, nicht so lang als der Thorax und bestehen aus 23 Gliedern, die gut mit Aesthetasken versehen sind. Die hinteren Antennen haben größeren Außen- als Innenast. Die hinteren M a xillipeden haben ein dickes Basalglied, welches größer als das 2. Basalglied ist, und einen Innenast, der noch kürzer als dieser ist.

Die Kauplatte der M a n dibel trägt verhältnismäßig starke Zähne. Der Innenast des 1. Fußpaares ist eingliedrig, der des 2. Fußpaares zweigliedrig und die Außenäste des 1. bis 4. Paares sind dreigliedrig. Das 5. F u $\mathrm{p}$ a a r besteht jederseits nur aus einem dreigliedrigen Aste mit kurzen, dicken Basalgliedern und einem langen, dünnen Endgliede, welches am Ende einen starken gekrümmten, mit feinen Borsten am Außenrande versehenen Haken und an der Außenkante einen kleinen Dorn trägt.

$o$ ein wenig kleiner als $\circ$, gleicht diesem außer in der Form des 5. Fußpaares, da dieses zu einem Greiforgan umgebildet ist. Der linke Fuß besteht aus 5 Gliedern, von denen das 2. und 3. verlängert sind, während das Endsegment kurz und breit ist. Dasselbe endigt mit einem Dorn und einem kurzen, knopfartigen Fortsatz. Der rechte Fuß ist viergliedrig, hat ein kurzes, breites 2. Basalglied und zwei verlängerte distale Glieder mit einem langen, sichelförmigen Fortsatze, der nicht abgegliedert ist.

\section{Stephus antareticum Wolfenden. (Nat. Antarct. Exped. Nat. Hist. vol. IV. 1908.)}

Diese von mir im Discovery Report zuerst beschriebene Art erhielt ich nur in einem Exemplare von der Gauss-Station aus einem Fange von. 29. Juni 1902. Sie ist viel größer als Stephus longipes, da sie 1,8-2,0 mm lang ist. Das letzte Thoraxsegment ist fast symmetrisch, rechts nur ein wenig länger. Das Genitalsegment hat oben eine seitliche Anschwellung mit einem charakteristischen Bündel von feinen Dornen. Die vorderen Antennèn, mit 24 Gliedern, erreichen das 2. Abdominalsegment; der Außenast der hinteren Antenne ist länger als der Innenast; die Äste der Mandibeln sind von gleicher Länge. Das 1. Fußpaar hat eingliedrigen Innenast und dreigliedrigen Außenast, ohne Dorn am ersten Gliede. Beim 2. Fußpaare ist der Innenast zweigliedrig, der Außenast wie auch beim 3. und 4. Fuße dreigliedrig, und die Innenäste vom 3. und 4. Fuße sind ähnlich gegliedert. Das 5. Fußpaar ist verhältnismäßig groß, besteht jederseits aus 3 Gliedern; jeder Fuß hat 3 Dornfortsätze am Distalende, von denen der innere Dorn dick und hakenförmig gekrümmt und am äußeren Rande behaart ist. Die beiden äußeren Dornen sind klein nur halb so lang und dick als der innerste.

Deutsolhe Stidpolar-Expedition, XII. Zoologie IV. 
35. Stephus neptuni CLeVE. (Tafel XXIV Fig. 1-7, Textfig. 3 a. b.)

(Scolecithrix neptuni? Cleve, Plancton of the South African Seas 1904.)

o 1,75-1,8 mm lang; der $\mathrm{Cephalothorax}$ ist mehr als dreimal so lang als das $\mathrm{Ab}$ domen; der Vorderkörper besteht aus 5 Segmenten; der Kopf ist mit dem 1. Thoraxsegment
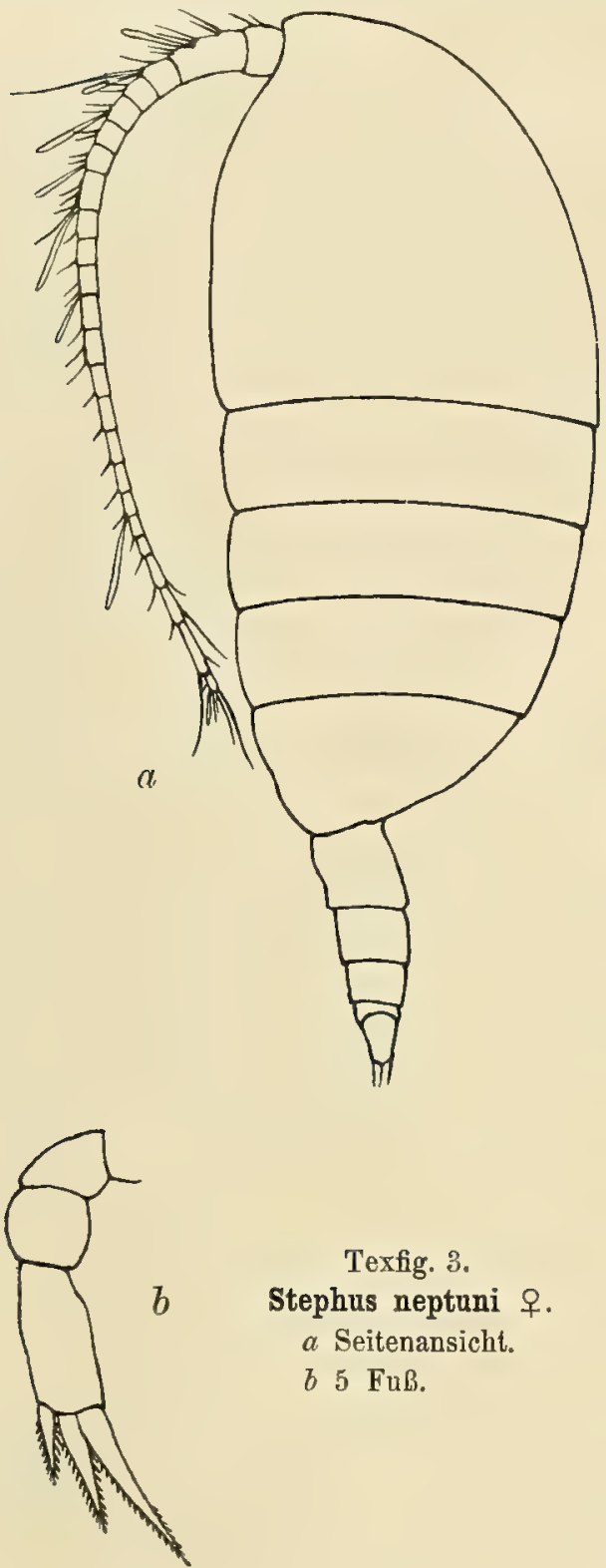

Texfig. 3. Stephus neptuni 우. a Seitenansicht. $b 5 \mathrm{FuB}$. vereinigt. Das letzte Thorakalsegment ist jedenfalls etwas verlängert, aber ganz symmetrisch mit gerundeten Rändern. Rücken und Stirn sind gleichmäßig gerundet. Rostrum oder Rostralfilamente sind nicht vorhanden. Das ganze Tier ist sehr rund und stämmig gebaut. (3a.) Das Abdomen hat 4 Segmente, von denen das Genitalsegment so lang als die drei folgenden ist. Das Analsegment ist sehr kurz, die Furkaläste sind fast zweimal so lang als breit und haben kurze, innere Nebenborsten.

Die vorderen $\mathbf{A} \mathrm{n} \mathbf{t}$ e $\mathbf{n} \mathrm{n}$ e $\mathrm{n}$ reichen etwa bis zum Ende des Cephalothorax mit ihren 24 Gliedern, von denen das zweite am längsten ist. Die beiden Endglieder sind getrennt. Die Glieder sind spärlich beborstet.

Die hinteren Antennen (XXIV. 1) haben einen sehr kurzen Innenast, der etwa nur bis zur Hälfte des 2. Gliedes des Außenastes reicht. Das 2. Glied des letzteren ist lang, das Distalglied ist von großer Länge und trägt 3 Endborsten. Am Innenast sind 13 Endborsten vorhanden, und das 2. Basalglied hat eine Borste.

Die Mandibeln (XXIV.5) haben einen sehr kleinen Außenast und einen langen Innenast und gleichen stark der Figur, welche Giesbrecht in der Fauna und Flora von Neapel von G. gyrans veröffentlichte. Das Basalglied hat 2 kurze, gekrümmte Randborsten. Die Kauplatte trägt starke innere Zähne, zahlreiche kleinere Zähne und ist stark behaart.

Die Maxillen (XXIV.4) haben einen sehr großen 1. Innenlobus mit dicken, starken Haken, während Basale und Innenast verhältnismäßig schwach erscheinen und der Außenast ganz unbedeutend, klein und mit 3 Borsten versehen ist. Am 1. Innenlobus finden sich 7 starke Borsten, am 2. und 3. 4 bzw. 3 Borsten.

Die vorderen Maxillipeden (XXIV.2) haben am distalen Ende ziemlich dichtgedrängte Loben, und die 3 distalen Loben tragen starke Hakenborsten, welche (besonders die distalen) mit steifen Randborsten bewaffnet sind. Der Innenast ist sehr klein und trägt 6 bis 7 schwache Borsten. Eine sorgfältige Untersuchung mehrerer abpräparierter Maxillipeden führte mich zu der Ctberzeugung, daß dieselben einfache und schwache Borsten sind und keineswegs als Sinnesfortsätze, wie sie bei Scolecithrix auftreten, angesehen werden können. 
Die Basalia der hinteren Maxillipeden (XXIV. 3) haben annähernd gleiche Länge, und der Innenast ist etwas mehr als halb so lang wie das 2. Basalglied. Das 1. Basalglied ist reich mit Borsten versehen, das 2. hat die gewöhnlichen 3 Randborsten, und die Borsten des Innenastes sind nicht länger als das 2. Basalglied.

Das 1. F u $\beta \mathrm{p}$ a a r (XXIV.6) ist mit eingliedrigem Innenast und dreigliedrigem Außenast versehen; jedes Glied trägt einen sehr langen äußeren Randdorn, welcher beim 1. Segment das Ende des ganzen Gliedes überragt.

Beim 2. Fußpaar (XXIV. 7) ist der Innenast zwei-, der Außenast dreigliedrig. Die 3 äußeren Randdornen des letzteren sind lang und kräftig, der Dorn des 2. Gliedes ist am längsten.

Das 3. und 4. Fußpaar haben dreigliedrigen Innen- und Außenast. Die Randdornen sind etwa gleich, und diejenigen des 3 . Gliedes stehen ziemlich dicht zusammen und teilen den Außenrand ungleichmäßig, so daß ein beträchtlicher Teil proximal unbewehrt bleibt.

Das 5. P a a r besteht aus einem gemeinsamen Basalstück und 3 Gliedern jederseits; das Endsegment ist mit 3 Dornen bewaffnet, von denen der innerste am größten, der äußere am kürzesten ist. Die beiden proximalen Glieder sind kurz, das Endglied ebensolang wie die beiden basalen und mehr als zweimal so lang als breit. Die Oberfläche der Füße ist nicht bedornt, und die Endsägen haben gekerbte Ränder. ( 3 b.)

Die Ähnlichkeit zwischen den vorliegenden Tieren und einer Art von der südafrikanischen Küste, welche CLEve als Scolecithricella neptuni beschrieb, ist sehr merkwürdig, und die Unterschiede sind in gleicher Weise bemerkenswert. Es ist schwer anzunehmen, daß die hier beschriebene Art nicht mit der früher von CLEVE gesehenen identisch sein soll. Doch existieren Unterschiede in der Segmentierung der vorderen Antennen, vielleicht auch in der Zahl der Borsten der Maxillarloben (ich bin darin nicht ganz sicher, da es schwer ist, ein vollständiges Exemplar zu erhalten) und im vorderen Maxillipeden nach der Zeichnung von CLeve. Keine dieser Abbildungen ist gut, die von dem vorderen Maxillipeden ist besonders irreführend, und die Endborsten des Innenastes sind derart gezeichnet, daß sie mehr oder weniger den Sinnesfortsätzen gleichen, wie sie bei Scolecithrix vorkommen, doch Cleve erwähnt im Text nichts davon. Auch die Zeichnung des 5. Fußes ist wahrscheinlich ungenau. - ClEve war augenscheinlich nicht geneigt, diese Art zur Gattung Scolecithrix zu stellen, und empfahl, dafür eine neue Gattung, Pseudoscolecithrix, anzunehmen, aber es erscheint mir natürlicher, sie der Gruppe anzuschließen, deren Typus Stephus gyrans darstellt. Daher rechne ich diese Art zur Gattung Stephrs, und da ich glaube, daß Cleves und meine Art identisch sind, behalte ich den Artnamen Clevess bei.

Etwa ein Dutzend Exemplare lagen von der Gauss-Station vor (29. Juni 1902 und 5. Januar 1903, $385 \mathrm{~m}$ Tiefe), doch waren sie für eingehende Untersuchung nicht sehr geeignet, da manche der zarteren Teile fehlten.

\section{Aetidius Brady.}

Lange Zeit, seitdem BraDY's Originalbeschreibung von Aetidius armatus im Challenger Report 1892 erschien, war es üblich, alle Exemplare dieser Gattung unter seinem Artnamen zu beschreiben.

Es war mir klar, wie ich schon im Marine Biol. Ass. Journal 1902 andeutete, daß die nördliche Art nicht mit BRADY's Art identifiziert werden könnte. SARS (Crust. of Norway vol. IV) hatte 
dieselbe Schwierigkeit bei der Charakterisierung der beiden Arten und stellte fest, daß BoEcK 1872 bereits Bradys Art unter dem Namen Pseudocalanus armatus beschrieben hätte.

Giesbrecht hatte Brady's Namen für einen im Mittelmeer und dem warmen südlichen Ozean gefundenen Aetidius angenommen, da er diesen mit BRADY's Art für identisch hielt.

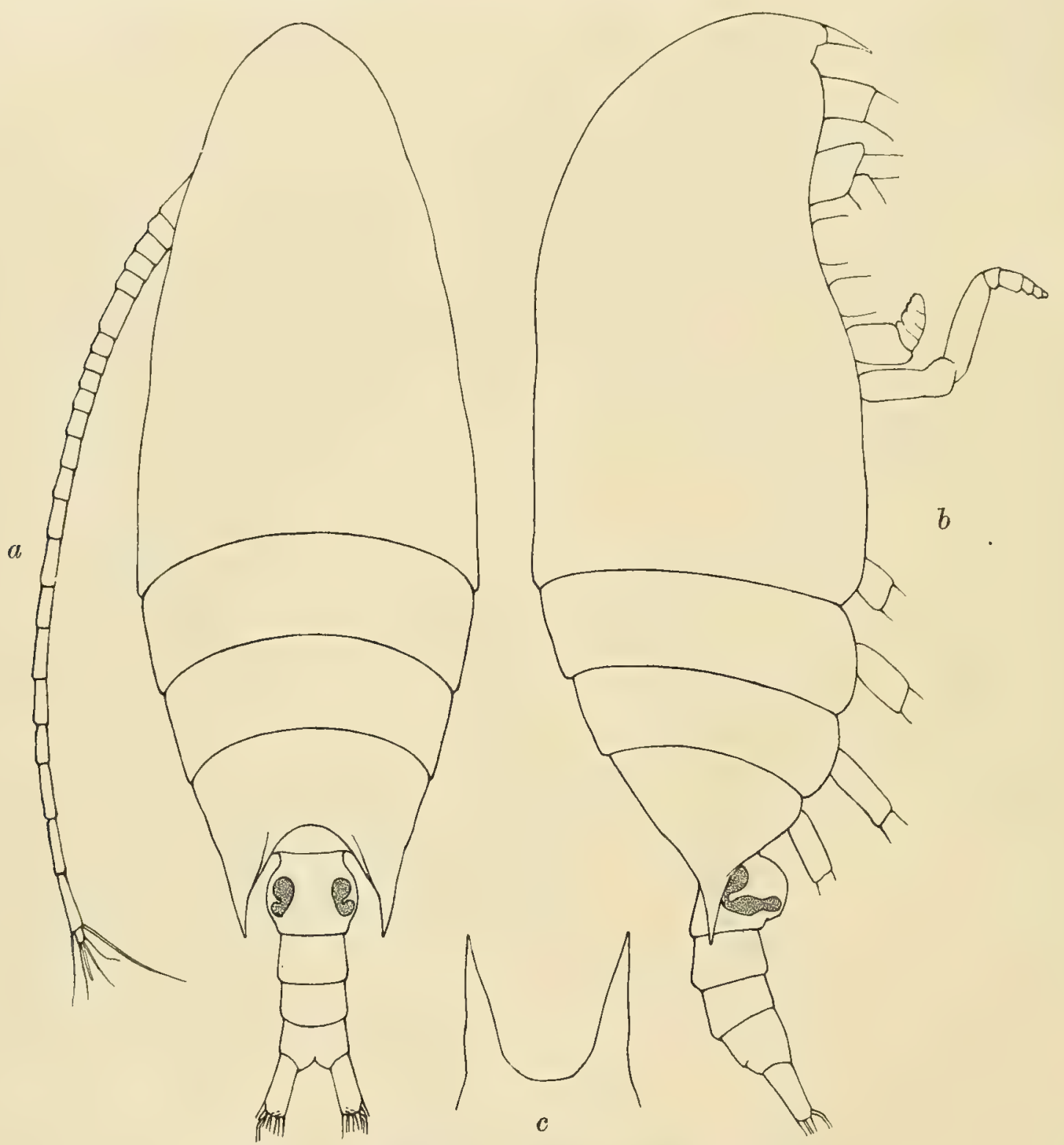

Textfig. 4. Aetidius armatus.

$a$ Rückenansicht. $\quad b$ Seitenansicht. $\quad c$ Rostrum.

Die im Atlantischen Ozean westlich von der irischen Küste, dem Faroe Channel (WoLFENDEN), an der norwegischen Küste (BOECK, SARS) angetroffene Art ist sicher in wesentlichen Merkmalen von der Art des Mittelmeeres, welche Giesbrecht beschrieb, sehr verschieden. Wie Sars sagt (Crust. Norway vol. IV, Copepoda p. 26), kann es nicht zweifelhaft sein, daß die nordische Art den wahren Pseudocalanus armatus von Botck (1872) repräsentiert, und daher war ein neuer Name nötig, um GIesbrecht's und Brady's Arten zu unterscheiden. Cleve (Plankton of the South 
African Seas) erwähnt die erstere als Aetidius giesbrechti und sagt, daß die südafrikanischen Exemplare völlig mit den nordischen übereinstimmen, nur etwas kleiner sind, 1,6 mm statt 1,8 mm (nach SARS) messen, und bemerkt ferner, daß Aetidius giesbrechti an der Ost- und Westküste Südafrikas sehr selten ist.

\section{Aetidins armatus BoECK. (Textfig. 4 a-c-c)}

In der Sammlung des ,Gauss" sind zahlreiche Exemplare von Aetidius vorhanden, und in Anbetracht der Unsicherheit, welche noch über diese Art herrscht, habe ich sie von neuem untersucht. Die Verschiedenheit beider Arten zeigt sich beim ersten Blick auf die beigegebenen Abbildungen. Die nördliche Art (von Faroe Channel) ist 1,7-1,8 mm lang, hat keinen Kiel auf dem Kopfe, der vollkommen gleichmäßig und kühn gerundet erscheint. Er tritt vorn nicht wie bei der zweiten Art hervor, und die Basis des Rostrums zeigt keine Chitinverdickungen. (4 c.) Das letzte Thorakalsegment ist seitlich in Fortsätze ausgezogen, welche mehr dornartig als bei der andern Art sind. Die Furkaläste sind verhältnismäßig länger, und die vorderen Antennen reichen bis zum Ende der Furka. (4 a. b.) Diese Exemplare stimmen mit den Figuren, welche Sars in Crust. of Norway vol. IV, Copepoda Taf. XIII und XIV, abbildet, überein, und wie SARS sagt, kann kein Zweifel an ihrer Identität mit Pseudocalanus armatus BoEck 1872 sein.

Dieses wäre also der wahre Aetidius armatus, und ein Vergleich mit den Abbildungen, welche BRADY im Challenger Report Taf. X gibt, zeigt zweifellos, daß sein Aetidius armatus mit der nordischen Art identisch ist.

Aetidius armatus ist im südlichen Atlantischen Ozean selten. Die Art wurde vom "Gauss" am 19. September 1903 (400 m), 26. September 1903 (3000 m) und im Indischen Ozean am 9. Mai 1903 (400 m) gefunden. Nach Cleves Untersuchungen über das südafrikanische Plankton findet sie sich spärlich im Süden der Kapkolonie.

Ich finde zwischen diesen und den norwegischen Exemplaren keine wesentlichen Unterschiede. Augenscheinlich ist die Art weit, obwohl spärlich verbreitet, ihre eigentliche Heimat aber scheint der nördliche Atlantische Ozean zu sein.

\section{Aetidius giesbrechti Cleve.} (Tafel XXIV, Fig. 8, Textfig. 5 a. b.)

Die zweite Art, für welche Cleve den Namen Aetidius giesbrechti (nom. nov.) vorschlug, ist sicher

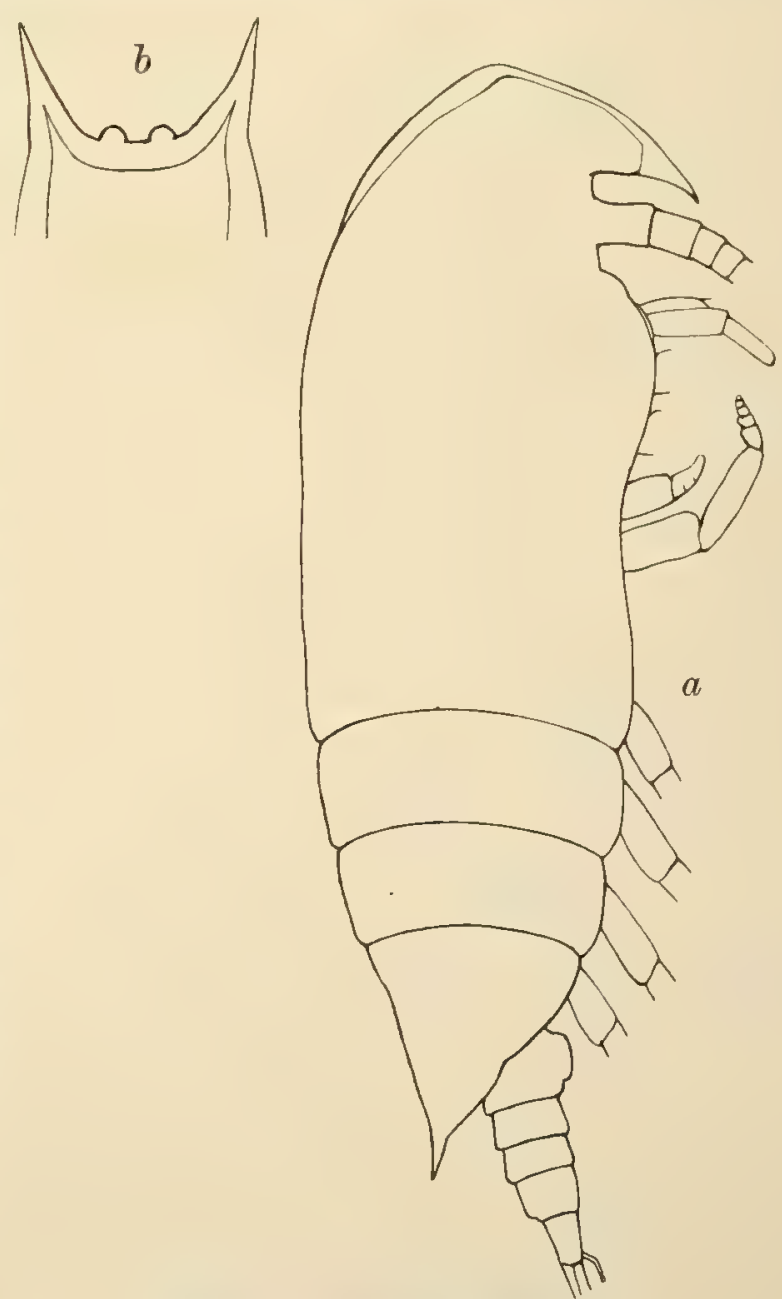

Textfig. 5. Aetidius giesbrechti.

a Seitenansicht.

$b$ Rostrum. 
die von Giesbrecht in Fauna und Flora von Neapel Bd. 29 beschriebene Art. Sie weicht von der nordischen Art darin ab, daß der Kopf mit einem dorsalen Kiel ausgestattet und nach vorn verlängert ist, ein starkes Rostrum mit basalen Chitinverdickungen trägt ( $5 \mathrm{~b})$ und da $\mathrm{B}$ das letzte Thorakalsegment beiderseits in flügelartige, spitz endigende Fortsätze ausläuft. (XXIV. 8, Textfigur 5 a.) Cleve traf diese Art sehr selten östlich und westlich von der südafrikanischen Küste an. Ich habe dieselbe in den Vertikalfängen des „Gauss" vom 5. November 1901 (1000 m), 18. Dezember 1901 (2500 m), 4. September 1903 (2000 m), 9. Oktober 1903 (3000 m) aus dem Atlantischen und vom 15. Mai $1903(400 \mathrm{~m})$ aus dem Indischen Ozean gefunden.

\section{Bradyidius Giesbrecht.}

\section{Bradyidius armatus Giesbrecht}

wurde in zwei Exemplaren bei Tiefenfängen aus $1200 \mathrm{~m}$ am 6. März 1903 und aus $3000 \mathrm{~m}$ am 10. März 1903 im Nordwesten von der Gauss-Station noch im Scholleneise erbeutet. Trotz sorgfältiger Untersuchung kann ich keine wesentlichen Unterschiede zwischen diesen Exemplaren und andern aus dem Nordmeere finden. Die Verbreitung dieser Art ist sicher sehr weit, von Grönland (VANHOEFFEN, Grönland-Expedition 1892-1893) bis zur Antarktis und bis zum Malediven-Archipel, wo ich sie in den Sammlungen von Professor Stanley Gardiner nachweisen konnte. Indessen scheint die Art nicht im offenen Ozean, sondern mehr in Küstennähe vorzukommen, am schlammigen Boden zu leben und nirgends in größerer Menge aufzutreten.

\section{Chiridius Giesbrecht.}

Diese Gattung wurde für die eine Art Chiridius poppei aufgestellt, welche zwar manche Charaktere der Gattung Aetidius hat, sich aber durch die Abwesenheit eines Rostrums, ferner durch verkürzte Äste der hinteren Antennen und der Mandibeln und kurzen Innenast der hinteren Maxillipeden von ihr unterscheidet. Nach der Originalbeschreibung im Jahre 1892 scheint die obengenannte Art nicht beobachtet zu sein, bis sie von mir in der Sammlung des „Gauss", dann von Farran (später als Chiridius gracilis noch einmal beschrieben) und von Cleve in Fängen von der südafrikanischen Küste angetroffen wurde (a. a. O. 1905).

SARs beschrieb im Bericht über die Copepoden der "Norwegian North Polar Expedition" 1900 Chiridius armatus, den er für identisch mit der von BoECK erwähnten, aber ungenügend bekannten Art Euchaeta armata hielt. In den Crust. of Norway vol. IV 1903 gab SARS dann eine andere Art als Chiridius armatus aus, welche er nun als identisch mit der ursprünglichen Art BoEcKs betrachtete, und gab der Art des Nordpolmeeres den Namen Chiridius obtusifrons. VANHOEFFEN revidierte die Synonymie (Zool. Jahrbücher 1907) mit besonderer Berücksichtigung der von ihm ursprünglich aus Grönland 1897 als Pseudocalanus armatus BoEcK beschriebenen Art (v. DRYGaLSKI, Grönland-Expedition der Gesellschaft für Erdkunde 1892-93), deren nahe Verwandtschaft mit der Gattung Chiridius ihm bereits aufgefallen war (Zool. Anz. Nr. 540, 1897, p. 322). SARs scheint diese Arbeiten VANHÖFFEN's nicht gekannt zu haben.

Der von VANHÖFFEN beschriebene und auf BoECKs Art bezogene Chiridius armatus (Crustaceen aus West-Grönland) ist sicher nicht mit dem unter demselben Namen von SARS beschriebenen Tiere (Crust. of Norway) identisch. VANHöFfEN's Art hat kein Rostrum, und das 5. Fußpaar des ô 
derselben zeigt keine Spur von Innenästen. Chiridius armatus SARS dagegen besitzt ein zweispitziges Rostrum, und das 5. Fußpaar ist abweichend gestaltet, besonders durch das Auftreten rudimentärer Innenäste. VANHöFFEN's Art ist ein echter Chiridius, die von SARS aber nicht. Wenn überhaupt den Gattungsdiagnosen einiger Wert beigelegt werden kann, muß man den Mangel eines Rostrum, den GIesbrecht als eines der bezeichnendsten Merkmale für die Gattung Chiridius angab, anerkennen, und die widersprechende Behauptung Farrans (Fisheries Ireland a. a. O.), daß dieses ein Charakter ohne generische Bedeutung sei, ist nicht stichhaltig. Demnach gehört Chiridius armatus VANHÖFFEN korrekt zur Gattung Chiridius GIESBRECHT, während Chiridius armatus SARS einer andern Gattung zugeteilt werden muß, für welche ich 1904 (Journ. Marine Biol. Soc. vol. VII no. 1) den Namen Pseudaetidius vorschlug und welcher Pseudocalanus armatus BoEcK = Chiridius armatus SARS angehört. Wie VANHÖFFEN bemerkt: ,,daher ist dann der Name Chiridius obtusifrons SARS überflüssig, .... und der an der norwegischen Küste gefundene Chiridius muß entsprechend der alten Bezeichnung Pseudoc. armatus BoEck jetzt Chiridius armatus BoEck heißen" (a. a. 0. p. 520). SARs hat neulich (Bull. Int. Ocean 1907) eine neue Art, Chiridius brevicaudatus, und FARRAN (a.a.O.) eine andere, Chiridius gracilis, beschrieben, welche beide in der Abwesenheit eines Rostrums der Gattungsdiagnose entsprechen, aber vom Typus im Vorhandensein eines größeren Innenastes der hinteren Antennen abweichen.

39. Chiridius polaris n. sp. (Tafel XXIV, Fig. 9-12, Textfig. 6 a. b.)

9 2,75 mm lang, davon Cephalothorax 2,1 mm, Abdomen 0,65 mm. (6 a.b.) Der Cephalothorax hat 4 Segmente, da Kopf und 1. Segment sowie die beiden letzten Segmente verschmolzen sind. Der Kopf erscheint von der Seite gerundet, vom Rücken ziemlich viereckig und zeigt keine Andeutung eines Rostrums. Kopf und 1. Segment sind mehr als doppelt so lang als der übrige Rumpf, und das letzte Segment ist in kurze Spitzen mit breiter Basis verlängert. Das Abdomen besteht aus 4 Segmenten, von denen
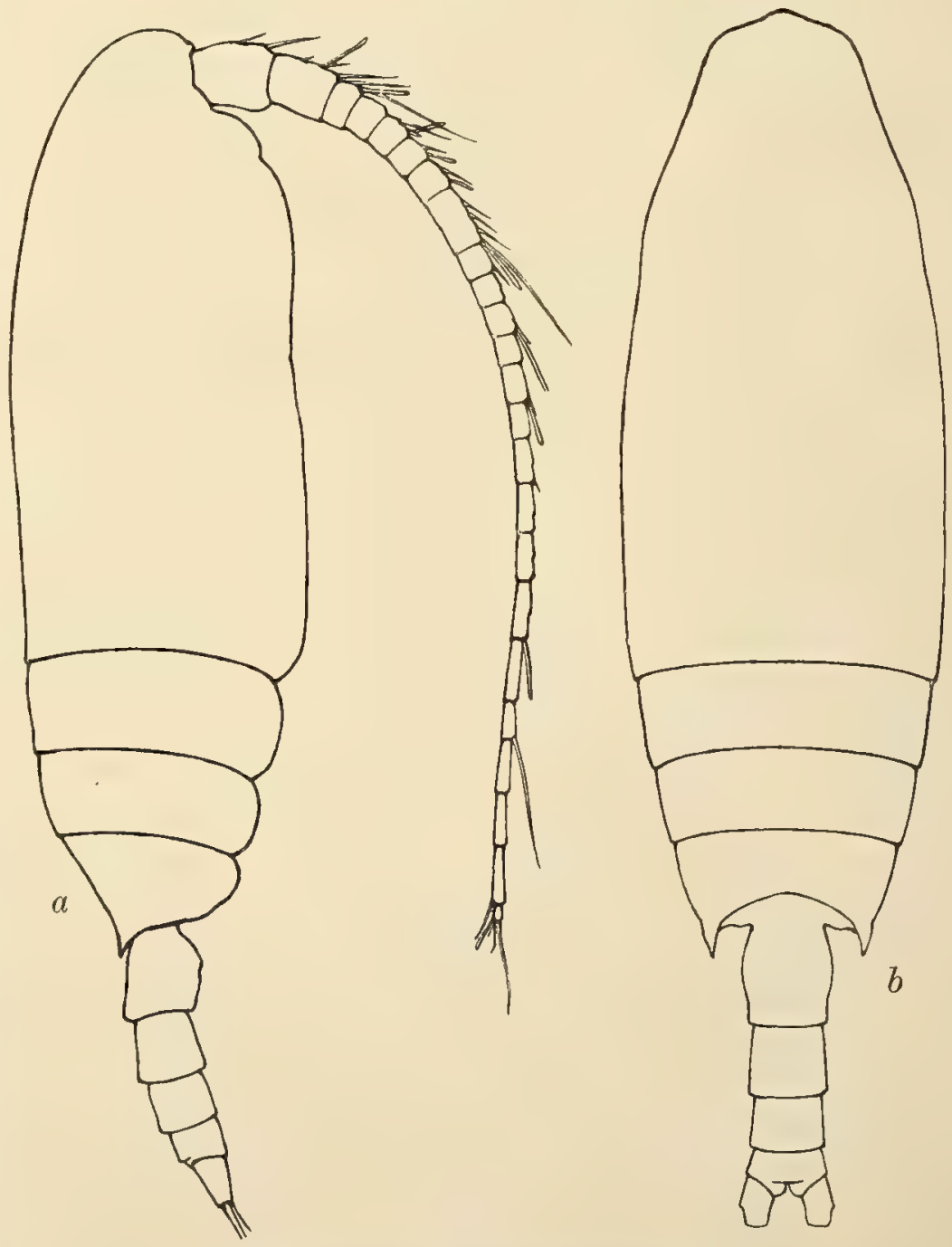

Textfig. 6. Chiridius polaris. $a$ Seitenansicht. $b$ Rückenansicht, 
das Genitalsegment doppelt so lang als das nächste ist; die beiden mittleren Segmente sind gleich, das Analsegment ist kürzer als das vorhergehende und die Furkaläste sind so lang als das Analsegment, dabei länger als breit.

Die vorderen Anten $\mathrm{n}$ e $\mathrm{n}$ reichen bis zum Ende des Genitalsegmentes und bestehen aus 24 Gliedern, von denen das 8. und 9. Glied verschmolzen, das 19. etwas länger als das 18. und viel länger als das 20. Glied ist.

Der Außenast der hinteren Antennen ist etwa doppelt so lang wie der Innenast. Bei den $\mathrm{M}$ a $\mathrm{ndibeln}$ ist der Außenast länger als der Innenast und der letztere sehr klein, unbedeutend und nur halb so dick als der Außenast. Nur 2 Randborsten sind am 1. Gliede des Innenastes vorhanden und 2 am Innenrande des 2. Basalgliedes, von denen die proximale sehr stark, die distale aber sehr schwach ist. Im Ganzen finden sich am Innenast 7 Endborsten.

Die vorderen M axillipeden haben ein großes $\mathbf{1}$. Basalglied und kräftige Loben und gleichen in der allgemeinen Gestalt denen von Chiridius obtusifrons SARs.

Die hinteren Maxillipeden (XXIV. 9) haben ein verlängertes 2.Basalglied, das fünfmal so lang als breit ist, und einen deutlich fünfgliedrigen Innenast, der kürzer als das halbe 2. Basalglied ist.

Das 2. Basalglied der Maxillen ist ebenfalls verlängert, länger als breit, mit 4 distalen Borsten. Der Außenast ist klein, nicht halb so lang als das 2. Basalglied, und der Innenast klein und nicht gegliedert.

Das 1. F u $\beta$ p a a r (XXIV. 10) hat eingliedrigen Innenast und dreigliedrigen Außenast mit langen, dünnen, äußeren Randdornen. Das 2. Fußpaar (XXIV. 11) hat einen eingliedrigen Innenast, der bis zum Ende des 2. Gliedes des dreigliedrigen Außenastes reicht. Die Äste des 3. und 4. Fußpaares sind dreigliedrig und die Segmente derselben verhältnismäßig weniger breit als bei Chiridius obtusitrons SARS. (XXIV. 12.)

Chiridius polaris und Chiridius gracilis FARRAN gleichen einander in der Größe, aber die antarktische Art unterscheidet sich von der letzteren durch längere vordere Antennen und kürzeren Innenast der hinteren Antennen. (Bei Chiridius gracilis sollen diese nach FARRAN den hinteren Antennen von "Chiridius armatus $\mathrm{SARS}^{\text {" }}=$ Pseudaetidius gleichen; bei welchem der Innenast völlig drei Viertel der Länge des Außenastes hat.) Bei Chiridius gracilis sind die Fußglieder mehr miteinander verschmolzen, so sind die beiden Proximalglieder des Außenastes vom 2. Fußpaare teilweise verwachsen und der Innenast des 3. Fußpaares ist unvollkommen dreigliedrig.

Ein Exemplar von Chiridius polaris lag mir aus einem Fange vom 10. März 1903 (3000 m), noch im Scholleneise nordwestlich von der Gauss-Station, vor.

\section{Chiridius poppei Giesbrecht.}

우 $1,9 \mathrm{~mm}$, davon Cephalothorax 1,5, Abdomen 0,9 mm lang. Der K o p f ist gleichmäßig gerundet, ohne Spur eines Rostrums. Das letzte Thorakalsegment ist in verhältnismäßig kräftige, stark divergierende Dornen verlängert. Das A b d o m e $\mathrm{n}$ besteht aus 4 Segmenten, deren Längen sich verhalten wie $3: 2 \frac{1}{2}: 2: 1$. Die Furkaläste sind doppelt so lang als breit und um ein Drittel länger als das Analsegment.

Die vorderen Antennen sind nicht so lang als der Cephalothorax und bestehen aus 23 Gliedern, da das 8. und 9. sowie das 24. und 25. verschmolzen sind. 
Die Borsten sind kurz, die Ästhetasken lang und dünn. Bei den hinteren Antennen ist der Außenast doppelt so lang als der Innenast, sein distales Glied lang und um ein Drittel länger als das 2.

Die $\mathrm{M}$ a $\mathrm{ndi}$ ibeln haben ein birnförmiges 2. Basalglied mit 2 kurzen Randborsten. Der Außenast ist deutlich dreigliedrig und mit langen und verhältnismäßig dicken Borsten versehen. Der sehr kleine Innenast besteht aus 2 Gliedern, von denen das proximale eine kurze, starke Borste, das 2. Glied 7 zarte und kurze Borsten trägt. Die Kauplatte hat starke Zähne, von denen die äußeren am längsten und stärksten sind. Die $\mathrm{M}$ a xille $\mathrm{n}$ tragen 7 Borsten am 1. Außenlobus, 8 am sehr kleinen Außenaste; das 2. Basalglied ist um ein Drittel länger als breit. Am sehr kurzen Innenaste sind 12 Borsten, 4 am 2. Basalgliede, 5 am 2. und 4 am 3. Innenlobus vorhanden.

Der Außenrand der vorderen Maxillipeden ist schwach konvex und die Loben derselben distal etwas zusammengedrängt; alle haben ungefähr dieselbe Größe; die 3 proximalen Loben tragen je 2 Stachelborsten und eine kurze Borste, der 4. Lobus zwei schlanke Haken und der 5. ist in einen kurzen, aber verhältnismäßig kräftigen Haken verlängert. Am Innenaste finden sich 5 divergierende Borsten.

Die $\mathrm{h}$ in ter e $\mathrm{n}$ M x $\mathrm{xll}$ i p e d e $\mathrm{n}$ haben sehr kurzen Innenast. Die Längen ihrer Basalia und des Innenastes verhalten sich wie $30: 34: 16$. Der Innenast ist deutlich fünfgliedrig, das 1. Basalglied etwas breiter als das 2. und das letztere fast viermal so lang als breit.

Das 1. F u B p a r hat deutlich eingliedrigen Innenast und dreigliedrigen Außenast mit 3 Randdornen. Das zweite Fußpaar hat ebenfalls nur eingliedrigen Innenast, dreigliedrigen Außenast. Eine Einschnürung am Rande des Innenastes zeigt eine Spur von Gliederung an, doch ist keine Querlinie erkennbar. Die Äste des 3. und 4. Fußpaares sind dreigliedrig. Die Randborste des 1. Basalgliedes vom 3. Fuß ist stark gefiedert.

Diese vom „Gauss" am 9. X. 03. (3000 m) erbeutete Art ist mit der von GIE SBRECHT aus dem Mittelmeer beschriebenen identisch. Chiridius poppei ist nach der ersten Beschreibung (Fauna und Flora von Neapel vol. 19) wenig bekannt geworden. Cleve erwähnt die Art in einer Liste südafrikanischer Copepoden als ,Chiridius poppei Giesbrecht Agulhas Current" (The Plankton of the South African Seas, Marine Invest. in South Africa vol. III, 1905), ohne jede weitere Beschreibung, dann führte FARRAN sie als an der Westküste Irlands vorkommend auf (Report Fisheries Ireland for 1902/03 Part II, 1905). Später aber beschreibt er dasselbe Tier als Chiridius gracilis (Fisheries Ireland Sci. Invest. 1906 II [1908], welche dort in tiefem Wasser von 280-1000 Faden sehr häufig zu sein scheint.

In Anbetracht der von SARS und FarRaN geäußerten Meinung von der Erweiterung der Gattung Chiridius zur Aufnahme anderer Formen, welche vom Typus Giesbrecht's erheblich abweichen, hielt ich es für wünschenswert, diese Art noch einmal zu beschreiben und die Gattungsdiagnose GIESBRECHT's zu vervollständigen.

\section{Faroella (WoLfenden.)}

Im Jahre 1902 (British Association, Belfast) schlug ich den Namen Pseudaetidius für eine neue Gattung vor, welche 2 Copepoden vom Faroe Channel, Pseudaetidius armatus und Pseudaetidius multiserrata umfassen sollte. Die erstere wurde seitdem von SARS als identisch mit 
BoECKs Euchaeta armata (Christ. Vid. Selsk. Forhandl. 1872) erkannt und zu GIESBRECHT's Gattung Chiridius gerechnet, was jedoch diese Gattung erheblich über die ursprünglich von GIESBRECHT gesteckten Grenzen erweitern würde. Für die zweite Art, Pseudaetidius multiserrata, stellte ich dann (Journ. Marine Biol. Assoc. April 1904) eine neue Gattung, Faroella auf, weil sie auf Grund einiger Merkmale nicht unmittelbar mit der andern verwandt erschien. Ich würde nun Faroella multiserrata und Aetidiopsis rostrata SaRs für identisch gehalten haben, nur durch die Größe verschieden (Aetidiopsis ist viel größer), wenn nicht Exemplare von Faroella, welche FARRAN sowohl mir wie auch SARS zur Bestimmung übergeben hatte, von letzterem als völlig verschieden von seiner Aetidiopsis rostrata erklärt worden wären ${ }^{1}$ ).

Faroella erscheint im kalten und tiefen Wasser der nördlichen sowohl wie der südlichen Meere, doch ist die südliche Art mit der aus dem Faroe Channel nicht identisch. Im Bericht über die Discovery Expedition ${ }^{2}$ ) beschrieb ich eine antarktische Art unter dem Namen Faroella antarctica. Außer dieser fand sich in den Sammlungen des "Gauss" noch eine zweite kleinere Art dieser Gattung.

\section{Faroella antaretica Wolfenden.}

Obwohl sehr ähnlich der Faroella multiserrata, unterscheidet sie sich doch deutlich durch die bedeutendere Größe von 3,55 mm, durch stärkeres Rostrum, etwas verschiedene Körperverhältnisse und mehr gleiche Größe der Äste der hinteren Antennen. Genaue Beschreibung und Abbildung findet sich im Discovery Report. Ein Exemplar lag vor von der Gauss-Station vom 26. Dezember 1902 .

\section{Faroella minor no sp.}

o 2,56 $\mathrm{mm}$ lang, wovon 1,86 $\mathrm{mm}$ auf den Cephalothorax, 0,7 mm auf das Abdomen kommen. Der Cephalothorax ist also $21 / 2 \mathrm{mal}$ so lang als das Abdomen, der Kopf ziemlich viereckig an der Stirn und seitlich ausgebaucht. Der Rumpf ist noch nicht halb so breit als lang. Die beiden letzten Segmente sind völlig gesondert, das hintere sehr kurz und tritt seitlich mit kurzen, starken und an der Basis breiten Spitzen hervor. Der Kopf ist teilweise durch eine dorsale Grube vom 1. Segment abgesondert. Das Rostrum ist klein und gegabelt, mit nicht divergierenden Spitzen. Das Genitalsegment ist größer als das Analsegment, da die Abdominalsegmente von vorn nach hinten allmählich an Größe abnehmen. Die Furkaläste sind länger als das Analsegment, zweimal so lang als breit und mit gerundeten Hinterrändern versehen. Das Genitalsegment springt nach unten vor und erscheint an den Seiten ziemlich kugelig gewölbt.

Die vorderen Antennen reichen bis zum Ende des Genitalsegments und bestehen aus 24 Segmenten, von denen das 8. und 9. verschmolzen sind, da dieses Glied so lang wie die beiden vorhergehenden Glieder und größer als die beiden folgenden ist.

Der Außenast der hinteren Antennen ist nur wenig größer als der Innenast. Die vorderen M a xilli p e d e n haben schwach konvexen Außenrand, und ihre 4 ersten Loben sind von nahezu gleicher Größe und mit je 3 Borsten ausgestattet. Am 4. Lobus findet sich ein schlanker Haken;

\footnotetext{
1) Farran Fisheries Ireland Sci. Invest. 1906 II [1908].
}

$\left.{ }^{2}\right)$ National Antaretic Expedition vol. IV, Copepoda p. 39. 
der 5. ist größer als die übrigen und trägt einen kräftigeren Haken. Bei den hinteren Maxillipeden ist der Innenast nur halb so lang als das 2. Basalglied, welches wieder um ein Viertel größer als das 1. Basale ist. Das 2. Basalglied ist etwa fünfmal so lang als breit. Die Außenäste der Mandibeln sind länger und dicker als die Innenäste.

Am 1. F u B pa a re sind die Innenäste eingliedrig, die Außenäste dreigliedrig, mit drei Randdornen und mit einem kleinen Dorn am äußeren Distalrande des 2. Basalgliedes versehen. Das 2. Fußpaar hat ebenfalls eingliedrige Innen- und dreigliedrige Außenäste. Das letzte Glied derselben ist breit, das zweite ebenso breit als lang und, die Endsäge hat die Länge des 3. Gliedes. Dieses ist nicht so lang wie das 1. und 2. Segment zusammengenommen. Die ersten Basalglieder haben einige wenige Dornen am Außenrand. Am Innenast ist durch eine sehr schwache und unvollkommene Linie eine Teilung in 2 Segmente nur angedeutet.

Beim 4. Fußpaare sind die Innenäste dreigliedrig und die beiden Basalglieder fast vollständig verschmolzen, da nur Einschnürungen am Rande die Grenze markieren. Die Außenäste sind dreigliedrig; das 3. Glied ist länger als das 1. und 2. Glied zusammen und die Endsäge noch etwas länger als das dritte Glied. Die Endsägen des 2. bis 4. Fußpaares sind durch ihren kräftigen Bau ausgezeichnet und durch die große Zahl von 50-60 dichtgedrängten Zähnen.

Diese Art weicht von Faroella antarctica nicht nur durch geringere Größe und weniger kräftiges Rostrum mit nicht divergierenden Spitzen ab, sondern auch in der Gliederung der Füße, welche hier (minor) unvollkommen ist, während bei Faroella antarctica die Innenäste des 2. Fußpaares deutlich zweigliedrig und beim 3. und 4. Fuße deutlich dreigliedrig sind. Die eigentümliche Zähnelung der Endsägen der Füße ist genügend, Faroella von verwandten Gattungen zu unterscheiden.

Zwei Exemplare von Faroella minor wurden im Scholleneise am 6. und 10. März 1903 nordwestlich von der Gauss-Station gefunden.

\section{Spinocalanus (Giesbrecht).}

Seitdem GIESBREChT seinen Spinocalanus abyssalis beschrieb ${ }^{1}$ ), waren keine neuen Arten dieser Gattung bekannt geworden bis zur Entdeckung des Spinocalanus magnus aus dem Atlantischen Ozean westlich von Irland 2), welcher häufig, obwohl nie reichlich, in den Fängen über dem Abfall zum Atlantischen Ozean von der Oberfläche bis zu r000 Faden Tiefe gefunden wurde ${ }^{3}$ ).

Das Gebiet dieser Art erstreckt sich im Atlantischen Ozean ziemlich weit nach Süden, und nach der Ausbeute des „Gauss" erscheint dieselbe im antarktischen Eismeere wieder. Eine andere, der nördlichen ähnliche Art, Spinocalanus antarcticus (WoLFENDEN), wurde bereits 1906 in „PlanktonStudien" von mir beschrieben. Dann erwähnte FARRAN Spinocalanus spinosus von der Westküste Irlands, und SARS charakterisierte kurz zwei neue Arten aus den Sammlungen des Fürsten von Monaco ${ }^{4}$ ), nämlich Spinocalanus latifrons und Spinocalanus hirtus. Endlich fand sich in den Sammlungen des "Gauss" aus dem Atlantischen Ozean noch eine weitere Art, welche mit keiner der früher bekannten übereinzustimmen scheint.

1) Atti Acad. Lincei Rend. ser. 4, 1888.

2) Wolfenden, Journal Marine Biol. Association 1904.

3) Farran, Fisheries Ireland. Sci. Invest. 1906 II [1908].

4) Bull. Inst. Oceanogr. 30. April 1907. 
43. Spinocalanus horridus n. sp. (Tafel XXV, Fig. 1 und 2, Textfig. 7.)

웅 $2,35 \mathrm{~mm}$. Der Kopf ist mit dem ersten Thorakalsegment verschmolzen, und dieses Segment ist viel größer als der übrige Teil des Thorax. (7.) Das Abdomen ist nicht völlig halb so lang als der Thorax. Der Kopf ist vorn schmal, ein Rostrum fehlt vollständig. Das letzte Thorakal-

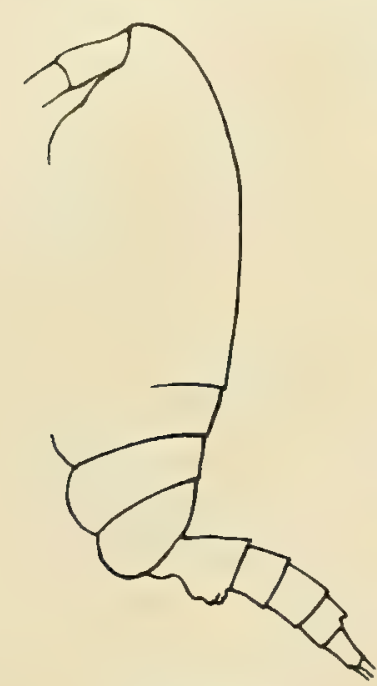

Textfig. 7.

Spinocalanus horridus. Seitenansicht. segment (XXV. 1) ist etwas gerundet, tritt jedoch seitlich nicht hervor. Das Genitalsegment übertrifft das folgende nnr wenig an Länge. Die Furkaläste sind nicht länger als das Analsegment, aber länger als breit und unbehaart.

Die hinteren Maxillipeden (XXV. 2) haben einen sehr langen Innenast, dessen erstes Glied verhältnismäßig sehr kurz erscheint, während das 2. sehr lang, das 3. kürzer ist und die beiden Endglieder klein sind. Das erste Basalglied trägt mehrere Reihen feiner Dornen auf seiner Oberfläche und einen kurzen, starken Dorn am Distalrande. Das 2. basale Glied ist am äußeren Rande und auf der Oberfläche mit einer Reihe von lang vortretenden Dornen ausgestattet, und der innere Rand ist mit einer Bewehrung von sehr feinen, dichtstehenden Dornen versehen.

Das 1. F u B p a a $\mathrm{r}$ hat einen eingliedrigen Innenast und dreigliedrigen Außenast mit 3 äußeren Randdornen, 4 inneren Randborsten und einer Endborste. Das 2. Fußpaar besitzt einen zweigliedrigen Innenast mit Kränzen von vorspringenden Dornen auf der Oberfläche. Der 3. und 4. Fuß waren bis auf die Basalia abgebrochen. Diese zeigten auf der Oberfläche Reihen feiner Dornen und Büschel von steifen Borsten. Das 5. Fußpaar fehlte.

Obwohl Antennen, Füße und andere Teile stark beschädigt waren, ließen doch der Gesamtcharakter und die Borsten des 1. Fußpaares die Art als Spinocalanus zugehörig erkennen. Die Ventralseite der Thorakalsegmente ist mit feinen Dörnchen bedeckt. Die Art hat mit Spinocalanus spinulosus FARRAN einige Ähnlichkeit, ist jedoch trotz bedeutenderer Größe nicht so kräftig als diese. Sie wurde am 11. Oktober 1901 in einem Vertikalfang aus $1200 \mathrm{~m}$ im Südwesten von Ascension erbeutet.

44. Spinocalanus magnus (Wolfenden). (Tafel XXV, Fig. 3-5, Textfig. 8 a. b.)

․ Die Durchschnittsgröße erwachsener Exemplare beträgt etwa 2,6 $\mathrm{mm}$, obwohl einzelne Exemplare von 2,75-2,80 mm Länge gefunden wurden. Der K o p f und das 1. Thorakalsegment sind $3 \frac{1}{2} \mathrm{mal}$ so lang als das Abdomen. Die beiden letzten Thoraxsegmente sind gesondert und der hintere Rand des letzten Segments ist seitlich in kurze Flügel ausgezogen. Der Kopf ist gleichmäßig gerundet und erscheint vom Rücken gesehen etwas dreieckig. Rostrum fehlt. Das ziemlich kurze A b d o m e $\mathrm{n}$ hat eine ventrale Anschwellung am Genitalsegment, welches größer als die beiden folgenden Segmente zusammen ist. Das Analsegment ist ebenso lang wie das vorletzte, und die Furkaläste sind etwas länger als das Analsegment, etwas länger als breit. Am linken Aste ist eine der Endborsten erheblich dicker als die übrigen. (8 a. b.)

Die vorderen Antennen haben 24 Glieder (8. und 9. verschmolzen) und überragen etwas die Furka. Die basalen Glieder sind dick, und die übrigen werden nach dem Ende zu allmählich 
schmäler. Die hinteren Antennen haben nahezu gleichlange Äste, und ebenso sind die Äste der M a n dibeln von fast gleicher Länge. Die Kauplatte zeichnet sich durch große Zähne aus. Die Maxillen haben einen großen 1. Innenlobus; der 2. Lobus hat 5, der dritte 4, das 2. Basalglied 5, der Innenast 15 Borsten. Der 2. äußere Lobus hat keine, der verhältnismäßig große Außenast 11 Borsten. An dem 1. und 5. Lobus der vorderen $\mathrm{M}$ a $\mathrm{x}$ illi pe de $\mathrm{n}$ finden sich 4, an den übrigen Loben 3 Borsten. Der 4. Lobus hat einen ziemlich kräftigen fein gezähnten Haken.

Die hinteren Maxillipeden (XXV. 3) haben einen langen Innenast, welcher länger als jedes der beiden Basalglieder ist und dessen 2. Glied die übrigen Glieder an Länge übertrifft. Das 4. Glied trägt eine starke, gefiederte Dorsalborste.

Das 1. Fußpaar hat einen eingliedrigen Inneriast und einen dreigliedrigen Außenast, dessen 3. Glied 4 innere Randborsten trägt. Am distalen Innenrande des 2. Basalgliedes findet sich eine Gruppe von Dornen. Das 2. Fußpaar (XXV,4) hat einen zweigliedrigen Innenast und dreigliedrigen Außenast. An einem Lobus des 2. Gliedes vom Innenast sind 8 lange, starke Dornen vorhanden. Auf den Basalgliedern fehlen Dornen, aber auf

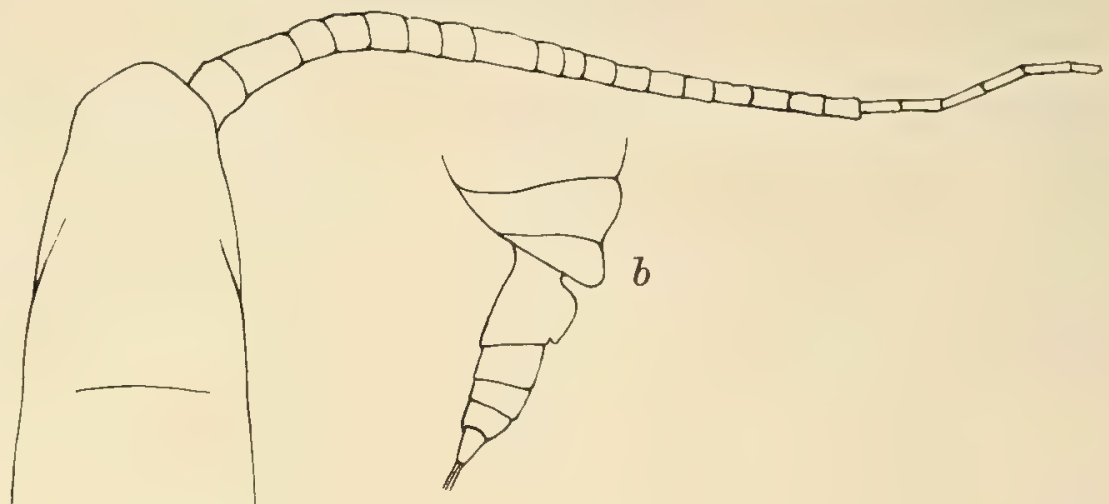
der Oberfläche des 3. Gliedes vom Außenast erscheint eine Reihe kurzer, starker Dornen und auf dem 2. Gliede eine schräge Reihe von 9 langen Dornen. Beim 3. Fußpaare findet sich auf dem 2. und 3. Gliede des Innenastes eine Reihe von hervorragenden Dornen, auf dem 2. Gliede des Außenastes erscheinen 12 lange Dornen in einer Reihe und auf dem 3. Glied einige kürzere. Am 4. Fußpaar (XXV.5) umgibt eine Reihe von steifen Dornen das 1. Basalglied, und das 2. und 3. Glied des Innenastes tragen auf der Fläche Reihen von starken Dornen.

Mehrere Exemplare dieser Art wurden in Vertikalfängen am 3. April 1903 aus 3423 m Tiefe und am 6. März 1903 aus $1200 \mathrm{~m}$ Tiefe noch im. Scholleneise nordwestlich von der Gauss-Station gefunden.

45. Spinocalanus antareticus n. sp. (Textfig. 9 a. b.)

ㅇ 2,25-2,30 mm lang. Der Cephalothorax ist viermal so lang als das Abdomen, der Kopf gerundet, nicht so verschmälert wie bei der vorigen Art; ein Rostrum fehlt. Die Rücken. 
krümmung des Körpers ist ausgesprochener als in Spinocalanus magnus, und die größte Breite liegt vor der Mitte des Körpers. Der Thorax ist nur 21/4mal so lang als breit, während er bei Spinocalanus magnus beträchtlich länger $\left(2^{3} /{ }_{4} \mathrm{mal}\right)$ und hinter der Mittellinie am breitesten ist. (9 a. b.)

Die seitlichen Vorsprünge des letzten Thoraxsegments sind nicht so auffallend bei Spinocalanus antarcticus wie bei den verwandten Arten. Das Genitalsegment ist nicht länger als die beiden folgenden Abdominalsegmente zusammen, und die Furkaläste sind fast ebenso lang als breit.

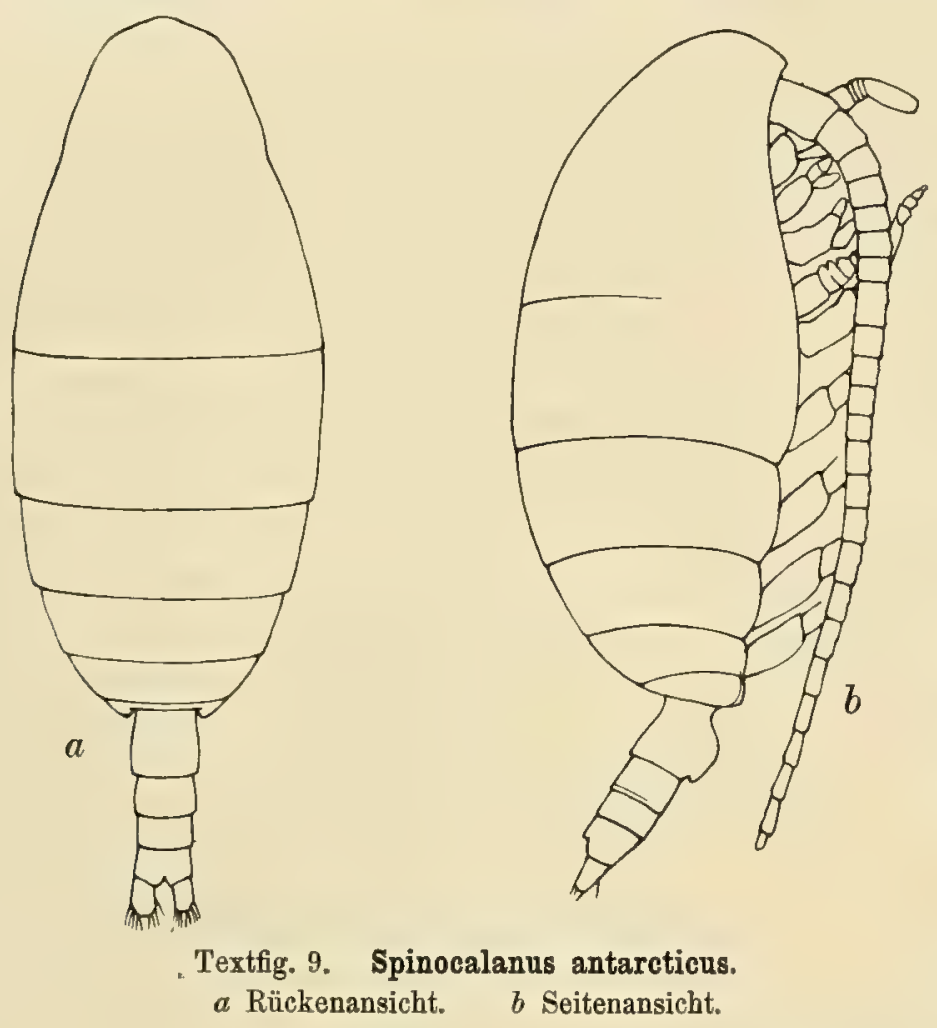

Die vorderen Antennen sind kürzer als bei Spinocalanus magnus und überragen das Genitalsegment nur wenig. Der Innenast der hinteren Antennen ist nur dreiviertel so lang als der Außenast und verhältnismäßig kürzer als bei Spinocalanus magnus.

Die übrigen $\mathrm{M} u \mathrm{nd}$ org a $\mathrm{n}$ e und die $\mathrm{F}$ ü B e gleichen im Bau denen von Spinocalanus magnus. Die wichtigsten Punkte, in denen diese Art von Spinocalanus magnus abweicht, sind demnach die mehr gerundete Form, die kürzeren vorderen Antennen, kürzere Innenäste der hinteren Antennen, kürzeres Genitalsegment und kürzere Furkaläste.

Mehrere Exemplare fanden sich am 6. März 1903 in einem Fang aus $1200 \mathrm{~m}$ Tiefe, darunter nur 1 ơ. Dasselbe war etwas kleiner $(2,05 \mathrm{~mm})$ als die Weibchen, die Mundorgane waren etwas rückgebildet, die vorderen Antennen reichten fast bis zur Furka; der Innenast der hinteren Antennen war nur halb so lang als der Außenast und das Basalglied mit einer großen Borstenreihe versehen.

Das 5. F u $B \mathrm{p}$ a a $\mathrm{r}$ bestand aus einem sehr langen rechten und einem sehr kurzen linken Fuße, von denen der erstere $2 \frac{1}{2} \mathrm{mal}$ so lang als der letztere war. Beide waren fünfliedrig und die Glieder zeigten folgende Längenverhältnisse:

\begin{tabular}{lccccc} 
& 1. & 2. & 3. & 4. & 5. \\
\cline { 2 - 6 } beim rechten Fuße & 27 & 24 & 30 & 14 & 5 \\
beim linken Fuße & 1. & 2. & 3. & 4. & 5. \\
\cline { 2 - 6 } & 10 & 8 & 7 & 7 & 4.
\end{tabular}

Das 2. Basale des rechten Fußes war am Ende keulenförmig und trug distal am Innenrand ein Büschel von kurzen Haaren; das erste Glied des Außenastes hatte ein Büschel von kurzen Randborsten, und das 3. Glied war löffelförmig. Das letzte Glied des linken Fußes war birnförmig und hatte einen kurzen, zarten Enddorn. 


\section{Spinocalanus abyssalis Giesbrecht}

wurde einigemal in den Sammlungen aus dem antarktischen Eismeere gefunden. Diese Exemplare waren von denen aus dem Nordatlantischen Ozean nicht verschieden.

\section{Hypsicalanus n. g.}

Kopf vom Thorax abgegliedert, und auch die beiden letzten Thorakalsegmente gesondert. Der Kopf hat stark hervortretende Crista. Die 1. Antenne setzt sich aus 23 Gliedern zusammen. Der Außenast der hinteren Antennen ist länger als der Innenast, der Innenast der Mandibel länger als der Außenast. Das 1. Fußpaar hat eingliedrigen Innenast, das 2. Paar einen zweigliedrigen Innenast, welcher an der Oberfläche mit vorspringenden Dornen bewehrt ist. Das 5. Fußpaar fehlt. Das letzte Glied der Außenäste der Füße hat 3 Außenranddornen, fein gesägte Endsägen und 5 Innenrandborsten. Beim 1. Fußpaare sind nur 4 vorhanden. Diese Gattung steht demnach der Gattung Spinocalanus sehr nahe, unterscheidet sich jedoch deutlich von ihr durch die Crista und das starke zweispitzige Rostrum.

\section{Hypsicalanus gracilis n. sp. (Tafel XXV, Fig. 6-11.)}

† 2,25 mm lang, wovon 1,75 mm auf den Cephalothorax, 0,50 $\mathrm{mm}$ auf das Abdomen kommen. Der Cephal oth or a $\mathrm{x}$ besteht aus 6 gesonderten Segmenten, von denen. das letzte jederseits etwas verlängert ist. Rücken und Vorderseite des Kopfes haben eine stark vorspringende, gerundete Crista, und vorn ist ein starkes, zweispitziges Rostrum vorhanden. Bei Dorsalansicht erscheint der Kopf seitlich erweitert. Der Kopf ist länger als der übrige Vorderkörper, und der letztere mißt an seiner breitesten Stelle $0,6 \mathrm{~mm}$. Der Thorax ist daher fast dreimal so lang als breit und das Abdomen etwa $1 / 3$ so lang wie der Rumpf. Das Genitals eg me nt ist größer als die beiden nächsten, das Analsegment etwas länger als das vorhergehende Segment, die Furka dreimal so lang als breit, nicht divergierend, jederseits mit 4 langen Schwanzborsten, die länger als das Abdomen sind, und einer sehr kurzen Außenborste. (XXV.6 u. 7.)

Die vorderen A n te n n e $\mathrm{n}$ bestehen aus 23 Gliedern, von denen das 8. und 9. sowie das 24. und 25. verschmolzen sind. Sie überragen die Furka mit $2 \frac{1}{2}$ Gliedern. Das 2. Glied ist lang, so lang wie die beiden nächsten; das kombinierte 8. und 9. Glied ist fast so lang wie die beiden folgenden und das 24. und 25. Glied zusammen $1 \frac{1}{2} \mathrm{mal}$ so lang als das vorletzte. Die hinteren Antennen haben einen längeren Außenast und kürzeren Innenast, und das 2. und 7. Glied des ersteren sind gleich lang. Das 2. Basalglied der M a n ${ }^{-2} \mathrm{i}$ be $1 \mathrm{n}$ (XXV.9) hat mehr oder weniger längliche Form, wird distal breiter und der Innenast ist etwas länger als der Außenast. Das 2. Basalglied hat 4 Randborsten. Die Zahnplatte ist kurz und trägt 7 spitze Zähne in gleichen Abständen, von denen der äußerste am größten ist.

Der 1. Außenlobus der Maxille hat 9 Borsten, von denen die beiden proximalen sehr kurz sind. Am 2. Außenlobus findet sich nur eine kurze Borste. Das 2. Basalglied ist nur ein wenig länger als breit und mit 5 Borsten versehen. Das 1. Glied des Innenastes hat 4, das 2. 5, das 3. 6 Borsten. Der Außenast ist groß und so lang wie Basalglied und Innenast zusammen, von ovalcı Gestalt und trägt 11 Borsten. Der 1. Innenlobus hat 9 Haken, der 2. Innenlobus 5 und der $\mathbf{3}$. Innenlobus 4 Borsten. 
Die v o rde re n Maxilli pede n sind klein, haben gleichmäßig abstehende Loben, von denen der 4. und 5. am längsten sind, während der 6. klein ist. Der 1. Lobus hat 6, der 2., 3. und 4. haben je 3, der 5. Lobus hat 4 und der 6. 2 Borsten. Zwei von diesen (eine am 4. und eine am 5. Lobus) sind zu dünnen Haken umgebildet. Der Innenast hat 3 deutliche Glieder und 5 Borsten. Die meisten von diesen Borsten haben ungefähr dieselbe Länge. Das 1. und 2. Basalglied und der Innenast der hinteren Maxillipeden (XXV. 8) sind etwa gleichlang. Das 2. Basalglied ist etwa viermal so lang als breit, und der Innenrand ist mit feinen, steifen Borsten fast in ganzer Länge bewehrt. Das 1. Basalglied trägt distal einen kurzen Dorn. Das 2. Glied des Innenastes ist doppelt so lang als das 1.; auf dem 4. Gliede findet sich eine dünne Dorsalborste, und alle die langen Innenborsten des Innenastes sind nackt.

Das 1. F u $\beta \mathrm{p}$ a a r (XXV. 10) hat eingliedrigen Innenast. Das 1. Basalglied hat keine Randborste, am dreigliedrigen Außenaste finden sich 3 Randdornen und von Innenrandborsten 0, 1, 4. Der Innenast hat 5 Randborsten. Das 1. und 2. Basalglied tragen Bündel feiner Dornen, das erstere auf beiden Rändern, das letztere distal am Innenrande.

Das 2. Fußpaar (XXV. 11) hat ein langes 1. und ein kurzes 2. Basalglied, das etwa halb so lang als das 1. ist. Die Ränder des 1. Basalgliedes sind mit Bündeln von feinen Dornen versehen. Der Außenast ist stark verlängert, sein 3. Glied, so lang wie die beiden proximalen Glieder zusammen mit dem 2. Basale, ist dreimal so lang als breit. Die Endsäge erreicht vier Fünftel der Länge des Gliedes und ist am Rande fein gesägt. Die äußeren Randdornen sind pfeilförmig, von Innenrandborsten sind am Außenast 1, 1, 5 vorhanden. Am Innenast ist das 2. Glied sehr lang und schmal, aber der ganze Innenast ist kurz und erstreckt sich nicht über das Ende des 2. Gliedes vom Außenaste hinaus. Das 2. Glied hat 5 Randborsten. Auf der Oberfläche dieses Gliedes finden sich 2 Kränze von kräftigen Dornen und auf dem letzten Gliede des Außenastes einige kleine Dornen.

Das 4. Fußpaar ist auch verlängert. Sein 1 . Basalglied ist $2 \frac{1}{2} 2 \mathrm{mal}$ so lang als das 2 . und trägt Dornenbündel am Rande. Das letzte Glied des Außenastes ist wie beim 2. Paare verlängert und fast viermal so lang als breit. Der Innenast ist etwas länger als bei dem 2. Paar und reicht bis zur Basis der 1. Innenrandborste des 3. Gliedes vom Außenast. Zwei Kränze von Dornen, von 4 und 3, finden sich auf dem 2. Glied, und auf der Oberfläche des letzten Gliedes erscheint im proximalen Teil eine kleine Gruppe von 2 Dornen. Am Innenaste sind 1, 1, 6, am Außenaste 1, 1, 5 Randborsten vorhanden. Die Endsäge ist ebensolang wie das letzte Glied.

Das Tier hat zierliche Form; der Besitz einer starken Crista zeichnet es aus innerhalb der Gruppe, zu welcher es augenscheinlich gehört. Die Crista und das zweispitzige Rostrum unterscheiden es von der Gattung Spinocalanus.

Zwei Exemplare wurden in Porte grande, St. Vincent, Kap Verden gefunden.

\section{Oxycalanus (Farran).}

Diese Gattung wurde von FARRAN für einen Copepoden aufgestellt ${ }^{1}$ ), der große Ähnlichkeit mit Spinocalanus zeigte, aber sich durch den Besitz eines Rostrums unterschied und weniger bedornte Schwimmfüße hatte, während diese sonst in bezug auf Gliederung und Beborstung denen von Spinocalanus ähnlich waren.

1) Fisheries Ireland Sei, Invest. 1906 II [1908]. 


\section{Oxycalanus gracilis n. sp. (Tafel XXV, Fig. 12-14, Textfig. 10.)}

우 1,8-1,9 mm; Cephalothorax 1,4 mm, Abdomen 0,5 mm lang, der Vorderkörper also etwa dreimal so lang als das Abdomen. Der Kopf erscheint oval gerundet, nicht so breit wie bei der verwandten Gattung, und trägt ein langes, leicht gegabeltes Rostrum. Der C e p h a I o t h o r a x besteht aus 4 Segmenten, indem der Kopf mit dem 1. Segment und das vorletzte mit dem letzten Segment verschmolzen ist. Das letzte Thorakalsegment springt jederseits vor mit gerundeten Lappen, ohne eine Spur von Dornen. Das Abdomen hat 4 Segmente; das Genitalsegment ist ventral nicht stark angeschwollen; die Furkaläste sind so lang wie das Analsegment und etwa um ein Viertel länger als breit. (XXV. 12.) Die vorderen Antennen bestehen aus 24 Gliedern, von denen das 8. und 9. teilweise vereinigt sind. Sie reichen bis zum Ende der Furka oder ein wenig darüber hinaus. Bei den hinteren Antennen ist der Außenast länger als der Innenast, und das 2. und 7. Glied des ersteren sind am längsten. Der Innenast der Mandibeln ist beträchtlich größer als der Außenast; die Kauplatte hat einen starken Außenzahn und 7 innere Zähne von gleicher Größe. Innenast und 2. Basalglied der M a xille sind verwachsen; der erstere trägt 5 Borsten. Der Außenast, der so lang ist wie Innenast und Basale zusammen, hat 11 Borsten. Der 2. Außenlobus ist klein und borstenlos, der 1. Innenlobus hat 5, der 2. 4 Borsten. Die vorderen M a $\mathrm{x}$ ill i pede $n$ haben 5 Borsten am 1., 3 am 2., 3. und 4. und 4 Borsten am 5. Lobus. Am 4. und 5. Lobus treten noch Haken auf; der 6. Lobus hat nur 2, der Innenast 5 Borsten. Die obere Kante des Gliedes ist proximal ganz gerade.

Das 1. F u B a a r (XXV. 13) hat einen eingliedrigen Innenast und dreigliedrigen Außenast; am 1. und 2. Basalgliede sind keine Borsten vorhanden, und das letzte Glied des Außenastes trägt 4 innere und 3 äußere Randborsten sowie eine Endborste.

Beim 2. Fußpaare (Textfig. 10) finden wir einen zweigliedrigen Innenast und dreigliedrigen Außenast. Das letzte Glied des letzteren ist länger als beide Basalglieder züsammen und hat 5 innere Randborsten. Die Endsäge hat eine gekerbte, nicht gezähnte Schneide. Das 2. Segment des Innenastes trägt

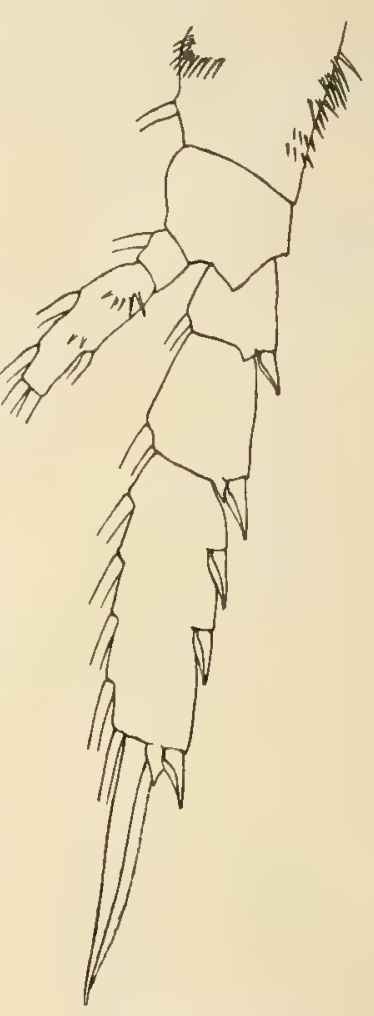

Textfig. 10 .

Oxycalanus gracilis. Zweiter Fuß. zwei kleine Gruppen von Oberflächendornen und das 1. Basalglied Gruppen von feinen Randdornen.

Die Äste des 3. und 4. Fußpaares sind dreigliedrig und die Glieder der Außenäste auf der Oberfläche mit Reihen feiner Dornen besetzt, und das 1. Basalglied trägt sowohl am Rande wie auch auf der Oberfläche Dornen. Beim 4. Fuße treten Reihen feiner Dornen auf der Oberfläche der Innenäste auf, mit zwei starken Dornenkränzen auf dem 2. Gliede. Dasselbe findet sich am letzten Gliede des Außenastes. Am 1. Basalglied ist eine hervorragende Reihe von etwa 18 langen Röhrenborsten vorhanden, die über den Distalrand des Gliedes hinausragen. Endlich ist ein dichtes Büschel von Haaren unter der inneren Randborste und eine Reihe von feinen Dornen proximal am äußeren Rande vorhanden. (XXV. 14.)

Das Tier scheint nicht ganz mit FARRANs Art, Oxycalanus spinifer, übereinzustimmen, ist zarter und kleiner. Es wurde bei Vertikalfängen am 4. September 1903 aus 2000 m, am 26. Sep- 
tember 1903 und 9. Oktober 1903 aus $3000 \mathrm{~m}$ im tropischen Atlantischen Ozean erbeutet. Da auch Farrans Exemplar bei einem Fange aus 1000 Faden heraufkam, müssen die beiden Arten dieser Gattung wohl als Tiefseeformen betrachtet werden.

\section{Gaidius (Giesbrech'T).}

Diese überall verbreitete Gattung ist in den Sammlungen des „Gauss" gut vertreten; sie wurde im Atlantischen Ozean und auch im südlichen Eismeer gefunden. Seit Gaidius pungens zuerst von Giesbrecht aus dem Pazifischen Ozean beschrieben wurde ${ }^{1}$ ), ist eine ganze Anzahl weiterer Arten hinzugekommen. Von diesen scheinen Gaidius tenuispinus und Gaidius brevispinus (SARS) ausschließlich den nördlichen und nordpolaren Meeren anzugehören. Beide erscheinen noch an der atlantischen Küste von Irland. Gaidius brevispinus, den FARRAN erwähnt ${ }^{2}$ ), scheint sicher nicht mit der nordischen Art von SARS identisch zu sein, da er die Lamellen an den hinteren Maxillipeden besitzt, und gehört wahrscheinlich zu Gaidius intermedius WoLFENDEN. Gaidius major WolfENDEN erscheint im südlichen Atlantischen Ozean und im Faroe Channel.

SARS hat dann 5 neue Arten hinzugefügt: Gaidius affinis, Gaidius notacanthus, Gaidius cryptospinus, Gaidius divaricatus und Gaidius minutus ${ }^{3}$ ), von denen die meisten nach der sehr kurzen Beschreibung schwierig zu bestimmen sind, und FARRAv (a. a. O.) noch zwei weitere Arten, Gaidius validus und Gaidius parvispinus. Die erstere Art ist wahrscheinlich eine unreife Form von Gaidius maximus Wolfenden, welche in Plankton Studies Febr. 1906 beschrieben wurde.

Zwei von den drei hier beschriebenen Arten, nämlich Gaidius intermedius und Gaidius maximus, weichen vom typischen Gaidius-Charakter erheblich ab durch den Bau der hinteren Antennen und der hinteren Maxillipeden und scheinen eine Zwischenstellung zwischen Gaidius und Gaetanus einzunehmen. Bei der letzteren Gattung besteht der Hauptcharakter nicht nur im Besitz eines Kopfhorns, sondern konstante Züge sind auch das Vorhandensein eines Zipfels am Außenaste der hinteren Antennen und einer eigentümlichen Chitinlamelle am Rande der hinteren Maxillipeden. Die beiden Arten Gaidius intermedius und Gaidius maximus besitzen zwei von diesen Charakteren und stimmen ferner mehr mit Gaetanus als mit Gaidius im Bau der Schwimmfüße überein. Wenn diese Gründe auch vielleicht nicht für ganz ausreichend angesehen werden sollten, so ist doch kein Zweifel, daß diese Arten Zwischenformen bilden, und daher wage ich es, für sie eine neue Gattung, Mesogaidius, aufzustellen. Ein ähnlicher Fall liegt bei der von SARS geschaffenen Gattung Mesorhabdus vor, welche für eine in der Mitte zwischen Heterorhabdus und Disseta stehende Copepodenform aufgestellt wurde.

Die unzweifelhafte Gaidius-Art, welche sehr häufig im Plankton der Antarktis erschien, ist so ähnlich dem Gaidius pungens, daß sie sehr leicht mit diesem verwechselt werden kann. Doch finden sich gewisse Abweichungen in der Gliederung der Füße, welche diese beiden Arten unterscheiden. Dagegen scheint sie mit der nordischen Art Gaidius tenuispinus Sars identisch zu sein.

1) Bull. Museum comp. Zoology Harvard College vol. XXV no. 12, 1895.

$\left.{ }^{2}\right)$ Fisheries Ireland. Sei. Invest. 1905.

3) Bull. Mus. Oceanograph. Monaco, Mars et Juin 1905. 
49. Gaidius tenuispinns (SARs). (Textfig. 11 a und b.)

ㅇ 3,25 mm lang; Cephalothorax 2,45 mm, Abdomen 0,8 mm. Im Habitus fast gleich Gaidius pungens. Der $\mathrm{K}$ o $\mathrm{p}$ ist mit dem ersten Thoraxsegment und die beiden letzten Thorakalsegmente sind miteinander verschmolzen. Die Dornen des letzten Segments sind zart, schwach gebogen, erheben sich von der Mitte des freien Seitenteiles und sind fast so lang als das Genitalsegment. Sie divergieren kaum etwas. (11 a.)

Das schlanke A b d o m e $\mathrm{n}$ erreicht ein Drittel der Rumpflänge; das Genitalsegment ist beträchtlich größer als die beiden folgenden Segmente und tritt ventral stark hervor; das Analsegment ist sehr kurz, und die Furkaläste sind viel länger als breit. Die vorderen A ntenne $n$ reichen bis zum Ende des Genitalsegments. Der Außenast der hinteren Antennen ist etwa um ein Drittel länger als der Innenast und besitzt keinen Zipfel.

Das 2. Basalglied der hinteren $M$ a $\mathrm{x}$ illipe de $\mathrm{n}$ (11 b) ist ein wenig länger als das 1. Basale und dreimal so groß wie der Innenast. Der Außenrand des 1. Basalgliedes ist gerade und zeigt keine Spur einer Lamelle. Die Loben des Innenrandes ragen hervor, und am Distalende des 1. Basalgliedes erscheint ein verhältnismäßig großer Lobus. Am 2. Basalgliede treten 3 zarte Randborsten auf, von denen 2 in der Mitte, die dritte distalwärts entspringen.

Das 1. F u B p a r hat zweigliedrigen Außenast mit nur zwei Randdornen. Der Außenrand des Proximalgliedes ist bei allen Exemplaren deutlich eingekerbt, aber nirgends tritt eine Spur von einer Querlinie auf, welche Gliederung andeuten könnte. Das 2. Fußpaar hat deutlich zweigliedrigen Innenast. Röhrenborsten fehlen den Basalgliedern des 4. Fußpaares.

Die $\mathrm{S} \mathrm{chwim} \mathrm{m} \mathrm{f} \ddot{\mathrm{B}} \mathrm{B}$ e sind schlanker als bei Gaidius pungens

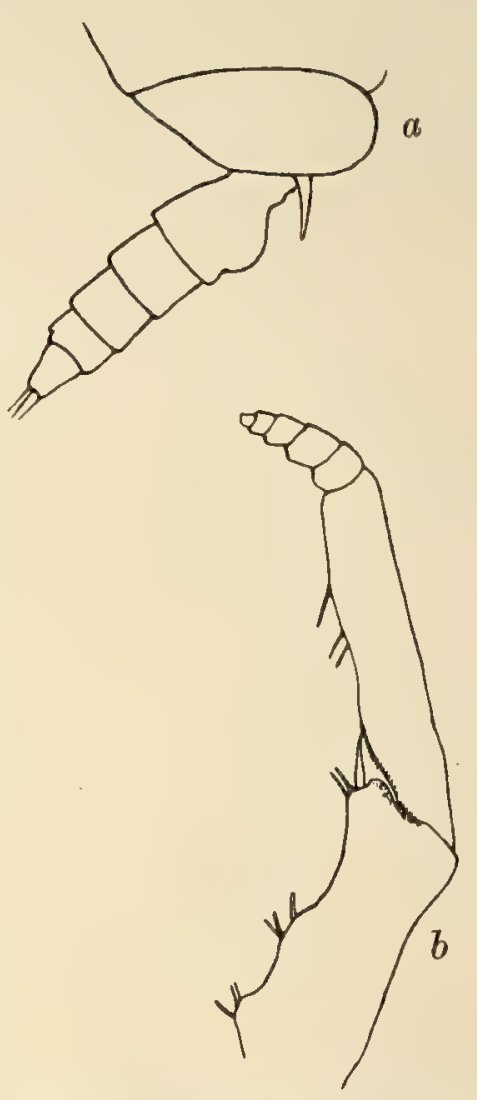

Textfig. 11. Gaidius tenuispinus. a Thoraxende und Abdomen. $b$ Hinterer Maxilliped. gebaut und die Zähne der Endsägen weniger dicht stehend und in geringerer Zahl wie bei dieser Art vorhanden. Einige Exemplare waren etwas größer als der oben angegebene Durchschnitt, doch erreichte keines davon $4 \mathrm{~mm}$ Länge. Gaidius pungens ist nicht nur kräftiger gebaut, sondern das 2. Fußpaar hat auch einen deutlich eingliedrigen Innenast.

Die südliche Form erscheint etwas kleiner als die nördliche, hat schlankere Füße und verhältnis mäßig längere Furkaläste, auch sind die Endsägen etwas gröber gezähnt; doch kann ich nach sorgfältigem Vergleich derselben mit Exemplaren aus dem Faroe Channel, wo Gaidius tenuispinus häufig ist, keine wesentlichen Unterschiede finden, die zur Abtrennung einer besonderen Art ausreichen würden.

Vom ,Gauss“" wurde Gaidius tenuispinus westlich vom Kap am 12. November 1901 (3000 m) und im südlichen Eismeer am 3. und 6. März 1903 (400 m) gefunden.

\section{Mesogaidius n. g.}

Die Weibchen dieser Gattung sind Gaidius sehr ähnlich, mit einigen Merkmalen von Gaetanus, wie der Zipfel am 2: Gliede des Außenastes der hinteren Antennen, ein auffallender Lappenfort- 
satz am 1. Basalgliede der hinteren Maxillipeden, dreigliedriger Außenast des 1. Fußpaares und stets zweigliedrige Innenäste des 2. Paares.

50. Mesogaidius intermedius (Wolfenden). (Tafel XXVI, Fig. 1-2, Textfig. 12 a-d.)

(G. intermedius Wolfenden, Plankton Studies 1905.)

o 4,0-4,15 mm lang. Der Cephaloth or a $\mathrm{x}$ besteht nur aus 4 Segmenten, da Kopf und 1. wie auch 4. und 5. Segment verwachsen sind. Das 1. Segment ist $2 \frac{1}{2}$ mal so lang als der übrige Teil des Rumpfes. Die Dornen des letzten Thorakalsegments sind kleiner und schwächer
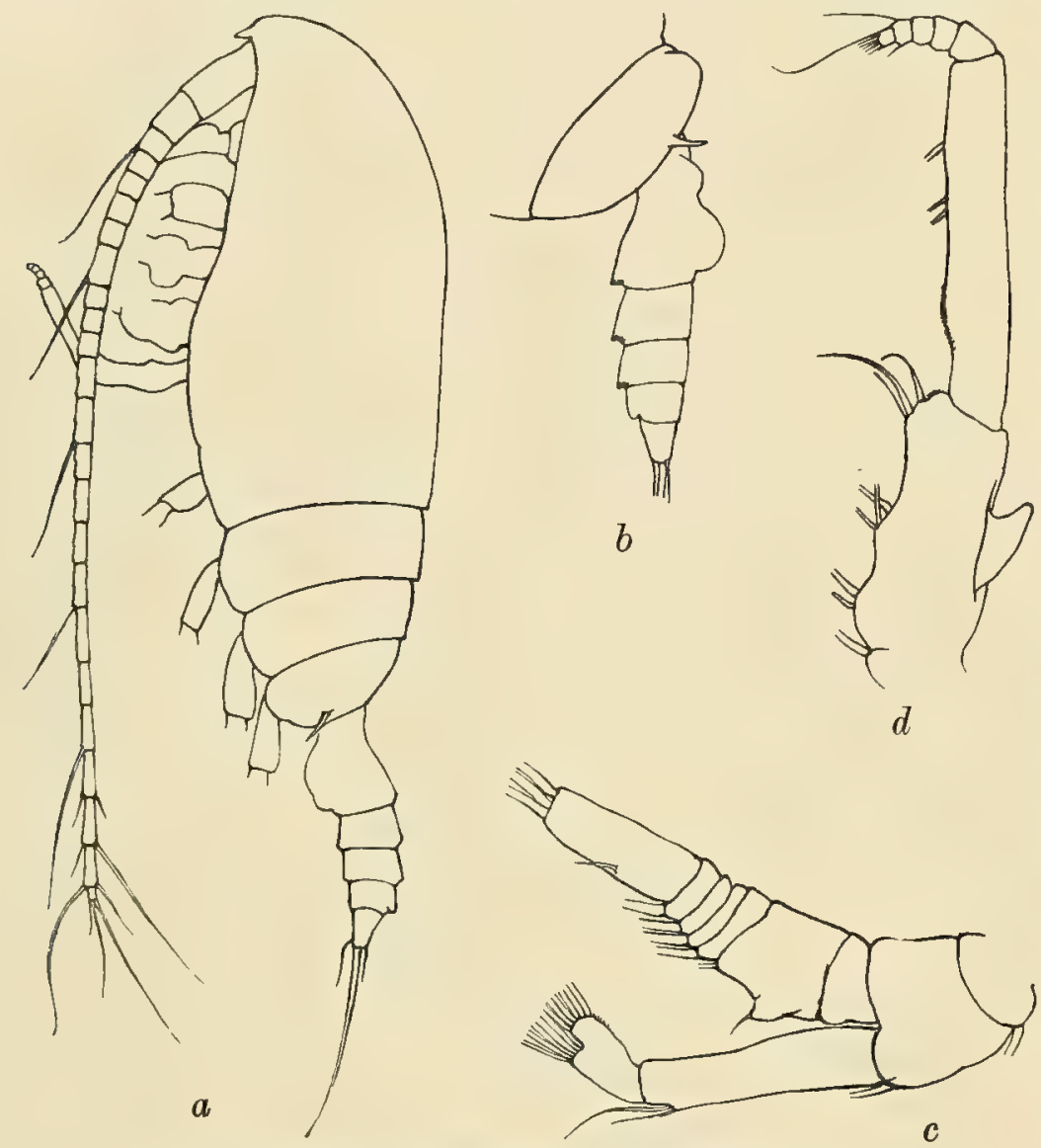

Textfig. 12. Mesogaidius intermedius.

$a$ Seitenansicht, $b$ Abdomen und letztes Thoraxsegment. $e$ Hintere Antenne. $d$ Hinterer Maxilliped. als bei Gaidius, etwas einwärts und bei seitlicher Ansicht stark nach vorn gerichtet. (12 a.b.) Das Abdomen erreicht noch nicht ein Viertel der Rumpflänge. Das Genitalsegment ist größer als die beiden folgenden zusammen, und das Analsegment größer als das vorhergehende Segment. Die Furka ist länger als breit und so lang wie das Analsegment.

Die vorderen Antennen reichen bis zum Ende der Furka. Der Innenast der hinteren Antennen ist nur wenig kürzer als der Außenast, welcher am Rande seines 2. Gliedes einen Zipfel mit kurzer Borste trägt. (12 c.)

Die hinteren M a $\mathrm{x} l 1 \mathrm{ipeden}$ (12 d) sind wie bei Gaidius gebildet, mit der Abweichung, daß die 3 Borsten des 2. Basalgliedes distal von der Mitte liegen und daß am Außenrande des 1. Basalgliedes eine vorspringende Lamelle wie bei den meisten Gaetanus Arten auftritt.

Das 1. F u B pa a r (XXVI. 1) hat dreigliedrigen Außenast mit nur 2 Randdornen. Das 2. Paar (XXVI. 2) ist mit zweigliedrigem Innenaste versehen, und am Basalgliede des 4. Paares finden sich Röhrenborsten, wie bei fast allen Gaetanus-Arten. Mesogaidius intermedius, der leicht mit Gaidius pungens verwechselt werden kann, war häufig im südlichen Atlantischen Ozean und im Eismeere, wurde am 12. November 1901 (3000 m) und 18. Dezember 1901 (2500 m), ferner am 10. Februar $1903(400 \mathrm{~m})$ und 6. März 1903 (1200 m) vom „Gauss" erbeutet.

51. Mesogaidius maximus (Wolfenden). (Tafel XXVI, Fig. $3-6$, Textfig. 13 a. b.) (Gaidius maximus Wolfenden, Plankton Studies 1906.)

Diese Art ist der vorigen sehr ähnlich, doch etwa doppelt so groß als jene. 
ㅇ 7,5-8 $\mathrm{mm}$ lang, wovon 6,0 $\mathrm{mm}$ auf den Cephalothorax, 1,5 $\mathrm{mm}$ auf das Abdomen kommen. Der Kopf ist dorsal gerundet, oben ein wenig abgeflacht und der Rücken ist etwas bucklig. Der Cephaloth or a $\mathrm{x}$ besteht nur aus 4 Segmenten, von denen die beiden ersten ebenso wie die beiden letzten miteinander verwachsen sind. Die Dornen des letzten Thorakalsegments sind stark, etwas gekrümmt und zeigen gerade nach unten. Sie sind halb so lang als das Genitalsegment. (13 a. b.)

Das A b d o m e $\mathrm{n}$ ist nur ein viertel so lang als der Rumpf; das Genitalsegment tritt ventral stark hervor und ist so lang als die beiden folgenden Segmente zusammen. Die Furkaläste sind sehr kurz, viel breiter als lang, und divergieren etwas. Die vorderen Anten $\mathrm{n}$ e $\mathrm{n}$ sind verhältnismäßig lang, überragen die Furka mit etwa 2 Gliedern.

Der Außenast der hinteren Antennen (XXVI. 3) ist nur ein wenig größer als der Innenast, und an seinem 2. Gliede sind zwei hervorragende Zipfel vorhanden.

Die Basalia der hinteren Maxilli peden (XXVI. 4) sind wie bei der vorigen Art gebildet,
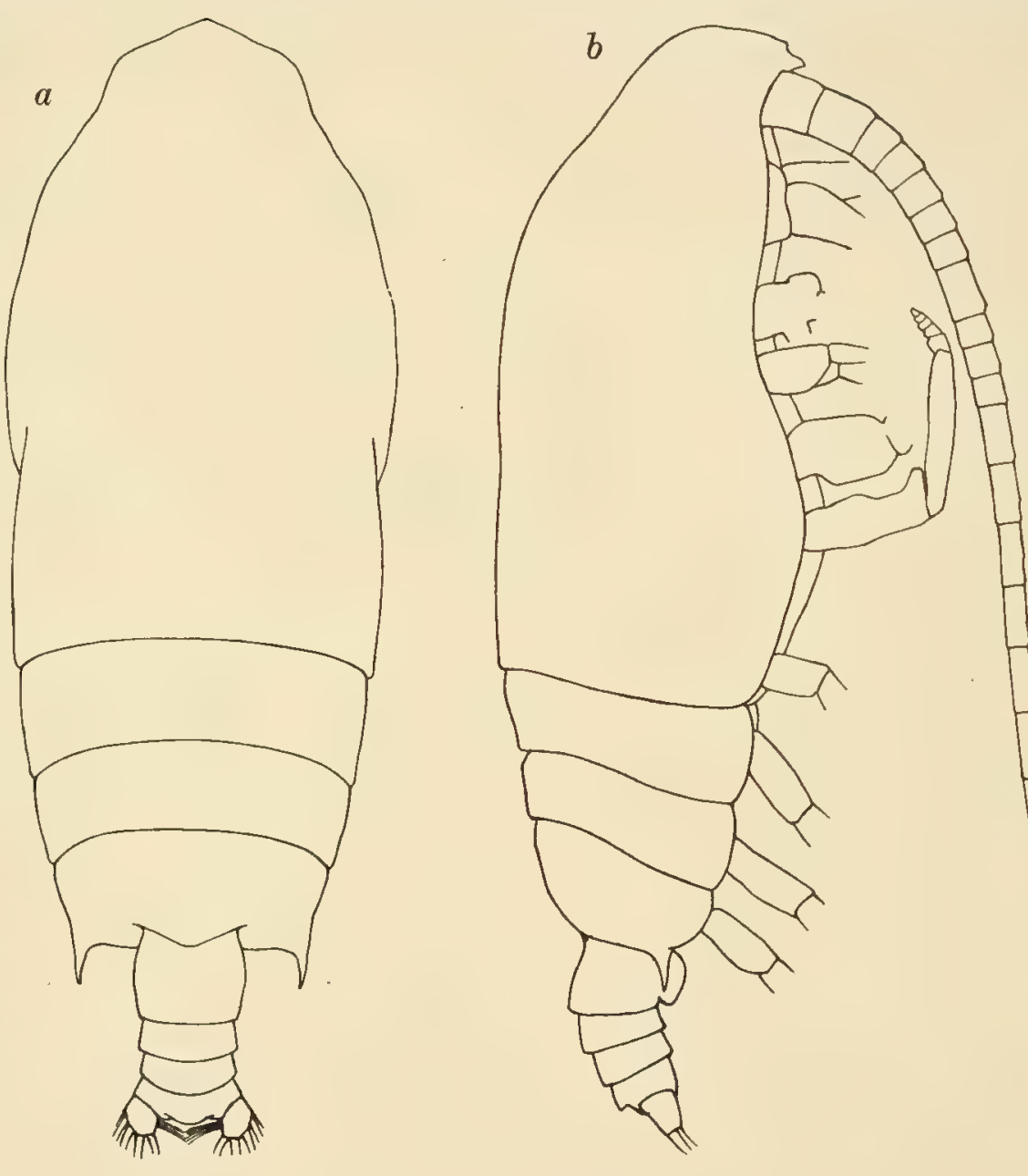

Textfig. 13. Mesogaidius maximus,

$a$ Rückenansicht. $\quad b$ Seitenansicht.

und die 3 Borsten des 2. Basalgliedes entspringen distal von der Mitte. Das 1. Basalglied trägt eine hervorragende Lamelle am Außenrande, welche etwas andere Form als die der vorigen Art hat.

Der Außenast des 1. F u B pa a e s (XXVI. 5) ist deutlich dreigliedrig und hat 3 Randdornen; der Innenast des 2. Paares (XXVI. 6) ist deutlich zweigliedrig und das 4. Paar zeigt am Basalgliede die üblichen Röhrenborsten.

Das Tier ist sehr kräftig, breit und von auffallender Erscheinung. FARRAN's Gaidius validus (Fisheries Ireland Sci. Invest. 1906 IX [1908]) ist wahrscheinlich ein unreifes q dieser Art. Gaidius 
affinis, welcher von demselben Autor und von SARS (a. a. O.) erwähnt wird, hat ebenfalls die charakteristische Lamelle an den hinteren Maxillipeden und gehört wahrscheinlich auch zur Gattung Mesogaidius.

Zwei Exemplare von Mesogaidius maximus wurden im Südatlantischen Ozean am 16. November 1901 vom „Gauss" in einem Vertikalfang aus $3000 \mathrm{~m}$ Tiefe gefunden.

\section{Gaetanus (Giesbrecht).}

Nach dem Erscheiden der Copepoden in „Das Tierreich“ sind mehrere neue Arten dieser Gattung bekannt geworden, nämlich Gaetanus kruppi (GIE SBRECHT), Gaetanus major (WoLFENDEN), Gaetanus holti (FARRAN), Gaetanus minor (FARRAN), Gaetanus robustus (SARS), Gaetanus inermis (SARS), Gaetanus curvicornis (SARS), Gaetanus antarcticus (WoLFENDEN).

Die Beschreibungen der drei Arten von SARS ${ }^{1}$ ) sind zu kurz, und da Abbildungen nicht beigegeben sind, ist es nicht leicht, diese Arten wiederzuerkennen. Ferner entbehrt Gaetanus inermis, der nach Sars keine Spur eines Kopfdornes und auch keine Dornen am letzten Rumpfsegment hat, zwei der Merkmale, welche diese Gattung hauptsächlich charakterisieren; daher erscheint der Verdacht gerechtfertigt, daß diese eigentümliche Art gar nicht zu Gaetanus gehört. SARs hat dann neuerdings ${ }^{2}$ ) eine weitere Art den früheren hinzugefügt: Gaetanus brachyurus, welche einige Ähnlich-

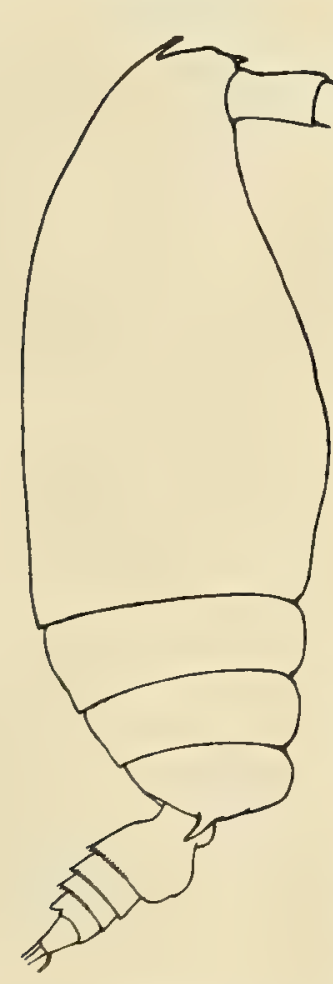

Textfig. 14.

Gaetanus divergens. Seitenansicht. keit mit dem unten beschriebenen Gaetanus divergens zu haben scheint, aber nach seiner kurzen Beschreibung nicht mit dieser identifiziert werden kann. Drei Arten, die nicht in der Sammlung des „Gauss" enthalten zu sein scheinen, wurden dann noch von EsTERLY erwähnt ${ }^{3}$ ): Gaetanus unicornis, Gaetanus brevicornis und als dritte Art Gaetanus clarus, der nur nach zwei männlichen Exemplaren beschrieben wurde.

Vom "Gauss" wurde eine große Zahl von Exemplaren aus dieser auffallenden Gattung gesammelt, unter denen ich fünf neue Arten gefunden zu haben glaube.

52. Gaetanus divergens n. sp. (Tafel XXVI, Fig. 7-10, Textfig. 14.)

ㅇ 4,3 $\mathrm{mm}$ lang, wovon $3,3 \mathrm{~mm}$ auf den Cephalothorax, $1,0 \mathrm{~mm}$ auf das Abdomen kommen. Der $\mathrm{K}$ o $\mathrm{p} f$ ist vom Typus des Gaetanus armiger, der Kopfdorn schwach, kurz und nach unten und vorn mehr oder weniger parallel zur Stirn gekrümmt. Die Linie des Kopfes vor dem Horn ist fast ganz gerade. Der Kopf und das 1. Thorakalsegment sind verwachsen, so daß dieses Segment mehr als $21 / 2$ mal so groß wird als die hinteren 3 Segmente. Das letzte Thorakalsegment trägt kurze, starke Dornen, die stark divergieren und nach hinten gekrümmt sind, aber nicht stark seitlich stehen, da sie sich mehr vom Rücken des Segmentes erheben. (Textfig. 14.)

Das $\mathrm{A} \mathrm{b} \mathrm{d}$ o m e $\mathrm{n}$ ist kurz, nicht ganz ein viertel so lang als der Cephalothorax, mit ventral hervortretendem Genitalsegment, welches so lang wie die folgenden 3 Segmente

1) Bull. Mus. Oceanograph. Nr. 26, 1905.

2) Bull. Inst. Oc. 1907.

${ }^{3}$ ) Addition to the Copepod Fauna of the San Diego Region. Univ. of California Zoology vol. 3, 1906. 
ist. Die Furkaläste sind $1 \frac{1}{2} \mathrm{mal}$ so lang als das Analsegment und ebenso lang wie breit. (XXVI. 7.)

Die vorderen Antennen sind nur um 2 oder 3 Glieder länger als der ganze Körper. Der Außenast der hinteren Antennen ist länger als der Innenast. Die vorderen Maxillipeden (XXVI. 8) tragen am 4. Lobus einen einzigen starken Haken, der sehr breit an der Basis und gekrümmt ist. Der 5. Lobus ist klein, trägt einen kurzen, dünnen Haken, und der Innenast ist sehr klein. Die hinteren Maxillipeden haben eine kurze Lamelle ohne den üblichen Buckel. Der Außenast des 1. Fußpa a res (XXVI. 9) ist dreigliedrig, hat aber nur 2 Dornen am äußeren Rande. Das 2. Fußpaar hat zweigliedrigen Innenast und dreigliedrigen Außenast. (XXVI. 10.) Das 4. Paar trägt die gewöhnlichen Röhrenborsten auf dem 1. Basalgliede.

Äußere Ähnlichkeit hat unsere Art mit Gaetanus brachyurus SARS; sie unterscheidet sich jedoch von dieser, abgesehen von andern Merkmalen, in der Größe und den Verhältnissen von Thorax zu Abdomen.

Gaetanus divergens wurde in Tiefenfängen von $3000 \mathrm{~m}$ im südlichen Atlantischen Ozean am 12. November 1901 und unter dem Äquator am 26. September 1903 gesammelt.

53. Gaetanus brevicaudatus n. sp.

(Tafel XXVI, Fig. 11-12, Textfig. 15 a. b.)

o $5,9 \mathrm{~mm}$; der Ce phalothorax ist $4,9 \mathrm{~mm}$, das Abdomen 1,0 mm lang. Der Kopf, mit dem 1. Segment verwachsen, ist zweimal so lang als der übrige Rumpf, und die größte Breite des Rumpfes ist noch nicht ganz gleich der halben Länge. Der Kopf ist vom Typus des Gaetanus miles. Das Kopfhorn ist sehr kurz und kräftig, bei viereckiger Stirn. Der Rücken ist nur schwach bucklig. Die Seitendornen des letzten Thorakalsegments sind lang, so lang wie das Genitalsegment, stark, sehr krumm, entspringen von der Vorderseite des Segments und sind nach unten gekrümmt. Vom Rücken gesehen erscheinen sie schwach divergent. (15 a.)

Das $\mathrm{Abdomen}$ ist kurz, noch nicht ein viertel

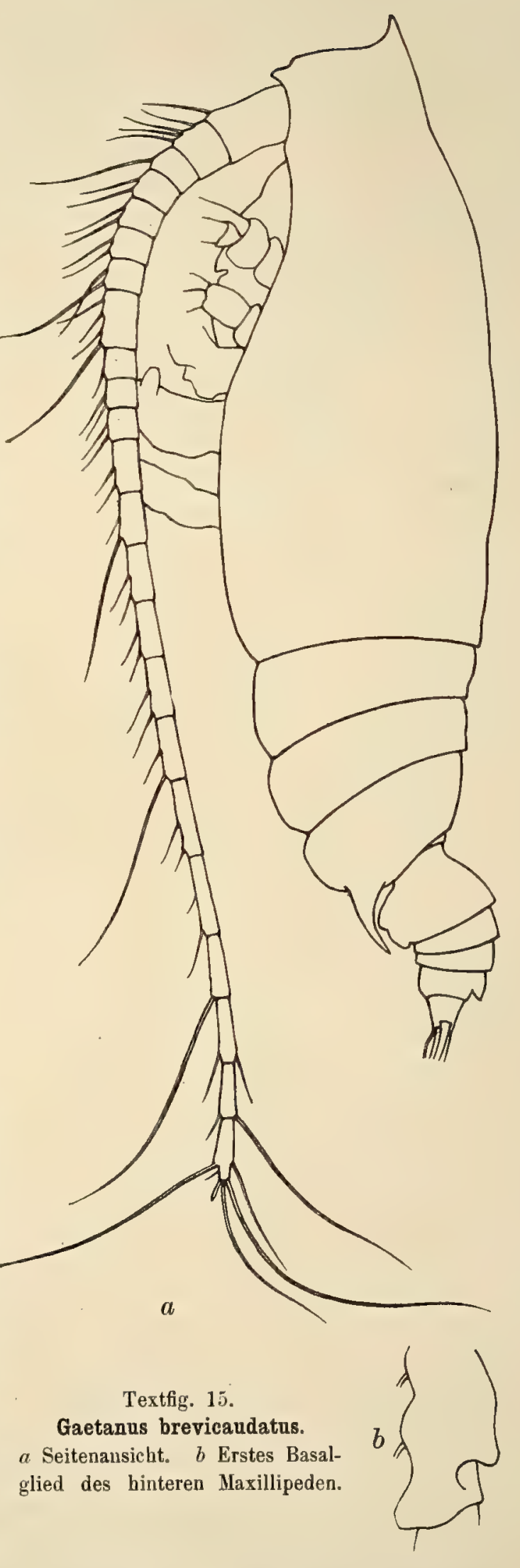
so lang wie der Cephalothorax, besteht aus einem großen Genitalsegment, zwei kleinen Segmenten 
und verhältnismäßig großem Analsegment. Die Furkaläste sind weit getrennt und wenig länger als breit. (XXVI. 11.)

Die vorderen A n t e $\mathrm{n} n$ e $\mathrm{n}$ überragen den Körper mit 2 oder 3 Gliedern und sind recht dicht

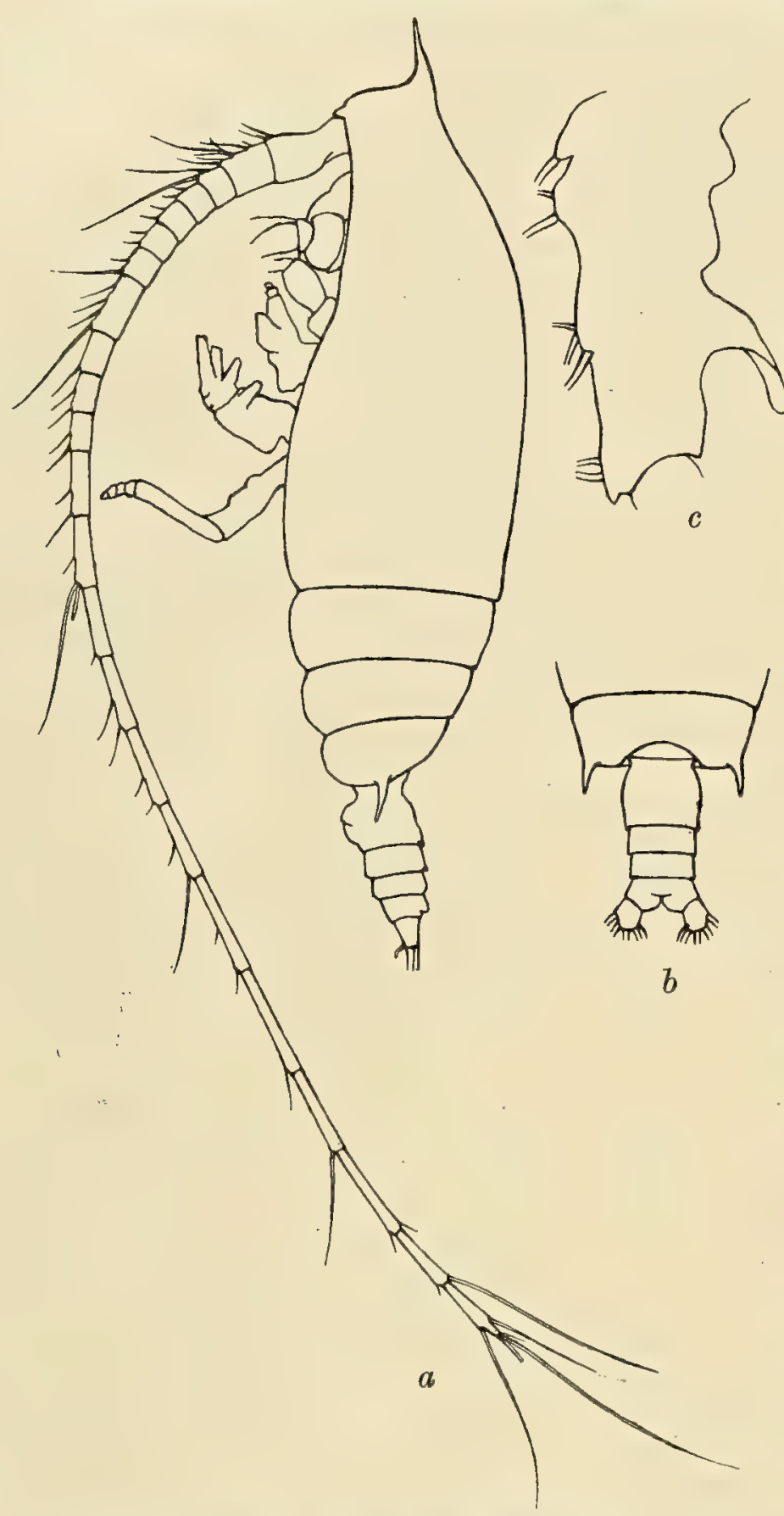

Textfig. 16. Gaetanus recticornis.

$a$ Seitenansicht. $b$ Abdomen und letztes Thoraxsegment. c Erstes Basalglied des hinteren Maxillipeden. mit Borsten besetzt, von denen die des 13., 17., 20. und des Endgliedes durch besondere Länge auffallen.

Die hinteren Antennen haben zwei fast gleiche Äste, von denen der Außenast keinen Zipfel trägt. Die vorderen Maxill ipeden zeigen nicht so tief ausgebuchteten Rand wie die einiger anderer Arten, und die Haken der Endloben sind nicht besonders stark. Am 1. Basalgliede der hinteren Maxillipeden (15 b) findet sich ein kurzer, lamellöser Fortsatz, ohne Wucherung. Das 1. Fußpa ar (XXVI. 12) hat dreigliedrigen Außenast mit 3 äußeren Randdornen; beim 2. Paar ist der Innenast deutlich zweigliedrig, und am Basalgliede des 4. Paares sind große Röhrenborsten vorhanden.

Diese Art scheint weder mit Gaetanus curvicornis (SARS) noch mit Gaetanus robustus (SARS), die ja zu dürftig beschrieben sind, oder sonst einer andern Art identisch zu sein. Sie wurde am 19. Oktober 1901 bei einem Vertikalfang aus $800 \mathrm{~m}$ Tiefe unter $19^{\circ} \mathrm{s} . \mathrm{Br}$., $20^{\circ}$ w. L. im Atlantischen Ozean gefunden.

\section{Gaetanus recticornis n. sp.}

(Tafel XXVI, Fig. 13, Textfig. 16 a-c.)

Diese Art ist Gaetanus miles merkwürdig ähnlich; der Kopf hat bei beiden den gleichen Typus, doch ist er bei Gaetanus recticornis kräftiger gebaut, und die vorderen Antennen sind hier viel kürzer, nicht mehr als $1 \frac{1}{2} \mathrm{mal}$ so lang als der Körper, während sie bei Gaetanus miles stets mehr als doppelt so lang sind. Wegen der Unterschiede der Gestalt des Kopfes und des Kopfhorns, besonders aber wegen geringer Länge der Antennen habe ich Bedenken, diese Form unter dem Namen Gaetanus miles zu beschreiben, da diese Unterschiede konstant bei mehreren Exemplaren beobachtet werden konnten. 
o 4,6-5 mm lang; der Cephalothorax ist viermal so lang als das Abdomen. (16 a). Bei einem Exemplar von $5 \mathrm{~mm}$ Länge waren die vorderen A n t e $\mathrm{n} n$ e $\mathrm{n}$ nur $8 \mathrm{~mm}$ lang. Das Kopfhorn ist mehr aufrecht als bei Gaetanus miles und zeigt keine Krümmung; zwischen seiner Basis und dem Rostrum findet sich ein großer, fast geradlinig begrenzter Zwischenraum. Die Dornen des letzten Thorakalsegments sind fein und divergieren sehr wenig. (16 b.)

Das 1. F u ß pa a r (XXVI. 13) hat einen zweigliedrigen Außenast mit nur 2 Randdornen, das 2. einen zweigliedrigen Innenast und das 4. Paar die gewöhnlichen Röhrenborsten. An den Basalgliedern der hinteren M axillipeden (16 c) findet sich eine kleine Lamelle, und die vorderen Maxillipeden haben stark konkav-konvexen Außenrand. In dieser Hinsicht stimmt unsere Art mit Gaetanus miles überein, aber wenn der letztere nicht sehr stark variiert, nicht nur in der Größe, sondern auch in der Länge der Antennen, so muß Gaetanus rectirostris als gute Art anerkannt werden. Gaetanus unicornis EsterLy (a.a. 0.) hat einen ähnlich gestalteten Kopf, ist jedoch viel größer und hat viel kürzere Antennen, auch eine kleinere Lamelle am hinteren Maxilliped. Sie ist augenscheinlich mit unserer Art, welche im südlichen Atlantischen Ozean am 16. November 1901 aus $3000 \mathrm{~m}$ Tiefe erbeutet wurde, nicht identisch.

\section{Gaetanus antareticus (WOLFENDEN). PJankton Stndies, Part I Copepoda, London 1905.}

Diese Art, die durch ihre bedeutende Größe vor allen andern Arten der Gattung ausgezeichnet ist, wurde von mir nach den Sammlungen der „Discovery" beschrieben und auch in der Ausbeute des ,Gauss" wiedergefunden.

q $8 \mathrm{~mm}$; der Körper ist sehr kräftig und der Rücken bucklig. Der Kopf ist mit dem 1. Thorakalsegment verwachsen, und dieses vereinigte Segment ist viel länger als der übrige Teil des Cephalothorax. Das Kopfhorn ist kurz und kräftig; es erhebt sich von breiter Basis und ist nur schwach gekrümmt. Der Raum zwischen der Basis des Hornes und der Stirn ist beträchtlich und fast geradlinig begrenzt. Das letzte Thorakalsegment hat kurze, starke, gekrümmte und nach hinten gerichtete Dornen. Das A b d o m e $\mathrm{n}$ ist kurz, noch nicht ein viertel so lang als der Rumpf; das Genitalsegment, so lang wie die beiden folgenden Segmente, tritt ventral hervor und erscheint dorsal etwas zugespitzt.

Die vorderen A n t e n n e n sind nicht so lang wie der ganze Körper und spärlich beborstet. Die hinteren Antennen haben viel längeren Außenast und kürzeren Innenast. Die hinteren Maxillipeden tragen eine kurze Lamelle am 1. Basalgliede, haben keinen Höcker und reichen nicht bis zum Distalrande dieses Gliedes. Das $1 . \mathrm{Fu} \mathrm{B} \mathrm{p}$ a a $\mathrm{r}$ hat dreigliedrigen Außenast mit 3 Randdornen. Das 2. Paar ist mit deutlich zweigliedrigem Innenast und das 4. Paar mit den gewöhnlichen Röhrenborsten an den Basalgliedern versehen.

Die Art erschien in einem Fang aus $2000 \mathrm{~m}$ am 27. März 1903 noch im Gebiete des Scholleneises.

56. Gaetanus pileatus (Farran). (Tafel XXVII, Fig. 1 und 2, Textfig. 17 a-c.)

\section{(? Gaetanus caudani CANU.)}

Gaetanus caudani wurde von CANU nach einem unreifen Männchen aus dem Golf von Gascogne beschrieben ${ }^{1}$ ). Unter diesem Namen beschrieb ich auch Copepoden von der atlan-

1) Ann. Univ. Lyon vol. 26. 
tischen Küste von Irland, und SARS erwähnte dieselbe Art aus den Sammlungen des Fürsten von Monaco.

FARRAN ${ }^{1}$ ) verweist auch auf diese Art, welche an der Westküste Irlands in beträchtlicher Menge aufzutreten schien, und prüfte die Frage nach der Identität der irischen Form mit der Originalbeschreibung der Art. Er kam zum Schlusse, daß die irischen Exemplare von Gaetanus caudani

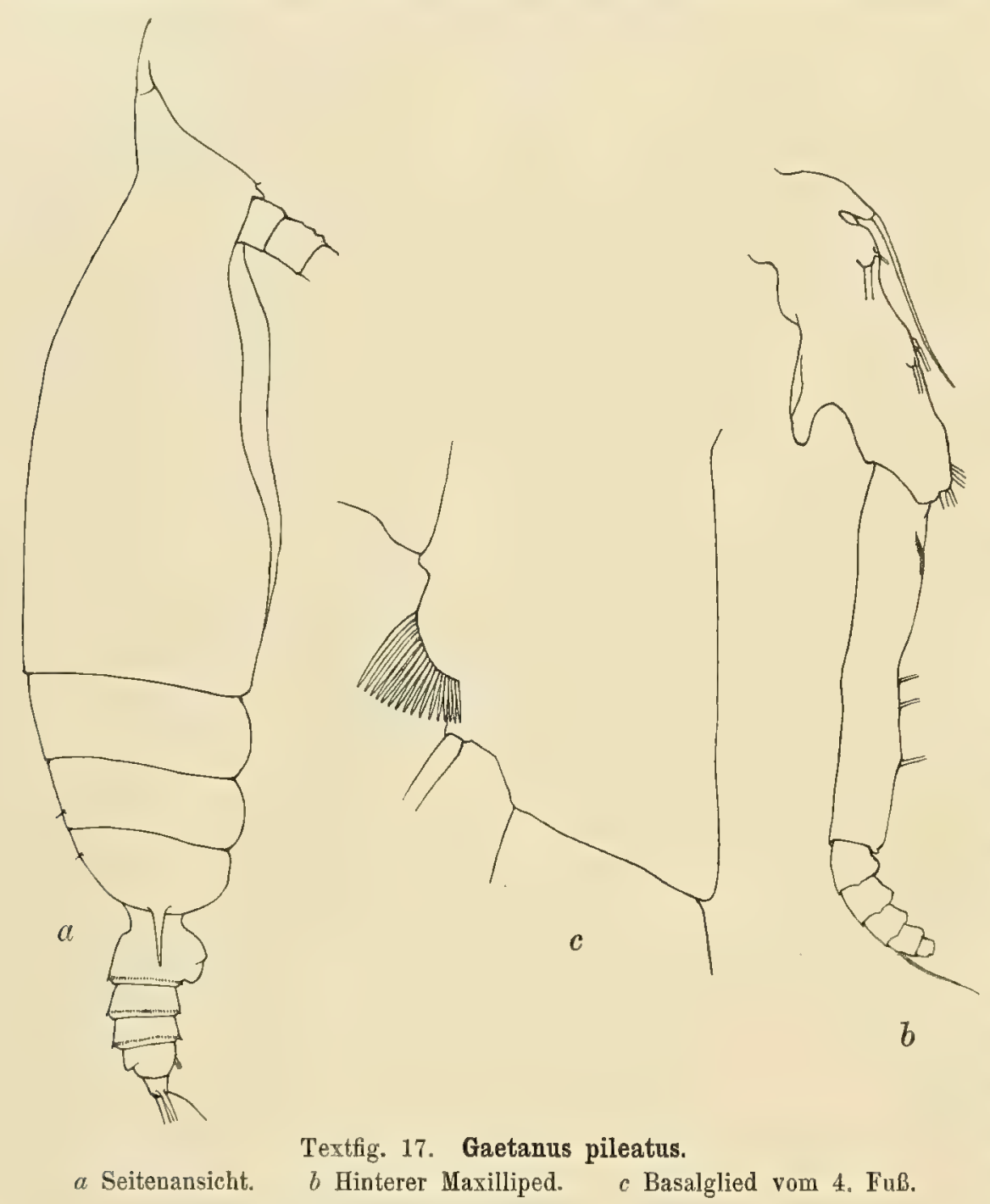
verschieden wären, und gab ihnen den Namen Gaetanus pileatus.

Wenn man in Betracht zieht, daß CANU's Beschreibung ein männliches und nicht erwachsenes Exemplar behandelt, so ist es wahrscheinlich, daß die atlantische Art mit seiner identisch ist. Sie ist im Atlantischen Ozean sehr häufig anzutreffen. Die Unterschiede, auf die FARRAN sich beruft, sind der zweigliedrige Außenast des 1. Fußpaares mit 3 Außendornen bei CANU's Gaetanus caudani und das Vorhandensein eines kleinen Lobus mit 2 Borsten am 1. Glied des Außenastes der hinteren Antennen, während bei Gaetanus pileatus der kleine Lobus fehlt und der zweigliedrige Außenast des 1. Fußpaares nur 2 Randdornen hat. (XXVII.2.) Farrans Exemplare scheinen mit meiner früheren Beschreibung übereinzustimmen (Journ. Mar., Biol. Assoc., April 1904), und augenscheinlich sind Gaetanus pileatus und Gaetanus caudani sehr nahe verwandt.

Bei Gaetanus pileatus ist der Kopf in der Gegend des Halses ein wenig verschmälert; das Kopfhorn ist sehr stark, schwach gekrümmt und etwas nach hinten gerichtet. Von der Basis des Horns bis zur Stirn verläuft der Kopf in fortschreitender Kurve, so daß der Kopf weniger viereckig als bei einigen andern Arten erscheint. (XXVII. 1, 17 a.) Die Dornen des letzten Thorakalsegmentes sind dünn, ziemlich lang und fast gerade. Die vorderen Antennen überragen mit 6 Gliedern etwa die Furka. Die Lamelle der hinteren Maxillipeden ist ganz klein. (17 b.) Das 4. Fußpaar trägt die gewöhnlichen Röhrenborsten. (17 c.)

1) Fisheries Ireland Sci. Invest. 1906 II [1908]. 
Diese Art hat augenscheinlich eine sehr weite Verbreitung, da sie weit südlich im Atlantischen Ozean noch gefunden wurde.

\section{5\%. Gaetanus major (WOLFENDEN).}

Diese von mir im Plankton des Faroë Channel zuerst beschriebene Art ${ }^{1}$ ) wurde von der Deutschen Südpolar-Expedition im Atlantischen Ozean angetroffen und dann von FARRAN ${ }^{2}$ ) als einer der charakteristischsten Copepoden von der Westküste Irlands erkannt. Sie kann beim ersten Anblick für ein großes Exemplar von Gaetanus armiger gehalten werden, doch sind zwischen beiden deutliche Artunterschiede vorhanden.

ㅇ 5-5,6 mm; Ce phaloth or a x 4,5 mm, Abdomen 1,1 mm lang. Der Kopf zeigt den Typus von Gaetanus armiger, ist vorn gerundet und trägt ein sehr kurzes und fein zugespitztes Horn, das nach vorn und unten gerichtet ist. Der Rücken ist schwach bucklig, das letzte Thorakalsegment gerundet und mit kurzen Enddornen versehen, die kaum ein viertel so lang als das Genitalsegment und schwach nach vorn gerichtet sind.

Das A b d o m e $\mathrm{n}$ ist etwa ein fünftel so lang als der Rumpf, das Genitalsegment so lang wie die beiden folgenden Segmente und ventral stark geschwollen. Die Furkaläste sind viel länger als breit und länger als das Analsegment. Der Analdeckel ist sehr deutlich und die Abdominalsegmente werden hinten von stark gezähntem Saum eingefaßt. Die vorderen Antennen reichen ungefähr mit den beiden letzten Gliedern über die Furka hinaus.

Der Außenast der hinteren Antennen ist etwa um ein viertel größer als der Innenast; ein Zipfel ist am Außenast nicht vorhanden.

Die vorderen M a xilli p e d e n sind am proximalen Ende tief ausgehöhlt. Das 2. Basalglied der hinteren Maxillipeden ist nur ein wenig größer als das 1. Basale und etwa dreimal so lang als der Innenast (1. Basale : 2. Basale : Innenast $=10: 12: 4$ ). Die gewöhnlichen lamellösen Fortsätze des ersten Basale fehlen dieser Art.

Das 1. Fußpaar hat deutlich dreigliedrigen Außenast, dessen 1. Glied jedoch keinen äußeren Randdorn aufweist; der Innenast des 2. Paares ist zweigliedrig und das 4. Paar trägt die üblichen Röhrenborsten.

Gaetanus major, der ein Tiefseebewohner zu sein scheint, wurde vom „Gauss" unter dem Äquator am 26. September 1903 (3000 m) und im südlichen Atlantischen Ozean am 16. November 1901 (3000 m) erbeutet.

\section{こ8. Gaetanus miles (GIESBRECHT)}

erschien in mehreren Fängen aus dem Atlantischen Ozean in der Sammlung des „Gauss“, so z. B. am 16. November $1901(3000 \mathrm{~m})$ und 19. Oktober $1901(800 \mathrm{~m})$. Diese gut bekannte Art ist ausgezeichnet durch ihre Größe, die Gestalt des Kopfes und die außerordentliche Länge der Antennen, die doppelt so lang als das ganze Tier sind, ferner durch den zweigliedrigen Außenast des 1. Fußpaares, den Lamellenanhang der hinteren Maxillipeden und durch das Fehlen des Zipfels am Außenaste der hinteren Antennen. Die durchschnittliche Größe wird von GiesBrecht als 3,5 mm angegeben, doch sind die atlantischen Exemplare gewöhnlich kleiner, etwa $3 \mathrm{~mm}$.

$\left.{ }^{1}\right)$ Proc. Zool. Soc. 1903.

2) Fisheries Ireland Sci. Invest. 1906 II (1908). 
59. Gaetanus rectus n. sp. (Tafel XXVI, Fig. 14-16, Textfig. 18 a. b.)

ㅇ 3,5 $\mathrm{mm}$ lang; Cephalothorax 2,8 mm, Abdomen 0,7 mm. Der Kopf hat den Typus von Gaetanus armiger, aber das Kopfhorn ist weniger kräftig. Das 1. Segment des C e p h a 1 o th o r a x ist mehr als doppelt so lang wie die übrigen Segmente desselben. Die Dornen des letzten Thorakalsegments entspringen von breiter Basis, sind kurz, kaum halb so lang als das Genitalsegment, gekrümmt, nach hinten gerichtet und divergieren stark bei der Ansicht vom Rücken. (XXVI. 14.)

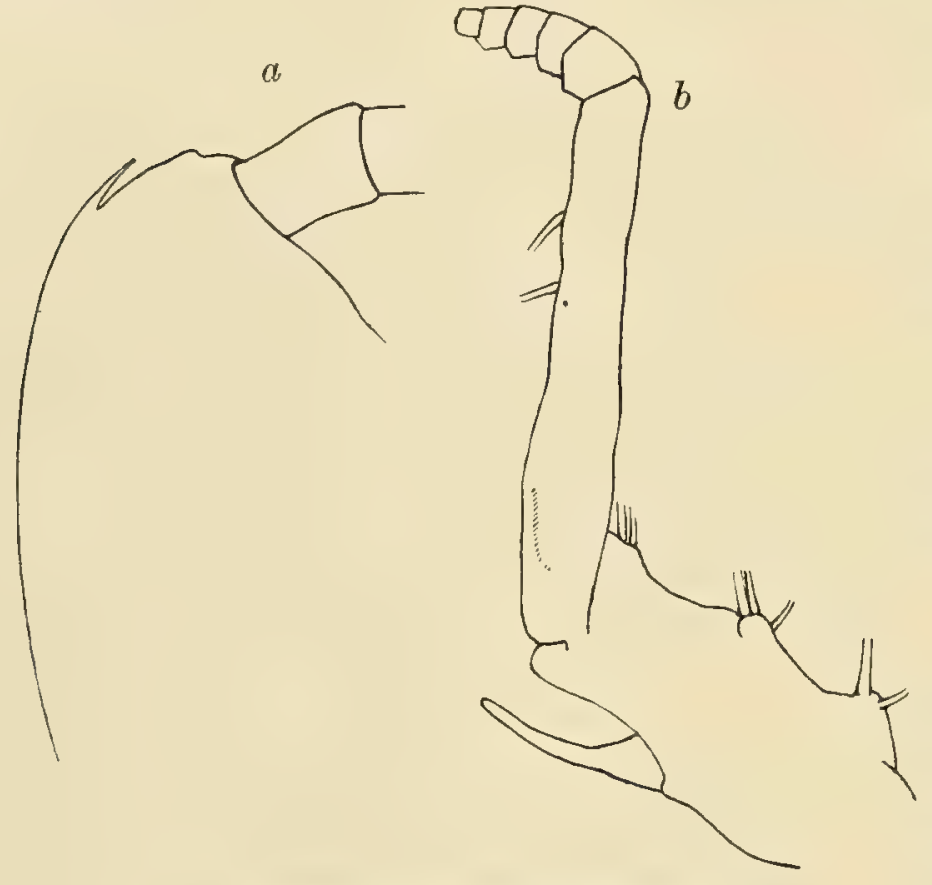

Textfig. 18. Gaetanus rectus. $a$ Kopf von der Seite. $\quad b$ Hinterer Maxilliped.

Das $\mathrm{A} b \mathrm{~d}$ o men ist kurz, nur ein viertel so lang als der Rumpf, das Genitalsegment ebenso breit als lang, mit gerundeten Seitenrändern und ventral in der unteren Hälfte stark vorspringend. Die Furkaläste sind länger als das Analsegment und ebenso breit als lang. (XXVI.15.)

Die vorderen A $\mathrm{n}$ t e $\mathrm{n} n$ e $\mathrm{n}$ erstrecken sich bis zum Ende der Furka. Der Innenast der hinteren Antennen ist fast so lang als der Außenast, welcher am 1. Segment einen Zipfel trägt.

Die vorderen $\mathrm{M}$ a $\mathrm{x}$ ill i ped e $\mathrm{n}$ sind stärker als bei jeder andern Art, im Proximalteile des äußeren Randes ausgehöhlt; der 5. Lobus ist verhältnismäßig groß und mit dickem, starkem, schwach gekrümmtem Haken versehen, der viel größer als der des 6. Lobus ist.

Das 2. Basalglied der hinteren Maxillipeden (18 b) ist etwas länger als das 1 . und viermal so lang als der Innenast. Das 2. Basale ist sehr schlank und etwa zehnmal so lang als breit. Der Lamellenfortsatz des 1. Basale ist schmal und steht aufrecht.

Das 1. F u B pa a r (XXVI. 16) ist mit zweigliedrigem Außenast versehen, dessen beide Proximalglieder nur teilweise, am äußeren Rande, geteilt sind. Nur 2 Randdornen sind vorhanden. Das 2. Fußpaar hat zweigliedrigen Innenast und das 4. trägt die üblichen Röhrenborsten.

Die stark divergierenden, kurzen und kräftigen Spitzen des letzten Thoraxsegments unterscheiden diese Art von den übrigen Arten.

Zwei Exemplare des ,Gauss" liegen vor (4. September 1903 aus $2000 \mathrm{~m}$ ) vom tropischen Atlantischen Ozean.

60. Gaetanus holti (Farran). (Textfig. 19.)

Diese auffallende Art wurde 1905 von FARRAN von der irischen Küste beschrieben ${ }^{1}$ ), ferner von G. O. Sars unter dem Namen Gaetanus latifrons nach den Sammlungen des Fürsten von Monaco ${ }^{2}$ )

1) Fisheries Ireland Sci. Invest. 1905.

2) Bull. Mus. Oceanograph. 1905. 
und etwa gleichzeitig von mir aus dem nördlichen Atlantischen Ozean unter dem Namen Gaetanus longispinus ${ }^{1}$ ) erwähnt. Die Priorität dürfte wahrscheinlich Farran haben.

Sie ist sofort an dem mächtigen, gekrümmten Kopfhorn zu erkennen, welches nach hinten gerichtet ist, ferner an der verhältnismäßig langen Stirn und einem schwachen Kamme des stark viereckig erscheinenden Kopfes und auch an den sehr stark gekrümmten und nach unten vorspringenden Dornen der letzten Thorakalsegmente, welche sich fast vom ganzen vorderen Teile des Segments erheben.

Die vorderen A $\mathrm{n} t$ e $\mathrm{n} \mathrm{n}$ e $\mathrm{n}$ reichen bis zum Ende der Furka. Die hinteren M a xillipe d e n tragen eine kleine Lamelle auf dem 1. Basalgliede; das 1. Fußpa ar hat dreigliedrigen Außenast mit 3 Randdornen, die Innenäste des 2. Paares sind zweigliedrig und das 4. Paar trägt die gewöhnlichen Röhrenborsten. Das $q$ ist etwa $3,75-4 \mathrm{~mm}$ lang. Gaetanus holti ist anscheinend im Atlantischen Ozean sehr häufig, erscheint von dort auch in den. Fängen des ,Gauss" und erstreckt sich nach Norden bis zur Westküste Grönlands.

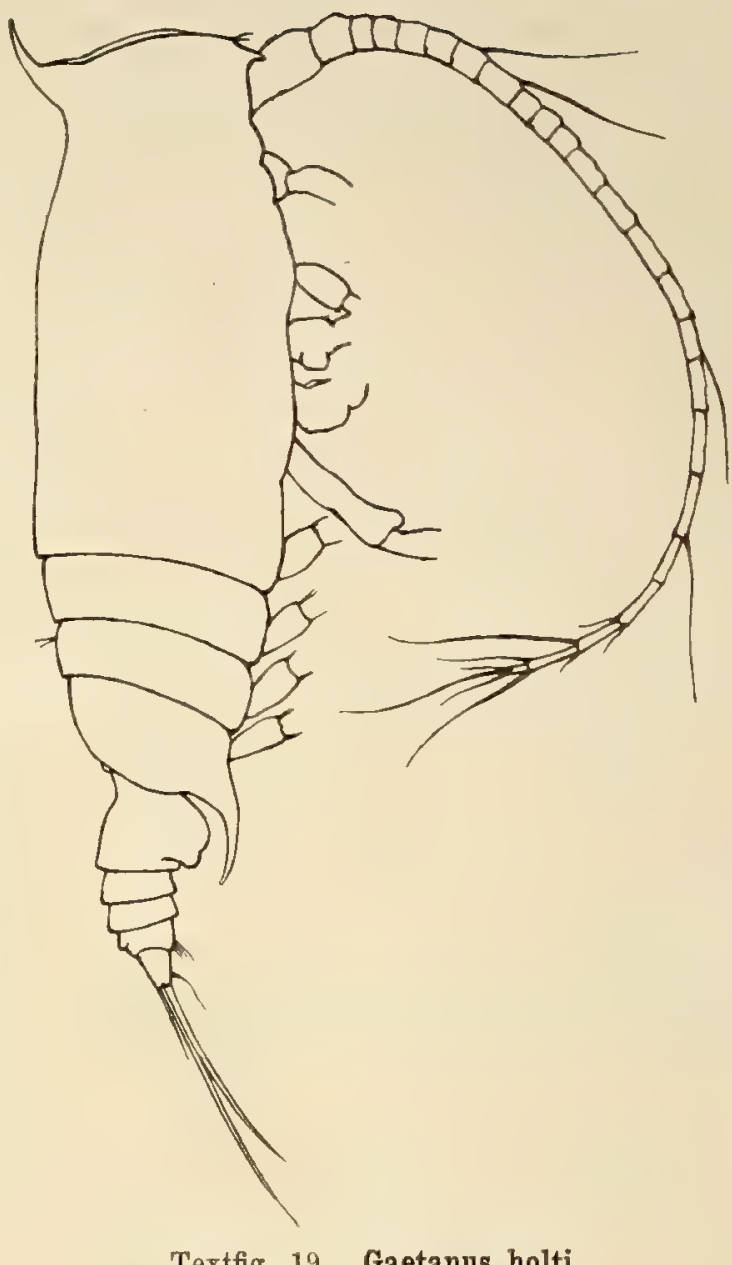

Textfig. 19. Gaetanus holti.

61. Gaetanus minor Farran (Textfig. 20, a-e)

wurde zuerst von FARRAN $^{2}$ ) als kleinste Art dieser Gattung beschrieben. Seine Messungen ergaben 2,4 mm, aber bei der Gauss-Expedition erschienen identische Exemplare, die nicht größer als 2,0 mm sind. Ein völlig erwachsenes Weibchen sogar, vom 19. Oktober 1901 (500 m), war nicht größer als $1,75 \mathrm{~mm}$. Es stimmt im allgemeinen mit FARRAN's Originalbeschreibung überein mit der Ausnahme, daß der Innenast der hinteren Antennen verhältnismäßig größer (mehr als dreiviertel so lang als der Außenast), der Haken des vorletzten Lobus der vorderen Maxillipeden viel länger und stärker als der des letzten Lobus und die Borste des 1. Lobus nicht, wie FARRAN angibt, stärker als die der übrigen ist. Wenn es sich als wünschenswert herausstellen sollte, diese Form von Gaetanus minor zu trennen, kann sie als Gaetanus minimus bezeichnet werden.

Gaetanus minor aus dem Atlantischen Ozean ist nur 2,0 mm lang, das Abdomen nicht ganz ein viertel so lang als der Rumpf (Cephalothorax 1,65 mm, Abdomen 0,35 mm). Der Kopf (20 a) zeigt den Typus von Gaetanus armiger, das Kopfhorn ist dünn und nach vorn gekrümmt. Die Dornen des letzten Thorakalsegments sind dünn, gerade und etwa so lang wie das Genitalsegment. (20 bu.c.) Dieses ist groß, springt ventral vor und hat gerundete Seitenränder. Es ist ebenso lang

1) Planktonstudien.

2) Fisheries Ireland Sci. Invest. 1905. 
wie die beiden folgenden Segmente zusammen. Die Furkaläste sind länger als breit, und kürzer als das Analsegment.

Die vorderen A nte $\mathrm{n} \mathbf{n}$ e $\mathbf{n}$ erstrecken sich nicht bis über das Genitalsegment hinaus. Der

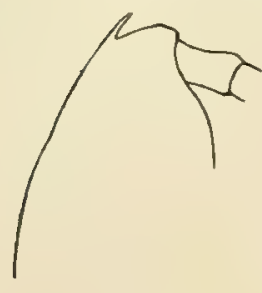

a

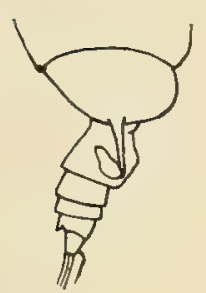

$b$

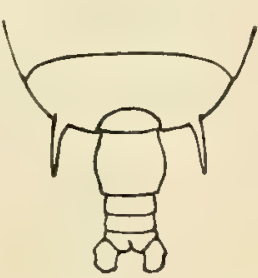

$c$

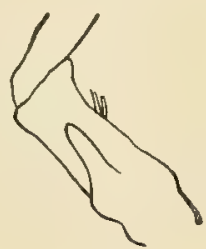

$d$

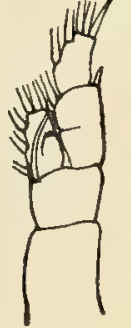

e

Textfig. 20. Gaetanus minor.

$a$ Kopf von der Seite. $b$ und $c$ Abdomen und letztes Thoraxsegment. $d$ Erstes Basalglied vom hinteren Maxilliped. $e$ Erster Fuß.

Innenast der hinteren Antennen ist kurz und kaum drei viertel so lang als der Außenast. Der letztere trägt einen vorspringenden Zipfel mit kurzer Borste an seinem 2. Segment. Die Borsten der proximalen Loben der vorderen M a xillipeden haben alle ungefähr gleiche Größe, der Haken des 5. Lobus ist stärker als der des letzten. Das 2. Basalglied der hinteren Maxillipeden ist ein wenig länger als das 1. und etwa sechsmal so lang als breit, und in der proximalen Partie springt der Rand mit einem deutlichen Buckel hervor. Proximal von diesem tritt am Rande eine Reihe sehr kurzer, aber kräftiger, steifer Borsten auf. Das 1. Basalglied trägt einen kurzen Lamellenfortsatz. (20 d.)

Das 1. F u B p a a r (20 e) hat zweigliedrigen Außenast mit nur 2 Randdornen, und das 2. Fußpaar zeichnet sich durch eingliedrigen Innenast aus, welcher keine Andeutung einer Teilung erkennen läßt. Am 4. Paare finden sich die gewöhnlichen Röhrenborsten.

Ich hege kaum Zweifel wegen der Ubereinstimmung dieser Form mit Gaetanus minor. Gaetanus minimus würde, wenn sich seine Berechtigung als gute Art erweisen sollte, durch die noch geringere Größe und durch das Fehlen eines Zipfels an der hinteren Antenne charakterisiert sein. Unter den Sammlungen des „Gauss" erschien diese Art in den Tiefenfängen aus dem Atlantischen Ozean vom 19. Oktober $1901(800 \mathrm{~m})$, 5. November 1901 (1000 m) und vom 30. September 1903 (1500 m).

\section{Euchirella Giesbrecht.}

In den Sammlungen des "Gauss" aus dem Atlantischen Ozean ist diese Gattung besonders reich an Individuen und Arten vertreten. Seit Abfassung der Copepoden in „Das Tierreich“ von GtesbRecht und SchmeIl sind zahlreiche neue Arten derselben beschrieben. Diesen werden 7 weitere Arten hier hinzugefügt. Farran (1. c.) beschrieb eine neue Art, Euchirella wolfendeni, und neulich wurden von G. O. SARS (Bull. Mus. oceanogr.) 6 Arten unter dem Namen Undeuchaeta erwähnt (Undeuchaeta obtusa, pustulifera, scopularis, dubia, palliata und lobata), welche alle zum Genus Euchirella zu gehören scheinen, wenigstens wenn man die ursprüngliche Gattungsdiagnose GIESBREcht's anerkennt. Es ist möglich, daß einige der Arten von SARs mit den unten neu beschriebenen identisch ist, aber da die von diesem Autor veröffentlichten Notizen fragmentarisch und nicht von Figuren begleitet sind, ließ sich dieses nicht mit einiger Sicherheit feststellen. Von einer Art wenigstens, die FARRAN (a. a. O.) beschrieb und abbildete, nämlich Euchirella obtusa, gab er an, daß sie wahrscheinlich identisch mit Undeuchaeta obtusa SARs ist. Das konstante Vorkommen von Dornen an der Basis des 4. Fußpaares rechtfertigt es, alle diese Arten zur Gattung Euchirella zu rechnen. 
62. Euchirella spinosa n. sp. (Tafel XXVII, Fig, 3-7.)

q 6,2 mm lang. Der C e pha lothorax ist ungefähr viermal so lang als das Abdomen. Der Kopf ist ziemlich schmal, ohne Spur einer Crista und mit kurzem, starkem Rostrum versehen. Das letzte Thorakalsegment (XXVII. 3 u. 4) ist jederseits in kurze, starke Dornen verlängert, die nach unten gerichtet und etwa halb so lang als das Genitalsegment sind. Das letztere ist nicht so lang wie die beiden folgenden Segmente zusammen, etwas in der oberen Hälfte der Ventralfläche angeschwollen, aber ohne seitliche Auswüchse. Die Furkaläste sind breiter als lang und kürzer als das Analsegment. Der Hinterrand der Abdominalsegmente ist kurz kammartig gesäumt. Die vorderen A n t e n n e $\mathrm{n}$ setzen sich aus 23 Gliedern zusammen, sind nicht so lang als der Körper (etwa $5 \mathrm{~mm}$ ). Der Innenast der hinteren Antennen (XXVII. 5) ist nur halb so lang als der Außenast, und ein Zipfel ist am letzteren nicht vorhanden. Der Innenast hat $8+6$ Borsten. Die M a xille hat 5 Borsten am 2. Basalgliede, 15 am Innenast und 11 am Außenaste, der sehr klein ist. Die vorderen M a $\mathrm{x}$ i 11 i p e d e $\mathrm{n}$ haben starke Haken am 4. und 5. Lobus, von denen der erste einwärts gekrümmt, der andere gerade ist. Das 2. Basale der hinteren Maxillipeden ist zweimal so lang als das 1. und siebenmal so lang als breit. Die Verhältnisse der beiden Basalia und des Innenastes sind =14 : $28: 9$. Das 2. Basalglied hat einen vorspringenden Buckel am inneren Distalrande.

Der Außenast des 1. F u B p a a r e s ist zweigliedrig, da das 1. und 2. Glied verwachsen sind, doch sind 3 Randdornen vorhanden. Das 2. Paar (XXVII. 6) hat sehr deutlich zweigliedrigen Innenast, und seine Randdornen sind alle gleich groß. Das 4. Paar (XXVII. 7) trägt auf dem 1. Basalglied ein Polster mit 13 langen Dornen, von denen die der inneren Seite etwas stärker als die äußeren sind.

Euchirella spinosa ist zum Unterschiede von den übrigen Arten ihrer Gattung durch den Besitz sehr starker Seitendornen am letzten Thorakalsegment und durch den sehr deutlich zweigliedrigen Innenast des 2. Fußpaares ausgezeichnet. Sie wurde in Tiefenfängen aus dem Atlantischen Ozean am 11. Oktober 1901 (1200 m), 26. September 1903 (3000 m) und 9. Oktober 1903 (3000 m) gefunden.

\section{Euchirella rostrata CLAUS.}

Sie wurde sehr häufig vom ,Gauss“ im Atlantischen Ozean angetroffen und erreichte eine Durchschnittsgröße von $3 \mathrm{~mm}$ Länge. Doch zeigte sich die Größe ziemlich variabel, da z. B. Exemplare vom 5. September 1903 (400 m) nur 2,75 mm Länge erreichten, während andere vom 12. November $1901(3000 \mathrm{~m}) 3 \mathrm{~mm}$ und etwas darüber maßen. Eine Form, welche dieser im Habitus sehr ähnlich ist, erschien häufig in der Antarktis, doch unterscheidet sie sich durch so wichtige Eigentümlichkeiten, daß sie als besondere Art betrachtet werden muß. Sie wird unten beschrieben werden. Euchirella rostrata wurde vom ,Gauss“" am 12. November 1901 (3000 m), 18. Dezember 1901 (2500 m), 3. September $1903(400 \mathrm{~m})$, 5. September $1903(400 \mathrm{~m})$, 10. September 1903 (3000 m), 11. September 1903 (400), 30. September $1903(1500 \mathrm{~m})$, 9. Oktober 1903 (3000 m), also im tropischen Atlantischen Ozean und in der Westwinddrift gesammelt.

64. Euchirella rostromagna $n$. sp.

ㅇ $6 \mathrm{~mm}$; Cephalothorax 4,95 mm, Abdomen 1,05 mm. Der Kopf zeigt kühne Profillinie, mit starkem Rostrum, wie bei Euchirella rostrata. Das letzte Thorakalsegment hat gerundete Ränder. Das Genitalsegment ist stark an der Ventralseite geschwollen. Die Furkaläste sind länger als breit 
und länger als das Analsegment. Die vorderen Antenn en erreichen fast die Furka. Der Innenast der hinteren Antennen ist ungefähr halb so lang als der Außenast. Der letztere trägt $8+6$ Endborsten und proximal von diesen einen Dorn. Die vorderen M a xilli p e d e n weisen ähnliche Haken am 4. und 5. Lobus auf, und der Proximalteil des Außenrandes ist ausgehöhlt, doch nicht annähernd so stark wie bei andern Arten. Die 2. Basalglieder der hinteren Maxillipeden sind beinahe sechsmal so lang als breit, und die Längenverhältnisse ihrer 3 Glieder sind wie $13: 17: 5$. Die $M$ a xille $\mathrm{n}$ tragen am 2. Basalgliede 3 Borsten, 3 am Innenaste, die lang sind und ziemlich weit voneinander abstehen, 7 am 1. Innenlobus, je 2 am 2., 3. Innenlobus und 10 am Außenaste. Die Außenäste des 1. Fußpa ares sind wie bei Euchirella rostrata gebaut, zweigliedrig mit 3 Randdornen; das 2. Paar hat eingliedrigen Innenast und das 4. Paar trägt ein Kissen mit 11 Dornen, von denen der innerste einen großen, konischen Zahn darstellt, während naç außen hin die Dornen der Reihe an Größe abnehmen, dort klein und zusammengedrängt sinå.

Dieser Copepod stimmt in seinen meisten Merkmalen mit Euchirella rostrata überein, ausgenommen in der Größe, welche die der letzteren Art um das Doppelte übertrifft. Er wurde bei der Annäherung an das Scholleneis am 10. Februar $1902(2700 \mathrm{~m})$ und im Scholleneise selbst nordwestlich von der Gauss-Station am 9. März 1903 (400 m) und andern Fängen gefunden.

\section{Euchirella carinata Wolfenden.}

Diese Art, welche von mir zuerst aus dem Atlantischen Ozean westlich von Irland beschrieben wurde, identifizierte FARRAN (1. c.) später mit Chirundina streetsi, doch ergibt sich aus der Abwesenheit von Dornen oder Spitzen am letzten Thorakalsegment schon ihre Verschiedenheit von der letzteren. Ferner hat unsere Art eine verhältnismäßig größere und mehr dreieckige Crista auf dem Kopfe. In jeder Hinsicht gleicht sie Euchirella, nur darin, daß an den Basalgliedern des 4. Fußpaares die Dornen fehlen, nähert sie sich Chirundina.

Vom ,Gauss ${ }^{66}$ wurde Euchirella carinata im Atlantischen Ozean am 12. November 1901 und am 13. Oktober 1903 bei Vertikalfängen aus $3000 \mathrm{~m}$ erbeutet.
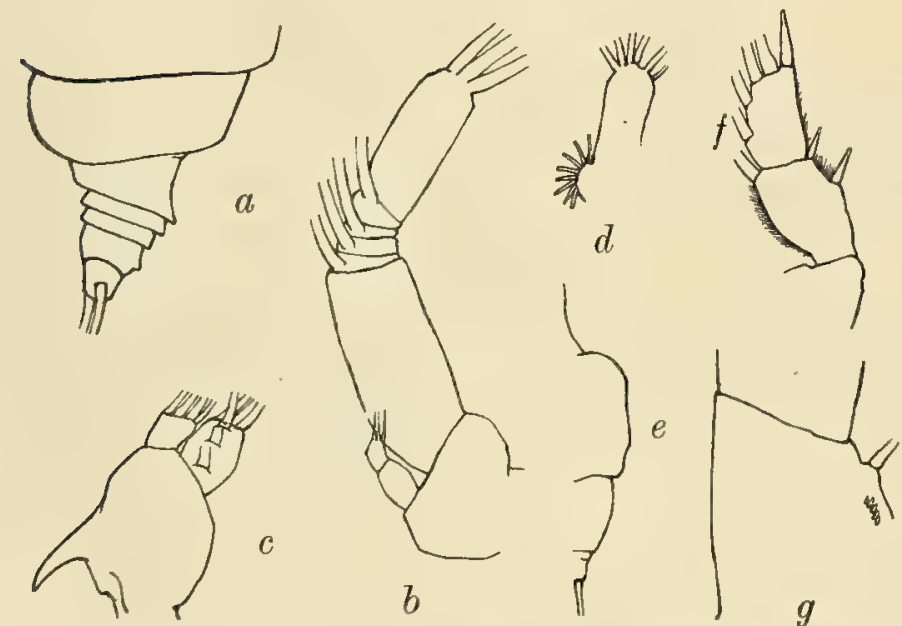

Textfig. 21. Euchirella brevis f. $^{2}$

$a$ Abdomen und letztes Thoraxsegment. $b$ Hintere Antenne. c Mandibelpalpus. $d$ Haxille. $e$ Außenwand yom hinteren Maxilliped. $f$ Außenast rom 1. Fuß. $g$ Basalglied vom 4. Fuß.
66. Euchirella curticauda (GTESBRECHT) erschien in den Vertikalfängen aus dem Atlantischen Ozean vom 11. Oktober 1901 (1200 m) und 26. September 1903 (3000 m).

6\%. Euchirella brevis (G. O. SARS) (Textfig. $21 \mathrm{a}-\mathrm{g}$ )

war nicht selten in den Fängen aus dem Atlantischen Ozean vorhanden und ist charakterisiert durch den gerundeten, breiten Kopf, kleines Rostrum, sehr kurzes Abdomen (21 a) mit breitem Genitalsegment, zusammengedrängte folgende Segmente, kurze vordere Antennen, die nicht das Ende des Cephalothorax erreichen, rudimentären Innen- 
ast der hinteren Antennen (21 b), eigentümlichen Mandibularpalpus (21 c), der am inneren Rand einen gekrümmten Haken mit dicker Basis und 7 äußerst kurze Dornen an den 1. Basalgliedern des 4 . Fußpaares $(21 \mathrm{~g})$ trägt. Sie trat regelmäßig in den tiefen Vertikalfängen auf vom 22 . August $1903(1500 \mathrm{~m})$, 4. September $1903(2000 \mathrm{~m})$, 10. September 1903 (3000 m), 26. September 1903 $(3000 \mathrm{~m})$ und 13. Oktober $1903(3000 \mathrm{~m})$, während sie in den dazwischen liegenden Planktonfängen aus $400 \mathrm{~m}$ vermißt wurde.

\section{Euchirella messinensis (GIESBRECHT).}

Diese charakteristische Art wurde einigemal in Fängen aus dem tropischen und südlichen Atlantischen Ozean beobachtet, so am 16. November 1901 (3000 m), 30. September 1903 (800 m) und besonders am 9. Oktober $1903(3000 \mathrm{~m})$. Diese Exemplare haben zwei lange Dornen an den Basalgliedern des 4. Fußpaares und die deutlich ausgeprägten dorsalen Schwellungen, welche GIESBRECHT beschreibt.

69. Euchirella gracilis n. sp. (Tafel XXVII, Fig. 8-10, Textfig. 22.)

Beim ersten Anblick könnte man diese Art für Euchirella venusta halten, welche von GIESBRECHT aus dem Pazifischen Ozean beschrieben wurde, doch fanden sich bei den zahlreichen vom „Gauss" erbeuteten Exemplaren so konstante Abweichungen von der Originalbeschreibung von Euchirella venusta GIESBRECHT, daß ich sie als besondere, wenn auch dieser nahestehende, Art erwähnen muß.

† 5,6-6 mm lang; A bdomen. kurz, nur wenig länger als ein Fünftel des Rumpfes. (XXVII. 8.) Der Kopf ist gleichmäßig gerundet, ohne Spur einer Crista, und trägt ein kurzes, starkes Rostrum. Das letzte Thorakalsegment ist jederseits einfach gerundet. Das Genitalsegment tritt ventral hervor und erscheint auf der linken Seite schwach angeschwollen, doch ohne Auswüchse. Die Furkaläste sind kurz, so breit als lang und ziemlich divergent.

Die vorderen Antenn en sind etwas länger als der ganze Körper. Der Innenast der hinteren Antennen (XXVII.9) ist halb so lang als der Außenast, und bei dem ersteren sind $8+7$ Endborsten, also mehr als bei Euchirella venusta, vorhanden. Am 2. Segment des Außenastes findet sich ein Zipfel.

Die Mundorgane haben den für Euchirella typischen Bau. Beim 2. Fuß-

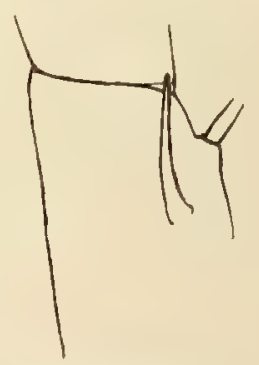

Textfig. 22 . Euchirella gracilis. 2. Basalglied rom 4. FuB. pa ar (XXVII. 10) ist der äußere Dorn des 2. Gliedes vom Innenaste besonders groß und reicht bis zur Basis des 1. Dornes vom 3. Gliede. Das 4. Fußpaar hat am 2. Basalglied (Textfig. 22) einen kräftigen und langen Dorn, welcher das Ende des Gliedes ein wenig überragt. Dieses scheint ein konstanter Charakter zu sein, da eine große Anzahl von Tieren daraufhin untersucht wurde und nur einen Dorn zeigte.

Wesentliche Unterschiede von Euchirella venusta bieten auch die Mierkmale der hinteren Antennęn, der äußeren Dornen des 2. Fußpaares und die Bewaffnung des 4. Paares.

Euchirella gracilis fand sich am 12. November $1901(3000 \mathrm{~m})$, 26. September und 9. Oktober 1903 $(3000 \mathrm{~m})$ und an andern Stationen des Atlantischen Ozeans. 
70. Enchirella similis n. sp. (Tafel XXVIII Fig. 1 u. 2, Textfig. 23 a-d.)

Auch diese Art kann leicht mit Euchirella venusta verwechselt werden, von der sie sich doch durch einige sichere Merkmale unterscheidet.

o etwa $4 \mathrm{~mm}$ lang; das $\mathrm{A} \mathrm{b}$ d o $\mathrm{m}$ e $\mathrm{n}$ ist kaum ein viertel so lang als der Cephalothorax; der Kopf zeigt gleichmäßige Krümmung, ohne Spur einer Crista. (23 a.) Ein kleines Rostrum ist vorhanden. Das letzte Thorakalsegment ist gerundet. (23 b.) Das Genitalsegment ist bei allen Exemplaren durch eine große Wucherung auf der rechten Seite ausgezeichnet, welche stets auf diese

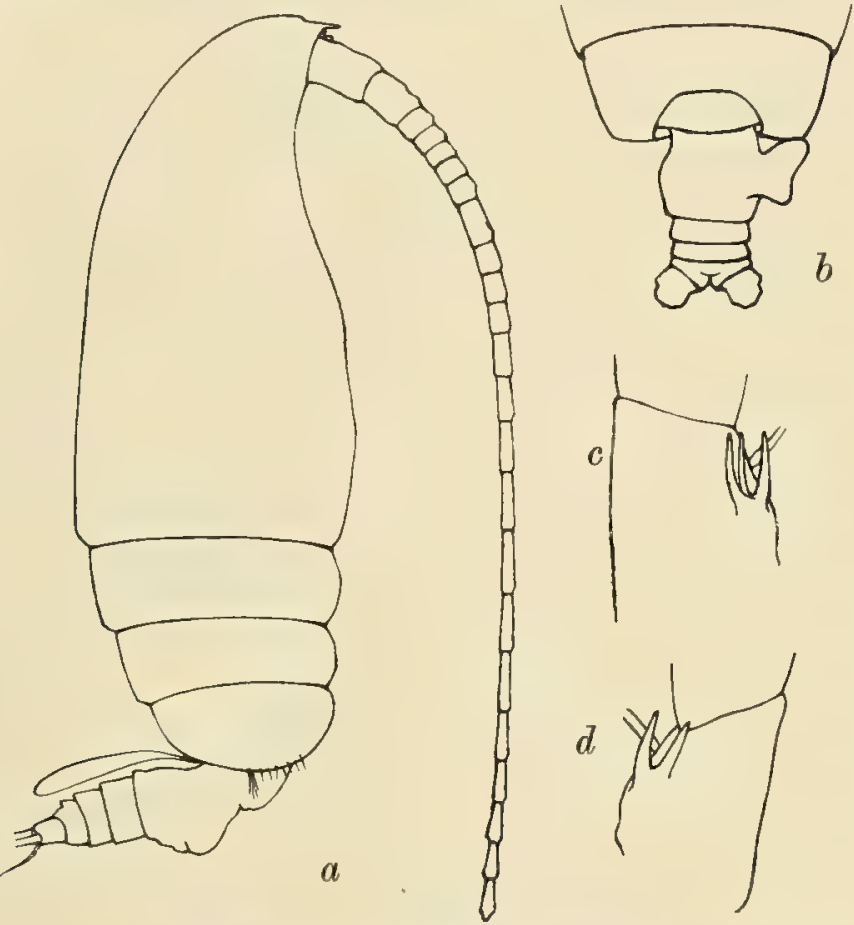

Textfig. 23. Euchirella similis.

a Seitenansicht. $b$ Letztes Thoraxsegment und Abdomen. $c$ und d Basalglieder vom 4. Fuß. Seite beschränkt zu sein scheint. Die vorderen A $n$ te $n n$ e $n$ reichen etwa bis zum Hinterrande des 2. Abdominalsegmentes. Die hinteren Antennen (XXVIII. 1) sind durch sehr kleinen und schwachen Innenast ausgezeichnet, der nur $5+4$ Endborsten, wie bei Euchirella messinensis, trägt. Der AuBenrand der hinteren $\mathrm{Maxi} 11 \mathrm{ipeden}$ ist nicht so tief ausgehöhlt wie bei einigen andern Arten. Beim 2. Fußpaare (XXVIII. 2) reicht der äußere Randdorn des 2. Gliedes vom Außenast nicht über die Basis des 1. Dorns des 3. Gliedes hinaus. Die Basalia des 4. Fußpaares tragen 2 oder gelegentlich 3 lange, dünne Dornen (23 c u. d), von denen der innere am kräftigsten und dicksten ist. Sie überragen nicht das Ende des Gliedes. Mehrere Exemplare wurden vom ,Gauss" am 12. und 16. November 1901 (3000 m), 22. August 1903 (1500 m), 26. September 1903 $(3000 \mathrm{~m}), 30$. September $1903(1500 \mathrm{~m})$,

9. Oktober $1903(3000 \mathrm{~m})$ und an einigen andern Tagen im Atlantischen Ozean gefangen.

Unter den 4 Arten, Euchirella messinensis, venusta, gracitis und similis, besteht eine erhebliche Familienähnlichkeit, aber während bei der ersten die dorsale Anschwellung auf der linken Seite des Abdomens groß und charakteristisch ist, fehlt sie völlig bei Euchirella venusta und beinahe bei Euchirella gracilis und ist als großer, lappenartiger Fortsatz auf der rechten Seite von Euchirella similis, entwickelt. Bei den ersten beiden Arten ist der Innenast und die Beborstung der hinteren Antennen völlig verschieden. Die Randdornen des 2. Fußpaares sind bei Euchirella messinensis und Euchirella venusta ganz verschieden von denen bei Euchirella similis und Euchirella gracilis, und die Bedornung des 4. Fußpaares ist auch nicht übereinstimmend. Da viele Exemplare vorlagen, erweisen sich diese Merkmale als konstant und können kaum als gelegentliche Variationen gedeutet werden.

71. Euchirella maxima n. sp. (Tufel XXVII Fig. 3-5, Textfig. 24 a. b)

ist eine der größten Euchirella-Arten, die bekannt sind. $\$ 7,5-8 \mathrm{~mm}$, ein sehr großes Exemplar maß8,7 mm); Cephal o thorax viermal so lang als das Abdomen. (XXVIII.3.) Auf dem Kopfe findet 
sich eine stark vortretende, dreieckige Crista, deren äußerer dünner Chitinrand bei älteren Exemplaren mehr oder weniger gerundet erscheint. Doch springt auch bei diesen die Crista mehr als bei Euchirella galeata hervor. Vorn ist der Kopf in eine starke Spitze verlängert, die das kleine, aber deutliche Rostrum bildet. Das letzte Thorakalsegment läuft in kurze, dreieckige, zugespitzte Lappen aus. Das $\mathrm{A} \mathrm{b} \mathrm{d} \mathrm{o} \mathrm{m}$ e $\mathrm{n}$ ist weder dorsal noch seitlich angeschwollen, sondern zeigt nur ventral eine sehr deutliche Wucherung an der unteren Hälfte; der obere Teil der Genitalschwellung ist ausgehöhlt.

Die vorderen Antennen überragen das Ende des Genitalsegments. Der Innenast der hinteren Antennen (XXVIII. 4) ist sehr kurz, nur etwa ein drittel so lang wie der Außenast; $5+5$ Borsten sind vorhanden, von denen die inneren sehr kurz sind. Das 2. Glied des Außenastes trägt einen Zipfel. Der Innenast der M a xille hat 5 Borsten am 2. Basalgliede, der Außenast 11. (XXVIII. 5.) An den vorderen M a xillipeden ist der 4. Lobus mit einem starken, Textfig. 24. Euchirella maxima. der 5. mit viel kürzerem und schwächerem Haken ausgestattet. Der Außenrand ist proximal ausgehöhlt. Die Basalglieder und der Innenast

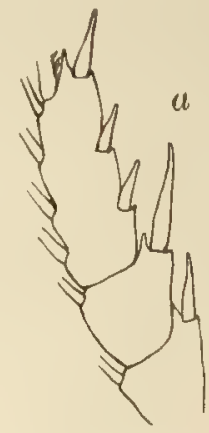
der hinteren Maxillipeden stehen im Längenverhältnis von $17: 22: 9$, und das 2. Basalglied ist etwa siebenmal so lang als breit.

Das 2. $\mathrm{Fu} \mathrm{B}$ p a a $\mathrm{r}$ ist durch sehr langen Außendorn am Distalrande des 2. Segments vom Außenast ausgezeichnet (24 a), welcher die Spitze des 1. Dornes vom 3. Segment ïberragt. Die Basalglieder des 4. Fußpaares tragen einen kräftigen Dorn mit breiter Basis, welcher nicht uiber das Ende des Gliedes hinausreicht. (24 b.)

Von Euchirella galatea unterscheidet sich diese Art besonders durch die hinteren Antennen und durch das Abdomen. Bemerkenswert ist, daß die Art seit ihrer ersten Beschreibung auch von FARRAN an der Westküste Irlands angetroffen wurde (a. a. O.). In der Ausbeute des "Gauss" liegt sie aus dem tropischen Atlantischen Ozean vom 16. November 1901 (3000 m), 26. September $1903(3000 \mathrm{~m})$ und 30. September $1903(1500 \mathrm{~m})$ vor.

72. Euchirella elongata n. sp. (Tafel XXVIII Fig. 6, Textfig. 25.)

o 7,5-7,7 mm lang. Der Ce phalothorax ist etwa $3 \frac{1}{2} 2 \mathrm{mal}$ so lang als das Abdomen; Kopf und 1. Segment sind teilweise getrennt, und die beiden letzten Thorakalsegmente sind nicht

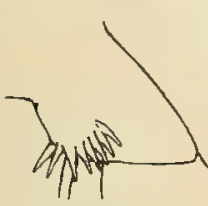

Textfig. 25 .

Euchirella

elongata.

1. Basalglied vom

4. Fub. verwachsen. Das letzte Rumpfsegment endigt mit gekrümmten dreieckigen Lappen, welche bei Dorsalansicht als scharfe Spitzen erscheinen. Der rechte Lappen ist etwas länger als der linke und nach innen gekrümmt. Der Thorax ist vorn verschmälert und hinter der Mitte am breitesten. Dorsal fallen am Kopfe zwei Pigmentflecke auf; der Kopf erscheint vom Rücken gesehen ziemlich schmal und hat gleichmäßige Krümmung, ohne Spur einer Crista. Ein kurzes, starkes Rostrum ist vorhanden. Das Genitalsegment ist seitlich angeschwollen, und zwar rechts etwas mehr als auf der linken Seite; ventral tritt die Anschwellung wenig hervor und im Umriß erscheint sie gelappt. Die Furkaläste sind etwa ebenso lang als breit. Die vorderen A n tennen sind nur so lang als der Cephalothorax; ihr 8. und 9. sowie das 24. und 25. Glied 
sind verwachsen. Der Innenast der hinteren Antennen ist nur halb so lang als der Außenast, ein Zipfel am Außenaste fehlt, und das letzte Glied des Innenastes trägt 15 Borsten. An den vorderen M a xill i p e d e n sind der 4. und 5. Lobus gleich groß und mit je einem starken Haken versehen, von denen der des 4 . Lobus nach innen, der des 5. Lobus nach außen gekrümmt ist. Der Außenrand der vorderen Maxillipeden ist nicht proximal ausgehöhlt.

Das 2. Basalglied der hinteren Maxillipeden ist $1^{3} /{ }_{4} \mathrm{mal}$ so lang wie das 1 . und achtmal so lang als breit, und das 1.. Basalglied hat am inneren Rande des Distalendes einen starken Buckel.

Beim gewöhnlichen Typus der M a xill e n von Euchirella treten am Innenaste 15 Borsten auf, 5 am 2. Basalgliede, 11 am Außenast und 9 am 1. Außenlobus. Das 1. F u B p a a r hat dreigliedrigen Außenast mit 3 Randdornen. Das zweite Paar hat eingliedrigen Innenast und verhältnismäßig kurzen Randdorn am 2. Gliede des Außenastes. Das 4. Fußpaar trägt ein Polster am 1. Basalgliede mit 7 oder 8 gleichen starren Dornen, von denen die inneren stärker als die äußeren sind.

Ein Exemplar wurde vom „Gauss“ am 10. März $1903(3000 \mathrm{~m})$ im Gebiet des südlichen Scholleneises gefunden.

73. Euchirella hirsuta n. sp. (Tafel XXVIII Fig. 7-9).

Sie ist die größte aller bekannten Euchirella-Arten. क 8,5-9 mm lang; Abdomen kurz, kaum mehr als ein viertel der Länge des Rumpfes erreichend. Der K o p f ist vorn ziemlich schmal, aber gleichmäßig gerundet, ohne Spur einer Crista und mit kurzem und starkem Rostrum. Die letzten beiden Thorakalsegmente sind unvollkommen gesondert und das hintere derselben in Lappen verlängert, welche an den Rändern mit kurzen Haaren bedeckt sind. (XXVIII. 7.)

Das kurze $\mathrm{A}$ b d o m e $\mathrm{n}$ hat ein sehr großes Genitalsegment, welches ebenso lang wie die drei folgenden Segmente ist, seitlich verbreitert, aber nicht ventral geschwollen erscheint. Das 2. Segment trägt ein auffallendes Haarbüschel auf der Ventralseite, und kleinere Haarbüschel treten auch auf den folgenden Segmenten auf. Die Furkaläste sind sehr klein, ebenso breit als lang. (XXVIII. 8.)

Die vorderen A n te $\mathrm{n} n$ e $\mathbf{n}$ reichen etwa bis zum 3. Abdominalsegment. Der Innenast der hinteren Antennen ist ungefähr halb so lang als der Außenast, und das letzte Glied des Innenastes trägt $8+6$ Borsten. Ein Zipfel des Außenastes ist nicht vorhanden.

Die Maxille n haben die üblichen 15 Borsten am Innenaste, 5 am 2. Basalglied und 11 am Außenaste. Die vorderen M a xilli peden sind im Proximalteil am Außenrande tief ausgehöhlt. Das 2. Basalglied der hinteren Maxillipeden ist fast zweimal so lang als das 1. und siebenmal so lang als breit. Das Längenverhältnis der Basalglieder und des Innenastes ist wie $19: 30: 12$.

Das 1. F u B p a a $\mathrm{r}$ hat dreigliedrigen Außenast mit 3 Randdornen und das 2. Paar deutlich zweigliedrigen Innenast. Das 4. Paar trägt am 1. Basalglied ein Polster mit 14 starken, fast gleichgroßen Zähnen. (XXVIII. 9.) Das 2. und 3. Glied des Innenastes sind dicht mit feinen Haaren bedeckt, welche auch, allerdings weniger dicht, auf den Gliedern des Außenastes erscheinen. Diese Beharung ist sehr charakteristisch für die Art, welche vom „Gauss“" sowohl in der Antarktis am 13. Februar $1902(3000 \mathrm{~m})$ als auch im südlichen Atlantischen Ozean am 12. und 16. November 1901 (3000 m) entdeckt wurde. 
74. Euchirella pulchra LuBbock

wurde im Atlantischen Ozean am 19. Oktober 1901 (500 m) und 26. September 1903 (3000 m) gesammelt.

\section{Euchirella galatea Giesbrecht}

fand sich in den Vertikalfängen aus dem Atlantischen Ozean vom 5. November 1901 (1000 m) und 4. September $1903(2000 \mathrm{~m})$.

\section{Chirundina Gresbrech't.}

Die Gattung wurde von Giesbrecht für die Art Chirundina streetsi (Bull. Mus. Comp. Zool. Harvard College vol. 25) aufgestellt. Sie ist nahe mit Undeuchaeta und Euchirella verwandt, und es ist nicht leicht, dieselbe zu definieren, zu der eine ganze Anzahl von Arten gehören dürfte. Während im Habitus und in den Körperverhältnissen sowie im Besitz einer Crista des Kopfes Undeuchaeta major, Chirundina streetsi, einige Arten von Euchirella und Mesundeuchaeta einander gleichen, liegen die wichtigsten Gattungsunterschiede zwischen Undeuchaeta und Chirundina im Bau des Außenastes der Maxille, in der Länge des Innenastes der hinteren Antennen und den gerundeten (Undeuchaeta) oder zugespitzten Enden des letzten Thorakalsegments. Die kurzen mittleren Borsten des Außenastes der Maxillen unterscheiden die Gattung Undeuchaeta sofort von den übrigen, während sonst die Erkennung Schwierigkeit machen würde.

Die von SARS als Chirundina angulata (Bull. Mus. oceanogr.) neuerdings beschriebene Art wird nun von ihm zu Undeuchaeta major GIESBRECHT gerechnet. Sowohl Chirundina als auch Euchirella unterscheiden sich von Undeuchaeta unter anderem nicht nur durch die Anhänge der Maxille, sondern durch das Vorhandensein von Dornen auf den Basalgliedern des 4. Fußpaares bei allen Arten von Euchirella mit Ausnahme von Euchirella carinata, wo diese fehlen. Für eine abweichende Form, welche zwischen Undeuchaeta und Euchirella zu stehen scheint und welche in den Sammlungen des „Gauss" häufig angetroffen wurde, habe ich eine neue Gattung Mesundeuchaeta geschaffen.

76. Chirundina streetsi Giesbrecht (Textfig. 26)

wurde zuerst von Giesbrecht aus dem Pazifischen Ozean beschrieben, dann von FarRan (a. a. O.) als häufig im Nordosten des Atlantischen Ozeans an der Küste Irlands und von SARs in den Sammlungen des Fürsten von Monaco nachgewiesen. Vom „Gauss" wurde sie in verschiedenen Vertikalfängen, z. B. am 12. November 1901 (3000 $\mathrm{m})$ und am 13. Oktober $1903(3000 \mathrm{~m})$, aus dem Atlantischen Ozean gefunden.

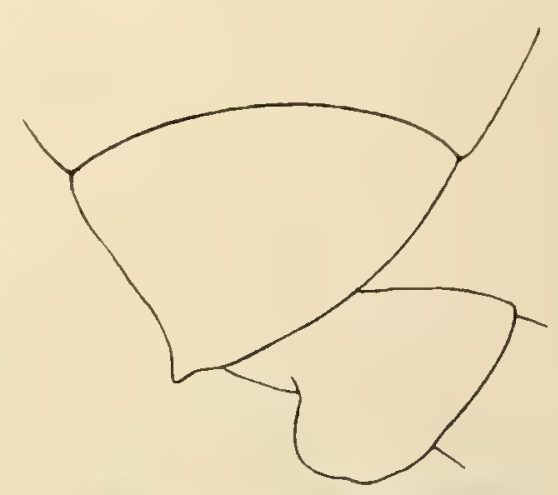

Textfig. 26. Chirundina streetsi. Letztes Thorakalsegment.

7\%. Chirundina magna n. sp. (Tafel XXVIII, Fig. 10-13, Textfig. 27 a und b.)

q 6-6,6 mm lang, davon kommen auf den Cephalothorax 5,5, auf das Abdomen 1,1 mm. Diese Art ist nicht nur größer als Chirundina streetsi, sondern hat auch am letzten Körpersegment vollkommen gleichmäßig gerundete Seitenränder, welche teilweise das Genitalsegment überdecken, von der Seite gesehen ziemlich dreieckig erscheinen und nur eine Spur von Spitzen erkennen lassen, 
während diese bei Chirundina streetsi kräftig sind. Der K o p f hat eine kurze Crista und ziemlich dünnes Rostrum. Kopf und 1. Segment sind nur teilweise getrennt, die beiden letzten Rumpfsegmente dagegen völlig verschmolzen. Das große Ge nit a ls e g m e nt tritt im oberen Teile ventral hervor und trägt weder Dornen noch Haare. Es ist ebenso lang als der übrige Teil des Abdomens. Das kurze Analsegment ist ventral mit einem großen Haarbüschel verziert und die Ränder der Abdominalsegmente sind kammartig gesäumt. (XXVIII. 10.)

Die vorderen Antennen überragen den ganzen Körper mit 4 oder 5 Gliedern, und von

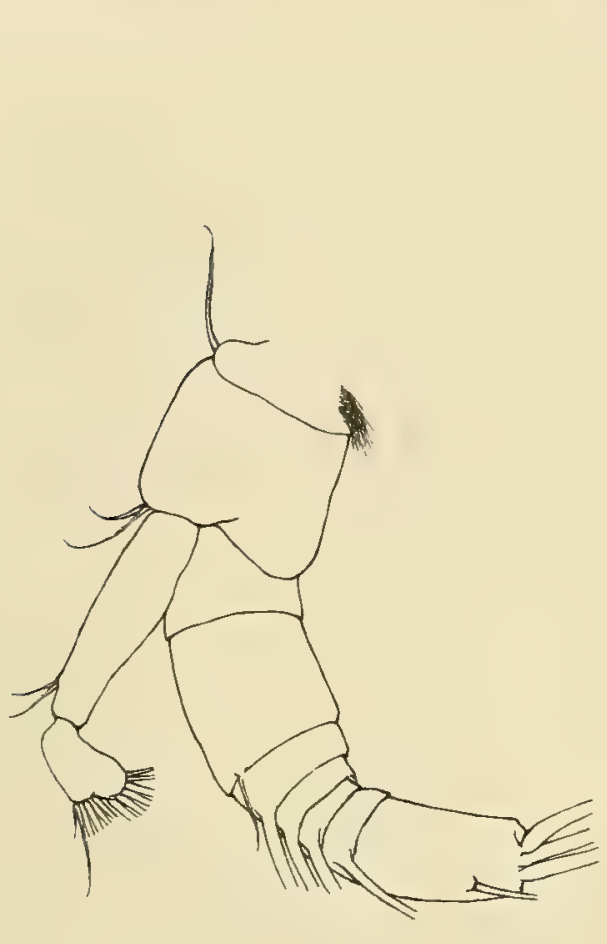

a

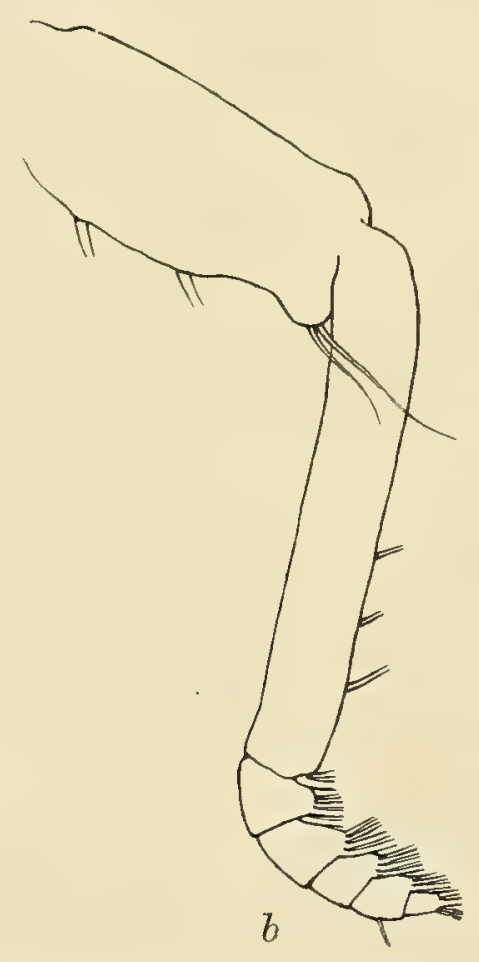

Textfig. 27. Chirundina magna 우.

$a$ Hintere Antenne. $b$ Hinterer Maxilliped. den 24 Gliedern sind nur das 8. und 9. verschmolzen, die beiden letzten aber deutlich getrennt. Sie sind von kurzen Borsten ziemlich dicht behaart.

Der Innenast der hinteren Antennen ist kurz, nur halb so lang und viel dünner als der Außenast. Letzterer ist vollständig segmentiert, besteht aus 7 Gliedern. Das Endglied des Innenastes trägt $7+6$ Borsten. (26 a.)

Die vorderen Maxillipeden gleichen denen von Chirundina streetsi. Das 2. Basalglied der hinteren Maxillipeden $(26 \mathrm{~b})$ ist dreimal so lang als der Innenast und fast siebenmal so lang als breit. Die Maxillen (XXVIII. 11) tragen je 4 Borsten auf dem 2 . und 3. Innenlobus; die 11 Borsten des Außenastes zeigen nichts Besonderes und sind nicht wie bei Undeuchaeta verkürzt. Das 2. Basalglied ist verlängert, der Innenast sehr klein und der 1. Innenlobus ist mit 9 vortretenden Haken und 3 Borsten versehen.

Das 1. Fußpa a r (XXVIII. 12) hat eingliedrigen Innenast; der Außenast ist deutlich dreigliedrig und trägt 3 Randdornen, während er bei Chirundina streetsi zweigliedrig ist. Das 2. Paar hat zweigliedrigen Innenast. (XXVIII. 13.) Der äußere Randdorn des 2. Gliedes vom Außenast ist sehr lang und stark und reicht weit über die Spitze des 1. Dornes vom 3. Gliede hinaus. Die beiden mittleren Dornen dieses Gliedes sind verhältnismäßig klein. Die Basalia des 4. Fußpaares sind dornenlos.

Diese Art unterscheidet sich demnach von Chirundina streetsi besonders durch die bedeutendere Größe, durch Abwesenheit der kurzen stumpfen Dornen des letzten Rumpfsegments und den dreigliedrigen Außenast des ersten Fußpaares. Mehrere Exemplare derselben wurden vom "Gauss" im Atlantischen Ozean am 5. November 1901 (1000 m), 12. November 1901 (3000 m) und 26. September 1903 (3000 m) erbeutet. 
78. Chirundina antaretica n. sp. (Tafel XXIX Fig. 1-3.)

ㅇ 6,0 $\mathrm{mm}$ lang; der Cephalothorax ist ungefähr $3^{1} /{ }_{2} \mathrm{mal}$ so lang wie das Abdomen; der Kopf vorn schmal, ohne Crista, hat ein kurzes einspitziges Rostrum. Der Rücken ist etwas bucklig. Die beiden ersten und die beiden letzten Thorakalsegmente sind verschmolzen; die letzteren haben gerundete Ränder ohne die Spitzen von Chirundina streetsi und treten nicht so stark wie bei Chirundina magna hervor. (XXIX. 1.)

Das kurze Abdomen zeigt ein großes Genitalsegment und großes Analsegment, welches letztere ebenso groß als das vorhergehende Segment ist. Die Furkaläste sind ebenso breit wie lang und kürzer als das Analsegment. Der Rücken des Genitalsegments und die Oberfläche der beiden nächsten Segmente tragen Reihen feiner Haare und das Genitalsegment tritt ventral im unteren Teile stark hervor. (XXIX. 2 u. 3.)

Die vorderen A $\mathrm{n}$ te $\mathrm{n} n \mathrm{n} \mathrm{n}$ bestehen aus 23 Gliedern, von denen das 8. und 9., ferner das 24. und 25. verwachsen sind, reichen etwa bis zum Ende des Genitalsegments und sind spärlich beborstet. Der Außenast der hinteren Antennen ist viel länger als der Innenast, da dieser eine etwa bis zum Ende des 1. Gliedes vom Außenaste reicht. Die Medianborsten des Außenastes der M a xille sind nicht verkürzt, sondern von gewöhnlicher Länge.

Die vorderen M a $\mathrm{x} 1 \mathrm{I}$ i p e d e $\mathrm{n}$ gleichen denen von Chirundina magna; die hinteren haben ein verlängertes 2. Basalglied und sehr kurzen Innenast. Das 1. F u B p a a r hat eingliedrigen Innenast und einen dreigliedrigen Außenast mit 3 Randdornen. Das 2. Fußpaar besitzt zweigliedrigen Innenast und das 4. Fußpaar entbehrt der Dornen an den Basalgliedern. Demnach weicht diese Art in vielen Einzelheiten von Chirundina streetsi ab.

Zwei Exemplare derselben fanden sich in einem Vertikalfang aus der Antarktis vom 10. März $1903(3000 \mathrm{~m})$.

\section{Undeuchaeta (Giesbrecht).}

Von der Deutschen Südpolar-Expedition wurden im Atlantischen Ozean viele Exemplare der typischen Arten Undeuchaeta major und Undeuchaeta minor erbeutet. SARs hat vor kurzem mehrere andere Arten von Undeuchaeta beschrieben (Bull. mus. oceanogr.), Undeuchaeta obtusa, pustulifera, scopularis, dubia, palliata, lobata und eine siebente aus dem Nordpolarmeer, Undeuchaeta spectabilis (SARS, North Polar Expedition p. 59). Bei der letzteren Art trägt der Außenast der Maxille 10 gleiche Borsten, was nicht als Charakter von Undeuchaeta anerkannt werden kann. In jedem Fall auch hat das 4. Fußpaar Reihen von 4-12 vorspringenden Dornen. Daher ist der Schluß unvermeidlich, daß diese Arten sicherlich nicht zur Gattung Undeuchaeta, sondern wahrscheinlich zu Euchirella gehören. Die sehr kurzen Diagnosen, welche Professor SaRs (1. c.) ohne Abbildungen veröffentlicht hat, machen die Erkennung dieser Arten, bis eingehendere Beschreibung vorliegt, sehr schwer.

\section{Undenchata major GiesBrecuT}

war sehr häufig in den Planktonfängen aus dem Atlantischen Ozean und wurde z. B. am 5. November $1901(1000 \mathrm{~m})$, 12. November 1901 (3000 m), 18. Dezember 1901 (2500 m), 22. August $1903(1500 \mathrm{~m})$, 4. September $1903(2000 \mathrm{~m})$, 26. September 1903 (3000 m), 30. September 1903 $(1500 \mathrm{~m})$ 9. und 13. Oktober $1903(3000 \mathrm{~m})$ gefunden. 
80. Undeuchaeta minor Giesbrecht

erschien weniger häufig als die vorige Art in den Tiefenfängen aus dem Atlantischen Ozean, so am 14. Oktober 1901 (1900 m), 19. Oktober 1901 (800 m), 12. November 1901 (3000 m), 22. August 1903 (1500 m), 9. Oktober 1903 (3000 m).

\section{Mesundeuchaeta n. g.}

Die Gattung wurde für eine in der Mitte zwischen Undeuchaeta und Euchirella stehende Art geschaffen, welche der ersteren durch verkürzte Mittelborsten des Außenastes der Maxillen gleicht, ferner im allgemeinen Bau der Mundorgane, und sich Euchirella durch den Besitz einer Reihe sehr kleiner Dornen an den Basalgliedern des 4. Fußpaares nähert. Das letzte Thorakalsegment ist sehr unsymmetrisch, auf der rechten Seite verkürzt, mit gerundetem Rande, links dagegen länger und mit einer Spitze endigend. Auch das Genitalsegment ist sehr unsymmetrisch gebaut. Eine ziemliche Anzahl von Exemplaren lag aus den atlantischen Vertikalfängen des „Gauss“ vor, welche, obwohl Charaktere jeder der drei Gattungen zeigend, doch weder zu Euchirella noch zu Undeuchaeta oder Chirundina gerechnet werden können.

81. Mesundeuchata asymmetrica n. sp. (Tafel XXIX, Fig. 4-7, Textfig. 28.)

ㅇ 5,5-6 mm lang, Cephalothorax 4,5 mm, Abdomen 1,0 mm messend. Der Kopf ist dorsal vom Thorax teilweise durch eine Grube getrennt und die beiden letzten Thorakalsegmente zeigen an den Seitenrändern Anzeichen von Trennung. (XXIX. 4.) Vom Rücken gesehen erscheint der Kopf ziemlich dreieckig, und eine Crista ist wie bei Undeuchaeta major vorhanden. Das letzte Thorakalsegment ist sehr unsymmetrisch, an der linken Seite verlängert mit kleiner Spitze, während es rechts nur wenig hervortritt und keine Spitze zeigt. Diese Seite ist erheblich kürzer als die andere. (XXIX. 5 u. 6.)

Dieser Umstand scheint beträchtlichere Schwellung der rechten Seite des GenitaIsegments zu gestatten. Dieses ist sehr unsymmetrisch, springt ventral mit gelapptem Umriß vor und rechts findet sich eine Wucherung. Die linke Seite ist im unteren Teil mit sehr kurzen, steifen Haaren bedeckt, die sich auch über die ganze Ventralfläche dieses und des folgenden Segments ausbreiten. Das Genitalsegment ist größer als die drei folgenden, das 3. Segment größer als das 2., das Analsegment sehr kurz und die Furkaläste sind auch kurz und so breit wie lang, mit Haarbüscheln auf beiden Seiten. Die ventrale Nebenborste ist sehr zart und kurz. Die vorderen Anten $\mathrm{n}$ e $\mathrm{n}$ bestehen aus 23 Gliedern, wie bei Undeuchaeta, und sind so lang wie der Körper. Die hinteren Antennen haben einen kurzen Innenast, der nur halb so lang wie der Außenast ist. Der Innenast der M a $\mathbf{n}$ $\mathrm{d}$ ibe $1 \mathrm{n}$ ist länger als der Außenast. Die $\mathrm{M}$ a $\mathrm{xi} 11 \mathrm{e} \mathrm{n}$ haben einen kleinen Außenast mit 11 dicht befiederten Borsten, von welchen die proximale am größten ist. Vom proximalen Ende beginnend sind dann die 6. und 7. am kürzesten, die 8. nur wenig größer and die 3 distalen Borsten sind dann wieder viel größer als die mittleren. Hierin gleicht der Außenast dem von Undeuchaeta.

Die vorderen Maxillipeden tragen auf dem 5. Lobus einen kurzen geraden Haken. Die hinteren Maxillipeden haben sehr kurzen Innenast und verlängertes 2. Basalglied, das viermal so lang wie der Innenast ist. Die Längen der Basalia und des Innenastes verhalten sich wie $12: 20: 5$. Die langen und starken Borsten des Innenastes sind nur spärlich befiedert. Der 
Innenast des 1. F u B pa a es ist nur eingliedrig, der Außenast hat zwei Glieder, da die beiden proximalen Glieder verschmolzen sind und nur schwache Andeutung teilweiser Trennung an den Rändern erkennen lassen. Am 1. Gliede fehlt ein Randdorn, am 2. jedoch ist ein großer und starker Dorn vorhanden.

Beim 2. Fußpaar ist der Innenast eingliedrig, der Außenast dreigliedrig. Das 2. Basalglied desselben trägt einen starken Dorn am äußeren Distalrande. Das 1. Basalglied des 3. Fußpaares ist am Innenrande dicht behaart, und am 1. Basalgliede des 4. Paares (Textfig. 28) findet sich eine Reihe sehr feiner Dornen am Innenrande dicht unterhalb der inneren Randborste. Das erste und zweite Glied des 4. Fußpaares zeigen starke Spitzen am distalen Außenrand.

Der Innenast aller Füiße ist sehr kurz.

Die Auswïchse am Genitalsegment erinnern an die bei gewissen Arten von Euchirella, besonders von Euchirella similis. Der Dorn, welcher bei Ventralansicht des Genitalsegments so regelmäßig bei Undeuchaeta major erscheint, fehlt hier, doch findet sich bei einigen Exemplaren ein mehr oder weniger deutlicher kleiner, zugespitzter Knopf. (XXIX. 7.)

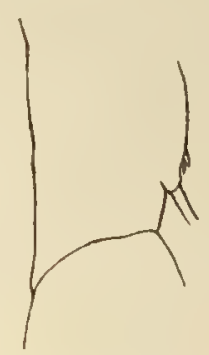

Textfig. 28.

Mesundeuchaeta asymmetrica Basalglied des 4. Fußes.

Die Unregelmäßigkeit des letzten Thorakalsegments ist konstant bei den vielen untersuchten Exemplaren und findet sich stets vergesellschaftet mit beträchtlicher Anschwellung der rechten Seite des Genitalsegments und scheint eine Vorbedingung für die letztere zu sein. Hierin unterscheidet sich diese Art von Undeuchaeta major, bei der die Seitenränder des letzten Thorakalsegments ganz symmetrisch und gleichmäßig gerundet sind, wie auch das Genitalsegment symmetrisch ist und keine seitlichen Auswüchse besitzt.

Mesundeuchaeta asymmetrica, die wahrscheinlich der Tiefsee angehört, wurde am 5. November $1901(1000 \mathrm{~m})$, 12. und 16. November $1901(3000 \mathrm{~m})$, 9. und 13. Oktober $1903(3000 \mathrm{~m}) \mathrm{im}$ tropischen und südlichen Atlantischen Ozean gefunden.

\section{Drepanopsis n. g.}

Diese Gattung erscheint nach der Definition Gie SBREcht's (Fauna und Flora des Golfs von Neapel p.201) nahe verwandt mit Drepanopus (BRADY), unterscheidet sich doch von ihr durch einige sehr markante Eigentümlichkeiten, wie in dem Fehlen eines Rostrums oder von Rostralfilamenten, durch die vollständige Trennung der beiden letzten Thorakalsegmente, durch die sehr ungleichen Äste der hinteren Antennen, von denen der innere länger als der äußere ist, und durch den sehr kleinen Innenast der Mandibeln; ferner besonders im Bau des 5. Fußpaares, welches jederseits einästig und dreigliedrig ist und ein Paar kleine, borstenartige Haken am Ende des distalen (3.) Segments trägt.

In der Gliederung der Füße und Antennen und durch die gekerbten, nicht gezähnten Ränder der Endsägen stimmt sie mit Drepanopus überein.

82. Drepanopsis frigidus n. sp. (Textfig. $29 \mathrm{a}$, b.)

o 2,25-2,35 mm lang, davon der Cephalothorax 2,0 mm; das Abdomen 0,35 mm.

Der $\mathrm{K}$ o p f ist gleichmäßig gerundet und endigt vorn stumpf, ohne jede Spur eines Rostrums. Er ist mit dem 1. Thorakalsegment verschmolzen. Die beiden letzten Segmente des Thorax sind 
dagegen getrennt; das letzte Segment ist klein und läuft seitlich in dreieckige Spitzen aus. Das A b d o m e n, nurein viertel so lang als der Rumpf, besteht aus 4 Segmenten, von denen das Genitalsegment länger als die beiden folgenden ist. Die Furka ist so lang als das Analsegment

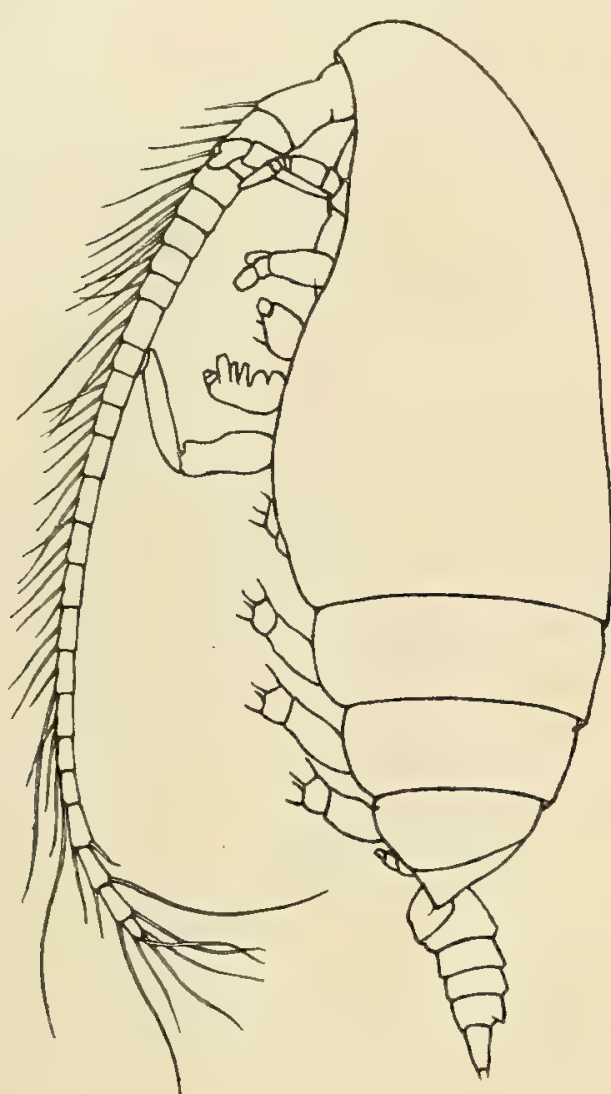

$a$

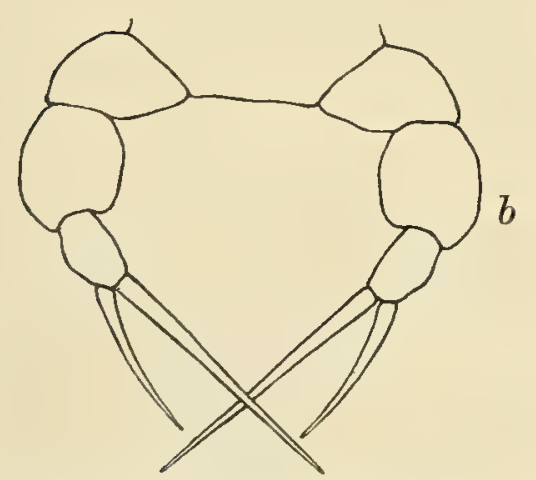

Textfg. 29. Drepanopsis frigidus 오. a Seitenansicht, b. 5. Fußpaar. und fast doppelt so lang als breit. Eine kurze akzessorische Borste ist auf der vorderen Fläche vorhanden. (29 a.)

Die vorderen Ante $\mathrm{n} n$ en reichen bis zum Ende des Genitalsegments und bestehen aus 24 Gliedern; das 8. und 9. derselben sind verschmolzen, das 24 . vom 25 . aber getrennt. Alle Glieder sind gut beborstet. Das 8. + 9. Glied ist das größte, die übrigen distal davon sind sehr klein und etwa gleichgroß.- Die hinteren Antennen haben größeren und viel dickeren Innenast und kleineren Außenast.

Der Innenast der $\mathrm{M}$ a $\mathrm{ndibeln}$ ist sehr klein und besteht aus 2 Gliedern. Er trägt distal 6 Borsten, von denen die äußersten lang sind, die inneren sehr klein. Der Außenast ist viel größer und dicker als der Innenast und trägt 5 lange Borsten. Die Kauplatte hat starke Zähne.

Die vorderen Maxillipeden sind klein; der 4. Lobus derselben ist am größten und mit kurzem, aber kräftigem Haken versehen. Der Innenast hat 4 sehr lange und 2 kurze Borsten. Das 1. und 2. Basalglied und der Innenast der hinteren Maxillipeden stehen im Längenverhältnis. von $30: 36: 23$. Der Innenast ist deutlich fünfgliedrig; am Rande der 1. Basalia finden sich kurze steife Haare, und die 2. Basalglieder tragen distal von der Mitte 3 Borsten.

Die Maxille $\mathrm{n}$ haben am 1. Außenlobus 8 Borsten; der Außenast derselben ist klein und mit 11 Borsten besetzt, der Innenast ist vom 2. Basalgliede deutlich getrennt und trägt 15. Borsten. Das 2. Basalglied hat 5 Borsten, der 2. und 3. Innenlobus je 4. Der 1. Innenlobus ist viereckig und seine Haken sind nicht so lang wie der Lobus. Der Innenast des 1. F u B p a a r e s ist eingliedrig, der Außenast dreigliedrig mit 3 äußeren Randdornen. Das 2. Paar hat zweigliedrigen Innenast und dreigliedrigen Außenast mit 3 Randdornen. Das 1. und 2. Glied des Innenastes trägt arf der Oberfläche Reihen sehr feiner Dornen. Das 3. und 4. Fußpaar haben dreigliedrige Äste, und auf dem 1. und 2. Glied ihres Innenastes finden sich einige wenige feine Dornen. Das letzte Glied des Außenastes trägt beim 2. bis 4. Fußpaare 4 innere Randborsten. Die Ränder der Endsägen sind tief gekerbt, nicht gezähnt. Das 5. Fußpaar (29 b) besteht aus gemeinsamen Basale und einem dreigliedrigen Fuße jederseits. Das 1. und 2. Glied sind gleichbreit, das 3. viel schmäler und kürzer. Das 2. Glied ist ziemlich kugelig gestaltet, das 
letzte trägt 2 Endborsten, die hakenartig gekrümmt sind und von denen die innere etwa um ein viertel länger als die äußere ist.

Erbeutet wurde die Art am 6. März 1903 (1200 m) und 26. September 1903 (3000 m), also im südlichen Eismeer und unter dem Äquator im Atlantischen Ozean.

\section{Valdiviella STeuER.}

Seit Valdiviella oligarthra von Steuer beschrieben wurde (Zool. Anz. Bd. XXVII S. 593), wurde sie auch von SARS in den Sammlungen des Fürsten von Monaco angetroffen. Jetzt erscheint sie in der Ausbeute des "Gauss" aus dem Atlantischen Ozean und in den Fängen von Stanley GaRdiner aus dem Indischen Ozean im Gebiete des Chagos-Archipels. Eine Valdiviella oligarthra sehr ähnliche Form wurde ferner von FarRAN (a.a. O.) aus dem Atlantischen Ozean westlich von Irland beschrieben. In Anbetracht ihrer weiten Verbreitung erscheint es sehr merkwürdig, daß die Gattung so lange unbekannt geblieben ist.

\section{Valdiviella oligarthra $\mathrm{S}_{\text {TEUER. }}$}

Diese von STEukr gut beschriebene Art ist charakterisiert durch die Verschmelzung der Fußglieder. Das 1. und 2. Glied der Außenäste sind bei allen 4 Fußpaaren vollständig verwachsen; die Innenäste des 1. und 2. Paares sind eingliedrig und beim 3. und 4. Paare nur zweigliedrig. Die vorderen Antennen sind kurz, erreichen nur das Ende des 2. Thorakalsegments. Dieses scheinen die einzigen wichtigen Differenzpunkte zwischen dieser Art und Farran's Valdiviella insignis zu sein. Die beginnende Gliederung der Füße bei der letzteren scheint nicht sehr zuverlässig, da ich bei einigen Exemplaren, welche sonst STEUER's Beschreibung entsprechen, Andeutung einer Gliederung der Füße finde. Das einzige sichere anatomische Merkmal ist die Kürze der vorderen Antennen bei Valdiviella oligarthra und ihre verhältnißmäßig größere Länge bei Valdiviella insignis, welchen Verhältnissen auch die Gliederlänge entspricht. Abgesehen davon würde ich geneigt sein, beide als identische Arten zu betrachten.

Mehrere Exemplare liegen vor vom 26. September 1903 (3000 m), 30. September 1903 (1500 m) und 20. Oktober $1903(3000 \mathrm{~m})$.

84. Valdiviella insignis Farran. (Tafel XXXX, Fig. 6 u. 7.)

Die Hauptunterschiede zwischen dieser Art und Valdiviella oligarthra sind, wie bereits vorher erwähnt, die beginnende Gliederung der Füße und die verschiedene Länge der vorderen Antennen. Valdivia insignis ist stets etwas größer als die typische Valdivia oligarthra. Das größte vom „Gauss“ erbeutete Exemplar ist 10,38 mm lang, nicht ganz so lang wie FARRAN's Originalexemplar. Der $\mathrm{K}$ o $\mathrm{p} f$ ist vorn schmal, zeigt einen zugespitzten Stirnbuckel und ein kurzes Rostrum. Teilweise Trennung des Kopfes vom 1. Segment des Körpers ist nur durch kurze, seitliche Linien angedeutet. Das letzte Segment tritt jederseits mit gerundeten Rändern etwas hervor, Der Vorderkörper ist ungefähr $2 \frac{1}{2} \mathrm{mal}$ so lang als das $\mathrm{Abdomen}$. Das Genitalsegment ist so lang wie die beiden folgenden Segmente und zeigt ventral etwas lappige Kontur und einen Spalt zwischen oberem und unterem Teile. Die beiden nächsten Segmente tragen ventral Haarbüschel und haben gekämmte Ränder. Die Furkaläste sind etwa so lang als breit und tragen ventral eine kurze, akzessorische Borste. 
Die vorderen Ante $\mathrm{n} n$ e $\mathrm{n}$ erreichen das Ende des Thorax und bestehen aus 23 Gliedern, ₹on denen das 8. und 9. wie das 24. und 25. verschmolzen sind. Bei den hinteren Antennen ist der Außenast etwas länger als der Innenast; der innere distale Lobus des letzteren trägt 5 lange und 1 kurze, der äußere distale Lobus 6 lange und 1 kurze Borsten. Am Ende des Außenastes finden sich 3, an den mittleren Gliedern 4 Borsten, und am 2. Basalgliede tritt 1 kurze Borste auf. (Die Zahl der am Innenast auftretenden Borsten scheint nach F ARRAN's Beschreibung bei seiner Form etwas abweichend zu sein.) Der 2. Innenlobus der M a xille hat 4 Borsten, das 2. Basalglied 3, der Innenast ebenfalls 3 und der Außenast 11 Borsten. Die Maxille ist ähnlich wie bei Euchaeta komprimiert. Der 2. und 3. Innenlobus sind nur durch einen einzigen Lobus repräsentiert. Die Medianborste des 1. Außenlobus ist am größten und dicksten. Die vorderen Maxillipeden und Mandibeln sind wie bei Valdiviella oligarthra gebaut.

Die hinteren Maxill i p e de n haben 3 Glieder im Verhältnis von $30: 48$ : 11. Der Proximalteil des Innenrandes vom 2. Basalglied ist mit steifen, kurzen Haaren bewehrt. Das 1 . F u B p a a r ist wie bei Valdiviella oligarthra gebaut, die beiden Proximalglieder vollständig verschmolzen und mit 2 Randdornen versehen. Das 1. und 2. Glied des 2. Fußpaares sind am Außenaste nur durch eine schwache Abgrenzungslinie getrennt, und der Randdorn des 1. Gliedes ist wenig von denen des letzten Gliedes verschieden. Der Innenast ist nur eingliedrig. Bei dem 3. und 4. Fußpaar ist die Grenzlinie zwischen den beiden proximalen Gliedern des Außenastes noch schwächer als beim 2. Paar angedeutet, und die Trennung der beiden Basalglieder des Innenastes fehlt bei den meisten Exemplaren ganz.

Es zeigit sich also, daß die Unterschiede zwischen dieser Art und Valdiviella oligarthra sehr gering sind und daß diese wohl als identisch betrachtet werden könnten. Die hierher gerechneten Exemplare wurden vom „Gauss" am 14: und 26. Oktober 1901 (1900 und $1300 \mathrm{~m}$ ) und vielleicht noch in einigen andern atlantischen Fängen mit Valdiviella oligarthra erbeutet.

85. Valdiviella brevicornis G. O. SARS.

Diese Art beschrieb SARs als abweichend von Valdiviella oligarthra nicht nur durch die Größe, sondern durch verhältnismäßig geringere Größe des Genitalsegments, größere Furkaläste mit sehr kurzen akzessorischen Borsten und wegen der, ,soudure des articles dans les rames des pattes moins parfaite que chez Valdiviella oligarthra"s (Bull. mus. ocean. Mars 1905 p. 17).

Ein Exemplar, das mir mit dieser Art übereinzustimmen scheint, fand sich am 4. September $1903(2000 \mathrm{~m})$. Es ist 6,6 mm lang; das Abdomen halb so lang als der Rumpf, das Genitalsegment nicht annähernd so lang als die beiden folgenden (im Verhältnis von 15:20), das 2. und 3. Segment tragen ventral Haarbüschel, und die akzessorischen Borsten der Furka sind sehr kurz.

Das 1. Fußpaar zeigte eine schwache Trennungslinie zwischen den beiden Proximalgliedern, und Randdornen, wie bei Valdiviella oligarthra. Die übrigen Füße ließen ebenfalls undeutliche Grenzlinien zwischen den beiden proximalen Gliedern des Außenastes erkennen. In diesen Einzelheiten stimmt die Beschreibung nicht ganz mit der von SARS überein, doch hat das Exemplar, ein erwachsenes Weibchen mit wohlentwickeltem Genitalsegment, nur wenig mehr als die halbe Größe von Valdiviella oligarthra, welcher es sonst gleicht. 
86. Valdiviella minor n. sp. (Tafel XXIX, Fig. 8-11.)

ㅇ 4,3 $\mathrm{mm}$ lang, davon kommen 3,0 $\mathrm{mm}$ auf den Cephalothorax, 1,3 $\mathrm{mm}$ auf das Abdomen. Der $\mathrm{K}$ o p $\mathrm{f}$ ist gerundet, mit kleinem Stirnbuckel und sehr kleinem Rostrum, das zwischen den Antennen völlig versteckt ist. Die beiden ersten Thorakalsegmente sind vollkommen verschmolzen; das $G$ e $n$ i t a 1 s e g $m$ e $n t$ ist so lang wie die beiden folgenden, springt ventral vor und hat eine Auszackung im unteren Teil, aber keinen Spalt in der Mitte wie Valdiviella oligarthra. Auf der Hinterfläche dieses Segments findet sich im oberen Teil eine starke, chitinöse Querfalte. Die Abdominalsegmente haben weder Haarbüschel noch kammartige Randsäume. Die Furkaläste sind $1 \frac{1}{2} \mathrm{mal}$ so lang als breit, länger als das Analsegment, und die Borsten derselben sind ziemlich von gleicher Länge. Lange Borsten fehlen, aber ein Paar sehr kurzer und zarter akzessorischer Borsten ist vorhanden. (XXIX. 8.)

Die vorderen A $\mathrm{n}$ te $\mathrm{n} \mathbf{n}$ e $\mathbf{n}$ reichen etwa bis zum Ende des 1. vereinigten Thoraxsegments, und ihre Glieder sind mehrfach verschmolzen, so da B nur 20 deutlich getrennt erscheinen. Der Außenast der hinteren Antennen ist etwa um ein viertel länger als der Innenast, das 2. Basalglied hat eine kurze Borste, der Außenast 7, wie bei Valdiviella oligarthra, und der Innenast $6+6$ Borsten.

Die M a $\mathrm{x}$ ille $\mathbf{n}$ sind wie bei Valdiviella oligarthra gebildet, außer daß am 1. Außenlobus nur 4 Borsten auftreten. Die vorderen und hinteren M a xillipede $\mathrm{n}$ und die Mandibeln sind nur kleiner, sonst wie bei Valdivia insignis gebaut.

Beim 1. Fußpaar (XXIX. 9) sind die beiden proximalen Glieder des Außenastes vollständig verschmolzen, doch sind 3 Randdornen vorhanden. Der Außenast des 2. Fußpaares (XXIX. 10) hat 3 deutliche Glieder, während beim Innenast nur an den Rändern die Teilung in 2 Glieder angedeutet ist. Das 3. (XXIX. 11) und 4. Fußpaar haben dreigliedrigen Außen- und Innenast.

Während diese Art von Valdiviella oligarthra weit verschieden ist, zeigt sie gewisse Ähnlichkeit mit Valdiviella brevicornis, doch ist sie viel kleiner, das Abdomen, besonders das Genitalsegment ist sehr abweichend gestaltet und die Gliederung der Füße ist viel vollständiger.

Ein Exemplar wurde vom ,Gauss" am 11. Oktober 1901 in einem Vertikalfang aus $1200 \mathrm{~m}$ Tiefe gefunden.

\section{Scolecithrix.}

Die Familie Scolecithrichina umfaßt so viele verschiedene Formen, daß sie als eine der schwierigsten Copepodengruppen anerkannt werden muß. GIEsBRecht (Belgica Report p. 26) ist der Ansicht, daß es noch unmöglich ist, diese Gruppe in gut definierte Gattungen zu zerlegen. Indessen nimmt GIEsBRecht die Gattung Racovitzanus an, die durch unpaariges Rostrum und durch einen rudimentären Innenast des 5. Fußpaares charakterisiert sein soll. Aber unter den antarktischen Copepoden des ,Gauss" fand sich ein Racovitzanus ( $R$. simplex), bei welchem das 5. Fußpaar keine Spur von einem Innenaste zeigt.

G. O. Sars (Crust. of Norway vol. IV p. 42) rechnet zur Familie Scolecithricidae die verschiedenen Formen, welche von andern Autoren der Gattung Scolecithrix Bradx zugeteilt werden, und ist der Meinung, daß wenigstens einige von diesen Formen als besondere Gattungen abgetrennt werden müssen, weil sie sich durch wesentliche Merkmale im Vorhandensein oder Fehlen des 5. Beinpaares beim of oder verschiedenen Bau desselben Beines beim $\hat{\alpha}$ unter anderem unter- 
scheiden. Er nahm zunächst 4 verschiedene Gattungen an: Scolecithrix BRAdy, Lophothrix GIESBREсHT, Amallophora Sсотт und Scolecithricella G. O. SARS, und fügt dann noch die Gattung Diaixis für Scolecithrix hibernica Sсотт hinzu.

Sсотт (Trans. Linnean Soc. 1893) stellte die Gattung Amallophora auf wegen des eigentümlichen Baues der Sinnesanhänge, mit denen die vorderen Maxillipeden ausgestattet sind. Sie wurde von SARS (a.a. O.) angenommen, welcher seine Nordpolarart Scaphocalanus acrocephalus mit ScotTs Amallophora magna identifizierte. Sars hat dann neulich noch die Gattung Heteramella geschaffen (Bull. Inst. ocean. 1907), welche die Art Amallophora dubia Тн. Sсотт aufnehmen soll. SARS nahm ferner die Gattung Lophothrix GIESBRECHT an, welche von GIESBRECHT erst für Lophothrix frontalis aufgestellt wurde, während er diese Art später aus der Gattung entfernt und zu Scolecithrix gerechnet hat.

Die Gattung Scolecithrix wächst so schnell und umfaßt so verschiedene Arten wie Scolecithrix minor, Scolecithrix (Lophothrix) frontalis, Amallophora (Scaphocalanus) magna, daß sie unübersichtlich wird, und ich stimme daher völlig darin mit SARs überein, daß sie wenigstens in die 3 Gattungen Scolecithrix, Amallophora und Lophothrix geteilt werden muß. Die Einteilung, welche Tн. Sсотт nach dem Unterschied im Bau der Sinnesfortsätze vornahm, ist gut, und allein nach diesem Merkmal lassen sich die 3 Typen sicher unterscheiden. So hat Scolecithrix Sinnesfortsätze in Gestalt wurmförmiger Schläuche und Amallophora eine Anzahl von Fortsätzen mit eigentümlicher Gestalt (wie Getreidegarben = amallae), während sie bei Lophothrix teils wurmförmig, teils pinselförmig sind. Bei der letzteren Gattung ist auch die Gestalt des Kopfes mit mehr oder weniger hervortretender Crista und die Form der Rostralfortsätze deutlich vom Scolecithrix-Typus verschieden. Vorläufig scheint mir diese Einteilung zu genügen, mit dem Vorbehalt, den schon GIESBRECHT gemacht hat, daß die Zeit für Aufteilung der Scolecithrichina in gut definierte Gattungen noch nicht gekommen ist.

\section{Scolecithrix BRADY.}

$\mathrm{Zu}$ dieser Gattung rechne ich solche Arten, welche in ihrem allgemeinen Bau dem der typischen Arten, z. B. Scolecithrix danae LuBBock und Scolecithrix minor BRADY, entsprechen und bei denen die Sinnesanhänge der Maxillipeden nur wurmförmiges Aussehen haben.

\section{Scolecithrix abyssalis GIESBRECHT.}

Es ist auffallend, daß diese wohlbekannte, weitverbreitete Art nur an zwei voneinander weit entfernten Stationen, im Atlantischen Ozean am 14. Oktober 1901 (1900 m) und im Indischen Ozean am 25. Mai 1903 (400 m), beobachtet wurde.

88. Seolecithrix scotti GiesBrecht.

Ein ô, welches der Beschreibung von Scotт (Trans. Linn. Soc. 1893) entspricht, fand sich am 9. Oktober $1903(3000 \mathrm{~m})$. Da das of fehlt, ist es schwierig, diese Art einzuordnen.

\section{Scolecithrix danae LuBbock}

ist die häufigste Art unter den vom „Gauss" gesammelten Copepoden. Sie fand sich an 20 atlantischen Stationen in Fängen aus Tiefen von $400-3000 \mathrm{~m}$, am 12. November 1901 (3000 m), 19. bis 
23. August $1903(400 \mathrm{~m})$, 4. bis 26. September $1903(400-3000 \mathrm{~m})$, 4. bis 13. Oktober 1903 $(100-3000 \mathrm{~m})$ und im Indischen Ozean am 20. Mai 1903 (400 m). Cheve erwähnt sie (a. a. O.) von der Süd- und Westküste Südafrikas.

\section{Scolecithrix bradyi Giesbrecht}

wurde am 4. September 1903 (2000 m), 5. September 1903 (400 m), 10. September 1903 (3000 m), 11. September 1903 (400 m) und 7. Oktober 1903 (200 m) im tropischen Atlantischen Ozean gefunden.

\section{Scolecithrix persecans Giesbrecht.}

Das $q$ dieser Art ist noch unbekannt. Sie wurde ursprünglich nur nach einem einzigen Exemplar beschrieben, dann zum zweiten Male von Esterly (Copepoda of the San Diego Region 1905), welcher angibt, daß er eine beträchtliche Menge von Männchen gesehen habe, daß der Außenast des 5. Fußpaares dreigliedrig ist, also bei GIESBREсHT's Exemplar das letzte Glied abgebrochen gewesen sei. Es finden sich einige kleine Differenzen in den Abbildungen Esterly's (a. a. O.) und GIE SBRECht's (Bull. Mus. Harvard vol. 25 und „Das Tierreich“, Copepoden 1898 S. 48, 6. Lief.). Ein Exemplar erschien in den Fängen vom „Gauss" am 16. November 1903, und obgleich einige geringe Abweichungen im Aussehen des 5. Fußes (im Endgliede des linken Fußes) zu konstatieren waren, stimmt doch die Anatomie der übrigenTeile so genau mit GIESBRECHT's Darstellung überein, daß ich kein Bedenken habe, die Individuen zu identifizieren. Cleve (Plankton of the South African Seas) erwähnt das Vorkommen dieser Art im Agulhasstrom (900 m).

92. Scolecithrix glacialis GiEsBREcht. (Textfig. 30, a-c.)

Die vom „Gauss" gesammelten Exemplare stimmen in allen Einzelheiten mit der Originalbeschreibung und Abbildung. GIesbrecht's im Belgica Report überein. Die Art ist nahe mit Scolecithrix abyssalis verwandt, von dem sie sich durch längeren 5. Fuß im Verhältnis zu seiner Breite, durch den langen Außendorn vom 1. Gliede des Außenastes beim 2. Fußpaar und durch den mit 3 kleinen Dornen bewehrten distalen Innenrand der 2. Basalia unterscheiden. Sie wurde an mehreren Stationen vor dem Sockel des antarktischen Kontinents. im Scholleneise gefunden: 24. Februar $1903(400 \mathrm{~m})$,

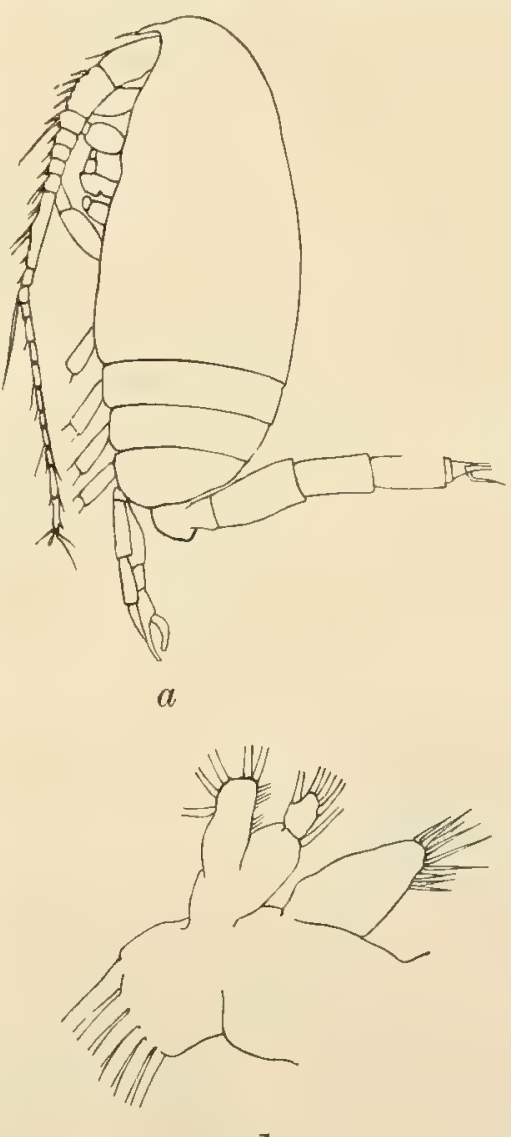

$b$

Textfig. 30. Scolecithrix glacialis $\sigma^{7}$. $a$ Seitenansicht. $b$ Maxille. $c 5$. FuB.

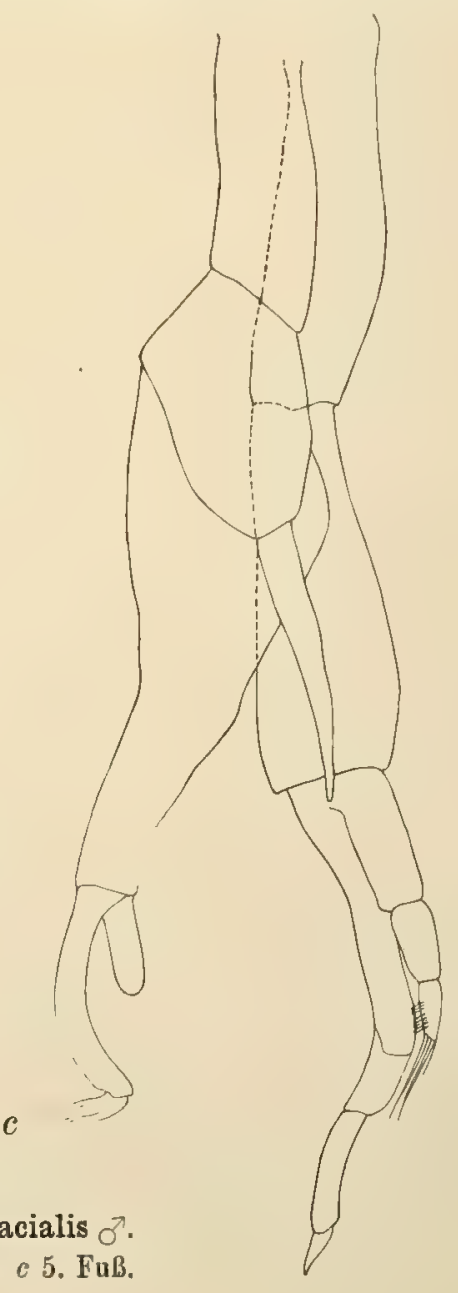




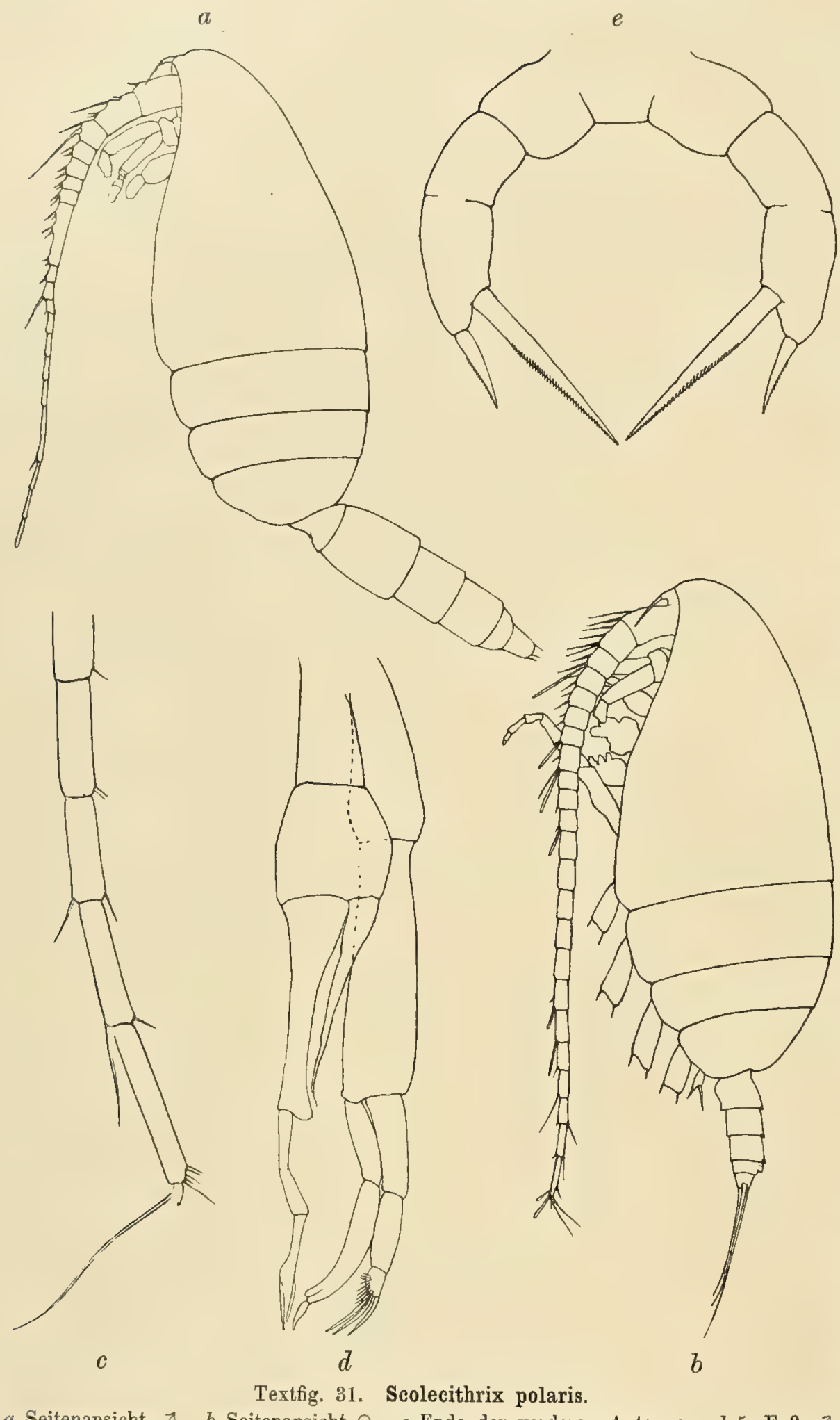

$a$ Seitenansicht $\overrightarrow{0}$. $b$ Seitenansicht 0 . $c$ Ende der vorderen Antenne, $d 5$. Fuß 7 . e 5. Fuß .
3. März $1903(400 \mathrm{~m})$, 6. März 1903 (1200 m), 9. März 1903 $(400 \mathrm{~m}), 27$. März 1903 $(2000 \mathrm{~m}), \quad$ 1. April 1903 $\left(\begin{array}{ll}150 & \mathrm{~m}\end{array}\right), \quad 3$. April 1903 $(3423 \mathrm{~m})$. Ein Exemplar, welches ich für das ơ dieser Art halte, erschien am 27. März 1903. Der 5. Fuß desselben ist in Fig. $30 \mathrm{c}$ abgebildet. Es ist $1,8 \mathrm{~mm}$ lang, die vorderen Antennen reichen bis zum Ende des Thorax und ihre Gliederzahl ist reduziert. Der Außenast der hinteren Antenne ist länger als beim \%. Die Mundorgane sind etwas verkümmert, die Kauplatte der Mandibeln rudimentär. Die Schwimmfüße gleichen denen des $q$, auch der Kopf ist wie bei diesem gebildet und die beiden letzten sowohl wie die beiden ersten Thorakalsegmente sind verschmolzen.

93. Scolecithrix polaris $\mathrm{n}$. $\mathrm{sp}$. (Tafel XXX, Fig. 1 und 2 , Textfig. 31 a-e.)

우 $3,5-4,0 \mathrm{~mm}$, wovon 2,8 $\mathrm{mm}$ auf den Cephalothorax, 0,7 $\mathrm{mm}$ auf das $\mathrm{Ab}$ domen kommen. Der Kopf zeigt eine vollkommen gleichmäßige Kurve; eine Crista ist nicht vorhanden. Die letzten beiden Thorakalsegmente sind verschmolzen, die Hinterenden gerundet und schwach dreieckig. Das A bdomen ist nur einviertel so lang als der Rumpf, das Analsegment ist sehr kurz, das Genitalsegment doppelt so lang als das folgende und die Furkaläste sind etwas länger als breit. 
Das Rostrum ist zweispitzig und trägt 2 Filamente. (31 b.) Die vorderen A $\mathbf{n}$ te $\mathbf{n} \mathrm{n}$ e $\mathrm{n}$ bestehen aus 23 Gliedern und reichen gewöhnlich bis zum Ende des Genitalsegments, doch bei einigen Exemplaren, welche sonst identisch zu sein scheinen, bis zum Ende der Furka. (31 c.)

Der Außenast der hinteren Antennen ist länger und erheblich dicker als der Innenast; das letzte Glied desselben ist so lang als das 2. (XXX. 1.)

Das 2. Basalglied der Maxillen trägt 4 Borsten, der Innenast 7, der Außenast 9 und der 1.Außenlobus 6 Borsten. Der 1. Innenlobus ist verlängert, das 2. Basalglied, Innenast und Außenast stark nach der Innenseite übergeneigt. Der 2. Innenlobus hat 2, der 3. Innenlobus 4 Borsten.

Die vorderen M a ill i p e d e n tragen am letzten Lobus einen langen und schwachen Haken, der Außenrand ist nur schwach konvex und etwa 7 wurmförmige Sinnesanhänge sind vorhanden. (XXX. 2.)

Bei den hinteren Maxillipeden findet sich ein Sinnesanhang am 1. Basalgliede. Das 1. und 2. Basalglied sind etwa gleichlang, der Innenast, ungefähr drei viertel so lang, hat 5 Glieder.

Das 1. F u B p a a r hat eingliedrigen Innenast und dreigliedrigen Außenast mit sehr kurzen Randdornen, von denen der distale länger als die beiden andern ist.

Das 2. Fußpaar hat zweigliedrigen Innenast, 3 Reihen von Dornen auf dem 2. Glied, eine Reihe auf jedem der proximalen Glieder des Außenastes und viele kleine Dornen auf der Fläche des 3. Gliedes.

Beim 3. Fußpaare finden sich Dornenreihen auf dem Innenaste; beim 4. sind die Randdornen des Außenastes kurz und gekrümmt und der Innenast reicht nicht bis zur 1. Innenrandborste des 3. Gliedes vom Außenaste.

Die Glieder der Außenäste vom 2. bis 4. Fußpaare sind breit im Verhältnis zur Länge und die Endsägen dicht mit sehr feinen Zähnen besetzt, die Innenäste verhältnismäßig kurz.

Das 5. Fußpaar hat ein gemeinsames Basalglied und 2 zweigliedrige Äste. Das distale Glied ist an beiden Seiten eingekerbt, aber nicht geteilt und ungefähr dreimal so lang als breit. Ein kurzer Dorn ist an der Spitze eingelenkt und ein langer Dorn, gelenkig mit dem Gliede verbunden, erhebt sich vom distalen Innenrand; er ist doppelt so lang als der Enddorn und ebenso lang wie das distale Glied. Alle beide Dornen sind am Außenrande mit kurzen, steifen Borsten besetzt. (31 e.)

Dieser Copepod, welcher an mehreren Stationen im südlichen Scholleneise erschien, hat große Ähnlichkeit mit Scolecithrix validus, der kürzlich von FARRAN aus dem Gebiete westlich von Irland beschrieben wurde, doch der 5. Fuß ist anders gestaltet und auch die Verhältnisse der Äste der hinteren Antennen sowie die Borsten der Maxillen sind verschieden.

Eine Form, welche ich für das ồ dieser Art halte, wurde in Fig. 31 a u. d abgebildet. Die Zahl der Antennenglieder und auch die Mundorgane desselben sind etwas reduziert. Es wurde am 10. März 1903 ebenfalls in der Eisregion gefunden.

94. Scolecithrix acutus n. sp. (Textfig. 32 a-f.)

ㅇ 2,65 mm lang, davon Cephalothorax 2,15 mm, Abdomen 0,5 mm. Der $\mathrm{Kopf}$ ist vorn verschmälert und hat eine kleine Crista. Das Rostrum ist gerade nach unten gerichtet, dicker als sonst gewöhnlich bei Scolecithrix, und zweispitzig. Die beiden letzten Segmente des Thorax sind deutlich getrennt und das hintere Segment endet mit kleinen, seitlichen Spitzen. (32 a u. c.) 
Das A b d o m e $\mathrm{n}$ ist nur ein viertel so lang als der Rumpf, das Genitalsegment beinahe so lang als die 3 folgenden Segmente, das Analsegment so lang als das vorhergehende und die Furkaläste so lang als das Analsegment und ein wenig länger als breit. Sie sind am Innenrande behaart. ( 32 b.)

Die vorderen A n te $\mathrm{nn}$ e $\mathrm{n}$ bestehen aus 23 Gliedern und sind 2,15 $\mathrm{mm}$ lang, reichen also etwa bis zum Ende des Cephalothorax. Die hinteren Antennen haben ungefähr gleiche Äste;

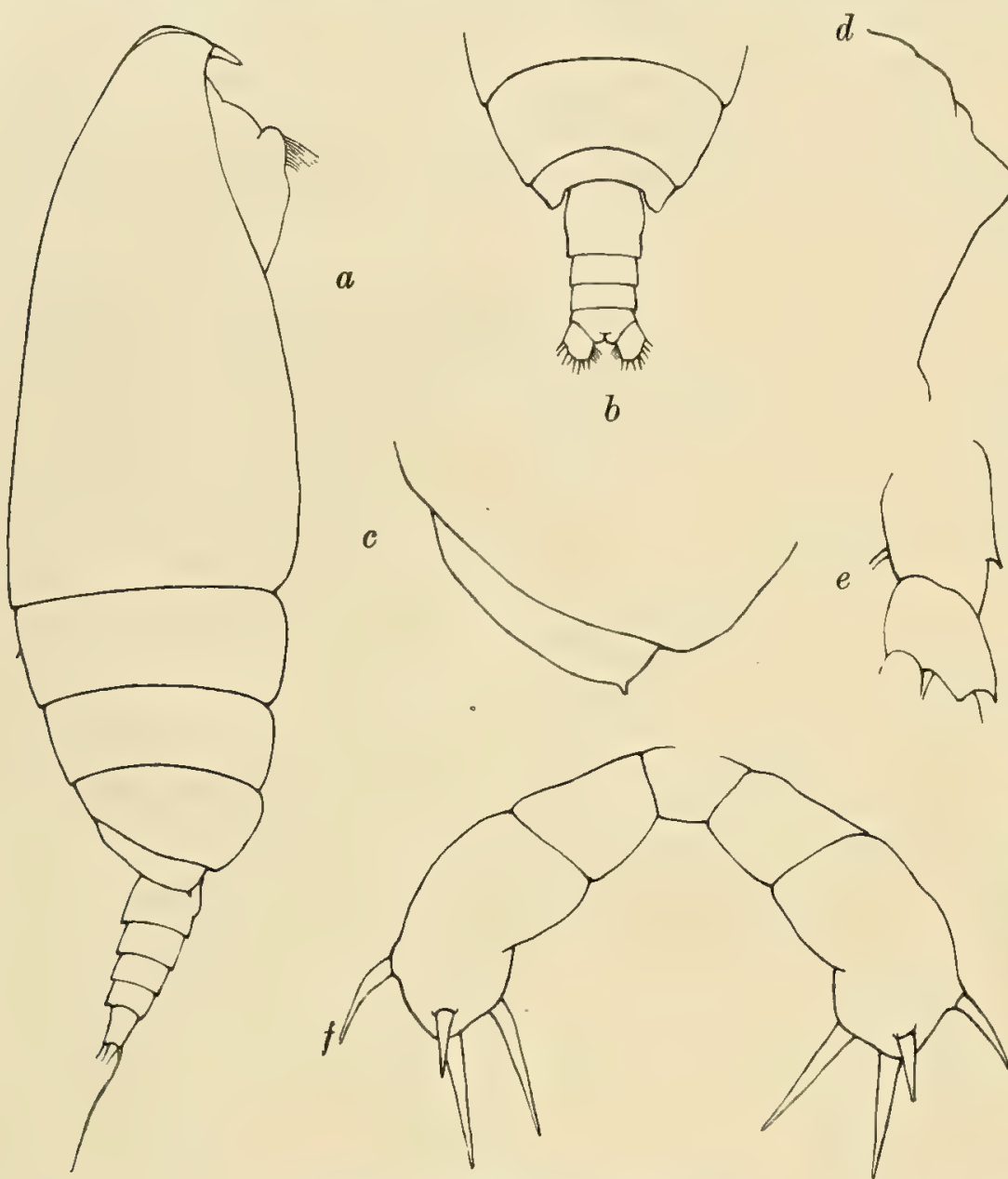

Textfig. 32. Scolecithrix acutus.

$a$ Seitenansicht. $b$ Abdomen. $c$ Letztes Thoraxsegment. $d$ Außenkante des vorderen Maxilliped. $e$ Basalglied vom 3. Fuß. $f$. Fußpaar. das 7. Glied des Außenastes ist nicht so lang als das 2.

Die vorderen Maxillipeden zeigen eigentümlich gestalteten Außenrand mit vorspringendem dreieckigen Buckel. (32 d.) An den Loben finden sich keine Haken, sie werden ersetzt durch starke Borsten mit weitstehenden Randstacheln. Die Sinnesanhänge sind lang und dick und scheinen alle wurmförmig zu sein.

Bei den hinteren Maxillipeden sind die beiden Basalglieder etwa von gleicher Länge; der Innenast ist kürzer, fünfgliedrig und trägt lange Borsten. Das 2. Basalglied der $\mathrm{M}$ a x ill e $\mathrm{n}$ hat 5 , der Innen. ast hat ebenfalls 5 Borsten.

Das 1. Basalglied des 1. F u B p a a r es trägt keine Borste; der Innenast desselben ist eingliedrig, der Außenast dreigliedrig, doch ohne Dorn am Außenrande des 1. Gliedes.

Beim 2. Fußpaar ist der Innenast zweigliedrig, und der Dorn des 2. Gliedes vom Außenast ist der stärkste von den 3 Außenranddornen. Am 2. Gliede des Innenastes findet sich ein Kranz von Dornen, und das 2. und 3. Glied des Außenastes haben Gruppen von Dornen.

Beim 3. Fußpaare tritt ein deutlicher Dorn etwas distal von der Mitte am Außenrande des 1. Basalgliedes auf (32 e); am 2. und 3. Gliede des Innenastes finden sich große Dornen, aber auf den Gliedern des Außenastes erscheinen nur wenige und sehr kleine Oberflächendornen.

Das 4. Fußpaar hat am 1. Basalgliede keine Innenrandborste; das 2. und 3. Glied seines Innenastes tragen Kränze von Oberflächendornen und die äußeren Ränder des 1. und 2. Gliedes der Innenäste sind in starke Dornen verlängert. 
Das 5. Fußpaar zeigt eigentïmlichen Bau, zwei zweigliedrige Äste mit gemeinsamem Basal. gliede. Das 1. Glied ist klein, das 2. keulenförmig, etwa $1 \frac{1}{2} 2 \mathrm{mal}$ so lang als breit und etwa auch $1 \frac{1}{2} \mathrm{mal}$ so lang als das proximale Glied. Etwas distal von der Mitte des Innenrandes findet sich die Andeutung einer Teilung. Das distale Glied hat eine konische Spitze mit 4 Dornen, von denen 2 dicht beieinander an der Spitze liegen. Der eine derselben ist doppelt so lang als der andere; ferner findet sich ein langer Dorn am Innenrand in der Nähe der Spitze und entsprechend am Außenrand ein ziemlich kurzer Dorn. Diese Dornen scheinen nicht mit Borsten bewehrt und nur unvollkommen eingelenkt zu sein. (32 f.)

Die allgemeine Gestalt des Tieres, Kopf, Rostrum und Bau der Mundorgane nähern dasselbe mehr Amallophora als Scolecithrix, aber trotz sorgfältiger Untersuchung zeigten sich an den vorderen Maxillipeden keine andere als wurmförmige Sinnesanhänge. Deshalb rechne ich es zu Scolecithrix.

Nur ein Exemplar wurde am 13. Oktober 1903 bei einem Vertikalfang aus 3000 m angetroffen.

95. Scolecithrix aequalis n. sp. ('Textfig. 33 a-c.)

† $3,65 \mathrm{~mm}$, Cephalothorax 2,95 mm, Abdomen 0,7 mm lang. Der K opf zeigt keine Spur einer Crista, ist gleichmäßig gerundet und hat ein zweispitziges Rostrum. Kopf und 1. Segment verschmolzen; das letzte Thorakalsegment gerundet mit gleichmäßiger Krümmung, nicht in der Mitte niedergedrückt. Die beiden letzten Segmente sind auch verschmolzen. (33 a.)

Das $\mathrm{A} b \mathrm{do} \mathrm{m}$ e $\mathrm{n}$ ist nicht ganz ein viertel so lang wie der Rumpf; das Genitalsegment etwas kürzer als die beiden folgenden Segmente, das Analsegment klein und die Furkaläste sind so lang wie breit und divergieren etwas.

Die vorderen Antennen sind so lang wie der ganze Körper, $3,7 \mathrm{~mm}$, und ungleich auf beiden Seiten, da sie links 22 , rechts 23 Glieder haben. Das vereinigte 8. und 9. Glied ist nicht so lang wie die beiden folgenden Glieder, und die Längen der letzten 5 Glieder verhalten sich wie $25: 24: 19: 20: 20$. Das 2. Glied ist nur so lang als die beiden nächsten. Beide Antennen sind reichlich mit Ästhetasken versehen.

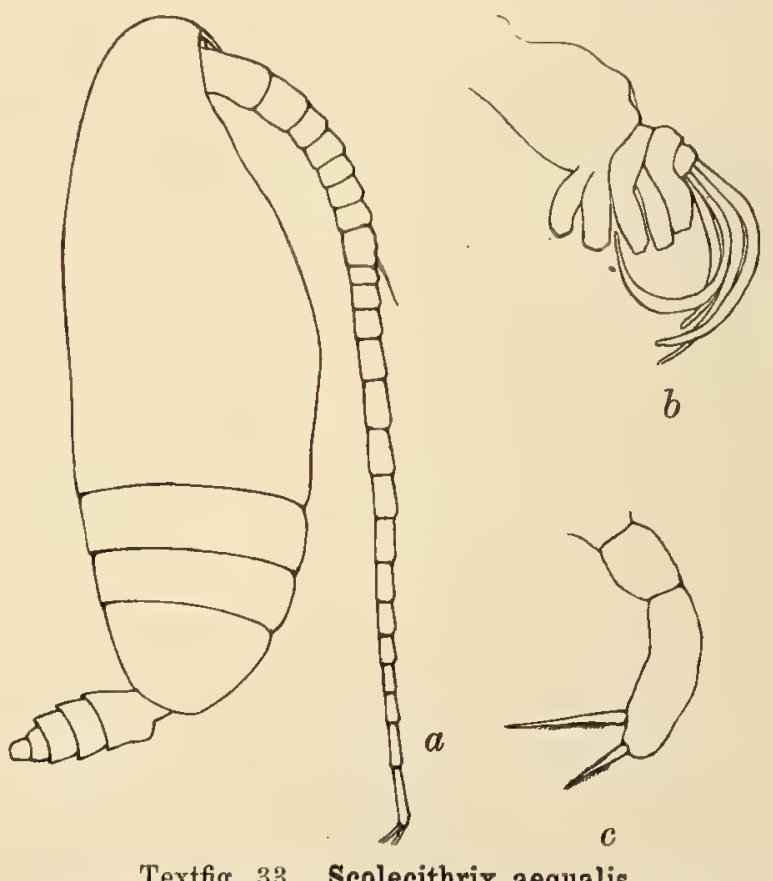

Bei den hinteren Antennen ist der Außenast $a$ Seitenansicht. $b$ Sinnesanhang vom vorderen Maxilliped um die Hälfte länger als der Innenast; das 1. und c 5. Fuß ㅇ․

2. Glied des Außenastes sind getrennt und das 2. ist viel länger als das 7. Glied.

Bei den vorderen $\mathrm{M}$ a xill i peden ist der Haken des 5. Lobus ein wenig dicker als der des 4., lang, gekrümmt und ziemlich schwach. Alle Sinnesanhänge sind wurmförmig. (33 b.) Das 1. Basalglied der hinteren Maxillipeden ist viel länger als das 2. und der Innenast ist kürzer als das 2. Basalglied. Die Längen dieser 3 Teile verhalten sich wie $46: 30: 26$. Das 1 . Basalglied trägt einen 
Sinnesanhang. Die M a xille n haben einen etwas verlängerten Innenlobus, der länger als die Haken ist. Der Innenast und das Basalglied tragen 7 bzw. 5 Borsten.

Das 1. F u B p a r hat eingliedrigen Innenast und dreigliedrigen Außenast mit 3 normal gestalteten äußeren Dornen; der Innenast des 2. Fußpaares hat 2 Glieder, der Außenast 3; das 2. Glied des Innenastes trägt 3 Reihen von Dornen: 2 große Dornen distal, 3 kleinere median und 7 auf einer polsterartigen Erhebung proximal. Das 1. Glied des Außenastes trägt distal einige Dornen, das 2. Glied einen Kranz von etwa 14 langen Dornen, und das 3. ist mit kleinen Dörnchen und 3 Kränzen kleiner Dornen besetzt. Die Endsäge ist etwas länger als das 3. Glied und hat dichtstehende Zähne. Die Randdornen des 3. Gliedes haben gewöhnliche Form, und der Außendorn des 1. Gliedes ist weder länger noch kürzer als die übrigen. Bei dem dritten und 4. Fußpaare sind beide Basalglieder mit Dörnchen bedeckt. Die 3 Glieder des Außenastes und das 1. und 2. Glied des Innenastes erscheinen auf der Oberfläche von vielen kurzen Dornen punktiert, welche nur undeutlich in Gruppen angeordnet sind. Die Endsäge ist nicht ganz so lang als das 3. Glied beim 3. Fußpaar und viel kürzer beim 4. Paare. Beim 3. und 4. Paare sind die Glieder der Innenäste am Außenrande distal in Dornen verlängert, und die äußeren Randdornen der 1. Glieder der Außenäste sind kurz, nicht lang wie bei Scolecithrix auropecten. Das 5. Fußpaar hat einfache Form, besteht aus gemeinsamem Basale und nur zweigliedrigen Füßen, deren distales Glied länger ist. Es ist nicht ganz viermal so lang als breit und trägt am Distalende 2 Dornen, einen kürzeren auf der Innenseite der Spitze und einen viel längeren Dorn am Innenrande. Beide sind an der Außenseite allein mit kurzen, steifen Borsten versehen. (33 c.)

Diese Art ist Scolecithrix emarginatus FARRAN sehr ähnlich (Report Fisheries Ireland. Sci. Invest. 1905), doch kleiner als Farran's Exemplar, und die ungleiche Gliederung der beiden vorderen Antennen dürfte die beiden Arten genügend unterscheiden. FARRAN gibt an, daß er Exemplare an Professor G. O. SARS schickte, welche dieser für identisch mit Amallophora obtusifrons SARS erklärte. Demgemäß ist die Bezeichnung im Report Fisheries Ireland Sci. Invest. 1906 II [1908] in Scolecithrix obtusifrons geändert. Dieses kann jedoch kaum korrekt sein, da SARs die Größe zu $5,60 \mathrm{~mm}$ angibt und hinzufügt, „lobes latéraux du dernier segment du métasome obtusement arrondis .... Pattes de la $5^{\circ}$ paire bi-articulées, article terminal un peu courbée, et muni en dedans d'une épine assez forte et allongée, et en outre de 2 petits denticules, l'un apical, l'autre sortant du bord éxterieur".

Scolecithrix emarginatus (FARRAN), inornatus (ESTERLY) und aequalis werden sich wahrscheinlich bei weiterer Prüfung als identisch erweisen. Esterly's Art aus dem Pazifischen Ozean scheint einige Eigentïmlichkeiten in Maxillen und Sinnesanhängen zu haben und etwas größer zu sein.

Scolecithrix aequalis erhielt die Deutsche Südpolar-Expedition am 4. September 1903 $(2000 \mathrm{~m})$ im tropischen Atlantischen Ozean.

96. Scolecithrix medius n. sp. (Tafel XXX, Fig. 3-5, Textfig. $34 a-c$ ).

† 3,75 mm lang; der Kopf ist gleichmäßig gerundet und zeigt keine Spur einer Crista. (34 a.) Die Ränder des letzten Thorakalsegments sind ein wenig ausgezackt in der Mitte, und beim Anblick vom Rücken erscheinen sie etwas zugespitzt. 
Das Ge nitals e g m e $n$ t ist so lang wie die nächsten 3 Segmente; das Analsegment ist sehr klein, und die Furkaläste sind ebenfalls klein, nur wenig länger als breit. (34 b.)

Die vorderen A n te $\mathrm{n} n$ e $\mathrm{n}$ bestehen nur aus 23 Gliedern, von denen das 2. so lang wie die beiden folgenden ist, und das vereinigte 8 . und 9. Glied ist so lang wie die beiden nächsten Glieder. Die Längen der letzten 5 Glieder verhalten sich wie $30: 25: 20: 20: 20$. Die Antennen sind $4 \mathrm{~mm}$ länger als das ganze Tier, bis zum Ende der Furkaläste gemessen. Der Außenast der hinteren Antennen ist ein wenig länger als der Innenast; das 1. und 2. Glied des Außenastes sind getrennt, und das 2. Glied ist länger als das 7 .

Die vorderen M a xilli pede $\mathrm{n}$ haben am 5. Lobus einen Haken, der ein wenig dicker und stärker als der des 4 . Lobus ist, und nur wurmförmige Sinnesanhänge. Das 2. Basalglied der hinteren Maxillipeden (XXX.5) ist etwas länger als das 1. und der Innenast kürzer als dieses letztere. Das 2. Glied des Innenastes ist so lang wie das 3. und 4. Glied zusammen. Ein starker Dorn findet sich am Distalrande des 1. Basalgliedes, und am Innenrande tritt eine Sinnesknospe auf.

Der 1. Innenlobus der M a xille $\mathrm{n}$ ist verlängert, länger als seine Haken; das 2. Basalglied hat 4, der Innenast 7 , der 2. Innenlobus 2 und der 3. Innenlobus 4 Borsten.

Das : 1. Fu B p a $\mathrm{r}$ hat eingliedrigen Innenast und dreigliedrigen Außenast mit 3 gleichgroßen Randdornen.

Das 2. Fußpaar (XXX. 3) hat zweigliedrigen Innenast. Das 2. Glied ist mit 3 Dornenkränzen besetzt: eine Reihe von 7 Dornen proximal auf polsterartiger Er-

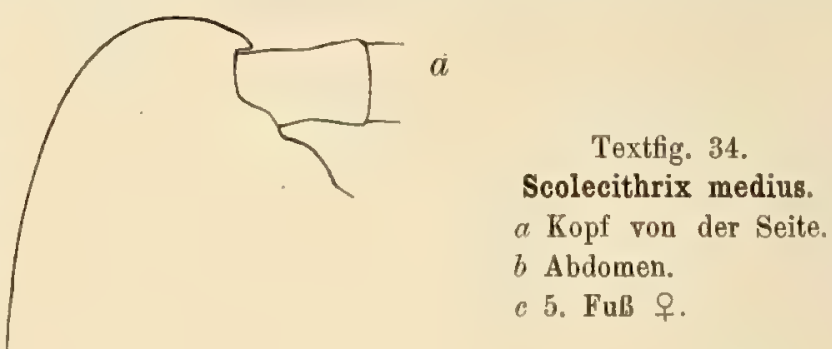
hebung, eine mittlere Reihe von 4 mäßig großen Dornen und eine distale Reihe von 3 oder 4 sehr langen Dornen. Beim 2. Gliede des Außenastes findet sich distal eine Reihe von 14 kurzen Dornen, und die Oberfläche desselben ist mit zahlreichen Dörnchen besetzt. Auch das 3. Glied des Außenastes trägt zahlreiche Dörnchen. Die Endsäge ist beinahe ebenso lang als das letzte Glied des Außenastes und hat sehr dicht stehende Zähne. Die Außenranddornen sind normal, die des 2. Gliedes vom Außenast etwas größer als die übrigen.

Beim 3. (XXX.4) und 4. Fußpaar ist der Außenrand der Glieder des Innenastes in starke Dornen verlängert und beim 4. Paare sind die Oberfläche der Glieder des Außenastes und die beiden distalen Glieder des Innenastes sehr stachelig. Die Endsäge des 4. Fußpaares ist viel kürzer als das letzte Glied und mit doppelter Zahnreihe versehen. Alle Randdornen desselben sind sehr kurz.

Die Oberflächen der Glieder des 3. Fußpaares sind sehr stachlig, Reihen von langen Dornen treten nur an den beiden distalen Gliedern des Innenastes auf. Das 5. Fußpaar (34 c) ist dreigliedrig, 
das distale Glied etwas länger als das mittlere. Das Endglied trägt 4 Dornen: einen kurzen an der Spitze, mit einem sehr kleinen Dorn außen daneben, einen langen starken Dorn am Innenrande, der ungefähr in der Mitte des Gliedes eingelenkt ist, und in entsprechender Lage am Außenrande einen kleinen Dorn. Die beiden größten Dornen sind mit kurzen, steifen Borsten an der Außenseite verziert. Der große innere Dorn ist mehr als doppelt so groß wie der größere Enddorn. Gefunden wurde Scolecithrix medius am 26. September 1903 unter dem Äquator im Atlantischen Ozean bei einem Vertikalfang aus $3000 \mathrm{~m}$ Tiefe.

97. Scolecithrix magnus n. sp. (Textfig. 35 a u. b.)

q 6,0 mm, davon der Cephalothorax 5,0 mm, das Abdomen $1 \mathrm{~mm}$. 'Der K o p f zeigt gleichmäßige Krümmung und hat zweispitziges, starkes Rostrum. Die Seitenränder des letzten Thorakal-

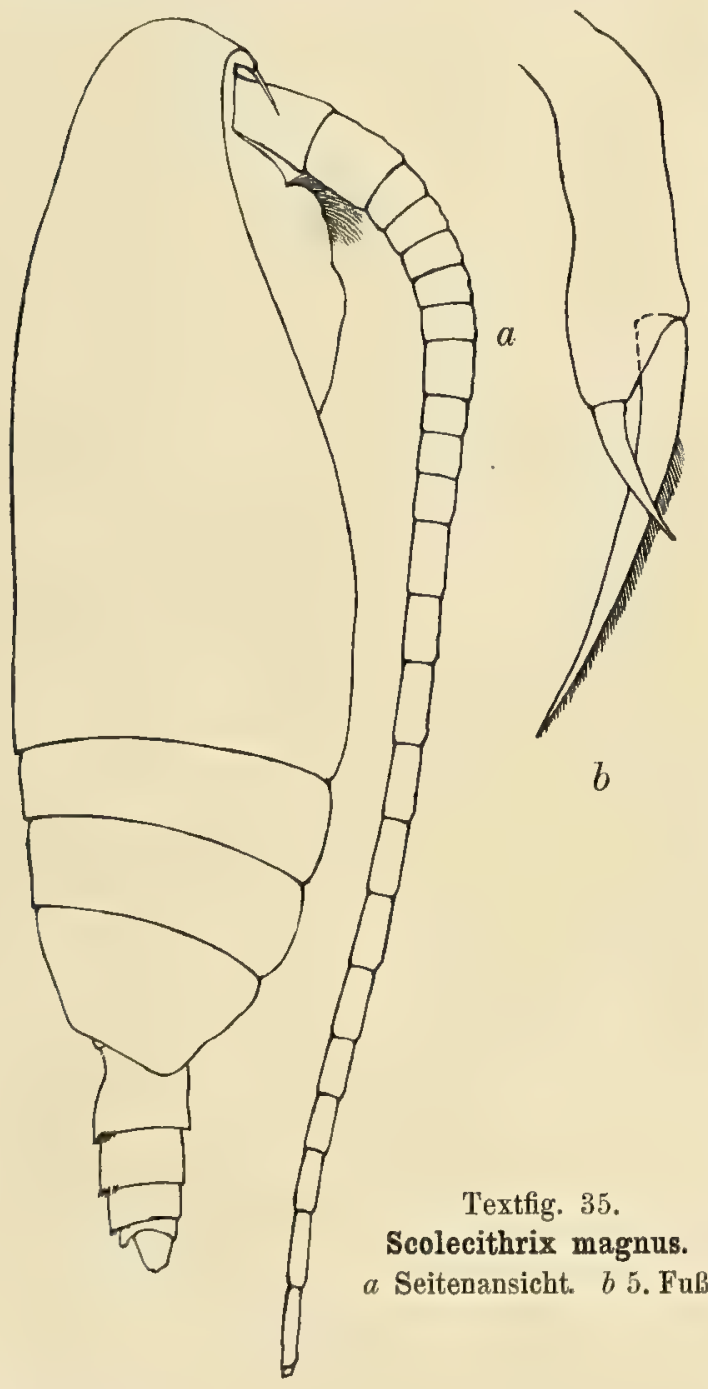
segments sind gerundet und treten in der Mitte etwas hervor. Das A b d o me $\mathrm{n}$ ist verhältnismäßig kurz; das Genitalsegment länger als die nächsten 3 Segmente; das Analsegment sehr klein und die Furkaläste sind fast quadratisch, ebenso breit als lang und divergieren stark. Die Abdominalsegmente sind kammartig gesäumt und die Innenseiten der Furkaläste behaart.

Die vorderen Antennen bestehen aus 23 Gliedern und reichen über das Ende der Furka hinaus, da sie 6,7 mm lang sind. Das 8., 9. und 24. und 25. Glied sind verwachsen, haben jedoch in beiden Fällen am unteren Rande eine Grenzlinie, welche Trennung andeutet. Die Längen der letzten 5 Glieder verhalten sich wie $7: 6: 6: 7: 8$. Der Innenast der hinteren Antennen ist etwa halb so lang als der Außenast, und das Endglied des letzteren ist ebenso lang als das 2. Glied.

Bei den vorderen Maxillipeden ist die Hakenborste des letzten Lobus etwas dicker und ein wenig länger als die übrigen, und die Sinnesanhänge des Innenastes sind alle wurmförmig. Bei den hinteren Maxillipeden sind die beiden Basalglieder ungefähr gleich lang, der Innenast ist um ein fünftel kürzer und das 2. Glied desselben ist fast so lang wie die $\mathbf{3}$ olgenden.

Die M a xille $\mathrm{n}$ haben einen stark verlängerten ersten Innenlobus, und die Hakenborsten sind noch nicht drei viertel so lang; der 2. Innenlobus hat 2, der 3. Innenlobus 4, das 2. Basalglied 5, der Innenast 3, der Außenast 3 und der 1. Außenlobus 9 Borsten.

Das 1. F u ß p a a r hat eingliedrigen Innenast und der Randdorn des 2. Gliedes vom Außenast ist schwächer und kürzer als die beiden übrigen. Der des 1 . Gliedes ist ebenfalls schwach, aber länger, 
und der des Endgliedes ist am längsten und kräftigsten. Der zweigliedrige Innenast des 2. FuBpaares trägt auf dem 2. Gliede Kränze von langen Dornen, der Außenast Reihen kleiner Dornen auf dem 2. und 3. Glied und zahlreiche feine Dörnchen. Die Endsäge ist ebenso lang wie das 3. Glied und besitzt anscheinend eine doppelte Zahnreihe.

Beim 4. Paare finden sich Gruppen großer Dornen auf dem 2. und 3. Gliede des Innenastes und nur kleine Dornen und zahlreiche Dörnchen auf der Oberfläche der drei Glieder des Außenastes. Die Endsäge ist kurz und hat wie beim 2. Paar eine doppelte Zahnreihe. Die Borste des 1. Basalgliedes fehlt. Das 5. Fußpaar ist klein; jeder Fuß besteht nur aus zwei Gliedern an gemeinsamem Basale. Das letzte Glied ist viermal so lang als breit und trägt an der Spitze einen kurzen, nackten Dorn und distal am Innenrand einen sehr langen und kräftigen Dorn, welcher mehr als fünfmal so lang als der Enddorn, länger als das ganze Glied und an einer Seite mit feinen Haaren bekleidet ist. $(35 \mathrm{~b}$.)

Diese Art zeigt große Ähnlichkeit mit einigen andern, wie Scolecithrix polaris WoLFENDEN, Scolecithrix validus FARRAN und Scolecithrix emarginatus FARRAN, ist aber viel größer als diese. Obwohl das 5. Fußpaar nach dem gleichen Plan wie bei diesen gebaut ist, sind die Längenverhältnisse der Enddornen sehr verschieden. Ferner gleicht es wegen der großen Länge des Innenranddornes der Scolecithrix californicus Esterly, aber die Lage der Dornen ist abweichend und der innere Dorn ist nicht so lang wie bei EsTERLY's Art. Scolecithrix magnus ist auch mehr als doppelt so groß als die letztere. Charakteristische Unterschiede von den andern Arten zeigen auch die Maxillen. Gefunden wurde Scolecithrix magnus in einem Vertikalfang aus 3000 m Tiefe am 12. November 1901.

\section{Racovitzanus Gresbrecht.}

Als GIESBRECHT diese neue Gattung beschrieb, hielt er es für nötig, die folgenden Bemerkungen zu machen: „Gegen die Aufstellung des n. g. Racovitzanus sprechen zwei Umstände, einmal daß es einer Gruppe (Scolecithrichina) angehört, in welcher die Grenzen zwischen den Genera noch schwanken, und ferner, daß ein etwas defektes o nur eine schwache Basis für ein neues Genus ist. Dafür spricht aber andererseits, daß die Selbständigkeit des n. g. den übrigen Genera der Gruppe gegenüber durch wenigstens zwei Merkmale gesichert ist: durch Unpaarigkeit des Rostralanhanges und das Vorhandensein eines Endopoditenrudimentes am 5. Beine des o" (Belgica Report p. 26).

98. Racovitzanus antareticus Giessrecht. (Tafel XXX, Fig. 6, Textfig. 36 a-e.)

GiesBrechts Beschreibung war nach einem einzigen Exemplar gegeben. In der Sammlung des „Gauss" war ein halbes Dutzend gut erhaltener Exemplare vorhanden, und ich bin daher imstande, die Genauigkeit von Professor Giesbrecht's Beschreibung zu bestätigen und einige neue Einzelheiten hinzuzufügen. Nur in einem Punkte finde ich die Beschreibung für diese Exemplare nicht ganz zutreffend, nämlich in bezug auf das 5. Fußpaar. Etwas variieren diese 6 Exemplare. Bei einigen zeigt das Endglied die Andeutung einer Teilung durch eine Linie, welche vom Innenrand ausgeht, aber sich nicht quer über das Glied erstreckt, was den Eindruck hervorruft, als ob ein elementarer Versuch gemacht wäre, einen Innenast zu bilden. Bei andern findet sich weder von Segmentierung noch von einem Innenast eine Spur. Auch der Dorn an der Spitze des 5. Fußes variiert in der Länge ebenso wie der innere Randdorn; während dieser bei einigen Exemplaren anscheinend 
ganz nackt ist, ist er bei anderen mit den üblichen kurzen Borsten in der äußeren Hälfte des oberen Randes bewaffnet. Aber bei keinem der Exemplare findet sich solche Anlage eines Innenastes, wie sie GIEsBRecht abbildet. Es ist kaum nötig, anzunehmen, daß zwei verschiedene Arten existieren, da die Tiere so vollkommen in allen andern Einzelheiten übereinstimmen, sondern ich halte es für wahrscheinlich, daß der Bau des 5. Fußpaares beträchtlichen Variationen unterworfen ist. ( $36 \mathrm{~d}$ u. e.) Alle Tiere aus der Sammlung des „Gauss" sind erwachsene $q$ mit gut entwickeltem Genitalsegment.

ㅇ 2,1 mm, davon Cephalothorax 1,5 mm, das Abdomen 0,6 mm. Der $\mathrm{Kop} \mathrm{f}$ ist gerundet und vorn in eine stumpfe Chitinplatte ohne Filamente verlängert. Die ersten und die letzten

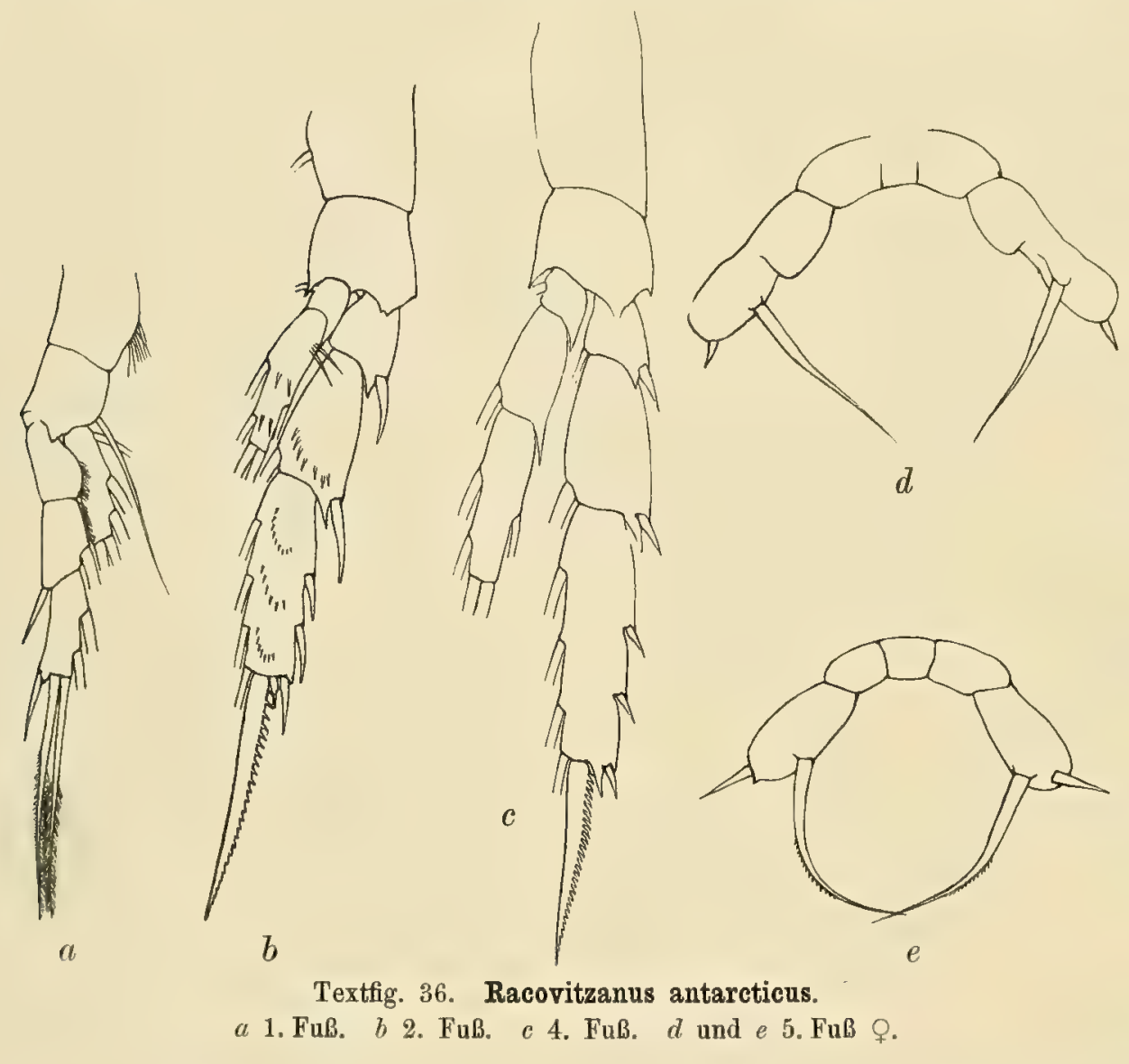
beiden Segmente des Cephalothorax sind verschmolzen, das letzte Segment hat seitliche Spitzen. Das Genitalsegment ist doppelt so lang als das folgende, und das Analsegment verhältnismäßig groß. Die 4 Abdominalsegmente verhalten sich wie $20: 10: 9: 14$. Die Furkaläste sind etwa halb so lang als das Analsegment und um ein Drittel länger als breit, divergieren und tragen 2 lange Schwanzborsten, die so lang wie dasAbdomen sind, und schwache Innen- und Außenborsten. (XXX.6.) Die vorderen An tennen, mit 23 Gliedern, reichen gerade über das Ende des Thorax hinaus. Die beiden letzten Glieder sind getrennt. Ästhetasken sind reichlich vorhanden, besonders am 3., 8. und 12. Gliede. Bei den hinteren Antennen sind Außenast und Innenast gleich lang, und das 1. und 2. Glied des Außenastes sind gleich. Der Innenast ist viermal so lang als breit, etwas kräftiger als der Außenast gebildet und trägt $8+7$ Endborsten, die alle mit Ausnahme der beiden innersten und der äußersten stark sind.

Der Außenast der $\mathrm{Mandibeln}$ ist viel länger und dicker als der Innenast und mit sehr langen Borsten versehen. An den M a xille $\mathrm{n}$ hat der Innenast 8, das 2. Basalglied und der Außenast je 5 und der 1. Außenlobus 7 Borsten, von denen die proximale Borste sehr klein ist. Das Basalglied und der Innenast sind zum 1. Lobus hinübergeneigt wie bei Scolecithrix. Die vorderen 
Maxillipeden haben an den Endloben einen verhältnismäßig großen und zwei kleinere Haken. Der Innenast hat nur wurmförmige Anhänge und der Außenrand des Basalgliedes ist stark konvex.

Bei den hinteren $\mathrm{M}$ axillipeden ist das 1 . Basalglied viel länger als das 2, welches ebenso lang wie der Innenast ist. Dieser hat 5 deutliche Glieder und sehr lange Borsten.

Das I. F u $B$ p a a r (36 a) hat eingliedrigen Innenast und dreigliedrigen Außenast. Das 1. Glied des letzteren hat keinen Randdorn, das 2. und 3. Glied haben sehr lange äußere Dornen. Der Innenast ist mehr als dreimal so lang wie breit, hat keinen Lobus auf der Oberfläche und reicht nicht ganz bis zum Ende des 2. Gliedes vom Außenast. Am 1. Basalglied ist keine Randborste vorhanden. Das 2. Fußpaar $(36 \mathrm{~b})$ hat zweigliedrigen Innenast und auf der Oberfläche des 2. Gliedes desselben finden sich lange und starke Dornen. Auf der Fläche des 2. und 3. Gliedes vom Außenaste sind Kränze von Dornen vorhanden. Die Endsäge hat starke Zähne. Die Außenranddornen der Glieder des Außenastes sind sehr stark und gekrümmt.

Beim 3. Fußpaare sind lange Dornen auf der Fläche des 2. und 3. Gliedes vom Außenaste vorhanden und die Außenranddornen sind kürzer als beim 2. Fußpaare. Das 4. Fußpaar (36 c) hat keine Innenrandborste am 1. Basalglied. Alle Füße sind sehr lang; die des 4. Paares sind so lang wie das Abdomen.

Das 5. Fußpaar ( $36 \mathrm{~d} u$. e) hat ein gemeinsames Basalglied, an welchem jederseits ein langes Glied auftritt mit kurzem Enddorn und einer sehr langen Innenrandborste, die am Außenrande mit kurzen, steifen Börstchen besetzt ist. Bei einigen Exemplaren deutet teilweise eine Linie Teilung in zwei Glieder an, aber bei keinem derselben findet sich eine Spur eines Innenastes, wie ihn GiesBRECHT abbildet.

Gefunden wurden die 6 Exemplare im Scholleneise nordwestlich von der Gauss-Station am 9. März 1903 bei einem Fange mit dem Vertikalnetz von $1 \frac{1}{2} \mathrm{~m}$ Durchmesser aus $400 \mathrm{~m}$ Tiefe.

\section{Amallophora Sco't.}

Sсотт gab ursprünglich für diese Gattung folgende Merkmale an: vordere Antennen 20- bis 23 gliedrig; Mundorgane und Schwimmfüße etwa wie bei Scolecithrix, außer daß die vorderen Maxillipeden mit einem oder mit mehreren Sinnesanhängen in Gestalt von Filamentbündeln versehen

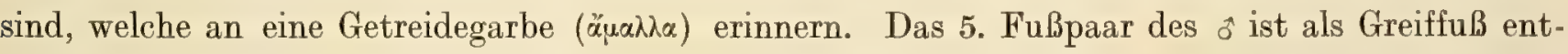
wickelt, ein- oder zweiästig, das des + einfach, einästig gebildet.

Die Gattung wurde von SARs angenommen und erweitert, und obwohl dieselbe von einigen anderen Autoren, wie Giesbrecht, Farran, Esterly, nicht anerkannt wurde, scheint es mir doch zweckmäßig, sie beizubehalten. Die Tiere dieser Gruppe, deren Typus Amallophora magna Scotт (= Scolecithrix cristata GresвRechт) darstellt, unterscheiden sich von Scolecithrix durch längeren Körper, schmalen, zuweilen mit Crista versehenem Kopf, im Bau des 5. Fußpaares und durch abweichende Form der Sinnesanhänge der Maxillipeden. Scotт beschrieb 4 Arten: Amallophora typica (seitdem von GIEsBrecht zu Xanthocalanus gestellt), Amallophora dubia (von Giesbrecht in Scolecithrix scotti umgetauft), Amallophora magna und Amallophora robusta. SARs fügte dann erst eine neue Art hinzu: Amallophora brevicornis (Crust. Norway) und später noch 3 andere: Amallophora affinis, Amallophora obtusifrons und Amallophora media (Bull. mus. ocean. Monaco). Diese sind nur kurz beschrieben und nicht abgebildet. Es ist daher möglich, daß eine oder die andere 
der unten beschriebenen neuen Arten sich später mit solchen von SARS als identisch erweisen, einstweilen müssen sie aber als eigene Formen betrachtet werden. Diese Arten können sehr leicht für größere oder kleinere Varietäten von Amallophora magna gehalten und so übersehen werden, bei genauer Betrachtung jedoch zeigen sie erhebliche Unterschiede, besonders im Bau des 5. Fußes.

\section{Amallophora magna Sсотт.}

Unter obigem Namen wurde diese Art zuerst aus dem Golf von Guinea beschrieben (Sсотт, Trans. Iinn. Society vol. IV part I p. 55), dann erhielten Exemplare aus dem Pazifischen Ozean von GIesBRecht den Namen Scolecithrix cristata (Bull. Mus. Harvard 1895), und andere aus dem Nordpolarbecken wurden von SARS Scaphocalanus acrocephalus benannt. In den Crustacea of Norway aber nennt er die Art jedoch Amallophora magna (Crust. Norway vol. IV, Copepoda, 1903).

Es scheint mir jedoch nicht ganz klar, ob der Copepod aus dem Nordpolarbecken (Scaphocalanus acrocephalus) völlig identisch mit der südlichen Art ist, da er beschrieben wird mit ,the tail (scarcely) twice as long as broad, and the $5^{\text {th }}$ feet biarticulate with a spine on the $2^{\text {nd }}$ joint well defined but not reaching beyond the end of the segment", während die Exemplare von der norwegischen Küste gekennzeichnet werden durch ,,the tail about as long as broad, and the $5^{\text {th }}$ feet imperfectly triarticulate with a very small denticle on the outer margin". Beide waren $5 \mathrm{~mm}$ lang. Es scheinen da doch Variationen, wenn nicht Artunterschiede vorzuliegen.

Die Art wurde häufig im südlichen Atlantischen Ozean und auch in dem antarktischen Gebiet angetroffen, so daß man sie für einen der am weitesten verbreiteten Copepoden ansehen könnte. Die antarktischen Exemplare sind regelmäßig kleiner als die von SARs beschriebenen, nämlich nur etwa 4,25 mm lang, und die aus dem südlichen Atlantischen, Ozean sind noch kleiner, messen nur 3,7 mm. Giesbrecht's Exemplare aus dem Pazifischen Ozean und ScotT's einzelnes Individuum aus dem Golf von Guinea waren $4,5 \mathrm{~mm}$ groß, worin sie etwa mit den antarktischen Exemplaren übereinstimmen. Diese Größenunterschiede ließen auch spezifische Unterschiede vermuten. Ich habe daher eine sehr sorgfältige Untersuchung und eingehenden Vergleich der Tiere aus dem südlichen Atlantischen Ozean vom 30. September 1903 (1500 m), 26. September 1903 (3000 m) und aus dem antarktischen Eismeere vom 6. März $1903(1200 \mathrm{~m})$ vorgenommen, fand dieselben aber, abgesehen von der Größe, in allen Punkten übereinstimmend. Auch mit der Beschreibung von SARS ist gute Ubereinstimmung vorhanden, nur scheinen der Kopf nicht so stark gerundet und die Verhältnisse der Dornen des 5. Fußpaares verschieden zu sein.

Bei der nordischen Art erscheint der äußere Dorn nur als kleiner Zahn, während er bei den Exemplaren aus dem südlichen Atlantischen Ozean über das Ende des letzten Gliedes hinausragt, und der Enddorn hat bei diesen drei Viertel der Länge des langen inneren Randdornes, während er bei der nördlichen Form nur halb so lang ist. Bei der südlichen Art ist das Genitalsegment größer als die beiden folgenden, und die Furkaläste sind länger als das Analsegment; in anderer Hinsicht gleichen sie der nördlichen Form.

100. Amallophora subbrevicornis n. sp. (Textfig. $37 \mathrm{a}-\mathrm{c}$.)

Diese Art gleicht Amallophora brevicornis SARS, unterscheidet sich von ihr jedoch durch die Form des letzten Thorakalsegments, welches bei der Art von SARS in Spitzen verlängert, hier aber gerundet, ohne Spitzen erscheint. Hier sind auch längere Antennen vorhanden. 
o 1,75 mm lang, davon Cephalothorax $1,3 \mathrm{~mm}$, Abdomen 0,45 mm. Der $\mathrm{K}$ o p f ist gerundet, ohne Spur einer Crista. Das letzte Thorakalsegment hat gerundete Kontur, ist nicht in dreieckige Spitzen verlängert. Das Genitalsegment ist nicht so lang wie die beiden folgenden, die Furkaläste sind mehr als zweimal so lang als breit und nur ein wenig länger als das Analsegment. (37 a.) Der. Thorax ist viel schmäler als bei Amallophora brevicornis. Die vorderen Antennen waren bei den beiden vorliegenden Exemplaren abgebrochen, müssen jedoch länger als bei Amallophora brevicornis gewesen sein, wie die vorhandenen Teile erkennen lassen. Denn die vorhandenen 15 Glieder überragten das Ende des 1. Thorakalsegments. Das 2. Glied ist lang und die folgenden Glieder sind stark verdickt.

Bei den hinteren Antennen ist der Innenast um ein Drittel länger als der Außenast, und das 7. Glied des letzteren ist viel länger als das 2. Die Sinnesanhänge der vorderen $\mathrm{Maxillipeden} \mathrm{sind} \mathrm{teils} \mathrm{wurmförmig,} \mathrm{teils}$ garbenförmig.

Das 1. F u B p a a h hat eingliedrigen Innenast, und am Außenast ist der Außenranddorn des 2. Gliedes sehr klein, während er am 1. Gliede fehlt.

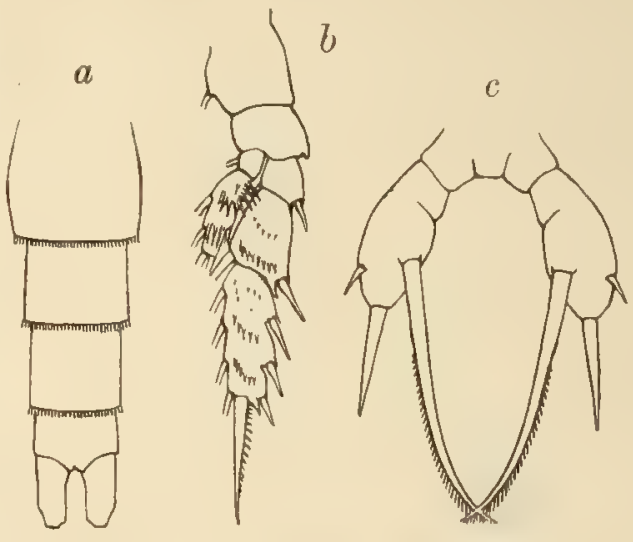

Textfig. 37. Amallophora subbrevicornis. a Abdomen, $b$ 2. Fuß. $c$ 5. Fußpar.

Beim 2. Paar ist der Innenast nur zweigliedrig, und das 2. Glied trägt 3 Kränze von langen Dornen; das 1. Glied des Außenastes hat 3 Reihen, das 2. Glied 2 Kränze und das 3. Glied 3 Reihen von Dornen. Der Außenranddorn des 1. Gliedes ist nicht gekrümmt und viel kleiner als die Dornen des 2. und 3. Gliedes. (37 b.)

Das 3. und 4. Fußpaar besitzt auf dem 2. und 3. Gliede der Außenäste Kränze großer Dornen und eine Anzahl kleiner am Rande des 2. Basalgliedes dicht neben dem äußeren Randdorn. Das 5. Fußpaar ( $37 \mathrm{c}$ ) besteht aus gemeinsamem Basalglied und 2 unvollkommenen dreigliedrigen Füßen. Das Distalglied ist unvollständig in ein kurzes, proximales und ein doppelt so langes distales Glied geteilt. Ein sehr langer Dorn, der nur an der Außenseite kurze Borsten trägt, erhebt sich vom Innenrand über die Mitte des unvollkommenen 3. Gliedes, ferner ist ein nackter Enddorn, kaum von halber Länge, endlich ein kleines Zähnchen am Außenrande, dem langen Dorn gegenüber, vorhanden. Zwei Exemplare liegen vor aus einem Planktonfang im Gebiet der antarktischen Tiefsee vom 6. März $1903(1200 \mathrm{~m})$.

\section{Amallophora impar n. sp. (Textfigur 38 a-d.)}

우 2,4 $\mathrm{mm}$, wovon 1,8 $\mathrm{mm}$ auf den Cephalothorax, 0,6 mm auf das Abdomen kommen. Der K o p f ist gerundet, ohne Spur einer Crista. Der Kopf mit dem 1. Segment vereinigt ist doppelt so lang als die folgenden Segmente, und der Rumpf ist kaum halb so breit als lang. Das letzte Thorakalsegment hat gerundete, vorn etwas hervortretende Ränder. (38 a.)

Das Genitalsegment ist $1 \frac{1}{4} \mathrm{mal}$ so lang als das folgende Segment, und das Analsegment $2 / 3$ so lang als das vorhergehende. Die Furkaläste sind länger als das Analsegment und mehr als doppelt so lang als breit. $(38 \mathrm{~b}$.) 
Die vorderen Antennen sind etwas länger als der Cephalothorax und bestehen aus 22 Gliedern. Das 2. Glied ist lang, länger als die 3 nächsten, und vom 3. bis 12. sind die Segmente stark verbreitert. Die Längen der letzten 5 Glieder verhalten sich wie $14: 11: 9: 8: 7,5$. Ästhetasken sind zahlreich vorhanden; das vereinigte 8 . und 9. Glied ist so lang wie die 3 folgenden. Der Innenast der hinteren Antennen ist etwas länger als der Außenast, das 1. und 2. Glied des letzteren sind getrennt und das zweite und siebente Glied von gleicher Länge.

Die vorderen $\mathrm{M}$ axillipede $\mathrm{n}$ sind ziemlich zart; die Hakenborsten des 4. und 5. Lobus

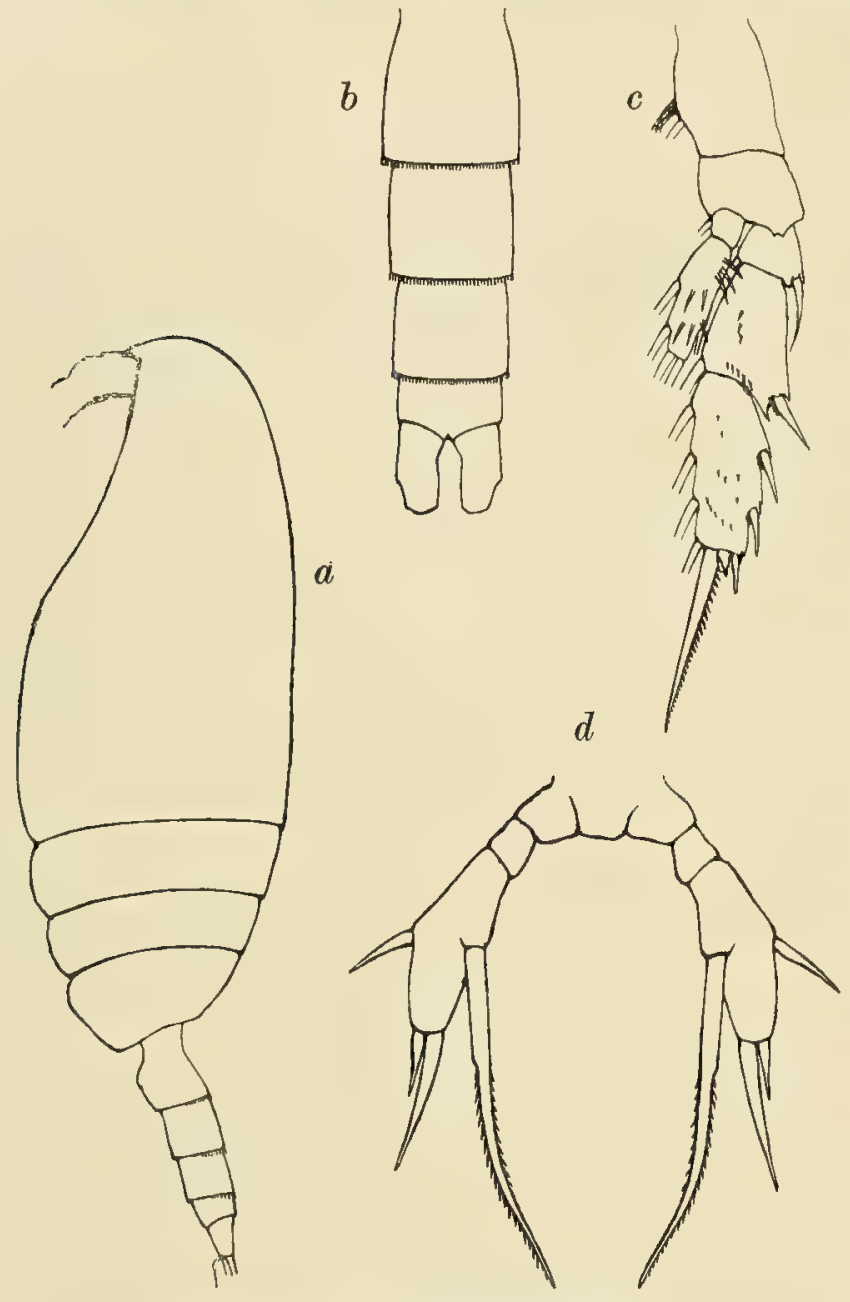

Textfig. 38. Amallophora impar.

$a$ Seitenansicht. $b$ Abdomen. $c$ 2. Fuß. $d 5$. Fußpaar. verhältnismäßig lang und dünn und von ungefähr gleicher Länge; die Sinnesanhänge des Innenasts sind wurmförmig und garbenförmig.

Die hinteren Maxillipeden haben 3 Glieder, deren Länge sich verhält wie $23: 20: 17$. Am 1. Basalgliede findet sich eine Sinnesknospe.

Bei den $\mathrm{M}$ a xille $\mathrm{n}$ ist das 2. Basalglied und der Innenast stark dem 1. Innenlobus zugeneigt, und die Zahl der Borsten beträgt beim 2. Innenlobus 4 , beim dritten 2 , beim 2 . Basalglied und Innenast 14.

Das 1. Fußpaar hat eingliedrigen Innenast; das 1. Glied seines Außenastes hat keinen, das 2. einen sehr kleinen und das 3. Glied einen sehr langen Randdorn. Beim 2. Fußpaar (38 c) ist der Innenast zweigliedrig mit vorspringender Reihe von Dornen auf dem 2. Gliede; der Außenast zeigt einige Dornen auf dem 1. Glied, eine Reihe solcher im distalen Teile des 2. Gliedes, 3 kleine Gruppen langer Dornen und mehrere zerstreut auf der Oberfläche des 3. Gliedes. Der äußere Randdorn des 1. Gliedes ist lang und gekrümmt, die Endsäge etwas länger als das 3. Glied und mit starken Zähnen bewehrt. Beim 3. und 4. Fußpaare treten einige lange Dornen auf dem 2. und 3. Gliede des Außenastes und ebenso auf dem 1. und 2. Gliede des Innenastes auf. Die Endsäge ist viel kürzer als das letzte Glied.

Das 5. Fußpaar (38d) besteht aus gemeinsamem Basalglied und 3 Gliedern jederseits, von denen das 3. so lang wie die beiden ersten zusammen und fast dreimal so lang als breit ist. An der Innenseite des letzten Gliedes findet sich etwa in der Mitte ein langer Dorn, der fünfmal so lang wie die Breite des Gliedes und an beiden Seiten mit kurzen, steifen Borsten bewehrt ist. Ein sehr kleiner Dorn tritt auf der Außenseite gegenüber dem langen Innendorn auf. Zwei Dornen stehen an der Spitze, von denen die inneren doppelt so lang sind als die äußeren. Diese Dornen sind unbewehrt. 
Das 5. Fußpaar scheint von dem bei Amallophora affinis und Amallophora obtusitrons SARs ab. weichend gebildet zu sein.

Nur ein Exemplar fand sich im Antarktischen Eismeer am 6. März 1903 (1200 m).

102. Amallophora gracilis. (Textfig. 39 a-c.)

o 4,85 mm, davon Cephalothorax 3,75 mm, Abdomen 1,1 mm. Der K o p f ist gerundet, mit einer Crista versehen und Amallophora magna sehr ähnlich. Das Rostrum besteht aus einer Chitinlamelle mit 2 Spitzen, die weniger stark als bei Amallophora magna ist. Die größte Breite des Rumpfes beträgt 1,2 mm. Der Kopf und das 1 . Thorakalsegment sind verschmolzen, und das letzte Segment endigt mit schwachen, seitlichen Spitzen. (39 a.)

Das Genitalsegment ist fast so lang wie die beiden nächsten Segmente, das Analsegment sehr klein und die Furkaläste sind etwas länger als breit.

Die vorderen Antennen reichen bis zum Ende des Genitalsegments und bestehen aus 22 Gliedern. Das 2. Glied ist so lang wie die 3 folgenden Glieder; hinter dem 2. ist die Antenne etwas eingeschnürt und die folgenden Glieder bis zum 12. sind verhältnismäßig breit. Der Innenast der hinteren Antenne ist um ein Viertel länger und stärker gebaut als der Außenast. Das 2. Glied des Innenastes ist sechsmal so lang als breit; das 7. Glied des Außenastes ist länger als das 2.

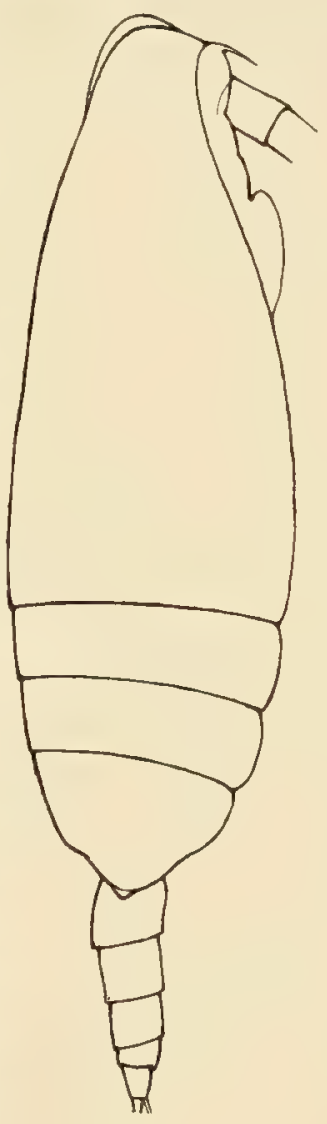

$a$

Textfig. 39. Amallophora gracilis. $a$ Seitenansicht. $b$ 1. FuB. $c$ 5, Fuß.

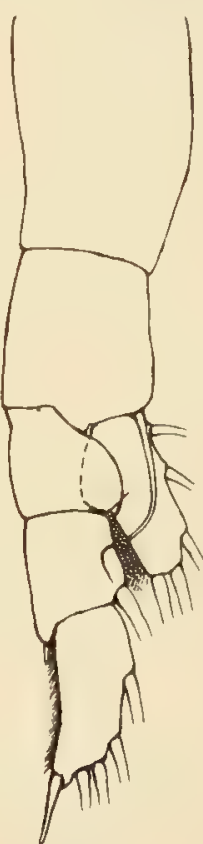

$b$

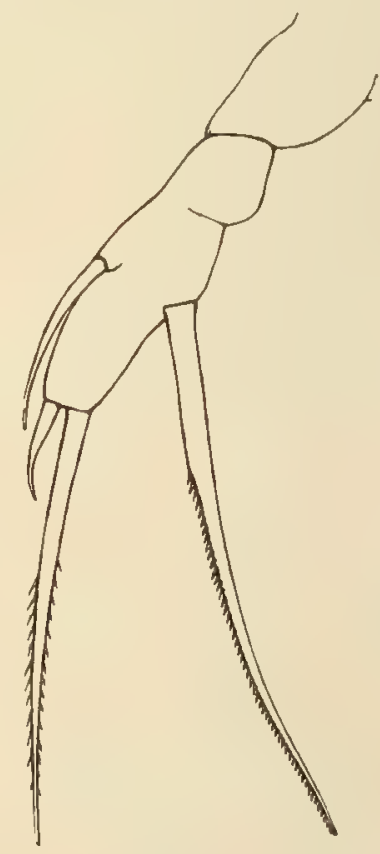

$c$

Der Haken des 5. Lobus der vorderen Maxillipeden ist nur wenig länger und stärker als der des 4. Lobus. Der Innenast hat wurmförmige und 2 oder 3 garbenförmige Sinnesanhänge. Die hinteren Maxillipeden haben kurzen Innenast und 2 fast gleichlange Basalglieder im Verhältnis von $40: 42: 25$. Am 1. Basalgliede findet sich ein großer pinselartiger Fortsatz.

Der 1. Innenlobus der M a xille $\mathrm{n}$ ist nicht so wie bei andern Arten verlängert und nicht länger als die Haken.

Das 1. F u B p a a r (39 b) hat eingliedrigen Innenast; ein äußerer Randdorn am 1. Gliede des Außenastes fehlt, und am 2. Glied ist nur ein sehr kleiner vorhanden. Beim 2. Fußpaar ist der Innenast zweigliedrig und das 2. Glied trägt Kränze von großen Dornen; das 2. Glied des Außenastes ist distal mit großem Kranze von Dornen versehen, und das 3. hat 3 Reihen kleinerer Dornen. 
Die Endsäge ist sehr wenig länger als das letzte Glied und dicht mit Zähnen besetzt. Das 3. und 4. Fußpaar waren stark verletzt, doch zeigte der Innenast des 4. Fußes Dornenkränze am 2. und 3. Glied und die ganze Oberfläche mit feinen Dörnchen besetzt. Auch die Basalglieder waren sehr stachelig.

Das 5. Fußpaar hat ein gemeinsames Basalglied, ein kurzes 1. und langes, unvollkommen geteiltes 2. Glied. Der distale Teil desselben (3. Glied) ist lang, dreimal so lang als breit und trägt 4 Dornen. Der in der Mitte des Innenrandes stehende ist am längsten, doppelt so lang fast als das letzte Glied. Der lange Enddorn ist um ein Viertel kürzer. (39 c.)

Nach außen von diesem findet sich ein kurzer Dorn, und am Außenrand gegenüber dem langen Dorn ein dünner, gekrümmter, welcher über den Endrand des letzten Segments hinausragt. Die beiden innersten Dornen sind mit kurzen, steifen Borsten bewehrt, der Enddorn trägt nur wenige Borsten, und die beiden äußeren Dornen scheinen nackt zu sein.

Das 5. Fußpaar unterscheidet diese Art von Amallophora affinis und Amallophora obtusifrons SARS nach der Beschreibung derselben. Gefunden wurde sie im südlichen Atlantischen Ozean am 5. November $1901(1000 \mathrm{~m})$.

103. Amallophora elegans n. sp. (Tafel XXX, Fig. 7-13, Textfig. 40.)

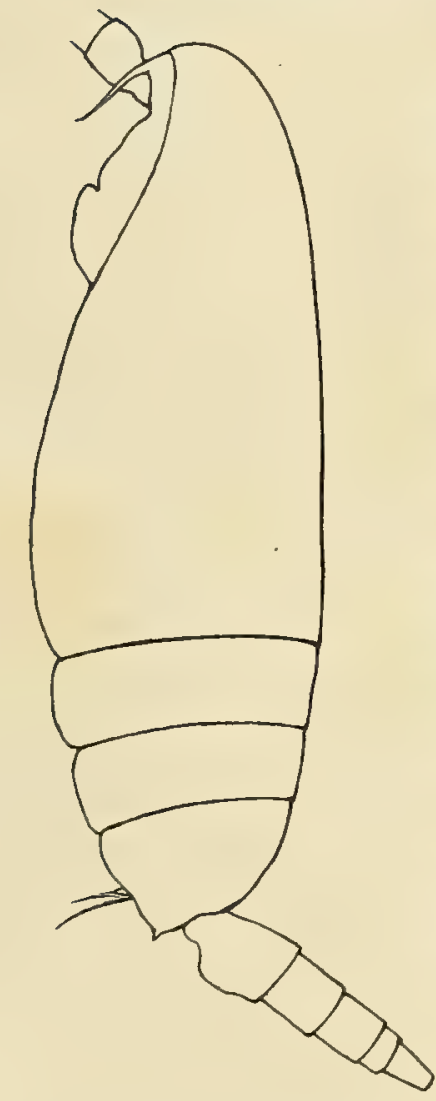

Textfig. 40.

IAmallophora elegans. Seitenansicht.

Diese Art gleicht Amallophora magna in der Gestalt, ist jedoch viel kleiner und weicht von ihr auch ab durch den gerundeten Kopf ohne jede Spur eines Kiels. In dieser Hinsicht erinnert sie mehr an Amallophora brevicornis (SARS) oder Amallophora subbrevicornis (WoLFENDEN), aber sie ist größer als diese beiden, und das letzte Thorakalsegment, welches vorn mit kleinen, aber deutlichen Spitzen endigt, scheint verschieden zu sein. (Textfig. 40.)

i $2,6 \mathrm{~mm}$, davon kommen $1,85 \mathrm{~mm}$ auf den Cephalothorax, $0,75 \mathrm{~mm}$ auf das Abdomen.

Der $\mathrm{Kopf}$ ist vorn nicht verschmälert, hat eine vollkommen gleichmäßige Krümmung ohne Crista und endet mit langem, schwachem Rostrum. Das Genitalsegment ist so groß wie die beiden folgenden Segmente, das Analsegment kürzer als das vorhergehende, die Furkaläste sind etwas länger als breit und halb so lang als das Analsegment.

Die ersten Antennen sind leider abgebrochen bis auf 13 Glieder, welche zeigen, daß die ganze Antenne wahrscheinlich bis zum Ende des Cephalothorax oder ein wenig darüber hinausreichen würde, da diese 13 Glieder die Basis des 4. Fußpaares noch erreichen. Das 2. Glied ist länger als die beiden nächsten und vom 3 . bis zum vereinigten 8 . und 9. Gliede sind die Antennenglieder verbreitert.

Der Innenast und Außenast der hinteren Antennen (XXX. 7) ist etwa gleichlang; das 2. Glied des Außenastes ist etwas kürzer als das 7. Die Hakenborsten des 4. und 5. Lobus der vorderen $\mathrm{M}$ a xill i p ed e $\mathrm{n}$ (XXX. 9) sind von fast gleicher Länge, lang, dünn und gekrümmt und die wurmförmigen Sinnesanhänge sind dick, die garbenförmigen dünn. 
Bei den hinteren Maxillipeden (XXX. 10) ist das 2. Basalglied doppelt so lang als das 1. Der Innenast ist viel kürzer. Die Längen verhalten sich wie $10: 23: 17$. Am 1. Basalgliede findet sich ein pinselförmiger Fortsatz. Am 1. Außenlobus der Maxille n (XXX. 8) sind 9, am Außenast 7, am 2. Basalgliede 4 und am Innenast 7 Borsten vorhanden.

Das 1. F u B p a a r (XXX. 11) hat eingliedrigen Innenast. Am 1. Gliede fehlt ein Randdorn, am 2. ist ein sehr kleiner vorhanden. Beim 2. Fußpaare (XXX. 12) hat das 2. Glied des Innenastes 3 Reihen langer Dornen; alle 3 Glieder des Außenastes tragen kleine Dornen auf der Oberfläche; der Außenranddorn des 1. Gliedes vom Außenast ist kurz und gekrümmt und der des 2. Gliedes ist am längsten von allen. Die Endsägen haben dichtstehende Zähne. Das 3. und 4. Fußpaar sind nicht so stachelig wie bei andern Arten; ihre Endsägen sind mit ziemlich weitstehenden Zähnen besetzt.

Das 5. Fußpaar (XXX. 13) hat ein gemeinsames Basalglied und auf jeder Seite 3 Glieder von ziemlich gleicher Größe. Das mittlere Glied ist ein wenig größer als jedes der beiden andern Glieder. Auf der Innenseite des mittleren Gliedes erhebt sich ein langer Dorn, der länger als der ganze Fuß ist. Von der Mitte des letzten Gliedes entspringt auf der Innenseite ein Dorn, welcher sich erheblich über das Ende des letzten Gliedes hinaus erstreckt und halb so lang als der Enddorn ist. Der Enddorn ist lang, so lang wie der Fuß und fast dreiviertel so lang als der lange Innendorn. Beide langen Dornen sind mit kurzen, steifen Borsten bewehrt, der kurze Dorn ist dagegen nackt. Das 5. Fußpaar ist von dem von Amallophora magna durch die Länge der Dornen verschieden und von ihr und einigen andern Arten durch die dreigliedrigen Extremitäten. Von dem der Amallophora obtusifrons scheint es auch in vielen Einzelheiten abzuweichen.

Amallophora elegans fand sich etwa unter dem Äquator im Atlantischen Ozean am 30. September 1903 in einem Vertikalfang aus $800 \mathrm{~m}$ Tiefe.

\section{Lophothrix Giesbrech'.}

Diese Gattung wurde von GIESBRECHT ${ }^{1}$ ) folgendermaßen beschrieben: ,,Vorderkörper gestreckt; Kopf mit dem 1. Thoraxsegment verschmolzen; die letzten beiden Thoraxsegmente ebenfalls verschmolzen; Rostrum starr, zweizinkig; die beiden Zinken dick, am Ende mit je einer kleinen Spitze. Vordere Antennen 24 gliedrig; 8. und 9. Glied verschmolzen, 24. und 25. Glied getrennt. Äste der hinteren Antennen ungefähr gleichlang, Endglied des Außenastes verkürzt. Mandibellade gedrungen, kurz, ähnlich wie bei Scolecithrix. Die Schläuche am vorderen Maxillipeden mit Pinselspitzen. 5. Fußpaar dreigliedrig. o unbekannt."

Später (in Das Tierreich, Copepoda, 1898) gab GIEsBREcht die Gattung auf. Es ist jedoch zweckmäßig, sie beizubehalten, und ohne Zweifel sind die anatomischen Merkmale des typischen Lophothrix weit von denen eines typischen Scolecithrix verschieden. SARs erkannte auch die Gattung an und stellte eine zweite Art auf, Lophothrix humilifrons, von 6,30 mm Länge, die Lophothrix frontalis sehr nahe steht, von der jedoch nichts bekannt ist, außer daß der Kopf eine kleinere Crista und das Rostrum schärfere Spitzen als bei Lophothrix frontalis hat.

$\left.{ }^{1}\right)$ Bull. Mus. of Comp. Zool. Harvard College vol. XXV. 
104. Lophothrix frontalis Gressrecht.

Diese Art hat ein sehr weites Verbreitungsgebiet; im Atlantischen Ozean wurde sie von der Westküste Irlands bis zur Breite von Kapstadt gefunden. In der Sammlung des „Gauss" trat sie in den Vertikalfängen vom 22. Oktober 1901 (3000 m), 26. Oktober 1901 (1300 m), 5. November $1901(1000 \mathrm{~m})$, 12. und 16. November $1901(3000 \mathrm{~m})$ und 9. Oktober $1903(3000 \mathrm{~m})$ auf. Die südatlantischen Exemplare stimmen nach GIESBRECHT's Beschreibung nicht ganz mit den pazifischen überein; sie sind kleiner, 5,5-6,0 $\mathrm{mm}$ im Maximum, während die pazifischen 6,6 $\mathrm{mm}$ messen. Der Kopf scheint spitzer zu sein, und außerdem finden sich kleinere Differenzen in der Bestachelung der Füße. Abgesehen von diesen kleinen Abänderungen aber sind die Tiere identisch.

105. Lophothrix securifrons Тн. Sсотт.

Ursprünglich wurde diese Art von Scot' als Scolecithrix securifrons (Trans. Linn. Society 1893) beschrieben. Dain stellte SARs eine neue Gattung, Scottocalanus, dafür auf, welche „différe de Scolecithrix, entre autres choses par la forme singulière de la partie frontale de la tête, par le rostre très-fort bifurqué et par la structure des pattes de la $5^{\text {e }}$ paire chez les deux sexes. Genre établi pour enfermer l'espèce anomale décrite par Тн. SсотT comme Scolecithrix securitrons" (Bull. Mus. Monaco Nr. 20, 1905).

Da die Art mit Lophothrix sehr nahe verwandt zu sein scheint und die Gestalt des Kopfes und des Rostrums der von Lophothrix frontalis sehr ähnlich ist, scheint mir die Aufstellung einer neuen Gattung nicht genügend begründet zu sein.

Lophothrix securifrons fand sich in den Vertikalfängen vom 12. November 1901 (3000 m), 26. Oktober 1901 (1300 m), 8. Oktober $1903(400 \mathrm{~m})$, 9. Oktober 1903 (3000 m), 13. Oktober 1903 $(3000 \mathrm{~m})$ und trat gelegentlich in beträchtlicher Anzahl auf. Auch diese Art scheint weit über den Atlantischen Ozean verbreitet zu sein, da sie häufig von mir auch an der Westküste Irlands angetroffen wurde (Journ. Mar. Brit. Ass. vol. VII, 1904 und FARran, Fisheries Ireland Sci. Invest. 1906 Part II [1908]).

Der Grad der Zuspitzung des letzten Thorakalsegments scheint etwas variabel zu sein, was SARS veranlaßte, Scottocalanus acutus als besondere Art mit scharfen Spitzen am letzten Thorakalsegment von Scottocalanus securifrons abzutrennen. In der Abbildung, welche ScotT (Taf. IV, Fig. 56) gibt, zeigt sich, daß auch hier das letzte Thoraxsegment deutlich zugespitzt ist, und bei der Untersuchung einer Anzahl von Exemplaren des „Gauss“ fand ich es schwierig, auf Grund der von SARS angeführten Punkte zwei besondere Arten zu unterscheiden. Ich habe sie daher als identisch behandelt.

\section{Lophothrix simplex n. sp. (Textfig. 41 a u. b.)}

ㅇ $5,5 \mathrm{~mm}$. Der Habitus ist wie bei Lophothrix frontalis, aber der Kopf hat keine Spur einer Crista, obwohl er vorn etwas verlängert ist und mit ähnlichem Rostrum wie bei Lophothrix frontalis endigt. (41 a.) Die beiden ersten und die beiden letzten Segmente des Thorax sind verschmolzen. Die vorderen Antennen überragen etwas die Furka und gleichen denen von Lophothrix frontalis. Auch die Mundorgane und die ersten $4 \mathrm{Fußpaare}$ sind wie bei Lophothrix frontalis gebaut. Das 5. Fußpaar (4l b) ist zweigliedrig, doch ist das distale Glied auf der Innenseite unvollkommen 
geteilt. Die Glieder sind ungefähr gleich groß; das gemeinsame Basalglied der Füße ist kurz. Das 1. Glied hat eine Anzahl von kurzen, steifen Borsten oder feinen Dornen am distalen Außenrande. Das letzte Glied trägt, wie bei Lophothrix frontalis, 3 Dornen. Der hauptsächlichste Unterschied zwischen unserer Art und Lophothrix frontalis ist die völlige Abwesenheit einer Crista und die mehr gerundete Form des Kopfes. Sie wurde am 26. September 1903 in einem Vertikalfang aus $3000 \mathrm{~m}$ im Atlantischen Ozean unter dem Äquator angetroffen.

107. Lophothrix similis n. sp. (Tafel XXXIV, Fig. 1 und 2.)

q 5,5 mm. Der Kopf (XXXIV. 1) ist wie bei Lophothrix simplex gestaltet, ohne Crista, nur etwas verschmälert und höher. Das A bdomen ist nur einviertel so lang wie der Rumpf, und das Genitalsegment kommt an Länge

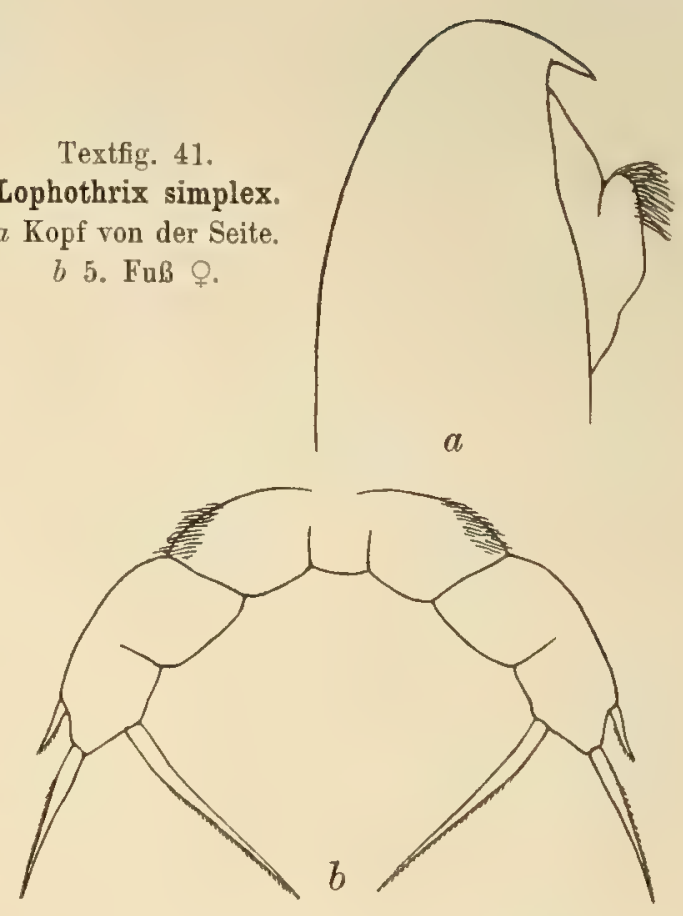
den drei nächsten gleich. Die Furkaläste divergieren etwas und sind ebenso lang wie breit.

Die vorderen Antennen überragen ein wenig die Furka.

Die Äste der hinteren Antennen sind gleich lang, das letzte Glied des Außenastes ist nicht mehr als ein drittel so lang wie das zweite, und das zweite Glied des Innenastes etwas länger als ein viertel des ersten Gliedes.

M u n d o r g a n e und erstes bis viertes Fußpaar sind wie bei Lophothrix frontalis gebildet.

Das fünfte Fußpaar (XXXIV.2) hat ein gemeinsames Basalglied und jederseits 3 Glieder von ungefähr gleicher Länge. Das letzte Glied trägt 4 Dornen, von denen der innerste am längsten und etwa zwei und ein viertel mal so lang wie die Breite des Gliedes ist. Der innere Enddorn ist nur etwa dreiviertel so lang, der äußere Enddorn sehr kurz, kaum halb so lang wie der Enddorn, und der Dorn am Außenrand ist noch kleiner. Die ersten Glieder sind weder mit Dornen noch mit Borsten bewehrt. Gefunden am 16. November $1901(3000 \mathrm{~m})$ im südlichen Atlantischen Ozean.

108. Lophothrix quadrispinosa n. sp. (Tafel XXXIV, Fig. 3, Textfig. 42.)

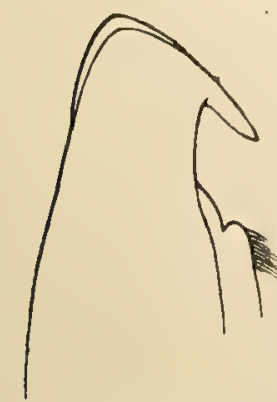

Textfig. 42.

Lophothrix quadrispinosa.

o 5,6 mm. Der Körper ist kräftiger und der Kopf mit hervorragender Crista versehen, weniger gerundet und spitzer wie bei Lophothrix frontalis. (Textfig. 42.) Die vorderen Antennen reichen bis zum Ende der Furka. Die 3 letzten Glieder verhalten sich bei Lophothrix quadrispinosa wie 23:21:10 und bei Lophothrix frontalis wie 25:20:10. Das letzte Glied des Außenastes der hinteren Antennen ist nicht halb so lang wie das 2. Glied. Die M u n do $\mathrm{r} g$ a $\mathrm{n}$ e und die 4 ersten Fußpaare gleichen denen von Lophothrix frontalis. Das 5. Paar (XXXIV. 3) dagegen ist verschieden gestaltet, hat 4 Dornen am Glied, einen an Außen-, einen an Innenrand und 2 Enddornen. Diese Kopf von der Seite. vier Dornen haben weniger ungleiche Längen als bei andern Arten. Der Innen- 
randdorn etwa in der Mitte des Gliedes ist der längste von ihnen. Die beiden Enddornen sind fast gleichlang, der innere etwas länger, und der Außenranddorn, der kleinste von ihnen, liegt nicht dem großen Dorn gegenüber, sondern mehr distal von der Mitte des Gliedes, näher der Spitze.

Die ersten Glieder haben am Außenrand eine dichte Anhäufung von feinen, kleinen Dornen (oder steifen Borsten) und distal am Außenrande jedes zweiten Gliedes einen sehr feinen Dorn bzw. eine Borste.

Der Unterschied zwischen dieser Art und Lophothrix frontalis beruht hauptsächlich auf der Gestalt von Kopf und Crista und auf dem Bau des 5. Fußpaares. Sie wurde am 5. November 1901 (1000 m) im südlichen Atlantischen Ozean gefunden.

109. Lophothrix varicans n. sp. (Tafel XXXIV, Fig. 4 u. 5.)

\& 5,9 $\mathrm{mm}$; Cephalothorax davon 4,7 mm, Abdomen 1,2 $\mathrm{mm}$. Der $\mathrm{K}$ op $\mathrm{f}$ ist vorn zu einer Spitze verlängert und hat eine starke Crista. (XXXIV. 4.) Das letzte Thorakalsegment tritt jederseits mit gerundeten Rändern weit hervor. Das Ge nit a ls e g m e nt ist länger als die beiden nächsten Segmente, die Furka ebenso breit als lang und so lang wie das Analsegment. Die vorderen A $\mathrm{n}$ te $\mathrm{n} \mathrm{n}$ e $\mathbf{n}$ reichen bis zum Ende des Genitalsegments. Die Äste der hinteren Antennen sind etwa gleichlang. Die vorderen und hinteren M a x ill i p e d e n sind klein, sonst aber wie auch die vorderen Fußpaare ähnlich denen von Lophothrix frontalis. Das 5. Fu B pa a r (XXXIV. 5) jedoch ist völlig verschieden von dem jener Art und besteht aus gemeinsamem Basalgliede mit dreigliedrigen Füßen. Das 1. der 3 Glieder ist kurz, etwa so lang als breit, das 2. ist breiter als lang, und sein distaler Innenrand ist in einen verhältnismäßig großen Fortsatz erweitert, der an der Spitze einen feinen Dorn trägt. Einige sehr kleine Dornen finden sich auf der Oberfläche dieses Gliedes, nahe an dem äußeren Rande. Das 3. Glied ist länger und schmäler als die übrigen und trägt 5 Dornen: einen kurzen Dorn in der proximalen Hälfte am Außenrande, 3 Enddornen, von denen der mittlere etwas länger als der innere und der äußere sehr kurz ist, und einen langen Innenranddorn, welcher der größte von allen 5 ist und nahezu rechtwinklig vom Glied absteht. Alle Dornen sind mit kurzen, steifen Randborsten, der innerste am dichtesten, bekleidet.

Erbeutet am 26. September $1903(3000 \mathrm{~m})$ im Atlantischen Ozean unter dem Äquator. Die Unterschiede der letzten 4 Arten, welche alle fast dieselbe Größe haben, beruhen hauptsächlich auf der Gestalt des Kopfes und den Merkmalen des 5. Fußpaares.

\section{Subfamilie Xanthophylina.}

Sie ist von der Subfamilie Scolecitrichina unterschieden durch die gewöhnlich vorhandene Trennung von Kopf und 1. Rumpfsegment, durch die stets 24gliedrigen ersten Antennen, durch die bei vielen Arten (Oncho-, Cornu-, Talacalanus) modifizierten Endborsten eines oder beider Maxillipeden, die in mehr oder weniger gut entwickelte Klauen umgebildet sind, häufig durch die extreme Borstenbedeckung der Füße, durch die Eigentümlichkeiten des 5. Fußpaares, welches einfach, zwei- oder dreigliedrig und sehr dornig sein kann, durch das Auftreten von Sinnesorganen an den vorderen Maxillipeden, die fast ausschließlich als Pinsel erscheinen und bisweilen durch besondere Anhänge der hinteren Maxillipeden und Maxillen (Talacalanus). Die Gliederung der 
Schwimmfüße zeigt denselben Typus wie bei der Subfamilie Scolecitrichina. Auch sind die Arten der Xanthophylina gewöhnlich größer und kräftiger gebaut als die der Scolecitrichina.

\section{Xanthophylinae ${ }^{1}$.}

Die Gattung Xanthocalanus, zuerst von GIESBRECHT aufgestellt, ist so erweitert worden, daß sie jetzt manche Formen einschließt, welche erheblich vom ursprünglichen Typus abweichen. Zu den 3 von diesem Autor (Das Tierreich, Copepoden p. 50) ursprünglich erwähnten Arten Xanthocalanus minor, agilis und typicus sind nun hinzuzufügen: Xanthocalanus borealis, propinquus (Crust. Norway, Copepoda), profundus, echinatus (Bull. Inst. oceanogr. Okt. 1907), muticus (Bull. Mus. oceanogr.) nach SARS; Xanthocalanus greenii, obtusus, pinguis (Fisheries Ireland Sci. Invest.) nach Farran; Xanthocalanus similis Esterly (Univ. California Zool. vol. 3, 1906), Xanthocalanus hirtipes VanHÖFFEN (Zool. Jahrb. 1907), Xanthocalanus simplex, subcristatus, magnus, calaminus WolfendeN (Plankton Studies 1906), Xanthocalanus subagilis, atlanticus, cristatus Wolfenden (Journ. Marin. Biol. Ass. 1904); Xanthocalanus antarcticus Wolfenden (National Antarct. Exp. vol. IV, 1908); Xanthocalanus gracilis, tenuiserratus WoLfEnden, giesbrechti Thompson (siehe unten). Xanthocalanus fragilis AUrivilluus (Kongl. Sv. Vetensk. Akadem. Handlingar XXX, 1898) hält Cleve für synonym mit Xanthocalanus borealis SARS.' VANHöFFEN hat die Bedeutung verschiedener Merkmale erörtert und legt den folgenden Punkten diagnostischen Wert bei: Größe, Länge der vorderen Antennen, Bedornung und Endsäge der Füße und Bau des 5. Fußpaares. (Zool. Jahrb. 1907 p. 514.)

Unterschiede in der Form des Rostrums und der vorderen und hinteren Maxillipeden veranlaßten FARran, eine neue Gattung, Brachycalanus, zu schaffen, welche die von mir früher als Xanthocalanus atlanticus beschriebene Art aufnehmen sollte. Die Gattungsmerkmale derselben bestehen ,mainly in the shape of the rostrum, which forms a broad truncated plate, and in the extreme shortness of the $1^{\text {st }}$ antennae"; ferner eine zweite Gattung, Oothrix, bei welcher das Rostrum zwar ähnlich dem von Brachycalanus ist, die Sinnesanhänge des 1. Maxillipeden aber ,are short

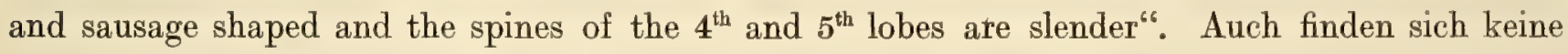
Dornen auf der Fläche der Füße. (Fisheries Ireland Sci. Invest. 1. c.)

Dann hat G. O. SARs kürzlich die Gattung Onchocalanus aufgestellt mit folgender Diagnose „Voisin du Xanthocalanus, mais en diffère par les appendices rostraux, transformés en une lamelle chitineuse bifurquée à l'extrémité; par des maxillipedes antérieurs se terminant en une griffe très forte et aiguë, combée en avant; par les maxillipèdes postérieurs grèles et allongés; enfin par les pattes nageoires ayant toutes les deux rames hérissées à la face postérieure de nombreuses épines fines“. Zwei Arten werden kurz beschrieben: Onchocalanus trigoniceps „n'ayant la face dorsale que très peu voũtée ... partie frontale triangulaire formant en dessus une sallie arrondie " und Onchocalanus hirtipes, deren vorderer Abschnitt beschrieben wird als ,plus renflée ... partie frontale egalement arrondie“". (Bull. Mus. oceanogr. No. 26, 1905.)

WolfENDEN endlich hat neulich die Gattung Cornucalanus abgetrennt, welche von Xanthocalanus hauptsächlich in der Gestalt des Kopfes abweicht, der bei einer Art (Cornucalanus magnus)

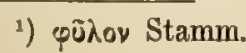


ein kurzes Horn trägt, und in der außerordentlichen Umbildung der Anhänge der vorderen und hinteren Maxillipeden zu spezialisierten Klauen.

Es scheint mir, daß die Charaktere der beiden Maxillipeden und der Sinnesanhänge am meisten für die Trennung der Gruppen dieser Unterfamilie in Betracht kommen, und daher kann die Cattung Onchocalanus angenommen und ergänzt werden. Die Sinnesanhänge von Talacalanus calaminus sind so merkwürdig, daß sie zur Aufstellung einer neuen Gattung berechtigen. Cephalophanes (Sars) gehört natürlich auch zu dieser Gruppe. Die Gestalt des Kopfes und die Rostralanhänge sind zwar bei verschiedenen Mitgliedern dieser Gruppe ungleich, doch stimmen alle im Besitz hauptsächlich pinselförmiger Sinnesanhänge überein, welche die Borsten des Innenastes der vorderen Maxillipeden ersetzen, ferner in der Gliederung der 4 ersten Fußpaare und in der Bedornung derselben sowie im einfachen Bau des 5. Fußpaares, dem der Innenast fehlt und welches zweigliedrig ist bei Xanthocalanus minor, hirtipes, muticus oder dreigliedrig bei Xanthocalanus greenii, propinquus, obtusus, pinguis, simplex, cristatus, subcristatus, magnus, atlanticus, subagilis, borealis, agilis, giesbrechti, magnus, tenuiserratus, calaminus, gracilis.

Die Gattungen Onchocalanus und Cephalophanes SARS sind von ihrem Autor nur kurz charakterisiert (Bull. Mus. oceanogr. und Bull. Inst. oceanogr. 1907), und ohne Zweifel wird er später weitere Aufklärung darüber geben, doch scheinen sie mir schon jetzt ganz gut gekennzeichnet, so daß die hier angenommene Gliederung der Gruppe berechtigt sein dürfte.

\section{Xanthocalanus Giesbrecht.}

Diese Gattung soll jene Arten umfassen, welche mehr oder weniger genau in ihrem Habitus mit Xanthocalanus agilis und minor GIESBRECHT übereinstimmen, d. h. mit jenen Arten, bei denen die vorderen Maxillipeden in gewöhnlicher Weise bewehrt sind, nämlich mit Hakenborsten an den letzten Loben, welche, obwohl gekrümmt, nicht von bedeutender Stärke oder sichelförmig sind und bei denen die Endborsten der hinteren Maxillipeden den gewöhnlichen Bau zeigen.

Das 1. Fußpaar hat einen eingliedrigen, das 2. einen zweigliedrigen Innenast, und die Flächen der Glieder, besonders beim Innenast, sind mit starken Dornen besetzt. Bei allen ist der Kopf vom 1. Rumpfsegment abgegliedert und die Sinnesanhänge sind vorwiegend pinselförmig.

Das 5. Fußpaar besteht entweder aus 2 oder aus 3 Gliedern mit Enddornen am letzten Gliede.

Die bekannten Arten sind: Xanthocalanus agilis, minor (GIEsBrechT), typicus (T. SсотT), propinquus (fragilis AURIVILLIUs), borealis, profundus (?), echinatus (?) (G. O. SARS), subagilis, simplex, tenuiserratus, gracilis (WoLFENDEN), hirtipes (VANHÖFFEN), greenii, pinguis (FARRAN).

Dazu kommen zwei neue, von der Deutschen Südpolar-Expedition entdeckte Arten, nämlich Xanthocalanus tenuiserratus und gracilis.

110. Xanthocalanus tenuiserratus $\mathrm{n}$. sp. (Textfig. $43 \mathrm{a}-\mathrm{f}_{\text {。 }}$ )

o $3,0 \mathrm{~mm}$. Cephalothorax 2,3 mm, Abdomen 0,65 mm. Der Kopf ist gerundet und mit starkem, zweispitzigem Rostrum versehen. Alle Cephalothoraxsegmente sind getrennt und die hinteren Ränder des Thorax in ziemlich scharfe, dreieckige Flügel ausgezogen, aber doch ohne Spitzen. Das A b dome $\mathrm{n}$ ist etwas mehr als einviertel so lang wie der Vorderkörper und das Genitalsegment nur wenig länger als das folgende. 
Die vorderen A n t e $\mathrm{n} n$ e $\mathrm{n}$, aus 24 Gliedern bestehend, reichen nur bis zum Ende des Thorax, das 8. und 9. Glied sind verschmolzen, das 24. und 25. getrennt und das letzte etwa dreiviertel so lang als das vorletzte. (43 a.) Der Außenast der hinteren Antennen ist nur sehr wenig länger als der Innenast. Die $\mathrm{M}$ a $\times$ i 11 e $\mathrm{n}(43 \mathrm{~b})$ tragen je 4 Borsten am 2. und 3. Innenlobus, 10 am Außenast, 7 am Innenlobus, 5 am 2. Basalgliede, 7 am Innenast. Der 1. Innenlobus ist nicht so verlängert als bei einigen andern Arten und etwa nur doppelt so lang als breit. Seine Hakenborsten sind doppelt so lang als der Lobus. Das 2. Basalglied und der Innenast sind stark verlängert.

An den vorderen Maxillipeden sind die Haken der letzten beiden Loben wenig gekrümmt, lang und dünn und beinahe gleich. Die Sinnesanhänge sind meist pinselförmig. Das 2. Basalglied der hinteren Maxillipeden ist etwas länger als das 1. und der Innenast etwas mehr als halb so lang wie das 2. Basalglied. Das 2. Glied des Innenastes ist nicht so lang wie bei andern Arten, noch nicht zweimal so lang als das proximale. Die Borsten des Innenastes sind zart und nackt. Am Basalglied findet sich ein großer pinselförmiger Anhang.

Das 1. FuBparr hat auf

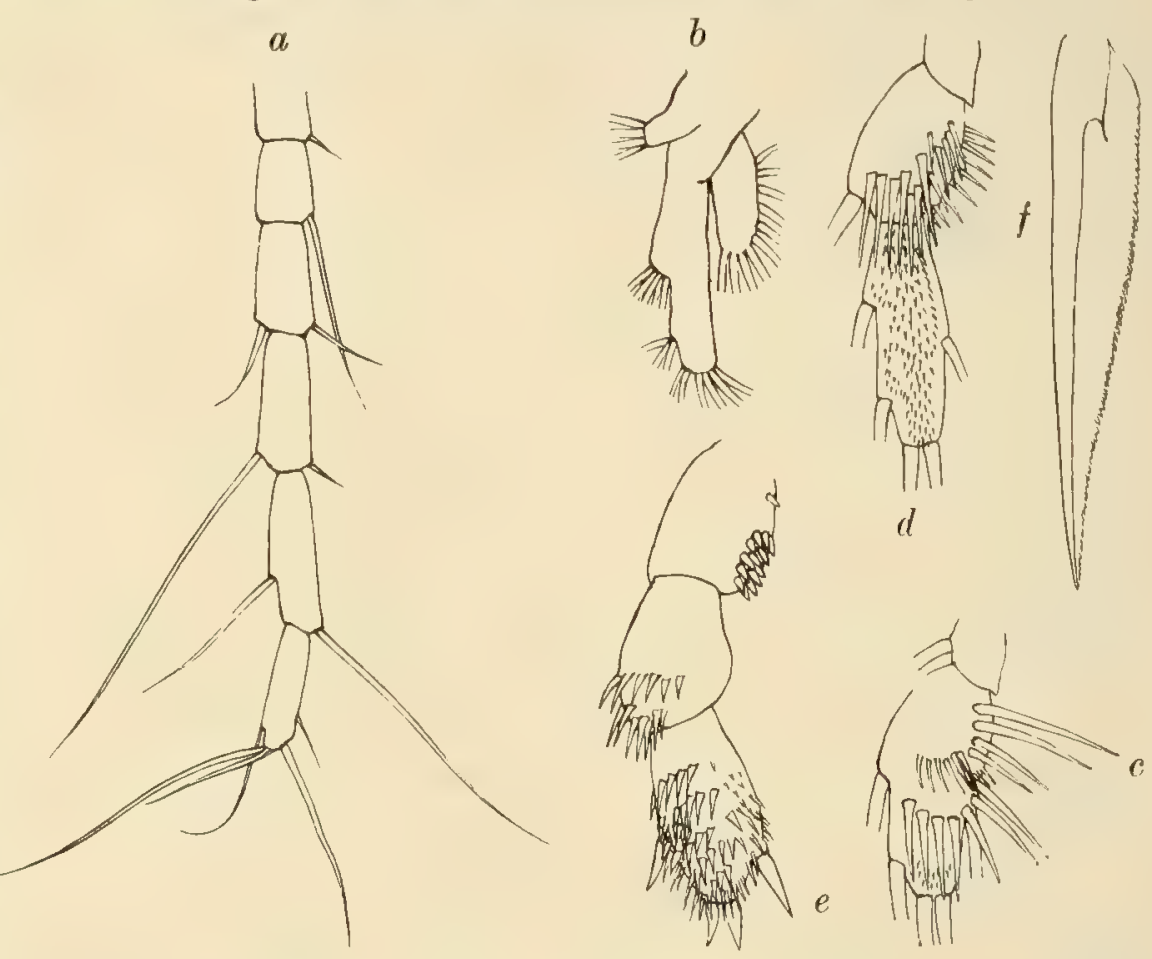

Textfig. 43. Xanthocalanus tenuiserratus.

Ende der vorderen Antennen. $b$ Maxille. c 2. Fuß, Innenast. $d$ 3. Fuß, Innenast. e 5. Fuß. $f$ Endsäge eines Fußes.

der Fläche der Äste keine Dornen. Das 2. Paar (43 c) hat auf dem 2. Glied des Innenasts einen Kranz von 7 starken Dornen und eine proximale Reihe von 11 Dornen, und auf dem 3. Glied eine kleinere Reihe, aber keine Dornen auf den Gliedern des Außenastes. Das 3. Paar (43 d) hat eine diagonale Reihe von Dornen auf dem 2. Gliede des Innenastes, und der ganze Rand. desselben ist mit weitstehenden Dornen besetzt. Das 3. Glied des Außenastes ist mit feinen Dörnchen besetzt. Die Endsägen haben breite Basis und eine einfache Reihe von kleinen Zähnchen am Rande. (43 f.)

Das 5. Fußpaar ist einfach und jederseits dreigliedrig. (43 e.) Die beiden proximalen Glieder sind gleich lang; das distale Glied ist um ein Drittel länger und nicht ganz doppelt so lang als breit. Das Proximalglied trägt einen Haufen plumper, kleiner Dornen am Innenrande, das 2. Segment hat zwei Gruppen feiner Dornen und das 3. viele feine Dornen dicht gedrängt am distalen Teile der Fläche und am Außenrande. Zwei Enddornen von fast gleicher Länge, ein innerer Randdorn länger als diese und ein äußerer Randdorn sind vorhanden, von denen der letztere dem Innenranddorn nicht gegenïber, sondern etwas proximal davon entspringt. 
Die Bedornung der Füße, besonders die des 3. und 5. Paares, scheint diese Art von der andern zu unterscheiden. Sie wurde am 5. August 1902 bei der Gauss-Station gefunden.

111. Xanthocalanus gracilis n. sp. (Tafel XXXI, Fig. 1 u. 2.)

ㅇ $3,2 \mathrm{~mm}$, davon Cephalothorax $2,5 \mathrm{~mm}$, Abdomen $0,7 \mathrm{~mm}$. Der $\mathrm{K}$ opf ist gleichmäßig gerundet, ohne Crista und mit zweispitzigem Rostrum. Die beiden ersten Thoraxsegmente sind gesondert, aber die Trennungslinie ist nur schwach; die letzten beiden Thorakalsegmente sind deutlich getrennt und die Hinterränder des letzten Segments dreieckig, zugespitzt und verlängert. Das A b d o m e n ist nur etwa ein viertel so lang als der Vorderkörper, das Genitalsegment so groß wie die beiden folgenden Segmente, und die Furkaläste sind doppelt so lang als breit und nicht divergierend. (XXXI. 1.)

Die vorderen A $n$ t e $n \mathrm{n}$ e $\mathrm{n}$ haben 24 Glieder, von denen das 8. und 9. verschmolzen sind. Sie reichen nur bis zum Ende des Cephalothorax; das letzte ist halb so lang als das 24. Glied. Das 2. Basalglied und der Innenast der $\mathrm{M}$ a $\mathrm{x}$ i 11 e $\mathrm{n}$ sind verlängert und von Borsten sind am 2. Basalgliede 5, am Innenast 7, am Außenast 10 vorhanden. Der 1 . Innenlobus ist doppelt so lang wie breit, seine Borsten sind doppelt so lang als der Lobus, und die mittlere Borste ist bei weitem am längsten.

Die vorderen M a xillipeden haben auf dem 4. und 5. Lobus zwei starke Haken, welche fast gerade und mit kräftigen Zähnen bewehrt sind. Die des proximalen Hakens sind etwas feiner als die andern. Die Sinnesanhänge sind Pinsel mit großen Endknospen. Die hinteren Maxillipeden haben ungefähr gleich lange Basalglieder und einen Innenast von zwei Dritteln der Länge. Das 2. Glied des letzteren ist das längste. Die Borsten des Innenastes sind einfach und nicht so lang wie das 2. Basalglied.

Das 1. Fu ß p a a r hat keine Dornen auf den Flächen seiner Äste. Das 2. Paar trägt nur auf dem Innenaste Dornen, und zwar finden sich zwei Reihen auf der Fläche des 2. Gliedes, ein distaler Kranz von 9 und ein proximaler Haufen von 6 sehr großen Dornen. Beim 3. Fußpaare finden sich auf der Fläche des Außenastes, keine Dornen, aber nahe am Außenrande des 2. Gliedes vom Innenast ist eine Gruppe von solchen vorhanden, und beim 3. Glied erstreckt sich eine Dornenreihe quer über die Fläche. Die Endsägen des 2. und 3. Fußpaares (das 4. Paar ist abgebrochen und fehlt) haben eine einfache Zahnreihe und sind ebensolang wie das 3. Glied des Außenastes.

Das 5. Fußpaar ist einfach und besteht jederseits aus 3 Gliedern. (XXXI. 2.) Das 1. und 2. Glied sind gleich lang, das 3. nur zwei drittel so lang als die andern. Das proximale Glied ist breiter als lang, der Innenrand tritt stark konvex hervor, mit einer Reihe feiner Dornen am konvexen Rande. Auf der Fläche sind nur wenige vorhanden. Das mittlere Glied ist ziemlich kugelig, mit wenigen feinen Dornen am Innenrand und einer Anzahl solcher am distalen und äußeren Teil seiner Fläche. Das 3. Glied ist etwas konisch und weder so lang noch so breit als die übrigen Glieder. Es trägt zwei kurze Randdornen, einen äußeren und einen inneren Randdorn und 2 Enddornen, von denen der äußere viel kleiner als der innere ist. Alle diese Dornen sind verhältnismäßig kurz und an beiden Rändern mit kurzen Borsten besetzt. Der distale Teil der Fläche ist von feinen Dornen bedeckt. 
Das 5. Fußpaar ist ähnlich dem von Xanthocalanus borealis, aber die Dornen der Basalglieder sind verschieden und die Enddornen weniger lang. Die letzten beiden Thorakalsegmente sind auch deutlich getrennt, aber die Bestachelung der Füße scheint verschieden zu sein. Unsere Art scheint sich etwas mehr Xanthocalanus pinguis FARRAN zu nähern, doch sind mehrere Differenzpunkte vorhanden. Endlich ist das Tier viel zierlicher als alle übrigen gebaut, welche plump sind. Es wurde bei der Gauss-Station am 20. Oktober 1902 aus $385 \mathrm{~m}$ Tiefe erhalten.

\section{Onchocalanus SARS.}

Kopf entweder ohne Crista oder gelegentlich wie bei Onchocalanus cristatus, subcristatus und similis (EsterLY), mit mehr oder weniger deutlichem Helmfortsatz oder einer Crista versehen. Die Endanhänge der vorderen Maxillipeden sind pinselförmig, und die Hakenborste des letzten Lobus ist stark, mit breiter Basis aufsitzend, gekrümmt und sichelförmig. Die Borsten der hinteren Maxillipeden haben normale Form. Das 5. Fußpaar ist mehr oder weniger mit verhältnismäßig langen Dornen bedeckt; dazu kommen noch die Randdornen des letzten Segments. Die von mir früher als Xanthocalanus magnus und Xanthocalanus antarcticus (National Antarctic Exp. 1908), Xanthocalanus cristatus (Journ. Mar. Biol. Ass. 1904) und Xanthocalanus subcristatus (Plankton Studies 1906) beschriebenen Arten müssen, wie ich glaube, zu dieser Gattung gestellt werden. Xanthocalanus similis EsTERLY scheint auch hierher zu gehören, wegen des starken Hakens an den vorderen Maxillipeden und der Charaktere des 5. Fußpaares.

112. Onchocalanus magnus Wolfenden. (Tafel XXXI, Fig. 3-5.)

Im Bericht über die Copepoden der National Antarctic Expedition vol. IV, 1908 beschrieb ich diese Art unter dem Namen Xanthocalanus magnus und gab auch eine Abbildung derselben. Ich bemerkte dort in betreff der Größe der Exemplare, daß einige nur 6,0 mm lang waren, während andere fast $8 \mathrm{~mm}$ oder noch etwas mehr an Länge erreichten. Dieses sehr große Variieren in der Größe ließ spezifische Unterschiede vermuten, doch scheinen die Differenzen im allgemeinen Bau kaum genügend dieses zu bestätigen. Nach weiterer genauer Untersuchung der verschiedenen Exemplare bin ich nun zu dem Schlusse gekommen, daß, da kaum ein so ungewöhnlicher Grad von Variation angenommen werden kann, es besser ist, die größeren und die kleineren Individuen als besondere Arten zu betrachten. Die früher als Xanthocalanus magnus beschriebene Art ist in völlig erwachsenen Exemplaren konstant von gleicher Größe, während die Größe erwachsener Weibchen von der größeren Art, von $8 \mathrm{~mm}$ und darüber, gleichfalls konstant ist. Die Gestalt des Kopfes ist etwas verschieden, und bei der größeren Form hat das letzte Thoraxsegment kleine Endspitzen, während bei der kleineren Form die Hinterecken gerundet sind. Außerdem scheinen Differenzen im Bau des 5. Fußpaares aufzutreten.

q 6,0 $\mathrm{mm}$ lang, davon Cephalothorax 4,6 mm, Abdomen 1,4 mm. Der K opf (XXXI. 4) ist gerundet, ohne Crista, vorn nicht sehr vortretend, und das Rostrum besteht aus einer Chitinplatte, mit zwei fast geraden, kurzen Ästen. Die Hinterränder des letzten Thoraxsegments sind seitlich in dreieckige Flügel verlängert, aber nicht mit Spitzen am Ende versehen. Der Kopf und das erste Thorakalsegment sowie die beiden letzten Segmente sind mehr oder weniger vollständig ab- 
gesondert. Das Ge n it a ls e g m e n t ist nicht ganz so lang wie die beiden nächsten Segmente, das Analsegment sehr kurz und die Furka etwas länger als breit. (XXXI. 3.)

Die vorderen A nte n n e n sind 24gliedrig, da das 8. und 9. Glied verschmolzen, das 24. und 25. aber getrennt sind. Sie reichen bis zum Ende des Genitalsegments oder etwas darüber hinaus. Bei den hinteren Antennen ist der Innenast etwas länger als der Außenast. Der 1. Innenlobus der M a xill e n ist stark verlängert, mehr als zweimal so lang als breit. Am Außenaste finden sich 10, am Innenaste 10, am 2. Basalgliede 5, am 3. Innenlobus 4 und an dem 1. Außenlobus anscheinend nur 7 Borsten.

Die vorderen M a xillipeden sind im Proximalteil am Außenrande stark konkav, im distalen Teile stark konvex. Der letzte Lobus trägt einen sehr langen, sichelförmig gekrümmten Haken, der an der Basis sehr breit, an der Spitze dünn ist. Alle übrigen Borsten sind schwach. Die Sinnesanhänge des Innenastes sind fast alle pinselförmig. Das 2. Basalglied der hinteren Maxillipeden ist verhältnismäßig lang, neunmal so lang als breit und fast doppelt so lang als das 1 . Beim Innenast ist das 2. Glied groß, fast zweimal so lang als das 1. Die Endborsten sind schwach, nicht länger als das 2. Basalglied, und am 1. Basalglied ist ein pinselförmiger Sinnesanhang vorhanden.

Das 1. F u B p a a r trägt eine Reihe sehr langer Dornen im distalen Teil der Fläche des 1. Basalgliedes und einen Kranz starker Dornen auf dem Gliede des Innenastes.

Beim 2. Fußpaare sind die beiden Glieder des Innenastes mit Kränzen langer Dornen besetzt, und auf der Oberfläche des 2. und 3. Gliedes vom Außenaste finden sich Vertikalreihen von Dornen. Am Außenrande des 1. Basalgliedes ragt ein Dorn hervor, und die distale Fläche des 2. Basalgliedes trägt eine Gruppe starker Dornen. Die Endsäge hat grobe Zähne in einfacher Reihe.

Beim 4. Fußpaare sind alle Glieder beider Äste, ausgenommen das 1. Glied des Innenastes, an der Oberfläche mit Bündeln langer, dünner Dornen bedeckt, ebenso wie die Außenränder der Glieder des Außenastes und die Außenränder der Basalglieder. Die Außenranddornen der Glieder sind an den Rändern gesägt und die Endsäge hat eine einfache Reihe grober Zähne.

Das 5. Fußpaar (XXXI.5) ist einfach und seine 3 Glieder sind dicht mit kurzen, feinen Dornen bekleidet. Am Ende des Gliedes finden sich 2 Randdornen, welche sehr kurz und unbedeutend und unter den dichten, feinen Dornen kaum sichtbar sind, und 2 kurze Enddornen. Keiner von diesen ist eingelenkt. Die Längen der 3 Glieder verhalten sich wie 14 (distal) : $20: 20$, und das letzte Glied ist beinahe zweimal so lang als breit.

Fundort: Antarktisches Meer.

113. Onchocalanus frigidus n. sp.

o 8-8,8 $\mathrm{mm}$. Der K o p f ist vorn verschmälert, doch ohne Spur einer Crista; nach vorn ist er beträchtlich verlängert und nicht so gleichmäßig gerundet wie bei der letzten Art. Die ersten beiden und die letzten beiden Thorakalsegmente sind mehr oder weniger gesondert, da die Trennungslinie dorsal deutlich, aber nicht so klar an den Seiten zu erkennen ist. Der Hinterrand des letzten Segments hat kleine Endspitzen. Die A b d o min a ls e g m e n t e haben dorsal einen kammartigen Saum und sind ventral stark behaart. Das Genitalsegment tritt ventral stark hervor und die Geschlechtsöffnung ist durch zwei zugespitzte Chitinplatten geschützt. 
Die vorderen Antennen reichen etwa bis zur Mitte des Genitalsegments; der Außenast der hinteren Antennen ist länger als der Innenast; die M a x i ll e n und Mandibeln gleichen denen der vorigen Art. Die vorderen M a xilli pe d en sind mit ähnlichem, starkem, gekrümmten Haken wie bei Onchocalanus magnus versehen, nur ist hier der Haken fein gezähnt und die proximalen Borsten sind Stachelborsten, während sie bei Onchocalanus magnus fast nackt sind. Das 1. und 2. Basalglied und der Innenast der hinteren Maxillipeden verhalten sich wie $10: 18: 9$. Der Innenast ist daher etwa halb so lang als das 2. Basalglied. Dieses ist nur drei- bis viermal so lang als breit; das 2. Glied des Außenastes ist nicht doppelt so lang als das 1.; die Borsten des Innenastes sind kurz und kräftig, nicht länger als das 2. Basalglied. Dieses Glied trägt einen pinselförmigen Sinnesanhang. Die hinteren Maxillipeden sind daher von denen bei Onchocalanus magnus verschieden.

Das 1. bis 4. $\mathrm{FuBp}$ a a $\mathrm{r}$ ist wie bei Onchocalanus magnus gebaut, aber die Kränze starker Dornen fehlen auf der Oberfläche der Außenäste, während diese mit feinen Dörnchen bedeckt sind. Ein Haufe großer Dornen findet sich auf der Oberfläche der Basalglieder des 2. Paares, dagegen fehlen solche beim 4. Fußpaar, auch sind diese Partien viel weniger dornig als bei Onchocalanus magnus. Besonders deutlich zeigt das 4. Paar diesen Charakter. Die Endsägen haben eine doppelte Zahnreihe.

Das 5. Fußpar ist klein, nicht so lang wie die beiden Basalglieder des 4. zusammen. Das erste Glied ist kürzer als das 2. und dieses kürzer als das 3. Die Längen derselben verhalten sich wie $18: 21: 32$. Das letzte Glied ist viermal so lang als breit, nicht so breit als die beiden proximalen Glieder, es verschmälert sich nach dem Ende zu und trägt zwei kurze Enddornen und zwei seitliche Dornen, die sich nicht gegenüberstehen, da der innere Randdorn mehr dem Ende des Gliedes genähert ist. Die beiden proximalen Glieder tragen Bündel feiner, langer Dornen auf der Oberfläche und den Rändern, aber keineswegs so dicht wie bei Onchocalanus magnus. Die beiden seitlichen Dornen und einer der Enddornen scheinen eingelenkt zu sein. Eine Anzahl von Randdornen in der Nähe des Endes vom letzten Glied ist bei dem vorliegenden Exemplar ebenso wie einer der Enddornen völlig abgebrochen. Der Enddorn scheint jedoch kurz gewesen zu sein. Fundort: Antarktisches Meer.

\section{Onchocalanus cristatus WOLFENDEN.}

Xanthocalanus cristatus Wolfenden. Journ. Marine Biol. Association 1904.

Onchocalanus trigoniceps Sars. Bull. Mus. Ocean. 1905. Mars.

Diese Art wurde von mir zuerst von der Westküste Irlands beschrieben, dann von FARRAN auch dort angetroffen, endlich von $\mathrm{SARS}_{\mathrm{A}}$ in den Sammlungen des Fürsten von Monaco beobachtet und 1905 in Bull. Mus. Oceanogr. als Onchocalanus trigoniceps beschrieben. Obwohl Farran zugab, daß die Arten identisch seien, und SARS in Bull. Inst. oceanogr. 1907 den Namen Onchocalanus cristatus angenommen hat, sind doch gewisse Differenzen vorhanden, welche mich hindern, die Identität beider Arten anzuerkennen. Onchocalanus cristatus war nur $5 \mathrm{~mm}$, Onchocalanus trigoniceps $7 \mathrm{~mm}$ lang. Der Kopf ist bei Onchocalanus cristatus deutlich vom 1. Thoraxsegment gesondert, „,complètement soudée" bei Onchocalanus trigoniceps; das Abdomen war sehr kurz bei Onchocalanus cristatus ,,nur ein viertel so lang als der Rumpf", bei Onchocalanus trigoniceps ,pas en longeur un tiers de la division antérieure“. Sonst stimmt die Beschreibung von SARS gut mit der von Onchocalanus cristatus überein. 
Die Antennen reichen bis zum Ende der Furka, das 24. und 25. Segment sind getrennt; die Äste der hinteren Antennen sind gleich lang. Die M a xille n sind etwas anders wie bei andern Arten gestaltet, da das 2. Basalglied verlängert ist und am Außenaste 10, am Innenaste 10 und am 2. Basalgliede 5 Borsten auftreten. Die vorderen M a xilli p e d e $\mathrm{n}$ tragen am letzten Lobus einen langen, krummen Haken mit dicker Basis, und die Anhänge am Innenaste sind pinselförmig.

Die hinteren Maxillipeden haben ein langes 2. Basalglied, das siebenmal so lang als breit ist, und die Endborsten sind lang und dünn. Das 2. Glied des Innenastes ist groß.

Das 1. F u B pa a r hat dicht behaartes 2. Basalglied und Reihen langer Dornen auf dem 1. Gliede des Innenastes, ferner einige lange Dornen auf dem 2. und 3. Gliede des Außenastes. Das 2. Fußpaar trägt auf der Oberfläche des 2. Basalgliedes Dornen, dazu eine Reihe auf dem 1. Gliede des Außenastes; am 2. Gliede sind viele auf der Oberfläche und eine Reihe am Außenrande vorhanden, und das 3. Glied erscheint mit kurzen Dornen dicht besetzt. Die Dornen des Innenastes sind viel länger, von ihnen findet sich eine Reihe auf dem 2. und drei Reihen auf dem 3. Gliede. Das 2. Basalglied des 4. Fußpaares ist dicht bedornt, und alle Glieder des Innenastes sind dicht mit langen, dünnen Dornen bekleidet; die Glieder des Außenastes sind mit kurzen Oberflächendornen bedeckt. Der Außenrand des 1. Gliedes vom Außenast ist dicht gezähnt. Die Endsägen der Füße haben breite Basis und sind im proximalen Teile doppelt gezähnt.

Das 5. Fußpaar ist einfach und dreigliedrig; das 1. Glied ist so breit als lang, das 2 . halb so lang als breit und das 3. mehr als doppelt so lang als das 1. Alle diese Glieder sind dicht bedornt, besonders das 3., und mit 2 Enddornen, einem kürzeren äußeren, längeren inneren, sowie mit einem 3. Dorn am Außenrand etwas distal von der Mitte versehen.

Charakteristisch für diese Art ist das Auftreten einer deutlichen Crista, die sowohl seitlich als auch bei der Ansicht vom Rücken sichtbar ist. Onchocalanus trigoniceps wird beschrieben als ,n'ayant la face dorsale que très peu voutée".

Obwohl die Sammlung der Deutschen Südpolar-Expedition kein Exemplar von Onchocalanus cristatus enthielt, schien es mir doch zweckmäßig, diese Art hier zum Vergleich mit Onchocalanus trigoniceps und der folgenden Art Onchocalanus subcristatus genauer als es ursprünglich geschah zu beschreiben.

\section{Onchocalanus subcristatus n. sp. (Tafel XXXI, Fig. 6-8.)}

o 7,0 mm, wovon auf den Cephalothorax 5,85 mm, auf das Abdomen 1,15 mm kommen. Der Kopf ist bei Dorsalansicht stark dreieckig, hat eine kurze Crista und ein zweispitziges Rostrum mit dicker Basis. (XXXI. 7.) Das 1. und 2. Segment sind deutlich getrennt, die beiden letzten Segmente dagegen zeigen keine Spur einer Trennungslinie. Die Hinterecken sind spitz, treten aber nicht so lang wie bei Onchocalanus cristatus hervor. Das Genitalsegment ist um ein Drittel länger als das folgende, die Furkaläste sind sehr kurz, und die Abdominalglieder alle reichlich an den Seiten behaart. (XXXI. 6.)

Die M u n orga n e gleichen denen von Onchocalanus cristatus, aber das 1. Basalglied des vorderen Maxillipeds ist proximal tiefer gespalten, der Haken des letzten Lobus ist sehr stark und krumm und die Anhänge sind pinselförmig. Das 2. Basalglied der hinteren Maxillipeden ist länger 
als bei Onchocalanus cristatus, nämlich über doppelt so lang als das 1. Basalglied; der Innenast ist nur halb so lang.

Die $\mathrm{S}$ c hw i m m $\mathrm{m} \ddot{B}$ e gleichen denen von Onchocalanus cristatus; das 1. Paar ist jedoch weniger bedornt; die Außenränder des 1. und 2. Gliedes sind behaart und auf dem 1. Gliede des Innenastes erscheint ein Kranz starker Dornen. Beim 2. Paare sind die Dornen auf dem 2. Gliede des Innenastes recht spärlich. Beim 4. Paare finden sich am äußeren und inneren Rande des 1. Basalgliedes und am Innenrande des 2. Basale steife, borstenartige Dornen, und ebensolche treten auf am Außen- und Innenrande des 1. Gliedes von Außenast und Innenast und am Innenrande des 2. Gliedes vom Innenast und des 2. und 3. Gliedes vom Außenast.

Einige feine, steife Dornen finden sich auf der Oberfläche des 1. und 2. Gliedes vom Außenaste, dem 3. Gliede des Innenastes und des Außenastes aber fehlen Dornen.

Das 5. F u B p a a r (XXXI. 8) ist jederseits dreigliedrig; das distale Glied ist am längsten und wird nach dem Ende zu schmäler. Das Basalglied trägt steife Dornen am Innenrande. Das mittlere Glied hat ähnliche Dornen am Innen- und Außenrand, und auch auf dem Distalgliede treten solche an Oberfläche und Rändern auf. Die Spitze desselben ist mit 2 kleinen Dornen bewehrt, von denen der äußere nur halb so lang als der innere ist.

Von Onchocalanus cristatus unterscheidet sich unsere Art durch die kürzeren vorderen Antennen, welche nicht das Genitalsegment überragen, durch den etwas größeren Außenast der hinteren Antennen, welcher etwas länger als der Innenast ist, durch das viel längere 2. Basalglied der hinteren Maxillipeden mit schwachen Endborsten und besonders durch die erheblich geringere Bedornung der Füße. Das 5. Fußpaar hat nur 2 kleine Endzähnchen, statt 3 bei Onchocalanus cristatus. Onchocalanus subcristatus ist außerdem viel größer.

Gefunden wurde die Art am 12. November 1901 (3000 m) im südatlantischen Ozean.

\section{Talacalanus ${ }^{1}$ ) Wolfenden.}

Diese Gattung wurde für den von mir früher als Xanthocalanus calaminus beschriebenen Copepoden geschaffen, bei welchem die Haken der vorderen Maxillipeden von ganz besonderem Charakter sind. Sie sind nicht klauenförmig wie bei der vorigen Gattung, sondern stark und gezähnt; die Endborsten der hinteren Maxillipeden sind breit und einem Federkiel ähnlich, und die gewöhnlichen Hakenborsten der Maxillen werden durch ungewöhnliche Fortsätze vertreten, die blattartig sind und gesägte Ränder haben. Die Gliederung der Füße verhält sich wie bei Xanthocalanus, auch sind Dornen auf der Oberfläche vorhanden. Die Endsägen und die Randdornen sind jedoch sehr kurz. Das 5. Fußpaar ist wie bei Xanthocalanus und Onchocalanus gebaut.

\section{Talacalanus calaminus Wolfenden. (Tafel XXXI, Fig. 9-12, Textfig. 44 a u. b.)}

o 5,5 mm lang, der Cephalothorax 4 1/2 mal so lang als das Abdomen. Der Kopf ist gleichmäßig gerundet, ohne Spur einer Crista, mit kleinem, zweispitzigem Rostrum, dessen Spitzen etwas divergieren. Kopf und 1. Segment sowie die beiden letzten Segmente sind gesondert; das hintere Segment ist seitlich in starke, dreieckige Zipfel ausgezogen. Das A b dom e $\mathbf{n}$ ist sehr

1) Talaus, einer der Argonauten. 
kurz, das Genitalsegment augenscheinlich noch nicht völlig entwickelt wie beim erwachsenen Tier, und die Furkaläste sind ebensobreit als lang und nur so lang als das sehr kurze Analsegment. Die vorderen $\mathrm{A} n \mathrm{t}$ e $\mathrm{n} \mathrm{n}$ e $\mathrm{n}$ sind abgebrochen.

Die hinteren Antennen haben gleich lange Äste, ohne Borsten an den Basalgliedern. Die Äste der M a n d ibeln sind fast von gleicher Länge, die Kauplatte ist viermal so lang als breit und trägt sehr kleine Zähne. Die M a x ille n haben einen sehr kleinen 1. Außenlobus mit 7 Borsten, (XXXI.9) der Außenast hat 10 Borsten wie bei Xanthocalanus; der 1. Innenlobus ist verlängert und seine Borsten sind in merkwürdiger Weise zu langen blattartigen Fortsätzen mit gezähnten Rändern umgebildet.

Die vorderen Maxilli peden (XXXI. 11) haben am 4. Lobus einen sehr kräftigen, gekrümmten Haken, der an der Basis sehr breit und mit ununterbrochener Reihe vorspringender Zähne

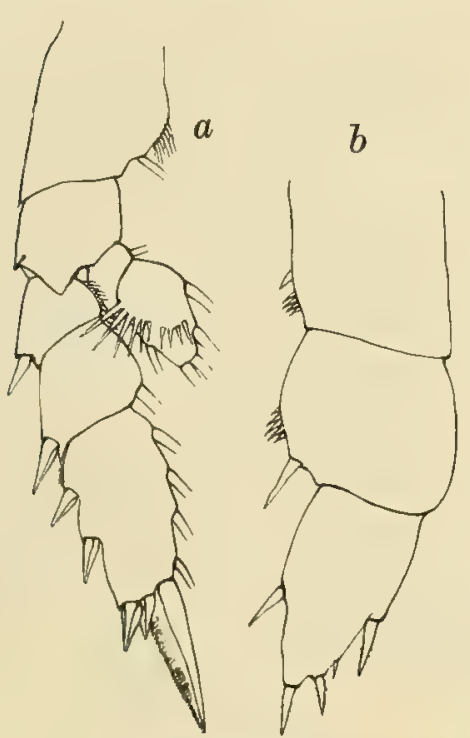

Textfig. 44 .

Talacalanus calaminus.

a 2. Fuß. b 5. Fuß. bewaffnet ist. Proximal von ihm findet sich auf demselben Lobus eine kräftige, aber kürzere und dünnere gerade Borste, welche auf der ganzen Länge der Innenseite mit dichtstehenden steifen Borsten besetzt ist. Am 5. Lobus sind 2 kräftige Haken vorhanden, die jedenfalls beträchtliche Iänge hatten. Leider waren sie bei beiden Maxillipeden kurz abgebrochen. Der proximale Haken ist augenscheinlich mit feinen, sehr dichtstehenden Zähnen bewehrt. Die Borsten des proximalen Lobus zeigen nichts Besonderes. Die Sinnesanhänge bestehen aus 7 Pinseln, von denen 3 sehr dick sind, aber ihre Endknöpfe sind kleiner als bei den bekannten Arten von Onchocalanus. Der am meisten distal auftretende Anhang ist wurmförmig

Die hinteren Maxillipeden sind kräftig gebaut. (XXXI. 10.) Das 1. Basalglied ist größer als das 2. und der Innenast länger als dieses. Die Borsten des Innenastes haben meist eigenartigen Charakter. Das 1. und 2. Glied haben je 3, das 3. und 4. Glied je 2 und das 5. Glied 2 sehr lange und 2 kurze Borsten. Jede dieser Borsten ist in der distalen Hälfte verbreitert, und wie bei einem Federkiel hat die breite Chitinlamelle auf der Innenseite einen fein gesägten Rand. (XXXI. 12.)

Das 1. Fu B p a a r hat eingliedrigen Innenast und dreigliedrigen Außenast. Die beiden proximalen Randdornen desselben sind sehr klein.

Das 2. Fußpaar hat zweigliedrigen Innenast. (44 a.) Auf dem 2. Gliede desselben findet sich ein Kranz starker Dornen, dagegen fehlen solche auf der Oberfläche des Außenastes. Die Endsäge ist kurz, hat sehr breite Basis und trägt eine einfache Reihe feiner Zähne. Das 3. und das 4. Fußpaar sind leider vollständig abgebrochen.

Das 5. Fußpaar ist sehr klein und nach demselben Typus wie bei Xanthocalanus gebaut. (44b.) Am gemeinsamen Basale sitzen jederseits 3 Glieder von ungefähr gleicher Länge, von denen die beiden proximalen etwas konisch und viel breiter als das Distalglied sind. An der Spitze findet sich ein kurzer Dorn und am Außenrande zwei kleine Dornen. Ferner ist ein kurzer Dorn am Innenrande des 2. Gliedes am distalen Ende vorhanden und 3 oder 4 kleine Zähne proximal davon, und endlich treten noch einige ähnliche Zähne am Rande des 1. Gliedes auf. 
Obgleich das Exemplar noch nicht völlig erwachsen und stark verletzt ist, Iassen sich doch die eigentümlichen Verhältnisse der beiden Maxillipeden und Maxillen erkennen, welche diese Art scharf von jeder andern Art der Gattungen Xantho- und Onchocalanus unterscheiden, obwohl sie unzweifelhaft mit diesen verwandt ist. Das einzige mir vorliegende Exemplar wurde von mir in der Bai von Biscaya gefunden. Obwohl die Art in den Sammlungen des „Gauss" nicht vertreten ist, halte ich es doch für zweckmäßig, sie hier zu beschreiben, um die Beziehungen der verschiedenen nahe verwandten Formen dieser Gruppe besser aufzuklären.

\section{Cornucalanus Wolfenden.}

Da es wahrscheinlich ist, daß J. C. Thомpson dasselbe Tier Scolecithrix chelifer nannte, welches ich später als Cornucalanus simplex beschrieb (Plankton Studies 1905), muß dieser Name in Cornucalanus chelifer TномеsоN umgeändert werden. Außer ihm ist in der Sammlung des ",Gauss"6 noch eine zweite Art dieser Gattung vorhanden, Cornucalanus magnus, welche besonders in den Charakteren des Kopfes verschieden ist. Die Gattung ist charakterisiert durch die eigentümliche Umbildung der Hakenborste der vorderen Maxillipeden in eine Klaue, die stärker ist und schärfer gebogen als bei Onchocalanus SARS und durch die beiden starken, Klauen ähnlichen Haken der hinteren Maxillipeden. Der Kopf von Cornucalanus magnus trägt ein kurzes, dorsales Horn, welches jedoch bei Cornucalanus chelifer fehlt.

Pearson (Fisheries Ireland Sei. Invest. 1906) stellte diese Art zur Gattung Onchocalanus Sars, doch ist das zweifellos ein Irrtum, weil in der letzteren Gattung die Borsten der hinteren Maxillipeden nicht in so eigenartiger Weise verändert sind.

11\%. Cornucalanus magnus n. sp. (Tafel XXXII, Fig. 1-10, Textfig. 45.)

o $7,80-8 \mathrm{~mm}$. Der $\mathrm{Kopf}$ ist ziemlich viereckig und trägt ein kurzes Dorsalhorn, das gerade nach vorn gerichtet ist. Zwischen ihm und dem starken und kurzen, zweispitzigen Rostrum ist das Profil des Kopfes fast gerade. (XXXII. 7.) Der Kopf und das 1. Segment sind vollständig abgeteilt, die beiden letzten Thoraxsegmente dagegen verschmolzen und das letzte Segment ist am Hinterrand in dreieckige Zipfel mit kleinen Spitzen verlängert. (XXXII. 1.)

Das A b d o m e $\mathrm{n}$ ist kurz, nicht ein drittel so lang als der Cephalothorax; das Genitalsegment ist so lang wie die beiden folgenden Segmente, und die Furkaläste, etwas breiter als lang, sind sehr kurz und divergieren. (XXXII. 9.)

Die vorderen $\mathrm{Antennen}$ bestehen aus 24 Gliedern und sind nicht so lang wie der Cephalothorax; das 8. und 9. Glied sind verschmolzen, das 21. ist kurz, das 22. länger, das 23. noch länger als dieses und das 24. Glied, welches deutlich abgetrennt ist, sehr klein. Der Innenast der hinteren Antennen ist dreiviertel so lang als der Außenast. Die Maxillen gleichen denen von Xanthocalanus; das 2. Basale hat 5, der Innenast 9, der Außenast 10 Borsten. Der 1. Innenlobus ist doppelt so lang als breit, und seine Hakenborsten sind doppelt so lang als der Lobus.

Die vorderen M a X ill i p e d e n (XXXII.2) tragen auf ihrem letzten Lobus einen eigentümlich geformten Haken. Er ist sehr stark, dick an der Basis, stark gekrümmt, zugespitzt und distal am Außenrande gesägt. Proximal von der Mitte des Innenrandes finden sich 3 Borsten, von denen 
2 sehr kurz sind, während die 3. so lang wie die Klaue ist. Der 4. Lobus hat auch einen starken Haken, der nicht annähernd so kräftig als der vorher erwähnte, etwas gekrümmt und am Rande gezähnt ist. Die Borsten des proximalen Lobus sind schwach; die 7 Sinnesanhänge sind kleine Pinsel, mit Ausnahme von einem, der schlank wurmförmig ist.

Das 1. Basalglied der hinteren M a xilli pe d e n (XXXII. 3) ist etwas länger als das 2., der kurze Innenast hat nur 4 Glieder, und das 2. Glied ist bei weitem das längste. Borsten finden sich spärlich am 1. Basalglied, und am Rande ist ein Sinnespinsel vorhanden. Das Distalende dieses Gliedes trägt einen sehr starken, kurzen Dorn. Der untere Innenrand des 2. Basalgliedes ist mit Zähnchen

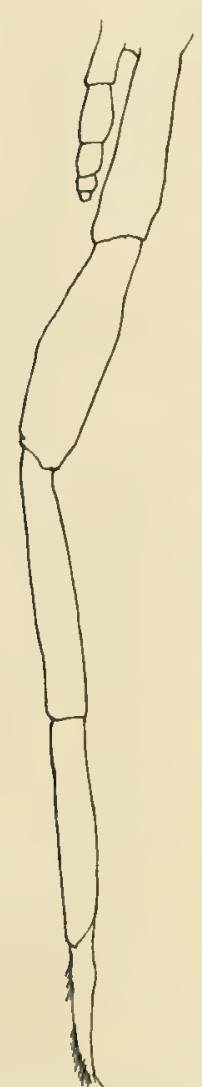

Textfig. 45. Cornucalanu magnus $\sigma^{7}$. 5. Fub. bewaffnet, von denen distal eine kleine Gruppe von 3 stärkeren Zähnen erscheint. Distal von diesen findet sich dann wenigstens ein starker konischer Zahn. Die 3 Randborsten sind sehr kurz und schwach und entspringen ein ganzes Stück distal von der Mitte. Das 1. Glied des Innenastes trägt 4 kurze, schlanke Borsten. Vom 2. Glied entspringt ein sehr kräftiger und dicker, gekrümmter Haken, der mit 9 bis 10 starken, weitstehenden Zähnen bewehrt ist. Auch 2 sehr kurze und schwache Borsten sind dort vorhanden. Das 3. Glied trägt einen ähnlichen starken Haken und eine lange, dünne Borste; das 4. Glied, welches sehr klein ist, hat 2 dünne Borsten von mittlerer Länge, und das letzte ist sehr unbedeutend und mit 4 äußerst kurzen und schwachen Borsten versehen.

Der eingliedrige Innenast des $1 . \mathrm{F} \mathrm{u} \mathrm{B}$ p a a res (XXXII. 4) ist breit und trägt auf der Oberfläche eine einzelne Reihe feiner Borsten; das 3. Glied des Außenastes hat keine Oberflächendornen, und die Dornen am Außenrande sind lang und dünn.

Beim 2. Paare (XXXII. 5) hat jedes der beiden Glieder des Innenastes Kränze großer Dornen an der Oberfläche, und die beiden distalen Glieder des Außenastes tragen auf der Oberfläche viele kleine Dörnchen. Die Glieder des Außenastes sind sehr kurz und breit, das 3. ist drei viertel so lang als breit, und die Endsäge um ein viertel ihrer Länge länger als das letzte Glied. Die Randdornen sind kräftig und die Endsägen am proximalen Ende doppelt gezähnt.

Beim 4. Fußpaar (XXXII. 6) ist das 3. Glied des Außenastes verhältnismäßig länger, und die Oberfläche des letzten Gliedes vom Außenast sowohl wie vom Innenast ist mit feinen Dörnchen bedeckt, und bei beiden Ästen findet sich auf der Oberfläche des 2. Gliedes ein Büschel feiner Dornen.

Das 5. Fußpaar ist sehr klein, nicht länger als das 1. Basalglied des 4. Paares. Jederseits sind 3 Glieder vorhanden, die ziemlich undeutlich abgeteilt sind. Die beiden proximalen Glieder tragen weder Dornen noch. Haare, und am letzten Gliede finden sich nur wenige Dornen distal am Außenrand und ein sehr kurzer, nicht eingelenkter Enddorn. (XXXII. 8.)

Das ơ ist kleiner, etwa $6 \mathrm{~mm}$ lang, hat gerundeten $\mathrm{K}$ opf, ohne Dorsaldorn. (XXXII. 10.) Der Thorax ist wie beim $q$ gebaut. Das $\mathrm{Abd}$ o m e $\mathrm{n}$ besteht aus 5 Segmenten. Die vorderen A n te n n e n haben 23 Glieder, von denen die basalen dick und reichlich mit Aesthetasken versehen sind. Die M u ndorg a n e sind etwas rückgebildet, und den Maxillipeden fehlen die Klauen des of. Die Kauplatte der Mandibeln ist gut ausgebildet, aber bei den Maxillen ist die Zahl der Borsten reduziert. 
Die $F \ddot{~ u ̈ ß e ~ s i n d ~ w i e ~ b e i m ~ o ~ g e b i l d e t, ~ a b e r ~ d a s ~ 4 . ~ F u ß p a a r ~ i s t ~ b e i ~ d e m ~ e i n z i g e n ~ v o r l i e g e n d e n ~}$ Exemplar unsymmetrisch, da die eine Seite des Außenastes nur 2 Glieder ohne Endsägen, aber 5 Enddornen und Randdornen hat. Das scheint mir jedoch eine ungewöhnliche Mißbildung zu sein. Der rechte 5. Fuß ist lang, mit 2 Basalgliedern, die fast dreimal so lang als breit sind und von denen das 2. etwas länger als das 1. ist. Von den 3 folgenden Gliedern ist das 1. viel länger als das 2. und das 3. ist sehr kurz, wenig mehr als halb so lang als das mittlere. Mit Ausnahme weniger kurzer Haare distal am Innenrande des letzten Gliedes ist die ganze Extremität nackt. Der linke Fuß ist sehr klein, nicht so lang als das 1. Basalglied der andern Seite. Es besteht aus 5 nackten Gliedern, von denen die 3 distalen sehr klein sind. (Textfig. 45.)

Fundort: 9. X. 03. 3000. 12. XI. 01. 3000. Atlantischer Ozean.

118. Cornucalanus ehelifer J. C. Thompsos. (Tafel XXXIII, Fig. 1 u. 2.)

Ein Exemplar dieser Art wurde am 26. September 1903 im Atlantischen Ozean unter dem Äquator, ein anderes bei der Gauss - Station am 10. März 1902 in einem Vertikalfang aus $3000 \mathrm{~m}$ Tiefe angetroffen.

Das o ist $6,8 \mathrm{~mm}$ groß und unterscheidet sich von der vorigen Art wesentlich in der Gestalt des Kopfes. Der Kopf ist vorn gleichmäßig gerundet und zeigt keine Spur eines Stirnhornes. (XXXIII. 1.) Das letzte Thorakalsegment ist wie bei der vorigen Art seitlich in Flügel verlängert und das Abdomen ist noch nicht ein drittel so lang als der Cephalothorax. Mundorgane und Füße entsprechen genau denen bei Cornucalanus magnus mit der Ausnahme, daß die letzteren vielleicht etwas weniger dornig sind. Das 5. Fußpaar (XXXIII. 2) nur ist ein wenig abweichend gebildet, indem das Endglied länger als das mittlere und das ebensolange proximale Glied ist; das distale Glied ist $2 \frac{1}{2} \mathrm{mal}$ so lang als breit, mit kurzem Enddorn versehen und am Ende mehr als bei Cornucalanus magnus gerundet. Die Spitze und die angrenzenden Ränder sind dicht mit feinen Dornen bekleidet, von denen einige auch auf der Oberfläche des Gliedes erscheinen.

Dieses ist meiner Ansicht nach die von J. C. Tномpson als Scolecithrix chelifer beschriebene Art. Die Originalbeschreibung derselben ist äußerst ungenau, aber ein Kopfhorn ist nicht erwähnt.

\section{Cephalophanes SARs.}

Diese Gattung wurde von SARs kurz beschrieben (Bull. Inst. oceanogr. April 1907) als Xanthocalanus ähnlich, aber zarter, mit einem Stirnende, das an eine Mönchskappe erinnert und 2 voluminöse Organe trägt, welche wie Leuchtorgane aussehen. Die Extremitäten sind wie bei Xanthocalanus gebildet.

Nur eine Art, Cephalophanes refulgens SARs, war bekannt, bei welcher Kopf und 1. Thorakalsegment gesondert sind, die Rostralfilamente als sehr fein beschrieben werden, das letzte Thorakalsegment mit seitlichen Spitzen endigt, das Abdomen sehr kurz ist, die vorderen Antennen den Körper überragen und der Außenast der hinteren Antennen länger als der Innenast ist. Das 5. Fußpaar ist sehr klein, dreigliedrig und mit 4 kurzen Enddornen versehen. Diese Art, welche $4,20 \mathrm{~mm}$ lang ist, wurde von FARRAN in der Nähe der irischen Westküste angetroffen. Eine zweite Art dieser Gattung ist durch ein Exemplar in den Sammlungen der Deutschen Südpolar-Expedition vertreten. 
119. Cephalophanes frigidus $\mathrm{n}$. sp. (Textfig. $46 \mathrm{a}-\mathrm{c}$.)

o $5 \mathrm{~mm}$ lang, davon Cephalothorax 4,1 mm, Abdomen 0,9 mm.

Der $\mathrm{Kopf}$ ist durchscheinend, die Chitinhülle dünn und bei Dorsalansicht breit dreieckig. Bei seitlicher Ansicht erscheint er vorn verlängert und stumpf kegelförmig. Weder von einem Rostrum noch von Rostralfilamenten ist eine Spur vorhanden. Die ,,voluminösen Leucht-

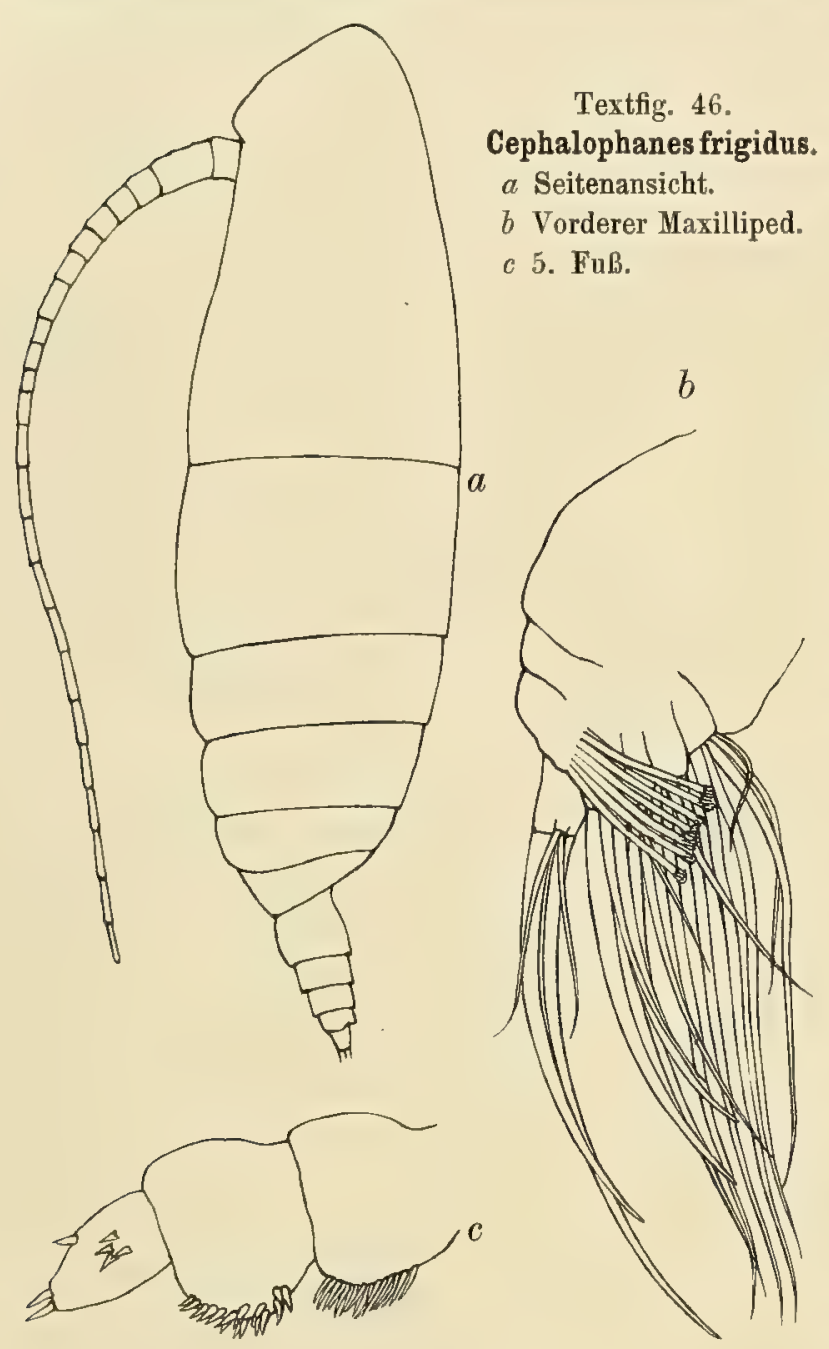
organe", welche SARs erwähnt, scheinen zu fehlẹn, aber es ist ein dunkler Kreis am Kopfe vorhanden, welcher eine frühere, seit der Konservierung verschwundene, Pigmentanhäufung andeuten könnte.

Gliederung zwischen Kopf und 1. Segment ist nicht erkennbar. Die letzten beiden Thorakalsegmente sind gesondert, das letzte Segment ist klein und seitlich in kurze, dreieckige Flügel mit stumpfen Spitzen ausgezogen. (46 a.) Das A b $\mathrm{d}$ o $\mathrm{m}$ e $\mathrm{n}$ ist kurz, nicht ein viertel so lang als der Cephalothorax, das Genitalsegment länger als die drei folgenden mit der Furka zusammen. Das Analsegment ist sehr kurz, die Furkaläste sind sehr klein, obwohl größer als das Analsegment und ebensobreit als lang. Sie stehen weit voneinander ab. Das Genitalsegment tritt ventral stark hervor.

Die vorderen A $\mathrm{n} \mathrm{t}$ e $\mathrm{n} \mathrm{n}$ e $\mathrm{n}$ reichen bis zum Ende des Genitalsegments und bestehen aus 24 Gliedern, von denen das 8. und 9. verschmolzen sind. Dieses kombinierte Glied ist das längste von allen, doppelt so lang als das nächste. Das 21. Glied ist etwas kürzer als das 20. und 22., und das letzte Glied drei viertel so lang als das vorletzte.

Der Innenast der hinteren Antennen ist drei viertel so lang als der Außenast. Die Äste der Mandibeln sind fast gleich; die Kauplatte ist schmal, länglich und mit einem starken äußeren und 6 ebensogroßen inneren Zähnen versehen.

Die M a xille n haben am Außenaste 10 Borsten, 5 am 2. Basalgliede, 7 am Innenaste, 3 am 2. Innenlobus, 2 am 3. Innenlobus und 9 am 1. Außenlobus. Der 1. Innenlobus ist ziemlich viereckig, und die Hakenborsten sind länger als der Lobus. Die vorderen M a xillipeden (46 b) haben etwa gleichlange und gleichdicke Hakenborsten, keine starken Haken. Sinnesanhänge sind am Innenast in Gestalt von Pinseln vorhanden. Das 2. Basalglied der hinteren Maxillipeden ist etwas länger als das 1. und ungefähr viermal so lang als breit; der Innenast hat nur die halbe Länge vom 2. Basalgliede und trägt nur schwache Borsten. 
Das 1. Fußpa ar hat eingliedrigen Innenast und dreigliedrigen Außenast. Oberflächendornen fehlen den Gliedern desselben. Das 2. Paar hat zweigliedrigen Innenast; das 2. Glied desselben trägt zwei Kränze von Oberflächendornen, einen oberen von 6 und einen unteren von 4 Dornen, von denen die proximalen sehr groß, die distalen erheblich kleiner sind. Die Endsäge ist so lang wie das letzte Glied und am Rande mit sehr dichtstehenden feinen Zähnen besetzt.

Beim 3. Fußpaare sind Reihen von Dornen auf dem 2. Gliede des Innenastes wie beim 2. Paar, aber sonst keine Dornen auf den andern Gliedern vorhanden. Die Endsäge ist so lang wie das letzte Glied des Außenastes und fein gezähnt. Das 4. Paar trägt auf dem 2. Gliede des Innenastes eine Längsreihe von 12 kleinen Dornen, und auch hier fehlen Dornen auf den übrigen Gliedern beider Äste. Die Endsäge ist etwas länger als das Endglied. Das 3. und 4. Paar besonders sind verlängert, da das letzte Glied des Außenastes dreimal so lang als breit ist. Die Glieder des Innenastes sind distal am Außenrand in starke Spitzen verlängert, und die Randdornen sind verhältnismäßig klein.

Das 5. Fußpaar besteht aus gemeinsamem Basalglied und dreigliedrigem Aste jederseits. (46c.) Das 1. Glied ist ziemlich kugelig und am Innenrande mit feinen, dichtstehenden Dornen besetzt. Das 2. Glied ist etwas kürzer als das 1., breiter als lang, im oberen Teile der Innenseite stark konvex und mit kurzen, dichtstehenden Dornen bewaffnet. Das letzte Glied ist schmal, nur halb so lang als das 2. und beinahe zweimal so lang wie breit. Es trägt zwei kleine Enddornen dicht nebeneinander und einen kurzen Dorn am Außenrande.

Die Beschreibung, welche G. O.SARs von Cephalophanes refulgens im Bull. Inst. Oceanogr. April 1907 veröffentlichte, ist nicht sehr ausführlich. FARRAN gibt 3 Abbildungen von demselben Tier in Fisheries Ireland Sci. Invest. 1906 II, jedoch ohne Beschreibung desselben. Während die oben beschriebene Art von der Beschreibung bei SARS in der Länge der vorderen Antennen und möglicherweise auch durch die hinteren Antennen abzuweichen scheint, unterscheidet sie sich nach Farran's Abbildung durch die Längenverhältnisse der Glieder des 5. Fußpaares und durch die Abwesenheit aller inneren Randdornen, welche bedingt, daß Cephalophanes refulgens 4 Enddornen anstatt 3 bei Cephalophanes frigidus hat. Allerdings fehlen diesem Exemplare die auffallenden „Leuchtorgane“, welche SARs erwähnt, aber die Gestalt des Kopfes, die Eigentümlichkeiten des Körpers und der allgemeine Bau des 5. Fußpaares dürften schon die Zuteilung desselben zur Gattung Cephalophanes genügend rechtfertigen.

Da Cephalophanes frigidus am 6. März 1903 (1200 m) noch im Scholleneise nordwestlich von der Gauss-Station gefunden wurde, scheint die Gattung eine weite Verbreitung zu haben, von der Westküste Irlands (FArRan) durch den Atlantischen Ozean (SARs) bis zum südlichen Polarmeere verbreitet zu sein.

\section{Phaenna Claus.}

\section{Phaenna spinifera Craus.}

In den Fängen aus dem tropischen Atlantischen Ozean vom 19. Oktober 1901 (500 m), 3. September $1903(400 \mathrm{~m})$ und 26. September $1903(3000 \mathrm{~m})$, ferner aus dem Indischen Ozean vom 25. Mai 1903 (400 m) wurde diese Art von der Deutschen Südpolar-Expedition in wenigen Exemplaren erbeutet. Sie scheint eine weite Verbreitung zu haben, da sie von Cleve unter den süd- 
afrikanischen Copepoden aus Ostafrika, ferner von mir früher schon aus dem Indischen Ozean (Fauna of the Maldive and Laccadive Archipelago, GARDINER) erwähnt wurde.

\section{Microcalanus SARs.}

\section{Microcalanus pusillus SARS.}

Unter dem Namen Pseudocalanus pygmaeus erwähnte SARs einen kleinen Calaniden aus dem Nordpolarmeere (Norweg. North Polar Exp. 1893-1896), für welchen er später eine neue Gattung Microcalanus aufstellte (Crust. of Norway IV). In dem letzteren Werke hat er eine nahe verwandte Art, Microcalanus pusillus, beschrieben, welche nur in geringfügigen Punkten von der ersteren abzuweichen scheint (Größe 0,70 mm, kürzere Antennen, weniger schlanke Schwimmfüße mit verbreitertem Enddorn).

GIESBRECHT beschreibt (Belgica Report) Pseudocalanus (= Microcalanus) pygmaeus, indem er auf die geringere Größe der südlichen Art, die kürzeren Antennen und die größeren Endsägen vom 2. bis 4. Fußpaare hinweist. Es scheint daher wohl sicher, daß die von GIE SBRECHT beschriebene Art nicht mit der polaren Form Microcalanus pygmaeus, sondern mit der von SARS als Microcalanus pusillus beschriebenen nordischen Form identisch ist. Die vom „Gauss“ gesammelten antarktischen Exemplare stimmen völlig mit der Beschreibung von Microcalanus pusillus überein, und GIESBRECHTS Annahme, daß die antarktische Art von der Nordpolarform verschieden sei, ist vollkommen korrekt. Microcalanus pusillus kann nicht als bipolare Form betrachtet werden, wie ich ursprünglich glaubte (Nat. Antarct. Exp. 1908 p. 7), sondern scheint mit der andern Art identisch zu sein, welche sich bis Bergen nach Norden ausbreitet. Sie erschien nicht selten bei der Gauss-Station. Die dort gesammelten Exemplare waren nur 0,6 mm lang, und die vorderen Antennen derselben überragten nicht das Ende des Genitalsegments.

\section{Metridia Boeck.}

\section{Metridia gerlachei GlesBrecht.}

Diese Art welche von GiesвRechт ausführlich beschrieben und abgebildet wurde, war eine der häufigsten in den Sammlungen der „Belgica“. Dasselbe war bei der englischen Südpolar-Expedition der Fall, und in gleicher Weise war kaum eine Planktonprobe von der Gauss-Station vorhanden, welche nicht diese sehr charakteristische antarktische Art enthielt. Sie wurde in allen Entwicklungsstadien gefunden, und es ist kaum zweifelhaft, daß im Antarktischen Meere das Entwicklungszentrum dieser besonderen Form liegt, von welchem aus sie sich in gewissen Grenzen über die südlichen Meere verbreitet. Außer in zahlreichen Fängen von der Gauss-Station während des Jahres 1902 und im Scholleneise bis zum 23. März 1903 wurde sie auch noch im Indischen Ozean am 13. Mai 1903 $(3000 \mathrm{~m}$ ) erbeutet. Metridia lucens, welche CLEve (a. a. O.) als häufig im Süden und Westen der Kapkolonie erwähnt, gehört ohne Zweifel zu dieser Art, da die echte Metridia lucens nicht so weit nach Süden geht und eine typische nördliche Form ist, zusammen mit Metridia longa, welche jedoch eine mehr beschränkte Verbreitung im Norden hat.

\section{Metridia curticauda Giesbrecht.}

Ursprünglich von Giesbrecht aus dem Pazifischen Ozean beschrieben, wurde diese Art nun auch im Atlantischen Ozean und Antarktischen Eismeere nachgewiesen. SARs erwähnt sie in dem 
Verzeichnis der vom Fürsten von Monaco gesammelten Arten, und vom „Gauss" wurde sie am 5. November 1901 (1000 m), 12. und 16. November $1901(3000 \mathrm{~m})$, 4. September $1903(2000 \mathrm{~m})$, 13. Oktober $1903(3000 \mathrm{~m})$ im Atlantischen Ozean erbeutet. Merkwürdigerweise fand sie sich in zwei Planktonfängen aus dem Antarktischen Eismeere vom 6. März 1903 (1200 m) und 10. März 1903 $(3000 \mathrm{~m})$. Eine sehr sorgfältige Untersuchung der Tiere ließ keinen Zweifel darüber, daß diese mit GiesbrechT's pazifischer Art identisch sind.

\section{Metridia normani Giesbrecht.}

Sie wurde nur am 9. Oktober $1903(3000 \mathrm{~m})$ westlich der Kapverdischen Inseln beobachtet und scheint überall spärlich vorzukommen. Nach Norden erstreckt sich ihr Verbreitungsgebiet bis zur Westküste Irlands und dem Faroer-Kanal (Giesbrecht, Wolfenden).

\section{Metridia princeps Giesbrecht. (Tafel XXXX, Fig. 8-13.)}

Seit der Entdeckung dieser Art sind zwei andere nahe verwandte Arten dieser Gattung beschrieben worden, nämlich Metridia macrura G. O. SARs (Bull. Mus. Oceanogr. 1905) und Metridia ignota Esterly (Univ. California Zool. vol. III 1906). Die Merkmale der letzteren, durch welche sie sich hauptsächlich von Metridia princeps unterscheidet, scheinen wesentlich in den Verhältnissen der Abdominalsegmente und in der verschiedenen Größe von 5,8 mm zu bestehen. Metridia macrura hat nach der Beschreibung von SARs die bedeutende Größe von 10,5 mm, Cephalothorax und Abdomen sind ungefähr gleich lang, die langen Furkaläste sind etwa so lang wie die beiden vorhergehenden Segmente, die vorderen Antennen sind schlanker, und die proximalen Glieder derselben zeigen nur schwache Spuren der starken Zähne, welche bei Metridia princeps vorhanden sind. Die Beschreibung von SARS ist sehr kurz und nicht mit Abbildungen versehen.

Bei den zahlreichen Exemplaren der Gauss-Sammlung von Metridia princeps finde ich erhebliches Varïeren in den Längenverhältnissen der Segmente und der Furka sowie in der Größe und den Verhältnissen der Länge von Vorderkörper und Abdomen. Es scheint nicht von der Lokalität abhängig zu sein, und so komme ich zu dem Schlusse, daß es unmöglich ist, auf Grund der von SARS angegebenen Merkmale Metridia macrura von Metridia princeps zu unterscheiden, da unter den größeren Exemplaren auch solche vorkommen, bei denen Vorderkörper und Abdomen gleich lang sind, während in anderer Hinsicht die Diagnose von SARS nicht zutreffend ist.

Wie ich früher schon andeutete, ist es schwierig, sich der Meinung, daß Metridia macrura und Metridia princeps identisch seien, zu erwehren (Nat. Antarct. Exp. vol. IV, 1908), und weitere eingehende Untersuchung bestätigt diese Ansicht. Allerdings muß zugegeben werden, daß diese Art einen unter Copepoden ungewöhnlichen Grad von Variabilität zeigt, und daher wäre es möglich, auf Grund geringer Unterschiede ein halbes Dutzend verschiedene Arten zu unterscheiden. Da wir noch in keinem einzigen Falle den bei den Arten dieser Gruppe möglichen Grad der Variation kennen, scheint es mir richtig, für alle diese Formen den Namen Metridia princeps GIEsBREcht beizubehalten.

Die folgenden Angaben über die Maße von 6 verschiedenen Exemplaren werden den Grad der Variabilität erkennen lassen. 


\begin{tabular}{c|c|c|c|c|c|c|c|c}
\hline & Größe & \multicolumn{2}{|c|}{ Länge von } & $\begin{array}{c}\text { Länge des } \\
\text { Genitalsegments }\end{array}$ & $\begin{array}{c}\text { Länge des } \\
\text { nächsten } \\
\text { Segments }\end{array}$ & $\begin{array}{c}\text { Länge } \\
\text { des } \\
\text { Anal- } \\
\text { segments }\end{array}$ & $\begin{array}{c}\text { Länge } \\
\text { der } \\
\text { Furka }\end{array}$ & $\begin{array}{c}\text { Länge zur } \\
\text { Breite der } \\
\text { Furkaläste }\end{array}$ \\
\hline $\mathbf{1}$ & $\mathrm{mm}$ & $\mathrm{mm}$ & $\mathrm{mm}$ & $\mathrm{mm}$ & $\mathrm{mm}$ & $\mathrm{mm}$ & $\mathrm{mm}$ & \\
2 & 9,85 & 4,85 & 5,0 & 1,8 & 1,15 & 0,55 & 1,8 & $8: 1$ \\
3 & 9,5 & 5,0 & 4,5 & 1,6 & 1,1 & 0,50 & 1,5 & $9: 1$ \\
4 & 8,15 & 4,65 & 3,5 & 1,4 & 1,0 & 0,55 & 1,2 & $9: 1$ \\
5 & 8,45 & 4,6 & 3,85 & 1,4 & 0,8 & 0,50 & 1,15 & fast $8: 1$ \\
6 & 10,0 & 5,0 & 5,0 & 1,75 & 1,0 & 0,65 & 1,65 & über $8: 1$ \\
& 10,45 & 5,65 & 4,8 & 1,20 & 1,15 & 0,55 & 1,5 & $7,5: 1$
\end{tabular}

In allen Fällen überragen die Antennen die Furka mit etwa 4 Gliedern.

Die Endsägen der Füße sind kurz und beim 4. Fußpaare nicht mehr als ein viertel so lang wie das letzte Glied des Außenastes. Das 5. Fußpaar (XXXX.10) hat 4 Glieder, von denen das Distalglied viel kleiner als die übrigen ist. Das 1. Glied trägt ein Büschel von langen, steifen Haaren auf der Oberfläche, das 2. hat am äußeren Distalrand eine lange Fiederborste, das 3. am äußeren Distalrand einen kurzen, aufrechten Dorn und das Endglied einen kleinen Enddorn und 3 lange, feine Borsten. Das 5. Fußpaar ist bei verschiedenen Exemplaren verschieden gestaltet; so ist bei dem einen der Dorn des 3. Gliedes durch zwei kurze Dörnchen am rechten Fuß ersetzt, während dafür am linken $F u ß$ überhaupt keine Dornen vorhanden waren; bei einem andern trug das Endglied der einen Seite zwei Borsten, während drei ihnen gegenüber erschienen. Die Bedornung der Glieder der vorderen Antennen ist stets schwach. In keinem Falle wurde der Cephalothorax bis $1 \frac{1}{2} \mathrm{mal}$ so lang als das Abdomen gefunden (nur wenig länger oder gleich lang); das Genitalsegment, obwohl gewöhnlich etwas länger als die beiden nächsten Segmente, kann gelegentlich sogar etwas kürzer sein; die Furkaläste sind viel mehr als doppelt so lang als das Analsegment und acht bis neunmal so lang als breit. (XXXX. 8 u. 9.) In diesen vier Punkten ist der Befund abweichend von der Beschreibung GIESBRECHTs, welche allerdings nur nach einem einzigen Exemplar entworfen wurde. Während es möglich sein würde, einige dieser Tiere mit Metridia macrura von SARS zu identifizieren, wegen der Ubereinstimmung in den wenigen Punkten, welche er erwähnt, würden sie sich von andern, welche mehr mit GIESBREchTs Metridia princeps übereinstimmen, nicht trennen lassen. Ich ziehe daher vor, sie alle zu einer variablen Art, Metridia princeps, zu rechnen.

Das ơ war unbekannt, bis ich es im Bericht über die Copepoden der National Antarctic Expedition (vol. IV, 1908, p. 17) beschrieb. Es ist kleiner als das $\circ$, der linke Furkalast ist gewöhnlich etwas größer als der rechte und sechsmal so lang als breit. (XXXX. 11.) Die linke Antenne ist zu einem Greiforgan umgebildet, da sich vor den letzten 4 Gliedern ein Gelenk findet. Der rechte 5. Fuß (XXXX. 13) hat ein langes 1. Glied und ein kurzes 2. mit sehr starkem und gekrümmtem Haken auf breiter Basis; das 3. Glied ist fast doppelt so lang wie das 2., und das 4. erscheint als langer, einfacher, löffelförmiger Fortsatz, der doppelt so lang als das 3. Glied ist. Beim linken Fuß ist das 1. Glied sehr klein, das 2. etwa zweimal so lang, das 3. kurz und das 4. ein sehr langer, einfach gekrümmter, löffelförmiger Fortsatz. An den Innenrändern der Glieder finden sich feine Haare. Die Füße sind etwa gleich lang. 
Gefunden wurde die Art im südlichen Atlantischen Ozean am 5. November 1901 (1000 m), 12. und 16. November $1901(3000 \mathrm{~m})$, 22. August $1903(1500 \mathrm{~m})$, 26. September $1903(3000 \mathrm{~m})$, 9. und 13. Oktober 1903 (3000 m), zwischen Heard Eiland und der Eiskante am 10. Februar 1902 $(2700 \mathrm{~m})$, 13. Februar $1902(2000 \mathrm{~m})$ und im Scholleneise der Antarktis am 6. März 1903 (1200 m) und am 10. März $1903(3000 \mathrm{~m})$.

\section{Pleuromamma Giesbrecht.}

126. Pleuromamma abdominalis (Lиввоск).

Die Art hat allgemeine oder sehr weite Verbreitung. Sie wurde von der Deutschen SüdpolarExpedition gefunden am 11. Oktober 1901 (1200 m), 12. November 1901 $(3000 \mathrm{~m}), 22$. August 1903 (1500 bzw. $400 \mathrm{~m})$, 10. und 26. September 1903 $(3000 \mathrm{~m})$, 9. und 13. Oktober $1903(3000 \mathrm{~m})$, ferner auf der Fahrt von Natal bis Simonstown an der Oberfläche, aus welchem Gebiet sie auch CLEVE bereits erwähnt hat.

12\%. Pleuromamma gracilis Claus.

Sie fand sich am 19. Oktober 1901 (500 m), 8., 11., 13. und 25. August 1903 (400 m), 22. August 1903 (1500 m), 4. September 1903 (2000 m), 8. September $1903(400 \mathrm{~m})$, 26. September $1903(3000 \mathrm{~m})$, 13. Oktober $1903(3000 \mathrm{~m})$; außerdem im Kapgebiet, wo sie auch von Cleve beobachtet war.

128. Pleuromammá xiphias Giesbrecht

wurde vom „Gauss“" am 11. Oktober 1901 (1200 m), 19. Oktober 1901 (500 m), 22. Oktober 1901 (3000 m), 5. November 1901 (1000 m), 12. November 1901 $(3000 \mathrm{~m})$, ferner bei Simonstown am 18. Juli 1903 (20 m) und am 30. September $1903(1500 \mathrm{~m})$, am 9. und 20. Oktober 1903 (3000 m) und von CLeve an der südafrikanischen Küste gefunden.

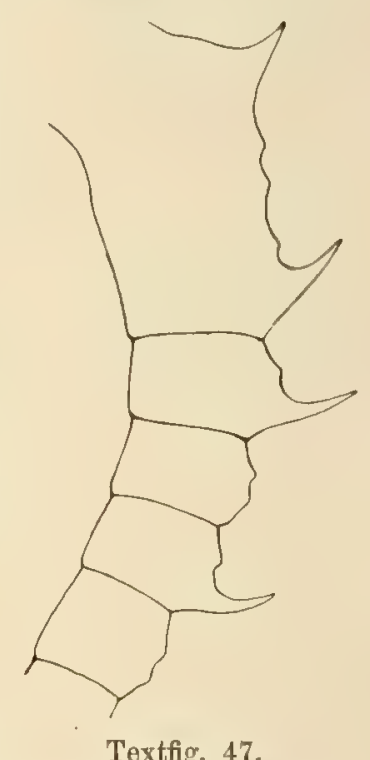

Pleuromamma quadrangulata.

Basalglieder der vorderen Antenne.

\section{Pleuromamma quadrangulata DAHL. (Textfig. 47.)}

Nur 2 q waren in den Fängen des „Gauss" aus dem Atlantischen Ozean vorhanden. Die auffallenden Haken der vorderen Antennen lassen die Art sofort von Pleuromamma abdominalis unterscheiden, welcher sie sonst ähnlich ist.

\section{Gaussia Wolfenden.}

Diese Gattung wurde für einen durch seine Größe und durch charakteristische Pigmentierung sehr auffallenden Copepoden geschaffen, welcher einige Merkmale von Pleuromamma, andere von Metridia hat. Ohne Zweifel gehört das ơ, welches T. SсотT im Golf von Guinea fand (Transact. Linn. Soc. Ser. 2 vol. 6) und als Pleuromamma princeps ausgab und dessen Name später von GIESBRECHT in Metridia scotti geändert wurde (Zool. Anz. vol. 20), derselben Art an. Das o war bis jetzt unbekannt. Nachdem es von mir 1905 (Plankton-Studien) beschrieben war, scheint es von Esterly im Pazifischen Ozean angetroffen und als Metridia atra beschrieben zu sein (Univ. California Zool. vol. 3 Nr. 5, Dezember 1906). Außer in den Sammlungen des „Gauss“ fand ich die 
Art dann auch in der Ausbeute von Professor Gardiner aus dem Indischen Ozean, und so ist es nicht zweifelhaft, daß sie eine weite Verbreitung hat. Die Tatsache, daß Sсотт das ô ursprünglich zu Pleuromamma stellte, während GIESBRECHT es zu Metridia rechnete, zeigt die Schwierigkeit, dieses Tier unterzubringen, welches tatsächlich Beziehungen zu jeder der beiden Gattungen zeigt, aber keiner von beiden zugeteilt werden kann.

Die Gattung Gaussia gleicht Pleuromamma in der Form des Kopfes und des Körpers, aber das letzte Thorakalsegment ist in scharfspitzige Flügel verlängert, das Abdomen sehr unsymmetrisch geschwollen, und ein Ocellus fehlt. Im Bau der Füße stimmt sie mit Metridia überein. Die Individuen sind groß und dunkel (blau bis schwarz) am ganzen Körper pigmentiert.

130. Gaussia scotti (Giesbrecht). (Tafel XXXIII, Fig. 3-12.)

ㅇ 10-10,5 mm lang. Cephalothorax 21/2mal so lang als das Ảbdomen. (XXXIII. 4.) Der $\mathrm{K}$ opf hat eine kurze Crista und ist in einen vorspringenden Stirnfortsatz verlängert, ähnlich wie bei Pleuromamma xiphias; auch ein kurżes Rostrum mit ein paar langen Fiederborsten ist vorhanden. (XXXIII.8.) Das letzte Thorakalsegment ist jederseits am vorderen Rande in stark gekrümmte, nach unten gerichtete und etwas divergierende Dornen verlängert. Das 1. Segment des verhältnismäßig kurzen $\mathrm{Abdomens}$ (XXXIII. 5) ist sehr breit, mehr als vier fünftel so breit als lang und ventral mit großer Genitalanschwellung versehen, welche regelmäßig, im Gegensatz zu der fast schwarzen Farbe des Körpers, tiefbraun gefärbt ist. Das 2. Segment ist sehr kurz; das Analsegment, zweimal so breit als lang und doppelt so lang als das vorhergehende, springt mit dorsolateralen Lappen über die Furkaläste vor. Diese sind ebenso breit wie lang, haben stark behaarte Ränder und 5 dicke, starke Schwanzborsten sowie eine innere zarte und kurze Schwanzborste.

Die längsten Schwanzborsten sind etwa drei viertel so lang wie das Abdomen. Am oberen Teile des Genitalsegmentes, dorsolateral, findet sich auf der rechten Seite ein kurzer, starker, gekrümmter Haken.

Die vordere Antenne, aus 23 Gliedern bestehend, überragt die Furka mit 4 1/2 Gliedern. Am 1. und 2. Gliede sind kurze, starke Dornen mit breiter Basis vorhanden, die nicht zurückgekrümmt sind, und am 4., 5. und 6. Gliede treten kleinere Dornen auf. Der Außenast der hinteren Antennen ist etwas länger als der Innenast; das Basalglied trägt 2 Borsten, und das 2. und 7. Glied des Außenastes sind ungefähr gleich. Der Innenast der Mandibeln ist viel länger als der Außenast, und das Basalglied hat 4 Randborsten.

Die Maxillen zeigen den Typus von Pleuromamma; der 2. Außenlobus scheint zu fehlen. Die Borsten des Außenastes bestehen aus 5 äußeren starken und 6 inneren, viel dünneren und schwächeren Borsten, der Innenast hat 16 und das 2. Basalglied 5 Borsten.

Bei den vorderen M a xilli p e d e n sind die Borsten der proximalen Loben mit weitstehenden Borsten (Stacheln) bewaffnet, der 4. und 5. Lobus tragen gerade und zarte Hörner, und die Borsten des Innenastes sind viel länger als die übrigen. Das 1. Basalglied der hinteren Maxillipeden ist etwas länger als das zweite und der Innenast länger als jedes der Basalglieder. Die Endborsten des Innenastes sind lang, dünn und am Außenrande gesägt aber sonst nicht bewaffnet. Die Borsten des ersten Basalglieds sind zahlreich und stachelartig. Das zweite Fußpaar 
(XXXIII. 9) trägt am ersten Glied des Innenastes ein paar Haken; am Fuß jederseits ist das Basalglied unmittelbar unter ihnen mit einem Büschel feiner Haare verziert. Die ersten Basalglieder tragen auf der Oberfläche Gruppen klenier Dornen.

Das dritte Fußpaar (XXXIII. 10) hat nicht den tiefen Sinus an der Basis des ersten äußeren Randdorns am Außenast, die Endsäge ist etwas länger als das letzte Glied des Außenastes, vollkommen gerade und hat ebenso wie die Randdornen sehr zart gekerbte Scheide.

Beim vierten Fußpaar sind die Endsägen äußerst kurz und nur $1 / 5$ so lang als das letzte Glied des Außenastes. (XXXIII. 11.)

Das 5. Fußpaar besteht jederseits aus 4 Gliedern, von denen die beiden Endglieder ungefähr gleich groß sind. Das letzte Glied trägt 3 Endborsten, von welchen die innerste am längsten, die mittlere nur halb so lang und die äußerste Borste sehr kurz ist. Abgesehen von den 3 Endborsten sind keine Haare oder Dornen auf Fläche und Rändern der Dornen vorhanden. (XXXIII. 12.)

Mit Ausnahme des vorderen Teiles des Kopfes ist der Rumpf der Tiere tief blauschwarz gefärbt. Alle Mundorgane und Füße, sogar die verschiedenen Borsten sind in gleicher Weise pigmentiert. Sorgfältige Untersuchung vieler Exemplare ergab das Fehlen eines Ocellus, der ja bei allen Arten von Pleuromamma vorhanden ist. Das Abdomen ist weniger als der Körper pigmentiert, von gelblichbrauner Farbe, mit tiefbrauner Genitalschwellung. Die vorderen Antennen sind auch völlig von schwarzbraunem Pigment gefärbt.

Das ${ }^{*}$ ist etwas kleiner als das $q$, und der Kopf ist vom 1. Thorakalsegment deutlich abgegliedert. (XXXIII.3.) Das letzte Thorakalsegment endigt mit stumpfen Fortsätzen, die Dornen des $q$ fehlen. Die rechte vordere A $\mathrm{n} \mathbf{t} \mathrm{e} \mathrm{n} \mathrm{n} \mathrm{e}$ ist zu einem Greiforgan entwickelt, mit 3 Gliedern jenseits des Gelenks. Sie besteht aus 20 Gliedern, von denen das 1. groß ist. Zwischen dem 12. und 13. ist eine Biegung, vom 13. bis 17. sind die Glieder etwas verbreitert; am 16. ist ein langer Dorn vorhanden, und am 17. tritt ein kürzerer Dorn parallel zum Rande auf. Zwischen dem 17. und 18. Gliede findet sich ein Gelenk; das 18. Glied trägt einen starken Dorn am distalen Ende, und zwei Dornen liegen proximal parallel zur Oberfläche. Die beiden letzten Glieder sind unvollkommen abgeteilt.

Das 5. F u B p a a r hat jederseits 3 Glieder. Beim rechten Fuß ist das 1 . größer als das 2., und das 3. erscheint als ziemlich unregelmäßig gestaltetes großes Glied mit Fortsätzen am proximalen Ende und an den Seiten, welche ihm ein mehr oder weniger pfeilförmiges Aussehen geben. Das Ende ist stumpf gerundet. Der innere Fortsatz ist an der Oberfläche und an seinen Rändern mit dichten, feinen Haaren bedeckt. Der linke Fuß hat ein großes 1., kleines 2. und großes, etwas blattartiges 3. Glied, das länger als breit ist. Dornen sind auf der Oberfläche und an den Rändern junger Exemplare nicht vorhanden, während bei älteren am mittleren Glied und auch beim letzten Glied des linken Fußes ein kleiner Dorn auftritt, beim rechten Fuße aber zwei kleine Dornen am Rande des letzten Gliedes erscheinen. (XXXIII. 6 u. 7.)

Der $\mathrm{K}$ opf ist wie beim o gebildet nur etwas schwächer; die Antennen tragen Dornen auf den proximalen Gliedern wie beim o. Die Mundorgane und Füße sind sehr ähnlich wie bei jenen gebaut, nur etwas reduziert. Die Füße des ô scheinen nicht ganz mit den Abbildungen von EsTERLY und T. SсотT übereinzustimmen.

Vom ,Gauss" wurde die Art am 22. Oktober 1901 (3000 m), 22. August 1903 (1500 m), 26. Sep. tember $1903(3000 \mathrm{~m}), 30$. September $1903(1500 \mathrm{~m})$ und 9. Oktober $1903(3000 \mathrm{~m})$ gefunden. 


\section{Chiridiella SARs.}

Von dieser sonderbaren Gattung, welche SARs 1907 (Bull. Inst. Oceanogr.) beschrieb, wurden zwei Arten erwähnt: Chiridiella macrodactyla und Chiridiella brachydactyla, doch sind von ihm keine Abbildungen veröffentlicht. FARRAN (a. a. O. 1908) bildete dann die erste Art nach Exemplaren von der Westküste Irlands ab. Unter dem Äquator, am 26. September 1903, wurden von der Deutschen Südpolar-Expedition im Atlantischen Ozean mehrere zu dieser Gattung gehörige Exemplare erbeutet, welche jedoch weder mit den Abbildungen FARRAN's noch mit der Beschreibung von SARS übereinstimmen, also eine neue Art repräsentieren.

131. Chiridiella atlantica n. sp. (Tafel XXXIV, Fig. 6-13.)

q 2,3 $\mathrm{mm}$ lang, davon Cephalothorax 1,95 mm, Abdomen 0,35 mm. Der $\mathrm{K}$ opf ist mit dem 1. Thoraxsegment nicht verschmolzen, und das letzte Segment tritt seitlich mit gerundeten Rändern etwas hervor. Der Körper ist breit, der Rücken gerundet, der Kopf vorn verschmälert, und das ganze Tier erscheint stark untersetzt. (XXXIV. 6.)

Das A b d o m e n ist sehr kurz, nur ein fünftel so lang als der Vorderkörper, das Genitalsegment groß, so lang als die drei folgenden Segmente und ventral angeschwollen. Die Furkaläste sind etwa so lang wie das Analsegment, etwas breiter als lang und tragen jederseits 4 Borsten, welche etwas länger als das Abdomen sind, außer einer kurzen, ventralen, akzessorischen Borste. Der Innenrand der Furkaläste ist dicht behaart.

Die vorderen A n te $\mathrm{n} n$ e $\mathrm{n}$ bestehen aus 24 Gliedern, da das 8. und 9. verschmolzen sind, aber nur ein kurzes Glied bilden. Das 3. bis 12. Glied erscheinen ziemlich zusammengedrängt, das 24. und 25. Glied sind getrennt, und das 21. bis 24. mit langen Borsten versehen.

Außenast und Innenast der hinteren Antennen sind ungefähr gleichlang; der Außenast besteht aus 7 Gliedern, von denen das 7. am längsten, länger als das 1. und 2. Glied zusammen ist; am 3. bis 6. Gliede treten sehr lange Borsten auf, und 3 ähnliche lange Borsten finden sich am Ende des letzten Gliedes. Der Innenast ist dick, sein 2. Glied nur um etwa ein fünftel länger als das 1., und dieses letztere sieben elftel so breit als lang; 13 Endborsten sind vorhanden, und das 2. Basalglied trägt 2 kurze Borsten.

Die Äste der Ma n dibeln (XXXIV. 7) sind ziemlich gleichlang; der Außenast ist etwas länger als der Innenast und viel dicker; der erstere hat deutlich 4 Glieder und sehr lange Borsten. Der Innenast ist nur zweigliedrig und mit sehr kurzen, schwachen Borsten versehen. Das 2. Basalglied von fast viereckiger Form entbehrt der Randborsten. Die Zahnplatte ist breit und mit starken Zähnen versehen: einem äußeren gekrünmten Zahne, der am größten ist, drei fast gleichgroßen starken, dreispitzigen Zähnen und einem konischen Innenzahne.

Die M a xillen (XXXIV. 8) tragen 6 Borsten auf dem 1. Außenlobus, haben einen kurzen Außenast mit 10 Borsten, 4 Borsten am vereinigten 2. Basale und Innenaste, 2 Borsten am 2. Innenlobus und 9 Haken am großen 2. Außenlobus.

Die vorderen Maxillipeden (XXXIV. 9) sind sehr eigentümlich gebildet und mit außerordentlichem Greifapparat ausgerüstet. Das 2. Basalglied ist verlängert, und seine proximalen Loben sind ganz unbedeutend; der 1. trägt zwei lange, der 2. eine lange und eine sehr kleine Borste, der 3., 4. und 5. Lobus sind zusammengedrängt, so daß der 4. in einer Ebene vor 
der 3. und der 5. Lobus hinter den beiden andern seinen Platz findet. Jeder ist basalwärts stark verlängert; der 3. trägt einen gekrümmten und der 5. einen kräftigeren, mehr gebogenen (sichelförmigen) Haken. Beide Haken sind weder mit Haaren noch mit Zähnen ausgestattet. Der 4. Lobus ist stark verlängert und trägt außen am Ende einen langen, gebogenen Haken mit dicker Basis, welcher auf der Unterseite mit dichtstehenden kleinen Zähnen besetzt ist. Proximal davon findet sich ein kurzer, dicker, kräftiger und gekrümmter Haken, der an der Außenfläche mit dichtstehenden, starken Zähnen bewaffnet ist. Ein Innenast fehlt, und statt seiner treten zwei winzige Borsten auf.

Die hinteren Maxillipeden (XXXIV, 10) haben ein verlängertes 1. Basalglied ohne Loben oder Borsten, ferner ein sehr langes 2. Basalglied, das im proximalen Teile stark verschmälert ist und distal von der Mitte nur zwei Borsten trägt. Der Innenast ist kurz, besteht deutlich aus 5 Gliedern und hat gehäufte, mäßig lange Borsten.

Das 1. Fußpa ar (XXXIV.11) hat nur eingliedrige Innen- und Außenäste. Am Außenaste findet sich nur ein Randdorn, und an der Stelle, wo der 2. Randdorn normal auftreten sollte, ein kleines Haarbüschel. Am Innenaste sind 5 und am Außenaste mit den Endborsten 4 Randborsten vorhanden.

Beim 2. Fußpaar (XXXIV. 12) ist der sehr kurze Innenast eingliedrig, der Außenast deutlich dreigliedrig; seine Glieder sind breit und haben 1, 1, 3 äußere Randdornen, 1, 1, 4 innere Randborsten und eine Endsäge mit sehr feinen und dichtstehenden Zähnen. Der kurze, eingliedrige Innenast ist mit 6 Randborsten versehen.

Das 3. (XXXIV. 13) und 4. Fußpaar haben dreigliedrige Äste; der Innenast ist sehr kurz und mit 1, 1,5 Randborsten, der Außenast mit 1, 1, 3 Außenranddornen und 1, 1,4 Innenrandborsten ausgestattet.

Die Innenäste aller Füße sind sehr kurz; das 3. Glied des Außenastes beim 2. bis 4. Fußpaar ist doppelt so lang als breit und viel länger als das 1. und 2. Glied zusammen.

Diese Art scheint in vielen Punkten, besonders in der Größe, den Charakteren der hinteren Antennen und vorderen Maxillipeden, ferner durch den Bau des 1. Fußpaares (vielleicht auch der andern Füße) von Chiridiella macrodactyla und Chiridiella brachydactyla, nach der Beschreibung von SARS und auch nach den Abbildungen, welche FARRAN von der ersteren Art gibt, erheblich abzuweichen.

Fundort: 26. IX. 1903. 300 m. Atl. Ozean unter dem Äquator.

\section{Euchaeta Philippr.}

Die charakteristischen Merkmale von Euchaeta barbata, welche BRADY zuerst im Challenger Report beschrieb, sind oft diskutiert worden, und ohne Zweifel haben seitdem verschiedene Autoren diesen Namen verschiedenen Arten von zweifelhafter Identität beigelegt. BRADY's Originalbeschreibung ist sehr kurz, und die einzigen Abbildungen, welche die Bestimmung unterstützen, sind Darstellungen des vorderen Maxillipeden und des 2. Fußes. Brady erwähnt bei Beschreibung der vorderen Maxillipeden: „, the longer setae ringed and densely pectinated, while the processes which bear the shorter (proximal) setae are clothed with fine hairs", zeichnet aber in der Abbildung nur die Endborste des Innenastes geringelt und gekämmt. Die Größe von BRADY's Exemplar betrug $8 \mathrm{~mm}$, und nichts wird über die Farbe gesagt.

Professor G. O. SARs beschreibt in den Crustacea of Norway (vol. IV, Copepoda) eine Euchaeta barbata, welche er mit erheblichen Bedenken auf BRADY's Art bezog. Ferner scheint es mir sehr 
zweifelhaft, ob die große Art aus dem Faroe-Kanal, welche ich früher als Euchaeta barbata erwähnte, mit Brady's Art übereinstimmt. Sicherlich ist der vordere Maxilliped, wie Brady ihn abbildet, völlig verschieden von dem jeder in den nordischen Meeren gefundenen Art. Meine nordischen Exemplare sind zweifellos mit der Euchaeta barbata von SARS identisch, aber bei der Nachuntersuchung derselben und dem Vergleiche vieler Exemplare aus dem Atlantischen Ozean komme ich zu dem Schlusse, daß Brady's Euchaeta barbata eine unbekannte Art bleiben muß, weil es unmöglich war, seine Beschreibung und Abbildung (besonders vom vorderen Maxillipeden) mit den Darstellungen der später als Euchaeta barbata bezeichneten Arten in Ubereinstimmung zu bringen. Die Abbildung des Abdomens in BraDy's Bericht könnte recht gut zu Euchaeta quadrata passen.

Ich glaube daher, daß die aus dem nördlichen Atlantischen Ozean als Euchaeta barbata von mir und von SARS beschriebene Art aller Wahrscheinlichkeit nach nicht das ursprünglich von BRADY beschriebene Tier repräsentiert und daß die Neubenennung dieser Art durch FARran (a. a. 0.) berechtigt ist, welcher ihr den Namen Euchaeta sarsi gab. Die von FARran angegebenen Punkte (hauptsächlich Größe und Farbe) widersprechen meiner Ansicht nach der Identifizierung mit Euchaeta barbata Brady, und der unter diesem Namen von T. ScotT (Entomostraca from the Gulf of Guinea, Transact. Linn. Soc. ser. 2 vol. 6) erwähnte Copepode gehört sicher nicht zu Brady's Art.

Die drei häufigen Arten von Euchaeta aus dem nördlichen kalten Gebiete sind: Euchaeta norwegica, Euchaeta sarsi (vel barbata) und Euchaeta glacialis. Sie haben charakteristische Merkmale in den Spitzen (Euchaeta norwegica) oder Haaren (Euchaeta sarsi und Euchaeta glacialis) des letzten Thorakalsegments, ferner in der Länge der Anhangsborsten (lang bei Euchaeta norwegica, sehr lang bei Euchaeta sarsi, kurz bei Euchaeta glacialis) und in der Form des Genitalsegments, die bei jeder der drei Arten verschieden ist. Die Farbe (tiefkarmin oder hellrot) welche bei allen 3 Arten charakteristisch ist, geht bei der Konservierung in Alkohol verloren ${ }^{1}$ ), und daher ist die Unterscheidung solcher Exemplare etwas schwieriger.

Die drei antarktischen Arten Euchaeta antarctica, Euchaeta austrina und Euchaeta similis lassen sich ebenfalls leicht unterscheiden. Dagegen bieten die im Zwischengebiet vorkommenden großen Euchaeta-Arten manche Schwierigkeiten bei der Bestimmung, besonders da die Konservierungsmethoden sie gewöhnlich der sehr wichtigen Farbenunterschiede beraubt haben.

$\mathrm{Zu}$ den 12 Arten, welche von GIESBREchT und SchmeIl im „Tierreich" erwähnt wurden, sind einige neue hinzugekommen, nämlich:

Euchaeta antarctica Giesbrecht,

Euchaeta austrina GIESBRECHT,

Euchaeta similis WOLFENDEN,

Euchaeta incisa G. O. SARS,

Euchaeta scotti FARRAN,

Euchaeta quadrata FARRAN,

Euchaeta rubicunda FARRAN,

Euchaeta bisinuata G. O. SARS,

Euchaeta tumidula G. O. SARS,

Euchaeta gracilis G. O. SARS,

Euchaeta affinis CLEVE,

Euchaeta californica EsterLy,

Euchaeta propinqua EsTERLY,

Euchaeta temis EsTERLY,

Euchaeta pubera G. O. SARS,

Euchaeta spinifera ESTERLY,

Euchaeta dubia ESTERLY.

2) Sie bleibt für viele Jahre, wenigstens bei Exemplaren, die mit Formalin in Seewasser abgetötet wurden, erhalten. Ich besitze solche 5 bis 10 Jahre alten Präparate, welche die Farben noch so frisch wie im Leben zeigen. 
Von diesen ist die Identifizierung der fünf von SARS aufgestellten Arten (Bull. Mus. oceanogr.) schwierig, da ausführliche Beschreibung und Abbildung fehlen. Euchaeta affinis CLEvE ist auch nur sehr kurz beschrieben, und die Zeichnungen von Abdomen und Genitalsegment erleichtern die Bestimmung nicht. Diese Art muß als zweifelhaft betrachtet werden.

Fünf von den oben erwähnten Arten haben eine Durchschnittsgröße von $8 \mathrm{~mm}$, nämlich: Euchaeta antarctica $(8 \mathrm{~mm})$, Euchaeta similis $(8-9 \mathrm{~mm})$, Euchaeta californica $(8 \mathrm{~mm})$, Euchaeta propinqua $(9 \mathrm{~mm})$ und Euchaeta rubicunda $(8,8 \mathrm{~mm})$. Zu dieser Gruppe können noch Euchaeta norwegica $(8 \mathrm{~mm})$, Euchaeta glacialis $(10 \mathrm{~mm})$ und Euchaeta sarsi $(12 \mathrm{~mm})$ hinzugefügt werden.

Sechs von diesen Arten sind durch mehr oder weniger intensive Färbung des Körpers ausgezeichnet, besonders Mundorgane, Antennen und Füße fallen durch tiefes Karminrot auf. (Euchaeta antarctica und Euchaeta similis konnten nur in konserviertem Zustande untersucht werden).

Für die Identifizierung ist ein Vergleich der folgenden Punkte nötig: die Zahl der Borsten des Außenlobus der Maxille, Länge der vorderen Antenne, Länge der akzessorischen Schwanzborsten, Form des Rostrums, Beschaffenheit des letzten Thorakalsegments, Behaarung der Abdominalsegmente, Längenverhältnisse derselben, anatomische Beschaffenheit des Genitalsegments und die Bedornung des 2. Fußpaares. Leider sind die Originalbeschreibungen mehrerer Arten so kurz, daß sie nicht alle die Punkte erwähnen, so daß völlig sichere Bestimmung nicht möglich ist.

Euchaeta propinqua EsTERLY hat sicher starke Ähnlichkeit mit Euchaeta barbata (SARS, WolFENDEN) und ist wahrscheinlich mit Euchaeta sarsi FARRAN identisch.

\section{Euchaeta antarctica GIESBRECHT.}

Diese zuerst von GiesBRecht im Belgica Report beschriebene, dann von mir aus den Sammlungen der ,Discovery“"erwähnte schöne Art findet sich in großer Zahl in den Planktonfängen von der Gauss-Station. Sie ist schon beim ersten Blicke an dem kurzen, aber vorspringenden Horn auf der Ventralseite der Genitalanschwellung zu erkennen. Die letztere nimmt die untere Hälfte des Genitalsegments ein, ist nach unten gerichtet und hat oben konvexen Rand. Die Genitalöffnung ist durch zwei seitliche Lappen geschützt, und über der Offnung finden sich zwei Chitinverdickungen und das kurze, ventrale Horn.

Das Rostrum ist kurz und kräftig, ohne Stirnvorsprung. Das letzte Thorakalsegment zeigt gerundete Ränder mit Haarbüscheln. Die Hinterränder der Abdominalsegmente sind stark gezähnt, und die beiden mittleren Segmente tragen auf der Ventralseite Büschel langer Haare. Die akzessorischen Schwanzborsten sind kurz, nur etwa halb so lang wie die beiden längsten Schwanzborsten, und nicht gekniet.

Das 1. F u $ß \mathrm{p}$ a a r hat am Außenast ein ziemlich langes Distalglied, welches sich distalwärts verschmälert und so lang wie die beiden verschmolzenen proximalen Glieder ist. Die letzteren sind stark konkav, mit einem Haarbüschel am Rande und seitlich mit kurzen Borsten versehen. Das 2. Fußpaar hat einen langen Dorn am 2. Gliede des Außenastes, und am 3. Gliede desselben überragt der Mediandorn nicht mit halber Länge das Ende des Gliedes. Der 1. (proximale) Dorn dieses Gliedes ist kurz, kräftig und stark gekrümmt. Der 2. (mittlere) Dorn ist etwa dreimal so lang als der 3. und mehr als doppelt so lang als der 1. 
Die vorderen Anten $\mathrm{n}$ en sind etwas länger als der Cephalothorax, und am 1. AuBenlobus der $\mathrm{Maxillen} \mathrm{finden} \mathrm{sich} 9$ Borsten. Größe des $q$ etwa $8 \mathrm{~mm}$, des ô ist etwas kleiner. Beim ö finden sich dieselben Geschlechtsunterschiede an Mundorganen und Füßen wie bei den übrigen Arten der Gattung Euchaeta.

Die Art war sehr häufig bei der Gauss-Station, liegt z. B. vor vom 6. XII. 02, $385 \mathrm{~m}$.

133. Euchata austrina Giesbrecht.

Im Belgica Report ist diese Art von GIESBRECht gut beschrieben und abgebildet. Sie ist im Durchschnitt $6 \mathrm{~mm}$ lang. Die Genitalanschwellung ist nicht so groß wie bei Euchaeta antarctica. Ein Ventralhorn fehlt, und die rechte seitliche Lamelle ist größer als die linke. Die Antennen und der 1. Außenlobus der Maxillen sind wie bei Euchata antarctica gebildet. Das Distalglied des Außenastes vom 1. Fußpaar ist nicht so lang wie bei jener und kürzer als die verwachsenen proximalen Glieder. Beim 2.Fußpaare ist der Außenranddorn des 2. Gliedes vom Außenaste lang; von den drei Außendornen des 3. Gliedes ist der mittlere nur wenig länger als die beiden andern, und die Ausbuchtung an der Basis des Mediandornes ist nicht so tief wie bei Euchaeta antarctica. Euchaeta austrina war in einigen Fängen von der Gauss-Station vorhanden, doch bei weitem nicht so häufig als Euchaeta antarctica.

134. Euchaeta similis Wolfenden. (Textfig. 48 a und b.)

Auch bei der Gauss-Station war diese von mir bereits nach den Sammlungen der „Discovery“ beschriebene Art vorhanden.

Das o ist regelmäßig größer im Durchschnitt als die Exemplare von Euchaeta antarctica und

$a$

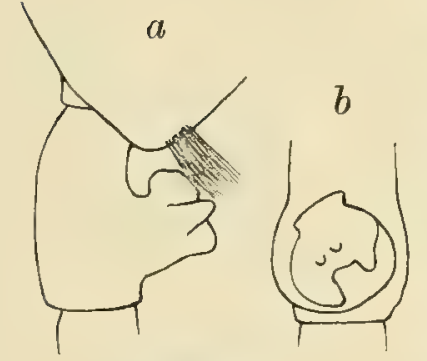

Textfig. 48.

Euchaeta similis.

$a$ Genitalsegment von der Seite.

$b$ Genitalsegment ventral. mißt 8,6-9,8 $\mathrm{mm}$ an Länge. Ein Stirnvorsprung fehlt, das Rostrum ist klein, kräftig und nach vorn gerichtet. Der Vorderkörper ist $2 \frac{1}{2} \mathrm{mal}$ so lang als das Abdomen. Das letzte Thorakalsegment erscheint an den Seiten etwas dreieckig und trägt jederseits ein schwaches Haarbüschel. Das Genitalsegment (48 a u. b) ist doppelt so lang als das nächste und hat eine stark hervortretende Anschwellung, welche die untere Hälfte des Segments einnimmt. Bei Seitenansicht scheint dasselbe aus einem Paar oberer und einem Paar unterer Lappen und einem Paare kleiner Tuberkeln in der Mitte zu bestehen. Der äußere Teil der oberen und unteren Anschwellung ist stark konvex und durch tiefe Bucht von dem übrigen Segment getrennt. Ventral gesehen erscheint die Genitalwucherung fast kreisrund, etwas schief gestellt und von zwei vorspringenden Lappen flankiert, von denen der der rechten Seite etwas niedriger als der linke ist. Zwei kleine Höcker finden sich oberhalb der Geschlechtsöffnung, und die beiden seitlichen Anschwellungen sind oben durch eine Chitinfalte verbunden.

Die Furkaläste sind kürzer als bei Euchaeta antarctica, die ventralen akzessorischen Borsten sind kurz, nicht so lang wie die beiden langen Schwanzborsten. Der untere Teil des Genitalsegments, das 2. und 3. Abdominalsegment und die Innenränder der Furka sind mit feinen Haaren bekleidet. tragen aber keine Haarbüschel. 
Die vorderen Anten $\mathrm{n}$ e $\mathrm{n}$ sind nicht länger als der Thorax; das letzte Glied derselben ist viel kleiner als das 19. Der Außenlobus der Maxille hat 9 Borsten.

Das 1. F u $\mathrm{p}$ a a r gleicht dem von Euchaeta antarctica, nur daß die Gliederung zwischen den beiden proximalen Gliedern unvollst:ndig ist. Das Distalglied erreicht nur dreiviertel der Länge der vereinigten Proximalglieder. Beim 3. Gliede des Außenastes vom 2. Fußpaare teilt die Ausbuchtung an der Basis des 2. Randdorns das Glied in der Weise, daß der distale Teil kürzer als der proximale ist; der 2. Randdorn erreicht nur das Ende des Gliedes und ist mehr als doppelt so lang als der 1. und über dreimal so lang als der distale Dorn. Der Randdorn des 2. Gliedes vom Außenaste reicht völlig bis zur Spitze des 1. Dornes vom 3. Gliede.

Auch diese Art scheint wie Euchaeta antarctica und wahrscheinlich auch Euchaeta austrina gänzlich auf die Antarktischen Meere beschränkt zu sein.

\section{Euchaeta quadrata Farran. (Tafel XXXV, Fig. 1, Textfig. 49 a-c.)}

Diese gut charakterisierte Art kann leicht an der eigentümlich gestalteten Schwellung des Genitalsegments erkannt werden. Nach FARRANs Originalbeschreibung sollen die vorderen Antennen, wenn sie ausgestreckt sind, bis zur Mitte des Genitalsegments reichen und die Maxillen am Außenlobus 9 Borsten haben. Seine im Westen von Irland gesammelten Exemplare hatten eine Durchschnittsgröße von $6,9 \mathrm{~mm}$.

Euchaeta quadrata erschien sehr häufig in den Atlantischen Planktonfängen der Deutschen Südpolar-Expedition. Sie weicht dort jedoch in drei Punkten von Farrans Beschreibung ab: sie ist nämlich kleiner, nur 5,85-6,0 $\mathrm{mm}$ groß, die vorderen Antennen sind kürzer, erreichen nicht das Ende des Cephalothorax, und der Außenlobus der Maxille hat nur 7 Borsten. Sonst scheinen die südlichen Exemplare mit den nördlichen völlig übereinzustimmen.

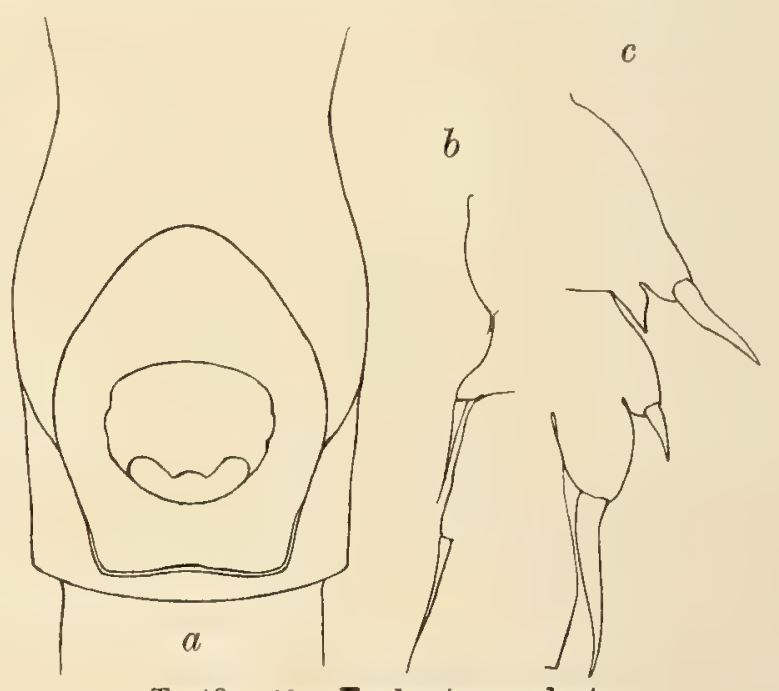

Textfig. 49. Euchaeta quadrata.

Das Ge n ita 1 s e g m e $\mathrm{nt}$ (49 a) ist fast so a Genitalsegment. $b$ Außenrand des Außenastes vom lang wie die beiden folgenden Segmente. Die Genital- 1. Fuß. c Außenrand des Außenastes vom 2. Fuß. anschwellung bildet einen fast viereckigen Vorsprung, der ebensobreit wie hoch und breiter als das Genitalsegment ist. Der obere Rand derselben ist in der Mitte schwach konvex, und die oberen sowohl wie die unteren Partien sind an der Vereinigungsstelle mit dem Segment schwach eingeschnürt. Ein kleiner Chitinknopf erscheint jederseits in der Mitte der Ventralfäche. Die Genitalschwellung erscheint bei Ventralansicht fast kreisrund zu sein, mit zwei Chitinlappen, welche die Vulva einschließen, zwei kleinen Chitinknöpfen unten und einer Chitinfalte oben.

Die Genitalanschwellung nimmt die Mitte des Segments ein. Den Abdominalsegmenten fehlen Haarbïschel, und nur sehr feine Haare treten am 3. und 4. Segment auf. Dagegen finden sich starke Haarbüschel am letzten Thorakalsegment. (XXXV. 1.) Die geknieten, akzessorischen Borsten der Furka sind sehr lang. 
Beim 1. F u $ß$ p a a r ist der Außenrand des Außenastes stark konkav-konvex. (49 b.) Der Dorn des 2. Gliedes reicht nicht bis zum Ende des 3. Gliedes. Das kombinierte 1. und 2. Glied zeigt keine Spur von Randborsten oder Haarbüscheln. Beim 2. Fußpaar (49 c) ist der Dorn des 2. Gliedes vom Außenaste sehr lang und erreicht das Ende des 1. Dornes vom 3. Gliede. Von den Dornen des 3. Gliedes sind der 1. und 3. klein und gleich lang, der 2. ist lang, reicht über das Ende des Gliedes hinaus. Der Sinus teilt das ganze Glied in zwei Teile, von denen der Proximalteil viel kürzer als der distale ist und die sich wie $4: 6$ verhalten.

In der Gestalt erinnert das Tier stark an Euchaeta norwegica, aber das Rostrum ist kleiner und der Stirnvorsprung nur schwach. Trotz der verschiedenen oben erwähnten Differenzpunkte glaube ich doch, daß unsere Form mit F ARR ans Art von der irischen Küste identifiziert werden muß ${ }^{1}$ ).

Viele Exemplare wurden am 9. Oktober 1903 (3000 m), 26. September 1903 (3000 m), 30. September $1903(1500 \mathrm{~m}), 22$. August $1903(1500 \mathrm{~m})$ und einigen andern Stationen im mittleren Atlantischen Ozean angetroffen.

136. Euchaeta tonsa GiesrRechr. (Textfig. 50 a-d.)

(Bull. Mus. Harvard Coll. 1895.)

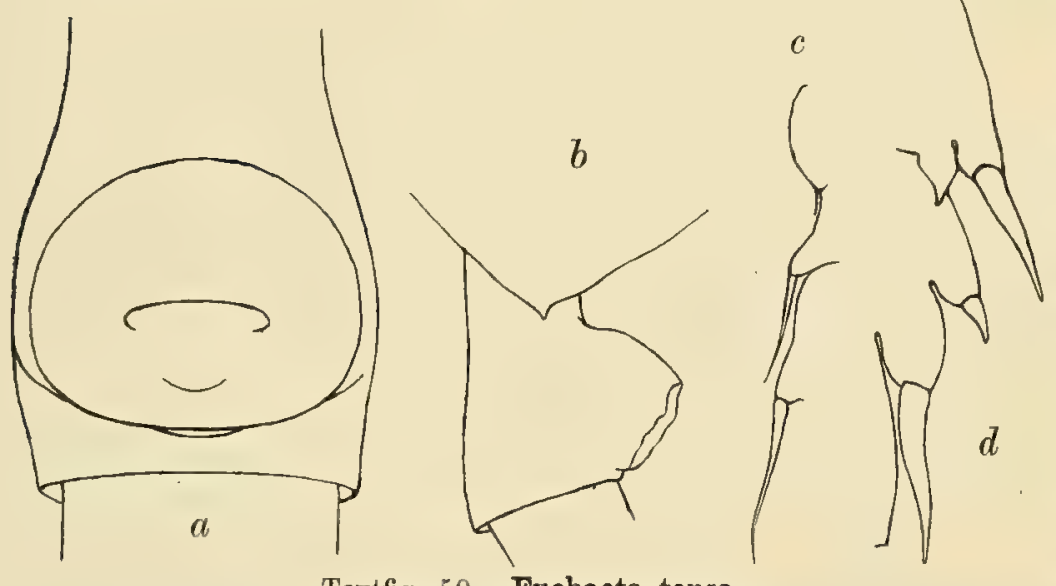

Textfig. 50. Euchaeta tonsa.

a Genitalsegment. $b$ Ende des Thorax und Genitalsegment. $c$ Außenrand rom Außenast des 1. Fußes. $d$ Außenrand rom Außenast des 2. Fußes.
Nach neueren Beobachtungen scheint diese ursprünglich aus dem Pazifischen Ozean beschriebene Art eine sehr weite Verbreitung zu haben, da F ARran sie an der irischen Küste in 13 von 34 Tiefwasserfängen antraf und sie auch in vielen Fängen des ,Gauss“", so am 5. November $1901(1000 \mathrm{~m})$, 12. November 1901 (3000 m), 26. September $1903(3000 \mathrm{~m})$, 9. Oktober $1903(3000 \mathrm{~m})$ und andern, gefunden wurde. Die atlantischen Exemplare stimmen in allen Einzelheiten, ausgenommen in der Größe, mit den

pazifischen überein. Denn sie sind gewöhnlich kleiner, nur 5-5,3 mm lang, während GIESBRECHT $6,1 \mathrm{~mm}$ als Länge der letzteren angibt.

\section{3\%. Euchaeta spinosa Giesbrecht}

die leicht zu erkennen ist, wurde an mehreren atlantischen Stationen vom „Gauss“ erbeutet. Ursprünglich war sie aus dem Mittelmeere beschrieben, und neuerdings ist sie von EsTERLY von der San Diego-Region in Kalifornien erwähnt worden.

1) Ein gewisser Grad von Variation ist bei dieser Art vorhanden, denn bei einem Exemplar vom 26. September 1903 $(3000 \mathrm{~m})$, das zusammen mit andern der obigen Beschreibung entsprechenden vorkam, reichten die vorderen Antennen bis zur Mitte des Genitalsegments. Die Maxille hatte wie oben 7 Borsten am Außenlobus. Das 1. Fußpaar stimmte vollkommen überein, aber beim 2. Paare reichte der Dorn des 2. Gliedes vom Außenast nicht bis zum Ende des nächsten Dornes, und der mittlere Dorn des letzten Gliedes reichte nicht bis zum Ende von diesem. Sonst war gute Ubereinstimmung vorhanden, bis auf die Länge von $6,25 \mathrm{~mm}$, die also etwas größer als bei beiden oben beschriebenen Exemplaren war. 
Gefunden am 26. August 1903 (400 m), 3. und 16. September 1903 (400 m), 26. September 1903 $(3000 \mathrm{~m})$.

\section{Euchaeta marina (Prestandrea).}

Diese universell verbreitete Art wurde in großer Zahl während der Fahrt des „Gauss“ durch den Atlantischen Ozean und auch an der Küste von Südafrika gefunden. Von dort, Natal und Kapkolonie hatte sie CLEvE bereits früher erwähnt.

\section{Euchaeta acuta Giesbrecht}

ist weit verbreitet im Atlantischen Ozean. Sie wurde gefunden am 19. und 24. August 1903 (400 m), 5. und 16. September $1903(400 \mathrm{~m})$, 10. und 26. September $1903(3000 \mathrm{~m})$, 30. September 1903 $(800 \mathrm{~m})$, 9. Oktober $1903(400 \mathrm{~m})$, 13. Oktober $1903(3000 \mathrm{~m})$ und an andern Stationen.

\section{Euchaeta coneinna Dana}

erschien in den Fängen aus dem südlichen Atlantischen Ozean nur bei wenigen Gelegenheiten, so am 26. August $1903(400 \mathrm{~m}), 10$. September $1903(3000 \mathrm{~m})$ und dann an den Stationen in der Nähe der südafrikanischen Küste.

141. Euchaeta grandiremis GiesBRechT.

Ein Exemplar nur wurde am 9. Oktober 1903 (3000 m) angetroffen.

142. Euchaeta robusta n. sp. (Tafel XXXVI, Fig. 1, Textfig. 51 a-d.)

† 7,8 mm lang, wovon dem Cephalothorax 5,5 mm, dem Abdomen 2,3 $\mathrm{mm}$ zukommen. Das längste Exemplar mißt $8 \mathrm{~mm}$. Der $\mathrm{K}$ o p f hat einen kleinen Stirnvorsprung und starkes Rostrum. Das letzte Thorakalsegment trägt seitlich dicke Haarbüschel und hat ziemlich dreieckige Gestalt. (XXXVI. 1.) Die drei hinteren A bdominalsegmente und die Furka sind dicht mit Haarbüscheln bekleidet. Die Furka hat zwei lange Schwanzborsten und zwei lange Anhangsborsten. Die Größen der 3 ersten Abdominalsegmente verhalten sich wie $20: 10: 10$. Das Genitalsegment hat einen großen, ventralen Höcker, welcher von der Seite gesehen als ein großer oberer Lappen mit konvexem oberem Rand und als kleinerer Lappen an der unteren Fläche nach innen $c$ zu gelegen erscheint. (51 a.) Dieser erscheint, ventral gesehen, aus zwei weit offenen seitlichen Klappen zu bestehen, welche unten durch ein Chitinpolster verbunden sind. (51 b.) Im oberen Teile hängen diese beiden Klappen durch ein kleineres Chitinpolster zusammen. Die Geschlechtsöffinung ist weit offen. Die Genitalwucherung nimmt die Mitte des Segments

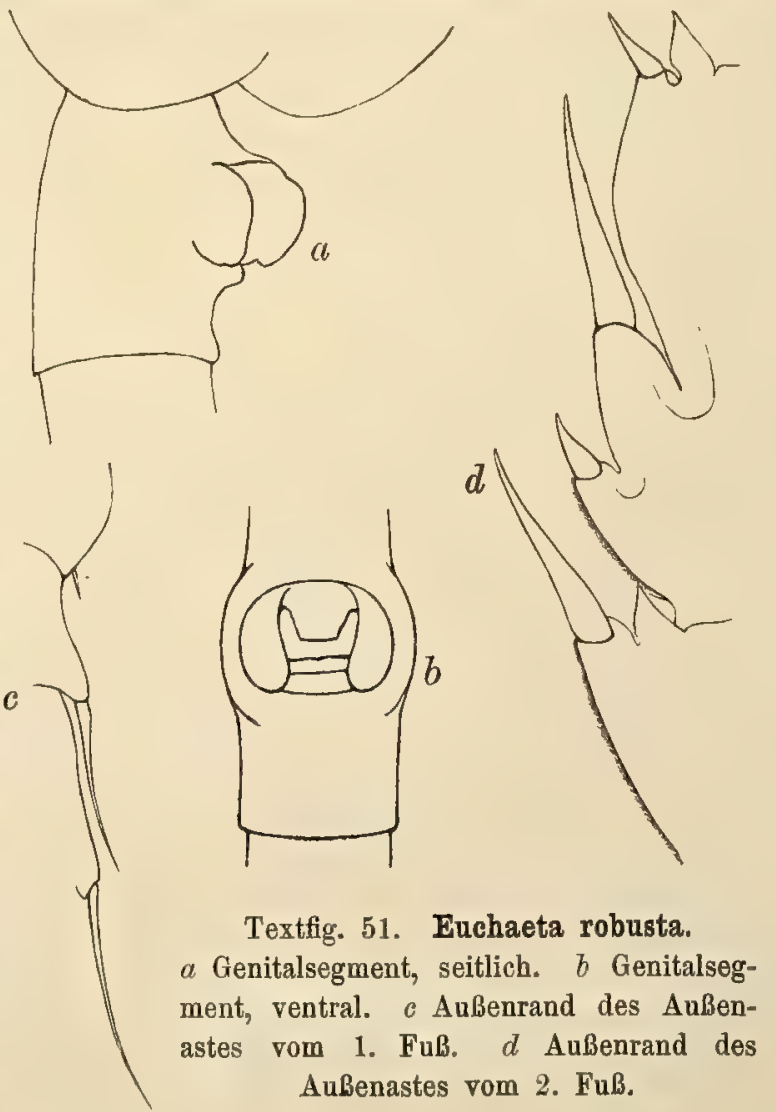


ein, welches dorsal nicht und seitlich wenig geschwollen erscheint. In Ventralansicht erscheint die Genitalöffnung mehr oder weniger oval in der Form, horizontal am breitesten.

Die vorderen A ntennen reichen nur bis zum Ende des Thorax. Der Außenlobus der Maxillen hat nur 6, der Außenast 11 Borsten. Das 1. FuB pa a r zeigt stark konkavkonvexen Außenrand. (51 c.) Der Außenast ist deutlich dreigliedrig; am äußeren Ende des 1. Gliedes tritt eine kleine Borste, aber kein Haarbüschel auf; die Dornen des 2. Gliedes reichen bis zum Ende des letzten. Beim 2. Fußpaare reicht der Dorn des 2. Gliedes vom Außenaste fast bis zurSpitze des nächsten Dornes. Der 1. Dorn des 3. Gliedes ist etwa halb so lang wie der 2., und der letztere erreicht nicht das Ende des letzten Gliedes. Die Ausbuchtung in der Höhe des 2. Dornes ist tief und teilt das Glied in einen kürzeren proximalen und größeren distalen Teil, im Verhältnis von 4:6.

Der Innenast des 2. Fußpaares zeigt Andeutung einer Teilung in zwei Glieder durch Einschnürungen an beiden Rändern und deutlicher Verbindungslinie derselben auf einer Seite des Gliedes. Die deutliche Gliederung des 1. Fußpaares und die Zahl der Borsten am 1: Außenlobus der Maxille zusammen mit der teilweisen Gliederung des Innenastes vom 2. Fußpaar unterscheiden dieses Tier von allen übrigen größeren Arten der Gattung.

Mehrere Exemplare wurden am 9. und 13. Oktober 1903 (3000 m) und am 12. November 1901 $(3000 \mathrm{~m})$ gefunden. Im Habitus und durch das stark behaarte Abdomen nähert sich diese Art mehr als jede andere BRADY's Euchaeta barbata.

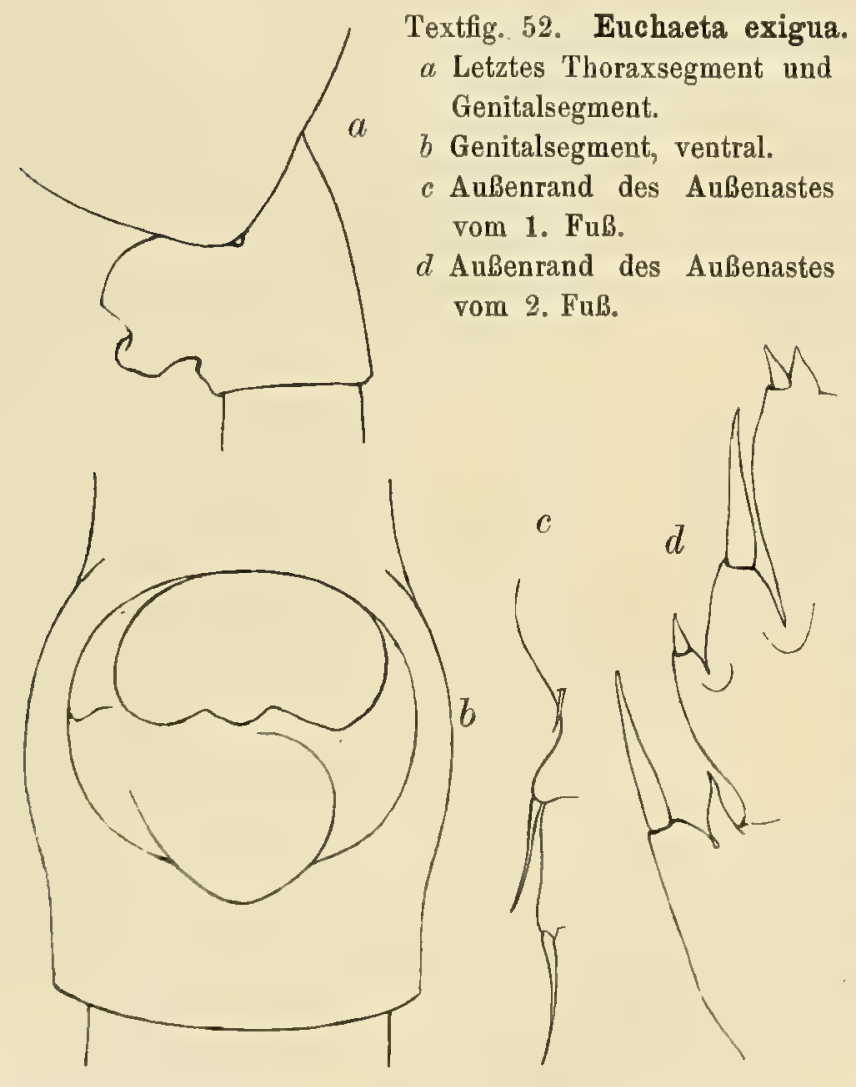
trägt einen kleineren Lappen, und zwischen beiden liegt eine tiefe Furche. Weit offenstehende Klappen wie bei Euchaeta robusta sind nicht vorhanden, sondern das Segment scheint solid zu sein.

143. Euchueta exigua n. sp. (Textfig. 52 a-d.)

f $6,7 \mathrm{~mm}$ lang, davon Cephalothorax 4,9 $\mathrm{mm}$, Abdomen $1,7 \mathrm{~mm}$. K o p f verschmälert, mit kleinem Stirnfortsatz und starkem, nach vorn gerichtetem Rostrum. Die vorderen Antennen reichen bis zum Ende des Cephalothorax. Auf dem Cephalothorax sind keine Haare vorhanden; das letzte Segment desselben ist ziemlich dreieckig gestaltet und endigt mit kurzen, stumpfen Spitzen. (52 a.) Das Abdomen ist vollständig haarlos. Das Genitalsegment ist nur wenig länger als das nächste Segment, die langen Schwanzborsten sind nur wenig länger als das Abdomen, und die geknieten Anhangsborsten sehr lang. Die Genitalschwellung nimmt die obere Hälfte des Segments ein und ist sehr groß, vertikal größer als horizontal und seitlich nicht so breit wie das Segment. (52 b.) Die obere Fläche ist konvex, und mehr als das halbe Segment wird von einem großen Lappen eingenommen; der untere Teil 
Am 1. Außenlobus der M a xill e n sind 9 Borsten vorhanden, von denen die beiden proximal gelegenen sehr kurz sind. Das 1 . F u B p a a r $(52 \mathrm{c})$ hat nicht so stark konkav-konvexen Rand wie bei manchen anderen Arten, auch sind weder Borsten noch Haare am Außenrande des proximalen Gliedes vom Außenaste vorhanden, und der Randdorn des 2. Gliedes ist ziemlich schwach und reicht nicht bis zum Ende des Gliedes. Beim 2. Fußpaare (52 d) reicht der Außenranddorn des 2. Gliedes vom Außenaste bis zur Spitze des nächsten Dornes. Der Mediandorn des 3. Gliedes erreicht das Ende des Gliedes, und dieses Glied zerfällt durch den Sinus in zwei Teile, von denen der distale größer als der proximale ist, und deren Längen sich wie $6: 4$ verhalten.

Das vorliegende Tier entspricht am nächsten der kurzen Beschreibung, welche SARS von Euchaeta incisa gab. Bei dieser wird, obwohl erwähnt ist, daß das letzte Thorakalgment haarlos sei, nichts von Spitzen gesagt. Auch das Genitalsegment wird als ein wenig vorn angeschwollen beschrieben, die Wucherung als sehr wenig hervortretend und in der Mitte durch einen Einschnitt in zwei Lappen geteilt und die hinteren Segmente als deutlich behaart. Bei unserer Art tritt die Genitalschwellung stark hervor und die Abdominalsegmente sind unbehaart. Ich glaube daher, daß es zwei verschiedene Arten sind. Die Größe von Euchaeta incisa SARs war 5,60 mm.

Mit den beiden Arten von Euchaeta, welche Spitzen an den Seiten des letzten Thorakalsegments haben an Stelle der gewöhnlichen Haarbüschel, nämlich Euchaeta tonsa und Euchaeta norwegica, hat Euchaeta exigua im Bau des Genitalsegments keine Ähnlichkeit.

Sie wurde am 12. November 1901 (3000 m) im südlichen Atlantischen Ozean westlich von Kapstadt gefunden.

144. Euchaeta scotti Farran. (Tafel XXXV, Fig. 2, Textfig. 53 a-c.)

+ 4,85 mm, davon Cephalothorax 3,75 mm, Abdomen 1,1 mm. Das Rostrum ist klein und nach vorn gerichtet, der Kopf nach vorn verschmälert, mit kleinem Stirnfortsatz. Das letzte Thorakalsegment ist abgerundet und jederseits mit starkem Haarbüschel ausgestattet. Die Längen der ersten drei Abdominalsegmente verhalten sich wie $10: 6: 6$. Am Analsegment und an der Furka finden sich einige Haare, und die Distalränder der Abdominalsegmente sind am Rücken fein gekämmt. (XXXV.2.)

Die Genitalschwellung tritt stark hervor und nimmt den mittleren und oberen Teil des Segments ein (s. Abb. 53 a). Sie besteht aus zwei seitlichen Lappen und einem Paare kleinerer Lappen darüber. Die Anhangsborsten sind sehr lang.

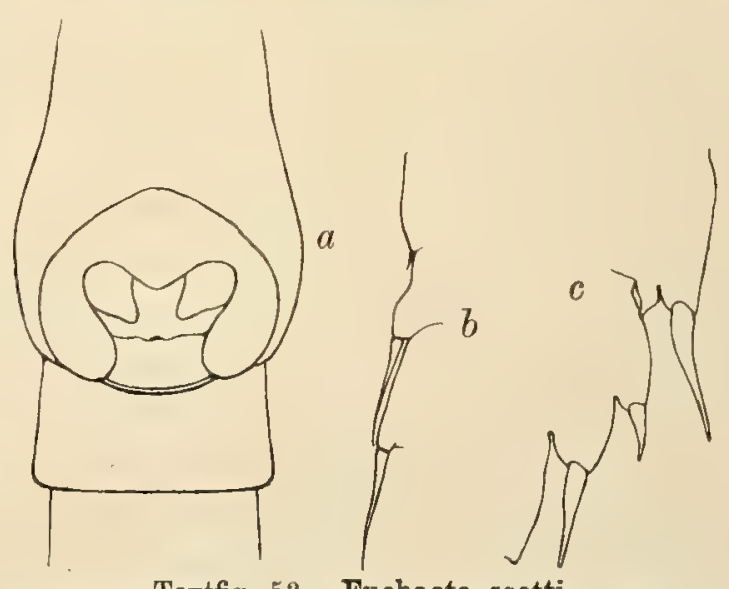

Textfig. 53. Euchaeta scotti.

Die vorderen Antennen sind nicht so lang $a$ Genitalsegment. $b$ Außenrand des Außenastes vom wie der Cephalothorax. Die Maxille hat am 1. Außen- 1. Fuß. c Außenrand des Außenastes vom 2. Fuß. lobus 5 Borsten, am Außenast 11. Beim 1. Fu B pa a r ist der Außenrand des Außenastes nur wenig konkav, und die kleine Borste ist sehr unbedeutend. (53 b.) Der Dorn des 2. Gliedes erreicht das Ende desselben. Beim 2. Fußpaar (53 c) erreicht der Außenranddorn des 1. Gliedes vom Außenaste beinahe die Spitze des nächsten Dornes; der 1. Dorn des 3. Gliedes ist klein, der 
2. Dorn erreicht das Ende des Gliedes, doch ist er bei einigen Exemplaren von anscheinend derselben Art nur dreiviertel so lang wie dieser Teil des Außenrandes, reicht also nicht bis zum Ende des Gliedes. Der Sinus an der Basis dieses 2. Dornes teilt das Glied in zwei annähernd gleiche Stücke.

In den meisten Einzelheiten scheint dieses Tier mit Euchaeta scotti nach der Beschreibung von FARRAN übereinzustimmen (Fisheries Ireland Sci. Invest. 1906 II [1908]), doch ist es gewöhnlich kleiner als Farrav's Art. Auch scheint es in der Größe erheblich zu variieren, da einige Exemplare nicht mehr als 4,2 mm lang sind. Dennoch scheinen sie alle derselben Art anzugehören.

Mehre Exemplare wurden im Fange vom 26. September 1903 (3000 m) unter dem Äquator beobachtet.

\section{Heterorhabdus Giesbrech'T.}

Die ursprüngliche Gattungsdiagnose wurde erweitert, um auch für Arten zu passen, welche erheblich vom ersten Typus abweichen. Die Artunterschiede waren in erster Linie begründet auf Eigentümlichkeiten der Maxillipeden, des fünften Fußpaars beim ô und sekundär auf der Bezahnung der Mandibeln sowie auf der Form und der Zahl der Schwimmborsten an den Füßen. G. O. SARS schlug vor, eine neue Gattung (Mesorhabdus) zu schaffen für ein mit Heterorhabdus nahe verwandtes Tier, welches jedoch in einigen wesentlichen Punkten verschieden war. Die Art Heterorhabdus grimaldi RICHARD weicht noch mehr vom Typus Heterorhabdus ab (der später beschrieben wird), und daher schlage ich vor, sie als Typus einer neuen Gattung, Hemirhabdus, zu betrachten. Während Disseta eine Zwischenstellung zwischen Lucicutia und Heterorhabdus einnahm, schieben sich nun zwischen ihr und Heterorhabdus noch die Gattungen Hemirhabdus und Mesorhabdus ein. Zwei sehr merkwürdige Arten, die zu einer neuen Gattung, Alloiorhabdus, gerechnet werden, scheinen weitere Glieder in der morphologischen Kette der Familie Heterorhabdidae zu bilden.

\section{Heterorhabdus longicornis GiesBrecht}

liegt vor vom 5. und 11. September $1903(400 \mathrm{~m})$ und vom 4. September 1903 (2000 m) aus dem Gebiete zwischen St. Helena und Ascension.

\section{Heterorhabdus spinifrons CLAUS}

wurde am 19. Oktober 1901 (500 m), 22. Oktober 1901 (3000 m), 12. November 1901 (3000 m) 22. August 1903 (1500 m) und 13. Oktober 1903 (3000 m) in etwa gleichen Abständen $20^{\circ}$ nördlich und südlich vom Äquator im Atlantischen Ozean gefunden.

\section{Heterorhabdus papilliger Clads}

fand sich am 19. Oktober $1901(500 \mathrm{~m})$, 5. November $1901(1000 \mathrm{~m})$, 26. August 1903 (400 m), 3., 4. und 5. September 1903 (400 m und $2000 \mathrm{~m})$, 9. Oktober 1903 (3000 m) im Atlantischen Ozean.

\section{Heterorhabdus brevicornis DAHL}

war bereits aus dem Atlantischen Ozean bekannt. Die vorderen Antennen sind kurz und ihr vorletztes Glied ist nicht doppelt so lang als breit. Sonst ist die Art Heterorhabdus vipera sehr ähnlich. Sie wurde am 12. November 1901 in einem Vertikalfang aus $3000 \mathrm{~m}$ beobachtet. 
149. Heterorhabdus Clansi Giesbrecht.

Diese wenig bekannte Art fand sich zusammen mit der vorigen am 12. November 1901 (3000 m).

\section{Heterorhabdus tropicus DAHL.}

Ein Exemplar, welches zu dieser Art gerechnet werden kann, wurde am 4. September 1903 (2000 m) zwischen St. Helena und Ascension gefunden.

151. Heterorhabdus vipera Giesbrecht.

wurde am 12. November $1901(3000 \mathrm{~m})$ im Südatlantischen Ozean gefunden.

152. Heterorhabdus abyssalis Giessrecht

fand sich am 9. und 13. Oktober 1903 (3000 m) westlich von den Kapverden.

\section{Alloiorhabdus n. g.}

Heterorhabdus austrinus wurde von GIESBRECHT nach einem einzigen Exemplar beschrieben, das ihm mit Heterorhabdus clausi nahe verwandt zu sein schien. Mehrere Abbildungen davon sind in dem Bericht über die Copepoden der „Belgica“ gegeben, und bei der Genauigkeit, die die Arbeiten GIESBRECHT's auszeichnet, kann man über die Merkmale der Art nicht zweifelhaft sein. GIEsBRECHT erwähnt jedoch nicht die Zahl der Borsten des Innenastes der Füße (ausgenommen das 5. Paar), und die Exemplare der Deutschen Südpolar-Expedition weichen darin erheblich vom Typus der Gattung Heterorhabdus ab. Bei dieser Gattung gruppieren sich die Borsten der Innenäste der Schwimmfüße sonst folgendermaßen $\left.{ }^{1}\right)$ :

1. Fuß 1, 2, 4; 2. Fuß 1, 2, 5; 3. Fuß 1, 2, 6; 4. Fuß 1, 2, 5; 5. Fuß 1, 1, 4;

bei den 6 Exemplaren $(4 \%, 2$ o) von Heterorhabdus austrinus, welche ich habe, dagegen:

1. Fuß 1, 2, 5; 2. Fuß 1, 2, 7; 3. Fuß 1, 2, 8; 4. Fuß 1, 2, 7; 5. Fuß 1, 1, 6.

In der Figur vom 5. Fußpaare bildet GIESBREchT auch 1, 1, 6 Borsten ab.

Die Zahl dieser Borsten der Innenäste ist ein wichtiger diagnostischer Faktor bei der Unterscheidung der Gattungen Disseta, Isochaeta, Heterorhabdus und Hemirhabdus. Die Exemplare vom „Gauss" scheinen sehr genau mit GiesBrechts Beschreibung übereinzustimmen. Sie sind etwas größer, nämlich bis $3,8 \mathrm{~mm}$ lang. Die vorderen A $\mathrm{n}$ te $\mathbf{n} \mathrm{n}$ e $\mathrm{n}$ sind etwas länger als das Tier, 4,2 $\mathrm{mm}$; die hinteren Antennen haben längeren Innenast und kürzeren Außenast, die M a xill e $\mathbf{n}$ sind mit sehr kleinem Innenaste, welcher 3 Borsten trägt, und sehr langem Außenast ausgestattet. der dreimal so lang als breit ist und 5 Borsten hat; am 1. Außenlobus sind auch 5 Borsten und am 2. Basalglied ist eine Borste vorhanden.

Die vorderen und hinteren M a $\mathrm{x} 11$ i p e d e $\mathrm{n}$ und das 5. Fußpaar entsprechen vollkommen den Abbildungen GIESBREchts. Die M a n d i b u la räste sind gleich und die äußeren Zähne der Zahnplatte verdickt und verlängert. Das vorletzte Glied der vorderen Antennen ist dreimal so lang als das Endglied und achtmal so lang als breit. Es ist kaum zweifelhaft, daß diese Tiere mit GIESBRECHTS Heterorhabdus austrinus identisch sind. Aber die eigentümliche Beborstung der Innenäste der Füße tritt noch bei einer andern antarktischen Art auf, welche in der Sammlung des ,Gauss“" vorkommt und welche später als Alloiorhabdus medius

\footnotetext{
1) Giesbrecht: Fauna und Fl. Neap. p. 64.
} 
beschrieben wird. Letzterer nimmt sich Heterorhabdus longicornis zum Muster, während Heterorhabdus austrinus nach GIESBRECHT Heterorhabdus clausi nachahmt. Wenn dieses zufällig wäre, würde es eine morphologische Merkwürdigkeit sein, aber da diese Charaktere

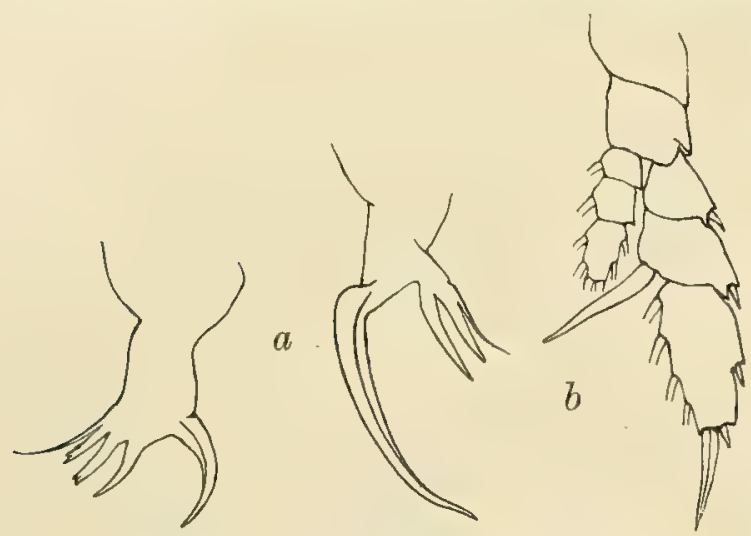

Textfig. 54. Heterorhabdus austrinus.

a Mandibel mit Zahnplatte der rechten und linken Seite. $b$ 5. FuB. bei 15 Exemplaren von Heterorhabdus vel Alloiorhabdus austrinus und 3 von Alloiorhabdus medius konstant sind, so erscheint es wohl angebracht, für diese abweichenden Formen eine neue Gattung zu bilden. Ich schlage für dieselbe den Namen Alloiorhabdus vor ${ }^{1}$ ).

Wenn man nicht den Gattungsbegriff Heterorhabdus erweitern will, so daß er gewisse abweichende Formen aufnehmen kann, welche sich erheblich vom normalen Typus in den Merkmalen ihrer Schwimmfüße unterscheiden, so ist es notwendig, die Südpolarformen in einer besonderen, aber nahestehenden Gattung zusammenzufassen. Bei dieser Gattung, welche sonst Heterorhabdus nachahmt, findet sich konstant eine größere Zahl von Borsten an den Innenästen der Schwimmfüße. Es sind vorhanden:

bei Heterorhabdus

1. Fuß 1, 2, 4; 2. Fuß 1, 2, 5; 3. Fuß 1, 2, 6; 4. Fuß 1, 2, 5; 5. Fuß 1, 1, 4; bei Alloiorhabdus

1. Fuß 1, 2, 5; 2. Fuß 1, 2, 7; 3. Fuß 1, 2, 8; 4. Fuß 1, 2, 7; 5. Fuß 1, 1, 6; bei Hemirhabdus

1. Fuß 1, 2, 5; 2. Fuß 1, 2, 7; 3. Fuß 1, 2, 7; 4. Fuß 1, 2, 7; 5. Fuß 1, 1, 6; bei Disseta

1. Fuß 1, 2, 5; 2. Fuß 1, 2, 8; 3. Fuß 1, 2, 8: 4. Fuß 1, 2, 8; 5. Fuß 1, 1, 6.

Hemirhabdus unterscheidet sich außerdem besonders durch die Charaktere der vorderen Maxillipeden und Disseta durch ihre Annäherung an Lucicutia in vielen anatomischen Eigentïmlichkeiten. Es scheint mir danach unmöglich, Alloiorhabdus austrinus und Alloiorhabdus medius zur Gattung Heterorhabdus zu rechnen, welcher sie sonst angegliedert werden müßten.

153. Alloiorhabdus austrinus Giesbrecht. (Tafel XXXV, Fig. 3 und 4.)

Heterorhabdus austrinus Gвт. Belgica-Report.

o 4,35 mm lang, davon kommen 2,85 mm auf den Cephalothorax, 1,5 mm auf das Abdomen. Der $\mathrm{K}$ op $\mathrm{f}$ und der übrige Körper ist genau wie bei Heterorhabdus gestaltet, nur daß die Hinterenden des letzten Thorakalsegments etwas zugespitzt sind. Das Rostrum ist sehr fein. Das Ge n i $\mathrm{ta}$ ls e g m e $\mathrm{n} t$ ist etwa so lang wie die beiden folgenden und tritt ventral stark hervor. Es ist etwas asymmetrisch, da es links etwas mehr als auf der rechten Seite angeschwollen ist. Das Analsegment ist etwas kürzer als das vorhergehende. Die Distalränder der Abdominalsegmente sind fein gekämmt. Der linke Furkalast ist etwas länger als der rechte, fünfmal so lang als breit und trägt eine lange Borste, die $2 \frac{1}{2} \mathrm{mal}$ so lang ist wie das Abdomen. Die äußeren Randborsten jedes 
Segments teilen dieses in einen distalen und einen proximalen Teil, so daß zwei Fünftel auf den distalen, drei Fünftel auf den proximalen Teil kommen. Die Borsten sind, mit Ausnahme der innersten, welche dünn ist, alle von gleicher Dicke.

Die vorderen A n te n n e n sind (nach MAss) etwa um 3 Glieder länger als die Furka. Das vorletzte Glied ist über fünfmal so lang als breit, und das 19. Glied ist sechsmal so lang als breit. Der Außenast der hinteren Antennen ist nur 3/4 so lang wie der Innenast; das 1. Basalglied hat 1, das 2. 2 sehr lange Borsten, und am distalen Teile des verlängerten Gliedes vom Innenaste sind 2 kurze Borsten vorhanden. Die M a n dibeln haben gleich lange Äste und genau gleiche Zähne der Kauplatte wie Heterorhabdus vipera. Der äußere Zahn ist verdickt und der der linken Seite sehr lang und gekrümmt. Auf der rechten Seite sind 3, auf der linken 2 weitere Zähne vorhanden. Die Maxille $\mathrm{n}$ haben verlängerten Außenast, der viermal so lang als breit ist und $\mathbf{5}$ Borsten trägt; der Innenast ist sehr klein und hat 5 Borsten, das Basalglied 1, der 1. Außenlobus 5 Borsten, während am 1. Innenlobus 8 Haken und 5 Borsten auftreten.

Die vorderen M a xillipede $\mathrm{n}$ (XXXV.3) gleichen denen von Heterorhabdus vipera, der 5. und 6. Lobus tragen eine lange, gekrümmte Kammborste, der 4. Lobus zwei Feilenborsten und eine lange und dünne Borste; der 3. Lobus ist mit einer Feilenborste und einer Stachelborste versehen. Die Borsten des Innenastes sind nur halb so lang wie die Haken. Der 5. Lobus ist ein sehr langer Zapfen. Die hinteren Maxillipeden haben keinen langen, gebogenen Dorn, aber am gerundeten Vorsprung des 2. Basalgliedes findet sich ein gerader Dorn, ferner ein zweiter kürzerer und eine Borste. Das 2. Basalglied ist dreimal so lang als breit und hat eine Längsreihe feiner Zähne auf der Oberfläche.

Beim 1. F u B p a a r ist das 2. Glied des Außenastes klein und breit; das 1. Glied ist etwas länger als das 3. und das letztere halb so breit als lang. Die äußeren Randdornen, zu 1, 1, 2 auftretend, sind sehr groß. Unter dem Dorne des 3. Gliedes findet sich noch ein kleinerer. Die Endsäge hat chitinisierten, gekerbten Rand. Der Innenast ist kurz, das 2. Glied breiter als lang und das 3. Glied am distalen Ende dicht behaart. Am äußeren distalen Rande des 2. Gliedes findet sich eine starke Spitze. Von Innenrandborsten sind 1, 2, 5 vorhanden.

Beim 2. Fußpaar ist das 3. Glied des Außenastes halb so breit als lang, und dieses Glied ist länger als das 1. und 2. zusammen. Die Außenranddornen, zu 1, 1, 3 auftretend, sind pfeilförmig und zwischen zwei kleinen Basaldornen eingeschlossen. Die Endsäge ist etwa eindrittel so lang als das letzte Glied. Der Innenast ist kurz, sein 1. und 2. Glied tragen starke Außenranddornen und 1, 2, 7 Innenrandborsten sind vorhanden.

Beim 3. Fußpaar ist das 3. Glied des Außenastes stark verbreitert, fast zwei drittel so breit wie lang, hat eine kurze und gekrümmte Endsäge, 3 Außenranddornen und 5 Innenranddornen. (XXXV. 4.) Am letzten Gliede des Innenastes finden sich 8 Randborsten.

Das 3. Glied des Außenastes vom 4. Fußpaar ist nicht verbreitert ( $1 / 2$ so breit als lang), und am letzten Glied des Innenasts treten 7 Randborsten auf.

Das 5. Fußpaar ist dem von Heterorhabdus vipera sehr ähnlich. Das 3. Glied des Außenastes ist ebenso lang wie das 2. + 1. Die Endsäge desselben ist 2/3 so lang wie das Glied. 1, 1, 6 Randborsten des Innenastes sind vorhanden, von denen die beiden am Innenrande schwächer als die übrigen sind. Die Säbelborste ist sehr dick und gekrümmt. 
Das ơ ist $4 \mathrm{~mm}$ lang und sehr ähnlich dem ?. Von den vorderen A n t e $\mathrm{n} n \mathrm{e} \mathrm{n}$ ist die linke gekniet, mit 4 Gliedern distal vom Gelenk, von denen die ersten beiden sehr lang sind und das vorletzte Glied dreimal so lang als das Endglied ist. Die Mundorgane und das 1. bis 4. Fußpaar sind wie beim of gebildet.

Das 5. F u ß p a a $\mathrm{r}$ hat sehr gedrungene Form. Das 2. Basalglied vom rechten Fuße springt mit gerundetem Rande stark vor und ist behaart. Das 1. Glied vom Außenast ist sehr kurz, das 2. so breit wie lang, mit eigentümlichem Fortsatz am Innenrande; das 3. Glied erscheint löffelartig, mit kurzem Enddorn und 2 kurzen Randdornen.

Beim linken Fuß ist das 2. Basalglied breit, ohne Fortsatz, und das letzte Glied ist etwas viereckig, mit einem Enddorn und einem besonderen dicken, gekrümmten Dorne, welcher vom Innenrand entspringt und mit kurzen Zähnen an der Unterseite bewaffnet ist. Das 2. Glied hat auch einen kleinen, aber dicken Randdorn. Die Innenäste aller Füße sind dreigliedrig und haben 0, 1, 6 Innenrandborsten.

Dieses Tier wurde von mir als ơ von Heterorhabdus austrinus in „Plankton Studies $1905^{\text {“ }}$ beschrieben.

Etwa 6 o und 3 ơ aus dem Gebiete des Scholleneises vom 6. März 1903 (1200 m) und 26. März $1903(2000 \mathrm{~m})$ waren in der Sammlung der Deutschen Südpolar-Expedition vorhanden, welche alle genau übereinstimmten.

Sowohl in den speziellen Charakteren der Borsten an den Füßen als auch in der Größe, der Länge der vorderen Antennen und ein wenig im Anhange der vorderen Maxillipeden sind diese Tiere von Heterorhabdus vipera verschieden. Das 5. Fußpaar des ơ, obgleich nach dem allgemeinen Typus dieser Familie gebaut, ist ganz anders gestaltet als bei irgendeiner Art von Heterorhabdus.

F undort: Antarktisches Meer.

154. Alloiorhabdus medius n. sp. (Textfig. $55 \mathrm{a}-\mathrm{i}$.)

우 5,2 mm lang, davon Cephalothorax 3,4 mm, Abdomen 1,75 mm. Der K ö r p e r ist ziemlich schmal, nicht ein drittel so breit als lang. Das Abdomen fast halb so lang als der Cephalothorax, das Genitalsegment seitlich geschwollen, ebenso breit wie lang, so lang wie die beiden folgenden Segmente, mit großem, ventralem Höcker und hervortretender Klappe an der linken Seite versehen. Die Furkaläste sind vom Analsegment vollständig abgegliedert; der linke ist länger und viermal so lang als breit. Die Außenrandborste teilt ihn in einen langen, proximalen und kurzen, distalen Teil, im Verhältnis von 7 : 3. Auf der linken Seite ist eine sehr lange Heterorhabdus-Borste vorhanden, die an der Basis viel dicker als die übrigen Schwanzborsten ist. (55 a.)

Die vorderen Anten $\mathrm{n}$ en sind sehr lang, 8,55 mm, und 7 bis 8 Glieder überragen die Furka. Die basalen Glieder sind breit und kurz, das 8. und 9. Glied nur schwach geteilt. Alle folgenden Glieder nach dem 13. sind stark verschmälert; das 19. und 20. Glied sind über 20 mal so lang als breit, ebenso das vorletzte, und dieses ist dreimal so lang wie das letzte Glied. Der Innenast der hinteren Antennen ist viel länger und dicker als der Außenast. Die Äste der M a n d beln sind ungefähr gleich, und die Zahnplatte trägt 4 gleich große Zähne wie bei Disseta. $(55$ c.) 
Die Maxille ist wie bei Heterorhabdus gebildet, der Innenast so lang wie das 2. Basalglied, der erstere hat 5, das letatere eine Borste. Der Außenast und 1. Innenlobus sind beide sehr
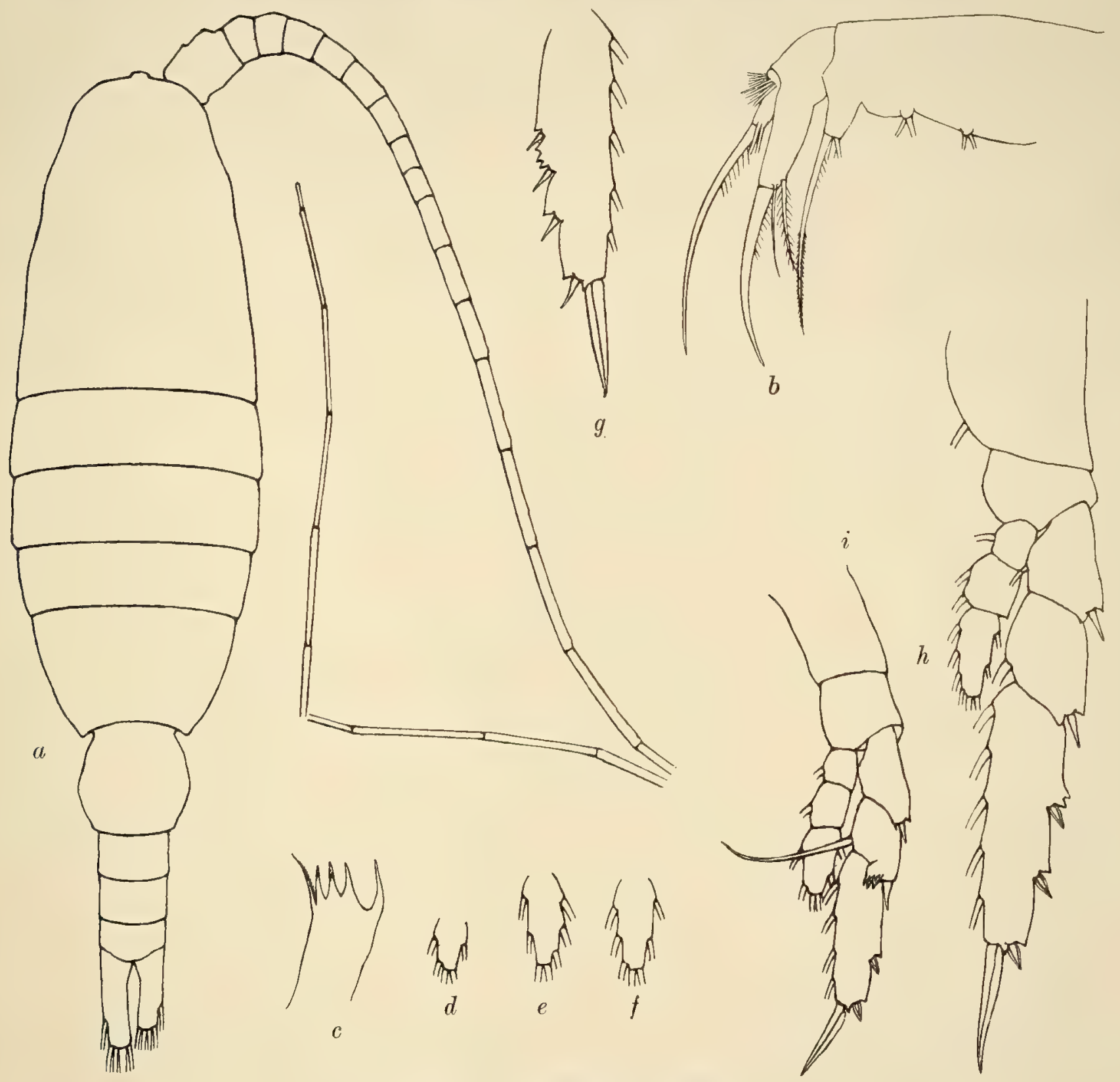

Textfig. 55. Alloiorhabdus medius.

$a$ Rückenansicht. $b$ hinterer Maxilliped. $c$ Zahnplatte. $d$ Letztes Glied des Innenastes vom 1. Fuß. $e$ Letztes Glied des Innenastes rom 2. Fuß. $f$ Letztes Glied des Innenastes rom 4. Fuß. $g$ 3. Fuß. $h$ 3. Fuß $i .5$. Fuß.

lang, der erstere trägt 5 lange Borsten, der letztere 8 (oder 9) lange Haken. Der 1. Außenlobus hat 4 lange Borsten, der 2. Innenlobus nur eine dicke und lange Borste.

Die vorderen M a xilli ped e $\mathrm{n}$ gleichen genau denen von Heterorhabdus longicornis, ebenso sind die sehr dünnen hinteren Maxillipeden denen von Heterorhabdus longicornis ähnlich. (54 b.)

Die Zahl der Randborsten an den Innenästen der S c h w i m m f ü B e stimmt genau mit der Zahl derselben bei der vorigen Art überein. Das 3. Glied hat beim 1. Paare 5, beim 2. Paare 7, 
beim 3. Paare 8, beim 4. Paare 7 und beim 5. Paare 5 Randborsten. (55 d-f.) Der Außenast des 3. Paares ist nicht verbreitert und halb so breit als lang; seine Endsäge ist halb so lang wie das letzte Glied. Die 3 Außenranddornen sind klein, nicht zwischen Dornen eingeschlossen und unmittelbar proximal vom 2. Dorn ist der Rand jederseits gezähnt, trägt 2 oder 3 Zähnchen. Die Innenäste vom 2. bis 4. Paar erstrecken sich bis über den Rand vom 2. Gliede des Außenastes; die Außenränder des 1. und 2. Gliedes tragen Dornen. Die Endsägen haben eine sehr fein gekerbte Kante der Chitinlamelle mit äußerst feinen, anliegenden Zähnchen. Beim 5. Paare sind 1, 1, 6 Randborsten des Innenastes vorhanden und 0, 1,4 am Außenaste. Die Endsäge ist nicht ganz halb so lang wie das letzte Glied des Außenastes. Das 2. Glied des Außenastes trägt am distalen Außenrand einen Haufen von Dornen, der aus 4 kleineren vorn, 3 größeren hinten und einem starken, konischen, äußeren Dorne mit dicker Basis besteht, was stark an Heterorhabdus longicornis erinnert. Die Säbelborste ist nicht dicker als eine der übrigen.

Die Tiere wurden am 13. Februar 1902 (2000 m), 18. Februar 1903 (400 m), 27. März 1903 $(2000 \mathrm{~m})$, also nur im tiefen Wasser vor dem antarktischen Sockel gefunden. Sie sehen einem größeren Heterorhabdus longicornis ähnlich (vielleicht dem wenig bekannten Heterorhabdus major DAHL), aber bei der sonst fast vollkommenen Nachahmung dieser Art ist die Zahl der Borsten der Füße bei Alloiorhabdus medius gänzlich verschieden und widerspricht ihrer Einreihung in die Gattung Heterorhabdus.

\section{Hemirhabdus n. g.}

Diese Gattung wurde für eine von RICHARD beschriebene Art, Heterochaeta grimaldi (Bull. Soc. zool. France vol. 18) und eine andere, viel kleinere aufgestellt, welche sich in den atlantischen Fängen des „Gauss" fand. Diese Tiere sind von Heterorhabdus erheblich verschieden, besonders im Bau der vorderen Maxillipeden und der Maxillen, und auch in der Zahl der Borsten an den Innenästen der Schwimmfüße. Die Körpergestalt ist von der bei Heterorhabdus etwas verschieden, kräftiger, gedrungen und die Furkaläste sind weniger unsymmetrisch. Die vorderen Maxillipeden tragen, an den beiden letzten Loben starke, sichelförmige Haken, die mit Zähnen bewaffnet sind. Diese sind gänzlich verschieden von den Feilenborsten von Heterorhabdus, den einfachen Hakenborsten von Mesorhabdus SARs und den schwachen Borsten von Disseta.

Die hinteren Antennen haben stets viel längeren Innenast als Außenast, sind dadurch von denen bei Heterorhabdus verschieden, wo die Äste gleich lang sind, und auch von Mesorhabdus, bei welchem der Außenast verhältnismäßig unbedeutend ist.

Die Maxillen sind von denen bei Heterorhabdus völlig verschieden, durch den großen ovalen Außenast und die Zahl der Borsten. Die Mandibeln gleichen mehr denen von Heterorhabdus als von den verwandten Gattungen Mesorhabdus und Disseta im Besitz eines dieken Außenzahnes und eines Paares starker, dreispitziger Zähne.

Die Schwimmfüße sind breit, ähnlich denen von Disseta, aber von denen aller verwandten Gattungen verschieden in der Borstenzahl der Innenäste. Bei Hemirhabdus finden sich am letzten Gliede des Innenastes 7, bei Disseta dagegen 8, bei Heterorhabdus und Mesorhabdus aber 5. Beim 5. Paare sind 6, beim 1. nur 4 Borsten vorhanden. 
155. Hemirhabdus grimaldii Richard. (Textfig. 56 a, b.)

o 9,0 mm lang, davon Cephalothorax 6,6 mm, Abdomen 2,4 mm. Der $\mathrm{K}$ o $\mathrm{p}$ fist schmal, gerundet und mit 2 kurzen Rostralfilamenten versehen, welche von kurzer Chitinplatte entspringen. (56 a.) Er ist vom 1. Thorakalsegment abgegliedert; das letzte Segment hat abgerundete Ränder. Das $\mathrm{A}$ b d o m e n ist etwas mehr als ein drittel so lang wie der Vorderkörper, das Genitalsegment groß, mit stark vorspringender Anschwellung. Die Furkaläste sind ungleich, der linke länger als der rechte und beide vom Analsegment abgegliedert. An jeder Seite treten 5 Schwanzborsten auf, von denen die 2 . von innen auf der linken Seite sehr dick und außerordentlich lang, wie bei Heterorhabdus ist. Die vorderen Antennen überragen mit etwa 3 Gliedern die Furka, das vorletzte Glied ist dreimal so lang als das Endglied und zehnmal so lang als breit. Der Innenast der hinteren Antennen ist länger als der Außenast um etwa ein drittel seiner Länge; das 1. und 7. Glied des Außenastes sind gleich lang, das 1. Glied des Innenastes ist verlängert und drei siebentel so breit als lang.

Die M a n d i be $1 \mathrm{n}$ haben etwa gleich lang Äste; die Zahnplatte hat jederseits einen verdickten und gekrümmten äußeren Zahn, dann nach einem breiten Zwischenraum einen kurzen, dreieckigen Zahn, ferner zwei gleich große, lang dreispitzige Zähne und einen inneren kurzen, dornigen Zahn.

Die M a xille n haben einen großen, ovalen Außenast mit 5 Randborsten, am kurzen Innenaste 6 Borsten, am 2. Basalglied 1 Borste, ferner am etwas vierseitigen Innenlobus 9 schwache Haken, am 2. Innenlobus 1 Borste und am unbedeutenden 1. Außenlobus 5 Borsten.

Die vorderen Maxillipeden haben sehr kleine Loben mit Ausnahme des 5., welcher ein kurzer Zapfenlobus ist. Der 1. Lobus hat 4 Borsten, der 2. fehlt, der 3. hat 2, der 4. 2 Borsten und eine sehr kurze, schwache Hakenborste, der 5. einen mächtigen, sichelförmigen Haken, der mit kurzen, weitstehenden (6 bis 7) Zähnen bewehrt ist, und eine kurze Borste, und der
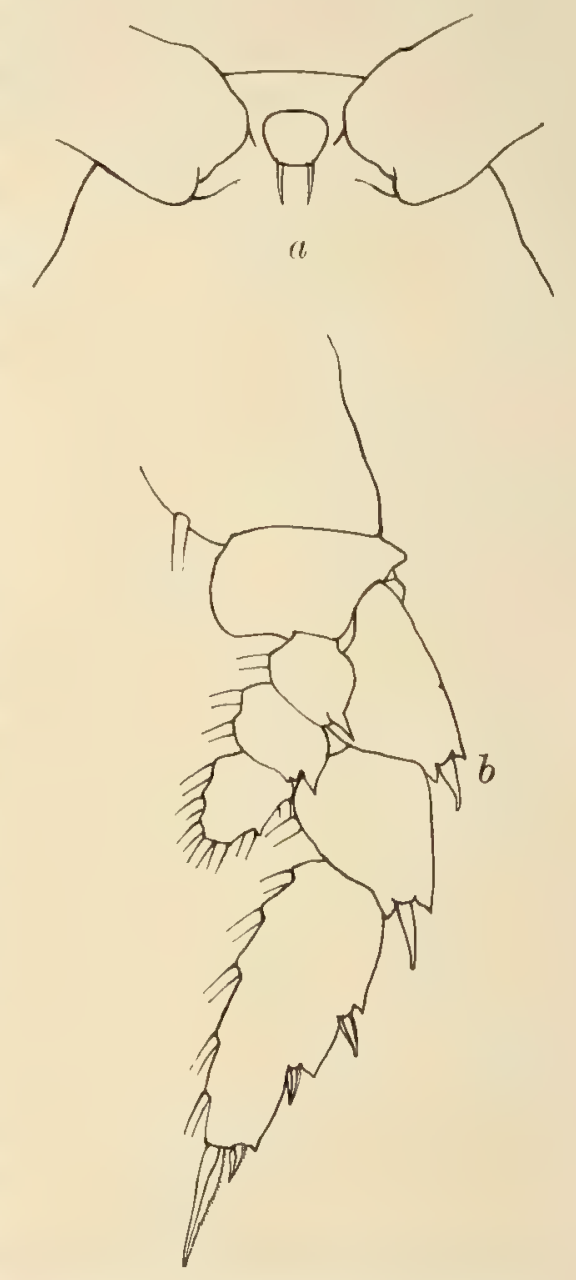

Textfig. 56. Hemirhabdus grimaldi. $a$ Kopf mit Rostrum. $b$ 2. Fuß. 6. Lobus einen längeren, aber schwächeren Haken gleicher Art mit 6 Zähnen und 3 kurzen Borsten. Der Innenast trägt nur kurze, schwache Borsten.

Die hinteren Maxillipeden haben ein kurzes 1. und ein längeres 2. Basalglied, das die Länge des Innenastes erreicht. Bei dem letzteren ist das 1. Glied länger als das 2., die Borsten der Basalia sind schwach, und Dornen sind nicht vorhanden. Die Borsten des Innenastes sind etwa so lang wie die beiden Basalglieder.

Alle $\mathrm{F}$ ü $ß$ e haben dreigliedrige Äste. Beim 1. Paare finden sich Randborsten an jedem Basalgliede; der Innenast erstreckt sich bis zur halben Länge des 3. Gliedes vom Außenaste. Der letztere hat 2 Außendornen, von denen der des 1. Gliedes lang und dünn ist. Auf die 3 Glieder des Innen- 
astes verteilen sich die Randborsten zu 1, 2, 5 und die Außenränder der beiden proximalen Glieder sind in starke Dornen verlängert.

Beim 2. Fußpaar (56 b) ist das 3. Glied des Außenastes so lang wie die beiden ersten Glieder und halb so breit als lang. Es hat 3 Außendornen und 5 Randborsten. Der Innenast ist klein und trägt 1, 2, 7 Randborsten. Beim 3. und 4. Paar ist das letzte Glied der Außenäste viel länger als die beiden proximalen Glieder und doppelt so lang als breit. Die Innenäste sind kurz, überragen nur ein wenig das Ende vom 2. Gliede der Außenäste. Die Außendornen des Außenastes und die Randborsten des Innenastes treten in derselben Zahl wie beim 2. Fußpaar auf $(1,2,7)$; die distale Borste am Rande des 3. Gliedes vom Außenast ist viel kleiner als die übrigen 4 Borsten.

Das 5. Fußpaar ist klein und hat breite Äste; der Innenast reicht nicht bis zum Ende des 2. Gliedes vom Außenaste; die Randborsten der ersten beiden Glieder vom Innenast sind breit, aber nicht lang und im distalen Teile stark mit Zähnen besetzt; die Borsten des Innenastes sind nach der Formel 1, 1, 6 angeordnet.

Das 2. bis 5. Fußpaar sind breit und ihre Endsägen kurz, mit breitem, gekerbtem (nicht gezähntem) Chitinrande.

Das ô gleicht dem + , hat auch dieselbe Größe. Die Mundorgane beider sind auch ähnlich, nur hat der 1. Innenlobus der Maxille beim ơ 4 Haken statt 9 beim ?.

Das 1. bis 4. Fußpaar ist wie beim o gebildet, das 5. wie bei den verwandten Gattungen modifiziert. Beim rechten Fuß ist das 2. Basalglied am distalen Innenrand erweitert und der ganze Rand ist mit steifen Borsten behaart. Das 2. Glied des Außenastes hat eine vortretende, eiförmige Erweiterung mit einem distalen Haarbüschel. Das letzte Glied ist etwas länger als das 2., trägt distal einen kurzen Dorn und hat dünnen Außenrand mit 2 kurzen Dornen, der etwas eingefaltet ist, so daß eine Art von Löffel gebildet wird. Beim linken Fuß ist der Innenrand des 2. Basalgliedes mit steifen, kurzen Borsten bedeckt, und die 3 Glieder des Außenastes sind ungefähr gleich lang. Das letzte Glied ist in einen stumpfen Dorn verlängert, mit kleinem Dorn am Innenrand. Am distalen Außenrande des 2. Gliedes vom Außenaste findet sich ein Dorn und ein kurzer am 1. Gliede. Die Innenäste beider Seiten sind dreigliedrig und tragen $0,1,6$ Randborsten.

156. Hemirhabdus falciformis n. sp. (Textfig. 57 a-f.)

q $5,6 \mathrm{~mm}$; Cephalothorax 4,2 mm, Abdomen 1,4 mm lang. K o p f und Körper sind sehr ähnlich wie bei Hemirhabdus grimaldii gestaltet, nur die Furkaläste sind weniger ungleich. Die linke Seite trägt eine lange, heterorhabdoide Borste. (57 a.)

Bei den hinteren A n t e n n e n (57b) sind die Äste mehr gleich an Länge, doch ist der Innenast noch beträchtlich länger als der Außenast, welcher nur bis zum Ende des 1. Gliedes vom Innenaste reicht. Das 1. und 2. Glied des Außenastes sind deutlich getrennt und das 8. Glied ist das längste. Die vorderen Maxillipeden weichen dadurch ab, daß die proximalen 4 Loben deutlicher abgegrenzt sind, daß die Borsten des 3. und 4. Lobus stark und gekrümmt und mit feilenartigen Borsten besetzt sind. Die Borste des 2. Lobus hat denselben Charakter, ist aber nicht gekrümmt. Die großen, sichelförmigen Haken des 5. und 6. Lobus sind dichter mit Zähnen besetzt als bei Hemirhabdus grimaldii, besonders beim 5. Lobus. Die Zähne der Mandi- 
b u la r p latte weichen dadurch ab, daß nur 3 vorhanden sind, ein äußerer starker Zahn (bei unserem Exemplar abgebrochen) mit weitem Zwischenraum zwischen ihm und den beiden inneren dreispitzigen Zähnen. (57 c u. d.)

Die $\mathrm{M}$ a $\mathrm{xi} 1 \mathrm{l}$ e (57 e) hat weniger Borsten als bei Hemirhabdus grimaldii: 3 am 1. Außenlobus, 4 am Außenast und 3 große Borsten mit 3 kleinen einfachen am 1. Innenlobus. Wie bei Hemirhabdus grimaldii hat der Innenast 6, das 2. Basalglied nur 2 Borsten. Die hinteren Ma xillipeden gleichen denen von Hemirhabdus grimaldii, aber das 1. und 2. Glied des Innenastes sind nicht so ungleich.
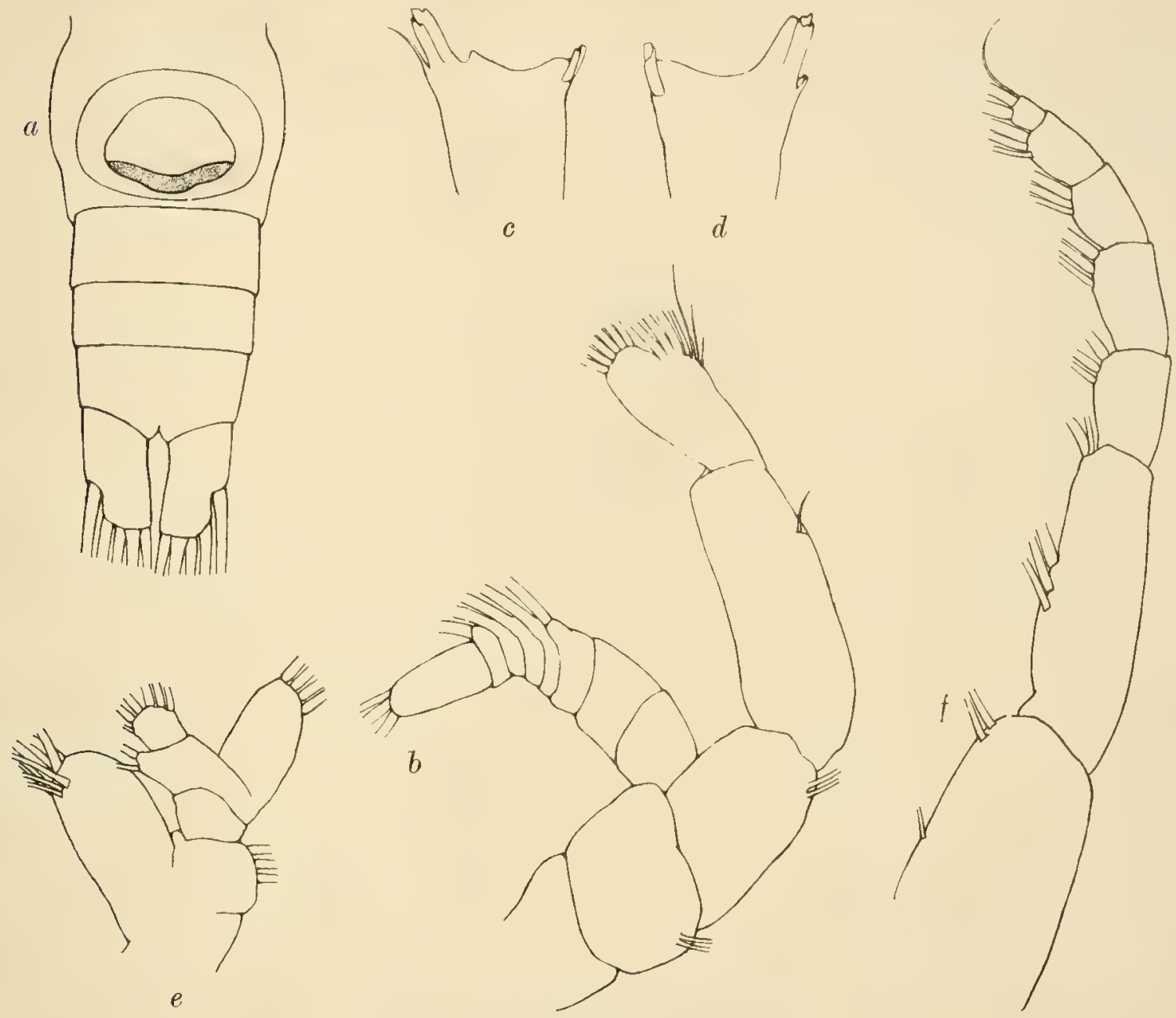

Textfig. 57. Hemirhabdus falciformis ㅇ․

a Abdomen. $b$ hintere Antenne. $c$ und $d$.Mandibel, Kauplatten, $e$ Maxille. $f$ hinterer Maxilliped.

Auch die $\mathrm{Schwimm} \mathrm{m}$ ü $\mathrm{Be}$ sind wie bei jener Art gebildet; die Innenäste der 2. bis 4. Paare haben 1, 2, 7, beim 1. Paar 1, 2, 5 Randborsten.

Das 5. Fußpaar weicht nur insofern von dem bei Hemirhabdus grimaldii ab, als das 1. Basalglied am Innenrand einen kurzen Dorn trägt, welcher die gewöhnliche Borste ersetzt und bei Hemirhabdus grimaldii fehlt; daß die beiden Borsten des 1. und 2. Gliedes vom Innenaste verhältnismäßig dicker und stärker gezähnt sind (eher gleich einer Pennatula) als bei Hemirhabdus grimaldii. Die Randborsten des Innenastes sind zu 1, 1, 6 angeordnet. 
Das 5. Fußpaar des ô weicht nur wenig von dem bei Hemirhabdus grimaldii ab. Es ist mehr gedrungen, die 2. Basalglieder sind am Rande stärker behaart, die Außenäste weniger lang und der Fortsatz am 2. Gliede des Außenastes vom rechten Fuße weniger eiförmig gestaltet.

Das Exemplar wurde am 22. Oktober 1901 im südlichen Atlantischen Ozean bei einem Vertikallang aus $3000 \mathrm{~m}$ erbeutet.

Mesorhabdus G. O. SARS.

\section{5\%. Mesorhabdus brevicaudatus WOLFENDEN.}

(Plankton Studies 1905.)

Diese Gattung sollte nach SARs (Bull. Mus. Oceanogr. Juni 1905) eine Mittelstellung zwischen Heterorhabdus und Disseta einnehmen, sich von der ersteren durch den Bau der Mandibeln und besonders durch den der vorderen Maxillipeden unterscheiden, bei denen alle Loben wohl entwickelt und mit Haaren ausgestattet sind. Einige von diesen sind in krallenförmige Dorne verwandelt.

Die Art Mesorhabdus annectens SARs soll (Bull. Inst. Ocean. 1907) nach SARS identisch mit Heterorhabdus brevicaudatus Wolfenden (Plankton Studies 1905) sein, und Farran erwähnt sie als Mesorhabdus brevicaudatus Wolfenden (Fisheries Ireland Soc. Inv. 1906 [1908]). Das Tier ist 3,15 mm lang, der Cephalothorax etwas mehr als doppelt so lang als das Abdomen, der Kopf deutlich vom 1. Segment abgegliedert; das Genitalsegment tritt ventral stark hervor und ist meist auf der linken Seite angeschwollen; die Furkaläste sind etwa 1/1⁄2mal so lang als das Analsegment, der linke von ihnen ist etwas länger als der rechte und nur doppelt so lang als breit.

Die vorderen A n t e $\mathrm{n} \mathbf{n}$ e $\mathbf{n}$ sind nur so lang wie der Körper; die hinteren Antennen haben einen sehr kurzen Außenast und längeren und dickeren Innenast, der dreimal so lang wie der Außenast ist. Die vorderen $\mathrm{M}$ a $\mathrm{x}$ ill i pede $\mathrm{n}$ sind von denen von Heterorhabdus in der Größe und der Stellung der Loben verschieden. Der 1. Lobus trägt 6 Borsten, der 2., 3. und 4. je 3, der 5. eine gekrümmte Hakenborste, der 6. einen ähnlichen, aber dünneren Haken, und die Borsten des Innenastes sind sehr lang. Die hinteren Maxillipeden haben Innenast und 2. Basalglied von gleicher Länge, und beide sind länger als das 1. Basalglied. Das 2. Glied des Innenastes ist etwas länger als das 1. Alle Borsten sind schwach und ein langer Dorn fehlt. Der Innenast der M a $\mathbf{n}$ d i b e ln ist viel länger als der Außenast; die Zahnplatte hat 6 etwa gleich weit voneinander abstehende Zähne, die denen bei Disseta gleichen.

Die Maxillen haben einen sehr großen, ovalen Außenast, am 2. Basalgliede 2 und am kurzen Innenaste 4 Borsten; der 1. Innenlobus ist lang, etwas viereckig, mit 7 Haken, von denen der eine sehr dick ist, und 3 Borsten. Wohlausgebildete Innenloben sind vorhanden, von denen der 2. 2 Borsten, der 3. nur 1 Borste hat. Der 1. Außenlobus hat 4 Borsten, ist aber unbedeutend.

Das 3. F u ß p a a r gleicht dem 4. Uber die Borsten dieser Füße ist nichts anzugeben, da sie fehlen. Das 5. Fußpaar hat dreigliedrige Äste; das 3. Glied des Außenastes ist größer als das 2., hat 4 Innenrandborsten und 2 Außendornen. Das 2. Glied trägt eine dünne Säbelborste; der Innenast ist kurz, der Außenrand des 1. und 2. Gliedes in Dornen verlängert und Randborsten treten entsprechend der Formel 1, 1,6 auf. 
Diese Art wurde von mir an der Westküste Irlands gefangen, gehört nicht eigentlich zu der Sammlung des „Gauss". Ich benutze die Gelegenheit, sie zu beschreiben, um die Beziehungen der verwandten Arten von Heterorhabdus zu der neuen Gattung von SARS zu erläutern. Wenn die Arbeit des letzteren ausführlich publiziert sein wird, wird es sich ergeben, ob die Meinung von SARS richtig ist, daß Mesorhabdus brevicaudatus WoLFENDEN (= Heterorhabdus brevicaudatus) mit seinem Mesorhabdus annectens identisch ist.

\section{Disseta Giesbrecht.}

Diese Gattung, 1892 von GIESBRECHT beschrieben, scheint im Atlantischen Ozean nicht angetroffen zu sein, bis ich sie 1904 in den Tiefseefängen bei der Westküste Trlands wiederfand und unter dem Namen Heterorhabdus grandis beschrieb (Journ. Marine Biol. Ass. 1904). Das von mir 1905 (Plankton Studies) als zu Heterorhabdus grandis gehörig beschriebene $\hat{o}$ muß also auch zu dieser Gattung gestellt werden. EsTERLY (University of California Zool. Dez. 1906.) erwähnt als Disseta grandis eine Art, welche in einigen Punkten von Disseta palumboi GIESBRECHT abzuweichen scheint. Die Exemplare, welche vom ,Gauss" mitgebracht wurden, scheinen zwischen diesen beiden Arten, die beide aus dem Pazifischen Ozean stammen, in der Mitte zu stehen. Esterlys Art Disseta grandis ist durch die bedeutendere Größe von $8,3 \mathrm{~mm}$ beim q ausgezeichnet auch durch Unterschiede im Bau der 5. Füße und der Kauplatte, ferner ist des letzte Thorakalsegment asymmetrisch, länger auf der linken Seite. Das Genitalsegment ist mehr gerundet und asymmetrisch. Der Darm enthält orangefarbenes Pigment und die Füße sind rötlich gefärbt.

Giesbrecht gibt die Größe von Disseta palumboi zu 5,7 $\mathrm{mm}$ an, während Disseta grandis mehr als $8 \mathrm{~mm}$ erreicht. Die atlantischen Exemplare sind alle $7 \mathrm{~mm}$ oder etwas darüber groß und weichen etwas von Disseta palumboi in den folgenden Punkten ab: Die vorderen Antennen sind nicht ganz so lang, reichen nur mit etwa 4 Gliedern, anstatt mit 6 bei Disseta palumboi, über die Furka hinaus. Der Innenast der hinteren Antennen und auch der Mandibeln ist viel länger als der Außenast, anstatt daß beide gleich sind, wie bei Disseta palumboi. Die Maxillen haben am 1. Gliede des Innenastes 3, am 2. und 3. 9 Borsten, also $12 \mathrm{im}$ ganzen gegen 9 bei Disseta palumboi. Das letzte Thorakalsegment ist auf beiden Seiten in gleicher Weise verlängert, und das Genitalsegment ist jederseits angeschwollen. Der Innenast des 1. Fußpaares hat 1, 2, 5 Randborsten, beim 2., 3. und 4. sind 1, 2, 8 und beim 5. 1, 1,6 vorhanden. Die frisch gefangenen Exemplare von der irischen Küste waren durch orangefarbene Pigmentierung des Vorderkörpers ausgezeichnet, welche bei konservierten Exemplaren verschwindet.

Sonst stimmt unsere Art mit GIESBRECHTs Beschreibung von Disseta palumboi überein, aber die oben erwähnten Unterschiede machen die Identität zweifelhaft. Dasselbe gilt für Disseta grandis, deren Größe auch schon eine Unterscheidung der Arten nahelegt. Da die atlantischen Exemplare also mit keiner der beiden pazifischen Arten genau übereinstimmen, schlage ich für sie den neuen Namen Disseta atlantica vor.

158. Disseta atlantica n. sp. Pl.35.fiq. 5

o $7 \mathrm{~mm}$ lang, Cephalothorax 2 $\frac{1}{2} \mathrm{mal}$ so lang als das Abdomen. Das Ge nitals e g m e $\mathrm{nt}$ ist so lang wie die beiden folgenden, der linke Furkalast viel länger und breiter als der rechte und 
trägt eine sehr dicke und lange Borste. Das Genitalsegment ist symmetrisch, sowohl rechts wie links, seitlich angeschwollen. Die vorderen A n te $\mathrm{n} n$ e $\mathrm{n}$ überragen mit 4 Gliedern die Furka, das vorletzte Glied über zweimal so lang als das letzte. Die ersten 7 Glieder sind klein, das 8., 9. und 10. fast vollständig geteilt, das 11. und 12. klein, das 13. länger, das 17, 18. und 19. am längsten von allen. Der Innenast der hinteren Antennen und ebenso der der $\mathrm{M}$ a $\mathrm{n}$ dibe $\mathrm{ln}$ ist länger als der Außenast. Die vorderen $\mathrm{M}$ a xilli peden haben $\mathbf{5}$ Borsten und einen kleinen Dorn am 1. Lobus; der 2., 3. und 4. Lobus haben 3 Borsten; von den 3 Anhängen des 5. Lobus ist einer ein feiner Haken, der gezähnt ist und sich auf der konkaven Seite findet; der 6. Lobus hat einen ähnlichen, aber dünneren Haken. Der Innenast trägt 6 lange Borsten.

Die M a xille n gleichen denen von Disseta palumboi bis auf die oben erwähnten Unterschiede.

Die $\mathrm{Schwimmfüße} \mathrm{sind} \mathrm{bei} \mathrm{diesen} \mathrm{beiden} \mathrm{Arten} \mathrm{gleich.}$

Das $o^{t}$ ist nur wenig kleiner als das $q^{\circ}$ Die linke, gekniete A n te n n e zeigt jenseits des Gelenks 4 Glieder. Die Längen der letzten 5 Glieder, also das letzte vor dem Gelenk noch mitgerechnet, verhalten sich wie $8: 19: 20: 10: 6$. Das 2. Glied ist unvollkommen in zwei geteilt. Das Glied vor dem Gelenk trägt an der oberen Fläche einen Dorn, der vorwärts gerichtet ist und fast parallel mit dem Gliede liegt (wie bei Metridia). Die M u n d o r g a n e gleichen denen vom \&, aber das 5. Beinpaar ist charakteristisch.

Der rechte $\mathrm{Fu} B$ des 5. Paares hat am 2. Basalglied einen kleinen aufrechten, lamellären Fortsatz, welcher am Innenrande behaart ist. Das 2. Glied vom Außenast ist kugelig, mit kräftigem, kurzem und etwas gekrümmtem Dorn, welcher sich von breiter Basis erhebt, und einem kurzen Zahn unter demselben. Das 3. Glied ist ziemlich viereckig, kurz, mit stark gekrümmtem Dorn, welcher sich von der distalen Innenkante, und einem kurzen Dorn, der sich nahe an der distalen Außenkante erhebt. Das 2. Glied vom Innenast ist in der Mitte am breitesten, und sein Innenrand ist stark behaart.

Das 2. Basalglied des linken Fußes hat konvexen Innenrand und einen kurzen, behaarten Fortsatz; das 2. Glied vom Außenaste trägt am Innenrande 2 starke Dornen, das 3. Glied hat einen Innenranddorn, einen Enddorn, einen langen gekrümmten Dorn am distalen Außenrand und einen kurzen Randdorn unter demselben. Das 2. Glied vom Innenast ist groß und trägt am Außenrand einen vorspringenden, mehr oder weniger viereckig gestalteten Anhang. Der Innenast dieses Fußes hat nur 2 Glieder.

Gefunden wurde diese Art am 26. September 1903 (3000 m), 9. und 13. Oktober 1903 (3000 m), 12. November $1901(3000 \mathrm{~m})$ im Atlantischen Ozean.

\section{Lucicutia Giesbrecht.}

Mehrere neue Arten wurden vor kurzem noch dieser Gattung angereiht, und es ist möglich, die bekannten Arten derselben in zwei Gruppen zu ordnen:

1. Gr u p pe, nicht über $2 \mathrm{~mm}$ lang:

a) der Innenast des 1. Fußpaares nur zweigliedrig,

Lucicutia clausi, longiserrata, ovalis,

B) der Innenast des 1. Fußpaares ist dreigliedrig,

Lucicutia flavicornis, longicornis, frigida, curta; 
2. Gruppe, über $3 \mathrm{~mm}$ lang,

a) der Innenast des 1. Fußpaares nur zweigliedrig,

Lucicutia magna,

ß) der Innenast des 1. Fußpaares dreigliedrig,

Lucicutia grandis, lucida, bradyana, aurita, maxima, major.

Bei den neuen Arten, Lucicutia gracilis, Lucicutia intermedia und Luticutia tenuicauda, wurde von SARs (Bull. Mus. Oceanogr. June 1905) der Bau der Füße nicht erwähnt, aber sie alle sind über $3 \mathrm{~mm}$ groß.

Den Namen Lucicutia magna erhielt 1903 von mir ein $\hat{o}$, von dem das of nicht bekannt war, aber 1904 beschrieb ich ein $q$ unter dem Namen Lucicutia atlantica, welches, wie ich glaube, das ? von Lucicutia magna sein dürfte. Lucicutia gracilis SARS soll nach SARS damit identisch sein, daher müssen die beiden Namen Lucicutia gracilis und Lucicutia atlantica fallen.

Was Lucicutia maxima STEUER anbetrifft, so hielt ich sie früher für wahrscheinlich identisch mit der von GIESBRECHT 1895 und 1898 als Lucicutia grandis beschriebenen Art, doch habe ich mich nun nach Untersuchung vieler Exemplare davon überzeugt, daß sie nicht gleichartig sind.

Lucicutia bicornuta WOLFENDEN (1905) kann vielleicht mit Lucicutia aurita SARS (1905) identisch sein, aber keiner der beiden Autoren scheint bemerkt zu haben, daß Cleve bereits 1904 Plankton of the S. African Seas) eine Lucicutia aurita beschrieb. Lucicutic bicornuta jedoch scheint ganz verschieden von Lucicutia aurita CLEVE zu sein, und die Art von SARS ist nicht genügend gekennzeichnet, um ihre Stellung beurteilen zu lassen.

Lucicutia bradyana CLeVE scheint nur in einigen unbedeutenden Punkten von Lucicutia grandis Giesbrecht verschieden zu sein, ist aber wahrscheinlich nicht mit BRAdy's Art (Challenger Report) verwandt. Die Natur dieser Art, welche BRADY unter dem Namen Lucicutia flavicornis beschrieb, muß noch zweifelhaft bleiben. Sie ist sicher nicht mit der letzteren Art verwandt, aber die Größe von 6,2 mm sowie die Gestalt des Analsegments lassen sie nahestehend, wenn nicht direkt identisch mit Steuer's Lucicutia maxima erscheinen. Ohne Zweifel variieren die Arten von Lucicutia beträchtlich, worauf GIESBRECHT schon (Fauna und Flora von Neapel) im Falle von Lucicutia flavicornis aufmerksam machte, aber eingehende Untersuchung der verschiedenen vom „Gauss" gesammelten Arten veranlaßte mich, meine Meinung von dem weitgehenden Variieren dieser Formen zu ändern. So hielt ich es früher für möglich, daß Lucicutia maxima und Lucicutia grandis identisch sein könnten, glaube aber heute nicht mehr daran. Die neulich von SARs beschriebenen Arten Lucicutia intermedia und Lucicutia tenuicauda sind nicht genügend gekennzeichnet, um ihre Beziehungen zu andern Arten festzustellen, aber Lucicutia aurita SARs dürfte sich wohl entweder mit Lucicutia aurita CLEVE oder mit Lucicutia bicornuta WOLFENDEN als identisch erweisen.

159. Lucicutia grandis Gifsbrecht. (Textfig. 58 a und b.)

Diese Art wurde nach einem einzigen of aus dem Pazifischen Ozean aufgestellt. Das $q$ wurde von mir erst später an der Westküste Irlands angetroffen (Journ. Marine Biol. Association vol. VII, 1904) und dann auch von FARRAN dort gefunden.

Das o ist etwa 6,5 mm lang und weicht von denen anderer Arten hauptsächlich in den Längenverhältnissen der Abdominalsegmente ab. (58 a.) Das G e $\mathrm{n}$ i t a $1 \mathrm{~s}$ e g $\mathrm{m}$ e $\mathrm{n}$ t ist nicht ganz so lang 


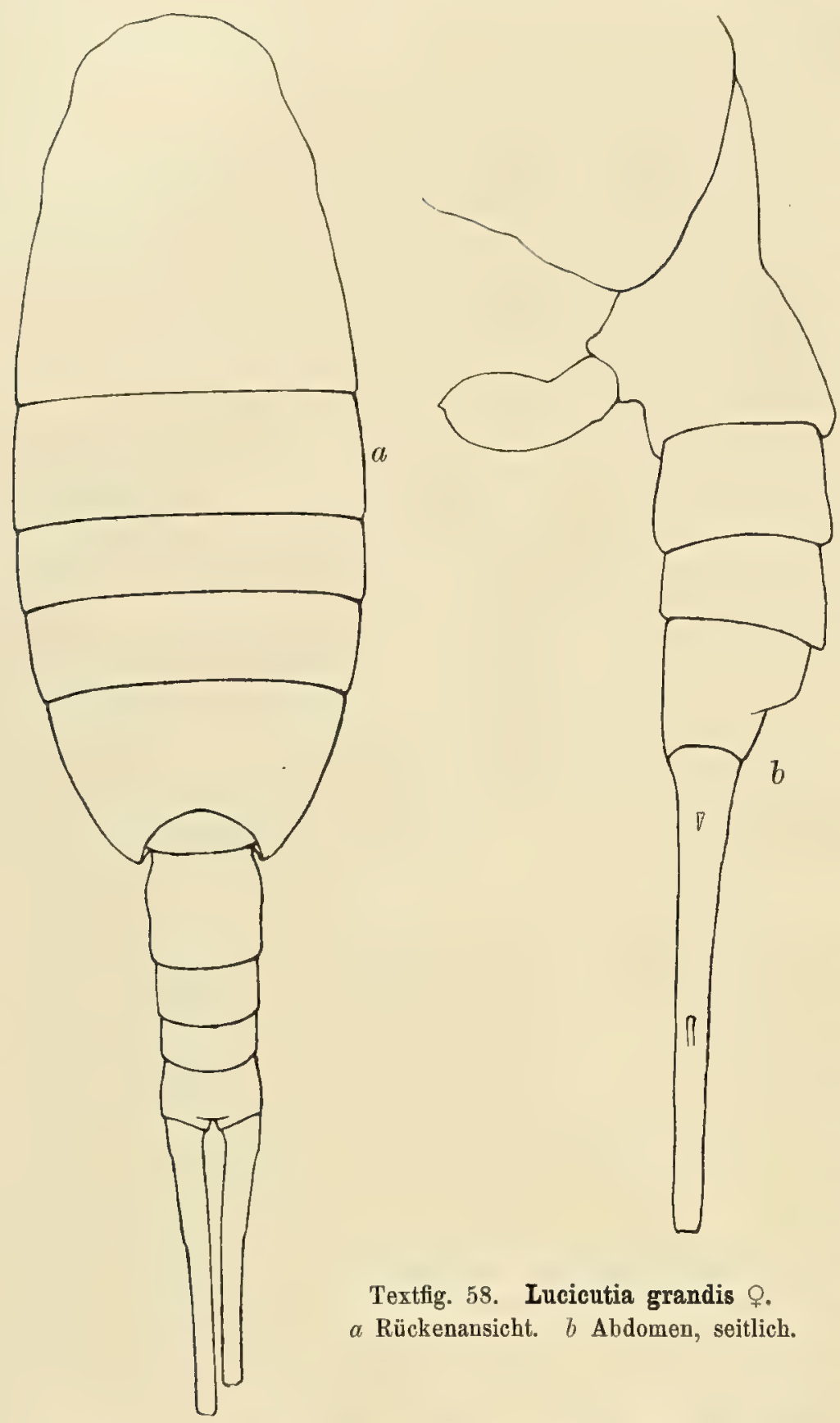

wie die beiden nächsten, welche untereinander ziemlich gleich lang und etwas kürzer als das Analsegment sind. Die Furkaläste sind etwa zweidrittel so lang als das Abdomen und ungefähr sechsmal so lang als breit. Die Genitalwucherung hat auf der linken Seite eine vorspringende Klappe. (58 b.)

Die vorderen Antennen überragen mit 4 oder 5 Gliedern die Furka. Bei den hinteren Antennen ist der Außenast etwas kürzer als der Innenast, und die $\mathrm{Mandibularäste}$ sind in ähnlicher Weise ungleich. Alle $\mathrm{F}$ ü $\mathrm{B}$ e haben dreigliedrige Äste. Das letzte Glied des Außenastes vom 5. Fußpaar ist ebenso lang wie das 2. und das halbe 1. zusammen und ungefähr $2 \frac{1}{4} \mathrm{mal}$ so lang als die Endsäge. Der Innenast ist kurz und seine Borsten (am Innenrand und an der Spitze) stehen zu 1, 1, 5. Das ô wurde von Giesbrecht ausführlich beschrieben.

Vom „Gauss“" wurde diese Art im Atlantischen Ozean am 5. November $1901(1000 \mathrm{~m})$, 18. Dezember 1901 (2500 m), 22. August $1903(1500 \mathrm{~m})$, 26. September 1903 (3000 m), 30. September $1903(1500 \mathrm{~m}), 9$. Oktober 1903 $(3000 \mathrm{~m})$ gefunden, ferner im südlichen

Eismeer am 6. März 1903 (1200 m), 10. März 1903 (3000 m) und 27. März 1903 (2000 m). Die antarktischen Exemplare sind allem Anscheine nach mit den atlantischen identisch.

160. Lucicutia magna Wolfenden. (Textfig. 59 a und b.)

Das ơ wurde von mir 1903 (Journ. Mar. Biol. Ass. 1903) als Lucicutia magna, das $q 1904$ wahrscheinlich als Lucicutia atlantica (Journ. Mar. Biol. Ass. 1904) von der Westküste Irlands beschrieben und auch von FARRAN dort angetroffen. Dann beobachtete ich diese Art in der Bai von Biscaya, und schließlich waren in den Sammlungen des „Gauss“" einige Exemplare aus dem Atlantischen Ozean und der Antarktis vorhanden. Da es mir nicht zweifelhaft erscheint, daß alle diese Exemplare derselben Art angehören, so hat diese eine sehr weite Verbreitung. 
o etwa $3,5 \mathrm{~mm}$ lang, der Cephalothorax etwa $1 \frac{1}{2} \mathrm{mal}$ so lang als das Abdomen. Das Genitalsegment ist ungefähr so lang wie die beiden folgenden Segmente; das Analsegment ist sehr wenig länger als das vorhergehende. Die Furkaläste sind etwa fünfmal so lang als breit und ebenso lang wie die letzten beiden Segmente, die vorderen A n t e $\mathrm{n} n$ e $\mathrm{n}$ um 4 Glieder länger als das ganze Tier. Die Äste der hinteren Antennen sind ungefähr gleich lang; das 1. Fußpaar hat zweigliedrigen Innenast, und die Endsäge des 5. Fußes ist halb so lang als das letzte Glied. Die Gliederung des 1. Fußes ist charakteristisch, da die einzigen andern bekannten Arten mit zweigliedrigem Innenast Lucicutia clausi, Lucicutia ovalis und Lucicutia longiserrata sind.

Gefunden wurde die Art im Atlantischen Ozean am 22. August 1903 (1500 m), 30. September 1903 (1500) m, 9. Oktober $1903(3000 \mathrm{~m})$ und im Eismeer am 10. März $1903(3000 \mathrm{~m})$ und 27. März $1903(2000 \mathrm{~m})$, zusammen mit der vorigen.

\section{Lueicutia major n. sp.}

of $8-8,2 \mathrm{~mm}$ lang. Der $\mathrm{K} \mathrm{op} \mathrm{f}$ ist vorn gerundet, ohne Seitenhaken, obwohl jederseits eine Ausbuchtung vorhanden ist. Der Vorderkörper ist am breitesten im 3. Segment und dort halb so breit als die Länge des Thorax. Das $\mathrm{A}$ b d o m e $\mathrm{n}$ ist drei viertel so lang als der Vorderkörper. Das Genitalsegment ist nur sehr wenig länger als das folgende und das 2 . wenig länger als das 3 ., welches wiederum etwas länger als das Analsegment ist. Die Furkaläste sind außerodentlich lang, länger als das übrige Abdomen, zehn- bis zwölfmal länger als breit und

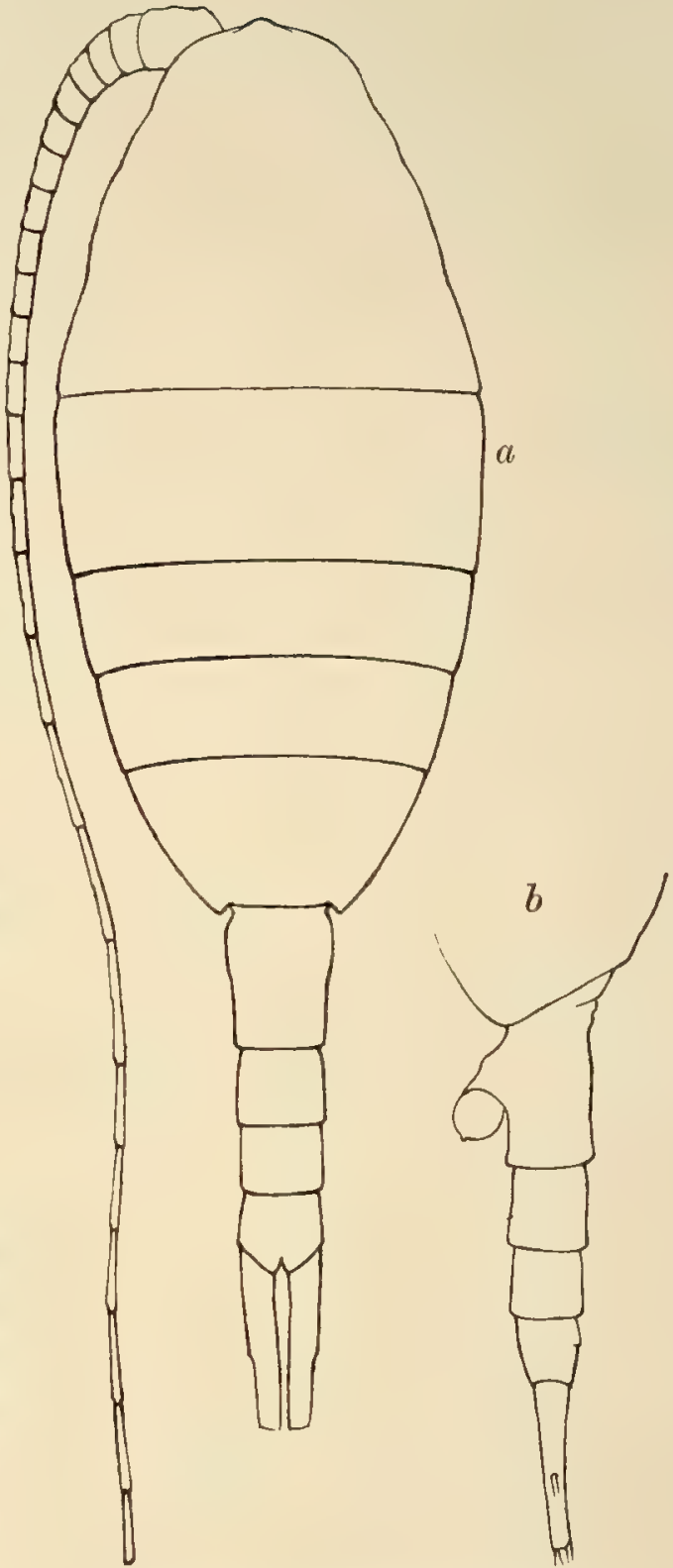

Textfig. 59. Lucicutia magna. a Rückenansicht. $b$ Abdomen, seitlich. dicker an der Basis als in der Mitte. Eine Seitenborste teilt die Furkaläste in zwei gleiche Hälften, und im proximalen Sechstel erhebt sich am Rande ein kurzer Dorn. Der linke Ast der Furka ist erheblich länger als der rechte. Am Ende finden sich 4 Borsten, von denen die zweite von innen am längsten und dicksten ist.

Die vorderen Antennen überragen die Furka mit 1 oder 2 Gliedern. Der Innenast der hinteren Antennen ist um ein Viertel länger und viel dicker als der Außenast; die Mandibeln haben ebenfalls längeren und dickeren Innenast. Die vorderen Maxillipeden haben am 1. Lobus 4 Borsten und einen kurzen Dorn. Die distalen Haken sind fein und gerade. Bei den hinteren Maxillipeden sind Basalia und Innenast etwa gleich lang, das 2. Basalglied ist etwa fünfmal so lang als breit und trägt nur schwache Borsten. Das 2. Basalglied der M a xille $\mathrm{n}$ hat 3 Borsten. 
Das 1. F u B p a a $\mathbf{r}$ hat dreigliedrige Äste. Beim 5. Paare reicht der Innenast bis etwa zur halben Länge des 2. Gliedes vom Außenaste. Das letzte Glied des Außenastes ist ebenso lang wie das 2. zusammen mit der Hälfte des 1. Gliedes. Die Endsäge ist wenig mehr als halb so lang wie das 3. Glied. Die Säbelborste ist ziemlich kräftig und etwa zweidrittel so lang wie das letzte

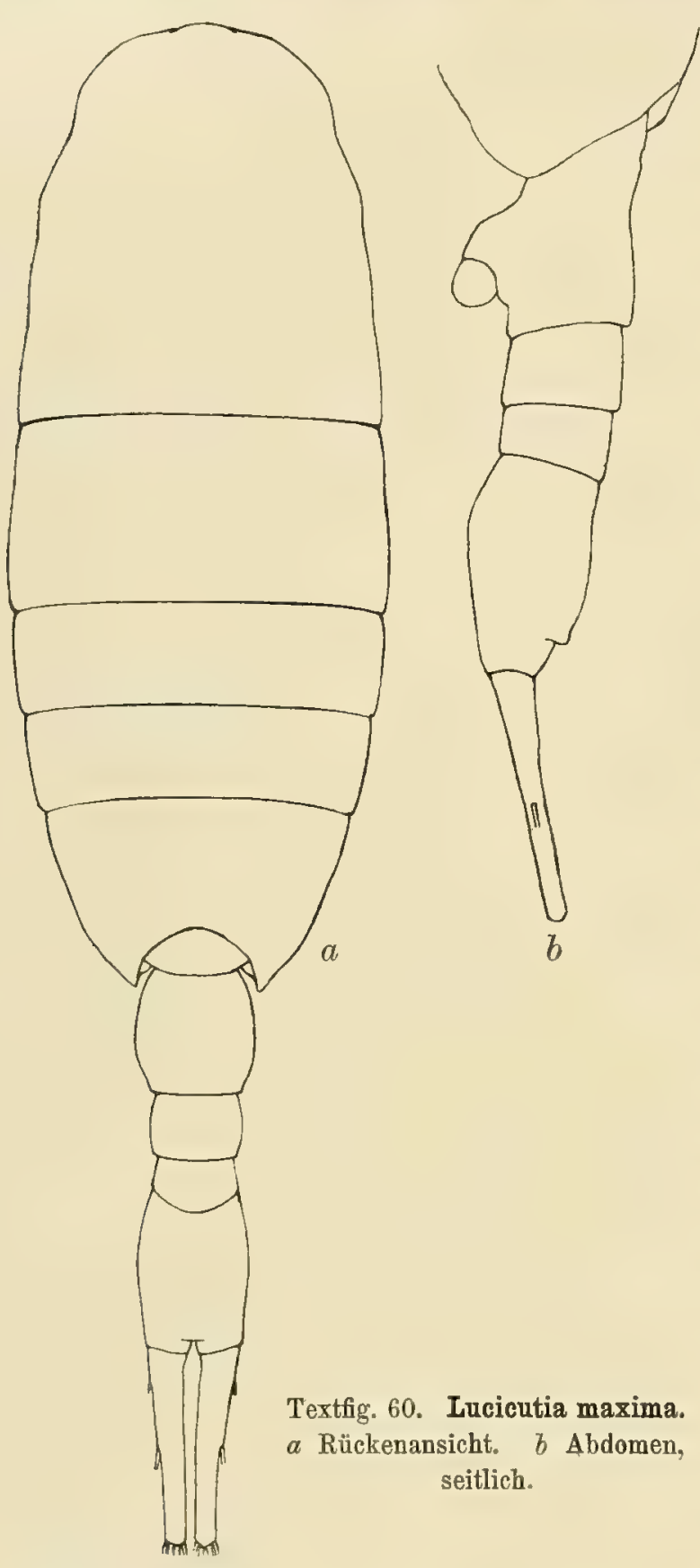
Glied. Die Innenborsten des Innenastes verteilen sich zu $1,1,5$.

In vielen Punkten zeigt diese Art mit Lucicutia - grandis und Lucicutia maxima Ubereinstimmung, aber die Länge der Antennen, der auffallend kurze Außenast der hinteren Antennen, die sehr langen und unsymmetrischen Furkaläste sind konstant bei mehreren Exemplaren, sie muß daher als selbständig anerkannt werden.

Sie fand sich in den Planktonfängen vom 26. September $1903(3000 \mathrm{~m})$ und 12. November $1901(3000 \mathrm{~m})$.

162. Lueientia maxima Steuer. (Textfig. 60 a und b.)

Die von Steukr unter diesem Namen beschriebene Art hat die erhebliche Größe von $8,7 \mathrm{~mm}$ und besitzt Seitenhaken am Kopf. Ich habe einige Exemplare in den atlantischen Fängen angetroffen, welche in manchen Einzelheiten mit STEUERS Beschreibung (Zool. Anz. Bd. XXVII) übereinstimmen, welche aber sehr deutlich in der Größe und durch die Abwesenheit der Seitenhaken am Kopfe verschieden sind. Das sind natürlich sehr wichtige Punkte, aber in Anbetracht dessen, daß bei andern Arten (z. B. Lucicutia clausi) Varietäten mit und ohne Seitenhaken vorkommen und daß alle Arten von Lucicutia erhebliche Größendifferenzen zeigen, habe ich trotz dieser Unterschiede meine Exemplare zu Lucicutia maxima STEUER gerechnet.

ㅇ $6,2 \mathrm{~mm}$, davon Cephalothorax $3,85 \mathrm{~mm}$, Abdomen 2,35 mm. Der Vorderkörper ist mehr als $1 \frac{1}{2}$ mal so lang als das Abdomen, der Kopf gerundet viereckig und die größte Breite des Körpers beträgt 1,5 mm. Das Genitalsegment ist etwa so lang als die beiden folgenden Segmente; das Analsegment, durch seine Länge und geschwollene Gestalt ausgezeichnet, ist länger als die beiden vorhergehenden und so lang wie das Genitalsegment zusammen mit dem halben folgenden, breiter als die übrigen und überall mit Drüsen ausgestattet. Die Furkaläste sind etwa so lang wie das Genitalsegment zusammen mit 
dem folgenden und etwas über fünfmal so lang als breit. Die lange Außenrandborste erhebt sich ein wenig proximal von der Mitte. Bei einem Exemplar ist der rechte Furkalast erheblich kürzer als der linke (um $0,3 \mathrm{~mm}$ ).

Die vorderen A nte n $\mathrm{n}$ e $\mathrm{n}$ reichen bis zum Ende der Furka. Die $\mathrm{M}$ undorg a n e sind wie bei der typischen Lucioutia maxima gebildet. Der 1. F u B hat dreigliedrige Äste.

Bei einigen Exemplaren findet sich eine seitliche Ausbuchtung an den Seiten des Kopfes, aber bei keinem ist eine Spur von Seitenhaken vorhanden, während bei andern die Kopfseiten ganz eben, ohne Schwellung erscheinen. Das Genitalsegment ist ventral angeschwollen und hat bei allen Exemplaren einen mißfarbenen, braunen, eiförmigen Anhang an der Geschlechtsöffnung.

Obgleich die Gestalt des Kopfes variiert und sogar die Symmetrie und Länge der Furkaläste, stimmen doch alle Exemplare im Besitze des verlängerten und verbreiterten Analsegments überein. Kein Exemplar ist länger als $6,5 \mathrm{~mm}$, und es bleibt immerhin zweifelhaft, ob diese Art mit Recht als identisch mit Lucicutia maxima betrachtet werden kann.

Sie wurde im Südatlantischen Ozean am 12. November 1901 (3000 m) und 10. September 1903 $(3000 \mathrm{~m})$ gefunden.

163. Lucicutia ovalis n. sp. (Tafel XXXV, Fig. 6, Textfig. 61 a-c.)

ㅇ 1,25-1,5 mm lang, davon Cephalothorax 1,0 mm, Abdomen 0,5 mm. Der $\mathrm{K}$ o p f ist etwas viereckig, seitlich gerundet; die Thorakalsegmente sind auf dem Rücken nicht deutlich abgegrenzt und nur am Seitenrande distinkt. Die Breite ist erheblich größer als die Hälfte der Länge. (XXXV. 6.) Das A b d o men ist ziemlich kurz, nur halb so lang als der Thorax; das Genitalsegment ist ebenso lang wie die 3 nächsten Segmente, ebenso breit als lang und mit einer sehr großen, braunen Anschwellung der Genitalöffnung versehen. Die beiden mittleren Abdominalsegmente sind kurz, breiter als lang, und das Analsegment hat etwa dieselbe Größe wie das vorhergehende. Die Furkaläste sind länger als die 3 vorhergehenden Segmente und dreimal so lang als breit. (61 a.) Durch die Außenrandborste werden sie in zwei Teile abgeteilt, von denen der proximale etwas länger als der distale ist. Hinter dieser Borste verschmälern sich die Äste. Die langen Schwanzborsten sind nicht ganz so lang als das
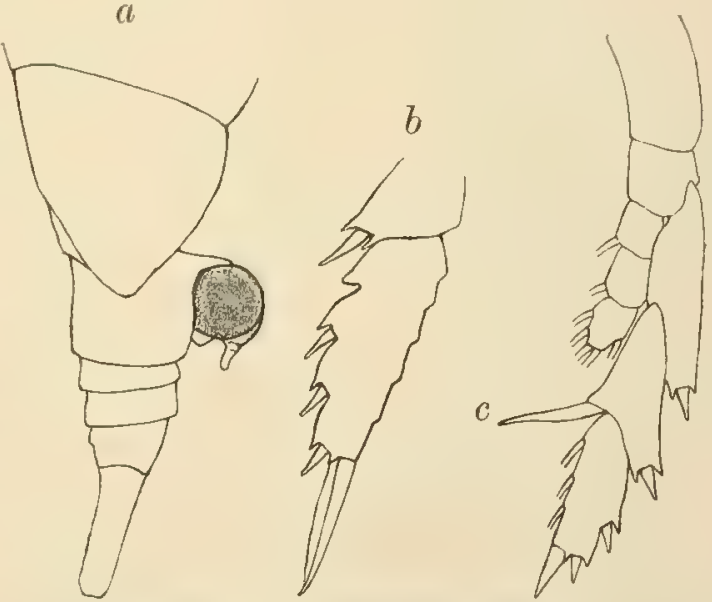

Textfig. 61. Lucicutia ovalis.

$a$ Abdomen, seitlich. $b$ Letztes Glied des Außenastes vom 4. Fuß. $c$ 5. Fuß. Abdomen.

Die vorderen A n t e n n e n überragen mit etwa 3 Gliedern die Furka. Die Äste der hinteren Antennen sind ungefähr gleich lang; das Distalglied des Außenastes ist beinahe so lang wie die beiden proximalen Glieder. Die vorderen $\mathrm{M}$ axilli p ed e $\mathrm{n}$ gleichen denen von Lucicutia favicornis. Das 1. Basalglied der hinteren Maxillipeden ist etwas kürzer als das 2., welches ebenso lang wie der Innenast ist. 
Die Innenäste des 1 . F u ß p a a es sind zweigliedrig; die des 2. bis 4. Paares sind kurz, reichen nicht bis über den Distalrand des 2. Gliedes vom Außenaste hinaus. Beim 2. Paar ist die Endsäge viel länger als das letzte Glied, im Verhältnis von 13:8. Beim 4. Fußpaar ist das 3. Glied des Außenastes länger als das 1. und 2. zusammen. und die Endsäge im Verhältnis von $14 \frac{1}{2}: 8$ länger als das Endglied. (61 b.) Unter dem proximalen Außenranddorne dieses Gliedes findet

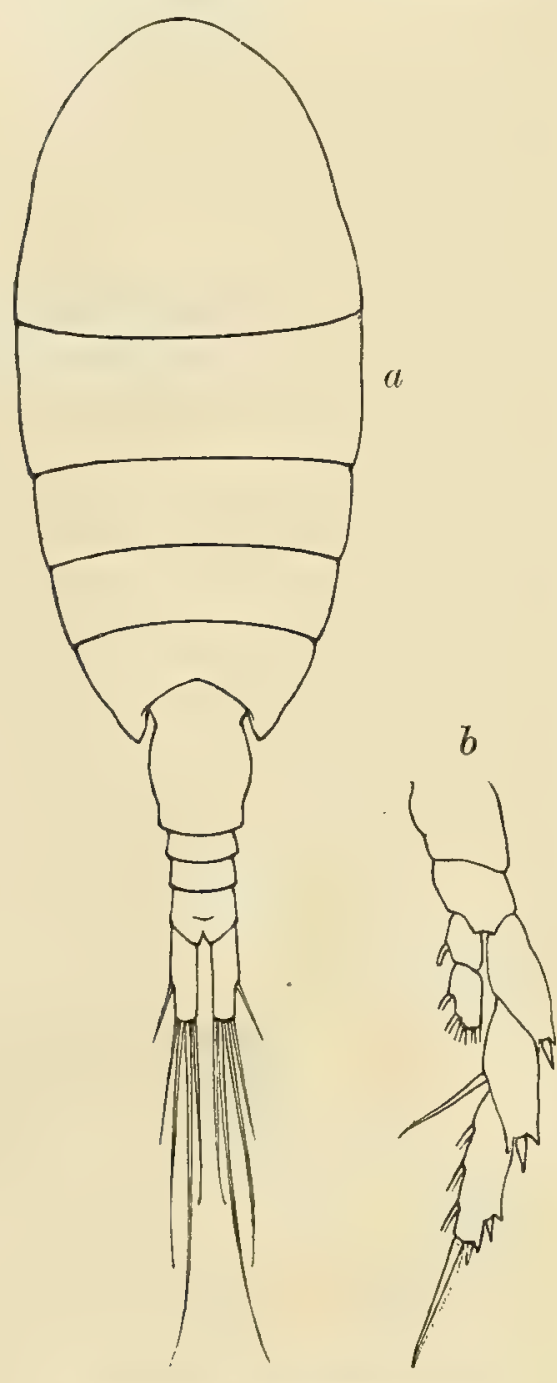

Textfig. 62. Lucicutia frigida. $a$ Rückenansicht. $b$ 5. Fuß. sich ein tiefer Ausschnitt am Rande ohne Spur eines Dornes. Beim 5. Paar ist der Innenast sehr kurz, nicht halb so lang wie der Außenast. Das 1. Glied des letzteren ist länger als das 2. und 3., welche ungefähr gleich lang sind. Die Endsäge des letzten Gliedes ist sehr kurz, nicht mehr als eindrittel so lang wie das Glied. Die Innenborsten der Innenäste vom 2. bis 5. Fuß sind nach der Formel 1, 1, 5 angeordnet. Die Säbelborste des 2. Gliedes vom Außenast ist nicht so lang wie das 3. Glied. (61с.)

Das Tier zeigt im Bau der Füße manche Ähnlichkeit mit Lucicutia clausi. Diese Art besitzt jedoch, nach den Exemplaren zu urteilen, welche ich gesehen habe, am Kopfe Seitenhaken, während diese den beiden vorliegenden Stücken von Lucicutia ovalis fehlen. Diese scheint auch deutlich kleiner als Lucicutia clausi zu sein, breiter und von mehr untersetzter Gestalt. Ich bin daher geneigt, Lucicutia ovalis als eigene Art zu betrachten.

Sie wurde nur in dem einen Fange vom 3. September 1903 $(400 \mathrm{~m})$ zwischen St. Helena und Ascension angetroffen.

164. Lneicutia frigida $n$. sp. (Textfig. 62 a und b.)

o 1,5-1,6 mm. Der $\mathrm{K}$ opf ist rundlich oval und deutlich vom Thorax abgegliedert. Letzterer ist an der breitesten Stelle gerade halb so breit als lang. Der Vorderkörper ist ungefähr doppelt so lang als das Abdomen. Das Ge nit a ls e g m e n t ist ebenso lang wie die 3 folgenden Segmente, von denen die beiden mittleren gleich lang sind, während das Analsegment länger als jedes derselben ist. Die Furkaläste sind $2 \frac{1}{2} \mathrm{mal}$ so lang als das Analsegment und beinahe fünfmal so lang als breit. Die Seitenrandborste teilt sie in zwei fast gleiche Stücke. Die 2. Schwanzborste von innen ist die längste, sie ist auf beiden Seiten gleich lang und etwas länger als das Abdomen. Der Kopf zeigt keine Spur von Seitenhaken, und das Genitalsegment ist im unteren Teile ventral angeschwollen. (62 a.)

Die vorderen A $\mathrm{n}$ t e $\mathbf{n} \mathbf{n}$ e $\mathbf{n}$ überragen das Genitalsegment, reichen bei einem Exemplare sogar bis zum Ende des Analsegments. Der Innenast der hinteren Antennen ist viel länger als der Außenast und trägt 2 kurze Randborsten am 1. Gliede distal von der Mitte. Ebenso ist der Innenast der Mandibeln viel länger als der Außenast. Die Maxillen tragen 5 Borsten am 2. Basalgliede, 9 am Innenast und 11 am Außenast, der verhältnismäßig sehr groß ist, bis zum Ende des 
Innenastes reicht und am Innenrande behaart ist. Das 2. Basalglied der hinteren Maxilli p e d e n ist ziemlich lang, etwas länger als das 1., und der Innenast ist nur drei viertel so lang als das 2.

Das 1. F u B p a a r hat dreigliedrigen Innenast. Beim 3. Fußpaar ist die Endsäge halb so lang als das letzte Glied des Außenastes, beim 4. Paar ist sie kürzer. Beim 5. Fußpaare hat der Innenast nur 2 Glieder, der Außenast 3. Der Innenast ist kurz, reicht nicht weiter als bis zur halben Länge des 2. Gliedes vom Außenaste. Von Randborsten findet sich eine am 1. Gliede, zwei am Innenrand und drei am Ende des 2. Gliedes. Das letzte Glied des Außenastes ist ebenso lang wie das 1., die Endsäge so lang wie das Endglied. Die dünne Säbelborste des 2. Gliedes ist nur dreiviertel so lang als das letzte Glied. (62 b.)

Diese Art repräsentiert die Gattung Lucicutia in der Antarktis. Sie hat viel äußere Ähnlichkeit mit Lucicutia Aavicornis, weicht jedoch von den verwandten Arten durch die Beschaffenheit der hinteren Antennen, der Maxillenborsten und besonders durch den zweigliedrigen Innenast des 5. Fußpaares ab.

Lucicutia frigida wurde im südlichen Scholleneise am 6. März 1903 (1200 m), 10. März 1903 (3000 m) und 27. März 1903 (2000 m) erbeutet.

165. Lueicutia bicornuta no sp. (Textfig. 63 a-c.)

q 6,75 mm lang, davon Cephalothorax 3,4 mm, Abdomen 3,35 mm. Der $\mathrm{K} \mathrm{opf}$ hat sehr charakteristische Gestalt, vorn 2 starke Dornen, die jederseits am. Seitenwinkel vorspringen und zwischen denen der Kopf breit viereckig erscheint. Außerdem finden sich 2 hervortretende, nach hinten gerichtete Seitenhaken. Das Genitalsegment ist etwa um die Hälfte länger als das folgende; die beiden mittleren Segmente sind gleich lang und das Analsegment ebenso lang wie das Genitalsegment. Die Furkaläste sind länger als das ganze Abdomen (1,85 mm), breiter am basalen Ende, von ungleicher Länge und zehn- bis zwölfmal so lang als breit. (63 a. b.)

Die vorderen A n t e n n e n überragen die Furka mit etwa 4 Gliedern. (63 a.) Die Innenäste der hinteren Antennen sowohl wie der $\mathrm{M}$ a n d i b e ln sind länger als ihre Außenäste, und am 1. Gliede der ersteren finden sich 2 kurze Randborsten. Die Innenäste der Mandibeln sind nicht behaart. Das 2. Basalglied der M a xille n trägt 3 Borsten. Die Längen des 2. Basalgliedes und des Innenastes vom hinteren Maxillipeden sind ungefähr gleich; das 2. Basalglied ist etwa viermal so lang als breit und am Innenrande mit einer Reihe steifer Borsten versehen.

Alle $\mathrm{S} \mathrm{c} \mathrm{h} \mathrm{w} \mathrm{i} \mathrm{m} \mathrm{m} \mathrm{fü} ß$ e haben dreigliedrige Äste. Beim 1. Paare trägt der Innenast 1, 2,5 Borsten, und am Distalrande des 2. und 3. Gliedes treten Dornen auf. Das 2. bis 4. Paar hat 1, 2,6 Borsten. Die Innenäste sind klein und erstrecken sich nicht bis über das Ende des 2. Gliedes vom Außenaste. Die Endsägen sind kurz, beim 3. Paare nicht halb so lang wie das Glied und beim 4. Paare noch kürzer. Das 3. Glied des Außenastes ist sehr lang, länger als die beiden ersten Glieder zusammen.

Beim 5. Fußpaar ist der Innenast nur wenig länger als das 1. Glied des Außenastes; das 1. und 3. Glied des Außenastes sind gleich lang und die Endsäge ist etwas mehr als halb so lang wie das letzte Glied des Außenastes. Der Innenast hat 7 Randborsten; die Säbelborste des 2. Gliedes vom Außenast ist dünn und gleicht den übrigen. 


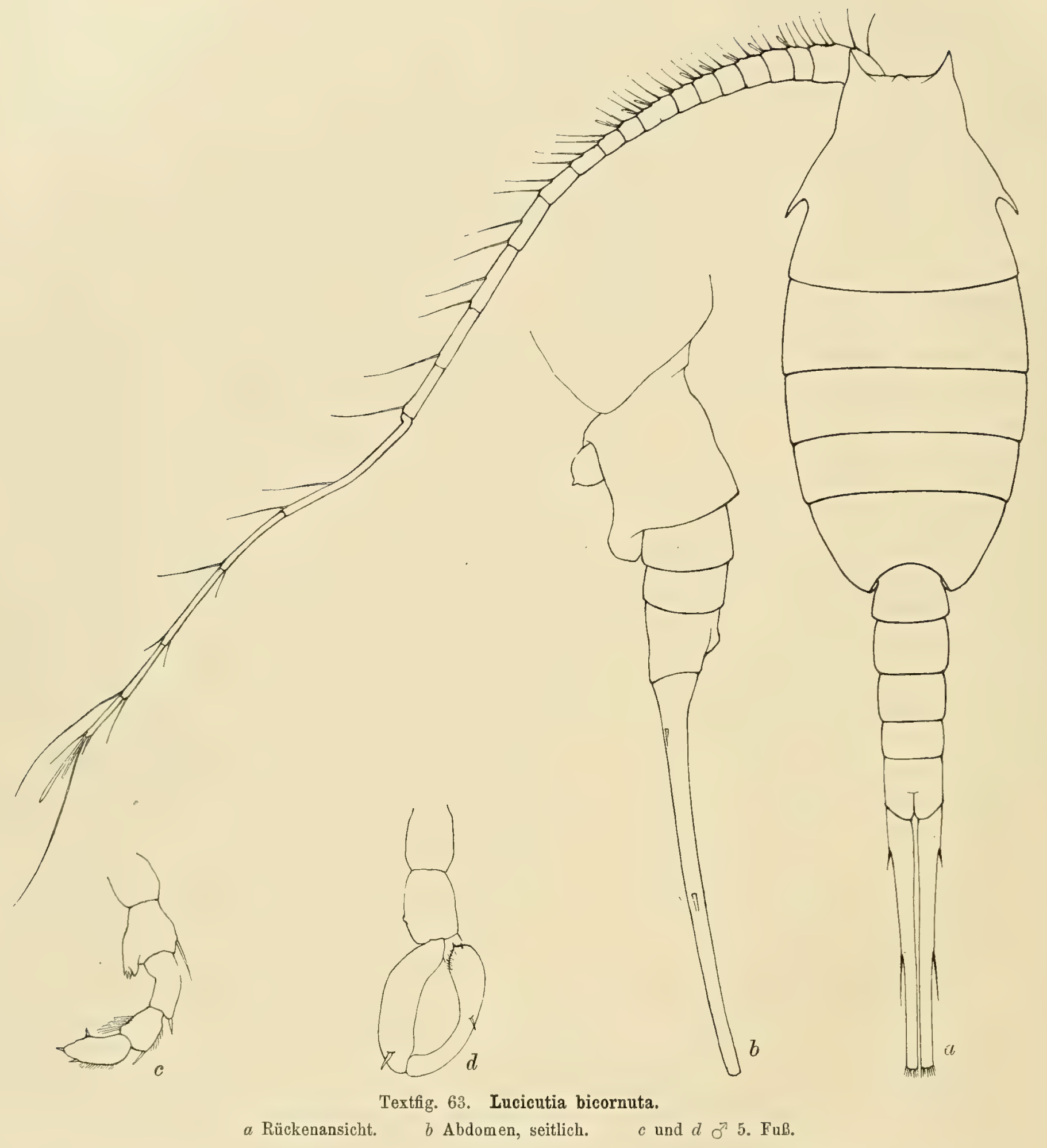

Das ot hat dieselbe Größe wie das ; Kopf, Mundorgane und Füße, abgesehen vom 5. Paare, sind ähnlich gebaut. Die Greifantenne auf der linken Seite hat jenseits des Gelenkes noch 5 Glieder. Das Glied vor dem Gelenk ist nur halb so lang wie das folgende. Die Längen der 6 letzten Antennenglieder sind $0,3 \mathrm{~mm}$ (Gelenk), $0,7 \mathrm{~mm}, 0,45 \mathrm{~mm}, 0,5 \mathrm{~mm}, 0,3 \mathrm{~mm}, 0,2 \mathrm{~mm}$. 
Der Vorderkörper ist nur sehr wenig länger als das Abdomen; die Furkaläste sind länger als das Abdomen, bisweilen ungleich und zehn- bis elfmal so lang als breit.

Das 5. Fußpaar ist ähnlich wie bei Lucicutia grandis gebildet. (63 cu.d.) Das 2. Basalglied des linken Fußes ist im distalen Teile stärker verlängert und trägt 4 Endborsten. Das Endglied des rechten Fußes erscheint mehr keulenförmig, am Ende gut doppelt so breit als in der Mitte; die Außenränder der Glieder des linken Fußes sind behaart und das letzte Glied trägt einen Enddorn und je einen Dorn in entsprechender Lage am Außen- und Innenrande. Das 2. Basalglied des rechten Fußes scheint nicht wie bei Lucicutia grandis Dornen zu tragen.

Zwischen Lucicutia bicornuta und Lucicutia aurita scheinen nach der Beschreibung CLEves zahlreiche unterscheidende Merkmale vorhanden zu sein, wie die Längenverhältnisse der Abdominalsegmente und der Furka, die Länge der vorderen Antennen und die Beborstung der Innenäste der Füße, so daß sie nicht als identisch betrachtet werden können. Auch scheint unsere Art, so weit die Beschreibung reicht, nicht völlig identisch mit Lucicutia aurita SARS zu sein, welche, wenn sie nicht mit Cleves Art identisch sein sollte, doch einen neuen Namen erhalten müßte.

Vier of und ein of wurden vom ,Gauss" am 22. Oktober 1901 (3000 m) im südlichen Atlantischen Ozean gefunden.

166. Lucicutia flavicornis CLAUS

erschien in den Fängen aus dem Altantischen Ozean vom 11. Oktober 1901 (1200 m), 14. Oktober $1901(1900 \mathrm{~m}), 20$. und 24. August $1903(400 \mathrm{~m})$, 4. September 1903 (2000 m), 5. September 1903 $(400 \mathrm{~m})$, 10. September $1903(3000 \mathrm{~m})$, 9. Oktober $1903(3000 \mathrm{~m})$ und im Indischen Ozean am 20. Мai $1903(400 \mathrm{~m})$.

16\%. Lucicutia longiserrata GIESBRECHT

wurde am 9. Oktober $1903(3000 \mathrm{~m})$ westlich von den Kap Verde-Inseln gefunden.

168. Lucicutia longicornis GIESBRECHT

war in den Fängen vom 9. Oktober $1903(3000 \mathrm{~m})$ und 19. Oktober 1901 (500 m) im tropischen Atlantischen Ozean, $20^{\circ}$ nördlich und südlich vom Äquator, vorhanden.

169. Haloptilus longicornis Claus

Haloptilus Giesbrecht.

wurde im Atlantischen Ozean am 11. Oktober 1901 (1200 m), 14. Oktober 1901 (1900 m), 19. Oktober $1901(500 \mathrm{~m}), 5$. November $1901(1000 \mathrm{~m})$, 12. und 16. November 1901 (3000 m), 20. August $1903(400 \mathrm{~m}), 22$. August 1903 (1500 m), 3. und 11. September 1903 (400 m), 10. September 1903 $(3000 \mathrm{~m})$, 13. Oktober $1903(3000 \mathrm{~m})$, im Indischen Ozean am 18. Mai $1903(400 \mathrm{~m})$ und vor der Eiskante der Antarktis am 13. Februar 1902 (2000 m) erbeutet.

170. Haloptilus ormatus Giesbrecht

wurde am 1. und 19. Oktober 1901 (800 m), 11. Oktober 1901 (1200 m), 16. September 1903 (400 m), 26. September $1903(3000 \mathrm{~m})$, 30. September 1903 (800 m) im Atlantischen Ozean gefunden.

171. Haloptilus plumosus CLAus

erschien in den Vertikalfängen vom 5. November 1901 (1000 m), 9. und 13. Oktober 1903 (3000 m). 
17\%. Haloptilus spiniceps Giesbrecht

war in den Fängen vom 14. Oktober 1901 (1900 m), 5. September 1903 (400 m), 10. September 1903 $(3000 \mathrm{~m})$, 9. und 13. Oktober $1903(3000 \mathrm{~m})$ vorhanden.

\section{Haloptilus chierchiae GIESBRECHT}

wurde am 26. September 1903 (3000 m) unter dem Äquator im Atlantischen Ozean erbeutet.

\section{Haloptilus oxycephalus Giesbrecht}

fand sich in einem Planktonfang aus dem Indischen Ozean am 18. Mai 1903 (400 m).

\section{Haloptilus ocellatus WOLFENDEN.}

Diese gut charakterisierte Art wurde bereits ausführlich im Bericht über die Copepoden der National Antarctic Expedition 1908 beschrieben. Sie erschien verhältnismäßig häufig in den Fängen des „Gauss" aus dem antarktischen Gebiet. Ihre bedeutende Größe, 8-9 mm, der vorspringende und fast gerade Stirndorn, das kurze Abdomen und der auffallende schwarze Ocellus auf der Mitte des Rückens im 2. Thorakalsegment machen sie leicht kenntlich. Die vorderen Antennen überragen etwa mit 4 Gliedern das Ende der Furka, und der Innenast der Maxillen trägt 5 Borsten.

\section{Haloptilus major n. sp.}

o 7,35 mm, davon Cephalothorax 6,0 mm, Abdomen 1,35 mm. Der $\mathrm{Kopf}$ ist gerundet und vorn etwas vorgewölbt. Das 1. Segment ist etwas länger als der übrige Vorderkörper, und das letzte Segment ist seitlich gerundet. Der Cephalothorax ist im breitesten Teil etwa ein viertel so breit als lang. Das Abdomen ist kurz, noch nicht ein viertel so lang als der Rumpf, das G e n i t a 1 s e g m e n t so lang wie der übrige Teil des Abdomens mit Einschluß der Furka. Die Seitenränder sind gerundet, das Segment ist ebenso breit als lang und mit großem Genitalvorsprung versehen. Die Furkaläste sind so lang wie breit und tragen 2 kräftige Borsten am Außenrande, 3 Endborsten und jederseits eine kurze akzessorische Borste.

Die vorderen · A n t e $\mathbf{n} n$ e $n$ überragen den ganzen Körper mit 2 oder 3 Gliedern. Die hinteren Antennen haben sehr kurzen, siebengliedrigen Außenast, der nur ein wenig den Distalrand des 2. Basalgliedes überragt. Der Innenast ist sehr lang und viel dicker als der Außenast.

Die Äste der M a n d i b e ln sind etwa gleich lang, aber der Innenast ist sehr dünn. Die Zahnplatte ist lang und schmal, mit 3 gleich großen und starken Zähnen, einem dünnen, gekrümmten äußeren Zahne, 2 kleinen Zähnen und einem größeren Innenzahn versehen. Der Innenast der M a xill e n hat nur 2 Borsten, der 2. und 3. Innenlobus sind klein und tragen je eine Borste, der Außenast ist lang und mit 2 starken, langen Borsten und einer sehr kurzen, feinen Außenborste bewaffnet. Das 2. Basalglied hat keine Borsten. Die vorderen $\mathrm{M}$ a xilli p e d e $\mathrm{n}$ sind wie bei Haloptilus ornatus gestaltet, die 5 proximalen Loben haben je 3 Borsten, der 6 . Lobus trägt 4, der Innenast 6 Borsten. Alle Borsten des 3. bis 6. Lobus sind stark bewehrt mit feinen Randzähnen und dicht stehenden Dornen auf der Oberfläche. Die Borsten des Innenastes sind weniger dicht und 3 von ihnen kaum bedornt. Keine der Borsten ist in einen Haken umgebildet. Die Borsten der beiden ersten Loben sind am kürzesten, die der zweiten stachelartig entwickelt. Die 
hinteren Maxillipeden sind sehr lang, die Längen des 1. und 2. Basalgliedes und des Innenastes verhalten sich wie $20: 13: 37$. Das 1. Glied des Innenastes ist am längsten. Die 3 Borsten der letzten 2 Glieder des Innenastes sind sehr lang und kräftig, fast hakenförmig, aber nicht bedornt und ganz verschieden von den Dornen des Haloptilus ornatus.

Das 1. F u B p a a r ist dem von Haloptilus spiniceps ziemlich ähnlich, aber das letzte Glied des Außenastes ist kürzer, die beiden großen Randdornen stehen dicht beieinander und die Ränder der Glieder sind nicht behaart. Das letzte Glied des Innenastes trägt 5 Borsten, von denen die äußerste lang und dünn und die nächste viel dicker als alle übrigen ist. Beim 2. Fußpaar ist die Endsäge so lang wie das letzte Glied des Außenastes. Das 3. und 4. Paar bieten nichts Besonderes, außer daß 8 Borsten am letzten Gliede vom Innenaste beim 3. Paar und 6 beim 4 . Paare vorhanden sind. Die Endsägen haben bei beiden etwa fünf siebentel der Länge des letzten Gliedes. Am Innenrande des 2. Gliedes vom Außenaste findet sich eine kurze und stark gekrümmte Borste mit kräftiger Basis. Nur 2 Außenranddornen sind am letzten Gliede vorhanden, die Endsäge erreicht nur die halbe Länge des Gliedes, und am Innenrande treten 3 Borsten auf. Das letzte Glied des Innenastes trägt 6 Borsten.

Haloptilus major hat einige Ähnlichkeit mit Haloptilus ornatus und Haloptilus plumosus, ist jedoch viel größer, zeigt auch Eigentümlichkeiten im Bau der vorderen und hinteren Maxillipeden, in der Beschaffenheit der Maxillarborsten, der Bewaffnung der Zahnplatte und im Bau des 5. Fußpaares. Die Art wurde am 1. Oktober 1901 (1330 m) unter dem Äquator im Atlantischen Ozean erbeutet.

\section{Pseudhaloptilus.}

Die Gattung wurde zur Aufnahme eines merkwürdigen Copepoden geschaffen, welchen ich früher zur Gattung Haloptilus rechnete, der sich jedoch in einigen wesentlichen Merkmalen abweichend erwies und besser als neuer Typus betrachtet wird. Der Körper ist breit und gedrungen, gänzlich unähnlich einem Haloptilus, der Außenast der hinteren Antennen ist länger als der Innenast, die Maxillen zeigen abweichenden Bau, haben sehr großen 1. Innenlobus; die vorderen und hinteren Maxillipeden sind mit eigentümlichen breiten Hakenborsten bewaffnet und der Innenast des 5. Fußpaares ist nur eingliedrig. Nur 2 Exemplare derselben Art angehörig wurden beobachtet.

17\%. Pseudhaloptilus longimanus Wolfenden. (Tafel XXXV, Fig. 7-13, Textfig. 64 a und b.) (Haloptilus longimanus WOLFENDEN. Plankton Studies 1906.)

o 6,72 mm, davon Cephalothorax 5,4 mm, Abdomen 1,3 $\mathrm{mm}$ lang. Die Gestalt ist sehr plump und erinnert an die breite, ungeschickte Form von Augaptilus rattrayi. Der Cephalothorax ist nur $1 \frac{1}{2} \mathrm{mal}$ so lang als breit. Der $\mathrm{K}$ o p f erscheint seitlich breit gerundet und endet vorn mit sehr kurzem, aber starkem, zweispitzigem Rostrum. (64 a.) Das letzte Segment endigt seitlich mit sehr kleinen Spitzen. Das A b d o m e n, nur ein viertel so lang als der Vorderkörper, hat ein großes Genitalsegment, das größer als die übrigen Segmente ist, sehr kleines Analsegment und Furkaläste, die etwa so lang wie die beiden letzten Segmente und breiter als lang sind. Die Schwanzborsten sind kurz, etwa so lang wie das Abdomen. (XXXV. 7.) 
Die vorderen A n t e n n e n haben 25 Glieder und reichen ungefähr bis zum Ende des Genitalsegments. Das 12. bis 15. Glied sind ungefähr gleich lang und etwas länger als das 16. bis 18. Glied; das 19., 20. und 21. Glied sind kleiner, das 22. nur wenig kleiner als jedes der vorhergehenden oder folgenden Glieder, und das 25. ist nur ein drittel so lang als das vorletzte. Bei den hinteren Antennen ist der Außenast etwa um ein viertel länger als der Innenast und besteht aus 8 Gliedern, von denen das letzte viermal so lang als breit und fast so lang ist wie die 6 proximalen Glieder. Der Innenast der M a n d ib eln ist länger als der Außenast. Der letztere ist deutlich fünfgliedrig; das 2. Basalglied ist drei viertel so breit als lang; die Zahnplatte ist breit und mit starken, unregelmäßig gestellten Zähnen besetzt (XXXV. 9.)

Die M a xille n (XXXV. 8) haben einen sehr großen 1. Innenlobus, der fast viereckig und mit starken Haken versehen ist. Die andern Loben sind klein, aber deutlich; der 2. Innenlobus trägt 5 starke Borsten, der' 3. 3, das 2. Basalglied 3, von denen 2 an der Basis sehr dick und kurz sind,

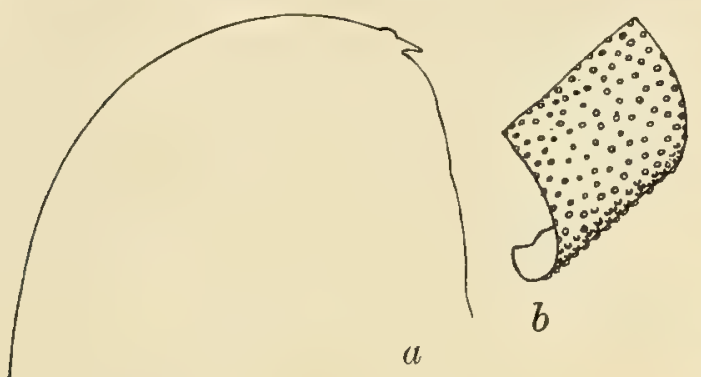

Textfig, 64.

Pseudhaloptilus longimanus.

a Kopf, seitlich. $\quad b$ Chitinstück. und der nicht gegliederte Innenast 5 Borsten. Der Außenast ist verhältnismäßig groß und trägt 9 Borsten, der 2. Außenlobus hat eine starke Borste; der 1. Außenlobus ist unbedeutend, aber mit 9 starken Borsten versehen. Die vorderen und hinteren $\mathrm{M}$ a xilli peden (XXXV. 10 u. 11) haben ungefähr dieselbe Länge und sind durch besondere Borsten der Innenäste ausgezeichnet. Mit Ausnahme von 2 winzigen Endborsten an den hinteren Maxillipeden sind es alle starke Hakenborsten, die in der distalen Hälfte mit dicht stehenden feinen Börstchen besetzt sind. Die beiden proximalen Loben der vorderen Maxillipeden tragen gewöhnliche

Borsten, das 2. Basalglied 2 starke Haken und distal eine kleine Borste. Am Innenaste finden sich 9 lange Haken.

Das 1. Basalglied der hinteren Maxillipeden ist etwas länger als das 2. sowohl wie auch als der Innenast und besonders breit; das 2. Basalglied ist etwas schmäler und der Innenast etwa um ein viertel kürzer als dieses. Dieser trägt 8 lange Hakenborsten, von denen die beiden distalen die längsten und stärksten sind.

Alle F ü B e mit Ausnahme des 5. Paares haben dreigliedrige Äste. Beim 1. Paar ist der Innenast viel kürzer als der Außenast und mit 1, 1,5 Randborsten versehen. Der Außenast hat 1, 1,4 Innenrandborsten, eine lange Endsäge und 1, 1,2 Außendornen. Der Außendorn des 1. Gliedes ist bei weitem am stärksten. Beim 2. Paare (XXXV. 12) trägt das letzte Glied des Außenastes 3 Außendornen, die Endsäge, die nicht halb so lang als das Endglied ist, und 5 Innenrandborsten. Der Innenast hat 1, 2, 7 Randborsten.

Das 3. und 4. Paar sind gleich gebildet, ihre Außenäste verhalten sich wie beim 2. Paare, die Innenäste haben 1, 2,7 Randborsten und Endsägen von halber Länge des letzten Gliedes. Beim zweiten bis vierten Paar ist der Innenrand des ersten Gliedes vom Außenast und der Außenrand vom ersten Gliede des Innenasts dicht behaart; die Endsägen sind sehr fein gezähnt. Das 5. Paar (XXXV. 13) hat dreigliedrigen Außenast und einen eingliedrigen Innenast, der sehr klein 
und unbedeutend und mit 4 Randborsten ausgestattet ist. Die Endsäge des Außenastes ist fast so lang wie das letzte Glied, welches 2 äußere Randdornen und 3 Innenrandborsten trägt. Der Chitinpanzer erscheint besonders am Kopfe dicht von kleinen Knötchen punktiert. (64 b.)

Zwei Exemplare von Pseudhaloptilus longimanus wurden am 9. Oktober 1903 (3000 m) und 22. August $1903(1500 \mathrm{~m})$ im Atlantischen Ozean erbeutet.

\section{Phyllopus Brady.}

BRADY hatte ursprünglich nur ein Exemplar, nach welchem er die Gattung beschrieb, und der zweizähnige Fortsatz des letzten Thorakalsegments gab Anlaß dazu, die Art Phyllopus bidentatus zu nennen (Chall. Report). Auch GiesBRecht besaß nur ein Exemplar für seine Beschreibung (Fauna und Flora des Golfs von Neapel p. 419), fand aber an diesem nicht den von Brady beobachteten Fortsatz. Exemplare von Phyllopus, welche ich 1904 in der Nähe der Westküste Irlands erbeutete, hatten ebensowenig den zweizähnigen Fortsatz wie FARRAN's Exemplare von derselben Lokalität. Aber vom „Gauss“" wurde im südlichen Atlantischen Ozean ein Exemplar gesammelt, bei welchem nicht nur das letzte Thorakalsegment auf der rechten Seite verlängert, sondern auch zweizähnig ist. Solche Formen existieren also, müssen aber sehr selten sein. Unglücklicherweise ist das Exemplar, welches für weitere Untersuchung beiseitegestellt wurde, verloren gegangen, so daß ich nicht sagen kann, ob ihm besondere Merkmale zukommen.

Farran hat zwei andere Arten Phyllopus helgae und Phyllopus impar beschrieben (Fisheries Ireland 1. c.), und G. O. SARs erwähnte neulich eine dritte Art Phyllopus muticus aus der Sammlung des Fürsten von Monaco, welche 4,10 mm lang, also viel länger als alle vorher beschriebenen Arten ist. BRADY's Exemplar, welches 3,6 mm Länge hat, und SARS'Art können vielleicht identisch sein. Das einzige Brauchbare aus der Beschreibung des letzteren ist: Körper länger, Seitenlappen des Thorax sehr kurz und am Ende abgestutzt; vordere Maxillipeden mehr ,ramassés ${ }^{6}$ und die Außendornen viel kürzer und stark gekrümmt; 5. Fuß etwas abweichend. (Bull. Inst. Oceanogr. 1907). Von den beiden Arten Farran's ist die eine viel kleiner (Phyllopus helgae, $2,4 \mathrm{~mm}$ ), die andere (Phyllopus impar) erreicht die Länge von $3,0 \mathrm{~mm}$.

- Der Hauptunterschied zwischen diesen beiden Arten scheint zu beruhen auf der Größe, der Form des letzten Thorakalsegments (gerundet und sehr wenig verlängert bei Phyllopus helgae, in zugespitzte seitliche Flügel, am stärksten auf der rechten Seite, ausgezogen bei Phyllopus impar), auf der unsymmetrischen Genitalanschwellung, der Vergrößerung der rechten Seite des Segments, der Länge des Segments, das so lang wie die drei folgenden und länger als breit bei Phyllopus helgae, kürzer, breiter als lang bei Phyllopus impar ist. In der Sammlung des „Gauss" finden sich Exemplare von Phyllopus, von denen einige der Beschreibung von Phyllopus helgae, andere mit in Flügel ausgezogenem letzten Thorakalsegment und unregelmäßig geschwollenem Genitalsegment der von Phyllopus impar entsprechen.

In einem Falle war der rechte Flügel des letzten Thorakalsegments deutlich zweizähnig, und bei einem männlichen Exemplare, das zusammen mit einem nach der Beschreibung zu Phyllopus helgae gehörenden $\uparrow$ gefunden wurde, ist eine entschiedene Andeutung von zweizähnigem Einschnitt in den rechten Flügel des Thorax vorhanden, welcher etwas mehr als auf der linken Seite verlängert 
ist. (65 b.) Das 5. Fußpaar stimmt völlig mit dem vom Phyllopus - ơ überein, welches ich im Journ. Marine Assoc. 1904 von der irischen Küste beschrieb.

Gewisse Variation ist demnach in dieser Hinsicht vorhanden, wie auch in den Verhältnissen der 5. Füße bei ${ }^{\hat{\alpha}}$ und क , und auch in der Länge der Antennen. So ist z. B. in der Fig. 65 a die rechte Antenne um 3 Glieder länger als die linke. Wie weit die Variation normalerweise bei dieser Gattung geht, ist noch zu untersuchen. Indessen zeigen die Merkmale des Abdomens bei beiden so bedeutende Unterschiede, daß FarraN's Arten Phyllopus helgae und Phyllopus impar anerkannt werden müssen.

178. Phyllopus helgae Farran. (Textfig. 65.)

q 2,15-2,25 mm. Cephalothorax etwas über doppelt so lang als das Abdomen. Das letzte

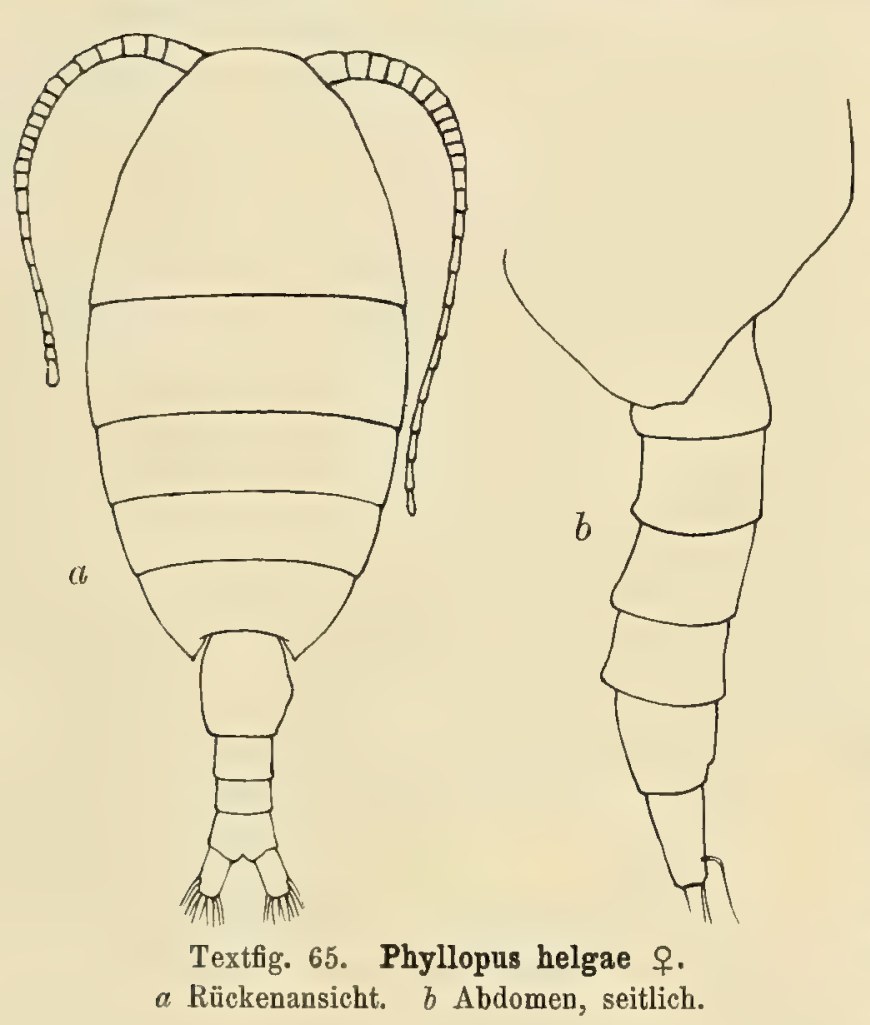

Thorakalsegment ist auf der rechten Seite in einen zugespitzten Flügel verlängert, der sich nicht bis zum Ende des Genitalsegments erstreckt, und nicht zweizähnig ist. Die gegenüberliegende Seite ist auch in eine kurze Spitze ausgezogen. Das Genitalsegment ist etwas länger als breit und rechts etwas mehr als links angeschwollen. Die beiden mittleren Abdominalsegmente haben etwa gleiche Größe, und das Analsegment ist länger als jedes der beiden. Die Furkaläste sind etwa so lang wie die beiden vorhergehenden Segmente, zweimal so lang als breit und nicht divergierend.

Diese Exemplare aus dem südlichen Atlantischen Ozean sind erheblich kleiner als die, welche Farran beschrieb, und die Abdominalsegmente weichen etwas ab, dennoch kann kaum ein Zweifel sein, daß beide derselben Art angehören.

Sie fanden sich am 5. November 1901 (1000 m), 12. November 1901 (3000 m), 26. September 1903 (3000 m), 30. September 1903 (1500 m), 9. Oktober 1903 $(3000 \mathrm{~m})$ im Atlantischen Ozean.

\section{Phyllopus impar Farran. (Tafel XXXVI, Fig. 2, Textfig. 66.)}

q $2,2 \mathrm{~mm}$; davon Cephalothorax 1,55 mm, Abdomen 0,65 mm. Der Vorderkörper ist daher erheblich mehr als doppelt so lang wie das Abdomen. Das letzte Thorakalsegment ist jederseits zugespitzt, aber asymmetrisch, und die Seiten sind verlängert. (Textfig. 66.) Das Genitalsegment ist groß und fast so lang wie die 3 folgenden Segmente. Die Furka ist doppelt so lang als breit und hat stark divergierende Äste. Die am 26. September 1903 unter dem Äquator im Atlantischen

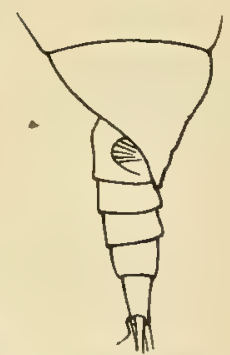

Textfig. 66 Phyllopus impar. Letztes Thoraxsegment und $\mathrm{Ab}$ domen. 
Ozean bei einem Vertikalfang aus $3000 \mathrm{~m}$ Tiefe erbeuteten Individuen scheinen mit den irischen Exemplaren Farran's und den von mir als Phyllopus bidentatus 1904 beschriebenen übereinzustimmen.

\section{Arietellus Giesbrecht.}

Giesbrecht beschrieb Arietellus setosus in der Fauna und Flora von Neapel Bd. 19 nach einem einzigen Exemplar, einem ơ. Später (Zoologischer Anzeiger vol. 20, 1897) beschrieb er auch das $q$ ausführlich, so daß kein Zweifel über die Diagnose dieser Art bestehen kann. Doch publizierte GIESBRECHT keine Abbildung, und soweit mir bekannt, existiert auch sonst keine Abbildung vom o des Arietellus setosus. Ich halte es daher für gut, eine solche zu geben, besonders da SARS einige neue Arten dieser Gattung zugeteilt hat, von denen eine oder mehrere gegenwärtig hier noch eine etwas zweifelhafte Stellung haben und ich sowohl wie auch andere (FARRAN, Fisheries Ireland Sci. Invest. 1906 [1908] p. 82) mit den Diagnosen dieser Arten Schwierigkeiten gehabt haben.

Der von T. Sсотт aus dem Golf von Guinea (Transact. Linn. Soc. London ser. 2 vol. 6) beschriebene Rhincalanus aculeatus gehört augenscheinlich zu Arietellus, ist aber nicht mit Arietellus setosus identisch, sondern vielleicht mit einer andern Art, welche ich Arietellus armatus genannt habe, obwohl sich das nicht mit Sicherheit feststellen läßt. Die von mir unten als Arietellus minor beschriebene Form könnte als ein kleines Exemplar von Arietellus setosus betrachtet werden, aber der Größenunterschied ist zu auffallend, und auch andere geringere Differenzen sind vorhanden. Arietellus armatus kann sich vielleicht mit einer der neuen Arten von SARS als identisch erweisen, doch ist bei keiner von diesen ein so außerordentlich gestalteter Kopf beschrieben. Die Gattung hat eine sehr weite Verbreitung im Atlantischen Ozean und ist wahrscheinlich eine Tiefseeform.

\section{Arietellus setosus Giesbrecht. (Tafel XXXVI, Fig. 3.)}

Sehr wenig nur habe ich der genauen Beschreibung GiesBREchT's (Zool. Anz. vol. 20, p. 254) hinzuzufügen. Größe des $q \mathbf{4 , 6} \mathrm{mm}$, Genitalsegment fast kubisch, mit kleiner Hervorragung jederseits, die linke äußere Schwanzborste ist dicker als die rechte, die Antenne gleicht der rechten Antenne des $\hat{\delta}$. Das 5. Fußpaar ist dreigliedrig, das mittlere Glied am dicksten, auf der linken Seite mit sehr kurzer, rechts mit sehr langer Borste, am Innenrande des distalen Endes mit 2 Borsten, dem Rudiment eines Innenastes, versehen. An der Außenkante dieses Gliedes findet sich noch ein schwaches Glied, welches an der Spitze eine pfriemförmige Borste trägt.

Die Größe der vom „Gauss“" gesammelren Exemplare erreicht 4,75 mm, Cephalothorax davon $3,75 \mathrm{~mm}$, Abdomen 1,0 mm. Der $\mathrm{K} \mathrm{opf}$ ist in der Halsgegend verschmälert und die Stirn nach vorn und etwas nach unten gerichtet. Hinter dem Halse ist der Körper breit und höckrig. Das letzte Thorakalsegment endigt mit starken, etwas divergierenden Spitzen, und der Hinterrand desselben hat kleine, sekundäre, innere Lappen. Das A b d o m e $\mathrm{n}$ hat etwas mehr als ein viertel der Länge des Vorderkörpers, das Genitalsegment ist größer als die beiden folgenden und breiter als lang. Die Furkaläste divergieren, sind etwas länger als breit und am Rande und der Außenseite stark behaart. Die äußerste Schwanzborste der linken Seite ist bei weitem am dicksten, kurz, aber dicht befiedert. Die innerste Borste ist auch kurz. Die 2, und 3, Borste von innen sind am 
längsten, die 2. 1⁄2⁄2mal so lang als der ganze Körper, und die 3. nur wenig kürzer. Am Ende sind diese Borsten fächerartig verbreitert. Sie haben alle karmoisinrote Farbe, welche auch die Grenzlinien der Thorakalsegmente zeigen. Die vorderen Antennen sind so lang wie der Cephalothorax.

Fundort: Atlantischer Ozean.

181. Arietellus armatus n. sp. (Tafel XXXVI, Fig. 4, Textfig. 67.)

우 4,5-5,1 mm. Der $\mathrm{K}$ o p f ist in einen starken Fortsatz verlängert, welcher mit stumpfer Spitze endigt und ein wenig nach vorn und unten gekrümmt ist. Dorsal hinter dem Halse ist der Thorax breit und stark bucklig. Das letzte Thorakalsegment ist seitlich in zwei sehr starke Spitzen ausgezogen, die krumm sind, divergieren und fast bis zum hinteren Ende des 3. Segments

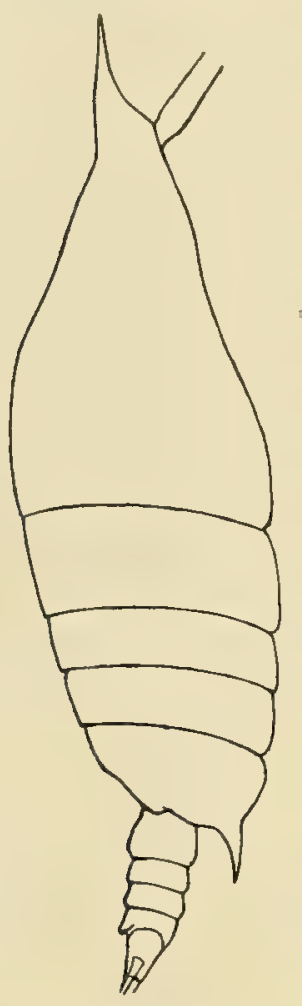

Textfig. 67.

Arietellus armatus. Seitenansicht. reichen. (67.) Das $\mathrm{Abdomen}$ ist kurz, noch nicht ein viertel so lang wie der Vorderkörper, das Genitalsegment so lang wie die beiden folgenden und das Analsegment ebenso lang wie die beiden vorhergehenden. Die Furkaläste haben etwas unregelmäßige Form, sind zwei drittel so breit als lang, divergieren stark und sind an den beiden Rändern stark behaart; der Außenrand und die Spitzen derselben sind gerundet. Die Schwanzborsten sind dicht befiedert, die 5. jederseits gleich dick, nicht verbreitert wie bei Arietellus setosus, die längste nicht so lang wie das Abdomen, und jederseits findet sich noch eine dünne, gekniete, akzessorische Borste. Die vorderen A n te n n e n sind viel länger als bei Arietellus setosus und überragen mit einem Gliede etwa die Furka. Die der linken Seite ist regelmäßig am letzten Gliede tief schokoladenbraun gefärbt, und derartig gefärbte Flecke treten auch auf den Thorakalsegmenten auf. Der Außenast der hinteren Antennen ist drei viertel so lang wie der Innenast, und der Innenlobus des letzten Gliedes von letzterem ist lang. Die M u nteile gleichen denen von Arietellus setosus. Das 5. F u B pa a r ist etwas abweichend gebaut. Es besteht wie bei Arietellus setosus aus gemeinsamem Basalglied, einem großen 2. Basale jederseits, mit einer langen, dünnen Borste am Außenrande, welche sich bis über das Ende der Furka hinaus erstreckt. Der Außenast ist durch einen kleinen, konischen Fortsatz repräsentiert,

Das ơ ist ebenso groß wie das $\subsetneq$; der Kopf und das letzte Thorakalsegment sind ähnlich wie bei diesem gebaut, das Abdomen besteht aus 5 Segmenten, und die linke vordere Antenne ist als Greiforgan entwickelt. Die Längen der drei letzten Antennenglieder verhalten sich wie $37: 60: 23$. Das Gelenk findet sich vor den beiden letzten Gliedern, und das letzte Glied zeigt schokoladenbraune Färbung, wie beim o. Das 5. Fußpaar des ồ gleicht dem von Arietellus setosus.

Diese Art erschien sehr häufig in den Fängen des ,Gauss". Die allgemeine Form von Rhincalanus (Arietellus) aculeatus T. Sсотт würde ihr mehr als Arietellus setosus gleichen. Aber die Abbildung des 5. Fußes, welche ScotT gibt, sieht weder dem Fuße von Arietellus setosus noch von Arietellus armatus ähnlich, und die vordere Antenne ist bei ScoтT's Art größer. 
Bei keiner der Arten von Sars ist das Stirnhorn erwähnt, das unsere Art so auffallend von Arietellus setosus unterscheidet und ein so charakteristischer Zug ist, der nicht übersehen werden konnte. Daher kann ich dieselbe mit keiner von diesen identifizieren.

Arietellus armatus wurde zahlreich am 26. September 1903 und 9. Oktober 1903 (3000 m) im tropischen Atlantischen Ozean gefunden.

\section{Arietellus minor n. sp. (Tafel XXXVII, Fig. 1.)}

o $\mathbf{3 , 3} \mathrm{mm}$; davon Cephalothorax 2,5 mm, Abdomen 0,8 mm. Der $\mathrm{Kopf}$ ist hinten nicht wie bei den andern Arten verschmälert, auch der Rücken nicht bucklig. Die Stirn hat nur einen kleinen Fortsatz, welcher als kleine Spitze nach unten geneigt ist. Das letzte Thorakalsegment hat verhältnismäßig schwache Spitzen, welche gerade nach hinten gerichtet sind. Das Ge n it a 1 s e g m e $\mathrm{n}$ t ist größer als das nächste zusammen mit der Hälfte des 3.; das Analsegment ist fast so lang als die beiden vorhergehenden. Die Furkaläste sind fast doppelt so lang als breit, überhaupt nicht am Außenrand und nur sehr schwach am Innenrande behaart.

Die 2. Schwanzborste von außen ist sehr lang, die 2. von innen hat mittlere Länge und ist von der Mitte bis zum Ende sehr zart und nicht befiedert. Die akzessorische Borste jederseits ist ziemlich kurz. Keine der Schwanzborsten, außer der innersten, ist stark befiedert, und keine dicke Schwanzborste, wie bei Arietellus setosus, ist vorhanden. Da sie abgebrochen sind, läßt sich die Länge der Schwanzborsten nicht genau angeben.

Die vorderen Antennen reichen bis zur Furka. Die Äste der hinteren Antennen sind fast gleich. Das 5. Fußpaar gleicht dem von Arietellus armatus, und der rudimentäre Außenast trägt einen feinen, gekrümmten Dorn an der Spitze statt der pfriemförmigen Borste von Arietellus setosus.

Das $\hat{o}$ gleicht dem $q$ in der Form, aber die Dornen des letzten Thorakalsegments sind etwas stärker. Die Schwanzborsten sind dicht gefiedert, wie bei Arietellus setosus, und am Ende auch fächerartig verbreitert. Das 5. Fußpaar gleicht dem von Arietellus setosus, doch sind einige Differenzpunkte vorhanden. So hat das letzte Glied vom Außenaste des linken Fußes 2 deutliche und fast gleich große Klauen, der Innenast ist keulenförmig und nicht in zwei Partien geteilt, wie bei Arietellus setosus. Der Fortsatz am 2. Gliede des Außenastes vom rechten Fuß ist größer und das innere Haarbüschel sehr dicht. Die Längen der letzten 4 Glieder der Greifantennen verhalten sich wie $6: 10: 10: 4$, das letzte Glied ist am kleinsten. Die Antennen sind nicht so dicht mit Ästhetasken und Borsten wie bei Arietellus setosus besetzt.

Diese Art wurde am 10. September 1903 (3000 m) in der Nähe von Ascension erbeutet.

\section{Arietellus simplex SARs. (Tafel XXXVI, Fig. 5, Textfig. 68 a und b.)}

o 5,60 $\mathrm{mm}$; davon Cephalothorax 4,35 mm, Abdomen 1,25 mm lang. Der $\mathrm{K}$ o p f ist ungefähr auf der Höhe der hinteren Antenne verschmälert und dahinter ist der Körper bucklig. Das letzte Thorakalsegment trägt keine Spitzen, sondern ist hinten gleichmäßig gerundet. Die Stirn hat vorn eine kleine, nach unten gekrümmte Spitze. Das G e n it a l s e g m e n t ist so lang wie die beiden folgenden Segmente; die Furkaläste sind doppelt so lang als breit, parallel gestellt und nur am Innenrande behaart. Die beiden äußeren und die innerste Schwanzborste sind nicht viel länger als das Abdomen, die mittleren sind leider abgebrochen. 
Die vordere Antenne reicht bis zum 4. Fuße. Der Außenast der hinteren Antennen ist fünf neuntelmal so lang als der Innenast. Das Haarbüschel am 2. Basalgliede der hinteren Maxillipeden scheint kleiner zu sein und die Zähne, welche auf den langen Borsten beider Maxilli-

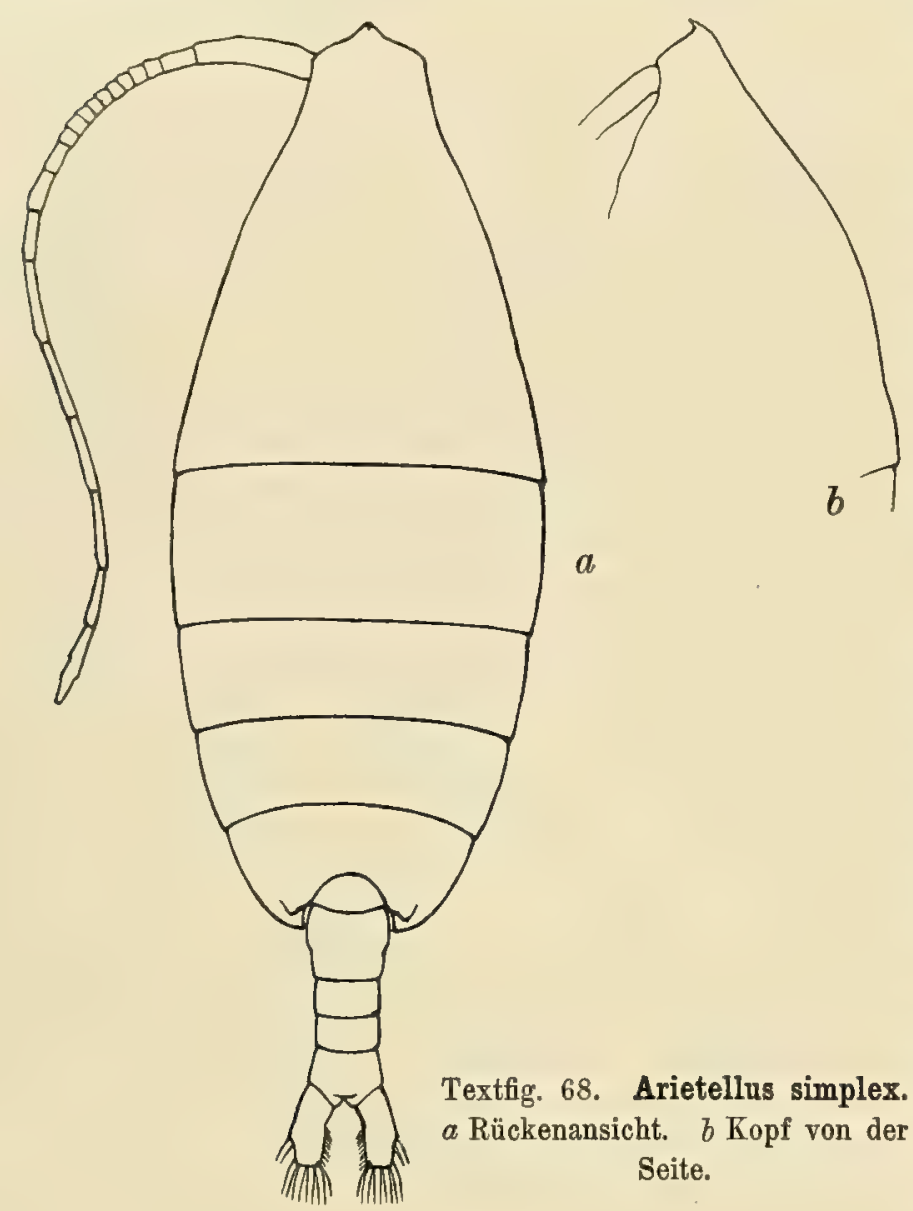
peden auftreten, scheinen länger zu sein als bei Arietellus setosus und dichter zu stehen.

Beim 2. Fußpa a $\mathrm{r}$ ist der Außenranddorn des 2. Gliedes vom Außenaste sehr groß und reicht bis zur Basis des 2. Dorns vom letzten Gliede. Das 5. Fußpaar zeigt denselben Typus wie bei Arietellus setosus, der rudimentäre Außenast ist größer und die beiden Borsten, welche den Innenast ersetzen, sehr klein.

Ein ô $5,0 \mathrm{~mm}$ lang, welches zu dieser Art gehören kann, war in demselben Fange vorhanden. Der Stirnfortsatz ist sehr klein und vom Rücken nur schwach sichtbar. Der Cephalothorax ist $2 \frac{1}{2} \mathrm{mal}$ so lang als das Abdomen, die Schwanzborsten sind viel kürzer als der ganze Körper und nicht mehr als doppelt so lang als das Abdomen. Das letzte Thorakalsegment hat schwache, divergierende Spitzen. Die letzten 3 Glieder der Greifantennen verhalten sich wie $43: 80: 30$. Das 5. Fußpaar gleicht dem von Arietellus setosus.

Alles dieses scheint sehr gut mit der Beschreibung von Arietellus simplex SARs (Bull. Mus. Oceanogr. 1905) übereinzustimmen, und ein abgerundetes letztes Thorakalsegment ist nur dieser Art und Arietellus pavoninus SARS eigentümlich. Sie wurde am 9. Oktober 1903 (3000 m) und 30. September $1903(1500 \mathrm{~m}) \mathrm{im}$ tropischen Atlantischen Ozean gesammelt.

\section{Augaptilus Giesbrecht.}

Zu den $8 \mathrm{im}$ „Tierreich“ erwähnten Arten sind zahlreiche neue hinzugekommen. So beschrieb StEUER Augaptilus fungiferus (Zool. Anz. XXVII, p. 597), FARRAN Augaptilus facilis, similis, horridus, anceps (Fisheries Ireland Sci. Invest. 1906 II [1908]). Esterly fügte Augaptilus rostratus (Univ. California Zool.vol. 3, 1906), Wolfenden Augaptilus zetesios (Journ. marine Biol. Assoc. 1902), Augaptilus magnus und gibbus (ibid. 1904) hinzu. Aber eine ganz außerordentliche Zahl neuer Arten beschrieb G. O. SARS nach den Sammlungen des Fürsten von Monaco: Augaptilus angustus, laticeps, oblongus, brevicaudatus, gracilis, elongatus, nodifrons, truncatus, longicirrhus, tenuicaudia, gibbus, longimanus, cucullatus, spinifrons, rigidus, latifrons, mixtus, clavatus. So ist die Zahl der Arten bereits auf 35 gestiegen, und von den 18 neuen Arten, welche SARS aufstellte, indem er kurze 
Diagnosen ohne jede Abbildung gab, sind mehrere äußerst schwer wiederzuerkennen. Im Bulletin Inst. Oceanogr. 1907 konstatiert Professor SARS jedoch, daß Augaptilus gibbus SARS (1905) synonym mit Augaptilus gibbus WoLFENDEN ist, welcher ein Jahr früher beschrieben wurde. Es ist klar, daß diese immer noch wachsende Gruppe bald nach vernünftigen Gesichtspunkten aufgeteilt werden muß.

184. Augaptilus cornutus n. sp. (Textfig. 69 a und b.)

o 6,50 $\mathrm{mm}$, davon Cephalothorax 4,5 mm, Abdomen 2,0 $\mathrm{mm}$ lang. Der $\mathrm{Kop}$ f ist vorn in einen kurzen, spitzen Fortsatz verlängert, stark vor demselben gekrümmt und endigt mit kurzem, nach unten gerichtetem Rostrum. Die Seitenränder des letzten Thorakalsegments sind scharf gerundet. Das Genitalsegment ist etwas größer als die beiden folgenden, die mittleren Segmente kürzer als das Analsegment, die Furkaläste länger als die beiden vorhergehenden Segmente und fast siebenmal so lang als breit. Die Außenrandborste teilt den Furkalast in zwei Teile, von denen der distale der bei weitem längere ist.

Die vorderen A n t e n $\mathrm{n}$ e n $(69$ a) sind um 4 Glieder länger als der ganze Körper und ihre proximalen 10 Glieder sehr dicht mit Borsten besetzt. Die hinteren Antennen haben stark verlängerte Äste von gleicher Länge. Der Außenast hat nur 4 deutliche Glieder, die beiden mittleren tragen lange Borsten, das 1. Glied ist viel länger als die übrige Antenne und das letzte mit 3 langen Borsten versehen. Das 1. Glied des Innenastes ist $2 \frac{1}{4} \mathrm{mal}$ so lang als das letzte Glied. (69 b.)

Die $\mathrm{M}$ a $\mathrm{ndibeln}$ haben nur einen Ast, der mit 2 Endborsten versehen ist, die Zahnplatte ist sehr lang und schmal, mit 2 Paaren langer, spitzer Zähne, die durch eine Chitinspalte getrennt sind und einen dünnen, spitzen, inneren Zahn. Der Außenzahn ist der stärkste; eine Innenborste ist nicht vorhanden. Uber die Maxille kann ich leider nichts angeben.

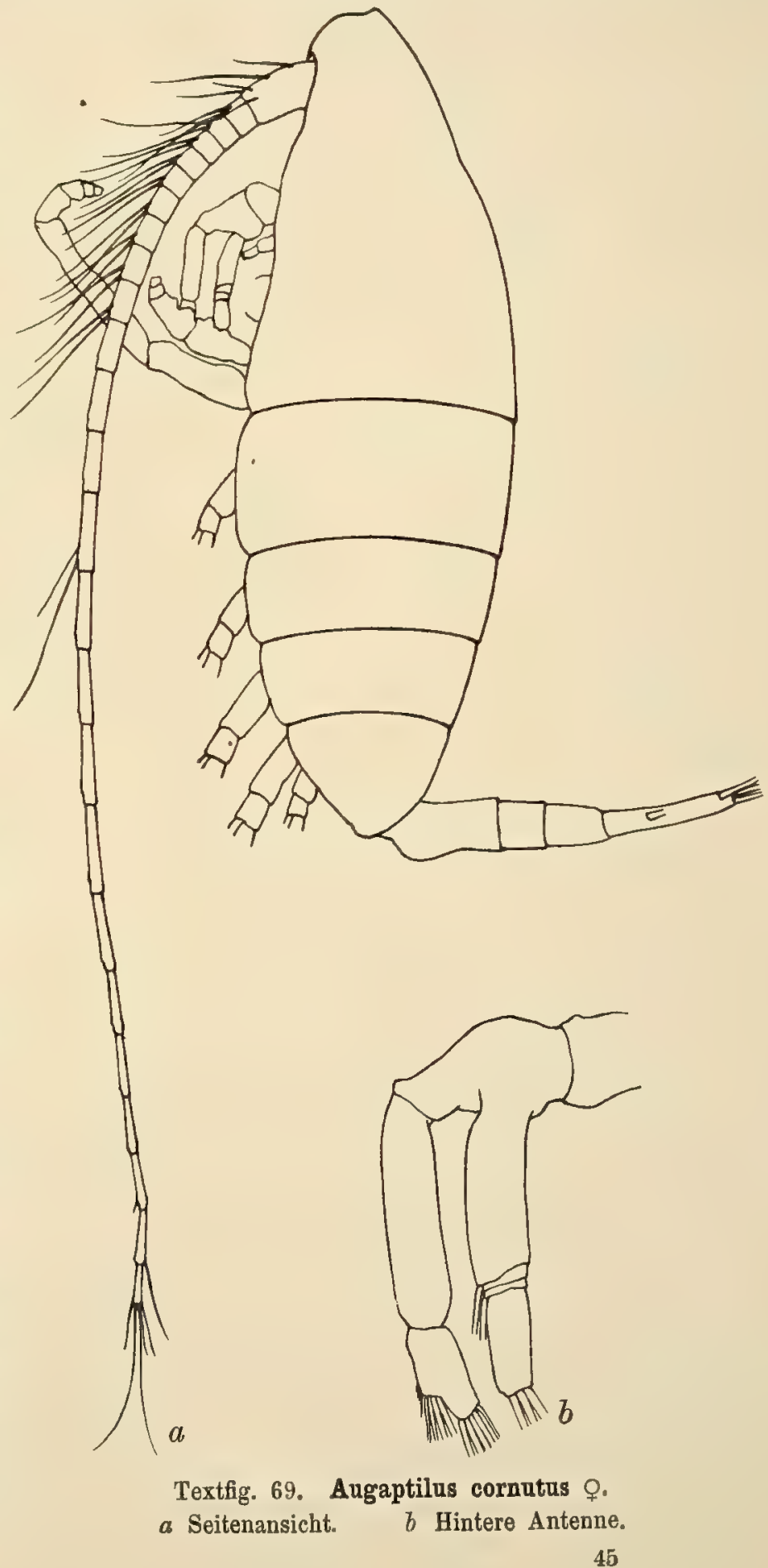


Die vorderen $\mathrm{M}$ a $\mathrm{x}$ ill i p e d e $\mathrm{n}$ haben 5 Loben, die 1, 2, 2, 2, 5 Borsten tragen. Der Innenast ist deutlich segmentiert und seine 3 Glieder haben 15 Borsten. Die proximale Borste des 4. Lobus

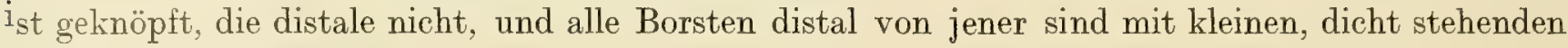
Knöpfchen ausgestattet.

Die hinteren Maxillipeden haben ein langes 2. Basalglied, das fünfmal so lang als breit ist. Die Längen der Basalia und des Innenastes verhalten sich wie 15:20:12. Das 1. Basalglied hat $3+3$ Borsten und das 1. Glied des Innenastes ist fast so lang wie die 4 distalen Glieder.

Die $\mathrm{F}$ ü $\mathrm{B}$ e sind stark zerbrochen, nur das 1. und 5. Paar intakt, das 3. beinahe. Beim 1. Paar ist die Außenborste des 1. Gliedes vom Außenast sehr lang und sehr kräftig und überragt weit das Ende des letzten Gliedes; die Außenborsten des 2. und 3. Gliedes (2 bei dem letzteren) sind von gleicher Länge. An den Basalgliedern sind keine Borsten vorhanden. Das letzte Glied vom Innenaste hat beim 1. Paare 5, beim 3. Paare 7 Randborsten.

Beim 5. Fußpaar ist die Borste des 2. Gliedes vom Außenaste kräftig, aufrecht und dreiviertel so lang wie das letzte Glied. Das letztere ist so lang wie die beiden proximalen Glieder, fast halb so breit als lang und fünf achtel so lang wie das 3. Glied. Es ist dünn und schwach. Das letzte Glied vom Innenaste hat 6 Borsten, an den Basalgliedern sind keine Borsten vorhanden.

Diese Art hat die meiste äußere Ähnlichkeit mit Augaptilus longicaudatus, von welchem sie jedoch nicht nur dadurch abweicht; daß sie doppelt so groß ist, sondern auch in der Gestalt des Kopfes und in vielen anderen Merkmalen. Auch von jeder der neuen Arten von SaRs ist sie verschieden. Von Augaptilus glacialis SARS unterscheidet sie sich besonders durch die Gestalt des Kopfes, den Bau des Abdomens und der Maxillipeden sowie durch bedeutendere Größe als die Nordpolarform.

Augaptilus cornutus wurde am 10. März $1903(3000 \mathrm{~m})$ im Scholleneise nordwestlich von der Gauss-Station gefunden.

185. Augaptilus antarcticus n. sp. (Tafel XXXVI, Fig. 6 und 7, Textfig. 70 a-f.)

우 8,55 mm lang, davon Cephalothorax 6,75 mm, Abdomen 1,8 mm; ein zweites Exemplar $\mathrm{ma} 9,65 \mathrm{~mm}$. Der $\mathrm{Kopf}$ ist gerundet, das Genitals eg ment mehr als doppelt so lang wie die beiden folgenden Segmente, das mittlere Segment kürzer als das Analsegment; die Furkaläste sind etwas länger als das Analsegment und drei viertel so breit wie lang. Vor der Analöffnung findet sich eine kleine Chitinklappe. (XXXVI. 6.) Die vorderen A n t e $\mathbf{n} \mathbf{n}$ e $\mathbf{n}$ überragen mit 6 Gliedern die Furka. Die Längen der letzten 5 Glieder verhalten sich wie 91/2:8 : $10: 8: 5$. Der Außenast der hinteren Antennen ist etwas kürzer als der Innenast und viel dünner. Er besteht aus 7 Gliedern, von denen das letzte ein wenig größer als das 1. ist. Die mittleren Glieder tragen keine, das 2. Basalglied hat 3 Borsten. (70a.)

Die Äste der M a n d i b e In sind ungefähr gleich lang, der Außenast ist aber dicker als der Innenast. Die Zahnplatte ist lang und trägt einen sehr starken, gekrümmten und spitzen Außenzahn mit einem ähnlichen dünnen Zahne daneben, dann 2 krumme und spitze Zähne, an denen auf der Innenseite der Chitinrand ausgehöhlt ist, ferner einen ziemlich dicken, gekrümmten, langen und spitzen Zahn, einen kleineren ähnlichen, äußeren Zahn und am Innenrand einen spitzen, borstenähnlichen Zahn. Der Innenast hat 6 kurze Endborsten. 
Die Ma xille $\mathrm{n}$ haben 3 dicke und lange und 3 winzige innere Borsten am Außenaste. Das 2. Basalglied hat 3, der 3. Innenlobus 2, der 2. Innenlobus einen sehr kräftigen Haken, der 1. Innenlobus 8 starke Haken mit einer dicken, proximalen Borste. Am 1. Außenlobus sind 3 Borsten vorhanden. $(70 \mathrm{~b}$. $)$

Die vorderen $\mathrm{M}$ axill ip ede $\mathrm{n}$ haben am 2. und 4. bis 6. Lobus 2, 2, 3, 2 Borsten. Der 3. Lobus ist viel größer als die übrigen; der Innenast trägt 10 Borsten. (XXXVI. 7.) Die 3 Glieder der hinteren Maxillipeden verhalten sich wie $20: 10: 15$. Das 2. Basalglied ist daher bei weitem am kürzesten: Die Borsten des 1. Basalgliedes stehen zu 1,3,3 und beim 2. Basalglied in 2 Gruppen zu 2. Das 1. Glied des Innenastes ist $1 \frac{1}{2} \mathrm{mal}$ so lang als das 2. (70 c.)

Beim 1. F u B a a re fehlt die lange Borste der Basalia, die Außenborste vom 1. Gliede des Außenastes ist stark, reicht aber nicht über das Ende des Außenastes hinaus; die beiden Randborsten des 3. Gliedes stehen dicht zusammen, sind klein und schwach, und die des 2. Gliedes ist ihnen ähnlich. Das letzte Glied vom Innenaste hat 5 Randborsten. Beim 2. Paar ist die Endsäge des Außenastes ungefähr drei viertel so lang wie das letzte Glied, und das letzte Glied des Innenastes hat 7 Borsten. Beim 3. Paar ist die Endsäge etwas mehr als halb so lang wie
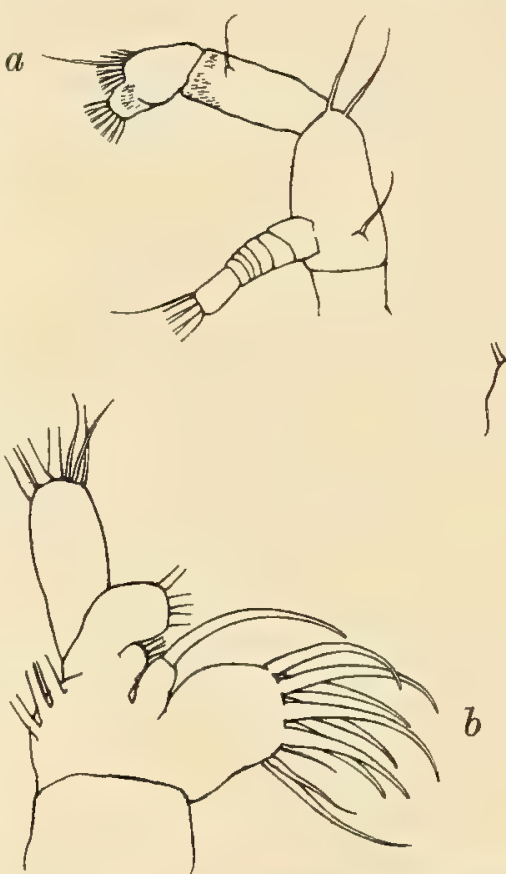

Textfig. 70. Augaptilus antarcticus ㅇ․

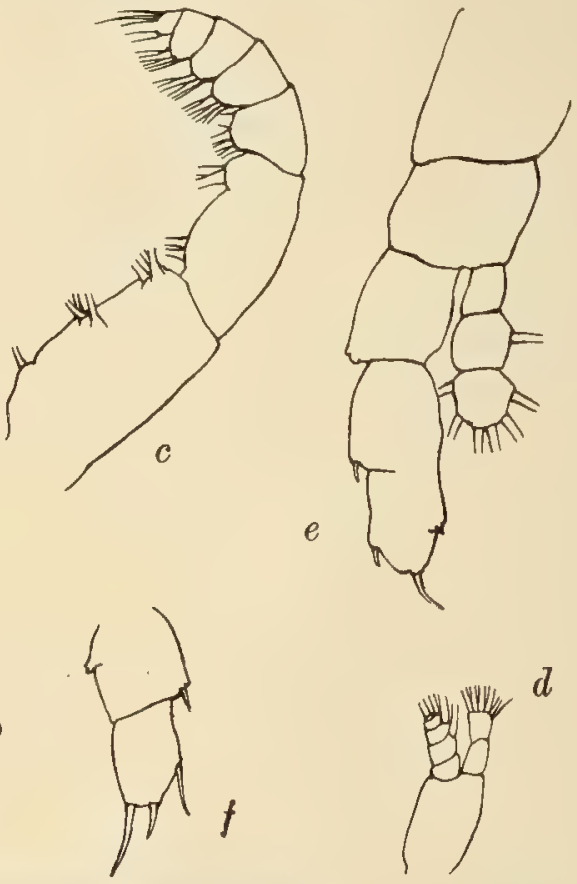

das letzte Glied, und am letzten a Hintere Antenne. $b$ Maxille. $c$ Hinterer Maxilliped. $d$ Mandibelpalpus. Gliede des Innenastes finden sich

$e$ 5. Fuß der einen Seite $\vec{\sigma} \cdot f \cdot 5 . F u ß$ der andern Seite $\vec{\sigma}$.

8 Borsten. Beim 4. Paar ist eine lange, peitschenförmige Borste am 2. Basalgliede vorhanden; die Endsäge ist so lang wie das letzte Glied des Außenastes, und das letzte Glied vom Innenaste trägt 7 Borsten. Beim 5. Fußpaar ist die Innenborste des 2. Gliedes vom Außenaste nicht viel mehr als ein drittel so lang wie die Borste darüber; die Endsäge ist etwas über zwei drittel so lang wie das letzte Glied vom Außenaste; das letzte Glied vom Innenaste hat 6 Borsten. Die peitschenartige Borste am Außenrande des 2. Basalgliedes ist vorhanden.

Diese die größte aller bekannten Arten von Augaptilus erinnert am meisten an Augaptilus fungiferus STEUER.

Das of ist 9,5 mm lang. Die M u $\mathrm{ndteile} \mathrm{gleichen} \mathrm{denen} \mathrm{des} q$, ausgenommen daß der Innenast der hinteren Antenne sehr kräftig und der Außenast nur drei fünftel so lang und nur halb so dick wie der Innenast ist; der Innenast der $\mathbf{M}$ a $\mathbf{n}$ d i b e $\mathbf{l n}$ ist etwas länger als der Außenast, und seine Borsten sind am längsten; die Zahnplatte ist kürzer, aber die Zähne verhalten sich wie beim ㅇ. Unglücklicherweise sind beide vorderen Antennen abgebrochen. Die Borsten des 


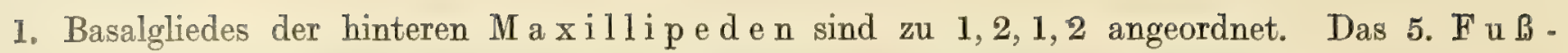
p a a r (70 e) hat gleich große Äste; das 3. Glied des Außenastes ist unvollkommen vom 2. getrennt und mit 2 Enddornen, von denen der innere der längere, und einem 3. langen Dorn am distalen Außenrande versehen. Das 2. Glied hat am Innenrande des linken Fußes (70 f)einen kurzen Auswuchs, und an keinem Gliede des Außenastes finden sich Borsten.

Drei Exxemplare dieser Art wurden am 6. März 1903 (1200 m) und 27. März 1903 (2000 m) im Scholleneise der Antarktis nordwestlich von der Gauss-Station gefunden.

186. Augaptilus fungiferus (?) Steuer. (Tafel XXXVI, Fig. 8, Textfig. 71 a und b.)

Eine sehr große Art fand sich in Fängen aus dem Südatlantischen Ozean, welche ich auf STEUER's Art beziehen möchte, obwohl ich nicht völlig sicher bin, daß diese Identifizierung korrekt ist. Das o ist 8,5 mm lang, der Vorderkörper 7,0 mm, das Abdomen 1,5 mm. Das Ge n it a l s e g m e n t ist doppelt so lang wie die beiden nächsten, das mittlere Segment nur halb so lang wie das Analsegment, die Furkaläste $21 / 4 \mathrm{mal}$ so lang wie das Analsegment und doppelt so lang als breit. (7l a.) Die Schwanzborsten sind leider abgebrochen, aber so weit man sehen kann, war keine Spur einer akzessorischen Borste vorhanden. Der Vorderkörper ist eindrittel so breit als lang, der Kopf gerundet. Der Körper ist daher im Verhältnis zur Länge schmäler als bei Augaptitus magnus. Die vorderen A $\mathrm{n}$ te $\mathrm{n} \mathbf{n}$ en überragen mit 6 Gliedern die Furka. Der Außenast der hinteren Antennen ist nur so lang wie das 1. Glied des Innenastes und dreigliedrig. Die beiden Äste der M a ndibeln haben gleiche Länge. Die 4 Borsten des Außenastes sind verhältnismäßig lang, die 6 des Innenastes sehr kurz und schwach. Die Loben der vorderen Maxillipeden haben 3, 2, 2, 3, 2, 3 Borsten, der Innenast hat 6. Die Längen der 3 Glieder der hinteren Maxillipeden verhalten sich wie $20: 13: 14$, und beim 1 . Basalgliede sind 1, 3, 3 Borsten vorhanden. Die Maxillen haben am 1. Außenlobus 4 Borsten, am Außenaste
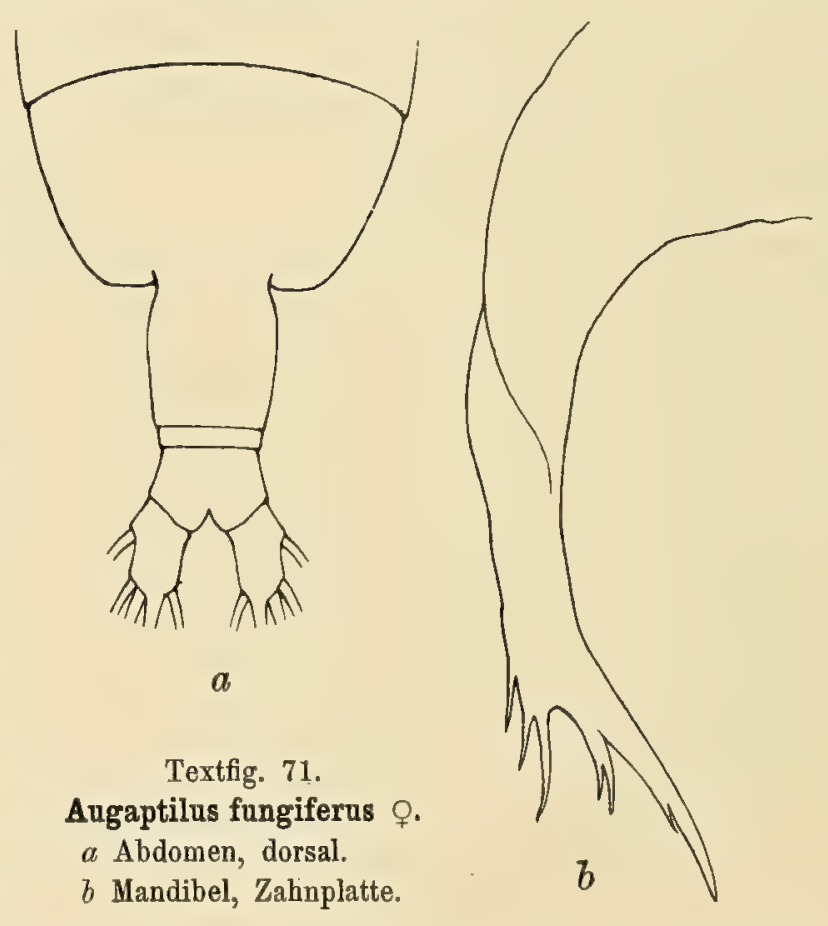
3 lange und 3 sehr kleine Borsten. Am 2. Basalgliede treten 3 starke Borsten auf, am 3 . Innenlobus 2; am 2. Innenlobus findet sich ein langer Haken, und der 1. Innenlobus ist mit 8 großen Haken und 2 Borsten versehen.

Die F ü $B$ e sind wie bei der Art Steuer's gebildet, und am letzten Gliede des Innenastes vom 1. Fuße finden sich 5 Borsten, beim 2. 7, beim 3. 8, beim 4. 7 und beim 5. Fuße 6 Borsten. Die Außenborste vom 1. Gliede des Außenastes beim 1. Paare reicht nicht bis zum Ende des letzten Gliedes, und die Borste vom 2. und die 2 Borsten vom 3. Gliede sind sehr klein und schwach. (XXXVI. 8.) Die Peitschenborste des 1. und 2. Paares scheint zu fehlen. Dieses Exemplar, welches am 9. Oktober 1903 (3000 m) erschien, scheint eine sehr große, äußere Ähnlichkeit mit 
Augaptilus antarcticus zu haben, doch sind wesentliche Differenzen vorhanden, welche zwischen diesen beiden Arten und Augaptilus magnus noch dazu hier zusammengestellt werden.

Augaptilus magnus, 6,65-7 mm lang, Körper breit, nicht doppelt so lang als breit, Kopf ziemlich viereckig; Abdomen ein viertel so lang wie der Vorderkörper; Genitalsegment länger als das übrige Abdomen, das mittlere Segment etwas kürzer als das Analsegment; Furkaläste nur so lang wie das Analsegment und fast so breit wie lang, mit akzessorischer Borste. Antenne um 4 Glieder länger als der Körper. Borsten der Mandibularäste kurz und schwach.

Augaptitus antarcticus, 8,55-9,65 mm lang, Körper schmal, Kopf gerundet. Genitalsegment doppelt so lang wie die beiden folgenden Segmente, mittleres Segment nicht viel mehr als halb so lang wie das Analsegment. Furkaläste etwas länger als das Analsegment und länger als breit, mit akzessorischen Borsten und zwei langen Schwanzborsten, die 21/2mal so lang sind als das Abdomen. Antennen um 6 Glieder länger als der Körper.

Augaptilus fungiferus, $8,5 \mathrm{~mm}$ lang $(7,5 \mathrm{~mm}$ nach STEUER). Cephalothorax dreimal so lang als breit, Kopf gerundet. Genitalsegment doppelt so lang wie die beiden nächsten, Analsegment doppelt so lang als das mittlere Segment, Furkaläste 21/4mal länger als das Analsegment und doppelt so lang als breit. Antennen um 6 Glieder länger wie der Körper. Innenast der hinteren Maxillipeden so lang oder länger wie das 2. Basalglied. 1. Außenlobus der Maxille mit nur 3 Borsten.

Es sind Unterschiede vorhanden in der Zahl der Borsten des ersten Außenlobus der Maxille zwischen dieser und StEuER's Beschreibung. Er erwähnt $9+5$ Borsten am Außenaste der Mandibeln und beschreibt auch die Furkaläste als kurz und breit. Die Furkaläste sind bei Augaptilus fungiferus viel länger als bei Augaptilus antarcticus.

18\%. Augaptilus gibbus Wolfenden. (Tafel XXXVII, Fig. 2 und 3, Textfig. 72 a-d.)

Diese Art wurde zuerst von mir im Journal Mar. Biol. Association vol. XII 1904 nach einem Exemplar aus dem Atlantischen Ozean in die Nähe der Westküste Irlands beschrieben. SARS hat unter seinen neuen Arten (Bull. Mus. Oceanogr. 1905) eine Art beschrieben, welche vielleicht mit jener identisch sein kann und für welche er denselben Namen vorschlug, ohne jedoch auf die frühere Art zu verweisen. Farran (Fisheries Ireland l. c.) erhielt, nachdem er ein Exemplar von der irischen Küste an Professor Sars eingesandt hatte, von diesem die Nachricht, daß Augaptilus gibbus SARS mit der früher von mir beschriebenen Art synonym wäre.

Die Größe des Originalexemplars von der irischen Küste betrug 2,75 mm, und ein Individuum aus der Sammlung des „Gauss" war 2,7 mm lang, während SARs die Größe zu 3,10 mm angibt. FARran's Exemplar war $3,36 \mathrm{~mm}$ lang. Es ist möglich, daß hier zwei verschiedene Arten zusammengeworfen sind, und ich gebe daher nach dem Exemplar vom „Gauss" einige Zusätze zur früheren Beschreibung.

i 2,7 mm lang, davon Cephalothorax 2,2 mm, Abdomen 0,5 mm. (XXXVII. 2.) Der $\mathrm{K} \oplus \mathrm{p} f$ ist gerundet und hat ein starkes, zweispitziges Rostrum. (72 a.) Auf dem 1. Thorakalsegment findet sich eine starke, höckerartige Anschwellung. Dieses Segment ist von den übrigen abgegliedert und der Kopf ist fast so lang wie der übrige Thorax. Das A b d o m e n ist nur ein viertel so lang wie der Vorderkörper. Das Genitalsegment ist länger als die beiden folgenden Segmente zusammen mit der halben Furka, das mittlere Segment ist sehr klein und das Analsegment doppelt so lang wie das mittlere. Die Furkaläste sind länger als das Analsegment und fast doppelt so lang als breit, haben gut entwickelte akzessorische Borsten und die längste Schwanzborste ist über doppelt so lang wie das Abdomen. Der Cephalothorax ist nur doppelt so lang als breit.

Die vorderen A n te n n e $\mathrm{n}$ überragen die Furka etwa mit einem Gliede. Die Längen der letzten 5 Glieder verhalten sich wie $14: 14: 14: 13: 11$.

Bei den hinteren Antennen (72 d) ist der Außenast nur halb so lang als der Innenast und hat nur 4 Glieder. Das 1. von diesen ist so lang wie die übrigen 3, die mittleren Glieder tragen keine 
Borsten. Das 1. Glied vom Innenast ist lang, zweimal so lang als das 2., am proximalen Ende verschmälert, distal etwas keulenförmig. Der Außenlobus des letzten Gliedes ist lang und hat 6 Borsten, der Innenlobus hat 8, von denen nur 3 lang, die 3 proximalen aber sehr kurz und schwach sind.

Die Mandibeln (72 b) sind zweiästig, mit viel längerem und dickerem Außenaste. Dieser hat 4, der Innenast 2 dickeBorsten und 1 kurze. Die Zahnplatte ist lang und schmal, die Zähne sind stark. Es sind vorhanden: ein äußerer krummer und dicker Zahn mit einem kleineren innen daneben, eine mittlere Gruppe von 2 langen, spitzen Zähnen und eine innere Gruppe von 2, von denen der innerste bei

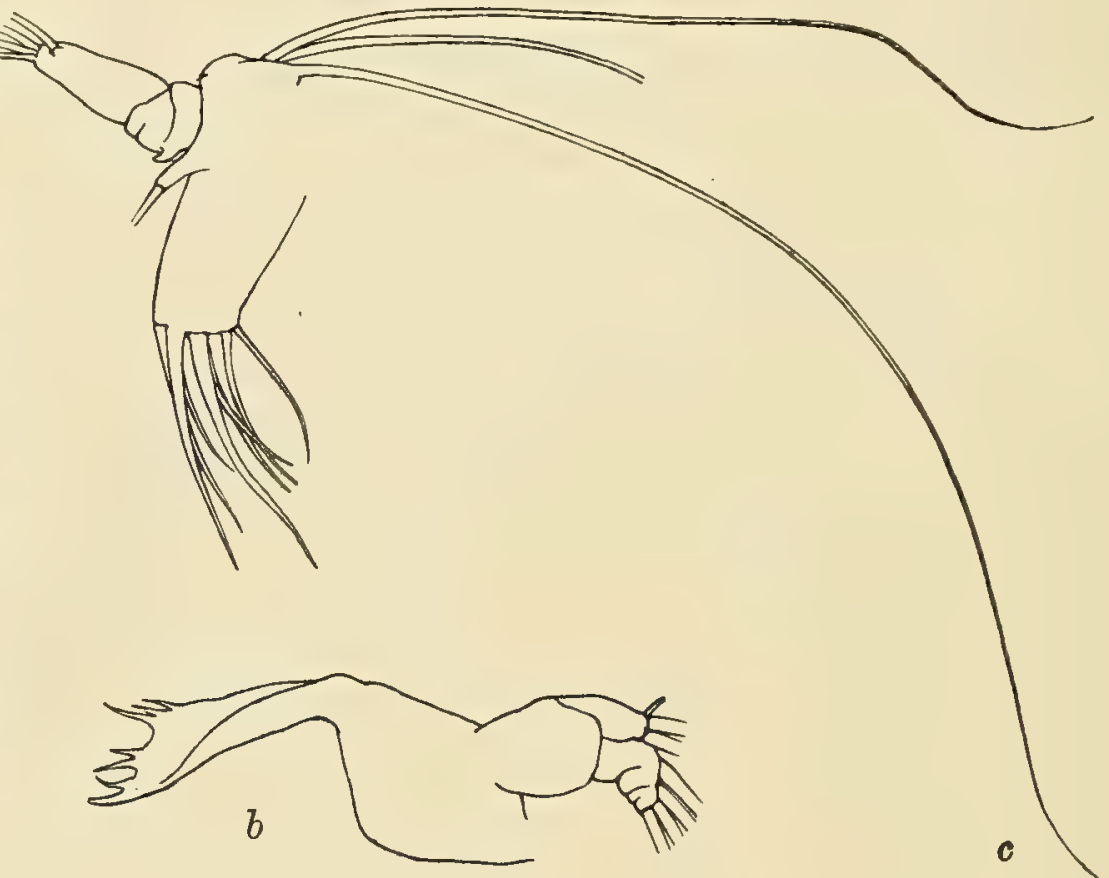
weitem der kleinste ist. An Stelle der Innenborste findet sich ein scharfer Dorn.

Die Maxille (72 c) gleicht der typischen Form, der 1.Außenlobus hat 3 Borsten. Der Außenast, zweimal so lang als breit, trägt 4 ( 3 lange und 1 kurze schwache) Borsten; das 2. Basalglied und der Innenast sind angedeutet, haben aber keine Borsten, ebenso ist der 3. Innenlobus borstenlos; der 2. Innenlobus trägt einen langen Haken und der 1. 5 schwache Haken und 3 Borsten. Der mittlere

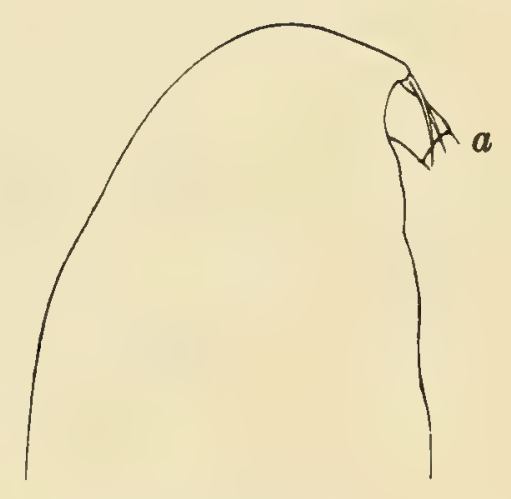

Textfig. 72. Augaptilus gibbus $O$. $a$ Kopf von der Seite. $b$ Mandibel. $c$ Maxille. $d$ Hintere Antenne.

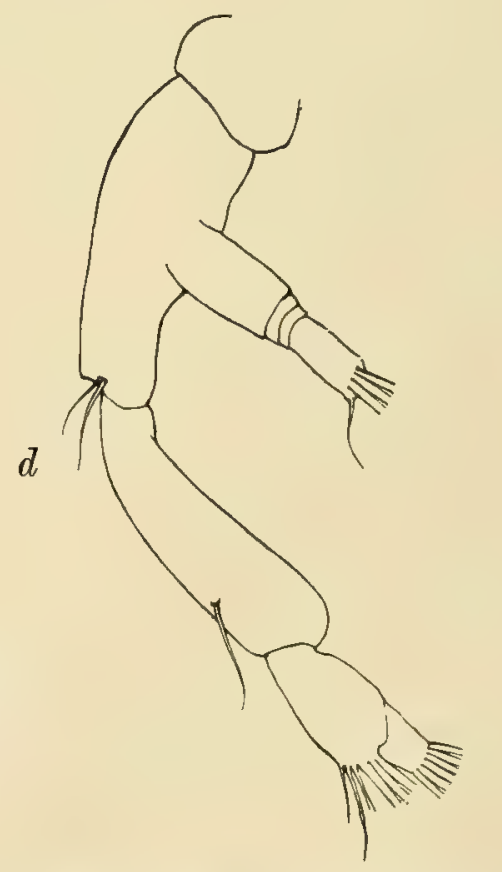

Haken ist sehr lang und die proximale Borste des 1. Außenlobus ist ebenfalls äußerst lang und dünn.

Die hinteren M a xillipe de n haben 3 ungefähr gleich lange Glieder, und die Basalia sind sehr dick. Nur ein Lobus mit 2 Borsten zeigt sich am 1. Basalgliede. Die Endborsten beider Maxillipeden sind dick und dicht mit Knöpfen besetzt.

Das 1. F и B p a r (XXXVII. 3) hat ein eigentümliches 2. Basalglied, dessen Außenkante einen Buckel mit langer, peitschenförmiger Borste trägt und welches auffallend gegen den fast 
geraden Außenrand des 1. Basalgliedes absticht. Die erste Außenborste erreicht kaum das Ende des Außenastes, und die 3 andern Borsten sind klein. Das letzte Glied vom Innenaste trägt 6 Borsten, beim 2. Fuße 7, beim 3. 8 und beim 4. 7. Das 5. Fußpaar ist klein und die Innenborste des 2. Gliedes vom Außenast ist schwach und kurz, nicht mehr als halb so lang wie das letzte Glied. Das letzte Glied vom Innenast ist mit 6 Borsten ausgestattet.

Dieses Exemplar stimmt genau mit der von mir beschriebenen Type überein, obwohl der Rücken etwas weniger bucklig und das Genitalsegment verhältnismäßig etwas länger ist. Sonst ist alles dasselbe.

Es wurde am 4. September 1903 (2000 m) zwischen St. Helena und Ascension gefunden.

188. Angaptilus cucullatus G. O. SARS.

Die Beschreibung dieser Art im Bulletin Mus. Oceanogr. 1905 ist so dürftig, daß die hier erwähnte Form möglicherweise nicht mit ihr identisch ist, aber so weit die Beschreibung von SARS geht, stimmt sie mit den vom „Gauss" erbeuteten Exemplaren überein.

Das i ist 6,2-6,7 mm lang, wovon 5,35-5,55 mm auf den Cephalothorax, 1,2 $\mathrm{mm}$ auf das Abdomen kommen. Das Abdomen ist daher nicht mehr als ungefähr ein fünftel so lang wie der Rumpf. Diese Art weicht von Augaptilus rattrayi darin ab, daß sie weniger untersetzt und breit ist, der Kopf länger erscheint, die Stirn konischer gestaltet und nicht behaart wie bei Augaptilus rattrayi ist. Das 1. Segment ist länger als der übrige Thorax. Das Genitalsegment ist länger als die beiden folgenden Segmente, das Analsegment doppelt so groß als das mittlere, und die Furkaläste sind nur halb so lang wie das Analsegment und ebenso breit wie lang.

Die vorderen Antennen reichen bis zum Ende des 4. Thorakalsegments. Der Außenast der hinteren Antennen ist kürzer und dünner als der Innenast und besteht aus 7 Gliedern, von denen das letzte lang, so lang wie die 5 Glieder vorher, ist. Der Innenast ist gut $3 \frac{1}{2} 2 \mathrm{mal}$ so dick wie der Außenast. Am Innenaste der Mandibeln finden sich 2, am Außenaste 4 Borsten, welche nicht so dicht wie bei Augaptilus rattrayi befiedert sind; die Zahnplatte hat einen starken äußeren, einen kleineren medianen und einen starken und spitzen inneren Zahn. Die M a xille n tragen am 1. Außenlobus 5, am 1. Innenlobus 3 (die beiden äußeren davon sind geknöpft), am Außenaste 3 Borsten und an dem 2. Basalgliede noch eine lange Borste. Die Basalia der beiden vorderen und hinteren $\mathrm{Maxilli}$ pede $\mathrm{n}$ sind sehr dick, und bei den letzteren ist der Innenast nur $1 / 3$ so dick wie das 1 . und nicht halb so dick wie das 2. Basalglied; die Endborsten sind bei beiden sehr dick und sehr dicht mit Knöpfen besetzt. Die Längen der 3 Glieder der hinteren Maxillipeden verhalten sich wie $13: 16: 14$.

Diese Art scheint in der Mitte zu stehen zwischen Augaptilus rattrayi ScoTt, von 4,9 mm Länge, und Augaptilus horridus FARRAN, welche $10 \mathrm{~mm}$ lang wird. Einige Exemplare fanden sich am 11. Oktober 1901 (1200 m) südwestlich von Ascension.

189. Augaptilus megalurus GIESBRECHT

wurde unter dem Äquator am 26. September 1903 (3000 m) im Atlantischen Ozean beobachtet.

190. Augaptilus hecticus Giesbrecht

erschien in den Fängen vom 9. Oktober $1903(3000 \mathrm{~m})$ und 11. Oktober $1901(1200 \mathrm{~m})$ im tropischen Atlantischen Ozean. 
191. Augaptilus palumboi GIEsBrecht

wurde zusammen mit dem vorigen am 9. Oktober $1903(3000 \mathrm{~m})$ gefunden.

192. Augaptilus longimanus SARS (Textfig. 73 a-c.)

ist erst kürzlich von SARS (Bull. Mus. Oceanogr. 1905) beschrieben worden und durch die außerordentliche Länge des 1. Gliedes vom Innenaste der hinteren Maxillipeden charakterisiert; es ist
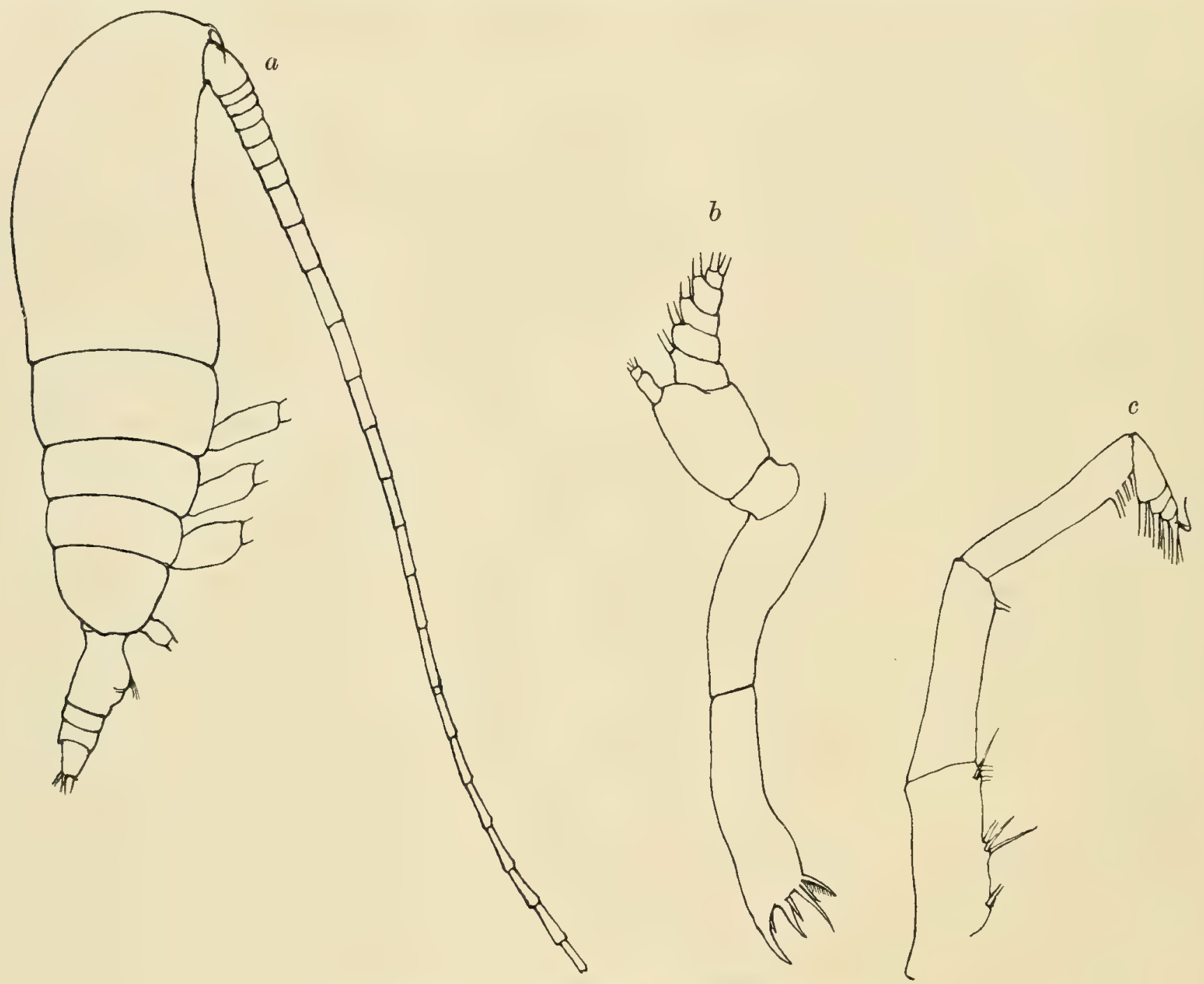

Textfig. 73. Augaptilus longimanus.

a Seitenansicht. $b$ Mandibel. $c$ Hinterer Maxilliped.

doppelt so lang als die 4 übrigen Glieder und kaum kürzer als das 2. Basalglied. Die vorliegenden Exemplare können zu dieser Art gehören, unterscheiden sich jedoch in einigen Punkten von der kurzen Beschreibung bei SARS.

Das o ist 5,3 mm lang, was der Angabe von SaRS entspricht; das Abdomen hat kaum mehr als ein fünftel der Länge des Rumpfes $(0,9: 4,4)$. Der $\mathrm{Kop} f$ ist gerundet, etwas gewölbt und mit einem Paare feiner Rostralfilamente ausgestattet. Das 1. Thorakalsegment ist länger als der übrige Thorax und dorsal stark gerundet. Das Genit a ls e g m e n t ist länger als die beiden 
folgenden und die Furka zusammen und ungefähr doppelt so lang wie die beiden folgenden Segmente. Die Furkaläste sind länger als das Analsegment. Das mittlere Segment ist etwas größer als das Analsegment. (73 a.)

Die vorderen Anten $\mathrm{n}$ en überragen mit etwa 6 Gliedern die Furka; der Außenast der hinteren Antennen ist viel kürzer als der Innenast. Die $\mathbf{M}$ a $\mathbf{n d i b u l a r a ̈ s t e ~ s i n d ~ u n g l e i c h , ~}$ der Innenast ist sehr unbedeutend, obwohl er aus 2 Gliedern mit 2 Endborsten besteht (SARS erwähnt nur eine), und der Außenast hat 5 wohlgebildete Glieder mit 6 Borsten. Die Zahnplatte ist sehr lang und mit 6 spitzen Zähnen ausgestattet, von denen 3 verhältnismäßig lang sind. Eine Innenborste ist vorhanden. (73 b.)

Die Loben der Maxille n sind rückgebildet; der 1. Außenlobus hat 3, der Außenast 3 und der 1. Innenlobus auch nur 3 Borsten. Am Innenaste findet sich nur eine kurze Borste. Die hinteren Maxillipeden (73 e) haben fast gleich lange Basalglieder; das 1. Glied des Innenastes ist doppelt so lang wie die 4 folgenden Glieder und fast so lang wie das 2. Basalglied. Am 1. Basalgliede finden sich 1, 3, 3 Borsten und am 2. anscheinend nur eine Borste. Auf der Ventralseite der Genitalanschwellung scheint ein kleines Haarbüschel vorhanden zu sein.

Abgesehen von den ungleichen Ästen der hinteren Antennen und dem Unterschied in der Beborstung der Mandibeln würde diese Charakteristik gut mit der Beschreibung von SARS übereinstimmen.

Augaptilus longimanus wurde am 11. Oktober 1901 (1200 m) im tropischen Atlantischen Ozean gefunden.

193. Augaptilus squamatus Giesbrecht

liegt aus den Fängen vom 14. Oktober 1901 (1900 m), 5. November 1901 (1000 m) und 30. September $1903(1500 \mathrm{~m})$ vor.

194. Augaptilus rattrayi Sсотт

war in den Fängen vom 14. Oktober $1901(1900 \mathrm{~m})$, 19. Oktober $1901(800 \mathrm{~m})$, 5. November 1901 $(1000 \mathrm{~m}), 30$. September $1903(1500 \mathrm{~m}), 9$. und 20 . Oktober $1903(3000 \mathrm{~m})$, also etwa von $30^{\circ} \mathrm{n}$. Br. bis $30^{\circ}$ s. Br. im Atlantischen Ozean, vertreten.

195. Augaptilus filigerus Giesbrecht

fand sich in den Fängen vom 19. Oktober 1901 (500 m), 22. Oktober 1901 (3000 m), 4. September $1903(2000 \mathrm{~m})$ im Südatlantischen Ozean.

\section{Augaptilus longicandatus Giesbrecht}

wurde am 12. November 1901 (3000 m), 4. September 1903 (2000 m), 26. September 1903 (3000 m), 30. September $1903(1500 \mathrm{~m}), 9$. Oktober $1903(3000 \mathrm{~m})$, also in weit zerstreuten Fängen aus dem nördlichen und südlichen Atlantischen Ozean gefunden.

197. Angaptilus magnus Wolfenden. (Tafel XXXVII, Fig. 4-9, Textfig. 73 a, b.)

(Journ. Marine Biol. Assoe. vol. VII, 1904.)

Diese Art wurde nach Exemplaren von der Westküste Irlands (Journal Marine Biol. Assoc. vol. VII, 1904) ursprünglich von mir beschrieben. Da Bedenken vurliegen, daß diese Art mit 
Augaptilus fungiferus STEUER identisch sein könnte, ist es nöthig, hier eine ausführliche Beschreibung zu geben.

Die südatlantische Form ist etwas kleiner als die nordische, nämlich 6,65 mm lang. Der $\mathrm{K}$ o p f erscheint bei Dorsalansicht ziemlich viereckig, mit vorspringender Papille; der Rumpf ist 5,5 mm, das Abdomen 1,15 mm lang. Der Cephalothorax ist verhältnismäßig breit, 2,9 mm breit in der Mitte, also halb so breit als lang. Das A b d o m e n ist einviertel so lang wie der Vorderkörper, das Genitalsegment sehr lang, länger als das übrige Abdomen und doppelt so lang wie die beiden folgenden Segmente. Das mittlere Segment ist etwas kürzer als das Analsegment; die Furkaläste

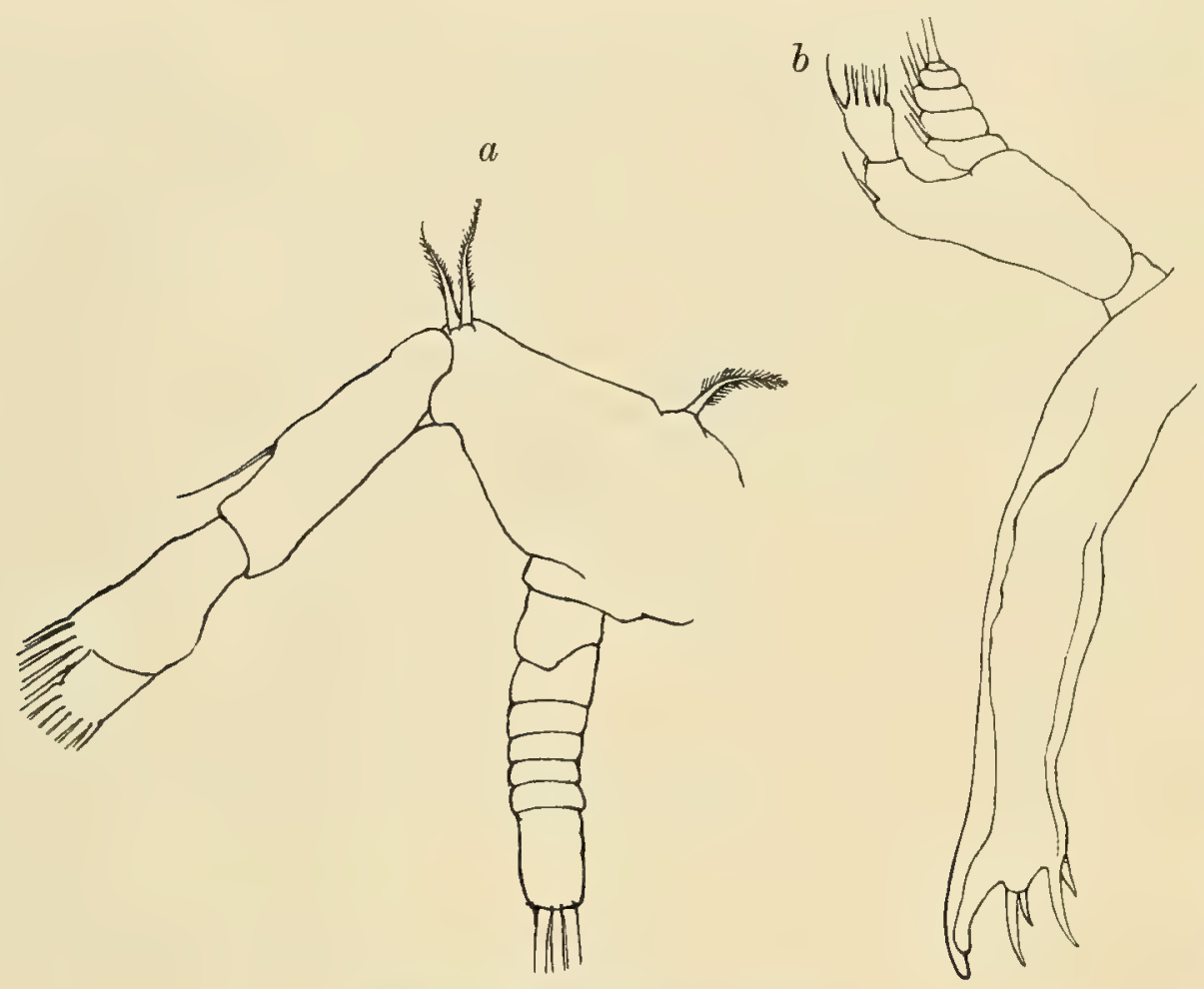
sind so lang wie das Analsegment und nur sehr wenig länger als breit. Auf jeder Seite findet sich eine sehr kurze, akzessorische Borste, und die längste Schwanzborste ist etwa doppelt so lang wie das Abdomen. (XXXVII. 4.)

Die vorderen $\mathrm{A} n \mathrm{t}$ e n$\mathrm{n}$ e $\mathrm{n}$ überragen etwa mit 4 Gliedern die Furka, und die Längen der letzten 5 Glieder verhalten sich wie $7: 5 \frac{1}{2}: 6: 6: 4 \frac{1}{2}$. Der Außenast der hinteren Antennen ist achtgliedrig und so lang wie das 1 . Glied vom

Textfig. 74. Augaptilus magnus $Q$. Innenaste. Die mittleren a Hintere Antenne. $b$ Mandibel.

Glieder haben keine, das letzte Glied hat 3 Borsten. (74 a.) Die Mandibeln sind zweiästig, der Außenast fünfgliedrig mit 6 Borsten, der Innenast kürzer, sehr kurz, mit 5 Borsten versehen. Die Zahnplatte ist lang und trägt 6 starke, spitze Zähne. (74 b.) Die M axille n haben 8 starke Haken am 1. Innenlobus, einen Haken am 2. Lobus, eine schwache Borste am 3. Innenlobus und am 2. Basalgliede, 2 dickeBorsten und eine sehr schwache am Außenast und 5 dicke Borsten mit 3 kurzen proximalen am 1. Außenlobus. (XXXVII. 5.) Die vorderen Maxillipeden haben an den Loben 3, 1, 2, 3, 2, 3 Borsten und 7 am Innenaste. Die beiden Basalglieder der hinteren Maxillipeden sind etwa gleich lang, der Innenast drei viertel so lang wie das 2. Basalglied, so daß sie im Verhältnis von $20: 20: 15$ stehen. Am 1. Basalgliede finden sich 1, 3, 3 Borsten. (XXXVII. 6 u. 7.) Das 1. F u $\beta$ p a a $\mathbf{r}$ trägt am Außenrande des 1 . Gliedes vom Außenast eine kurze, starke Borste. Die Dornen des 2. und 3. Gliedes sind gleich groß und schwach. Das letzte Glied des Innenastes hat 5 Borsten. (XXXVII. 8.) Beim 2. Fußpaare hat das letzte Glied vom Innenaste 7 Borsten und die Endsäge ist neun zehntel so lang wie das letzte Glied vom Außenaste. 
Beim 3. Fußpaare finden sich 8 Borsten am letzten Gliede des Innenastes, und die Endsäge ist so lang wie beim 2. Das 4. Paar hat 7 Borsten am Innenast, und die Endsäge ist nur halb so lang wie das letzte Glied vom Außenaste. Beim 5. Fußpaare (XXXVII. 9) sind 6 Borsten am Innenast vorhanden, und die Endsäge ist so lang wie das letzte Glied vom Außenaste. Die Innenborste des 2. Gliedes vom Außenast ist kurz und schwach und nur drei viertel so lang wie das letzte Glied. Die lange Peitschenborste des ersten und vierten Paares scheint bei dieser Art nicht vorhanden zu sein.

Sie wurde am 9. Oktober 1903 (3000 m), 4. September 1903 (2000 m), 30. September 1903 $(1500 \mathrm{~m}), 20$. Oktober $1903(3000 \mathrm{~m})$ erbeutet.

\section{Augaptilus subfiligerus $n$. sp.}

ㅇ 4,65 mm lang, davon Cephalothorax 3,65 mm, Abdomen 1,0 mm. Der Kopf ist gerundet und mit kurzem, zweispitzigem Rostrum versehen. Das Genitalsegment ist länger als die beiden folgenden zusammen; das mittlere Segment ist etwas kürzer als das Analsegment, und die Furkaläste sind ungefähr so lang wie dieses letztere und etwas länger als breit.

Die vorderen Ante n n e n überragen mit etwa 4 Gliedern die Furka, und die Längen ihrer 5 letzten Glieder verhalten sich wie $28: 28: 30: 28: 20$. Die Antennenglieder sind mit langen Haaren gut ausgestattet. Der Außenast der hinteren Antennen ist nur ungefähr halb so lang wie der Innenast und gerade so lang wie das 1. Glied des letzteren. Der Außenast hat 8 deutliche Glieder, von denen das letzte nur so lang wie die 3 vorhergehenden ist und 4 Borsten trägt. Die $\mathrm{M}$ a $\mathrm{n}$ d i b e 1 n sind zweiästig mit gleich langen Ästen. Der Innenast hat 6 verhältnismäßig kurze Borsten; die 5 Borsten des Außenastes sind viel länger. Die Zahnplatte ist lang und trägt 3 Zähne, von denen der äußere stark und gekrümmt ist, während die beiden inneren lang und zugespitzt sind. Die Maxille n haben am 1. Außenlobus 4 lange Borsten, der 2. Außenlobus trägt eine Borste, der Außenast 2, das Basalglied und der Innenast 2, der 3. Innenlobus 2 Borsten, der 2. Innenlobus einen sehr starken, krummen und langen Dorn, der 1. Innenlobus 9 Haken. Die vorderen M a xilli $\mathrm{p}$ e d e $\mathrm{n}$ haben an den 6 Loben 3, 1, 2, 3, 2, 3 Borsten, am Innenaste 7. Die hinteren Maxillipeden haben 3 Glieder, deren Längen sich wie $10: 10: 9$ verhalten, und das 1. Glied des Innenastes ist am längsten.

Beim 1. F u Bpa a r ist die Außenborste des 1. Gliedes vom Außenaste sehr lang, reicht über das Ende des Außenastes hinaus, das 2. Glied trägt eine kurze Borste und das 3. Glied 2 ähnliche Außenrandborsten. Beim 2. Fußpaare hat das letzte Glied des Innenastes 7 Borsten, beim 3. Paar 8 und beim 4. Paar 7. Die Endsäge des Außenastes vom 3. Paar ist vier fünftel so lang wie das letzte Glied, und beim 4. Paar ist sie kürzer. Beim 5. Paar ist sie so lang wie das Endglied; das letzte Glied vom Innenaste hat 6 Borsten, und die Innenrandborste des 2. Gliedes vom Außenast ist mäßig lang und gerade. Dieser Copepod hat bedeutende Ähnlichkeit mit Augaptilus filigerus, muß aber, besonders wegen der stark abweichenden Maxille, unterschieden werden. Er wurde am 4. September 1903 (2000 m) zwischen St. Helena und Ascension gefunden.

199. Augaptilus faeilis FarRan. (Tafel XXXVIII, Fig. 1 und 2, Textfig. 75 a und b.)

o 4,0 $\mathrm{mm}$, Cephalothorax davon 3,0 $\mathrm{mm}$, Abdomen 1,0 $\mathrm{mm}$. Der $\mathrm{K}$ o p f ist gerundet, nicht gewölbt und mit 2 feinen Rostralfilamenten versehen. Das Abdomen hat sehr langes Genitalsegment, 
das um ein drittel länger als die beiden folgenden Segmente ist. Das mittlere Segment ist nur ein drittel so lang wie das Genitalsegment und ebenso lang wie das Analsegment. Die Furkaläste sind so lang wie das Analsegment und fast so breit wie lang. (75 a.)

Die vorderen Ante $\mathrm{n} \mathbf{n}$ e $\mathbf{n}$ messen $7,7 \mathrm{~mm}$ und sind um 8 bis 9 Glieder länger als das Tier. Die Längen der 6 letzten Glieder verhalten sich wie $50: 44: 46: 43: 40: 27$. Der Außenast der hinteren Antennen ist nur zwei drittel so lang als der Innenast und besteht aus 8 Gliedern, von denen das 2. länger als das 8. ist. Die mittleren Glieder tragen die gewöhnlichen Borsten. Die M a n d ibeln sind zweiästig, die Äste klein und gleich lang, der Außenast ist fünfgliedrig und trägt 2, der Innenast 4 Borsten. Die Zahnplatte hat einen starken Außenzahn und 2 starke Innenzähne. Der 1. Innenlobus der M a xillen $(75 \mathrm{~b})$ ist groß, dreimal so lang als breit und mit 6 Haken und 2 Borsten versehen. Der Außenast ist lang, 31/2mal so lang als breit und hat 2 dicke Endborsten und 2 kleine Seitenborsten; am 1. Außenlobus finden sich 4 dicke Borsten, am

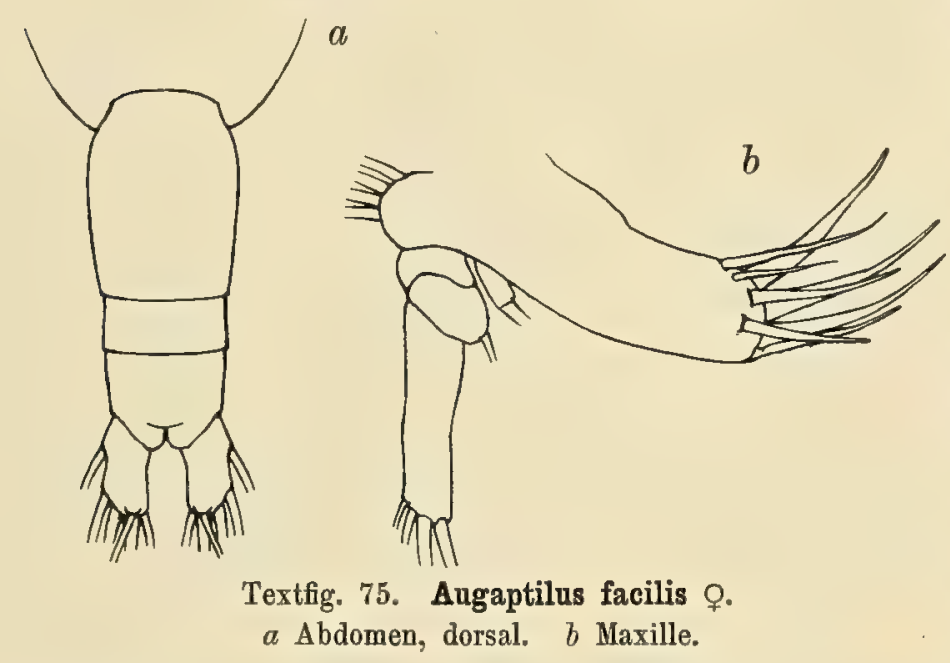
2. Innenlobus und dem 2. Basallobus je eine Borste von mittlerer Stärke. Die 6 großen Haken des 1. Innenlobus sind mit den für Augaptilus charakteristischen Näpfchen verziert.

Die vorderen Maxillipeden haben am 1. Lobus 3 Borsten und einen scharfspitzigen Dorn mit breiter Basis; die Loben distal davon haben 2, 2, 3, 2, 2 Borsten, und am Innenaste finden sich 7. Die Entfernung zwischen dem 5. und 6. Lobus ist größer als die zwischen den übrigen. Die hinteren Maxillipeden haben ungefähr gleich lange Basalglieder; der Innenast ist viel kürzer im Verhältnis von 10:10:7. Das 1. Glied des Innenastes ist viel länger als das 2. Alle Spezialborsten der Maxillipeden haben sehr dicht gestellte kleine Näpfchen.

Beim 1. F u B p a a re (XXXVIII. 1) sind die 3 Glieder des Innenastes und Außenastes klein. Die Außenborste vom 1. Gliede des Außenastes ist sehr lang, reicht über das Distalende des Außenastes hinaus; dem 2. Gliede fehlt der Außendorn völlig, und der des 3. Gliedes ist sehr kurz. Das 2. Basalglied trägt eine lange, geißelähnliche Borste, und am letzten Gliede des Innenastes sind 5 Randborsten vorhanden. Beim 2. Fußpaar ist das letzte Glied des Innenastes mit 7 Borsten ausgestattet und die Endsägen des Außenastes sind länger als das letzte Glied. Beim 3. Paare finden sich 8 Borsten am letzten Gliede des Innenastes; die Endsäge ist nicht so lang wie das. letzte Glied, und das 2. und 3. Glied des Außenastes sind an den distalen Außenrändern in vorspringende, gerundete Buckel verlängert. In ähnlicher Weise sind die Glieder des Außenastes vom 4. Paare verlängert; die Endsäge ist nicht so lang wie das letzte Glied, und das letzte Glied des Innenastes trägt 7 Borsten. Die Endsäge ist etwas krumm, nach innen gebogen. (XXXVIII. 2.) Beim 5. Fußpaar finden sich am Außenrande der Glieder vom Außenaste die gewöhnlichen Dornen, keine Buckel; die Endsäge ist lang, ebenso lang wie das 2. und 3. Glied zusammen. Die Innenborste 
des 2. Gliedes vom Außenast ist schwach und kurz. Das letzte Glied vom Innenaste hat 6 Borsten.

Trotz kleiner Unterschiede nach Farran's Beschreibung (Fisheries Ireland Sci. Invest. 1906 [1908]) glaube ich doch, daß diese mir vorliegenden Exemplare mit Augaptilus facilis identisch sind, wenn auch die Abdominalsegmente etwas abweichende Längenverhältnisse zeigen, die vorderen Antennen viel länger und die Borsten der Mandibularäste verschieden sind.

Vom „Gauss" wurde diese Art am 4. September 1903 (2000 m) zusammen mit der vorigen erbeutet.

200. Angaptilus simplex n. sp. (Textfig. 76 a-d.)

o $5,2 \mathrm{~mm}$, davon Cephalothorax $4,1 \mathrm{~mm}$, Abdomen $1,1 \mathrm{~mm}$ lang. Der $\mathrm{Kopf}$ ist gleichmäßig gerundet und mit kurzer Stirnpapille versehen. Das A b d o m e n hat ein großes

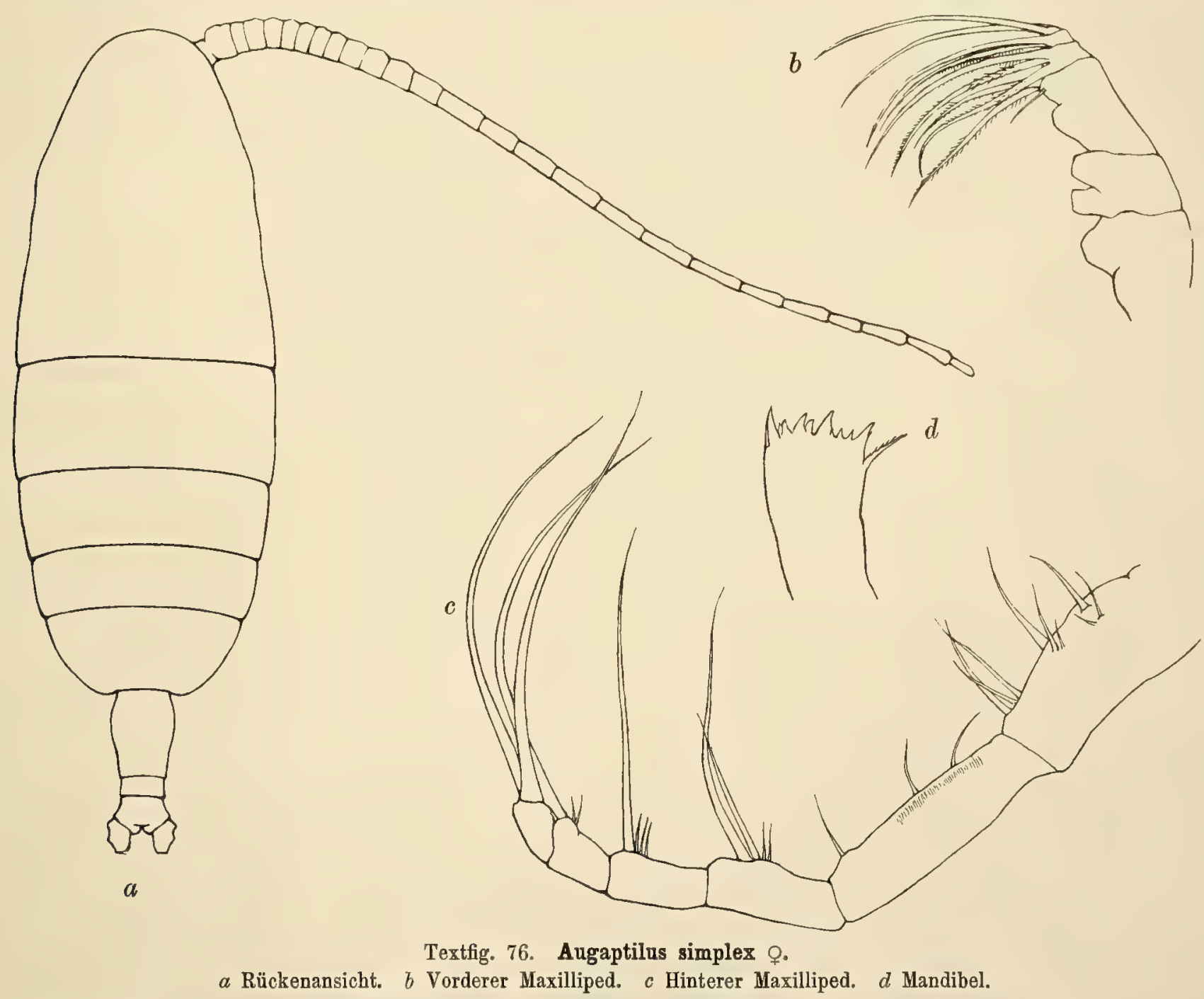

Genitalsegment, das nicht ganz symmetrisch, etwas mehr auf der rechten Seite angeschwollen ist. Die Geschlechtsöffnung scheint nach dieser Seite verlagert zu sein. Dieses Segment ist so lang wie die beiden folgenden zusammen mit drei viertel der Furka. Das mittlere Segment 
ist so lang wie das Analsegment, und die Furkaläste sind auch von gleicher Länge, drei fünftel so breit als lang und mit 2 seitlichen, 2 apikalen Borsten und einer Innenborste versehen. (76 a.)

Die vorderen A n te $\mathrm{n} n$ e $\mathrm{n}$ reichen bis zum Ende der Furka. Die hinteren Antennen haben einen sehr langen Innenast, dessen 1. Glied doppelt so lang als das 2. ist. Der Außenast ist nicht halb so lang und nur drei viertel so lang wie das 1. Glied des Innenastes und gerade so lang wie das verlängerte 2. Basalglied. Der Außenast erhebt sich vom proximalen Teil desselben und besteht aus 6 Gliedern, von denen das $\mathbf{1}$. so lang wie alle übrigen zusammen ist. Die $\mathbf{M}$ a $\mathrm{n}$ dibeln (76 d) sind zweiästig, ihre Äste gleich lang. Der Außenast hat 5 deutliche Glieder mit 6 Borsten (2 davon am Ende). Das 2. Glied des Innenastes ist um drei fünftel länger als das 1. Die Zahnplatte hat 8 starke Zähne, von denen 3, der äußere, der innere und ein mittlerer, viel stärker und länger als die übrigen sind.

Die Maxillen haben 5 Borsten am 1. Außenlobus, einen langen Außenast mit nur 2 Borsten, ein kurzes 2. Basalglied ohne Borsten und einen kurzen Innenast mit 2 Borsten. Der 2. und 3. Innenlobus haben jeder eine lange, ähnlich geformte Borste. Der 1. Innenlobus ist doppelt so lang als breit, mit 8 Haken, welche so lang wie der Lobus und ganz unbewehrt sind. Die Loben der vorderen M a xilli p e d e n (76 b) tragen 2, 3, 3, 3, 4 und der Innenast hat 7 lange Borsten. Haken sind nicht vorhanden, und die Distalborsten des Innenastes sind ganz glatt; nur die proximalen Borsten des Innenastes und die 5 Loben sind in ihrem distalen Teile mit feinen, seitlichen Börstchen besetzt.

Die hinteren Maxillipeden (76 c) sind sehr lang, der Innenast selbst ist so lang wie die vorderen Maxillipeden. Die Basalia und der Innenast verhalten sich wie 16:17:24. Das 1. Glied des letzteren ist länger als das 2. und so lang wie die beiden distalen Glieder. Die Borsten des 1. Basalgliedes sind zu 3,3,3, die des 2. zu 1, 1, 1 angeordnet und weit getrennt. Die Endborsten des Innenastes sind lang, $1 \frac{1}{3}$ mal so lang wie der Innenast und stark gekrümmt, aber ganz glatt.

Das 5. F u B p a a r hat einen kurzen Innenast, der sich nicht über das Ende des 2. Gliedes vom Außenaste hinaus erstreckt und auf dem distalen Innenrand einen kurzen, aber starken, gekrümmten Haken trägt. Das 2. Basalglied hat eine lange, dünne, geißelartige Borste.

Dieser Copepod gehört einer Gruppe an, deren Typus Augaptilus filigerus ist, aber die äußerst langen, hinteren Maxillipeden und die völlige Abwesenheit von Näpfchen der Maxillipeden, wie sie sonst bei Augaptilus sich finden, lassen es zweifelhaft erscheinen, ob diese und ähnliche Arten, wie sie von SARS neulich beschrieben wurden (Augaptilus gracilis, angustus, nodifrons), noch zur Gattung Augaptilus gerechnet werden können, da ihnen die charakteristischsten Merkmale dieser Gattung fehlen. Die sonstigen Merkmale, welche oben erwähnt wurden, lassen die Identifizierung mit irgendeiner der neuen Arten von SARS nicht zu. Das dreigliedrige Abdomen widerspricht der Einordnung in die Gattung Haloptilus. Am meisten scheint sie mit Farrav's Beschreibung von Augaptilus nodifrons übereinzustimmen, welche jedoch von der von SARS gegebenen verschieden ist.

Zwei Exemplare nur kamen aus einem V'ertikalfange im Südatlantischen Ozean vom 5. November 1901 (1000 m) zur Beobachtung. 


\section{Isocalanus $\mathrm{n} . \mathrm{g}$.}

Kopf vom 1. Thorakalsegment abgegliedert, Rostrum durch eine Chitinplatte ersetzt, ohne Filamente. Vordere Antennen mit 22 oder 23 Gliedern. Äste der hinteren Antennen und der Mandibeln annähernd gleich lang. Die proximalen Loben der vorderen Maxillipeden sehr unbedeutend, Endborsten in starke Haken umgewandelt; hintere Maxillipeden schlank; 1. Fußpaar mit eingliedrigem, 2. mit zweigliedrigem Innenaste; 5. Fußpaar nur einästig jederseits, mit 3 Gliedern und dornähnlicher Endborste. Die vorderen Maxillipeden sind verhältnismäßig stark und die Endhaken am distalen Ende ganz eigentümlich bewaffnet, so daß sie an einen Zahnkamm mit besonderen Chitinfalten an der Oberfläche erinnern und die Gattung von allen übrigen bekannten unterscheiden.

201. Isocalanus major n. sp. (Tafel XXXVIII, Fig. 3-5, Textfig. 77 a-c.)

Eine vorläufige Beschreibung dieser Art habe ich in den Planktonstudien vom Februar 1906 gegeben. o 3,6 mm lang. Der Cephalothorax ist mehr als $3 \frac{1}{2} \mathrm{mal}$ so lang wie das Abdomen und besteht aus 4 Segmenten. Der Kopf ist teilweise vom übrigen Rumpfe durch eine Dorsallinie abgegliedert, die seitlich nicht sichtbar ist. Die letzten beiden Segmente des Thorax sind fast vollständig verschmolzen und treten seitlich mit gerundeten Rändern hervor. (77 b.) Der $\mathrm{K} \circ \mathrm{p} f$ ist gerundet und endigt vorn mit stumpfer Chitinplatte, die am Ende dreieckig und zugespitzt erscheint und auf der oberen Fläche 2 kleine Dornen trägt. (77 a.) Das Rostrum ist nicht gegabelt und hat keine Filamente. Das $\mathrm{A}$ b d o m e n besteht aus 4 Segmenten, von denen das Genitalsegment etwas länger als das folgende ist; das 3. ist ein wenig kleiner als das mittlere und das Analsegment sehr groß. Die Furkaläste sind etwa so breit als lang, an den Enden schmäler als an der Basis und jederseits mit einer sehr dicken und einer sehr kurzen, ventralen, akzessorischen Borste ausgestaltet.

Die vorderen A ntennen, mit 22 Gliedern, sind etwa so lang wie der Cephalothorax, die proximalen Glieder sind klein und drängen sich stark zusammen, dann folgen 6 breitere und längere, und die letzten 3 Glieder sind am längsten. Die Antennen sind nur spärlich beborstet. Die hinteren Antennen haben un-

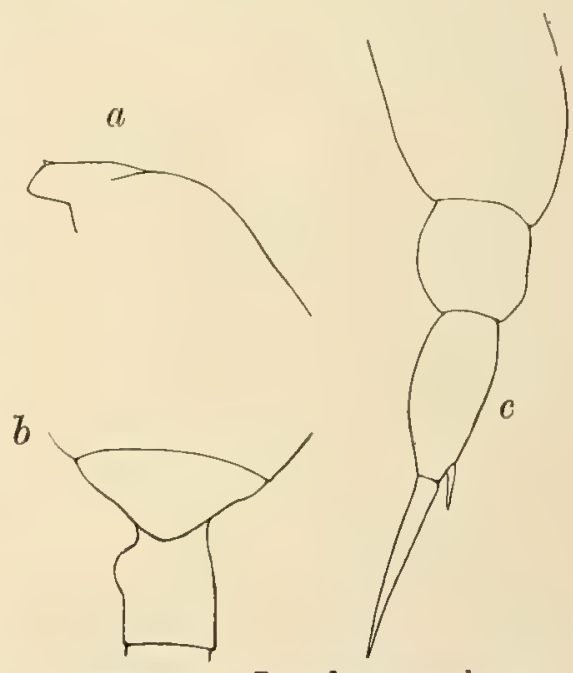

Textfig. 77. Isocalanus major. a Rostrum. $b$ Letztes Thoraxsegment. c 5. Fuß. gefähr gleiche Äste. Der Außenast der M a n d ibeln ist nur wenig größer als der. Innenast, die Zahnplatte ist kurz und die Innenrandborste dick. Nahe bei ihr findet sich ein Büschel steifer Haare, und auf der Chitinfläche sind 3 kleinere Büschel vorhanden. Von den 6 Zähnen sind die beiden inneren dünn und scharf, die beiden mittleren kurz und dick und die beiden äußeren auf breiter Basis, gekrümmt, zugespitzt und etwas von einander entfernt.

Die Außenloben der M a xill e n sind schlecht ausgebildet. Der 1. Außenlobus hat 4 Borsten; der Außenast ist groß, an der Spitze nach innen gekrümmt und mit 9 Borsten versehen; der 1. Innenlobus trägt 14 dünne und lange Haken und Borsten; der 2. und 3. Innenlobus sind verhältnismäßig groß und haben nur je eine Borste. Das 2. Basalglied und der Innenast sind ver- 
schmolzen, klein und nur mit einer Endborste ausgestattet. Die vorderen Maxilli p ede n sind verhältnismäßig groß, die beiden Basalia in gleicher. Weise lang, die proximalen Loben klein. Die ersten 3 derselben haben entsprechend 1, 2, 3 kurze Borsten, der 4. Lobus hat 5, von denen 2 kurz (eine davon kammartig) sind und eine als langer, gekrümmter und kammförmiger Haken mit breiter Basis erscheint. Der Innenast hat 5 lange, gezähnte Haken mit breiter Basis, die an der Spitze nach innen gekrümmt sind und nur im distalen Drittel Bewehrung zeigen.

Die hinteren Maxillipeden haben ungefähr gleich lange Basalia und einen etwas kleineren Innenast im Verhältnis von $6: 6: 4$. Das 1. Basalglied ist dicker als das 2 . und fast halb so breit als lang, mit einer kurzen und dicken Borste in der Mitte und 3 kurzen Borsten am distalen Ende. Das 2. Basalglied hat, wie sonst, 3 Borsten dicht nebeneinander in der Mitte, die alle sehr kurz sind und von denen die distale am dicksten ist. Das 1. und 2. Glied des Innenastes sind ungefähr gleich und haben nur kurze Borsten, von denen die längsten nur so lang wie der Innenast sind. Sie sind in der gewöhnlichen Weise gefiedert.

Das 1. F u B p a a r hat eingliedrigen Innenast und dreigliedrigen Außenast. Die beiden Basalglieder tragen je eine Innenrandborste; das 3. Glięd des Außenastes ist größer als das 1. und 2.; dem 1. und 2. Gliede fehlen die Randdornen, am 3. treten 2 auf, ein medianer am Außenrand und einer am distalen Rande. Der Außenast hat 4 Innenrandborsten am letzten Glied, und die Endsäge ist fast so lang wie der ganze Außenast und mit feinen Zähnen versehen. Der Innenast erstreckt sich bis über den Distalrand des 2. Gliedes vom Außenaste Beim 2., 3. und 4. Fußpaare sind Außen- und Innenäste dreigliedrig. Der Innenast des 2. Paares ist nur so lang wie das 1. und 2. Glied des Außenastes. Das 2. Glied ist fast doppelt so lang als das 1., und das 3. so lang wie die beiden proximalen Glieder. Der distale Außenrand des 1. Gliedes endigt mit einem Dorn. Das 3. Glied des Außenastes ist ebenso lang wie die beiden proximalen Glieder; das 2. Glied doppelt so lang als das 1. Die Endsäge ist kürzer als das Endglied, welches 5 Innenrandborsten und 3 Dornen am Außenrande hat. Das 2. Basalglied hat keine Borsten. Beim 3. Paare hat das. 2. Glied vom Außenast einen langen, dünnen Außenranddorn. Das 3. Glied trägt 3 kleine Außenranddornen.

Das 3. Glied vom Außenaste des 4. Fußpaares ist lang, länger als die beiden proximalen Glieder, die Endsäge ist nur halb so lang als das letzte Glied und stark gezähnt. 5 Innenrandborsten und 3 Außenranddornen sind vorhanden. Das 3. Glied des Innenastes ist viel länger als die beiden proximalen Glieder. Das 5. Fußpaar hat jederseits 3 Glieder, von denen das basale am größten, die beiden distalen klein sind; das letzte trägt am Ende einen langen Dorn, der fast so lang ist wie die beiden letzten Glieder, und einen sehr kleinen Enddorn nach außen von jenem. (77 c.)

Ein Exemplar wurde am 9. Oktober 1903 (3000 m) westlich von den Kapverden gefunden. Es ist wahrscheinlich ein noch nicht völlig reifes i und unterscheidet sich von Isocalanus minor, dem Typus der Gattung, durch die Längenverhältnisse der Abdominalsegmente und auch durch die Zahl der Glieder der vorderen Antenne. Die Körpergestalt ist auch bei beiden verschieden, bei Isocalanus major kräftiger und nicht so schmal, aber die Charaktere der Maxillipeden, speziell die Bewehrung des vorderen Paares und auch der Bau des 5. Fußpaares sind so ähnlich, daß ich beide Arten zu derselben Gattung stellen mußte. 
202. Isocalanus minor n. sp. (Tafel XXXVIII, Fig. 6-8, Textfig. 78 a und b.)

우 2,6 mm lang; der Ce pha lothor a $\mathrm{x}$ ist etwa dreimal so lang wie das Abdomen und ungefähr 31/2 mal so lang als breit. Er besteht aus 6 Segmenten, da der Kopf abgegliedert ist und die beiden letzten Segmente getrennt sind. Das letzte Segment ist sehr klein und hat gleichmäßig gerundete Ränder. Das A b dom e $\mathrm{n}$ hat 4 Segmente, von denen das Genitalsegment am größten und das Analsegment sehr klein ist. (78 a.) Die Furkaläste sind sehr klein, breiter als lang und jederseits mit 4 Endborsten ausgestattet, von denen die 2. von außen auf jeder Seite dicker als die übrigen und um ein drittel länger als das Abdomen ist.

Die vorderen A $\mathrm{nten} n$ e $n$ haben 23 Glieder und reichen bis zum Ende des Genitalsegments. Die ersten 12 Glieder sind gut mit Ästhetasken versehen, aber lange Borsten sind nicht vorhanden. Das 2. Glied ist so lang wie die beiden folgenden, das 3. bis 7. Glied klein, das 8. mit dem 9. verschmolzen; die nächsten beiden Glieder sind klein und die 3 Endglieder am größten. Die hinteren Antennen haben gleich lange Äste, aber der Innenast ist sehr dick; das 1. Glied ist ein drittel so breit als lang. Der Außenast besteht aus 6 Gliedern.

Die Äste der M a n d i b e 1 n haben ungefähr gleiche Größe, die Zahnplatte ist schwach, hat einen starken Außenzahn, der von dem nächsten, ebenfalls starken Zahne durch beträchtlichen Zwischenraum getrennt ist; ferner sind 3 kleine und schwache, dreieckige Innenzähne vorhanden. Der Innenrand trägt ein Büschel feiner Haare und hat anscheinend keine Innenrandborste.

Die Maxillen haben einen großen Außenast mit 10 Borsten, kleines 2. Basalglied und kleinen Innenast, am 2. Außenlobus eine Borste und die gewöhnlichen Borsten, aber keinen Haken am 1. Innenlobus. Der 2. und 3. Innenlobus sind klein und mit je einer Borste versehen.

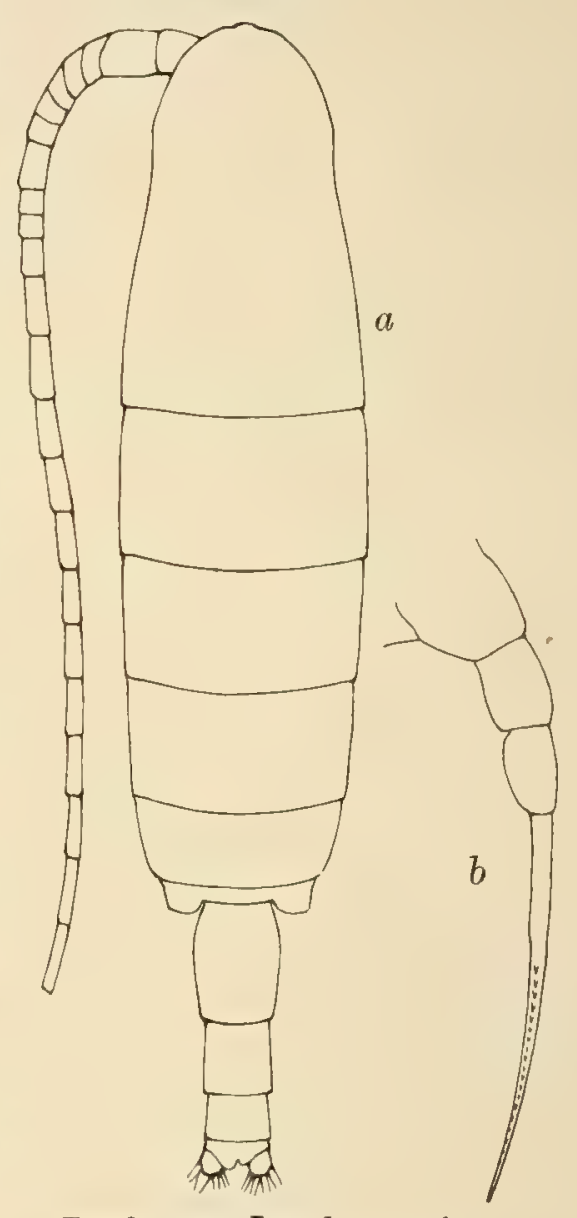

Textfig. 78. Isocalanus minor. $a$ Rückenansicht. $b$ 5, Fuß.

Die vorderen Maxillipeden haben ein langes und breites 1. Basalglied, das anscheinend keine Loben und Borsten trägt; das 2. Basalglied ist sehr kurz, hat 2 sehr kleine, distale Loben und trägt 5 sehr kurze Borsten, die mit Ausnahme einer Borste des letzten. Lobus unbedeutend sind. Der Innenast ist groß und mit 6 langen Hakenborsten versehen, welche im distalen Drittel Reihen kurzer und steifer Borsten, kammartig angeordnet, tragen und eine Reihe eigentümlicher Querfalten zeigen; das 1. Glied des Innenastes hat noch 2 sehr kurze, schwache Borsten und das 2. Glied eine kurze, kräftige, gekämmte und zurückgekrümmte Borste.

Die hinteren Maxillipeden sind verhältnismäßig schwach, das 1. Basalglied und der Innenast ungefähr von gleicher Länge; das 2. Basalglied ist nicht viel mehr als halb so lang wie jene. Das

1. Basalglied hat nur einen kurzen Dorn am distalen Ende, das 2. nur 2 sehr schwache Borsten. Deutsche Sudpolar-Expedition, XII, Zoologie IV. 
Der Innenast besteht aus 5 deutlichen Gliedern, von denen das 1. am längsten ist. Die Borsten des Innenastes sind kurz und dünn.

Der Innenast des 1. F u B p a r es ist nur eingliedrig, der des 2. Paares zweigliedrig, der des 3. und 4. Paares dreigliedrig. Die Außenäste haben bei allen 4 Paaren 3 Glieder. Beim 1. Paare sind am letzten Gliede des Außenastes 4 Innenrandborsten vorhanden, Außenranddornen fehlen dem 1. und 2. Gliede.

Beim 2. Fußpaare finden sich am letzten Gliede des Außenastes 5 Innenrandborsten und 3 Außenranddornen. Das 1. Glied ist sehr klein, das 2. fast doppelt so lang und das 3. so lang wie die beiden proximalen Glieder. Die Endsäge ist drei viertel so lang wie das Endglied und mit zahlreichen feinen Zähnen versehen. Beim 2. bis 4. Fußpaar ist die Innenrandborste des 2. Gliedes vom Außenaste dicker als die entsprechenden Borsten des 1. und 3. Gliedes; die Randdornen sind verhältnismäßig groß und schwach zurückgekrümmt.

Das 5. Fußpaar besteht jederseits aus 3 Gliedern und einem langen Dorn als Endborste. Das 1. Glied ist viel breiter und etwas länger als das 2. und 3., welche ähnlich gebaut sind; der Enddorn ist $1 \frac{1}{2} \mathrm{mal}$ so lang als der ganze Fuß. (78 b.)

Zwei Exemplare lagen vor vom 9. Oktober 1903 (3000 m) aus dem Atlantischen Ozean westlich von den Kapverden.

\section{Autanepsius.}

Mit oder ohne eigentliches Rostrum, welches von stumpfer Chitinplatte gebildet wird; Ränder des letzten Thorakalsegments in Spitzen ausgezogen; vordere Antennen kurz, mit 24 Gliedern; hintere Antenne mit gleichen Ästen versehen; vordere Maxillipeden kurz, hintere sehr lang. Ihre distalen Borsten mit eigenartiger Bewehrung, nicht mit Näpfen wie bei Augaptilus, sondern mit flügelartigen häutigen Fortsätzen versehen; Mandibeln mit sehr kurzem Innenaste; Maxillen mit sehr großen Außen- und Innenloben und kleinem Außenast; Innenast des 1. Fußpaares eingliedrig, beim 2. mit 2, beim 3. und 4. mit 3 Gliedern; 5. Fußpaar fehlt.

Diese Gattung steht wahrscheinlich der Gattung Pontoptilus SARs nahe, bei welcher jedoch die Maxillarborsten abweichend, die hinteren Maxillipeden wie bei Augaptilus gestaltet sind und ein 5. Fußpaar vorhanden ist.

203. Autanepsius major n. sp. (Textfig. 79.)

o bis 8,15 mm lang, Cephalothorax davon 6,6 mm, Abdomen 1,55 mm. Der $\mathrm{Kop}$ ist oval gerundet und endigt vorn mit kurzem, stumpfem, einspitzigem Rostrum. Der Thorax ist am breitesten in der Mitte, der Kopf mit dem 1. Thorakalsegment verschmolzen, die beiden letzten Segmente getrennt. Das letzte Segment endigt jederseits mit kurzer, stumpfer Spitze.

Das A b d o men ist kurz, das Genitalsegment ebenso lang wie breit und so lang wie die 3 übrigen Segmente. Die Furkaläste sind ebenso lang wie breit, etwas länger als das Analsegment und an der Basis etwas breiter wie am Ende. Die innerste Schwanzborste ist doppelt so lang wie das Abdomen, die nächst äußere ähnlich dick, ihre Länge unbekannt und die Außenborste dünn und kurz. Eine dünne, kurze Borste noch entspringt von der Mitte des Außenrandes. Der Innenrand der Furkaläste ist behaart und der Hinterrand der Abdominalsegmente gekämmt. 
Die vorderen Antennen, nicht ganz so lang wie der Thorax, bestehen aus 24 Gliedern, von denen das 8 . und 9. verschmolzen sind. Sie sind sehr dicht beborstet, mit vielen sehr langen

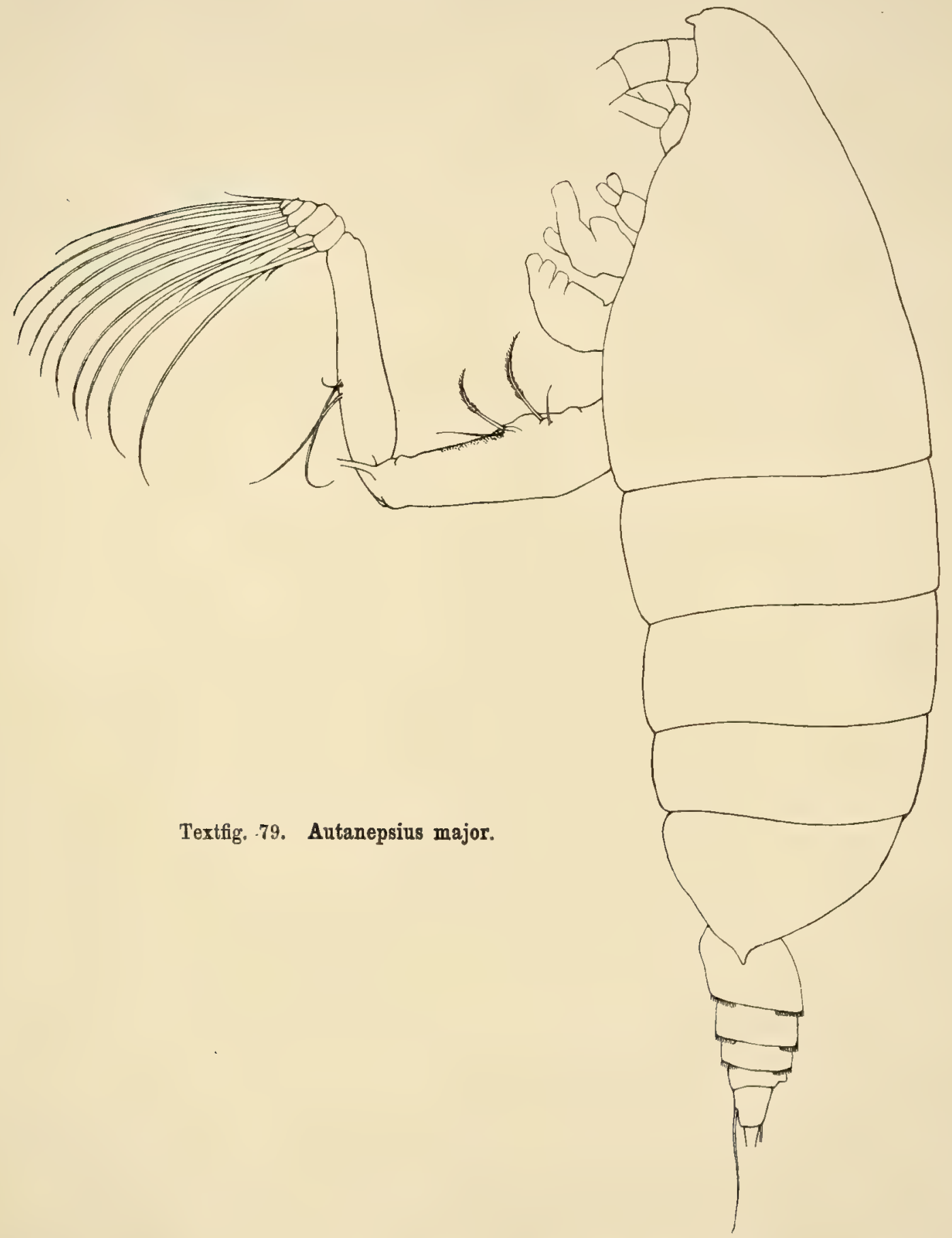

Borsten, besonders auf dem 3., 7., 8., 11., 13., 14., 20., 23. und 24. Gliede. Das 8. Glied ist doppelt so lang wie die vorhergehenden und folgenden Glieder; vom 9. bis 20. haben die Glieder ungefähr gleiche Länge; das 21. Glied ist kürzer als das 22., und das 24. nur halb so lang wie das 23. Der Außenast der hinteren Antennen ist etwas länger als der Innenast und besteht aus 7 Gliedern. 
Die $\mathrm{M}$ a n d ib eln haben sehr kleinen Innenast mit 2 Gliedern, der nur halb so breit und lang als der Außenast ist. Das 1. Glied hat eine, das 2. 5 sehr kurze und schwache Borsten. Die Zahnplatte hat 5 starke, äußere Zähne; die innersten sind dornartig, mit starkem Haarbüschel an der Basis. Die M a xille n haben ein langes 2. Basalglied, kurzen Innenast und kleinen Außenast. Der 1. Außenlobus ist klein und trägt 9 Borsten; der 1. Innenlobus hat 10 Haken, der 2. 3, der 3. 4, das 2. Basalglied 5, der Innenast 15 und der Außenast 11 Borsten.

Die vorderen Maxillipeden sind verhältnismäßig sehr klein, die Loben klein und zusammengedrückt; der Innenast hat 3 deutliche Glieder; die Borsten sind kräftig und fadenförmig. Zwei von den 3 Borsten des 5. Lobus sind gleichartig und der Lobus ist größer als alle 4 proximalen Loben, von denen jeder 3 kräftige Borsten trägt. Zwei von diesen Borsten sind wenigstens doppelt so lang als die dritte und mit kurzen, weit gestellten Seitenbörstchen bewehrt.

Die hinteren Maxillipeden sind sehr lang und kräftig gebaut, mehr als dreimal so lang als das vordere Paar und 1/1/2mal so lang wie das 4. Fußpaar. Der Innenast ist klein, seine Länge verhält sich zum 1. und 2. Basale wie $8: 28: 30$.

Die 5 Glieder des Innenastes tragen 10 lange, schwach gekrümmte, von breiterer Basis sch̄mäler werdende Borsten, die mit besonderen Sinnesanhängen versehen sind. Sie sind nicht napfförmig, wie bei Augaptilus, und nicht gestielt, sondern halbmondförmige, häutige Fortsätze.

Das 1. F u B p a a r hat eingliedrigen Innenast; beiden Basalgliedern fehlen die Randborsten, aber die Innenränder derselben sind behaart. Das 1. Glied vom Außenaste hat weder eine Innenborste noch einen Außendorn. Das 2. Glied trägt einen sehr starken Außendorn und eine Innenrandborste, das 3. einen Außenranddorn und 4 Innenrandborsten.

Beim 2. Paare hat das 1. Basalglied eine Borste, während sie dem 2. fehlt. Der Innenast hat nur 2 Glieder; das 1. Glied trägt eine Innenborste, das 2. ist dreimal so lang und mit 5 Randborsten versehen. Das 1. Glied des Außenastes ist klein, hat eine Borste und einen Außendorn; das 2. trägt einen langen, kräftigen Außendorn, einen kurzen Dorn nach innen von diesem und eine Innenborste; das 3 . Glied hat 3 Außenranddornen, von denen der distale viel länger als die beiden proximalen ist, 4 Innenborsten und eine Endsäge mit dichtstehenden Zähnen, die länger als das Endglied ist.

Beim 4. Fußpaar ist das 1. Basalglied mit einer Innenborste ausgestattet, während das 2. keine hat. Die Randdornen des 2. und 3. Gliedes vom Außenaste sind ziemlich groß; die Endsäge ist dicht gezähnt und viel länger als das letzte Glied. Das 3. Glied vom Außenast ist nicht ganz doppelt so lang wie das 2. Der Innenast hat mehr als die halbe Länge vom Außenast und am 2. Glied einen Dorn am distalen Außenrande. Von Innenrandborsten sind 1, 1,5 vorhanden. Das 5. Fußpaar fehlt.

Fundort: 30. IX. 03. 1500. Atlantischer Ozean, unter dem Äquator.

204. Autanepsius minor n. sp. (Tafel XXXVIII, Fig. 9 und 10, Textfig. 80 a und b.)

q 4,8 mm lang; der Cephalothorax ist fast viermal so lang wie das Abdomen, der $\mathrm{K} \mathrm{o} \mathrm{p} \mathrm{f}$ abgegliedert und das letzte Thorakalsegment mit schwach zugespitzten Seitenrändern versehen. Der Kopf ist gleichmäßig gerundet, aber der Rostralfortsatz, der bei der vorigen Art so deutlich war, fehlt hier. 
Die vorderen Anten nen haben 24 Glieder und sind nicht so lang wie der Cephalothorax. Die hinteren Antennen haben gleich lange Äste und achtgliedrigen Außenast. Die Äste der M a n dibeln sind wie bei der vorigen Art gebildet, aber die Zähne der Zahnplatte sind hier zwar kurz, aber stark. Die M a xille n tragen 8 Borsten am 1. Außenlobus, 13 Haken am 1. Innenlobus, 4 Borsten am 2. Innenlobus, an dem.zu einem langen und breiten Gliede verschmolzenen 2. Basale und Innenast $5+14$ und am sehr kleinen Außenast 11 Borsten.

Die vorderen Maxillipeden sind verhältnismäßig länger und die hinteren Maxillipeden verhältnismäßig kürzer als bei der vorigen Art. Die Loben der vorderen Maxillipeden sind dicht zusammengedrängt; die ersten 4 tragen je 3, der 5. Lobus hat nur 2 Borsten. Die 6 Borsten des Innenastes sind kräftig, nach außen gekrümmt und im distalen Drittel dicht gefiedert. Die hinteren Maxillipeden haben kurzen Innenast, der sich zu den beiden Basalgliedern wie $9: 22: 22$ verhält. Das 1 . Basalglied ist dreimal, das 2. viermal so lang wie breit. Von Randborsten sind am 1. Basalgliede 2, 3, 2 vorhanden, und die

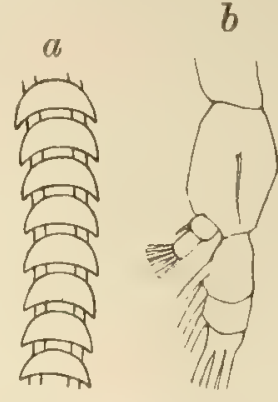
Textfig. 80. Autanepsius minor. a Teil einer Borste. b Mandibelpalpus. 3 Borsten des 2. Basalgliedes sind wie bei der letzten Art klein und stehen auch proximal von der Mitte dicht bei einander. Von den Borsten des Innenastes sind 9 mit den eigentümlichen halbmondförmigen Chitinplatten ausgestattet, wie sie von der letzten Art bekannt sind. (80 a.) Die Schwimmfüße sind wie bei dieser gestaltet, aber die Außenäste des 2. bis 4. Paares waren bei dem einzigen vorliegenden Exemplare stark verletzt. Das 5. Fußpaar fehlt.

Diese Art weicht von der vorigen ab durch viel geringere Größe, weniger stark zugespitzte Hinterenden des Thorax, Abwesenheit des Rostralfortsatzes und auch in einigen Eigentümlichkeiten der Mundorgane.

Fundort: 9. X. 03. 3000, westlich von den Kapverden.

\section{Paraugaptilus Wolfenden.}

Die Gattung wurde von mir im Journal of Marine Biol. Assoc. April 1904 für einen Copepoden von der Westküste Irlands gegründet. Er wurde dann von F ARran (Fisheries Ireland Sc. Invest. 1906 [1908]) wieder angetroffen. SArs hat denselben neuerdings (Bull. Mus. Oceanogr. 1907) zur Gattung Arietellus gerechnet. Doch gibt es einige Merkmale, besonders die Anhänge der vorderen Maxillipeden, in denen er wohl Augaptilus, nicht aber Arietellus gleicht. Im Bau mancher Mundorgane ist allerdings gewisse Ubereinstimmung mit der letzteren Gattung vorhanden, aber die einzige bekannte Art derselben, mit welcher sie genauere äußere Ähnlichkeit hat, ist Arietellus simplex. Paraugaptilus scheint daher eine Mittelstellung zwischen Augaptilus und Arietellus einzunehmen. Die Gestalt des Kopfes, Abwesenheit der Crista und der Bau des 5. Fußpaares lassen sie leicht von Arietellus unterscheiden.

205. Parangaptilus meridionalis n. sp. (Tafel XXXIX, Fig. 1-4, Textfig. 81, a und b.)

ㅇ 2,9 $\mathrm{mm}$ lang; davon Cephalothorax 2,15 mm, Abdomen 0,75 mm. Das 1. Thorakalsegment ist größer als der übrige Teil und der Körper vorn verschmälert (obwohl nicht so stark wie bei Paraugaptilus buchani); die Ränder des letzten Thorakalsegments sind vorn gerundet und tragen 
dorsal einen kurzen, stumpfen Dorn. Der Kopf erscheint vorn etwas verlängert und ist mit 2 sehr dünnen, divergierenden Rostralfilamenten ausgestattet. Das Genitalsegment ist nicht so lang wie die beiden folgenden Segmente zusammen, welche gleich lang sind; das Analsegment ist etwas kleiner, aber so lang wie die vorhergehenden Segmente. Die Furkaläste sind so lang wie die beiden vorhergehenden Segmente und tragen je 5 etwa gleich lange Borsten, die kürzer als das Abdomen sind, und eine akzessorische Borste.

Die vorderen Antennen sind nur so lang wie der Cephalothorax und bestehen aus 20 Gliedern, die dicht mit Borsten besetzt sind. Das 1., 12. und 20. Glied sind am längsten, und das 3. bis 11. Glied sind klein und erscheinen zusammengedrückt. Der Außenast der hinteren Antennen ist nur halb so lang wie der Innenast; das 2. Glied doppelt so lang wie das 1. und mit 3 sehr langen Endborsten versehen. Das 2. Glied des Innenastes ist doppelt so lang als
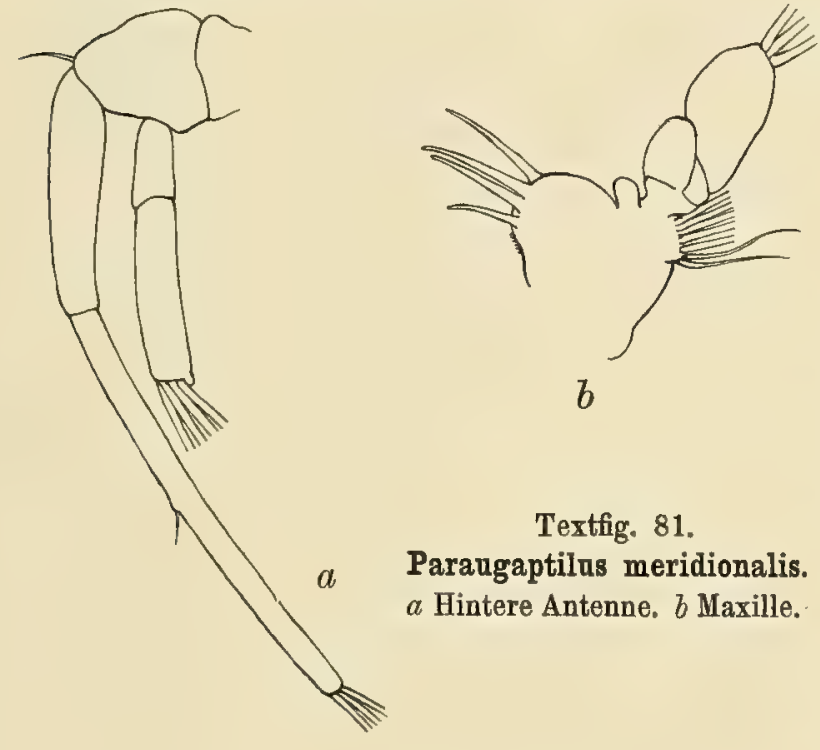

Textfig. 81. Paraugaptilus meridionalis. $a$ Hintere Antenne, $b$ Maxille. das 1., hat 5 sehr lange Endborsten und eine sehr kurze Randborste etwa in der Mitte.

Die Mandibeln sind einästig wie bei Arietellus; das 2. Basalglied ist viermal so 7ang wie breit und hat keine Borsten. Die 4 Endborsten sind sehr lang. Bei den M a xille $\mathrm{n}$ ist das 2. Basalglied mit dem Innenaste verschmolzen, und nur am letzteren sind 3 Borsten vorhanden. Der 1. Innenlobus ist verhältnismäßig groß und mit 4 (oder 5) Haken versehen; der 2. und 3. Innenlobus sind sehr klein und haben keine Borsten; der Außenast fehlt anscheinend; der 1. Außenlobus trägt' 5 lange und 2 kurze Borsten. Das 2. Basalglied der vorderen M a xillip e d e $n$ ist lang, mit weit voneinander abstehenden kleinen Loben, die 1, 2, 2, 1 kurze Borsten tragen; der Innenast ist klein, hat 7 lange, an der Spitze gekräuselte Borsten und eine kurze Borste, welche alle genau wie bei Augaptilus mit Näpfen versehen sind.

Der Innenast der hinteren Maxillipeden ist etwas länger als jedes der beiden Basalglieder, die gleich lang sind. Die Borsten des letzten Gliedes vom Innenaste sind sehr lang, an der Spitze gekräuselt und mit Näpfen wie bei Augaptilus versehen.

Das 1. bis 4. Fußpaar haben dreigliedrige Äste und gleichen denen von Arietellus. Das 1. und 2. Glied des Außenastes vom 2. Fußpaare tragen lange Außenranddornen. Das 5. Fußpaar ist ganz einfach, jederseits eingliedrig und hat eine kleine Hervorragung mit einer Fiederborste als Andeutung des rudimentären Innenastes. Die Spitze trägt auch eine mäßig lange, dicht gefiederte Borste.

Paraugaptilus meridionalis unterscheidet sich von Paraugaptilus buchani (XXXIX. 5-7) dadurch, daß der Vorderkörper nicht wie bei der letzteren Art vorn eingeschnürt ist, durch geringere Größe von 2,9 mm statt 3,25 $\mathrm{mm}$ bei Paraugaptilus buchani, durch die Länge des letzten Antennengliedes, das bei Paraugaptilus meridionalis so lang wie die beiden vorhergehenden, bei 
Paraugaptilus buchani nur wenig länger als das vorletzte Glied ist, durch die Länge der Furkaläste, die so lang wie die beiden vorhergehenden Glieder und doppelt so lang als breit bei Paraugaptilus meridionalis, bei Paraugaptilus buchani aber kürzer und breiter sind.

Zwei Exemplare wurden am 9. Oktober 1903 (3000 m) westlich von den Kapverden im Atlantischen Ozean beobachtet.

\section{Temoropsis n. g.}

Das einzige Exemplar, das mir von diesem merkwürdigen Copepoden vorliegt, ist ein nicht ganz vollständig erhaltenes $\hat{o}$, aber obwohl es mißlich ist, eine neue Gattung danach aufzustellen, besonders da auch das of fehlt, so weicht doch derselbe von allen mir bekannten Formen so wesentlich $a b$, daß es nicht möglich ist, ihn in einer bekannten Gattung unterzubringen.

206. Temoropsis simplex n. sp. (Tafel XXXVIII, Fig. 11, XXXIX, Fig. 8-14, Textfig. 82, a-d.)

of 1,6 mm lang; der Cephalothorax ist dreimal so lang wie das Abdomen und besteht aus 6 Segmenten. (82 a.) Der Kopf ist so lang wie der übrige Teil, das letzte Segment hat gerundete Ränder und ist vom 5. getrennt. Der Kopf ist ziemlich oval, erscheint etwas verlängert und trägt ein Rostrum. Das Abdomen besteht aus 5 Segmenten, von denen das 2. und 3. am längsten sind, und einer kurzen Furka, die nur so lang wie das Analsegment ist. (82 a.)

Die vorderen A n te $\mathrm{n} n$ e $\mathrm{n}(82 \mathrm{~b})$ sind leider beide abgebrochen, aber am Stummel der rechten Seite läßt sich noch erkennen, daß eine Greifantenne vorhanden war, mit vom 11. Gliede an stark verbreiterten Gliedern und einem scharfen Haken am proximalen und kurzem, stumpfem Dorn am distalen Ende des 15. Gliedes. (82 b.)

Die hinteren Antennen (XXXIX. 11) haben annähernd gleich große Äste und sechsgliedrigen Außenast, dessen 2. Glied am größten ist. Der Innenast hat ein großes und ziemlich breites 1. Glied.

Die Äste der Mandibeln (XXXIX. 12) sind gleich lang, der Außenast ist ungegliedert, der

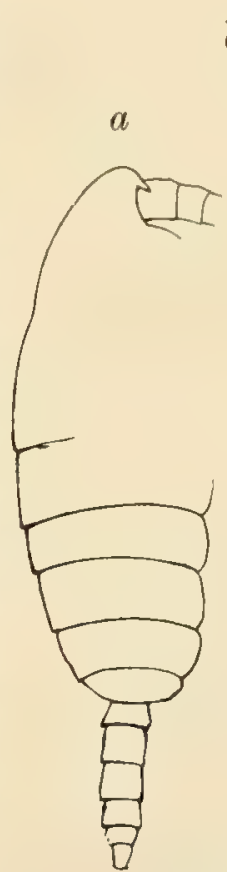

\section{$b$}
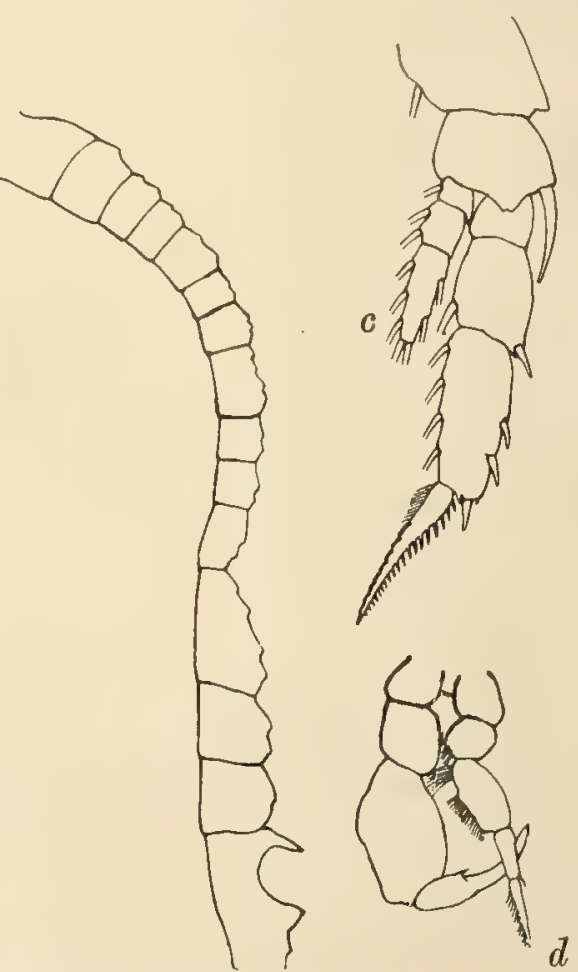

Textfig. 82. Temoropsis simplex.

$a$ Seitenansicht, $b$ Teil der vorderen Antenne, $c$ 3. FuB. d 5. Fub. Innenast zweigliedrig. Das 2. Basalglied ist ziemlich viereckig und trägt 2 lange und 2 kurze Borsten am Rande. Die M a xillen (XXXIX. 13) haben 5 Borsten am 1. Außenlobus, 9 am 1. Innenlobus, am kleinen 2. und 3. Innenlobus je eine Borste und am großen, mit dem Innenast verschmolzenen 2. Basalgliede nur 2 Borsten; der Außenast, kaum vom 2. Basalglied abgetrennt und mit nach der Innenseite gebogener Spitze, trägt 10 Borsten. 
Die vorderen Maxillipeden (XXXIX. 9) sind verhältnismäßig groß; die proximalen Loben derselben haben sehr kurze Borsten. Die Borsten des Innenastes sind besonders im distalen Teile sehr lang und distal auf der konkaven Seite merkwürdig gezähnt.

Die hinteren Maxillipeden (XXXIX. 8) sind verhältnismäßig schlank; ihr Innenast ist so lang wie das 2. Basalglied. Alle Borsten sind kurz und gefiedert, die des 2. Basalgliedes besonders schwach.

Das 1. F u $\mathrm{B}$ p a a r (XXXIX. 14) hat eingliedrigen Innenast und dreigliedrigen Außenast. Den beiden proximalen Gliedern des letzteren fehlen Außenranddornen. Das 2. bis 4. Fußpaar hat dreigliedrige Äste. Das 3. Paar (82 c) trägt am Außenrande des 2. Basalgliedes einen langen, krummen Dorn. Jeder Außenast hat 1, 1, 3 Außenranddornen. Beim 2. Paar (XXXVIII. 11) ist der Randdorn des 1. Gliedes ziemlich lang nach außen gekrümmt, während der des 2. Gliedes in einen wurstförmigen Anhang umgebildet erscheint, der vielleicht nicht normal ist. Am Außenaste des 2. Paares sind 1, 1, 5 Innenrandborsten vorhanden, bei dem des $\mathbf{3}$. und.4. Paares aber nur $0,1,4$. Die Innenäste sind kurz, ihr letztes Glied so lang wie die beiden proximalen Glieder; das 1. Glied setzt sich am Außenrand in einen Dorn fort. Von Randborsten sind 1, 2, 7 vorhanden, die Endsägen kräftig und dicht gezähnt.

Das 5. Fußpaar ( $82 \mathrm{~d}$ ) besteht jederseits aus 2 Basalgliedern, welche links einen dreigliedrigen Fuß tragen. 'Das 1. Glied desselben ist am längsten und breitesten und am Innenrande behaart, das 2. und 3. sind schmal, das Endglied dornartig mit behaartem Innenrande. Der rechte Fuß hat nur zweigliedrigen Außenast mit sehr breitem 1. und schmälerem 2. Gliede, das mit einem Haken endigt.

Temoropsis simplex erschien im Vertikalfange vom 10. Februar 1902 (2700 m) innerhalb der Eisbergzone des antarktischen Gebietes.

\section{Centropages KröYer.}

\section{0\%. Centropages violaceus Bradx}

war in den Fängen vom 14. Oktober 1901 (1900 m), 11. und 19. August 1903 (400 m), 26. September $1903(3000 \mathrm{~m})$, 13. Oktober $1903(3000 \mathrm{~m})$ vorhanden.

208. Centropages gracilis GiesBrecht

wurde im südlichen Atlantischen Ozean am 19. und 23. August 1903 (400 m) und 22. August 1903 $(1500 \mathrm{~m})$ gefunden.

209. Centropages chierchiae GIEsBrechT

erschien im Indischen Ozean bei Port Natal am 31. Mai 1903 an der Oberfläche.

210. Centropages furcatus BRady

wurde im Hafen von Simonstown am 19. Juni 1903 gesammelt.

211. Candacia longimana Craus

\section{Candacia Dana.}

liegt vor aus den Fängen vom 4. September 1903 (2000 m), 10. September 1903 (3000 m), 30. September 1903 (1500 m), 9., 13. und 20. Oktober 1903 (3000 m). 
212. Candacia simplex GIesBrecht

wurde am 19. Oktober $1901(500 \mathrm{~m})$, 4. September $1903(2000 \mathrm{~m})$, 5. September $1903(400 \mathrm{~m})$, 13. Oktober $1903(3000 \mathrm{~m})$ gefunden.

213. Candacia varicans GIESBrecert

wurde am 14. September 1901 im Porto grande, Kapverden und am 28. September 1901 abends mit dem Brutnetz an der Oberfläche, dann am 13. August $1903(400 \mathrm{~m})$, 30. September 1903 $(1500 \mathrm{~m})$, 9. Oktober 1903 (3000 m) im Vertikalnetz erbeutet.

214. Candacia aethiopica DaNA

liegt aus den Fängen vom 13., 19. und 20. August $1903(400 \mathrm{~m})$ und 30. September 1903 $(1500 \mathrm{~m})$ vor.

\section{Candacia pachydactyla Dana}

wurde an der Oberfläche am 14. September 1901 im Porto grande, Kapverden, ferner am 22. August $1903(1500 \mathrm{~m})$, 3. September $1903(400 \mathrm{~m})$, 10. September $1903(3000 \mathrm{~m})$, 30. September 1903 $(800 \mathrm{~m})$, 9. und 13. Oktober $1903(3000 \mathrm{~m})$ gefunden.

\section{Candacia curta DaNa}

wurde nur in einem Planktonfang aus $400 \mathrm{~m}$ am 5. September 1903, als das Netz größere Abtrift hatte, also wahrscheinlich an der Oberfläche gefunden.

\section{1\%. Candacia bispinosa Claus}

war in den Fängen vom 11. Oktober 1901 (1200 m), 8., 22. und 24. August 1903 (400 m), 5. September $1903(400 \mathrm{~m}), 10$. und 26. September $1903(3000 \mathrm{~m})$, 30. September 1903 (1500 m) aus dem Atlantischen Ozean und vom 18. Mai 1903 (400 m) aus dem Indischen Ozean vorhanden.

\section{Acartia negligens DANA}

\section{Acartia Dana.}

fand sich am 12. November $1901(3000 \mathrm{~m})$, 19. und 26. August 1903 (400 m), 22. August 1903 $(1500 \mathrm{~m})$, 13. Oktober $1903(3000 \mathrm{~m}), 20$. Oktober $1903(400 \mathrm{~m})$ im Atlantischen Ozean und am 15. und 20. Mai $1903(400 \mathrm{~m}$ ), 31. Mai 1903 (Oberfläche bei Port Natal) im Indischen Ozean.

\section{Acartia danae Giesbrecht}

wurde im Atlantischen Ozean am 11. Oktober 1901 (1200 m), 13. und 20. August 1903 (400 m) und 3. September $1903(400 \mathrm{~m})$ beobachtet.

220. Acartia centrura Giesbrecht

war in einem Fange vom 3. September 1903 (400 m) vorhanden.

221. Temora stylifera Giesbrecht

\section{Temora Baird.}

wurde in Porto grande bei St. Vincent, Kapverden am 13. bis 15. September 1901 an der Oberfläche gefunden. 
2จ2. Temora kerguelensis $\mathrm{n}$. sp.

Zwei Exemplare einer Temora von Kerguelen scheinen von den gewöhnlichen Arten (Temora longicornis und Temora turbinata) verschieden zu sein. Beide sind ơ von 2,0 mm Länge. Die Furkaläste sind nur so lang wie das Analsegment. Dieses ist sehr groß, fast gleich lang wie die 3 vorhergehenden Segmente. Die 2. und 3. Schwanzborste sind gleich dick und nicht nur an der Basis verdickt. Das letzte Thorakalsegment ist jederseits abgerundet. Die Loben des 1. Basalgliedes der hinteren Maxillipeden haben kein Haarbüschel an der Außenecke wie bei Temora longicornis, und am 3. und 4. Gliede des Innenastes sind nur 2 Borsten vorhanden; die 3 Borsten des 2. Basalgliedes sind ganz distal eingefügt.

Die 2. Furkalborsten sind nicht stark verdickt und asymmetrisch wie bei Temora turbinata, und das 4. Abdominalsegment ist kürzer als das 5. Das 2. Fußpaar hat dreigliedrige Äste und an den Endsägen nur eine Zahnreihe: auch das erste Fußpaar hat dreigliedrigen Außen- und Innenast und am 1. Basalgliede findet sich keine Borste. Der 2. Außendorn des 3. Gliedes vom Außenast ist nicht am Rande gezähnt.

Die vorderen Antennen tragen starke, gerade Dornen am 8., 10. und 11. Gliede. Die Glieder 8-12 sind stark zusammengedrückt. Von den 4 Gliedern jenseits des Gelenkes ist das 2. sehr lang, das letzte sehr kurz; das vorletzte Glied ist verlängert, so daß es segmentiert erscheint. Das 5. Fußpa ar scheint sowohl von Temora longicornis wie von Temora turbinata verschieden zu sein. Beim rechten Fuß ist das 2. Glied verbreitert und mit starkem Dorn am distalen Außenrande versehen, das Endglied ist blattartig und von eigentümlicher Gestalt. Der Innenast ist durch ein langes, griffelförmiges Glied repräsentiert, das so lang wie der andere Ast ist. Der linke Fuß ist ganz unbedeutend und besteht nur aus einem kurzen, griffelförmigen Aste. Da die beiden Exemplare bereits lange, bevor ich sie erhielt, auf einem Objektträger in Glyzerin eingebettet waren, so waren sie so brüchig geworden, daß es unmöglich war, das 5. Beinpaar unzerbrochen zu präparieren oder genau abzubilden.

Fundort: Kerguelen-Station.

\section{Copilia Dana.}

\section{Copilia quadrata DANA}

fand sich im Atlantischen Ozean am 19. Oktober 1901 (500 m), 22. August 1903 (1500 m), 24. August $1903(400 \mathrm{~m})$, 3. und 5. September $1903(400 \mathrm{~m})$, 10. September 1903 (3000 m), 30. September. 1903 $(800 \mathrm{~m})$, 9. und 13. Oktober $1903(3000 \mathrm{~m})$ und im Indischen Ozean am 18. Mai 1903 (400 m).

224. Copilia vitrea Giesbrecht

wurde am 3. und 5. September $1903(400 \mathrm{~m})$, 10. September $1903(3000 \mathrm{~m})$ und 30. September 1903 $(1500 \mathrm{~m})$ im Atlantischen Ozean gefunden.

\section{Copilia denticnlata Craus}

war in den Fängen vom 6. September 1901 (abends Oberfläche), 19. Oktober 1901 (500 m), 24. August $1903(400 \mathrm{~m})$, 5. September $1903(400 \mathrm{~m})$, 9. Oktober $1903(3000 \mathrm{~m})$ aus dem Atlantischen Ozean vorhanden. 
226. Copilia mirabilis DANA

wurde am 11. Oktober 1901 (1200 m), 24. August 1903 (400 m), 5. September 1903 (400 m), 26. September $1903(3000 \mathrm{~m})$, 30. September $1903(1500 \mathrm{~m})$, 9. und 13. Oktober 1903 (3000 m) im Atlantischen Ozean und am 5. Mai $1903(400 \mathrm{~m})$ im Indischen Ozean erbeutet.

22\%. Copilia lata Giesbrecht

wurde am 6. September 1901 (an der Oberfläche), 10. September 1903 (3000 m) und am 30. September $1903(800 \mathrm{~m})$ im Atlantischen Ozean gefunden.

\section{Corycaeus longistylus $\mathrm{D}_{\mathrm{ANA}}$}

\section{Corycaeus Dana.}

erschien in den Fängen vom 11. Oktober 1901 (1200 m), 22. und 24. August 1903 (400 cm), 4. September $1903(2000 \mathrm{~m})$ und 9. Oktober $1903(3000 \mathrm{~m})$.

229. Corycaeus venustus DaNa

wurde nur im Vertikalfang vom 4. September 1903 (2000 m) aus dem Atlantischen Ozean bemerkt.

230. Corycaeus pellucidus DANA

war in den Fängen vom 11. Oktober $1901(1200 \mathrm{~m})$, 19. Oktober $1901(500 \mathrm{~m})$, 3. und 5. September $1903(400 \mathrm{~m})$, 26. September $1903(3000 \mathrm{~m})$ aus dem Atlantischen Ozean und vom 8. und 15. Mai 1903 (400 m) und 31. Mai 1903 (Port Natal, Oberfläche) aus dem Indischen Ozean vorhanden.

\section{Corycaens furcifer ClauS}

liegt vor aus dem tropischen Atlantischen Ozean vom 3. und 19. September 1903 (400 m), 26. September $1903(3000 \mathrm{~m})$ und 9. Oktober $1903(3000 \mathrm{~m})$.

232. Corycaeus ovalis Clauts

wurde im Atlantischen Ozean am 24. August 1903 (400 m), 3. und 5. September 1903 (400 m), 4. September $1903(2000 \mathrm{~m})$, 10. September $1903(3000 \mathrm{~m})$, 30. September $1903(1500 \mathrm{~m})$ und 9. Oktober 1903 (3000 m) angetroffen.

233. Corycaeus alatus Gresbrecht erschien in den Fängen vom 19. Oktober 1901 (500 m), 22. August 1903 (1500 m) und 9. Oktober $1903(3000 \mathrm{~m})$.

\section{Coryeaeus speciosus DANA}

eine der auffallendsten und häufigsten Arten dieser Gattung, wurde am 28. September 1901 (Oberfläche), 11. Oktober 1901 (1200 m), 19. Oktober 1901 (500 m), 5. November 1901 (1000 m), 22. und 24. August 1903 (400 m), 5. September 1903 (400 m), 10. und 26. September 1903 (3000 m), 30. September $1903(1500 \mathrm{~m})$, 9. und 13. Oktober 1903 (3000 m) im Atlantischen Ozean, am 6. März 1903 $(1200 \mathrm{~m}$ ) im Eismeer und am 31. Mai 1903 (Oberfläche) bei Port Natal im Indischen Ozean gefunden.

235. Corycueus robustus Giesbrecht

wurde nur im Atlantischen Ozean am 4. September 1903 (2000 m) beobachtet. 
236. Corycaens danae GiesbreCHT

wurde im Atlantischen Ozean am 3., 5. und 8. September 1903 (400 m) und im Indischen Ozean rm 26. Mai 1903 (400 m) erbeutet.

23\%. Corycaeus elongatus CLAUS

war in den Fängen vom 19. Oktober 1901 (500 m) und 9. Oktober 1903 (3000 m) vorhanden.

238. Corycaeus rostratus Claus

wurde im Atlantischen Ozean am 19. Oktober 1901 (500 m) und 4. September 1903 (2000 m), ferner im Indischen Ozean am 20. Mai 1903 (400 m) angetroffen.

239. Corycaeus flaccus Giesbrecht

zeigte sich nur im Fange vom 19. Oktober 1901 (500 m).

240. Corycaeus obtusus Dana

fand sich in den Fängen vom 19. September $1903(400 \mathrm{~m})$ und 30. September $1903(500 \mathrm{~m})$.

241. Corycaeus gracilicaudatus Giesbrecht

wurde am 19. Oktober $1901(500 \mathrm{~m})$, 26. August 1903 (400 m) und 11. September 1903 (400 m) gefunden.

242. Sapphirina angusta DANA

\section{Sapphirina Tномғsоn.}

wurde am 19. Oktober 1901 (800 m) und 9. Oktober 1903 (3000 m) im Atlantischen Ozean angetroffen.

243. Sapphirina gemma DaNA

war nur aus dem Fange vom 11. Oktober 1901 (1200 m) vorhanden.

244. Sapphirina vorax GIESBRecht

wurde im Fange vom 22. August 1903 (1500 m) aus dem südatlantischen Ozean bemerkt.

245. Sapphirina metallina DANA

wurde im Atlantischen Ozean am 7. Oktober 1901 (400 m), 11. Oktober 1901 (1200 m), 19. Oktober $1901(500 \mathrm{~m}), 24$. August $1903(400 \mathrm{~m})$, 4. September $1903(2000 \mathrm{~m})$, 5. und 11. September 1903 $(400 \mathrm{~m})$, 10. September $1903(3000 \mathrm{~m})$, 9. und 13. Oktober $1903(3000 \mathrm{~m})$, dann am 6. März 1903 $(1200 \mathrm{~m})$ in der Antarktis gefunden.

246. Sapphirina opalina Dana

erschien in den Fängen vom 11. Oktober $1901(1200 \mathrm{~m})$, 19. Oktober 1901 (500 m), 5. und 8. September $1903(400 \mathrm{~m})$, 10. September $1903(3000 \mathrm{~m})$, 9. Oktober 1903 (3000 m).

247. Sapphirina intestinalis GIESBRecht

war in den Fängen vom 19. Oktober 1901 (500 m), 22. August 1903 (1500 m), 24. August 1903 $(400 \mathrm{~m}), 26$. August $1903(400 \mathrm{~m})$, 5. September $1903(400 \mathrm{~m})$, 9. Oktober $1903(3000 \mathrm{~m})$ vorhanden. 
248. Sapphirina ovatolanceolata DANA

liegt aus den Fängen vom 11. Oktober 1901 (1200 m), 19. Oktober 1901 (1500 m), 5. September 1903 $(400 \mathrm{~m})$ und 9. Oktober $1903(3000 \mathrm{~m})$ vor.

249. Sapphirina salpae Clads

wurde im nördlichen Atlantischen Ozean im Westen von Kap Finisterre am 24. August 1901 und im südlichen Atlantischen Ozean westlich von Kapstadt am 6. August 1903 , beide Male an der Oberfläche zusammen mit Salpen, erbeutet.

250. Sapphirina nigromaculata CLAus

wurde nur am 8. September $1903(400 \mathrm{~m})$ südöstlich von Ascension beobachtet.

\section{Labidocera Luввоск.}

251. Labidocera acutifrons $\mathrm{D}_{\text {ANA }}$

fand sich am 14. September 1901 im Porto grande, Kapverden und am 10. Oktober 1901 an der Oberfläche, ferner in den Vertikalfängen aus dem Atlantischen Ozean vom 22. August $1903(1500 \mathrm{~m})$ und 9. Oktober $1903(3000 \mathrm{~m})$ und am 27. März $1903(2000 \mathrm{~m})$ in der Antarktis.

252. Labidocera scotti GIESBRECHT

wurde am 7. August 1903 an der Oberfläche bemerkt.

253. Labidocera nerii KRÖYER

war in den Fängen vom 5. September $1903(400 \mathrm{~m})$ und 30. September 1903 (1500 m) vorhanden.

254. Labidocera wollastoni L兀ввоск

erschien am 24. September 1901 und 19. Oktober 1901 im tropischen Atlantischen Ozean an der Oberfläche.

255. Labidocera acuta DANA

wurde nur im Indischen Ozean am 18. Mai 1903 (400 m) und bei Port Natal am 31. Mai 1903 an der Oberfläche gefunden.

\section{Pontella Dana.}

256. Pontella fera Dana

fand sich am 17. August 1903 an der Oberfläche.

25\%. Pontella atlantica Mrlne-Edwards

wurde im Atlantischen Ozean am 7. und 11. August 1903 und 24. September 1901 an der Oberfläche und am 8. August $1903(800 \mathrm{~m})$ in einem Vertikalfang, ferner im Indischen Ozean am 5. und 31. Mai 1903 (Port Natal) an der Oberfläche gefunden.

258. Pontella securifer Brady

war am 24. September 1901 und 11. Juli 1903 (Simonsbai) an der Oberfläche vorhanden.

259. Pontella spinipes Giesbrecht

erschien im Porto grande, Kapverden, am 12. September 1901 an der Oberfläche. 
260. Pontellina plumata DANA

\section{Pontellina Dana.}

wurde am 28. September 1901 und im Hafen von Simonstown, im Juli 1903 an der Oberfläche, ferner am 22. und 24. August $1903(400 \mathrm{~m})$, 5. und 21. September 1903 (400 m), 30. September $1903(800 \mathrm{~m})$ gefangen.

\section{Pontellopsis regalis Dana}

\section{Pontellopsis Brady.}

fand sich am 8. und 10. September 1901 ferner im Porto grande, Kapverden, am 12. September 1901 und am 5. August 1903 an der Oberfläche.

\section{Oncaea Philippi.}

262. Oncaea conifera Giesbrecht.

Dieser kleine und weit verbreitete Copepod wurde am 15. März 1903 im Südlichen Eismeere, ferner im warmen Gebiet am 11., 18., 21. September und 1. Oktober 1903 in Paarung angetroffen, und zwar waren am 15. März 1903 in einem quantitativen Fange mit dem mittleren Netz aus 100 und $200 \mathrm{~m}$ je 4 Pärchen, am 21. September 1903 (400 m quant.) 5 Pärchen und an den übrigen je ein Pärchen konserviert. Einzeln lagen sie vor vom 18. und 23. bis 27. Februar 1903 (400 m), 6. März 1903 (1200 m), 15. März 1903 (100 m), 9. Oktober 1903 (3000 m), 12. November 1901 (3000 m).

263. Oncaea venusta PHILIPPI

wurde bei der Gauss-Station am 31. Dezember 1902 (385 m), im Indischen Ozean am 8. und 20. Mai $1903(400 \mathrm{~m})$ und im Atlantischen Ozean am 22. August $1903(400 \mathrm{~m})$, 4. September 1903 (2000 m) und 9. Oktober $1903(3000 \mathrm{~m})$ gefunden.

264. Oncaea mediterranea Gresbrecht

liegt vor vom 11. August 1903 (400 m), 3., 5., 8. und 16. September 1903 (400 m), 10. September $1903(3000 \mathrm{~m})$, 30. September $1903(1500 \mathrm{~m}), 20$. Oktober $1903(3000 \mathrm{~m})$ aus dem Atlantischen Ozean.

265. Oncaea notopus Giesbrecht

war nur im Vertikalfange vom 30. September 1903 (1500 m) vorhanden.

266. Oncaea curvata GIESBRECHT

wurde am 5. Januar 1903 (350 m), 6. März 1903 (1200 m), 15، März 1903 (50 m) beobachtet.

26\%. Oncaea media Giesbrecht

liegt vor vom 1. Oktober $1901(800 \mathrm{~m})$, 26. August $1903(400 \mathrm{~m})$, 5. und 8. September 1903 (400 m), 9. Oktober $1903(3000 \mathrm{~m})$, 11. Oktober $1903(400 \mathrm{~m})$.

268. 0ithona plumifera BAIRD

Oithona BaIRD.

Iag vor aus den Fängen vom 11. Oktober 1901 (1200 m), 19. Oktober 1901 (500 m), 5. November $1901(1000 \mathrm{~m}), 12$. November $1901(3000 \mathrm{~m}), 13 ., 19 ., 24$. August $1903(400 \mathrm{~m})$, 3. und 8. September $1903(400 \mathrm{~m})$, 4. September 1903 (2000 m), 30. September 1903 (1500 m), 9. Oktober 1903 
$(3000 \mathrm{~m})$ im Atlantischen Ozean und aus denen vom 20. und 26. Mai 1903 (400 m) im Indischen Ozean.

\section{Oithona similis CLAUS}

wurde in den Antarktis beobachtet am 3. März 1902, 29. August 1902 (385 m), 14. November 1902 $(350 \mathrm{~m}), 30$. November $1902(300 \mathrm{~m}), 10$. und 12. Dezember $1902(350 \mathrm{~m})$, 18. und 27. Februar 1903 (400 m), 6. März 1903 (1200 m), 15. März 1903 (300 m), 20. März 1903 (200 m), 27. März 1903 $(2000 \mathrm{~m})$, ferner im Indischen Ozean am 1. Mai 1903 (400 m) und im Atlantischen Ozean am 19., 20. und 24. August 1903 (400 m), 3., 5., 6., 15., 16. September 1903 (400 m), 10. September 1903 $(3000 \mathrm{~m})$, 9. Oktober $1903(3000 \mathrm{~m})$, 11. Oktober 1903 (400 m), 1. Oktober 1901 (800 m), 11. Oktober $1901(1200 \mathrm{~m})$, 19. Oktober 1901 (500 m), 12. November $1901(3000 \mathrm{~m})$

\section{Oithona linearis GIESBRECHT}

wurde am 20. August 1903 (400 m), 22. August 1903 (1500 m), 3. und 15. September 1903 (400 m) und 13. Oktober $1903(3000 \mathrm{~m})$ gesammelt.

971. Dithona frigida GIESBRECHT

erschien in Fängen aus dem Gebiete des Scholleneises am 2. Februar 1903 (150 m), 23. und 25. Februar $1903(400 \mathrm{~m})$, 3. März $1903(400 \mathrm{~m})$, 6. März $1903(1200 \mathrm{~m})$ und 15. März $1903(50 \mathrm{~m})$, 27. März 1903 (2000 m).

\section{Aegisthus GIESBRecht.}

272. Aegisthus mucronatus GIESBRECHT

war vorhanden aus den Fängen vom 11. Oktober 1901 (1200 m), 5. November 1901 (1000 m), 12. November 1901 (3000 m), 22. August $1903(1500 \mathrm{~m})$, 10. und 26. September $1903(3000 \mathrm{~m})$, 9. und 13. Oktober $1903(3000 \mathrm{~m})$.

\section{Lubbockia Craus.}

273. Lubbockia squillimana CLAUS

wurde am 11. Oktober 1901 (1200 m), 5. und 11. September $1903(400 \mathrm{~m})$, 30. September 1903 $(1500 \mathrm{~m}), 9$. Oktober $1903(3000 \mathrm{~m})$ gefunden.

274. Lubbockia aculeata GIesBRechT

wurde nur am 9. Oktober 1903 im Vertikalfang aus $3000 \mathrm{~m}$ beobachtet.

Ectinosoma Brady.

\section{Ectinosoma antareticum GiesBrecht}

liegt vor aus quantitativen Planktonfängen von der Gauss-Station vom 3., 10. und 15. März 1902 Am 3. März wurden in einem Fange mit dem mittleren Planktonnetz aus $100 \mathrm{~m}$ Tiefe 2 Exemplare, aus $200 \mathrm{~m}$ ebenfalls 2 und aus $300 \mathrm{~m} 6$ Exemplare gezählt. Sonst wurden das ganze Jahr hindurch nicht mehr als 4 Ectinosomen in einem quantitativen Fange beobachtet, so daß die Art jedenfalls nicht häufig war. 
276. Ectinosoma atlanticum Brady

wurde im Atlantischen Ozean, z. B. im September 1901, ferner am 11. September 1903 (400 m) und im Indischen Ozean am 8. Mai 1903 (400 m) beobachtet.

2\%\%. Corynura gracilis BBADY

Corynura Giesbrecht.

erschien im Vertikalfange vom 5. September 1903 (400 m) im Südosten von Ascension.

278. Setella gracilis Dana

Setella DANA.

wurde im Atlantischen Ozean am 26. September 1903 (3000 m), 13. und 20. Oktober 1903 (3000 m), 19. Oktober $1903(400 \mathrm{~m})$, im Indischen Ozean am 20. Mai 1903 (400 m) und im Juli 1903 in der Simonsbai, ferner auch bei Kerguelen und in der Antarktis gefunden ${ }^{1}$ ).

\section{Clytemnestra scutellata DaNA}

\section{Clytemnestra DaNa.}

war aus dem Atlantischen Ozean in den Fängen vom 26. August 1903 (200 m), 29. August 1903 (St. Helena), 7. September 1903 (200 m), 11. September 1903 (400 m), 1. Oktober 1903 (200 m), aus dem Indischen Ozean vom 8. und 20. Mai 1903 (400 m) vorhanden.

\section{Miracia efferata DANA}

Miracia Dana.

lag aus den Vertikalfängen vom 8. August 1903 (50 m), 11. August 1903 (200 m), 5. September 1903 $(400 \mathrm{~m})$ und 13. Oktober $1903(200 \mathrm{~m})$ vor. Ferner aus dem Indischen Ozean vom 15. Mai 1903 $(400 \mathrm{~m})$.

\section{Die Copepoden des antarktischen Gebiets.}

Während des Aufenthalts an der Winterstation vom 21. Februar 1902 bis 8. Februar 1903 wurden ziemlich regelmäßig in jedem Monat quantitative Planktonfänge mit dem mittleren Planktonnetze von $14 \mathrm{~cm}$ oberer Öffnung und aus Müllergaze Nr. 19 gemacht. Diese Fänge, von Professor VANhöFfen und Dr. LaAckmann gemeinsam unter ständiger gegenseitiger Kontrolle durchgezählt, ergaben eine gute Ubersicht über die Verteilung der Copepoden im La ufe d es Jahres bei der Gauss-Station. Am häufigsten wurden Oithona, dann Oncaea und die Calaniden Calanus acutus und C. propinquus gefunden; weit fielen dagegen Metridia gerlachei und Ectinosoma antarcticum ab, und noch spärlicher als diese, wenn auch in allen Monaten, war Stephus longipes vorhanden. Ctenocalanus scheint auch nicht häufiger als Stephus zụ sein, doch ist es möglich, daß er zum Teil mit den Calaniden gezählt wurde, da die gefundenen Zahlen sehr klein und unregelmäßig erscheinen. Von Oncaea kommt wohl nur Oncaea conifera, von Oithona wohl nur Oithona similis in Betracht. Die Bedeutung der einzelnen Komponenten der antarktischen Copepodenfauna ergibt sich aus der folgenden Tabelle, deren Zahlen einer Wassersäule von der angegebenen Tiefe des Fanges und der Weite der Netzöffnung 154 qcm (etwa $12 \mathrm{~cm}$ im Quadrat) entsprechen. Es würden demnach zur günstigsten Zeit etwa 55 Copepodenlarven, 6 Oithona, 1 bis 2 Oncuea und 1 Calanus auf 2 Liter Wasser der oberflächlichen Schichten kommen. Das Ansteigen der

1) Brady, Marine Copepoden I. Harpactida usw. Deutsche Südpolar-Expedition Bd. XI S. 508. 
Larvenzahl und die Anreicherung der Larven an der Oberfläche im Herbst, März und Anfang April ist verständlich, ebenso ihre Abnahme im Winter, Anfang Mai. Die erwachsenen Copepoden lassen nicht direkte Ansammlung an der Oberfläche erkennen, scheinen zwischen 100 und $200 \mathrm{~m}$ im April im Maximum aufzutreten. Im einzelnen gibt darüber die folgende Tabelle Auskunft:

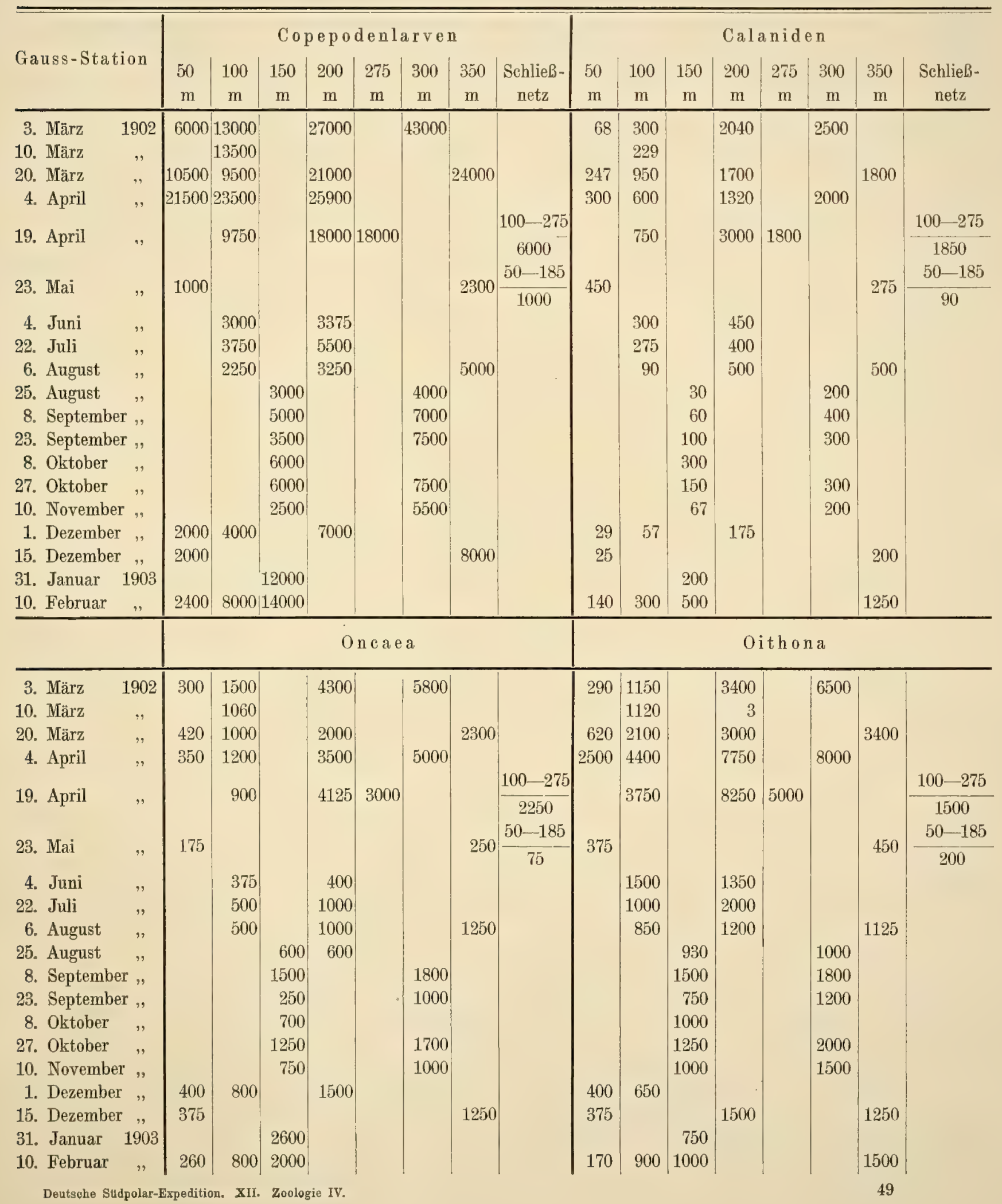




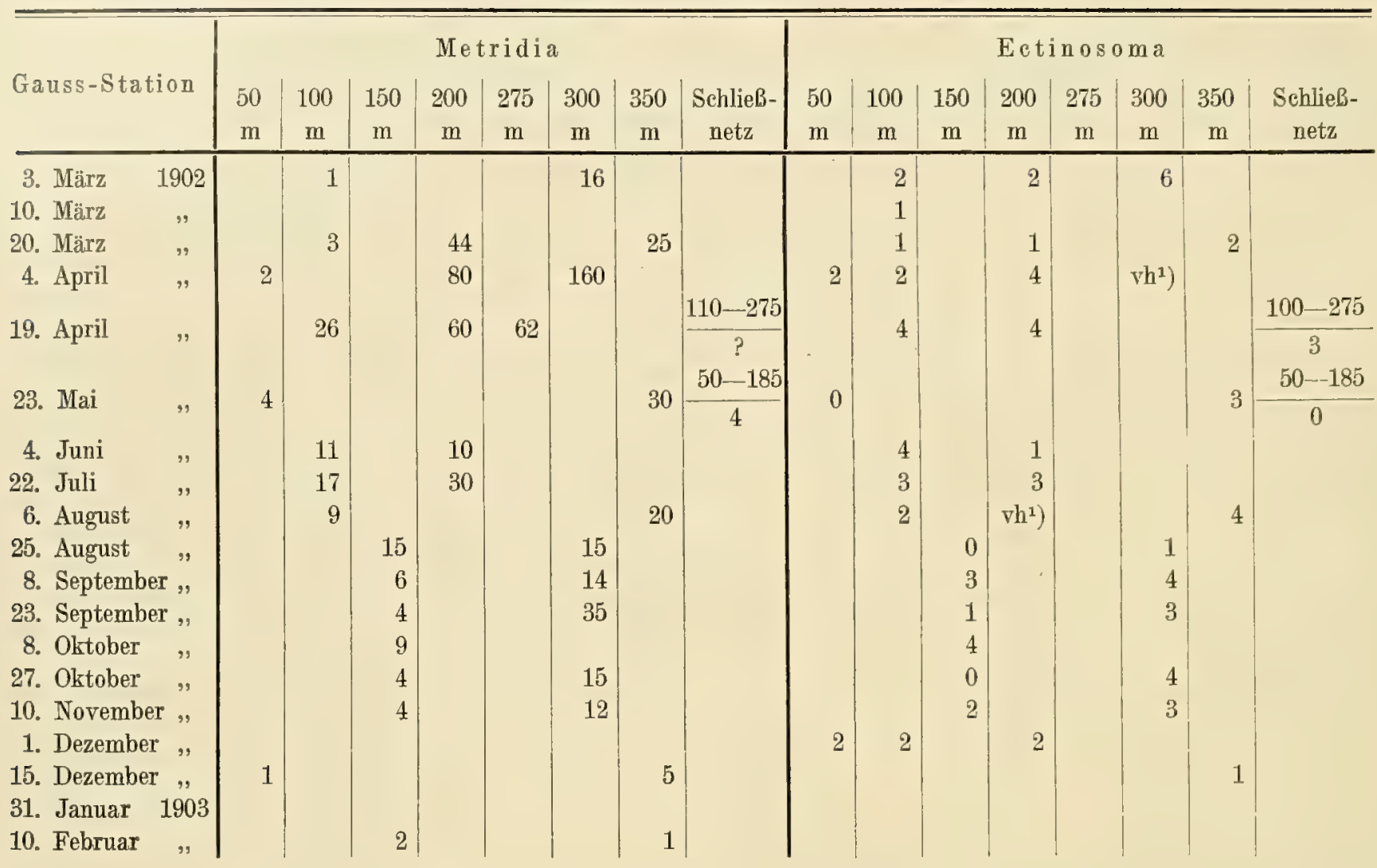

Wie sich dann die Arten mehren beim Erreichen größerer Tiefen, wo von außen durch Strömungen Zufuhr stattfindet und dauernde Eisbedeckung nicht hinderlich ist, ergibt ein V e r g l e i c h der von Dezember 1902 bis April 1903 beobachteten Arten.

Dezember 1902.

1. Dezember, 200 m, Oncaea, Oithona, Ectinosoma, Calanus, Metridia, Stephus, Ctenocalanus.

2. $\quad$ " $385 \mathrm{~m}$, Calanus acutus, Metridia gerlachei.

4. ", $385 \mathrm{~m}$, Calanus acutus, Metridia gerlachei, Rhincalanus grandis, Euchaeta antarctica.

5. $\quad \quad 350 \mathrm{~m}, \quad$ Calanus acutus, Calanus propinquus, Metridia gerlachei, Ctenocalanus vanus, Pleuromamma abdominalis.

6. „ $385 \mathrm{~m}$, Calanus acutus, Calanus propinquus, Metridia gerlachei, Euchaeta antarctica, Euchaeta similis.

8. $\quad$, $\quad 385 \mathrm{~m}$, Metridia gerlachei.

10. $\quad 350 \mathrm{~m}$, Metridia gerlachei, Oithona plumifera (?).

12. ", $350 \mathrm{~m}$, Calanus acutus, Metridia gerlachei, Oithona similis.

15. ". $350 \mathrm{~m}$, Oncaea, Oithona, Ectinosoma, Euchaeta, Ctenocalanus, Calanus, Metridia.

17. " $385 \mathrm{~m}$, Calanus acutus, Calanus propinquus, Metridia gerlachei, Euchaeta antarctica, Pleuromamma robusta.

1) vorhanden = bemerkt, aber nicht gezählt. 
20. Dezember 100 m, Calanus acutus, Metridia gerlachei, Ctenocalanus vanus, Stephus longipes.

22.,

26.

29. , ,

5. Januar,

$10 . \quad$,

17. , ,

31. ,,

2. Februar,

$4 . \quad$,

14.

15.

18. ,

19. ,

25.

26.

$27 . \quad$,

27.

$28 . \quad$,

3. März,

$6 . \quad$,
$350 \mathrm{~m}$, Calanus acutus, Calanus propinquus, Metridia gerlachei, Euchaeta antarctica, Oithona similis.

$385 \mathrm{~m}$, Calanus acutus, Metridia gerlachei.

$385 \mathrm{~m}$, Calanus acutus, Metridia gerlachei.

\section{Januar 1903.}

$350 \mathrm{~m}$, Calanus acutus, Metridia gerlachei, Oncaea curvata, Oncaea conifera, Stephus longipes, Oithona similis, Microcalanus pusillus, Rhincalanus grandis.

$350 \mathrm{~m}$, Rhinocalanus grandis.

$100 \mathrm{~m}$, Calanus acutus.

$150 \mathrm{~m}$, Oncaea, Oithona, Calanus.

\section{Februar 1903.}

$150 \mathrm{~m}$, Calanus acutus, Metridia gerlachei, Oithona frigida.

$150 \mathrm{~m}$, Ctenocalanus vanus, Heterorhabdus (juv.), Euchaeta (juv.).

$400 \mathrm{~m}$, Calanus acutus, Metridia gerlachei, Microcalanus pusillus, Rhincalanus grandis.

$385 \mathrm{~m}$, Calanus propinquus, Rhincalanus grandis.

$400 \mathrm{~m}$, Calanus acutus, Calanus propinquus, Metridia gerlachei, Euchaeta antarctica, Rhincalanus grandis, Oncaea conifera, Oithona similis.

$100 \mathrm{~m}$, Calanus acutus.

$400 \mathrm{~m}$, Calanus acutus, Calanus propinquus, Rhincalanus grandis, Clausocalanus arcuicornis, Microcalanus pusillus, Metridia gerlachei, Euchaeta antarctica, Euchaeta austrina, Euchirella rostromagna, Haloptilus ocellatus, Alloiorhabdus austrinus, Scolecithrix polaris, Oithona frigida, Oithona similis, Oncaea conifera, Oncaea curvata.

$150 \mathrm{~m}$, Haloptilus ocellatus.

$150 \mathrm{~m}$, Haloptilus ocellatus, Metridia gerlachei, Oncaea curvata.

$400 \mathrm{~m}$, Rhincalanus grandis, Calanus acutus, Calanus propinquus, Metridia gerlachei, Euchaeta antarctica, Oithona simitis.

$150 \mathrm{~m}$, Euchaeta antarctica, Oithona similis, Calanus propinquus, Rhincalanus grandis.

\section{März 1903.}

$400 \mathrm{~m}$, Calanus acutus, Calanus propinquus, Rhincalanus grandis, Metridia gerlachei, Microcalanus pusillus, Scolecithrix glacialis, Haloptilus major, Oncaea conifera, Euchaeta antarctica, Ctenocalanus vanus, Oithona frigida, Oithona similis, Ectinosoma antarcticum.

1200 m, Calanus acutus, Calanus propinquus, Metridia gerlachei, Metridia princeps, Alloiorhabdus austrinus, Lucicutia frigida, Spinocalanus antarcticus, 
Scolecithrix glacialis, Haloptilus ocellatus, Rhincalanus grandis, Mesogaidius intermedius, Aetidius armatus, Bradyidius armatus, Augaptilus antarcticus, Temoropsis simplex, Corycaeus speciosus, Metridia curticauda, Microcalanus pusillus, Euchirella rostromagna, Oncaea conifera, Sapphirina metallina, Gaidius tenuispinus, Ctenocalanus vanus, Lucicutia atlantica, Oithona frigida, Euchaeta antarctica, Euchaeta similis, Euchaeta austrina, Lucicutia grandis, Onchocalanus magnus, Scolecithrix polaris, Chiridiella atlantica, Cephalophanes frigidus, Amallophora impar, Amallophora subbrevicornis.

9. März

10. ,

15. , ,

15. ,

17. ,

23. "

27.,

30.

1. April,
$400 \mathrm{~m}$, Calanus acutus, Calanus propinquus, Metridia gerlachei, Rhincalanus grandis, Mesogaidius intermedius, Scolecithrix glacialis, Scolecithrix polaris, Racovitzanus antarcticus.

$3000 \mathrm{~m}$, Calanus acutus, Calanus propinquus, Metridia gerlachei, Metridia princeps, Rhincalanus grandis, Euchaeta antarctica, Euchaeta similis, Euchirella rostromagna, Mesogaidius intermedius, Bradyidius armatus, Amallophora magna, Spinocalanus antarcticus, Oncaea conifera, Alloiorhabdus austrinus, Haloptilus ocellatus, Haloptilus spiniceps, Lucicutia grandis, Faroella antarctica, Euchirella elongata, Onchocalanus magnus, Scolecithrix polaris, Oithona similis, Metridia curticauda, Microcalanus pusillus, Augaptilus cornutus.

$50 \mathrm{~m}$, Calanus acutus, Oncaea conifera, Oncaea curvata, Haloptilus ocellatus, Ectinosoma antarcticum, Oithona frigida.

$300 \mathrm{~m}$, Calanus acutus, Calanus propinquus, Rhincalanus grandis, Metridia gerlachei, Racovitzanus antarcticus.

$400 \mathrm{~m}$, Calanus propinquus, Euchaeta antarctica.

$400 \mathrm{~m}$, Calanus propinquus, Calanus acutus, Metridia gerlachei, Rhinocalanus grandis.

$2000 \mathrm{~m}$, Calanus acutus, Metridia gerlachei, Metridia curticauda, Rhincalanus grandis, Gaetanus antarcticus, Augaptilus antarcticus, Euchaeta antarctica, Euchaeta similis, Euchirella rostromagna, Euchirella magna, Haloptilus major, Alloiorhabdus austrinus, Amallophora magna, Mesogaidius intermedius, Spinocalanus antarcticus, Alloiorhabdus medius, Scolecithrix glacialis, Scolecithrix polaris, Lucicutia frigida, Lucicutia atlantica, Ctenocalanus vanus, Oithona frigida, Oithona simitis, Racovitzanus antarcticus, Oncaea conifera, Labidocera acutifrons.

$150 \mathrm{~m}$, Calanus acutus, Metridia gerlachei, Euchaeta (juv.).

April 1903.

$150 \mathrm{~m}$, Calanus acutus, Calanus propinquus, Metridia gerlachei, Scolecithrix glacialis, Rhincalanus grandis, Oncaea conifera, Microcalanus pusillus, Onchocalanus magnus. 

magna, Bradyidius armatus, Mesogaidius intermedius, Rhincalanus grandis, Scolecithrix glacialis, Spinocalanus antarctious, Alloiorhabdus, austrinus, Euchaeta antarctica.

Die hier behandelte Ausbeute der Copepoden der Deutschen Südpolar-Expedition zerfällt in zwei Partien, von denen die erste dem antarktischen Gebiet angehört, während die zweite bei der Hin- und Rückreise des „Gauss" auf der ganzen Länge des Atlantischen Ozeans vom englischen Kanal bis zum südlichen Eismeere gesammelt wurde. Die Auskunft über die erste Gruppe bildete den Hauptzweck der Untersuchung, obwohl die Sammlungen aus dem Atlantischen Ozean sehr reich und interessant waren, da durch sie das Vorkommen mancher neuen oder nur wenig bekannten Arten nachgewiesen wurde. Diese sollen jedoch bei der weiteren Diskussion nur so weit herangezogen werden, als sie zur Aufklärung der antarktischen Verhältnisse beitragen und zur Beantwortung der Fragen dienen können, welche GIESBRECHT im Belgica Report aufgeworfen hat, nämlich:

1. Ist die geringe Ubereinstimmung der antarktischen Copepodenfauna mit der der benachbarten Meere begründet in mangelhafter Erforschung oder darin, daB das Gebiet des Packeises seine eigene eigentümliche Fauna besitzt?

2. Findet eine Vermischung von arktischer und antarktischer Fauna in der Tiefsee statt oder verhindern die verschiedenen physikalischen oder biogenetischen Verhältnisse in den kalten und warmen Meeren solchen Austausch der Arten?

Es liegen jetzt die Berichte von vier antarktischen Expeditionen vor, deren Resultate es ermöglichen, die charakteristische Copepodenfauna der Antarktis, falls eine solche existiert, festzustellen. Diese sind:

1. Résultats du Voyage du S. Y. Belgica en 1897-1899, 1902.

2. National Antarctic Expedition Natural History vol. IV, 1908.

3. Deutsche Südpolar-Expedition 1901-1903.

4. Expédition antarctique Française 1903-1905.

Es dürfte daher von Interesse sein, die Ergebnisse der modernen SüdpolarExpeditionen über die Copepodenfauna, die bis jetzt vorliegen, in übersichtlicher Tabelle zu betrachten.

Der Teil der Ausbeute des „Gauss“, welcher zum Vergleiche herangezogen wurde, gehört dem Gebiete zwischen Kerguelen und dem Kaiser Wilhelm II.-Land an. Die Sammlungen der „Belgica“6 stammen aus dem Süden und Südosten von Peter I.-Insel zwischen $69^{\circ} 48^{\prime}$ und $71^{\circ} 18^{\prime} \mathrm{s}$. Br. und $81^{\circ} 19^{\prime}$ und $92^{\circ} 22^{\prime}$ w. L. Die Sammlungen der ,Discovery" wurden nur bei der Winterstation in Eislöchern gemacht. Demnach erstrecken sich die Untersuchungen der ,Gauss" auf ein weit größeres Gebiet als die der beiden andern Expeditionen, aber die Copepodenfauna zwischen 50 bis $60^{\circ} \mathrm{s}$. Br. und 70 bis $100^{\circ}$ o. L. ist im wesentlichen identisch mit der zwischen $60^{\circ} \mathrm{s}$. Br. und dem Gaussberge, so daß die obige Zusammenstellung der antarktischen Copepoden als zutreffend angesehen werden kann ${ }^{1}$ ).

$\left.{ }^{1}\right)$ Nördlich vom $50.0^{\circ} \mathrm{s}$. Br. bis zur Südspitze Südafrikas wird die Verteilung der Copepoden weniger übersichtlich durch den Einfluß des Agulhasstromes und den der Westwinddrift aus dem Pazifischen Ozean, und daher ist diese Fauna nach den 


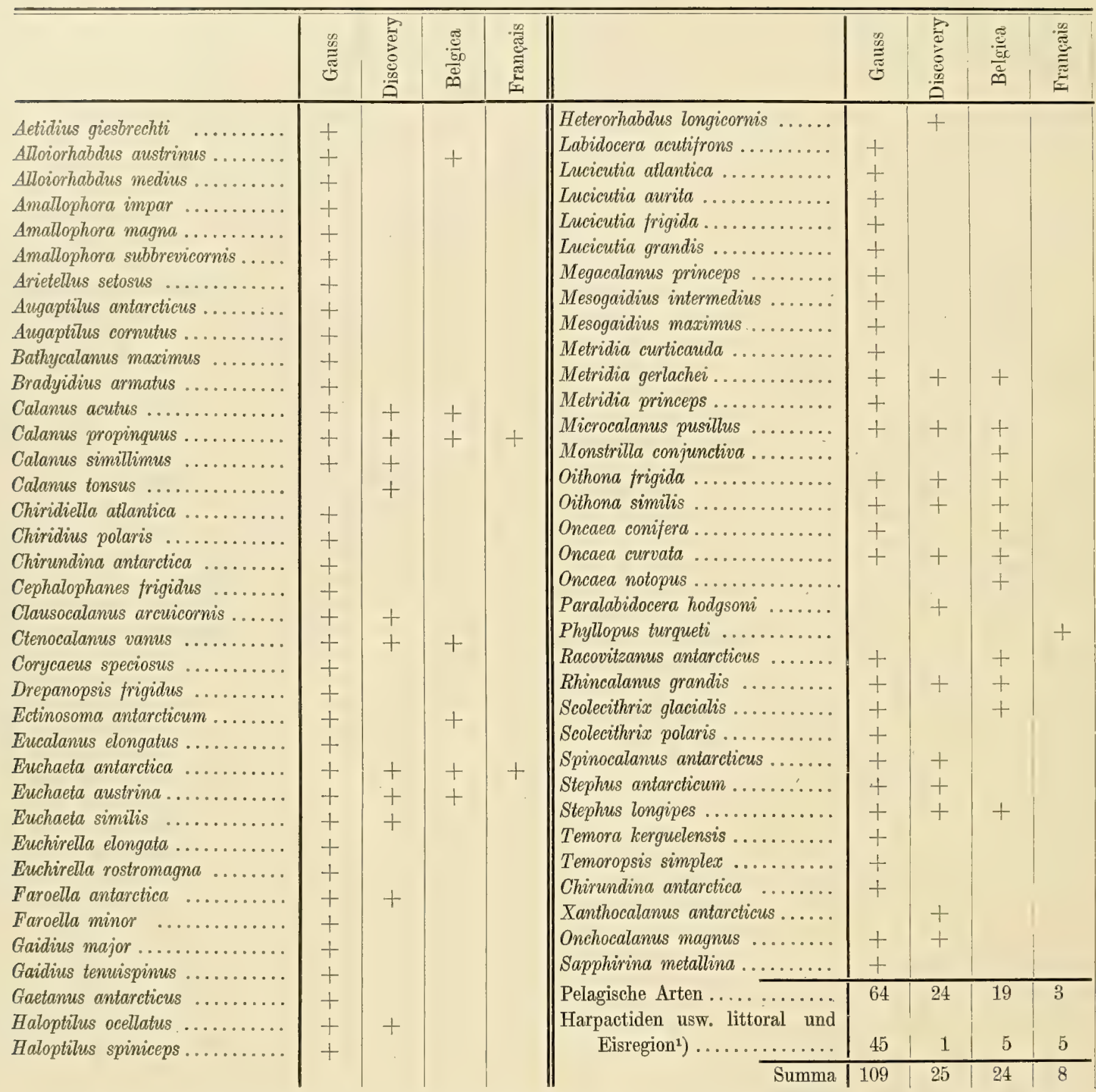

Jahreszeiten veränderlich. Das ergibt sich aus den Untersuchungen von Cleve (The Plankton of the South African Seas; Marine Investigations in South Africa, Cape of Good Hope Department of Agriculture vol. III, 1905), welcher zu zeigen versucht,

1. daß von den an der Westküste Südafrikas gesammelten Copepoden 43 Arten $=32 \%$ dem tropischen Atlantischen Ozean, $42 \%$ dem gemäßigten Atlantischen Ozean, $71 \%$ dem Mittelmeer angehören, $35 \%$ bis zum FaröerKanal heraufsteigen und 21\% noch nördlich davon gefunden sind,

2. daß von den auf der Agulhasbank beobachteten 27 Arten 78\% im Mittelmeer, 41\% im tropischen Atlantischen Ozean, 63\% im temperierten Atlantischen Ozean, 48\% noch nördlich vom Faröer Kanal vorkommen,

3. daß von den 92 Arten der Ostküste Südafrikas $80 \%$ aus dem westlichen Pazifisehen Ozean, $64 \%$ aus dem Indischen Ozean, 55\% aus dem temperierten Gebiet des Atlantischen Ozean, $50 \%$ aus dem Mittelmeer, $19 \%$ aus dem tropischen Atlantischen Ozean und $8 \%$ aus dem Gebiet nördlich vom Faröer-Kanal bekannt sind.

Die Resultate Creves können kaum mit denen des „Gauss" verglichen werden, weil seine Fänge von der Westseite und der Agulhasbank aus dem Küstengebiet stammen, welches die Deutsche Südpolar-Expedition nur auf der Fahrt von Port Natal nach Simonstown berührte.

1) BRADY, Die marinen Copepoden I., Deutsche Südpolar-Expedition Bd. XI. 
Nach dieser Liste erwähnte Giesbrecht von der „Belgica“ 19 pelagische Arten; 24 Arten waren in der Sammlung der „Discovery" und mehr als doppelt so viele in den Fängen des ,Gauss" erhalten. Von Giesbrechts Arten fehlt nur eine, Monstrilla conjunctiva, den beiden andern Sammlungen, während 3 Arten der "Discovery", Calanus tonsus, Xanthocalanus antarcticus und Paralabidocera hodgsoni, nicht in den Sammlungen der Belgischen und Deutsehen SüdpolarExpedition erscheinen.

Die in allen drei Sammlungen vertretenen Arten sind:

$\begin{array}{ll}\text { Calanus acutus, } & \text { Oithona similis, } \\ \text { Calanus propinquus, } & \text { Oncaea conifera, } \\ \text { Ctenocalanus vanus, } & \text { Oncaea curvata, } \\ \text { Euchata antarctica, } & \text { Microcalanus pusillus, } \\ \text { Metridia gerlachei, } & \text { Rhincalanus grandis, } \\ \text { Oithona frigida, } & \text { Stephus longipes }\end{array}$

Dazu kommen die von zwei Expeditionen gefundenen:

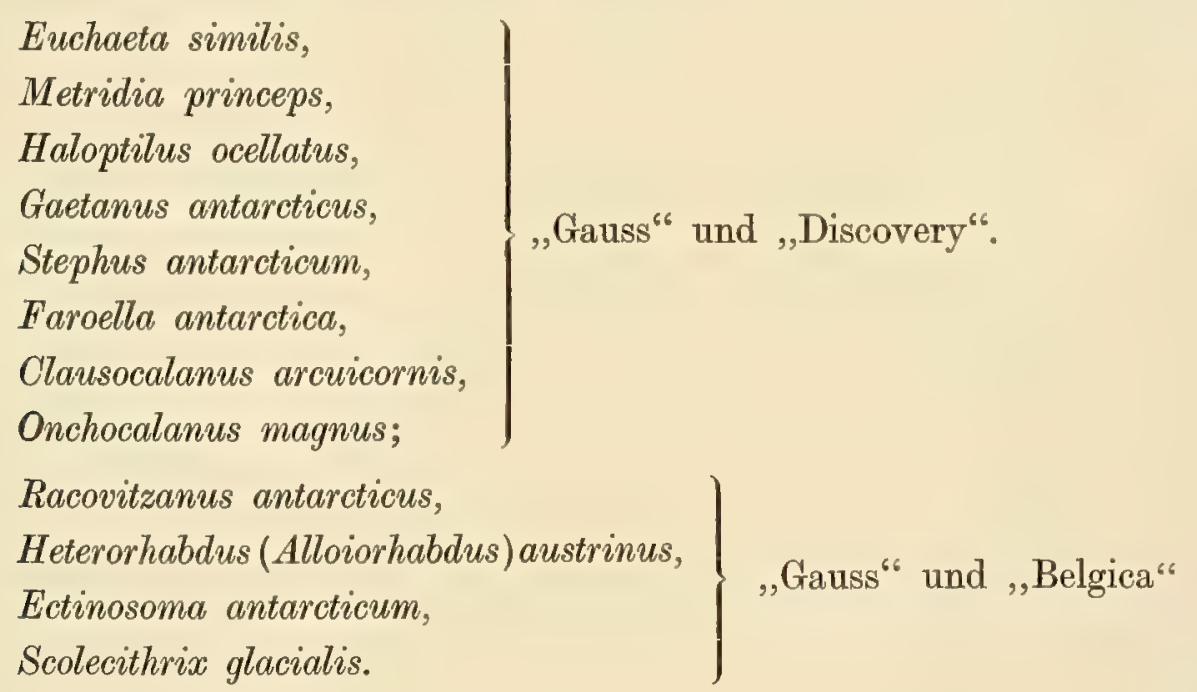

Die in allen drei Sammlungen und wahrscheinlich auch die in zwei von ihnen vorkommenden Arten, welche zu verschiedenen Zeiten und weit voneinander entfernten Orten gefunden wurden, können als die typische pelagische Copepodenfauna der Antarktis betrachtet werden. Ferner gehören zu diesen 24 Arten noch 8 aus der Sammlung des „Gauss":
Chiridius polaris,
Spinocalanus antarcticus
Chirundina antarctica, Augaptilus antarcticus,
Euchirella rostromagna,
Temoropsis kerguelensis,
Faroella minor,
Lucicutia frigida

und 2 von der Ausbeute der „Discovery“: Paralabidocera hodgsoni und Xanthocalanus antarcticus, welche wohl ausschließlich der Antarktis angehören.

Das ergibt eine Gesamtzah 1 von 34 antarktischen Arten (mit Ausschluf der wenig bekannten Monstrilla conjunctiva der Belgica-Expedition). Ohne Zweifel wird diese Zahl bei weiterem Nachsuchen erheblich größer werden. 
Von diesen 34 Arten wurden 7 auch weit verbreitet außerhalb des antarktischen Gebietes angetroffen:

$$
\begin{aligned}
& \text { Ctenocalanus vanus, } \\
& \text { Oithona similis, } \\
& \text { Oncaea conifera } \\
& \text { Microcalanus pusillus, }
\end{aligned}
$$

$$
\begin{aligned}
& \text { Metridia princeps, } \\
& \text { Clausocalanus arcuicornis, } \\
& \text { Heterorhabdus longicornis. }
\end{aligned}
$$

Ferner erhält eine andere Gruppe Copepoden, welche gut bekannten Arten sehr ähnlich sind, aber wegen Differenzen im Bau gewisser Organe oder wegen bedeutenderer Größe von mir als neue Arten anstatt besonderer Varietäten anerkannt wurden:
Chiridius polaris,
Chirundina antarctica,
Cephalophanes trigidus,
Onchocalanus frigidus,
Lucicutia frigida,
Euchirella rostromagna,

und die mit Ausnahme der letzten, häufigen Art in einzelnen seltenen Fällen gefunden wurden, also nicht als charakteristisch für die Antarktis betrachtet werden können.

Eine weitere Gruppe umfaßt jene Tiere, welche auch in weiter Entfernung vom antarktischen Gebiet im Atlantischen Ozean vorkommen:
Metridia princeps,
Aetidius armatus,
Euchirella elongata,
Bradyidius armatus,
Euchirella hirsuta,
Metridia curticauda,
Eucalanus elongatus,
Haloptilus spiniceps,
Bathycalanus maximus,
Lucicutia atlantica,
Megacalanus princeps,
Lucicutia flavicornis,
Amallophora magna,
Arietellus setosus,
Lucicutia grandis,
Corycaeus speciosus,
Labidocera acutifrons,
Sapphirina metallina.

Das Auftreten einiger dieser Arten, welche bisher als für das warme und temperierte Gebiet charakteristisch angesehen wurden, so weit südlich im kalten Eismeer, ist außerordentlich merkwürdig.

Es gibt demnach eine Beimischung atlantischer Formen zur rein antarktischen Fauna.

Während Aetidius armatus, Haloptilus spiniceps, Arietellus setosus, Saphirina metallina, Labidocera acutifrons nur je einmal erschienen, war Corycaeus speciosus zweimal vorhanden; die übrigen fanden sich mehrfach, und Amallophora magna wurde in ziemlicher Anzahl angetroffen.

Es verdient hier hervorgehoben zu werden, daß Dr. GIEsвRECHT im Bericht über die Copepoden der „Belgica" einige Angaben früherer Expeditionen (U. S. Exploring Exp., „Challenger", „Vettor Pisani") über Copepoden, welche in südlichen Meeren bis zur Packeisgrenze gesammelt waren, anzweifelte. Unter den 17 Arten ${ }^{1}$ ), welche als zwischen 45 und $65^{0} \mathrm{~s}$. Br. vorkommend anerkannt

$\left.{ }^{1}\right)$ Diese sind: Aetidius armatus $\left(50^{\circ} \mathrm{s} . \mathrm{Br}.\right)$, Calanus finmarchicus $\left(52^{\circ} \mathrm{s} . \mathrm{Br}.\right)$, Calanus patagoniensis $\left(47^{\circ} \mathrm{s} . \mathrm{Br}.\right)$, Calanus propinquus $\left(64^{\circ} 37^{\prime} \mathrm{s} . \mathrm{Br}.\right)$, Calanus simillimus $\left(52^{\circ}\right)$, Centropages brachiatus $\left(52^{\circ} \mathrm{s} . \mathrm{Br}.\right)$, Clausocalanus arcuicornis $\left(53^{\circ}\right)$, Clytemnestra scutellata $\left(46^{\circ}\right.$ s. Br. $)$, Drepanopus forcipatus (53 $\left.{ }^{\circ} \mathrm{s} . \mathrm{Br}.\right)$, Drepanopus pectinatus $\left(49^{\circ} 16^{\prime} \mathrm{s} . \mathrm{Br}\right.$.), Metridia boecki (450 s. Br.), Monstrilla grandis ( $49^{\circ} \mathrm{s} . \mathrm{Br}$.), Oithona similis $\left(52^{\circ} \mathrm{s}\right.$. Br. $)$, Paracalanus parvus $\left(52^{\circ} \mathrm{s} . \mathrm{Br}.\right)$, Rhincalanus

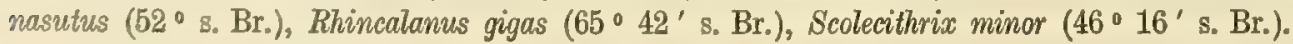




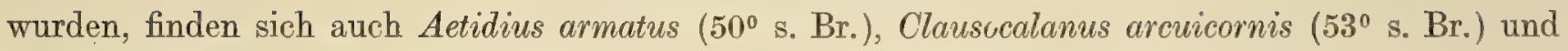
Oithona simitis $\left(52^{\circ} \mathrm{s} . \mathrm{Br}\right.$.), und zu den als ,ungenügend beschriebenen und nicht zuverlässig genug bestimmten Spezies" gehört Lucicutia flavicornis $\left(47^{\circ} 25^{\prime}\right)$.

Bei den Sammlungen der „Belgica“ „,ist der Mangel an Ubereinstimmung mit den früheren auffällig; nur 2 Arten sind beiden gemeinsam". Auch bei der Ausbeute der „Discovery "fällt dieser Unterschied auf; nur 4 Arten (Calanus propinquus, Calanus simillimus, Clausocalanus arcuicornis, Oithona similis sind gemeinsam. Bei der Sammlung des „Gauss" zeigt sich ebenfalls diese Verschiedenheit, da nur 5 von den 26 früher als zwischen 45 und $65^{\circ}$ vorkommend erwähnten Arten wiedergefunden wurden. Die einzige Sammlung, welche mit der des „Gauss“ direkt verglichen werden kann, ist die des „Challenger", welche zum Teil dasselbe Gebiet 50 bis $55^{\circ}$ ö. L. durch. fischte ${ }^{2}$ ).

Der Unterschied in den Ergebnissen läßt sich, wenigstens soweit der außerordentliche Reichtum an Arten im Materiale des „Gauss" in Betracht kommt, zum Teil dadurch erklären, daß die Netze der „Belgica“ nur bis $500 \mathrm{~m}$ Tiefe hinabgelassen wurden, daß die Planktonfänge der „Discovery" im wesentlichen von der Oberfläche oder nur wenig unter derselben stammen und daß die Copepoden des „Challenger" mit Ausnahme eines Fanges von 100 Faden Tiefe am Tage mittels des Oberflächennetzes gesammelt wurden (BRADY, Challenger Report vol. VIII p. 7).

Die Planktonnetze des „Gauss" wurden bis zu Tiefen von $3000 \mathrm{~m}$ herabgelassen, und diesem Umstand ist es zu verdanken, daß die Ausbeute so viel reicher als bei den andern Expeditionen war. Untersuchungen, welchesichnicht auf Planktonmaterial a us größeren Tiefen erstrecken, geben einen falschen Begriff von der Copepodenfauna der Antarktis, dieser Tatsache sollte bei späteren Expeditionen Rechnung getragen werden, und es scheint mir, daß eine der von Dr. GIEsBREcht aufgeworfenen Fragen damit beantwortet ist.

Die folgenden Arten wurden zahlreich in den Sammlungen aus dem Antarktischen Eismeere südlich vom $60 .{ }^{\circ} \mathrm{s} . \mathrm{Br}$. angetroffen: Calanus propinquus, Calanus acutus, Metridia gerlachei, Oncaea conifera, Oithona similis. Sie waren das ganze Jahr hindurch in allen Planktonfängen bei der GaussStation in großer Menge vorhanden; häufig, wenn auch in geringerer Zahl, fanden sich noch Rhincalanus grandis, Euchaeta antarctica, Haloptilus ocellatus, Heterorhabdus (Alloiorhabdus) austrinus, Scolecithrix polaris, Scolecithrix glacialis, Euchirella rostromagna, Ctenocalanus vanus, Amallophora

2) Challenger Report S. 8 u. 9:

St. 149. Betsy Cove, Kerguelen Island, Lat. $48^{\circ} 42^{\prime} \mathrm{S}$., Long. $70^{\circ} 2^{\prime} \mathrm{E}$. Betsy Cove.

St. 153. Lat. $65^{\circ} 42^{\prime}$ S., Long. $79^{\circ} 49^{\prime}$ E. Lat. $65^{\circ} 42^{\prime}$ S., Long. $79^{\circ} 49^{\prime}$ E. (100 Fathoms) Lat. $66^{\circ} 29^{\prime} \mathrm{S}$., Long. $78^{\circ} \dot{\mathrm{W}}$.

St. 154. Lat. $64^{\circ} 37^{\prime}$ S., Long. $85^{\circ} 49^{\prime} \mathrm{E}$.

St. 158. Lat. $50^{\circ} 1^{\prime}$ S., Long. $12^{\prime} 3^{\circ} 4^{\prime} \mathrm{E}$. St. 159. Lat. $47^{\circ} 25^{\prime}$ S., Long. $130^{\circ} 32^{\prime}$ E.

Drepanopus pectinatus.

Calanus propinquus.

Pseudothalestris imbricata, Zaus spinatus, Machairopus idyoides.

Rhincalanus gigas.

Pleuromma abdominale.

Saphirinella stilifera.

Calanus propinquus, Rhincalanus gigas, Pleuromma abdominale, Candace truncata.

Heterochaeta spinitrons, Aetidius armatus.

Calanus propinquus, Eucalanus attenuatus, Rhincalanus gigas, Pleuromma abdominale, Leucartia flavicornis, Euchaeta prestandreae. 
magna, IIicrocalanus pusillus, Euchaeta austrina, Oncaea curvata, Oithona frigida, Spinocalanus antarcticus, Stephus antarcticum und Stephus longipes.

Da diese Liste als Verzeichnis der typischen pelagischen Copepodenfauna der Antarktis betrachtet werden kann, ist es wichtig, so weit als möglich die Verbreitung der genannten Arten außerhalb dieses Gebietes festzustellen.

Oncaea conifera, Ctenocalanus vanus, Amallophora magna, Microcalanus pusillus, Oithona simitis sind Arten von sehr weiter Verbreitung; drei von ihnen finden sich vom Nordpolarbecken bis zum südlichen Eismeere, die beiden andern vom nördlichen Atlantischen Ozean bis zum äußersten Süden.

Calanus acutus, Calanus propinquus, Metridia gerlachei, Rhincalanus grandis, Euchaeta antarctica sind rein antarktische Arten. In dem Fange vom 18. Dezember 1901 nördlich Kerguelen wurden sie noch gefunden, und bei St. Paul im Indischen Ozean und am Kap der Guten Hoffnung traten bereits echte Warmwasserformen auf. Der Wechsel in der Copepodenfauna tritt ziemlich plötzlich ein, wenn man nach Norden herauffährt.

Die Verteilung von Calanus propinquus im Atlantischen Ozean wurde bereits von GIESBRECHT im Bericht über dieCopepoden der „Belgica“" erörtert, welcher zu der Ansicht kam, daß frühere Angaben über diese Art wahrscheinlich auf Irrtum beruhen und daß sie mit dem nahe verwandten Calanus simillimus verwechselt sein wird. Auch vom "Gauss" wurde sie nicht im Westen oder nördlich vom Kap der Guten Hoffnung gefunden. Ähnlich verhält es sich mit Rhincalanus grandis. Die Art, mit der er verwechselt sein kann, Rhincalanus gigas, erkannte GIESBRECHT als großes Exemplar von Rhincalanus nasutus. Auch Metridia gerlachei und Euchaeta antarctica verschwinden bereits in der Westwinddrift.

Gewisse atlantische Tiefseecopepoden, wie Bathycalanus, Megacalanus, Metridia princeps, Lucicutia grandis, Aetidius armatus, Arietellus, Eucalanus elongatus, die sich am 18. Dezember 1901 in einem Fange aus $2500 \mathrm{~m}$ zusammen fanden mit Undeuchaeta major, Pleuromamma robusta, Gaidius tenuispinus, zeigen, daß eine Mischung antarktischer und atlantischer Formen durch die Tiefsee erfolgt, aber eine Ausbreitung antarktischer Formen in nördlicher Richtung findet nicht statt. Nördlich und westlich von Kapstadt findet sich rein südatlantische Copepodenfauna.

Ostlich vom Kap findet sich indische Fauna, was sich aus den Fängen vom Mai 1903 während der Heimreise ergibt. Diese Stationen, welche die bekannten Warmwasserformen lieferten, folgen einer Linie, die etwas nördlich vom $300^{\circ} \mathrm{s}$. Br. verläuft und sich unter $70^{\circ}$ ö. L. bis Neu-Amsterdam nach Süden herabzieht. Unmittelbar nördlich von NeuAmsterdam ändert sich die Fauna plötzlich von deutlich antarktischem Charakter südlich vom $40 .{ }^{\circ}$ s. Br. zur deutlichen Warmwasserfauna des Indischen Ozeans nördlich davon. Es liegen keine Beobachtungen darüber vor, ob Tiefseeformen des Indischen Ozeans der antarktischen Fauna beigemischt sind, denn die in der antarktischen Region vorkommenden Arten der Tiefsee sind auch vom Atlantischen Ozean bekannt.

Es ist schwierig, über solche Arten etwas auszusagen wie Sapphirina metallina, welche nur einmal, und Corycaeus speciosus, welcher zweimal in Planktonfängen aus der Antarktis erschien. 
Sie können vielleicht durch Oberflächenströme aus dem Indischen Ozean oder den östlichen Meeren dorthin gelangt sein ${ }^{1}$ ).

Die von Giesbrecht angedeuteten Probleme, ob das Packeisgebiet seine eigene, besondere Fauna hat und ob eine Vermischung nordpolarer und antarktischer Formen durch die Tiefsee stattfindet, ferner ob solche physikalischen und biogenetischen Bedingungen in den Polargebieten vorliegen, daß sie solchen Austausch hindern, scheinen gewissermaßen durch die Sammlungen der Deutschen Südpolar-Expedition beantwortet zu werden. Die beiden ersten Fragen werden bejaht, und was die dritte anbetrifft, so zeigen die Beobachtungen an, $\mathrm{d}$ a $\beta$ e in e G re nze z wis chen dem südlichen Indischen und dem Antarktischen Ozean existiert, weIche die Arten des Indischen Ozeans in südlicher Richtung nicht überschreiten, und ebenfalls einesolchezwischendemsüd. atlantischen Ozean und der Antarktis, über welchedie rein antarktischen Arten nicht vordringen, obgleich sie zu gewissen Zeiten in geringer Zahl wohl bis zur südafrikanischen Küste gelangen mögen.

Ein Vergleich der Copepodenfaunen des nördlichen und südlichen Polargebietes ist ebenfalls instruktiv. Leider genügen die bisher publizierten Beobachtungen noch nicht für ein abschließendes Urteil, so daß nur erst Vermutungen ausgesprochen werden können. Aber durch die Resultate von Nansens „Norwegian North Polar Expedition“ haben wir einen Einblick in die Fauna, welche erwartet werden kann und welche ohne Zweifel in Zukunft gefunden werden wird:

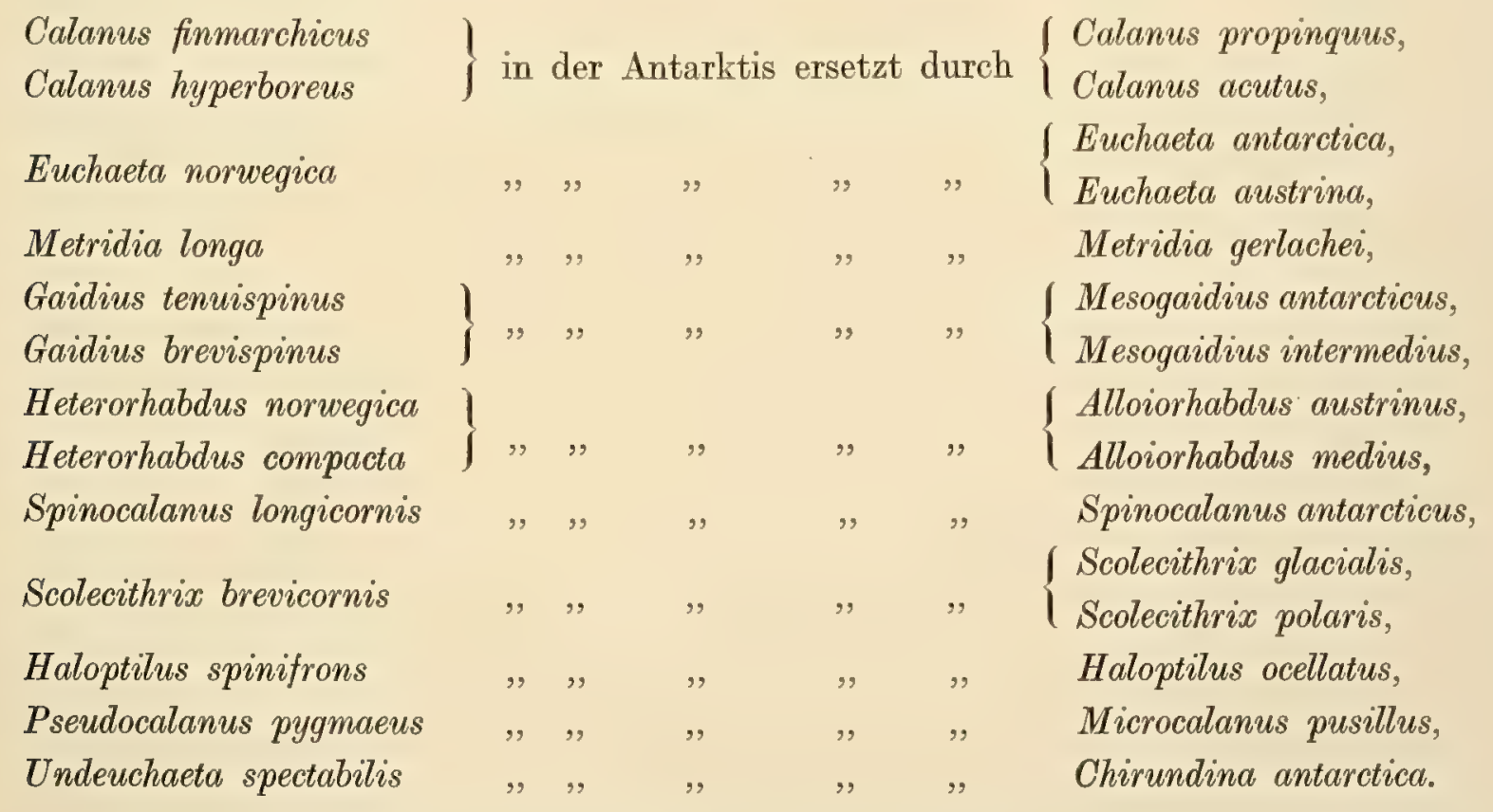

Drei Arten sind beiden Polargebieten gemeinsam: Oncaea conifera, Oncaea notopus und Amallophora magna (Scaphocalanus acrocephalus SARS), aber eine neue Oncaea (Oncaea curvata) erscheint in der Antarktis, welche sonst nicht bekannt ist.

1) Dr. BRADY erwähnt noch Setella gracitis aus Fängen von der Gauss-Station und Kerguelen. Die marinen Copepoden I., Harpacticidae usw. S. 508. 
Von den nordpolaren Arten verbreiten sich Calanus hyperboreus, Euchaeta norwegica, Metridia longa, Heterochaeta norwegica in südlicher Richtung nur bis zur Westküste Irlands, Calanus finmarchicus ist südlich von der Bai von Biscaya nicht bekannt.

Gerade wie Calanus finmarchicus und Calanus hyperboreus, Euchaeta norwegica und Heterorhabdus norwegicus ihr Entwicklungszentrum im äußersten Norden zu haben scheinen, so haben es Calanus propinquus, Calanus acutus, Metridia gerlachei, Euchaeta antarctica und Alloiorhabdus (Heterorhabdus) austrinus im äußersten Süden; dort erscheinen sie in größter Häufigkeit, während sie nach Norden hin weniger zahlreich werden und im temperierten Gebiete bald verschwinden.

Zwischen dem nördlichen Atlantischen Ozean und dem Nordpolarbassin existiert keine so plötzliche Grenze, wie sie im Süden zwischen dem Antarktischen Meer und Indischen Ozean aufzutreten scheint, aber ein Parallelfall findet sich im Norden beim Faröer-Kanal, wo im Westen und Süden vor dem Wyville Thompson-Rücken viele Warmwasserformen wegen der physischen Bedingungen plötzlich versehwinden, während einige der ausgesprochen nordischen Arten noch ihren Weg südlich bis zur Westküste Irlands finden können.

Die folgenden Resultate können als gesichert gelten:

1. Die Copepodenfaunader Antarktissetztsich a us drei Gruppen von Tieren zusammen: a) Arten, welche überall vorkommen (Oithona similis, Amallophora magna, Oncaea conifera, Ctenocalanus vanus usw.); b) F o r men, welehe im tiefen Wasser des Atlantischen Ozeans er scheinen und von Strömungen dem südlichen kalten Meer zu g e führt w e rden (Bathycalanus, Megacalanus, Metridia princeps, Metridia curticauda, Lucicutia grandis usw.); c) echte antarktische Formen, die den benachbarten Gebieten fehlen. (Calanus acutus, Calanus propinquus, Rhincalanus grandis, Euchaeta antarctica usw.).

2. Die charakteristische Copepodenfauna der Antarktis ver breitet sich nicht bis zum Indischen Ozean und zum Kapder Guten Hoffnung a ch Norden.

3. Die verirrten, nicht typisch antarktischen Arten haben das Eismeer wahrscheinlich dureh die Tiefseedes Atlantischen Ozeans erreicht.

4. A u B r wenigen, in allen Ozeanen vorkommenden Arten zeigt die Copepodenfauna der Antarktis wenig Ähnlichkeit mit jenerdes Nordpolargebietes. DieArten, obwohl auf alle Fälle nahe verwandt, sind verschieden genug, um für jedes Gebiet charakteristisch zu sein.

5. Verallgemeinerungen können nur mit dem Vorbehalt gemacht werden, daB diese Fauna, ebenso wie die jedes anderen Gebietes, a us hydrographischen Gründen von Jahr zu Jahr und mit den Jahreszeiten variieren mu. 
6. Es ist jedoch nicht wahrscheinlich, daßsich die typische Copepodenfaunader Antarktis, wiesiedurch die Expeditionen der,,Belgica", ,D iscovery"und des, ,Gaus " bekannt ge worden ist, viel ändern wird, sondern nurdie Zahl und die Umbildung der verirrten Formen, welche aus der Ferne in dieses Gebiet gelangt sind, wird veränderlich sein.

Die Abbildungen, welche diese Arbeit illustrieren, sind alle von $\mathrm{M}$ is $\mathrm{s}$ M a r i o n L e s gezeichnet.

\section{Tafelerklårung.}

T a f el XXII.

\section{Megacalanus princeps.}

Fig. 1. Rückenansicht ㅇ, 1a Fortsetzung des Fühlers.

,2. Maxille ㅇ.

, 3. Maxille $\delta^{2}$.

,. 4. Vorderer Maxilliped of.

.. 5. Mandibel $\hat{0}$.

" 6. Hinterer Maxilliped $\hat{o}$.

" 7. Erster Fuß 우

" 8. Zweiter FuB 우

" 9. Fünfter Fuß $\delta^{*}$.

, 10. Fünfter Fuß 옹

„11. Enddorn eines Fußes.

T a f e l XXIII.

\section{Bathyealanus maximus.}

Fig. 1. Seitenansicht 3 .

2. Vorderer Maxilliped $\hat{o}$.

3. Vorderer Maxilliped ㅇ.

4. Maxille ?.

5. Hinterer Maxilliped ㅇ.

6. Fünfter Fuß $\delta$.

7. Erster Fuß o.

\section{Bathycalanus richardi.}

Fig. 8. Erster Fuß.

Tafel XXIV.

\section{Stephus neptuni 오.}

Fig. 1. Hintere Antenne.

2. Vorderer Maxilliped.

" 3. Hinterer Maxilliped.

"4. Maxille.

" 5. Mandibel.

, 6. Erster Fub.

, 7. Zweiter Fuß.
Aetidius giesbrechti.

Fig. 8. Rückenansicht.

Chiridius polaris.

Fig. 9. Hinterer Maxilliped.

, 10. Erster Fuß.

11. Zweiter FuB.

12. Vierter Fuß.

$$
\text { Ta fel XXV. }
$$

Spinoealanus horridus o.

Fig. 1. Letzte 3 Thoraxsegmente.

,2. Hinterer Maxilliped.

\section{Spinocalanus magnus.}

Fig. 3. Hinterer Maxilliped.

4. Zweiter Fuß.

5. Vierter Fuß.

Hypsicalanus gracilis ㅇ.

Fig. 6. Seitenansicht.

7. Rückenansicht.

8. Hinterer Maxilliped.

9. Mandibel.

10. Erster Fuß.

11. Zweiter Fuß.

\section{Oxyealanus gracilis 오}

Fig. 12. Seitenansicht.

"13. Erster Fuß.

"14. Basalglied vom 4. Fuße.

T a f el XXVI.

Mesogaidius intermedius.

Fig. 1. Erster Fuß 우.

2. Zweiter Fuß 오. 
Mesogaidius maximus.

Fig. 3. Hintere Antenne.

.. 4. Hinterer Maxilliped

.. 5. Erster Fuß.

.. 6. Zweiter Fuß.

\section{Gaetanus divergens.}

Fig. 7. Abdomen und letztes Thoraxsegment.

. 8. Vorderer Maxilliped.

. 9. Erster Fuß.

., 10. Zweiter Fuß.

\section{Gaetanus brevicaudatus.}

Fig. 11. Abdomen und letztes Thoraxsegment.

", 12. Erster Fuß.

\section{Gaetanus recticornis.}

Fig. 13. Erster Fuß.

\section{Gaetanus rectus.}

Fig. 14. Abdomen und letztes Thoraxsegment, dorsal.

"15. Abdomen und letztes Thoraxsegment, seitlich.

"16. Erster Fuß.

\section{T a f el XXVII.}

\section{Gaetanus pileatus.}

Fig. 1. Rückenansicht.

,2. Erster FuB.

\section{Euchirella spinosa ㅇ․}

Fig. 3. Letztes Thoraxsegment und Abdomen, seitlich. " 4. Letztes Thoraxsegment und Abdomen, dorsal.

" 5. Hintere Antenne.

" 6. Zweiter Fuß.

"7. Vierter Fuß.

\section{Euchirella gracilis.}

Fig. 8. Rückenansicht.

"9. Hintere Antenne.

" 10. Zweiter Fuß, letztes Glied vom Außenaste.

\section{Taf el XXVIII.}

\section{Euchirella similis.}

Fig. 1. Hintere Antenne.

, 2. Außenast vom zweiten Fuße.

\section{Euchirella maxima.}

Fig. 3. Seitenansicht o.

. 4. Hintere Antenne.

, 5. Maxille, Außenast und Innenast.

\section{Euchirella elongata.}

Fig. 6. Rückenansicht.

\section{Euchirella hirsuta.}

Fig. 7. Seitenansicht 우.

" 8. Abdomen, dorsal.

". 9. Vierter Fuß.

\section{Chirundina magna 오}

Fig. 10. Seitenansicht.

"11. Maxille.

12. Erster FuB.

"13. Zweiter Fuß.

T a f e 1 XXIX.

\section{Chirundina antaretica 오}

Fig. 1. Seitenansicht.

" 2. Abdomen, dorsal.

, 3. Abdomen, ventral.

\section{Mesundeuchaeta asymmetrica 오}

Fig. 4. Seitenansicht.

"5. Abdomen, dorsal.

"6. Abdomen, ventral

"7. Genitalsegment eines anderen Exemplars.

\section{Valdiviella minor o.}

Fig. 8. Seitenansicht.

.9. Erster Fuß.

"10. Zweiter Fuß.

"11. Dritter Fuß.

\section{Tafel $\mathrm{xxx}$.}

Seolecithrix polaris 우

Fig. 1. Hintere Antenne.

2. Ende des vorderen Maxillipeds.

\section{Scolecithrix medius ㅇ․}

Fig. 3. Zweiter Fuß.

"4. Dritter Fuß.

, 5. Hinterer Maxilliped.

\section{Racovitzanus antarcticus 오}

Fig. 6. Seitenansicht.

\section{Amallophora elegans}

Fig. 7. Hintere Antenne.

8. Maxille.

"9. Vorderer Maxilliped.

" 10. Hinterer Maxilliped.

"11. Erster Fuß.

12. Zweiter Fuß.

" 13. Fünfter Fuß. 
Tafel XXXI.

Xanthocalanus gracilis .

Fig. 1. Seitenansicht.

"2. Fünfter FuB.

\section{Onchocalanus magnus 오.}

Fig. 3. Rückenansicht.

4. Seitenansicht vom Kopfe.

, 5. Fünfter Fuß.

Onchocalanus suberistatus

Fig. 6. Rückenansicht.

7. Kopf von der Seite.

8. Fünfter Fuß.

Talacalanus calaminus.

Fig. 9. Außenlobus der Maxille.

, 10. Hinterer Maxilliped.

"11. Vorderer Maxilliped.

"12. Endborsten vom hinteren Maxilliped.

T a f e l XXXII.

Cornucalanus magnus o

Fig. 1. Rückenansicht.

"2. Vorderer Maxilliped.

" 3. Hinterer Maxilliped.

4. Erster FuB.

5. Zweiter Fuß.

6. Vierter Fuß.

7. Kopf von der Seite.

8. Fünfter FuB.

9. Abdomen seitlich.

10. Kopf von der Seite $\delta^{\hat{\sigma}}$.

\section{T a f e I XXXIII.}

\section{Cornucalanus chelifer ㅇ.}

Fig. 1. Kopf von der Seite.

„2. Fünfter Fuß.

\section{Gaussia scotti.}

Fig. 3. Rückenansicht $\hat{\sigma}$.

, 4. Rückenansicht 웅.

" 5. Abdomen von der Seite o.

6. Fünftes Fußpaar ふ๋.

Fig. 7. Fünfter FuB einzeln $\delta$.

" 8. Kopf an der Seite ㅇ.

"9. Zweiter Fuß q.

"10. Dritter Fuß o, letztes Glied vom Außenaste.

"11. Vierter Fuß o , letztes Glied vom Außenaste.

,12. Fünftes Fußpaar 오.

$$
\text { Tafel XXXIV. }
$$

Lophothrix similis 우.

Fig. 1. Kopf von der Seite.

"2. Fünftes Fußpaar.
Lophothrix quadrispinosa f.

Fig. 3. Fünftes Fußpaar.

\section{Lophothrix varicans 우.}

Fig. 4. Kopf von der Seite.

, 5. Fünftes Fußpar.

Chiridiella atlantica 오.

Fig. 6, Seitenansicht.

, 7. Mandibel.

" 8. Maxille.

,9. Vorderer Maxilliped.

, 10. Hinterer Maxilliped.

"11. Erster Fuß.

"12. Zweiter Fuß.

"13. Dritter Fuß.

\section{Tafel XXXV.}

Euchaeta quadrata 우

Fig. 1. Letztes Thoraxsegment und Abdomen.

\section{Euchaeta scotti 웅.}

Fig. 2. Letztes Thoraxsegment und Abdomen.

Alloiorhabdus anstrinus ㅇ.

Fig. 3. Vorderer Maxilliped.

. 4. Dritter Fuß, letztes Glied vom Außenaste.

\section{Lucicutia atlantica i.}

Fig. 5. Abdomen.

\section{Lucieutia ovalis q.}

Fig. 6. Rückenansicht.

\section{Pseudohaloptilus longimanus of.}

Fig. 7. Rückenansicht.

$"$ 8. Maxille.

"9. Mandibel.

"10. Vorderer Maxilliped.

,11. Hinterer Maxilliped.

"12. Zweiter Fuß.

" 13. Fünfter Fuß.

\section{Tafel XXXVI.}

Euchaeta robusta ㅇ.

Fig. 1. Letztes Thoraxsegment und Genitalsegment.

\section{Phyllopus impar 오.}

Fig. 2. Rückenansicht.

\section{Arietellus setosus 오.}

Fig. 3. Rückenansicht. 
Arietellus armatus 오

Fị. 4. Rückenansicht.

$$
\text { Arietellus simplex 웅. }
$$

Fig. 5. Fünftes Fußpaar.

$$
\text { Augaptilus antareticus }
$$

Fig. 6. Letztes Thoraxsegment und Abdomen.

, 7. Vorderer Maxilliped.

\section{Augaptilus fungiferus 오}

Fig. 8. Erster Fuß.

$$
\text { T a f el XXXVII. }
$$

Arietellus minor o.

Fig. 1. Rückenansicht.

\section{Augaptilus gibbus 우}

Fig. 2. Rückenansicht.

3. Erster Fuß.

\section{Augaptilus magnus .}

Fig. 4. Rückenansicht.

5. Maxille.

6. Hinterer Maxilliped.

7. Teil einer der Borsten desselben.

8. Erster Fuß.

, 9. Fünfter Fuß.

\section{T a f e I XXXVIII.}

\section{Augaptilus facilis.}

Fig. 1. Erster FuB.

2. Vierter Fuß.

\section{Isocalanus major ㅇ.}

Fig. 3. Hinterer Maxilliped.

"4. Vorderer Maxilliped.

„5. Teil einer Borste desselben.

\section{Isocalanus minor o.}

Fig. 6. Vorderer Maxilliped.

"7. Teil einer Borste desselben.

" 8. Hinterer Maxilliped.
Autanepsius minor 오

Fig. 9. Seitenansicht.

, 10. Hinterer Maxilliped.

Fig. 11. Zweiter FuB.

\section{Temoropsis simplex.}

T a f el XXXIX.

Paraugaptilus meridionalis ${ }^{\circ}$

Fig. 1. Seitenansicht.

., 2. Rückenansicht.

, 3. Vorderer Maxilliped.

" 4. Fünftes Fußpaar.

\section{Paraugaptilus buchani ㅇ.}

Fig. 5. Rückenansicht.

"6. Letztes Thoraxsegment und Abdomen.

, 7. Fünftes Fußpar.

Temoropsis simplex.

Fig. 8. Hinterer Maxilliped.

,9. Vorderer Maxilliped.

, 10. Teil einer Endborste des hinteren Maxillipeds.

, 11. Hintere Antenne.

Fig. 12. Mandibelpalpus.

"13. Maxille.

, 14. Erster Fuß.

Tafel XXXX.

\section{Heterocalanus medius of.}

Fig. 1. Seitenansicht.

,2. Kopf von der Seite.

, 3. Kopf halb von der Seite.

"4. Kopf dorsal.

" 5. Erster Fuß.

Fig. 6. Rückenansicht.

$\because 7$. Seitenansicht.

Fig. 8. Seitenansicht 오.

\section{Metridia princeps:}

,9. Rückenansicht o.

, 10. Fünftes Fußpaar

,11. Abdomen seitlich ơ.

"12. Zweiter Fuß o.

, 13. Fünftes Fußpaar đo. 


\title{
DIE BRACHIOPODEN
}

\author{
DER
}

\section{DEUTSCHEN SÜDPOLAR-EXPEDITION 1901-1903}

VON

\section{PAUL EICHLER}

(TÜBINGEN)

MIT TAFEL XLII-XLIV 

Von den Brachiopoden der antarktischen Region sind am längsten die an der Südspitze von Amerika vorkommenden Arten, die sich aber alle mehr oder weniger weit äquatorwärts ausdehnen, bekannt. Eine größere Anzahl von Arten wurde dann durch die Challenger-Expedition (1872-76) im Kerguelengebiet nachgewiesen.

Aus dieser Gegend brachte später die „Valdivia“ (1898-99) wieder neues Material, und endlich wurde durch die jüngsten antarktischen Expeditionen unsere Kenntnis wesentlich gefördert, sowohl was die Zahl der vorkommenden Arten als auch was ihre geographische Verbreitung anlangt.

So wurde eine Anzahl Brachiopoden erbeutet von der „Belgica“" (1897-99), von der franz̈ösischen antarktischen Expedition unter Charcot (1903-05), von der Deutschen SüdpolarExpedition des „Gauss" (1901-03), von der englischen Expedition der „Discovery" (1901-04) und der schwedischen Südpolar-Expedition der ,Antarctic“ (1901-03).

Durch diese letzten Expeditionen wurden zum ersten Male die die Küsten des antarktischen Kontinents bewohnenden Arten bekannt.

Mit diesen in erster Linie soll sich auch die nachfolgende Bearbeitung der von dem „Gauss" gesammelten Brachiopoden beschäftigen, welche mir Herr Professor Dr. BlochmanN nach einer von ihm vorgenommenen Durchsicht des Materials überließ. Außerdem war es mir möglich, noch das Material der schwedischen Südpolar-Expedition, das gleichfalls Herrn Prof. Blochmann zur Bearbeitung übergeben wurde, für einzelne Punkte heranzuziehen.

Meinem hochverehrten Lehrer, Herrn Prof. Dr. Blochmann, für das stete, reiche Interesse, das er an meiner Arbeit genommen, auch an dieser Stelle meinen herzlichsten Dank auszusprechen, ist mir eine angenehme Pflicht.

Von der Gauss-Expedition wurden im Winterlager vor Kaiser Wilhelm II.-Land drei Arten von Testicardinen aufgefunden, die sich alle als neu erwiesen, Liothyrina antarctica, Magellania joubini, Macandrevia vanhoeffeni; außerdem wurde nicht weit davon eine Disciniscalarve gefangen.

Die beiden erstgenannten Arten liegen in zahlreichen, aber meist jüngeren oder ganz jugendlichen Exemplaren vor; auch von der dritten, die in geringer Zahl sich findet, ist nur ein Exemplar unter dem Material, das wohl für ausgewachsen gelten kann.

Es muß ganz besonders die große Sorgfalt anerkannt werden, mit welcher der Zoologe der Expedition, Prof. Vanhörfen, diese kleinen Objekte sammelte und konservierte. Dadurch wurde es möglich, an einer Liothyrina von der Küste des antarktischen Kontinents die Entwicklung der Spicula in lückenloser Reihe zu studieren, was noch für keine andere Art erreichbar war. 
Ich werde im ersten Teile eine Ubersicht über die bis jetzt von den Küsten des antarktischen Kontinentes bekannt gewordenen Brachiopoden, vor allem eine genaue Beschreibung der von dem .Gauss" gefundenen geben und die daran sich anknüpfenden tiergeographischen Fragen erörtern.

Im zweiten Teile finden die morphologischen Untersuchungen, die an dem Material vorgenommen werden konnten, eine Darstellung.

\section{Teil: Die aus der Antarktis bekannten Brachiopoden. Discinisea.}

(Taf. XLIV Fig. 22.)

F. MüLLER, Beschreibung einer Brachiopodenlarve. Müllers Archiv für Anatomie und Physiologie, 1860, S. $72-80$.

F. Mürler, Die Brachiopodenlarve von Sta. Catharina, 2. Beitrag. Archiv für Naturgeschichte, 1861, S. 53-56.

F. Blochmann, Die Larve von Discinisca. (Die Mưllerssche Brachiopodenlarve.) Zoolog. Jahrbücher. 11. Bd. 1898.

Zwei Larven brachte die Deutsche Südpolar-Expedition mit, sie wurden in der Nähe der Winterstation des „Gauss“" am 10. März 1903 aus $3000 \mathrm{~m}$ Tiefe gefangen. Das abgebildete Exemplar mißt im Durchmesser $787 \mu$, das andere Exemplar war etwas größer $(825 \mu)$.

Nach dem allgemeinen Bau ist die Larve sicher zur Gattung Discinisca zu stellen. Sie ähnelt sehr der von Blochmanv beschriebenen Larve von $D$. atlantica, ohne mit ihr identisch zu sein. Abweichend ist zunächst die Zahl der Borsten, es fanden sich jederseits vier stärkere, von denen die beiden hinteren etwas größer und kräftiger sind als die vorderen. Zwischen beiden Paaren liegt im dorsalen Mantelrand eine Reihe feiner Borsten, die in ihrer Länge nicht den Rand der Dorsalschale erreichen.

Die vier jederseits des kräftigen Mediantentakels gelegenen Cirren sind länger und schlanker als bei der MüLLerschen Larve. Die Reihenfolge vom Munde zum Tentakel ist die gleiche. Die zu beiden Seiten des Darmes gelegenen Gebilde, die von MüLler für Statocysten, von BlochmanN für Nephridientrichter gehalten wurden, scheinen mir Statocysten zu sein. Ein Statolith fehlte, doch kann derselbe auch bei der Präparation verloren gegangen sein.

Die von Blochmann erwähnten Ausführgänge, die für Nephridien sprächen, konnte ich nicht beobachten. Das schließt jedoch nicht aus, daß sich bei noch weiterer Beobachtung an einer größeren Anzahl von Larven die Existenz sowohl von Statocysten als auch Nephridien herausstellen kann.

Uber die Zugehörigkeit der beiden Larven zu einer bestimmten Art lassen sich nur Vermutungen aufstellen. Es ist natürlich möglich, daß die Art, von der sie stammt, eine noch unbekannte und dann wohl in der Tiefsee lebende Form ist. Man könnte aber auch, worauf mich Prof. Blochmann aufmerksam machte, daran denken, diese beiden Larven mit Discinisca atlantica in Beziehung zu bringen, der ja als Tiefseeform eine sehr weite Verbreitung zukommt, und die auch aus dem hohen Norden bekannt ist.

Die beiden Larven des "Gauss" sind wahrscheinlich in großer Tiefe (3000 m) gefangen, da in den sehr zahlreichen Fängen aus geringerer Tiefe keine gefunden wurden, und sind ungefähr doppelt so groß als die von Blochmann untersuchten Larven, die von der Oberfläche stammen. Man könnte also annehmen, daß die Larven im Begriffe sind, das pelagische Leben aufzugeben und zur sessilen Lebensweise überzugehen. Dabei wären die großen Borsten bereits verloren ge- 
gangen und die Cirren länger geworden. Auf eine solche Deutung weist direkt hin, daß F. MüLler 1861 S. 55 bei den älteren Larven das Verschwinden der großen Borsten und das Längerwerden der Cirren beobachtete. Wenn man die Tatsachen so deutet, so wäre eine Zugehörigkeit dieser Larven zu Discinisca atlantica wohl möglich. Deren Vorkommen in jenen Regionen erscheint nach dem, was sonst über ihre Verbreitung bekannt ist, durchaus annehmbar.

Crania lecointei JoubiN.

Joubrn, Résultats du Voyage du S. Y. Belgica en 1897-99. Zoologie: Brachiopodes. Anvers 1902. S. 9-11. Taf. II Fig. 13. 14. 15.

Die Dorsalschale ist flach, mit zahlreichen (etwa 50) Anwachsstreifen, die zum Teil stark vorspringen und der Schale ein blättriges Aussehen geben. Farbe ockergelb bis hellbraun. Im Umriß und in der Wölbung etwas unregelmäßig, was übrigens bei Cranien die Regel ist, da sie sich den Unregelmäßigkeiten der Unterlage anschmiegen.

Länge $6 \mathrm{~mm}$, Breite $7,5 \mathrm{~mm}$.

Fundort $70^{\circ} 23^{\prime}$ S., $82^{\circ} 47^{\prime} \mathrm{W}$., $500 \mathrm{~m}$ und $71^{\circ} 15^{\prime} \mathrm{S} ., 87^{\circ} 39^{\prime} \mathrm{W} ., 430 \mathrm{~m}$.

JouBin betont die ganz besondere Zartheit der Ventralschale. Darauf darf man wohl nicht allzu viel Wert legen, da das bei anderen Cranien, z. B. Crania anomala von derselben Größe auch nicht anders ist und es ja keineswegs feststeht, daß die gefundenen Tiere ausgewachsen sind.

Seine Bedeutung behält der Fund auf alle Fälle wegen der Beziehungen zu den Cranien der südamerikanischen Küste (vgl. dazu den allgemeinen Teil).

\section{Rhynchonella racovitzae JouBiN.}

Joubin, Résultats du Voyage du S. Y. Belgica en 1897-99. Zoologie: Brachiopodes. Anvers 1902. S. 5. Taf. I Fig. 1. 2. 3. 4. (?)

Beide Schalen sind stark und gleichmäßig gewölbt. Der Umriß vom Schnabelende an nach vorn sich stark erweiternd, Seitenränder in gleichmäßiger Rundung in den schön gerundeten Vorderrand übergehend. Stirnrand etwas dorsalwärts gekrümmt, Schnabel an den Seiten leicht gekielt, mit sehr kleinem Loch. Ob die Deltidialplatten vollkommen zusammenstoßen, ist nicht ganz sicher. Beide Schalen mit sehr wenig deutlichen Anwachsstreifen, sehr fein längsgestreift und ziemlich durchscheinend. In der Dorsalschale ein deutliches Medianseptum. Wahrscheinlich wohlentwickelte Zahnstïtzen der Ventralschale.

Vom Armgerüst und Weichkörper ist nichts Genaueres bekannt, leider auch nicht das Schalenmosaik, was für die Charakteristik der Form besonders wichtig wäre.

Länge $12 \mathrm{~mm}$, größte Breite $10,5 \mathrm{~mm}$.

Fundorte: $70^{\circ}$ S., $80^{\circ} 48^{\prime} \mathrm{W} ., 500 \mathrm{~m}$ und einzelne Trümmer: $71^{\circ} 18^{\prime} \mathrm{S} ., 88^{\circ} 02^{\prime} \mathrm{W} ., 450 \mathrm{~m}$, $70^{\circ} 48^{\prime}$ S., $91^{0} 45^{\prime}$ W., $350 \mathrm{~m}$.

JouBIN hat besonders die Unterschiede betont, die die neue Art von Rhynchonella cornea trennen. Sind diese schon zur Abgrenzung genügend, so muß doch noch besonders betont werden, daß nach alledem, was wir bis jetzt über die geographische Verbreitung der Brachiopoden wissen, ein Vorkommen von $R$. cornea in den antarktischen Regionen durchaus unwahrscheinlich ist, 
Rhynchonella gerlachei JouBrN.

Joubin, Résultats du Voyage du S. Y. Belgica. Anvers 1902. Taf. I Fig. 5. 6. 7. 8. 9. Taf. II Fig. 10.

Diese Art ist wenig genau bekannt. Sie gründet sich auf ein einziges ganz erhaltenes junges Exemplar von 4,8 mm größtem Durchmesser und eine Dorsalschale von 6,5 mm Länge.

Der Bau des Schlosses stellt die Form unzweifelhaft zur Gattung Rhynchonella. Die Schale ist auffällig rund; der Schnabel ist ziemlich groß mit breiter Stielöffnung. Dorsalschale viel flacher als Ventralschale. Anwachsstreifen wenig deutlich.

Beide Schalen durchsichtig, so daß ein Teil des Armapparats zu sehen ist. Der Schalenrand verläuft gleichmäßig ohne Krümmung. Dorsalschale mit sehr schwach entwickeltem Medianseptum, am rückwärtigen Rand in der Medianlinie ein kleiner konischer Höcker, der sich ein wenig gegen das Foramen erstreckt.

Schnabel sehr breit, nicht allzu lang, nur so weit gebogen, daß sein oberer Rand in gleicher Höhe mit dem Schalenrand verläuft. Die Deltidialplatten sind wenig entwickelt und berühren sich nicht. Das hängt vielleicht mit dem jugendlichen Alter des Tieres zusammen.

Das einzige unversehrte Exemplar hatte 4,8 mm im größten Durchmesser; außerdem fand sich eine einzelne Dorsalschale von 6,5 mm Länge.

Fundorte: $70^{\circ} 14^{\prime}$ S., $89^{\circ} 14^{\prime} \mathrm{W}$., $500 \mathrm{~m}$; (einzelne Dorsalschale): $70^{\circ}$ S., $80^{\circ} 48^{\prime}$ W., $500 \mathrm{~m}$.

Es ist wohl möglich, daß die Exemplare Vertreter einer besonderen Art sind. Doch ist weiteres Material zur Sicherstellung nötig.

\section{Liothyrina antaretica BLOchmañ.}

(Taf. XLII Fig. 1 a-c, Fig. 2, Fig. 3, Fig. 4 a u. b; Taf. XLIII Fig. 13 a -d, Fig. 19, Fig. 20; Taf. XLIV Fig. 25 (26-34 Spiculaentwicklung, s. II. Teil).

Blochmann, Neue Brachiopoden der „Valdivia"- und „Gauss"-Expedition. Zool. Anzeiger, XXX. Bd. 1906. S. 692.

Buochmann, Zur Systematik und geographischen Verbreitung der Brachiopoden. Zeitschr. f. wissensch. Zoologie. Bd. 90. 1908. S. 614 .

Diese Liothyrina gehört zu der von BlochmanN unterschiedenen Gruppe mit Cirrensockeln, und zwar ist es eine der kleinen Formen mit zarter Schale und mäßig entwickelten Spiculis.

Die Schale ist im Umriß meist breit eiförmig, wobei die größte Breite etwas vor der Mitte liegt. Die Seitenränder gehen gleichmäßig gerundet ohne Andeutung von Ecken in den Stirnrand über. Der Schnabel ist kurz und mäßig aufwärts gekrümmt. Die Deltidialplatten stoßen bei den erwachsenen Tieren zusammen. Der Stiel ist, wie in der Regel, kurz. Der Seitenrand ist leicht ventralwärts konkav, der Stirnrand fast gerade oder leicht dorsalwärts konvex. Beide Schalen sind etwa gleich tief und gleichmäßig gewölbt. Die Anwachsstreifen sind kaum erkennbar bis zart angedeutet, seltener nach dem Rande zu etwas deutlicher. Die Schalen sind dünn, bei jüngeren Tieren fast glasartig durchsichtig, bei älteren weißlich durchscheinend.

Auf dem Quadratmillimeter 120-150 Poren, deren innerer Durchmesser $15 \mu$ beträgt. Auf der Schalenaußenseite sind sie oval und messen $40-50 \mu$ auf $20-30 \mu$.

Bei jüngeren Exemplaren zeigt die Schaleninnenseite typische, wenn auch etwas unregelmäßige Schuppenstruktur, bei alten die endothelartige Zeichnung, wie sie sich meist bei Liothyrinen findet, wenn auch nicht gerade in sehr typischer Ausbildung (vgl. Taf. XLIII Fig. 19, 20). Genaueres über diese Dinge folgt weiter unten. 
Das Armgerüst (Taf. XLIII Fig. $13 \mathrm{a}-\mathrm{d}$ ) erreicht ein Viertel der Länge der Dorsalschale. Es ist dünn und zart. Die in die Crura übergehenden Platten sind stark divergent. Die Crura sind kaum angedeutet, ihre Cruralfortsätze unansehnlich. Die Schenkel sind kurz und gehen mit gerundeten, seltener schärfer ausgesprochenen Ecken in die Querbrücke über, die nicht breiter als die Schenkel und schwach ventralwärts gekrümmt ist.

Bei jungen Schalen ist der Ubergang der Schenkel in die Querbrücke stets gerundet.

In der dorsalen Körperwand spärliche Spicula (Taf. XLIV Fig. 25). Im Mantel fehlen solche ganz. Borsten sind vorhanden, aber klein.

Für die Spicula der Arme vgl. Taf. XLIV Fig. 26-34 und Genaueres auf S. 397 ff.

Stets sind wohlentwickelte Cirrensockel vorhanden, die gegen das Vorderende der Dorsalseite der Seitenarme aufhören. In den Cirren beider Reihen fehlen Spicula.

Länge des größten (ㅇ) Exemplares $15 \mathrm{~mm}$, Breite $12 \mathrm{~mm}$. Die Dicke war wegen Verletzung der Schale nicht festzustellen.

Maße eines anderen großen Exemplares:

Länge 12,5 mm, Breite $10,0 \mathrm{~mm}$, Dicke $6,5 \mathrm{~mm}$.

Fundort: Winterstation des „Gauss", Kaiser Wilhelm II.-Land, 385 m, zahlreiche, aber meist junge Exemplare.

Die meisten Exemplare saßen auf Bryozoenstöckchen.

Bei Liothyrina antarctica findet sich Brutpflege, eine sonst bei Brachiopoden sehr seltene Erscheinung. Die Eier werden zwischen den Windungen des Spiralteils der Arme untergebracht und machen hier ihre Entwicklung bis zur Larve durch.

Bis jetzt ist Brutpflege aus der Gattung Liothyrina überhaupt nicht, im übrigen nur bei Thecidium und Cistella bekannt. Das trächtige Exemplar wurde am 15. Februar 1903 in $400 \mathrm{~m}$ Tiefe erbeutet. Die Embryonen sind schon ziemlich weit fortgeschritten, so daß man wohl annehmen kann, daß die Fortpflanzungszeit schon im Januar beginnt.

$\mathrm{Zu}$ den Bemerkungen über die Verhältnisse des Schalenmosaiks sei noch Folgendes angeführt. Das Schalenmosaik ist insofern interessant, als es von dem bei Liothyrina in der Regel vorkommenden Typus abweicht.

Blochmann (1908, S. 610, Taf. 37 Fig. 15) hat darauf hingewiesen, daß bei Liothyrina, abgesehen vom Rande, in der Regel statt der sonst vorkommenden Schuppenstruktur eine eigentümliche endothelartige Zeichnung vorkommt, und auch schon bemerkt, daß diese bei $L$. antarctica am wenigsten ausgesprochen ist.

Bei jüngeren und mittelgroßen Tieren (Taf. XLIII Fig. 19) findet sich auf der ganzen Schaleninnenfläche eine ausgesprochene, wenn auch etwas unregelmäßige Schuppenstruktur. Bei alten Tieren dagegen (Taf. XLIII Fig. 20) ändert sich das. Stellenweise verschwinden die scharfen Konturen der Schuppen, so daß etwas größere, unregelmäßig begrenzte Felder entstehen; an anderen Stellen ist auf kürzere Strecken die Schuppenstruktur noch in etwas veränderter Ausbildung erkennbar.

Endlich sei noch auf Taf. XLII Fig. 4 a u. b hingewiesen. Zwischen den zahlreichen Exemplaren, über deren Zugehörigkeit zu der in Rede stehenden Art kein Zweifel bestehen kann, fanden sich auch andere Exemplare, wie sie in Taf. XLII Fig. 4 a u. b dargestellt sind. Die Schalen sind im Um- 
riß schlank birnförmig, der Ubergang der Seitenränder in den Vorderrand ist schön gerundet. Seitenränder und Vorderrand liegen fast in einer Ebene. Die Dicke der Schale ist im Verhältnis zur Länge und Breite wesentlich größer als bei den oben beschriebenen Formen, der Schnabel kräftiger entwickelt. Die Deltidialplatten stoßen zusammen. An beiden Schalen treten die Anwachsstreifen sehr kräftig hervor.

In den Porenverhältnissen ergeben sich keine deutlichen Unterschiede gegen die andere Form. Es liegen nur einige etwas angewitterte Schalen vor, so daß über das Schalenmosaik kein Urteil gewonnen werden kann. Am Armgerüst ist leider in allen Fällen das Querband ausgebrochen. Die Verbindung zwischen den Schenkeln und dem Querband ist bei den vorliegenden Exemplaren stets scharfwinkelig.

Es läßt sich auf Grund des spärlichen und ungenügend erhaltenen Materials nicht entscheiden, ob diese in der Gestalt ziemlich abweichenden Formen eine von $L$. antarctica verschiedene Art repräsentieren, oder ob sie nur eine durch irgend welche Besonderheiten bedingte zufällige Aberration vorstellen.

\section{Liothyrina uva BRODERIP.}

Die ältere Literatur bei Davidson, A Monograph of Recent Brachiopoda. The Transactions of the Linnean Society of London. II. Series-Vol. IV. Zoology London 1886-88, S. 10.

L. moseleyi Dav.: Fischer u. Oenlert, Mission scientifique du Cap Horn 1882-1883. Bull, soc. d'hist. nat. Autun V. 1892. S. 264.

L. wa Brod.: Oehlert D.-P. Bull. du Museum d'hist. nat. Paris 1906 N. 7. S. 555. und Expedition antaretique française, Vers et Brachiopodes. Paris 1908.

L. uva Brod.: Blochmann, Zeitschr. f. wiss. Zoologie, Bd. 90, 1908, S. 615.

L. uva DaLL, W. H. Bull. Mus. Comp. Zool. Harvard Coll. Cambridge Mass., vol. XLIII 1908 S. 443.

Durch die französische Expedition unter Charcot ist diese bisher mit voller Sicherheit nur aus der magellanischen Region sowie von der Westküste und dem südlichen Teil der Ostküste Südamerikas (bis Buenos Aires) bekannte Art auch aus dem eigentlichen antarktischen Gebiete nachgewiesen worden. Merkwürdigerweise findet sich in keiner der beiden Publikationen OeHLerts die genauere Angabe des Fundortes. Das Forschungsgebiet der Expedition lag an der Küste der Westantarktis, südwestlich der Süd-Shetlands-Inseln. Die schwedische Südpolar-Expedition hat die Art auch für Südgeorgien festgestellt, die sonst noch angegebenen Fundorte sind nach BLochmanN (1908) vorläufig noch als zweifelhaft anzusehen.

Die beste Beschreibung dieser Art findet sich bei Fischer und OeHLert (1892); allerdings hielten sie ihre Exemplare fälschlicherweise für L. moseleyi DAv.

Die Maße des größten Exemplares (OEHLERT) betrugen: $40: 30: 25 \mathrm{~mm}$, im Durchschnitt $21: 19: 11 \mathrm{~mm}$.

\section{Magellania joubini BlochmanN.}

(Taf. XLII Fig. 5 a—c; Fig. 6 a, b; Taf. XLIII Fig. 17, Fig. 18; Taf. XLIV Fig. 23, Fig. 24.)

M. joubini: BlochmanN, Zool. Anz. XXX. Bd, 1906, S. 697.

M. joubini: Blochmann, Zeitschr. f. wiss. Zoologie, Bd. 90. 1908, S. 609.

M. sulcata: Sмгтн, E. A. Natural History of the Nat. Antaretic Expedition (Discovery) 1901-1904, vol. II. Zoology, Lond on 1907.

Die Schale ist im Umriß oval. Der gerundete Vorderrand geht ohne Ecken in die Seitenränder über. Schalenrand fast vollkommen in einer Ebene liegend. Die Ventralschale ist tiefer als die dorsale, 
gleichmäßig gewölbt. Schnabel mit gerundeten Seiten, bis zur Kommissurenebene aufwärts gebogen mit großem Loch, das bei den beobachteten jungen Schalen nicht ganz vollständig durch die Deltidialplatten abgeschlossen wird. Dorsalschale von rechts nach links ziemlich gleichmäßig gewölbt, von vorn nach hinten eine Strecke weit ziemlich eben (Taf. XLII Fig. 5 a-c).

Besonders charakteristisch für die äußere Erscheinung sind die regelmäßig ausgebildeten, stark hervortretenden Anwachsstreifen und die für eine Magellania auffallend großen, ovalen äußeren Porenöffnungen (bei nicht mehr ganz jugendlichen Exemplaren 90 auf $60 \mu$ ), von denen auf den Quadratmillimeter 116-132 kommen.

Die Schalen sind milchweiß durchscheinend bis gelblich (bei ganz jungen Tieren fast glasartig durchsichtig). Dorsalschale mit unansehnlichem Schloßfortsatz. Die Schloßplatte geht in das etwa bis zur Schalenmitte reichende schwache Medianseptum über. Die Crura sind kurz, mit ansehnlichen, ziemlich breiten Cruralfortsätzen. Auch bei den größten, von dem „Gauss" gesammelten Exemplaren ist das Armgerüst noch nicht ganz vollständig entwickelt. Die absteigenden Schenkel sind breit und zeigen auch bei dem größten Exemplar (Taf. XLIV Fig. 23, 24) noch die dem Terebratellenstadium entsprechenden Fortsätze zu dem Medianseptum, der rechtsseitige steht noch in fester Verbindung mit dem Septum. Die aufsteigenden Schenkel und ihre Querverbindung zeigen nichts Besonderes. Maße des größten (aber noch nicht erwachsenen) Exemplares des „Gauss" (Taf. XLII Fig. $5 \mathrm{a}-\mathrm{c}$ ): Länge $15 \mathrm{~mm}$, Breite $12,5 \mathrm{~mm}$, Dicke $7,5 \mathrm{~mm}$.

Nach den Exemplaren der „Discovery“ gibt SмiтH folgende Dimensionen: Länge $28 \mathrm{~mm}$, Breite $23 \mathrm{~mm}$, Dicke $17 \mathrm{~mm}$.

Fundort: Winterstation des ,Gauss“ in $385 \mathrm{~m}$. Es wurden zahlreiche, aber fast ausschließlich junge oder ganz junge Exemplare erbeutet.

Blochmann hatte (1906, S. 697) angenommen, daß die von Joubin (Brachiopoden der „Belgica" Anvers 1902, S. 11 A und B Taf. II Fig. 16 u. 17) aus dem antarktischen Gebiet beschriebenen Fragmente zu jungen Exemplaren zu dieser Art gehörten. Nach nochmaliger genauer Vergleichung der in Betracht kommenden Punkte erscheint die Zusammengehörigkeit vielleicht doch nicht so ganz sicher. Vielleicht würde eine genaue Untersuchung des „Belgica“-Materials sicherere Feststellungen erlauben. Vorläufig kann also nur mit Reserve an eine Zusammengehörig. keit gedacht werden.

Mit viel größerer Sicherheit läßt sich die von E. A. Sмітн nach dem Material der „Discovery“ beschriebene M. sulcata Smith hier anreihen. Auch darauf hat bereits Blochmann (1908 S. 609) aufmerksam gemacht. Sмrтн selbst hebt als besonders auffallende Merkmale die große Dünne der Schale, die sehr kräftig hervortretenden Anwachsstreifen und die auffallend groben Poren hervor, wobei besonders betont wird, daß unter den lebenden Magellanien keine mit ebenso kräftigen Anwachsstreifen bekannt ist, als $M$. joubini. Für die Größe der Poren hatte Blochmann (1908) dasselbe bemerkt.

Wenn man die Abbildungen von SмIтн mit den hier gegebenen des größten „Gauss"-Exemplares vergleicht, so kann man sagen, daß der Umriß in der Dorsalansicht (bei Sмгтн Fig.3, unsere Fig. 5 a Taf. XLII) geradezu identisch ist. In der Seitenansicht (Taf. XLII Fig. 5 b und bei Sмiтн Fig. 4) ergibt sich ein kleiner Unterschied insofern, als bei dem von Sмiтн abgebildeten Exemplar die Dorsalschale recht stark gewölbt erscheint, während sie bei den „Gauss“-Exemplaren 
von hinten nach vorn eine große Strecke weit fast eben ist, um dann kurz zum Rande abzufallen. Das kommt jedenfalls daher, daß das von Sигтн abgebildete Exemplar ausgewachsen oder fast ausgewachsen ist (Länge $28 \mathrm{~mm}$, Breite $23 \mathrm{~mm}$, Dicke $17 \mathrm{~mm}$ ) d. h. also ungefähr doppelt so groß ist als unser in Taf. XLII Fig. 5 a $-c$ abgebildetes Tier, welches unbedingt einen noch nicht erwachsenen Zustand repräsentiert, wie weiter oben ausgeführt wurde. Sieht man genauer zu, so ist der hintere Teil der Dorsalschale in Fig. 4 bei Sмıтн auch weniger gewölbt als der vordere, der bei dem Gauss-Exemplar noch im Entstehen ist und erst bei den erwachsenen Tieren seine volle Ausbildung erlangt. Die Exemplare der „Discovery" stammen von Coulman Eiland (ungefähr $73^{\circ} 30^{\prime}$ S., $170^{\circ}$ O.) aus etwa $180 \mathrm{~m}$ und von dem Winterquartier der „Discovery“ in $78^{\circ} \mathrm{S} ., 164^{\circ} \mathrm{O}$ aus etwa $320 \mathrm{~m}$.

\section{Magellania frágilis SMITH.}

Surtн, E. A. Brachiopoda in Nat. Hist. of the Nat. Antaretic Expedition (Discovery) 1901-1904. Vol. II. Zoology. London 1907. Fig. 1 und 2.

Die Beschreibung dieser Art ist nicht sehr vollständig. SмIтн betont einerseits eine gewisse Ähnlichkeit mit $M$. venosa, andererseits mit $M$. kerguelensis, die beide ziemlich variieren. Die Schale ist wesentlich dünner als bei diesen beiden Formen und die Poren sind gröber als bei der ersteren. Genauere Angaben über Zahl und Durchmesser der Poren und über das Schalenmosaik dürften vielleicht gute Merkmale liefern.

Ich kann hier bemerken, daß sich unter dem Material der schwedischen Südpolar-Expedition ein Exemplar befindet, das nach dem allgemeinen Habitus vielleicht auf $M$. fragilis bezogen werden könnte. Da aber SмiтH ausdrücklich angibt, daß bei dieser die Poren gröber seien als bei $M$. venosa, so muß man doch wohl Bedenken tragen, beide Formen zu vereinigen. Denn bei den Exemplaren der schwedischen Expedition messen die ovalen äußeren Offnungen der Poren $20-25 \mu$ auf $45-50 \mu$, bei $M$. venosa dagegen $30-40 \mu$ auf $50-60 \mu$. Sмттн gibt für seine Exemplare lichtbraune Farbe an. Die Maße des größten Exemplares betragen: Länge 43,5 mm, Breite $39 \mathrm{~mm}$, Dicke $24 \mathrm{~mm}$. Fundort: Agassiz Eiland vor der Eisbarrière, $550 \mathrm{~m}$.

\section{Magellania kerguelensis Davidson.}

(Taf. XLII Fig. 7 a—e; Taf. XLIII Fig. 16.)

Waldheimia kerguelensis: Davidson, Challenger Report 5. Zoology. Vol. I. S. 40.

Waldheimia kerguelensis: Davidson, On Recent Brachiopoda, Transactions of the Linnean Society of London. II. Series. Vol. IV. Zoology. London 1886-88. S. 53. Taf. I Fig. 12, 13, 14, 15.

Das in unserer Fig. 7 a $-c$ Taf. XLII dargestellte Exemplar wurde von der Kerguelenstation des "Gauss" in der Observation-Bay in höchstens $10 \mathrm{~m}$ Tiefe gefischt. Es ist aus Mangel an genügendem Material nicht gelungen, das Exemplar mit Sicherheit als $M$. kerguelensis zu identifizieren. Immerhin scheint es am ersten' zu dieser von der Challenger-Expedition an verschiedenen Stellen des Kerguelengebiets in geringerer Tiefe erbeuteten Art zu gehören.

Die Dimensionen sind: Länge $16 \mathrm{~mm}$, Breite $12 \mathrm{~mm}$, Dicke $7 \mathrm{~mm}$.

Die allgemeine Form ergibt sich am besten aus den Abbildungen. Die Anwachsstreifen sind recht deutlich, die Farbe ist ein schmutziges Gelbbraun. Die Schnabelränder sind mäßig scharf ausgeprägt. Die Deltidialplatten stoßen nicht zusammen, das Armgerüst zeigt an den absteigen- 
den Schenkeln noch deutlich die Reste der Verbindungen zum Septum. Es handelt sich eben um eine junge Schale. Es ist eine deutliche Schloßplatte und ein etwa bis zur Mitte der Dorsalschale reichendes Medianseptum vorhanden.

Auf dem Quadratmillimeter stehen 140-160 Poren, deren innerer Durchmesser $15 \mu$, deren äußeres ovales Ende $45-50 \mu$ auf $60-80 \mu$ mißt. Auffallend sind regionenweise auftretende Verschiedenheiten in der Größe und Gestalt der äußeren Porenöffnungen. Man könnte auch an ein etwas abnormes Exemplar von $M$. kerguelensis vielleicht auch von Terebratella enzenspergeri denken. Eine sichere Entscheidung dürfte erst durch genügendes Vergleichsmaterial möglich werden.

\section{Macandrevia vanhöffeni BLOCHMANN.}

(Taf. XLII Fig. 8 a, b; Fig. 9 a-d; Taf. XLIII Fig. 14, Fig. 15, Fig. 21.)

Blochmann, Zool. Anzeiger, XXX. Bd., 1906, S. 696.

Für diese Form hat sich nur spärliches Material gefunden, so daß ich die von Blochmann in der zitierten vorläufigen Mitteilung gegebene Beschreibung im Folgenden wiederhole.

„Schale im Umriß breit eiförmig. Größte Breite etwa in der Mitte, nur wenig kleiner als die Länge. Der Seitenrand von der Mitte nach vorn zu weniger gebogen, durch eine gerundete Ecke in den flachgebogenen Vorderrand übergehend. Seiten- und Vorderrand in der Frontalebene verlaufend. Beide Schalen etwa gleich tief und gleich stark gewölbt, dünner als bei gleichgroßen Exemplaren von $M$. cranium und nicht wie bei dieser mit deutlichen Muskeleindrücken. Schnabel mit gerundeten Seiten, schief nach hinten abgestutzt. Loch groß, an den toten Schalen ohne Deltidialplatten. “

„In der Ventralschale kräftige Zahnstützen. Das Armgerüst sehr ähnlich dem von $M$. cranium, jedoch das Querband in die aufsteigenden Schenkel durch gerundeten Bogen übergehend, statt wie bei $M$. cranium durch scharfe Ecken. Auch die an den Umbiegungsstellen gegen den Schalenrand zu vorstehenden Zacken weniger ausgebildet als bei $M$. cranium."

„Das Mosaik der Schaleninnenfläche zeigt etwas andere Verhältnisse als bei M. cranium."

„Auf dem Quadratmillimeter 120-132 Poren von 25-30 $\mu$ Durchmesser (bei M. cranium $188-272$ von $10-15 \mu$ Durchmesser). $"$

„Maße des größten Exemplars: Länge $22 \mathrm{~mm}$, Breite $19 \mathrm{~mm}$, Dicke $11 \mathrm{~mm}$.“

„Farbe der toten Schalen schmutziggrau. Eine ausgewachsene und mehrere junge, leere Schalen, fast alle von Schnecken angebohrt, aus $385 \mathrm{~m}$ Tiefe an der Winterstation des „Gauss", Kaiser Wilhelm II.-Land".

Uber verwandtschaftliche Beziehungen dieser Macandrevia wäre Folgendes zu sagen:

Von Macandrevien ist allein $M$. cranium gut bekannt und wurde, was die Porenzahlen anlangt, nochmals speziell zum Vergleiche der vorliegenden Formen untersucht. Dabei ergaben sich die angeführten Unterschiede. Auch in der allgemeinen Form bestehen deutliche Verschiedenheiten.

Erwachsene Exemplare von $M$. cranium sind im Verhältnisse zur Länge schmäler und dicker. Das Armgerüst im erwachsenen Zustande konnte nicht untersucht werden, dagegen das von jüngeren Exemplaren. Für solche ergeben sich im Aufbau des Armgerüstes einige, wenn auch, wie ja zu erwarten, nicht sehr bedeutende Verschiedenheiten. Es sind bei $M$. vanhöffeni die Zähne an der Übergangsstelle des absteigenden und aufsteigenden Teiles des Armgerüstes besonders stark entwickelt. 
So ist es jedenfalls nicht zweifelhaft, daß die antarktische Form von der nordischen verschieden ist. Weiterhin käme die von DaLl (1895, Proceed. U. St. National-Museum vol. XVII S. 721 Abb. s. Taf. XXXII Fig. 1.4.7) beschriebene $M$. americana DaIL von der patagonischen Küste und aus dem Golf von Panama in Betracht.

Im Gesamtumriß besteht ziemlich große Ähnlichkeit. Dagegen ist $M$. americana dünner. Vom Armgerüst gibt Dall keine Abbildung, ebensowenig ist etwas über die Porenzahl bekannt. So ist es nicht möglich, beide Formen für identisch zu erklären. Auch die beiden anderen von DALL beschriebenen Macandreviaarten können nicht in Betracht kommen. Da außerdem die bis jetzt beschriebenen antarktischen Brachiopodenarten mit Ausnahme von Liothyrina uva von anderen Regionen nicht bekannt geworden sind, so sind die beiden Formen so lange für verschieden zu halten, bis ihre Identität durch gewichtige Gründe sichergestellt wird.

Terebratella enzenspergeri Blochmann.

(Taf. XLII Fig. 10 a, b, Fig. 11 a-c, d, Fig. 12.)

Blochmann, Zool. Anzeiger, XXX. Bd. 1906, S. 697-98.

T. dorsata Gmel.: Davidson, Challenger Report 1880, S. 44-45, Taf. IV, Fig. 4. und Davidson, Rec. Brachiopoda, 1887, S. 77.

Im Umriß rundlich. Schnabel kurz, breit, mäßig dorsalwärts gebogen, mit wohl ausgeprägter, doch gerundeter Kante an den Seiten. Loch groß. Deltidialplatten bei (den bis jetzt allein beobachteten) jüngeren Tieren nicht zusammenstoßend. Ventralschale etwas tiefer als die dorsale, beide Schalenklappen gleichmäßig gewölbt (kleinste Exemplare), oder die Dorsalschale (Taf. XLII Fig. 10) mit wohl ausgebildetem Sinus, die Ventralschale mit entsprechender Falte. Anwachsstreifen deutlich. Wenig ausgeprägte und vielfach unterbrochene Längsrillen (Taf. XLII Fig. 10), die besonders auf der Dorsalschale vorkommen und als Spuren einer Rippenbildung zu betrachten sind.

Auf dem Quadratmillimeter 84-112 Poren; innerer Porendurchmesser 20-30 $\mu$, Durchmesser der äußeren ovalen Porenöffnung $150 \mu$ auf $60 \mu$.

Die Dorsalschale mit wohl entwickeltem Schloßfortsatz. Schloßplatte geht in ein sehr niedriges und schwaches, etwa bis zur Schalenmitte reichendes Medianseptum über. Crura sehr kurz mit ansehnlichen Cruralfortsätzen.

Das Armgerüst, nur bei einem jungen Exemplar (des „Gauss" ${ }^{6}$ ) erhalten, bietet nichts Besonderes. Es wurde von Prof. Blochmann beobachtet, zerbrach aber bei weiterem Ausspülen des Schlammes, der die tote Schale erfüllte. Die Verbindungen der absteigenden Schenkel mit dem Septum waren besonders zart.

Farbe der (toten) Schalen ein schmutziges Grau bis Gelblichgrau.

Maße:

\begin{tabular}{|c|c|c|c|}
\hline & Exempl. d. „,Gauss" & Challenger-Exp. I. & Challenger-Exp. II. \\
\hline Länge & $15 \mathrm{~mm}$ & $25,8 \mathrm{~mm}$ & $16,0 \mathrm{~mm}$ \\
\hline Breite & $15 \mathrm{~mm}$ & $25,0 \mathrm{~mm}$ & $16,0 \mathrm{~mm}$ \\
\hline Dicke..... & $6.5 \mathrm{~mm}$ & $13.0 \mathrm{~mm}$ & $6.5 \mathrm{~mm}$. \\
\hline
\end{tabular}


Fundort: Kerguelen-Station des „Gauss" an der Observatory-Bay, 1 totes Exemplar. Challenger-Station 149 vor dem Royal Sound etwa 50 m, drei Exemplare, die von Blochmann nachuntersucht wurden (Taf. XLII Fig. 11, 12).

Davidson hatte die von der Challenger-Expedition heimgebrachten Exemplare für Terebratella dorsata GMeL. erklärt, hatte dabei aber schon hervorgehoben, daß sie von der typischen Form der T. dorsata verschieden seien. Er wollte sie mehr der von KiNG (Zool. Journ. Vol. V. 1835, S. 337) unterschiedenen $T$. Sowerbyi vergleichen, die aber nichts weiter ist als eine wenig berippte Varietät von $T$. dorsata. Immerhin sind bei dieser die Spuren der Berippung viel deutlicher als bei den Kerguelenexemplaren und besonders am Rande ganz regelmäßig.

Ganz klare Unterschiede ergeben sich durch die von Blochmann ermittelten Porenverhältnisse. Bei T. dorsata kommen auf den Quadratmillimeter 180-212 Poren, ihr innerer Durchmesser beträgt $10-12 \mu$, die äußere Öffnung mißt $60 \mu$ auf $25 \mu$. Die Größe der Verschiedenheit fällt bei bildlicher Darstellung besonders ins Auge (vgl. Zeitschr. f. wiss. Zool., Bd. 90, 1908, S. 609).

Bei T. dorsata ist das Septum der Dorsalschale viel derber, im vorderen Teil höher, die Crura länger und schlanker als bei $T$. enzenspergeri.

Die Schnabelkante ist bei $T$. dorsata stets recht scharf, bei $T$. enzenspergeri mehr gerundet. So kommt bei der ersteren Form eine viel deutlicher ausgesprochene flache Area zustande.

Davidson (Chall. Rep. S. 45) gibt eine ausführliche Beschreibung des Armgerüstes und sagt dann weiter unten, daß die drei vom „Challenger" erbeuteten Exemplare tot und ihre Schalen aus" einander gefallen waren. Es ist schwer verständlich, wie sich dabei das Armgerüst erhalten haben soll!

Nach dem hier Ausgeführten kann also das Kerguelenmeer nicht mehr als Fundort für Terebratella dorsata GMEL. gelten. Dadurch wird das Wohngebiet der letzteren Art zu einem einheitlichen und wohlumgrenzten.

Bei einem zusammenfassenden Uberblick über die bisher beobachteten antarktischen Brachiopoden wollen wir uns zunächst einmal auf die von der Küste des antarktischen Kontinents und den diesem direkt sich anschließenden Küsteninseln bekannten Arten beschränken, um später erst die Beziehungen zu entfernteren Regionen zu erörtern.

Es sind aus diesem Gebiet bis jetzt folgende Arten bekannt:

Discinisca sp., wahrscheinlich atlantica

Crania lecointei

Rhynchonella racovitzae

Rhynchonella gerlachei

Liothyrina antarctica

Liothyrina uva

Magellania joubini

Magellania fragilis

Macandrevia vanhoeffeni. 
Das sind im ganzen neun sicher konstatierte Arten. Berücksichtigt man weiter, daß für das Material der verschiedenen Expeditionen noch Angaben über das Vorhandensein von bis jetzt nicht sicher bestimmbaren Fragmenten vorliegen, die jedenfalls nicht zu den oben angeführten Arten gehören, so ist bestimmt zu erwarten, daß sich durch weitere Sammlungen die Zahl der im angegebenen Sinne rein antarktischen Brachiopodenarten noch vermehren wird, auch wenn man Liothyrina $u v a$, die vielleicht ein Eindringling aus der magellanischen Region ist, streicht.

Es handelt sich hier allerdings um eine sehr ausgedehnte Küste, man muß aber auch bedenken, daß von einer einigermaßen genauen Erforschung bis jetzt keine Rede sein kann. Was bekannt ist, bedeutet eigentlich nicht mehr als spärliche Stichproben.

Uber biologische Verhältnisse erfahren wir nur durch das Gauss-Material einiges. Von der Brutpflege der Liothyrina antarctica war schon oben die Rede. Man könnte vielleicht annehmen, daß hierin eine Anpassung an die Lebensbedingungen der polaren Meere zu sehen wäre, wie man ja vielfach beobachtet hat, daß arktische oder die Tiefsee bewohnende Formen Brutpflege treiben, auch wenn ihre nächsten Verwandten, die in anderen Regionen leben, dies nicht tun. Doch müssen noch weitere Beobachtungen in dieser Hinsicht abgewartet werden, da einerseits nur sehr wenige Brachiopodenarten daraufhin bekannt sind, und gerade die hinsichtlich Brutpflege längst bekannten Gattungen, Thrcidium und Cistella, den wärmeren Meeren angehören.

Da von zahlreichen Liothyrina-Arten Dutzende von Exemplaren von den verschiedensten Stellen und zu den verschiedensten Jahreszeiten gesammelt, untersucht wurden, so darf man doch wohl annehmen, daß sich bei ihnen Blutpflege nicht findet. Für Liothyrina affinis gibt KovaLEwsKx ${ }^{1}$ ) direkt an, daß keine Brutpflege stattfindet.

Bei der Beschreibung der einzelnen Arten wurde mehrfach betont, daß das „Gauss" ausschließlich aus jungen sowie ganz jungen Tieren bestehe. Blochmann (1906, S. 702) hat das Auffallende dieser Erscheinung hervorgehoben, da sonst in der Regel die jüngeren Exemplare in dem gesammelten Material seltener sind. VANHöFfen hat dann in einem Briefe an Blochmann auf Folgendes hingewiesen, was sehr wohl imstande ist, eine Erklärung für die auffallende Tatsache zu geben: wo das Material reichlich ist und große Exemplare sofort in die Augen fallen, wird der Sammler den kleinen und kleinsten Exemplaren wenig oder keine Beachtung schenken. Von dem „Gauss" wurde ein Fundplatz lange Zeit hindurch ausgebeutet, wobei auch dieses sonst vernachlässigte Material mit Sorgfalt gesammelt und konserviert wurde. Immerhin würden diese Verhältnisse nur erklären, daß kleine Exemplare in größerer Zahl in dem Material sich finden, nicht.aber, daß die großen so außerordentlich spärlich sind, ja daß für einzelne Arten vielleicht überhaupt keine ganz erwachsenen Tiere vorliegen.

Eine Erklärung dafür mag in dem gefunden werden, was VANHÖFFEN über die Verhältnisse des Grundes schreibt. Nicht nur bei Brachiopoden, sondern auch bei anderen Tiergruppen, z. B. bei Seeigeln und Mollusken sind die Jugendformen auffallend zahlreich. VANHöFfEN möchte das auf den sandigen Grund, die große Entfernung von der Küste und das von der Eisdecke herabrieselnde Moränenmaterial zurückführen. Es wäre dann zu vermuten, daß Kolonien

1) 1874. Observations on the Development of Brachiopoda. Proc. Imp. Soc. Amateur Naturalists etc. held at the University of Moscow, 11 th. year Vol. XIV. 
von Brachiopoden in größerer Nähe der Küsten, auf festem Grunde und gegen Uberschüttung von oben geschützt, größere Tiere liefern, wie das auch für Echinodermen und Mollusken gilt.

Auffallend sind auch die zahlreichen durch Schnecken angebohrten Schalen. Wie BLochmanN schon bemerkte, kommen solche bei Brachiopoden nicht gerade häufig vor. Es müssen, nach den Löchern zu schließen, recht kleine (ev. junge) Schnecken sein, die das Anbohren besorgen.

$\mathrm{Daß}$ stellenweise an der antarktischen Küste die Existenzbedingungen für Brachiopoden sehr günstige sein müssen, beweisen sowohl die großen Magellanien, von denen SмiтH berichtet, als auch die von der französischen Expedition heimgebrachten riesenhaften Exemplare von Liothyrina uva.

Es mag hier noch Folgendes bemerkt werden. Fischer und OEHLERT betonen in ihrer Abhandlung über die Brachiopoden vom Kap Horn, S. 133, die großen Dimensionen der dort vorkommenden Brachiopoden: Magellania venosa, Terebratella dorsata, Terebratulina crossei im Anschluß an eine Bemerkung von DARwiv über die bedeutende Größe der dort vorkommenden Molluskenarten. Man kann nur für Magellania venosa eine besondere Größe zugeben. Terebratella dorsata ist nicht größer als z. B. Terebratella coreanica, und die echte Terebratulina crossei von Japan ist größer als die mit ihr für identisch erklärte Form vom Kap Horn.

Neue Gattungen hat das „Gauss"-Material nicht ergeben, dagegen sind alle bis jetzt längs der Küsten des antarktischen Kontinents gefundenen Arten neu und aus anderen Gegenden nicht bekannt, mit Ausnahme von Liothyrina uva. Diese stellt, worauf noch zurückzukommen sein wird, direkt die Verbindung her zwischen der antarktischen und der magellanischen Brachiopodenfauna.

Verschiedenes weist darauf hin, daß einzelnen der antarktischen Formen eine zirkumpolare Verbreitung zukommen wird. Das würde den Verhältnissen der arktischen Arten entsprechen, von denen mehrere, so besonders Rhynchonella psittacea zirkumpolar verbreitet ist.

Nun ist weiterhin zu prüfen, ob irgend welche engeren Beziehungen der Brachiopoden von den Küsten des antarktischen Kontinents zu denen der angrenzenden Gebiete oder entfernterer Regionen bestehen. Da erhebt sich zunächst die Frage nach der so oft erörterten Bipolarität.

Ich muß mich bei dieser und den folgenden Erörterungen auf die Brachiopoden beschränken und kann nur anführen, was aus ihrer Verbreitung sich für die betreffenden Fragen ergibt.

Für die bis jetzt bekannten Arten der Brachiopoden läßt sich ein bipolares Vorkommen nicht nachweisen. Das stimmt auch mit den von Blochmann (1908) betonten, durch die Organisation und Lebensweise der Larven bedingten Verbreitungsmöglichkeiten der Brachiopoden, speziell der Testicardinen überein. Nur für Tiefseeformen könnte man ein gleichzeitiges Vorkommen derselben Arten in den beiden polaren Gebieten erwarten.

Was die Beziehungen der antarktischen Brachiopoden zu denen anderer nahegelegener Gebiete anlangt, so zeigt schon ein Blick auf die Karte der südlichen Hemisphäre, nach welcher Richtung in erster Linie ein Anschluß zu erwarten ist.

Die engsten räumlichen Beziehungen bestehen zwischen Grahamland und. Feuerland, also der magellanischen Region.

Durch Liothyrina uva werden, wie schon bemerkt, beide Faunen direkt verknüpft. Nach der großen Verbreitung, welche diese Art an den Küsten Südamerikas, den Falklandsinseln und Südgeorgien zeigt, vielleicht auch aus dem Umstande, daß sie bis jetzt nur an einer Stelle des ant- 
arktischen Kontinents gefunden wurde, könnte man annehmen, daß diese Form im Begriffe steht, aus der magellanischen Region in das antarktische Gebiet einzudringen.

Auch durch andere Arten werden, wenngleich weniger direkt als durch Liothyrina wva, Beziehungen zwischen den beiden in Rede stehenden Regionen vermittelt.

So ist die Gattung Magellania, die bis jetzt schon zwei sichere Vertreter in der Antarktis aufweist, zu nennen, und durch ihre Art $M$. venosa stellt sie geradezu eine Charakterform für die Südküste Amerikas vor.

Sмттн betont die besondere Ähnlichkeit seiner $M$. fragilis mit $M$. venosa. Allerdings darf man dabei nicht vergessen, da $B$ eine nahestehende Form auch aus dem Kerguelengebiet bekannt ist, und daß auch sonst auf der südlichen Hemisphäre Magellanien ziemlich verbreitet sind.

Weiter sind es noch andere Arten, die Beziehungen zwischen Antarktis und südamerikanischer Region vermitteln. Von den Brachiopoden des „Gauss" käme da zunächst Macandrevia vanhoeffeni in Betracht. Durch DALL ist von der Westküste Patagoniens eine andere Macandrevia (M. americana) bekannt geworden, die sich weiter nach Norden bis in den Golf von Panama ausdehnen soll, wo selbst noch zwei andere Arten derselben Gattung ( $M$. craniella Dall und $M$. diamantina DaLL) gefunden wurden.

Im übrigen ist die Gattung durch die bekannte und weitverbreitete $M$. cranium von den mittelatlantischen Gewässern bis in die arktische Region ausgebreitet, um im Norden ganz gemein zu werden. Aus anderen Gebieten sind bis jetzt keine Macandrevien bekannt geworden.

So wird auf diesem Wege längs der amerikanischen Küste ein zusammenhängendes Verbreitungsgebiet für die Gattung hergestellt. Die Arten aber sind von Strecke zu Strecke andere, möglicherweise lokal entstandene. Ähnlich verhält es sich mit der Gattung Crania, von welcher aus dem antarktischen Gebiet im engeren Sinne nur Crania lecointei Joub. vorliegt und $C r$. patagonica Dall aus dem Madre de Dios-Archipel von der Westküste Patagoniens bekannt ist.

Ebenda findet sich Crania pourtalesi ( $51^{0} 52^{\prime}$ S., $73^{0} 41^{\prime}$ W., DaLL 1895, S. 332). Dieselbe Art ist auch bei Florida gefunden ${ }^{1}$ ).

Weiter nördlich beginnt dann das Gebiet der Crania anomala. So wird auch hier wieder längs der amerikanischen Küste ein Weg möglich zur Verknüpfung der arktischen und antarktischen Formen. Dabei sei allerdings für Crania bemerkt, daß diese Gattung wohl auch sonst noch (Australien, Westafrika) vorkommt, obwohl über diese Funde die Nachrichten sehr dürftig sind.

Aus der Kerguelenregion sind zahlreiche Brachiopoden bekannt geworden. Irgend eine nähere Beziehung zu den antarktischen Formen in unserem Sinne läßt sich nicht erkennen. Magellania kerguelensis ist abweichend von den antarktischen Formen. Das Vorkommen von Liothyrina wva bei Heard Eiland kann, wie BlochmaNN (1908) ausführt, noch nicht für ganz sicher gelten. Andernfalls würde dadurch der schon mehrfach betonte Zusammenhang zwischen der magellanischen und der Kerguelenfauna eine weitere Stütze erhalten. In dieser Hinsicht wurde bisher auch das Vorkommen von Terebratella dorsata von der Südspitze Amerikas und von den Kerguelen angeführt. Nachdem sich aber, wie im speziellen Teil gezeigt wurde, ergeben hatte,

1) Dabei soll allerdings in Betracht gezogen werden, daß die Arten von Crania nicht so ganz sicher zu identifizieren sind. 
daß beide Formen leicht zu unterscheiden und als verschiedene Arten zu betrachten sind, geben die bis jetzt bekannten Brachiopoden keinen Anhaltspunkt mehr für eine engere Beziehung zwischen beiden Faunen.

$\mathrm{Zu}$ der ganz eigentümlichen Brachiopodenfauna der Südspitze von Afrika zeigen die Formen der Antarktis ebensowenig Beziehungen wie zu solchen Australiens und Neuseelands.

\section{Teil: Über die Spicula im Armapparat von Liothyrina antarctica Blochmann.}

(Taf. XLIV Fig. 25-34.)

Schon Deslongchamps (1865) hatte die von Art zu Art erkennbare Verschiedenheit der Kalkspicula bei den Testicardinen betont, und BLochmanN (1895) hat dann auf Grund von zahlreichen speziell auf diesen Punkt gerichteten Beobachtungen gezeigt, daß die Spicula sowohl des Armapparats als auch der Körperwand und des Mantels oft vortreffliche Anhaltspunkte zur Unterscheidung der Art geben, besonders auch in solchen Fällen, wo andere Merkmale zur sicheren Identifizierung versagen.

Um beurteilen zu können, welchen Grad der Sicherheit die Verwendung der Spicula zur Artunterscheidung gibt, war es nötig, durch vergleichende Untersuchungen festzustellen, wie groß die Variation in der Ausbildung und Verbreitung der Spicula bei verschiedenen erwachsenen Individuen ein und derselben Art ist und welche Unterschiede in dieser Hinsicht bei verschieden alten Individuen derselben Art bestehen.

Für die Spicula der Körperwand bei Terebratulina caput serpentis und einiger anderer Arten hat Blochmann (1908) solche Untersuchungen durchgeführt.

Zur Kenntnis dieser Verhältnisse des Armapparats bei Liothyrina antarctica kann ich hier einen Beitrag liefern, wenn auch die Zahl der Individuen, die geprüft werden konnte, eine beschränkte ist. Vor allem aber erlaubten die zahlreichen Jugendstadien des "Gauss"-Materials, für Liothyrina antarctica die im Laufe der Entwicklung des Armapparats aufeinanderfolgenden Veränderungen genau festzustellen.

Es wäre wichtig gewesen, wenn von einer Liothyrina ohne Cirrensockel, etwa von $L$. vitrea, ebenfalls einige frühe Jugendstadien hätten untersucht werden können, weil man wohl vermuten kann, daß auch bei diesen Formen Cirrensockel von vornherein angelegt, später aber wieder aufgelöst werden. Es ließ sich jedoch entsprechendes Material nicht beschaffen. Die angewandte Technik war die von Blochmann angegebene.

Bei den Jugendstadien wurde in der Regel die Ventralschale abgehoben und der mit der Dorsalschale in Verbindung bleibende Tierkörper ohne weitere Färbung aufgehellt.

Bei den untersuchten Exemplaren fanden sich Spicula nur in der dorsalen Körperwand (Taf. XLIV Fig. 25). Sie sind im ganzen spärlich und liegen einzeln, ohne einen geschlossenen Verband zu bilden, im weichen Gewebe. Im ventralen Teile der Körperwand und ebenso in der ganzen Ausdehnung der beiden Mantellappen fehlen Spicula vollständig. Daraus ergibt sich schon, daß unsere Art zu den Formen mit geringer Entwicklung der Spicula gehört, da in nicht seltenen Fällen, z. B. bei $L$. affinis, diese Gebilde so reichlich und dicht zusammenschließend in der Körperwand liegen, daß sie ein vollständig starres Gerüst bilden. Auch im Armapparat ist die Ausbildung der Spicula mäßig. 
Ich schildere zunächst die Verhältnisse beim erwachsenen Tier (Taf. XLIV Fig. 32 u. 33). Die Ausbildung der Spicula wird, wie das bei allen bis jetzt untersuchten Liothyrinen zutrifft, nach und nach unbedeutender, wenn man dem Verlaufe der Cirrenreihe vom Munde bis an das Ende der Spiralarme folgt. Die kräftigste Entfaltung der Spicula findet sich regelmäßig auf der Dorsalfläche der seitlichen Teile des Armapparats (= Seitenarme). So ist es auch hier. Zwei Gebiete dieser Seitenarme bleiben von Spiculis frei, das sog. Zwischenfeld (= die zwischen dem vor- und rückwärts verlaufenden Teile der Armfalte gelegene Fläche) und das Medianfeld (= die dem Spiralteil des Armapparats zugewandte Fläche). Nur ganz ausnahmsweise ist in diesen Gebieten einmal ein kleines Spiculum vorhanden (Taf. XLIV Fig. 32 im Medianfeld).

Die Cirren beider Reihen fanden sich bei allen untersuchten Exemplaren vollkommen frei von Kalkeinlagerungen. So vereinfacht sich die Ausrüstung der Arme mit Spiculis außerordentlich. Es bleiben nur die zwei von BLochmanN mit besonderen Namen belegten Elemente „Cirrensockel“ und „Hauptstücke“" übrig.

Die ersteren gehören zu den Cirren der äußeren Reihe und treten mit ihrer Spitze in die Basis der Cirren ein. Nur selten fehlt einmal der Cirrensockel in dieser oder jener Cirrenbasis (Fig. 32 auf der Dorsalseite). Gegen das Vorderende des Seitenarmes zu, wo die Cirrenreihe nach der Ventralseite umbiegt, verlieren die Cirrensockel an Masse, verändern ihre Gestalt und hören allmählich auf, so daß nur noch die Hauptstücke übrig bleiben. Ihrer Form nach sind die Sockelstücke etwas unregelmäßige, schwach bedornte Pyramiden, die auf der dem Hohlraum des Cirrus zugewandten Seite etwas ausgehöhlt sind. An ihrer Basis entsenden sie eine mehr oder minder große Zahl von Fortsätzen, durch die sie unter sich und mit den Hauptstücken in Verbindung stehen. Entwicklungsgeschichtlich gliedern sich, wie schon hier bemerkt sein mag, die Cirrensockel von den Hauptstücken ab. Das erklärt, daß auch gelegentlich bei erwachsenén Tieren dieser in frühen Entwicklungsstadien allgemein vorhandene Zusammenhang gewah rt bleibt (Fig. 33, dorsal rechts).

Aus diesen entwicklungsgeschichtlichen Verhältnissen erklärt sich weiterhin, daß im allgemeinen zu jedem Cirrensockel auch ein Hauptstück gehört. Doch in dieser Hinsicht ergeben sich häufiger Unregelmäßigkeiten, was aber auch durch die Entwicklung verständlich wird (vgl. später).

Die Hauptstücke sind in der Dorsalregion ziemlich umfangreiche Kalkplatten, die mäßig bedornt und von einigen Löchern durchsetzt sind. An ihrem Rande entsenden sie Fortsätze in großer Zahl, die in der Regel in der Fläche der Platte liegen. Von diesen Fortsätzen tritt meist einer mehr oder weniger deutlich hervor, der sich gegen die Basis der Cirrensockel hin erstreckt (besonders deutlich in Fig. 32). Andere Fortsätze verbinden die Hauptstücke untereinander, und eine größere Zahl derselben richtet sich einwärts gegen das Medianfeld, um hier in einer den Cirrenbasen annähernd parallelen Linie zu enden.

Von der Stelle an, wo die Cirrensockel aufhören, beginnt auch eine stetige Reduktion der Hauptstücke. Der mittlere plattenartige Teil wird weniger umfangreich, die Löcher treten mit peripheren Einbuchtungen in Verbindung, so daß schließlich der plattenartige Charakter gänzlich verloren geht und aus den ehemals mächtigen Hauptstücken zierlich verästelte Spicula ohne zentralen Teil geworden sind (Fig. 32 u. 33 auf der Ventralseite).

Dieser Reduktionsprozeß aller Kalkkörperchen geht, sich noch steigernd, auf dem Spiralteil der Arme weiter, so daß schon vor dem Ende der Cirrenreihe die Spicula gänzlich verschwunden 
sind (Fig. 34). Die Spicula liegen bei der untersuchten Art durchaus zwischen der äußeren Oberfläche der Seitenarme und dem kleinen bzw. großen Armsinus.

Was nun die aufgeworfene Frage anlangt, wie weit diese Verhältnisse bei verschiedenen, erwachsenen Individuen derselben Art variieren, so ist für $L$. antarctica zu sagen, daß sich bei den allerdings nicht zahlreichen erwachsenen Exemplaren, die untersucht werden konnten, keine bedeutenden Verschiedenheiten ergeben haben. Stets war das Median- und Außenfeld und die Cirren beider Reihen frëi von Spiculis, stets hörten die Cirrensockel ungefähr an derselben Stelle auf. Etwas weniger konstant ist, wie schon die beiden Abbildungen Fig. 32 u. 33 zeigen, die Gestaltung der Hauptstücke. Die Spicula sind also wohl zur Charakterisierung der Art verwendbar, wenn man, wie BLochmann verlangt, mehr Wert auf die Gesamtanordnung derselben, als auf die Form des einzelnen Spiculums legt. Es kommen aber auch Formen vor, bei denen die Variabilität der Spicula gerade in den Armen größer zu sein scheint; das fiel mir bei der Prüfung einer Anzahl von Exemplaren von $L$. wva auf.

Ich wende mich zur Beschreibung der Entwicklung der Spicula in den Armen (Fig. 26-31).

Das jüngste untersuchte Exemplar von $2 \mathrm{~mm}$ Länge (Fig. 26) zeigt den Anfang der Spiculabildung im Armapparat. Dabei ergibt sich das interessante Verhalten, daß in jeder Hälfte des hier noch kreisförmigen Armapparats der Hauptsache nach ein großes Spiculum liegt, welches Fortsätze in die Basen der einzelnen Cirren entsendet.

Bei wenig älteren Exemplaren (Länge 3 mm, Fig. 27) ist in der Ausbildung der Spicula schon ein bedeutender Fortschritt zu verzeichnen, insofern als die einheitlichen Kalkstücke des vorigen Stadiums sich in eine Anzahl gesonderter Spicula aufgelöst haben, die zum Teil schon eine größere Anzahl von Fortsätzen aufweisen, ihre Hauptspitze aber in die Cirren hineinstrecken, so daß man in diesen Gebilden die Anfänge der Cirrensockel und die davon noch nicht getrennten Hauptstücke erblicken darf. Ein Zwischenstadium zwischen Fig. 26 u. 27 lag mir nicht vor. In dem Stadium der letzteren Figur ist es zur spärlichen Entwicklung von Spiculis hinter dem Munde gekommen, wobei jedoch Sockelstücke nicht gebildet werden.

Auch von dem Befunde in Fig. 27 zu dem in Fig. 28 (Exemplar von 3,5 mm Länge) ist wieder ein ziemlicher Abstand. Immerhin sind die neuen Verhältnisse ohne Schwierigkeit zu verstehen. Die recht ansehnlich gewordenen Cirrensockel hängen noch mit den Hauptstücken zusammen; weiterhin erheben sich von diesen regelmäßig zwischen den großen (zu den äußeren Cirren gehörigen) Cirrensockeln liegende schlankere Spitzen ab, die Sockel der Cirren der inneren Reihe. Schon in diesem Stadium zeigt sich das Uberwiegen der Dorsalseite des Seitenarmes, denn alle die vollkommen. ausgebildeten Cirrensockel und Hauptstücke gehören dieser Seite an. Die in der Abbildung (Ansicht von der Ventralseite) höher liegenden unregelmäßigen und unansehnlichen Stücke sind als Hauptstücke der Ventralseite der Seitenarme aufzufassen, die nun, wo der Seitenarm sich mehr und mehr von dem dorsalen Mantel loslöst, sich zu entwickeln beginnen (vgl. dazu Fig. 32 u. 33).

Die dann folgenden beiden Entwicklungszustände (Fig. 29 u. 30), die von $4 \mathrm{~mm}$ bzw. $5 \mathrm{~mm}$ großen Exemplaren herrühren, zeigen unter sich keine großen Verschiedenheiten, aber einen bedeutenden Fortschritt gegen das letzte Stadium (Fig. 28). Mit der Loslösung der Seitenarme kommen die Spicula der Ventralseite auch zur Entwicklung, wobei die Cirrensockel, besonders der äußeren 
Reihe, recht stattlich ausfallen und durch ihre lange, schlanke Form auffallen. Die Cirrensockel reichen auf der Ventralseite in diesem Stadium noch sehr weit nach hinten gegen die Mundöffnung, worin sich neben ihrer gestreckteren Form ein wesentlicher Unterschied gegenüber dem fertigen Zustand ausspricht.

Das folgende Entwicklungsstadium (Fig. 31) bildet den Uebergang zu den in Fig. 32 u. 33 dargestellten und eingangs schon besprochenen Verhältnissen des erwachsenen Tieres. An letzteres erinnern die in ihrer Länge reduzierten Cirrensockel, an die früheren Stadien (Fig. 29 u. 30) dagegen erinnert der Umstand, daß die Sockelstücke sich noch weit auf der Ventralseite finden. Vergleicht man nun Fig. 31 mit Fig. 32 u. 33, so ist in allen dreien die Zahl der Cirrensockel fast vollkommen gleich. Man kommt dadurch zu der Vorstellung, daß die in den jüngeren Stadien auf der Ventralseite der Seitenarme liegenden Sockel und Hauptstücke bei der weiteren Entfaltung der Arme auf die Dorsalseite verlegt werden, und daß für weiterhin neu gebildete Abschnitte der Arme Cirrensockel und Hauptstücke nicht mehr angelegt werden. Es sind also nach dieser Ansicht diese Kalkelemente nicht etwa später durch Resorption verschwunden.

Konnte nun weiter oben hervorgehoben werden, daß die Spicula im Armapparat der erwach. senen Individuen nach Bau und Anordnung im ganzen ziemlich weitgehende Übereinstimmung zeigen, so zeigt es sich weiter, daß im Laufe der Entwicklung bedeutende Wandlungen in dem Spicularapparat sich vollziehen, etwa wie das Armgerüst in den verschiedenen Phasen seiner Bildung ebenso ganz verschiedene Zustände aufweist.

Man wird also als Ergebnis dieser entwicklungsgeschichtlichen Untersuchung angeben können, daß bei sehr jungen Individuen, noch ehe der Armapparat eine endgültige Form angenommen hat, auch seine Spiculaverhältnisse noch so weit von denen des erwachsenen Tieres verschieden sind, daß sie zu systematischen $Z$ wecken nicht verwendbar erscheinen. Dagegen wird der endgültige Zustand schon verhältnismäßig früh erreicht. Weiter kann man aus unserem Beispiel ersehen, daß bei der Umbildung der Spicula auch Resorptionen eine Rolle spielen - Veränderungen an den äußeren Cirrensockeln und gänzliches Verschwinden der inneren. Andererseits fehlen in den Cirren selbst j e d e r z e i t die Spicula. Dieser Umstand kann, falls er sich in anderen Fällen bestätigt, unter Umständen bei der Identifizierung von Jugendformen ein Hilfsmittel abgeben.

\section{Tafelerklärung.}

Tafel XLII.

Liothyrina antarctica. BLOCHManN.

Fig. 1. Ein großes Exemplar, 2/1.
a) von der Dorsalseite,
b) von links,
c) von vorn.

Fig. 2u. 3. Zwei Exemplare an Bryozoen festsitzend, 2/1.

Fig. 4. a u. b Liothyrina antarctica? aberrante Form? 2/1.

Magellania joubini BLochmanN.

Fig. 5. a-c Größtes von dem „Gauss" erbeutetes Exemplar von dorsal, von links und von vorn, 2/1.

Fig. 6. a u. b Ein zweites Exemplar, 2,5/1. 
Fig. 7. a-c Ein Exemplar in drei Ansichten, 2/1.

\section{? Magellania kerguelensis DAvIDsox.}

Macandrevia vanhoeffeni BLochMarN.

Fig. 8. a u. b Ein junges Exemplar, 2/1.

Fig. 9. a-d Das größte von dem "Gauss" erbeutete Exemplar, 1,5/1.

$a-c$ Die drei Normalansichten

in a) zwei Bohrlöcher einer Schnecke,

d) schief von unten, so daß durch das große Loch der Ventralschale die Zahnstützen sichtbar werden.

Terebratella enzenspergeri BLochManN.

Fig. 10. a u. b Das einzige von dem „Gauss" erbeutete junge Exemplar, aus der Observatory-Bay der Kerguelen, $2 / 1$.

Fig. 11. a-c Die drei Normalansichten des gröBten vom "Challenger" im Royal Sound der Kerguelen gefischten Exemplares, $1,5 / 1$.

d) Innenansicht der Dorsalschale desselben Exemplares, 2/1.

Fig. 12. Dorsalansicht eines kleinen Challenger-Exemplares, 1,5/1.

Die Exemplare der Fig. 11 und 12 im British Museum.

T a f e 1 XLIII.

Fig. 13. a-d Liothyrina antarctica Blochmann, Armgerïste

a) Exemplar von $13 \mathrm{~mm}$ Länge, ca. 3/1

b) Zwei mittlere Exemplare ca. $4 / 1$

d) $\quad, \quad, \quad$ ca. $5 / 1$

Fig. 14. Macandrevia vanhoeffeni Blochmann, Dorsalschale mit dem Armgerüst von einem jungen Exemplar, 4/1.

Fig. 15. Dasselbe schief von der linken Seite, 6/1.

Fig, 16. ? Magellania kerguelensis Davidson, Armgerüst, 3/1.

Fig. 17. Magellania joubini Blochmann, Exemplar der Fig. 5 Taf. XLII. Schalenmosaik, etwas vor der Mitte der Ventralschale, 175/1.

Fig. 18. Dasselbe von einem jungen Exemplar von etwa 5 mm Länge, 175/1.

Fig. 19. Liothyrina antarctica Blochmann, Schalenmosaik eines jüngeren Exemplares, 175/1.

Fig. 20. L. antarctica Blochmans, Sehalenmosaik eines erwachsenen Exemplares.

Fig. 21. Macandrevia vanhoeffeni Blochmann, Schalenmosaik eines jungen Exemplares, 175/1.

\section{Ta f el XLIV.}

Fig. 22. Larve von Discinisea (wahrscheinlich atlantica), 100/1.

Fig. 23. Magellania joubini Blochmanx, Armgerüst des größten (in Taf. XLII Fig. 5 a-c abgebildeten) Exemplares, Ventralansicht, $5 / 1$.

Fig. 24. Dasselbe schief von rechts und ventral, $5 / 1$.

Fig. 25. Liothyrina antarctica Blochmann, Spicula der dorsalen Körperwand, 62/1.

Fig. 26-34. Liothyrina antarctica BLochмалN, Spiculaentwicklung im Armapparat.

Die schraffierten Teile liegen tief.

Dr $=$ zwischen den Cirrenbasen liegende Drüsen,

$\mathrm{CS}=$ Cirrensockel,

$\mathrm{Hpt}=$ Hauptstücke.

Fig. 26. Exemplar von $2 \mathrm{~mm}$ Länge, Dorsalansicht, 80/1.

Fig. 27. Exemplar von $3 \mathrm{~mm}$ Länge, von der Ventralseite, 80/1.

Fig. 28. Exemplar von 3,5 mm Länge, rechter Arm von der Ventralseite, 80/1.

Fig. 29. Exemplar von $4 \mathrm{~mm}$ Länge, linker Arm von der Ventralseite, 80/1.

Fig. 30. Exemplar von $5 \mathrm{~mm}$ Länge, linker Arm von der Ventralseite, 80/1.

Fig. 31. Exemplar von $6 \mathrm{~mm}$ Länge, linker Arm von der Medialseite, 80/1.

Fig. 32. Exemplar von $8 \mathrm{~mm}$ Länge, linker Arm von der Medialseite, 85/1.

Die Cirren der inneren Reihe sind in dieser und den folgenden Figuren weggelassen.

Fig. 33. Rechter Arm des größten Exemplares, von der Medialseite, 95/1.

Fig. 34. Rechter Spiralarm eines erwachsenen Exemplares, von der Medialseite, 95/1. 



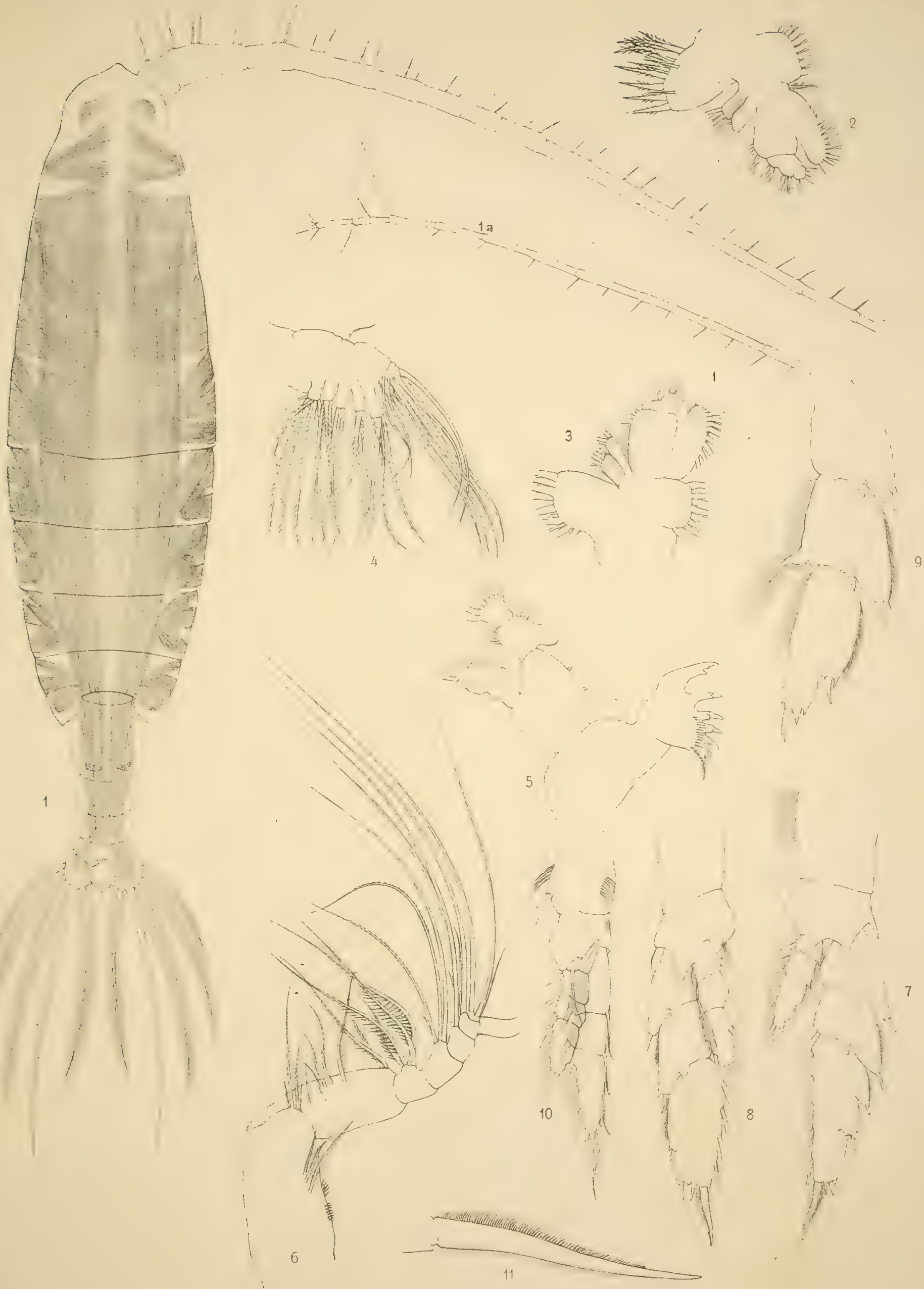


Deutsche Súdpolar-Expedition. 1901-3.

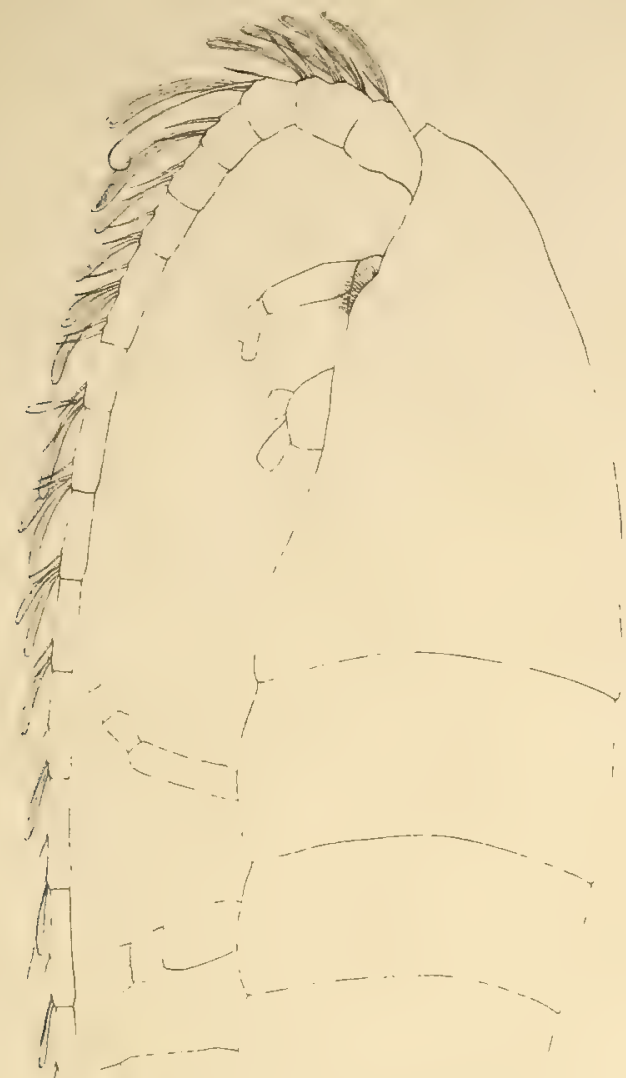

$\int_{i} \frac{2}{2}$
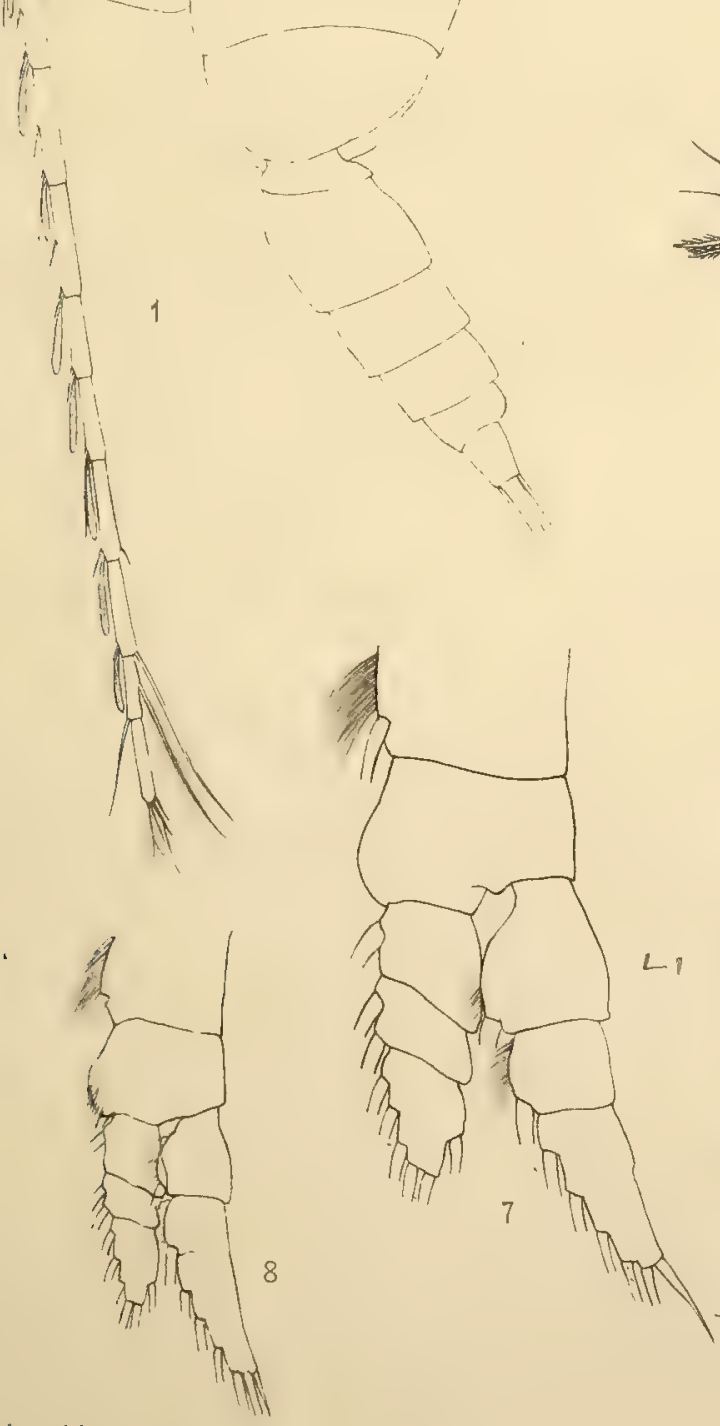

Marion Lees del.
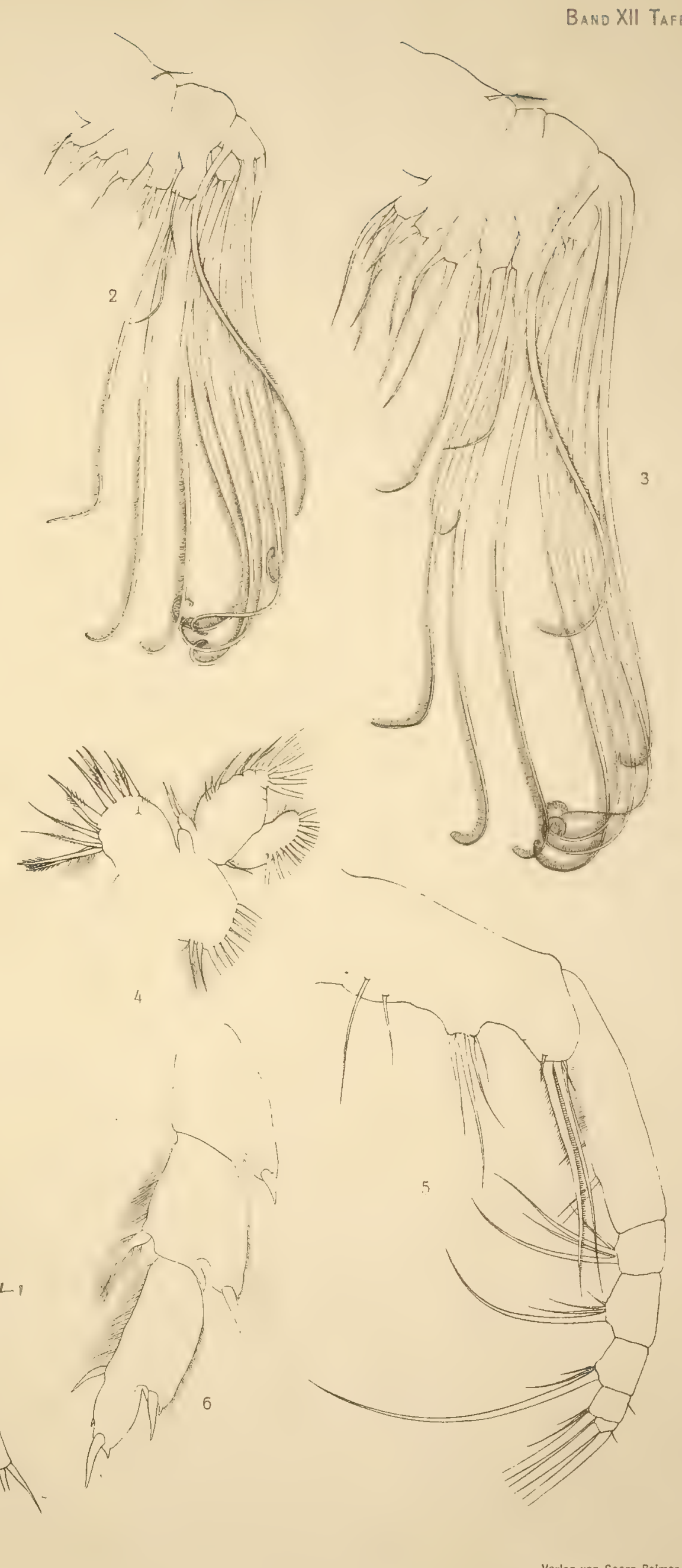

1-7 Bathycalanus maximus, 8 Bathycalanus richardi.

B. bradu! W., 

DeUtSChe Súdpolar-EXpedition. 1901-3.

Band XII Tafel XXIV.

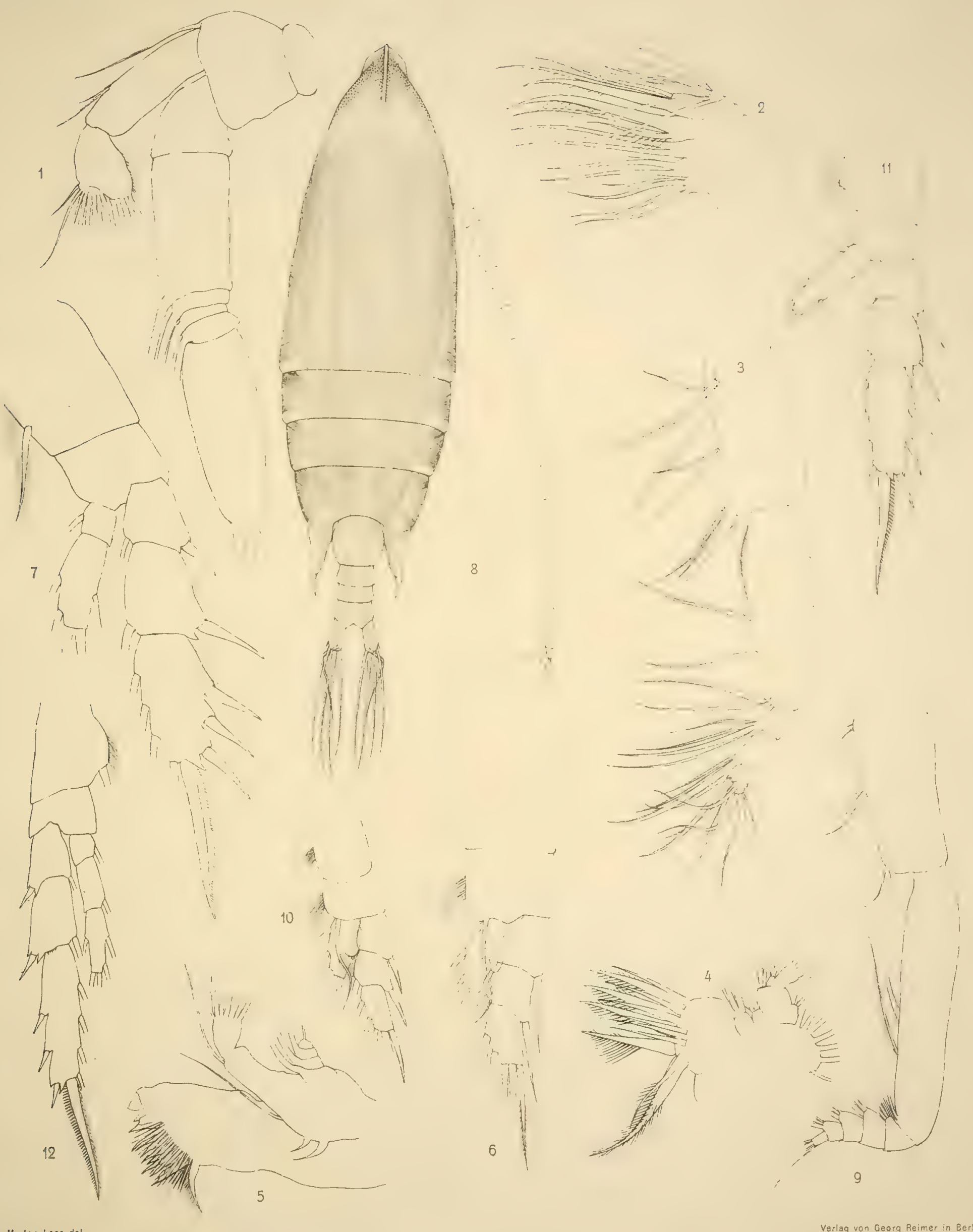

Marion Leos del.

1-7 Stephus neptuni, 8 Aetidius giesbrechti, 9-12 Chiridius polaris. 


\section{,}




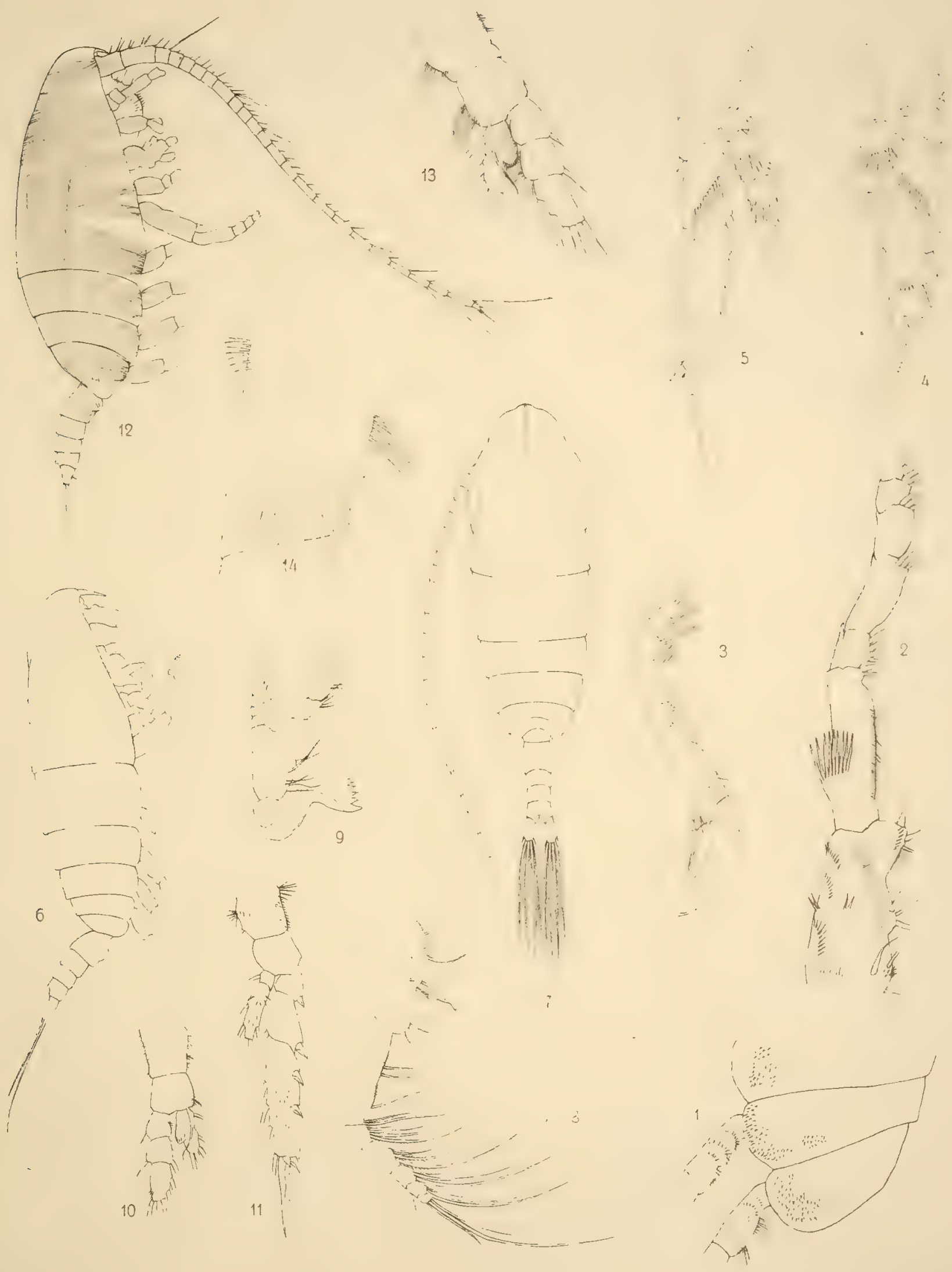

Marion Lees del. 


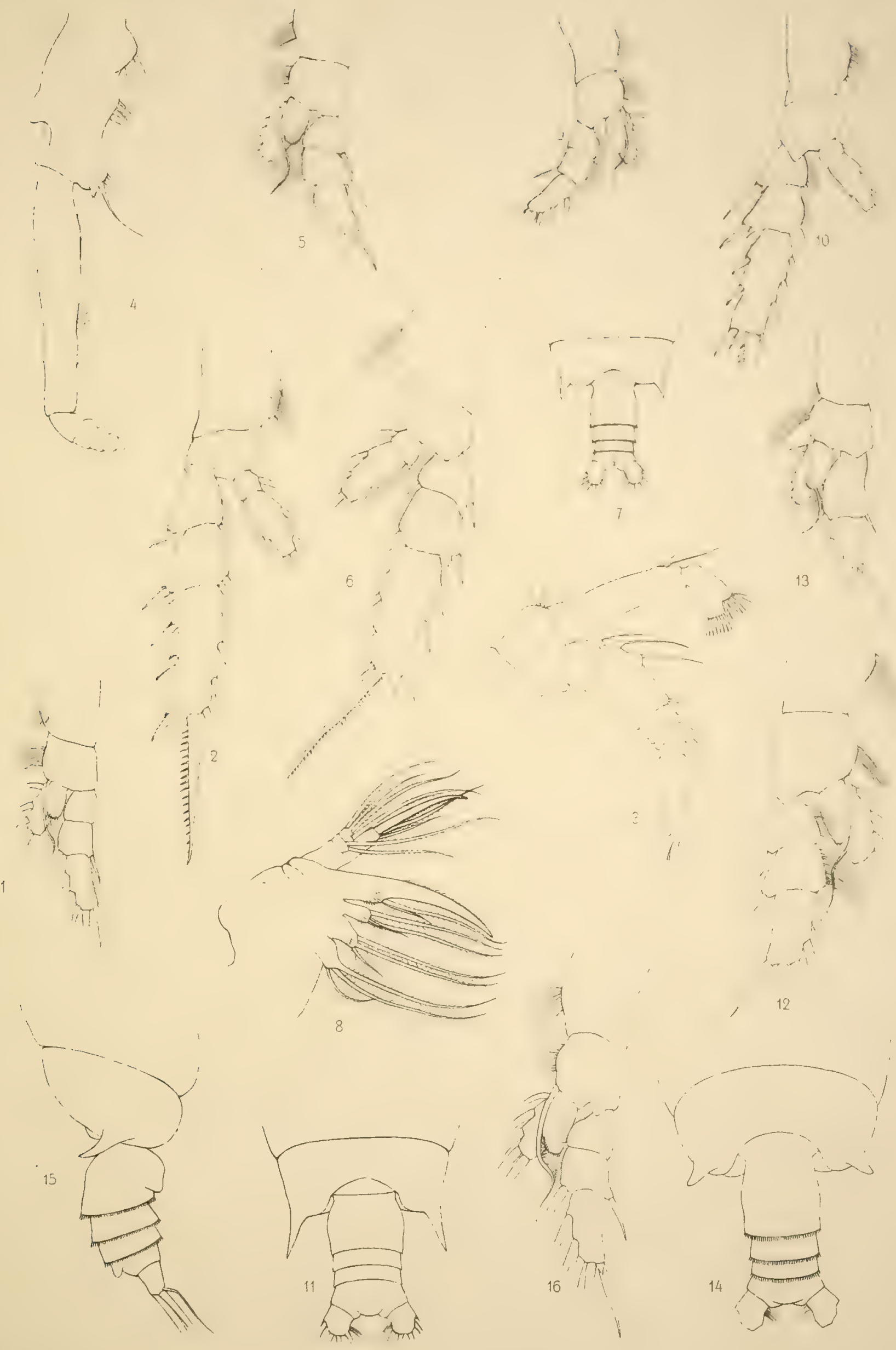
11-12 Gaetanus brevicaudatus, 13 Gaetanus recticornis, 14-16 Gaetanus rectus. 

Deutsche SüdPolar-EXPEDITION. 1901-3.

Band XII Tafel XXVII.
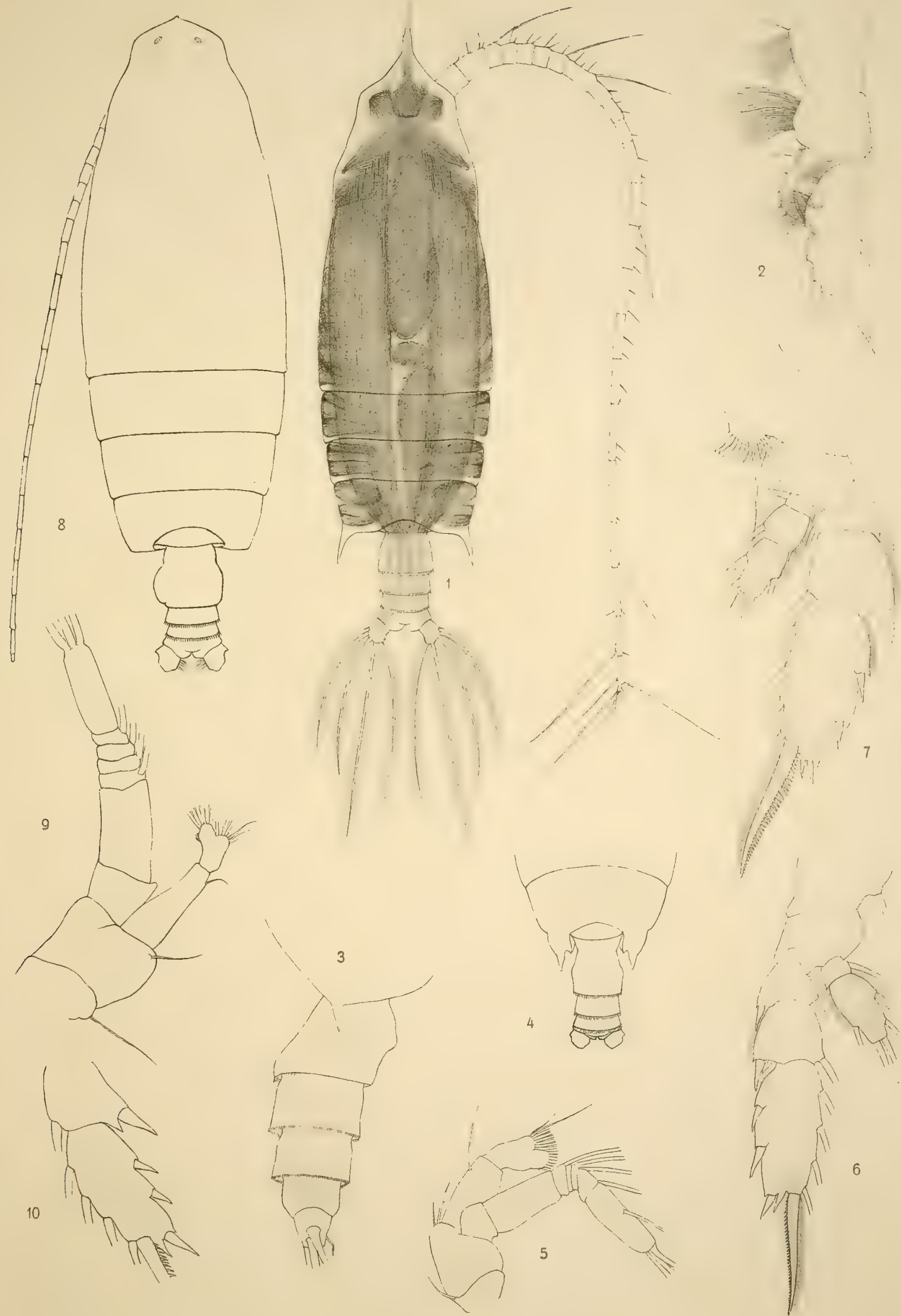

Marion Lees del. 



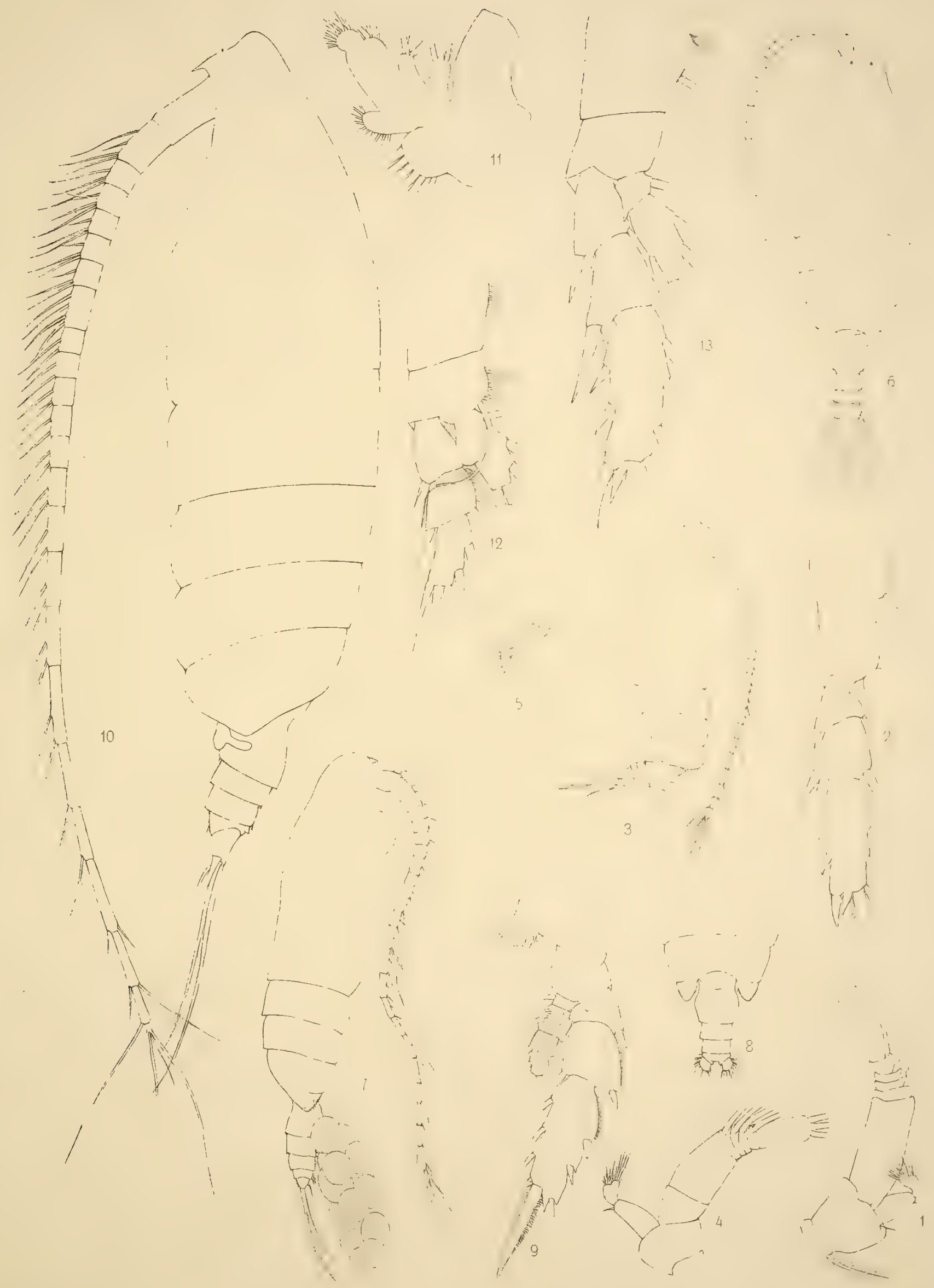





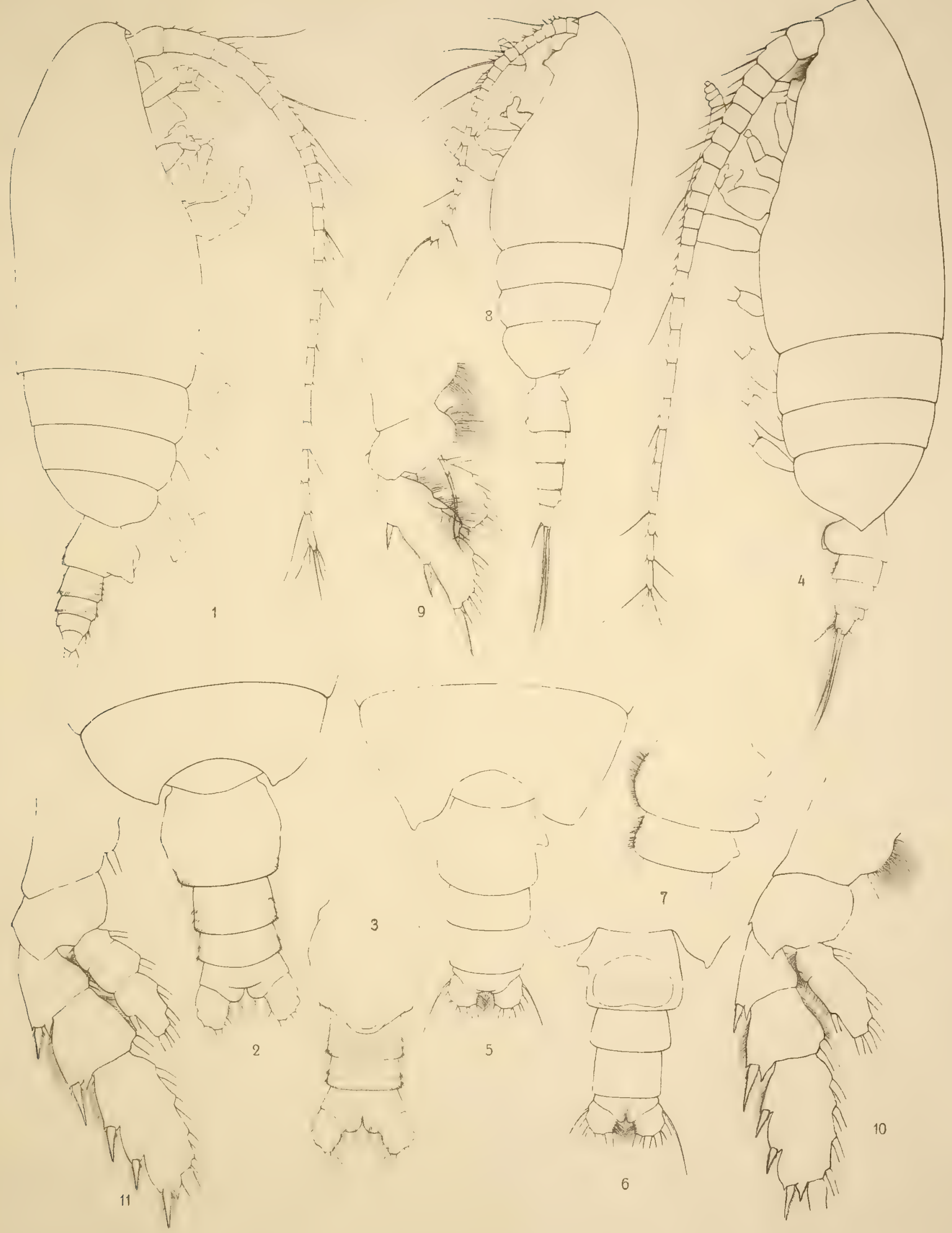




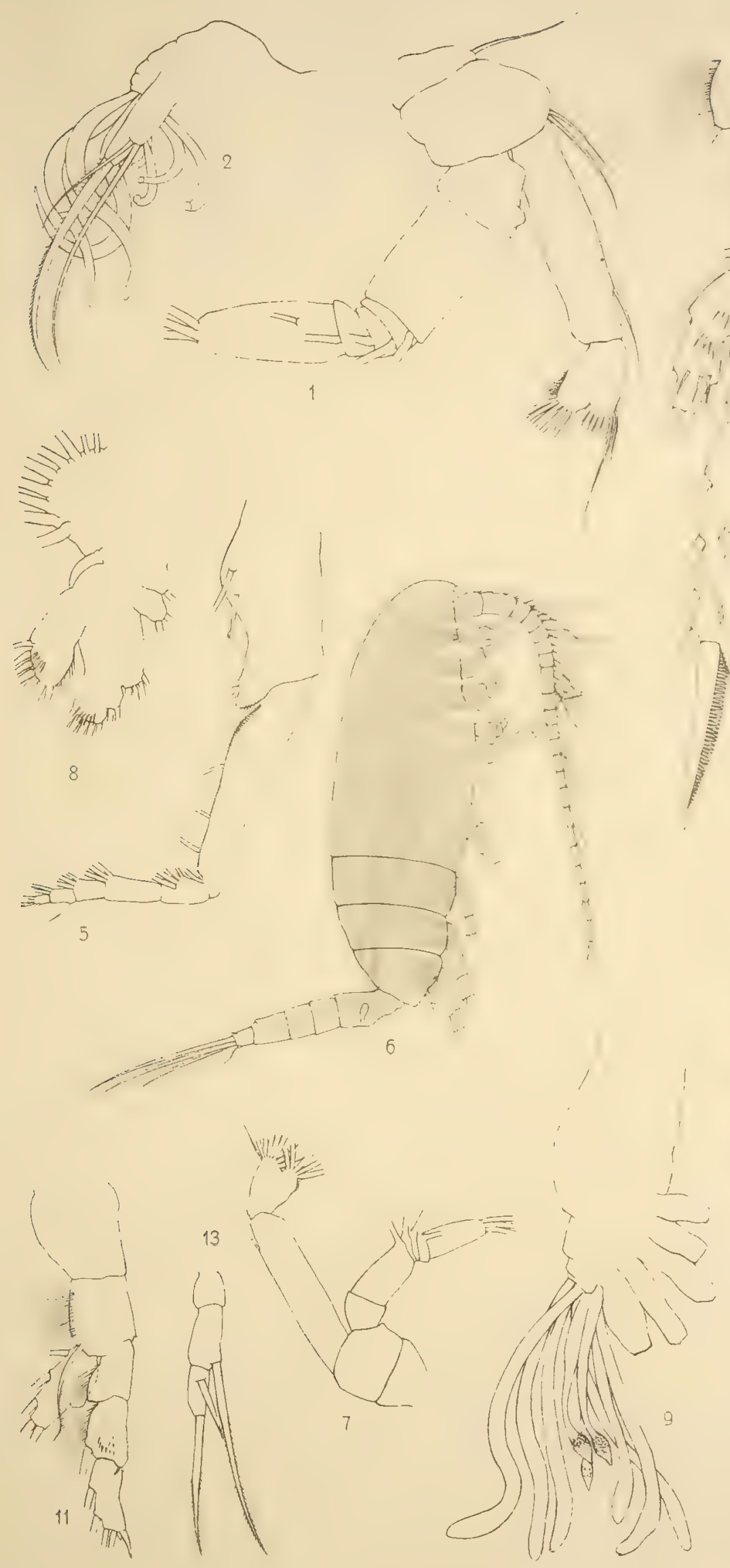
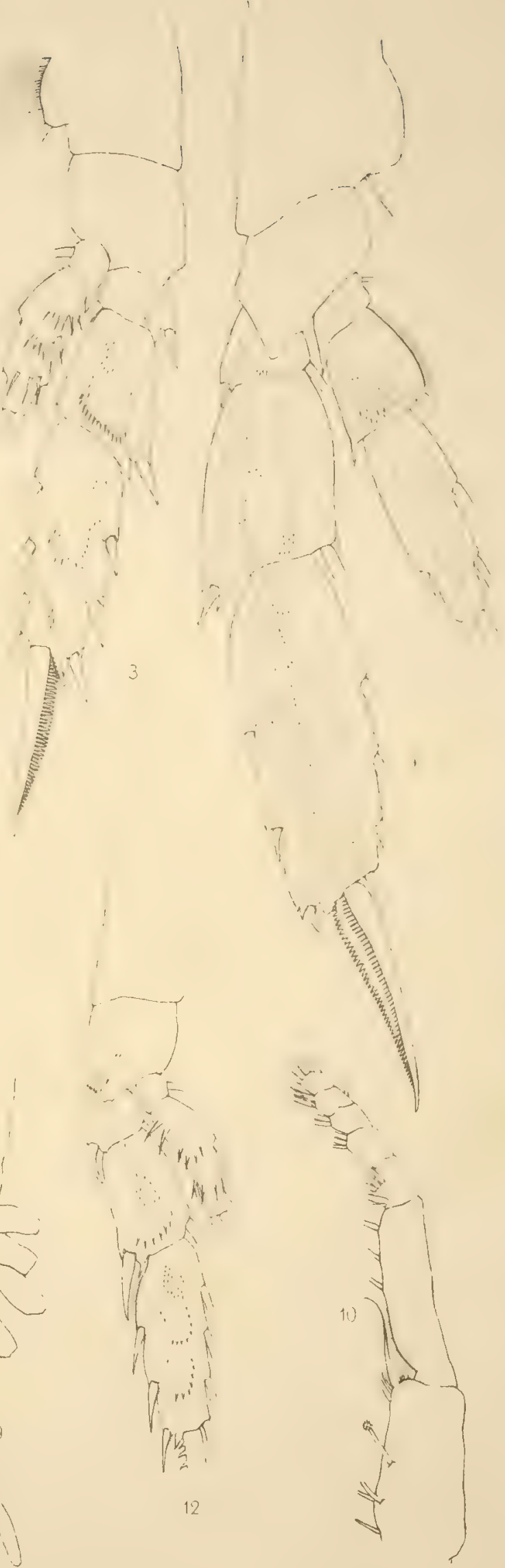

Verlag von Georg Relmer In Berl h. 



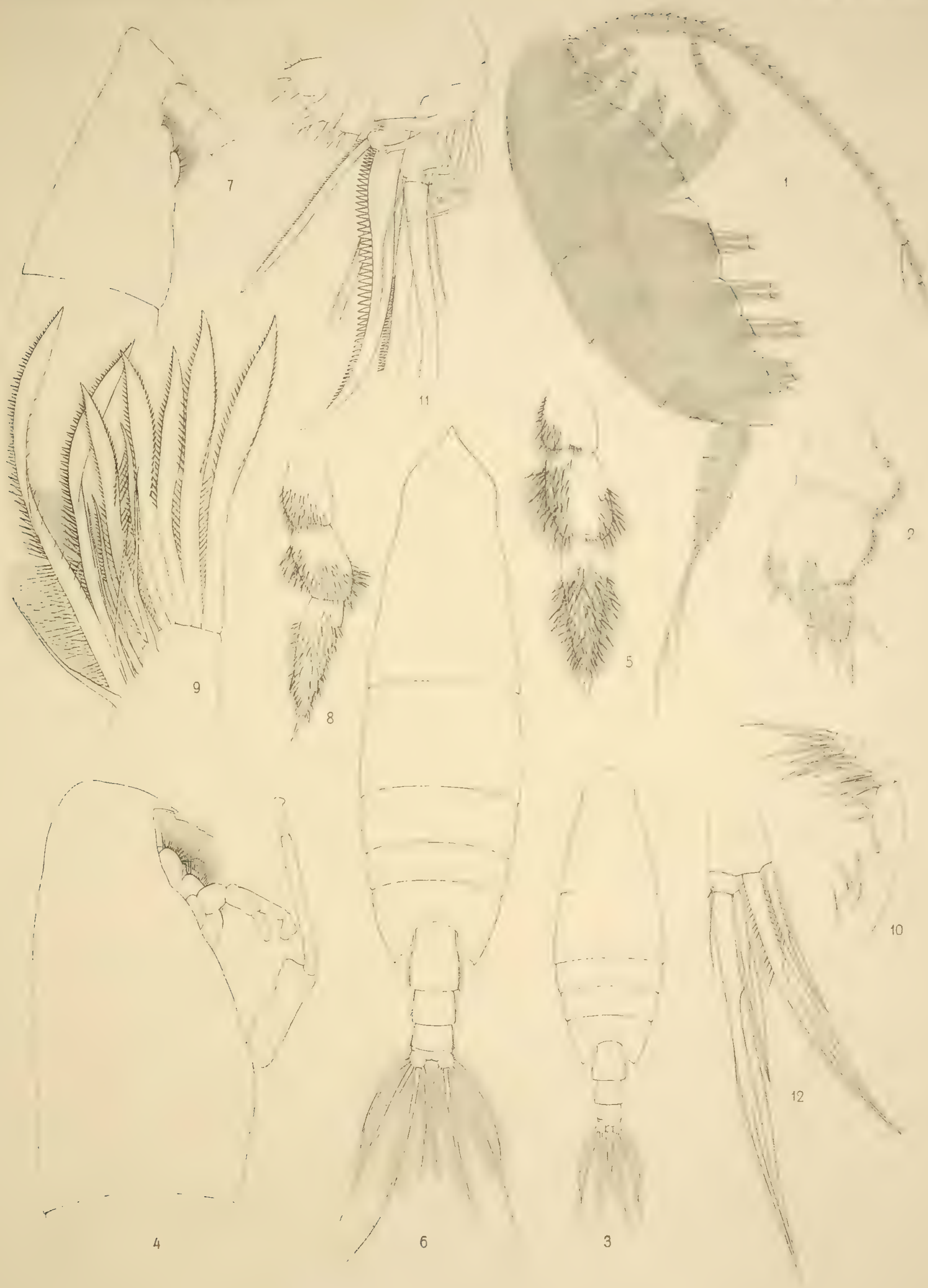

Verlag von Gearg Reimer in Berlin. 

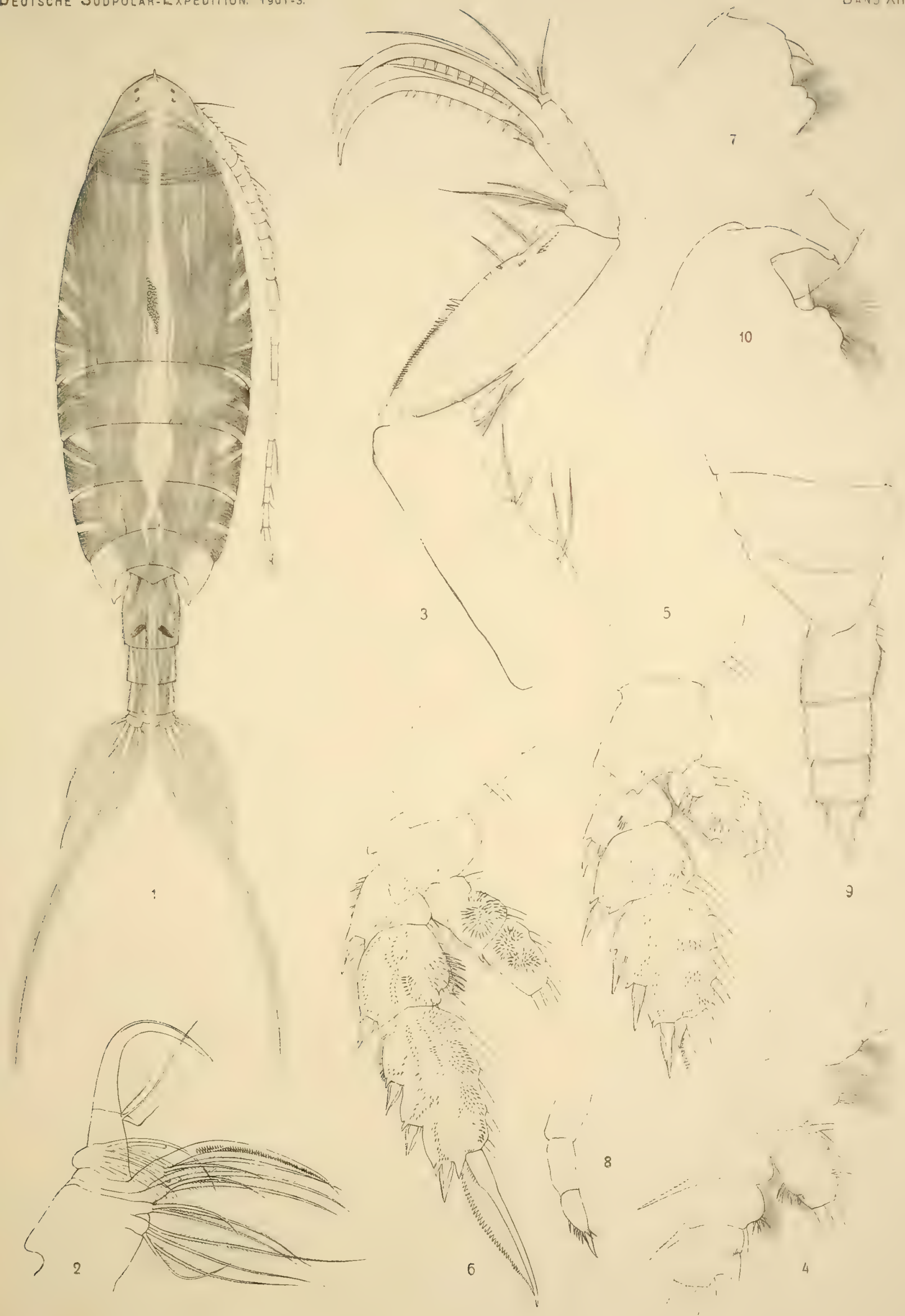

Bañ XII TAFEL XXX:I

Marion Lees del. 




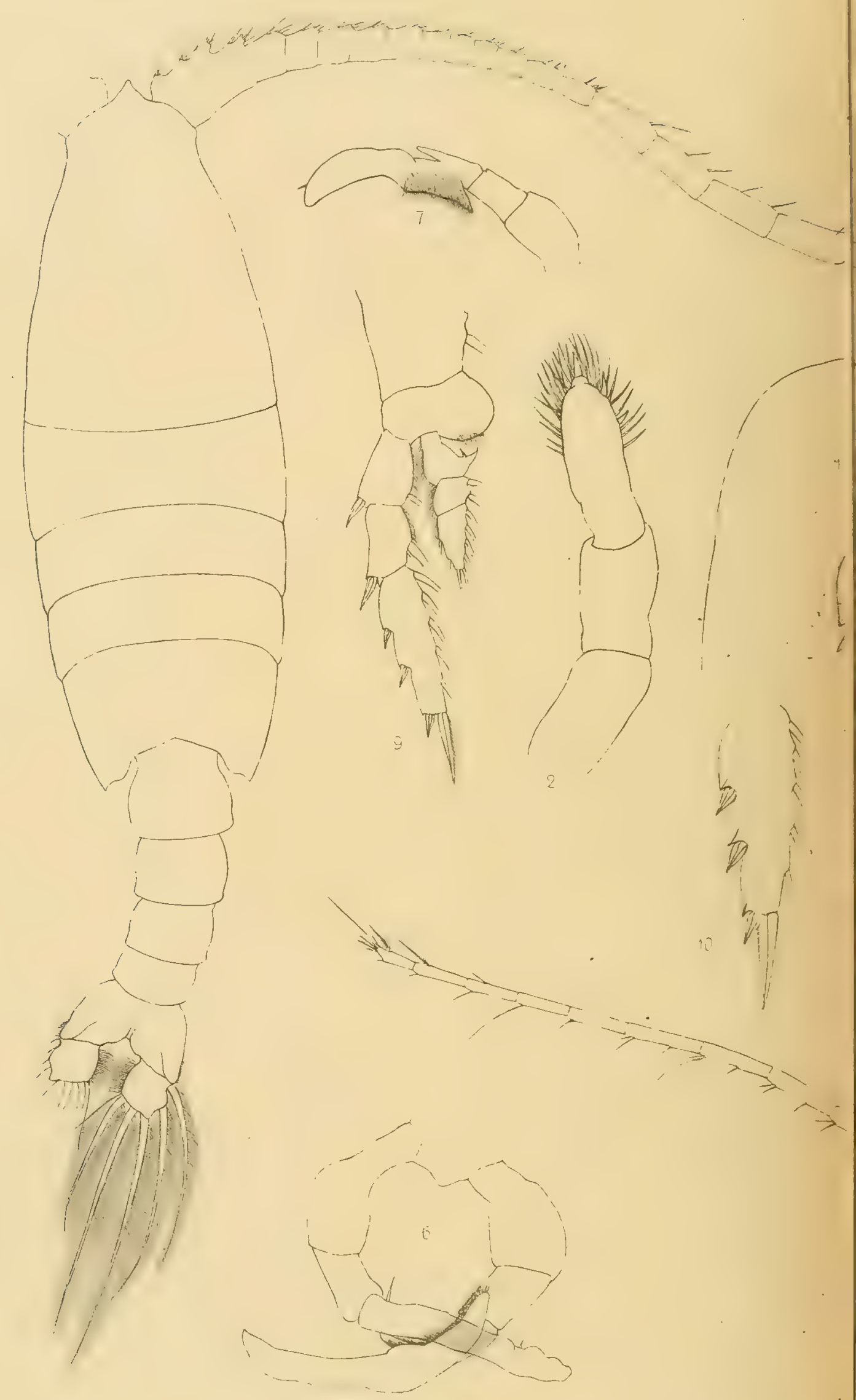

Marion Lees dol. 




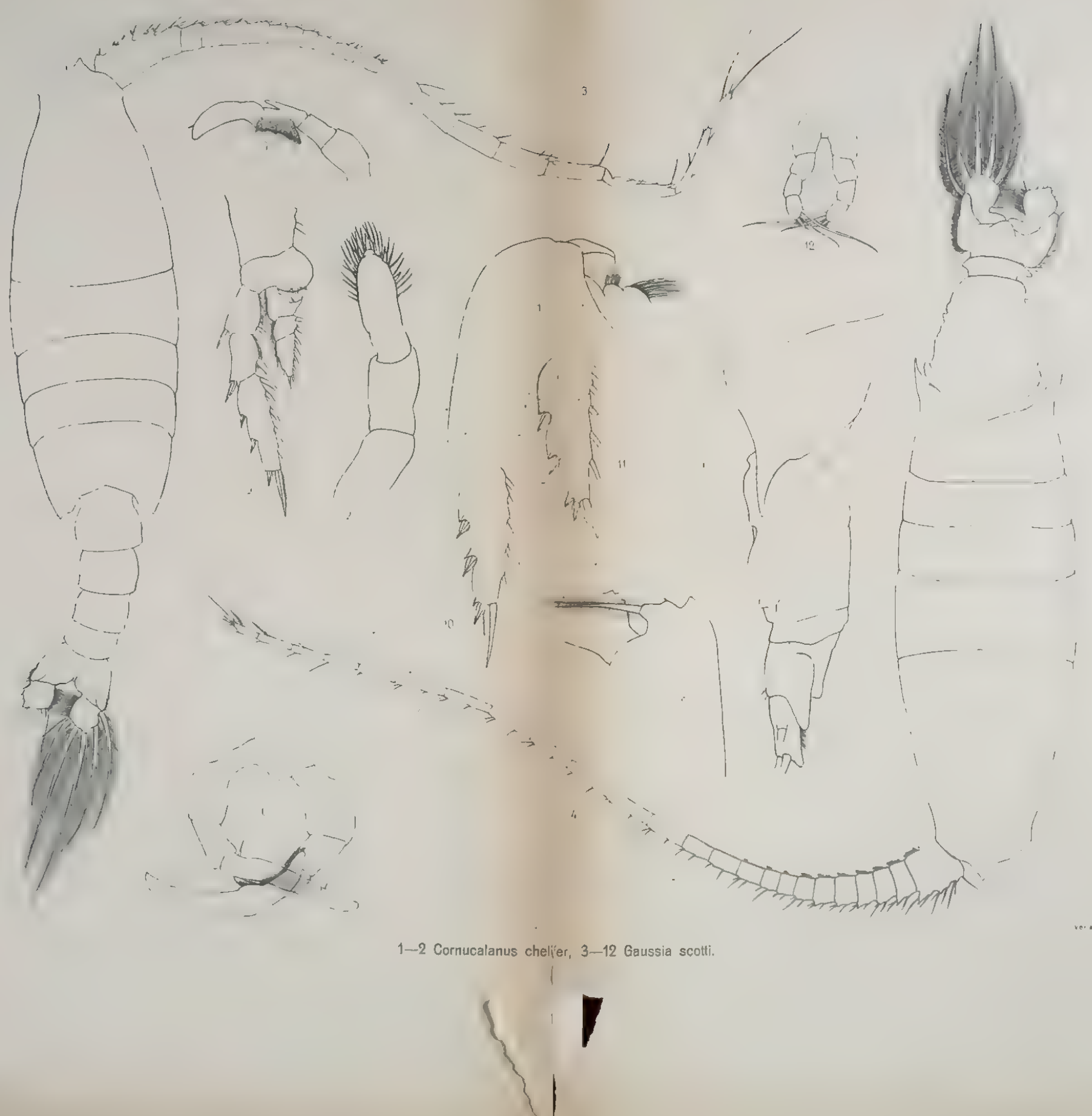





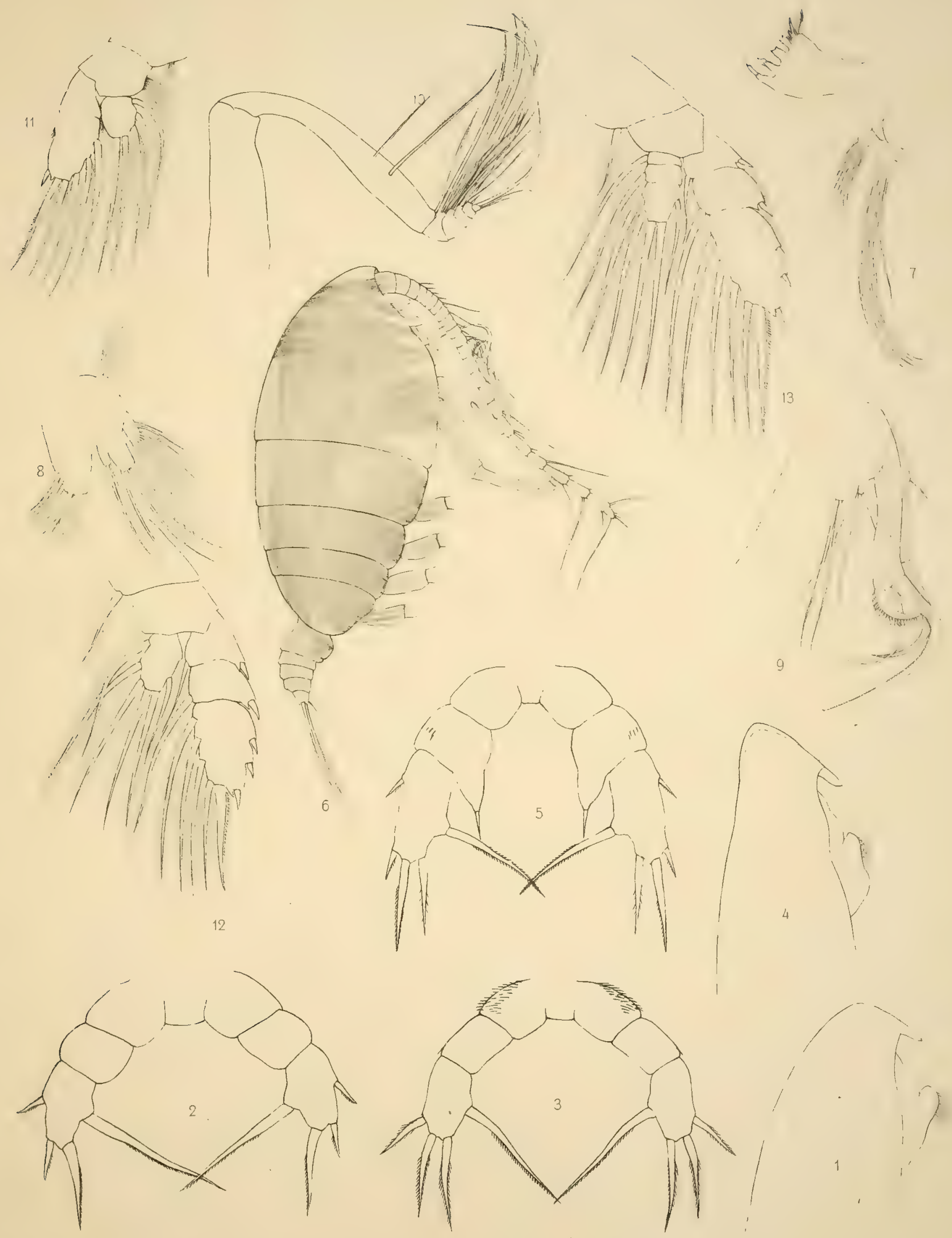





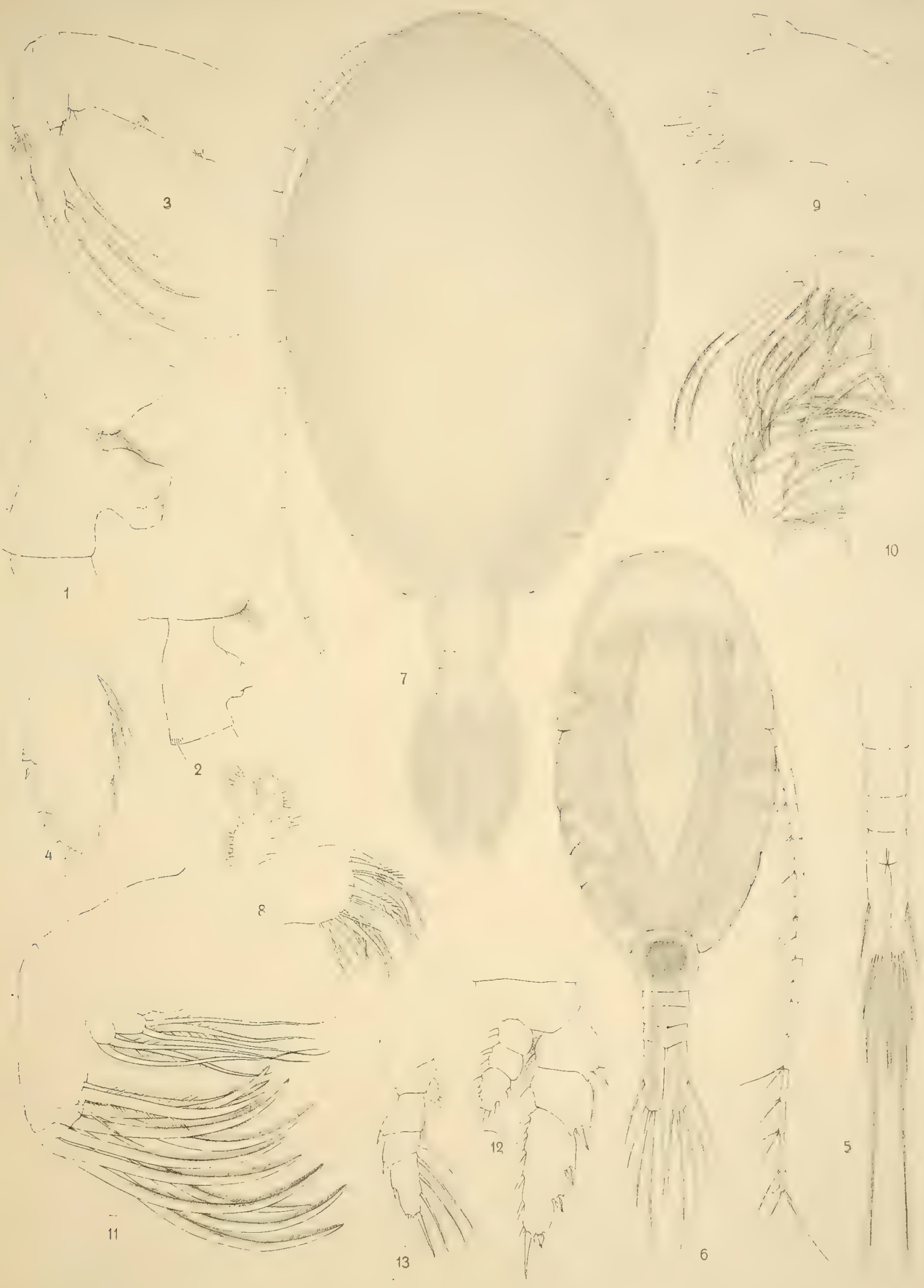





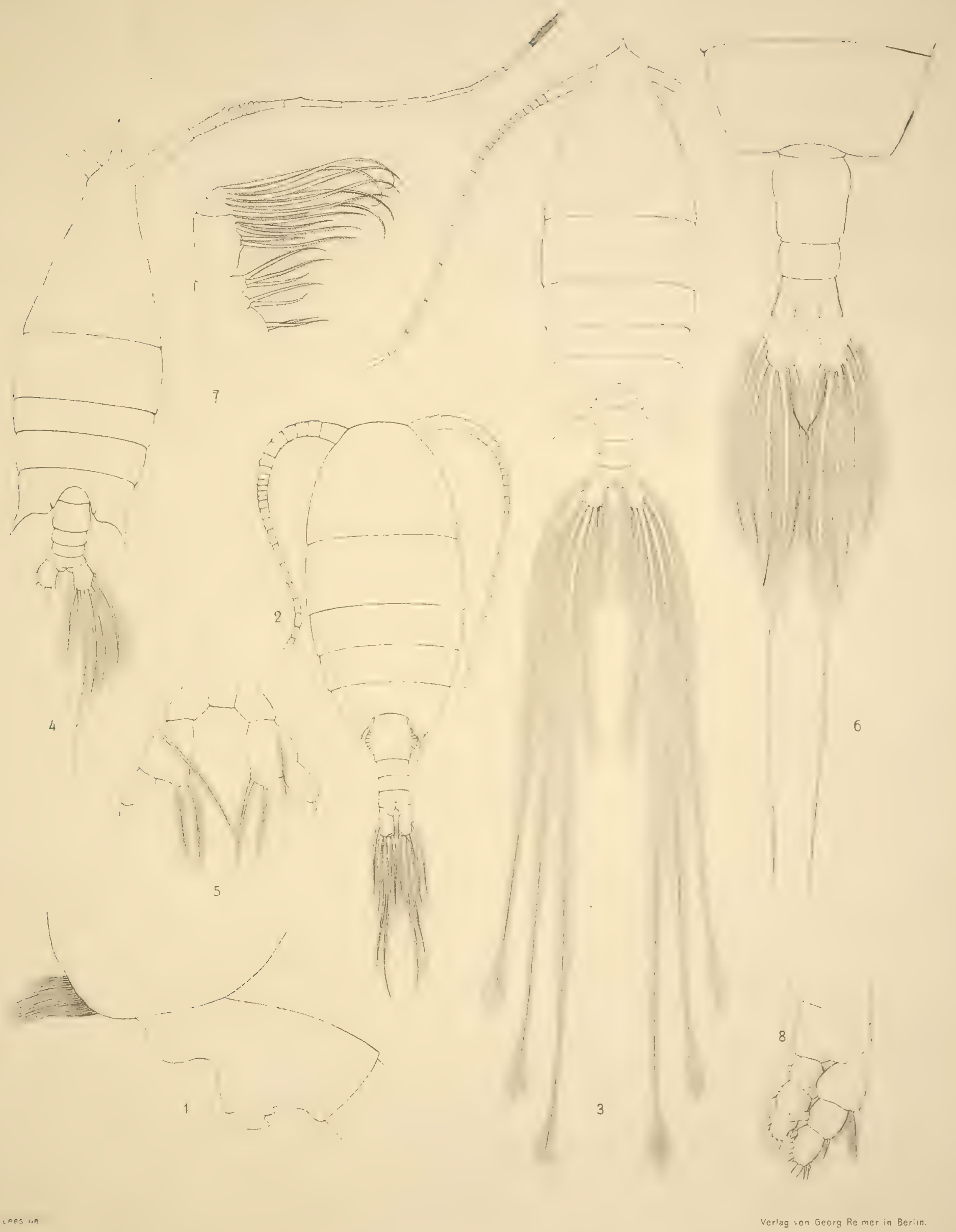

1 Euchaeta robusta, 2 Phyllopus impar, 3 Arietellus setosus, 4 Arietellus armatus, 5 Arietellus simplex, $6-7$ Augaptilus antarcticus, 8 Augaptilus fungiferus. 



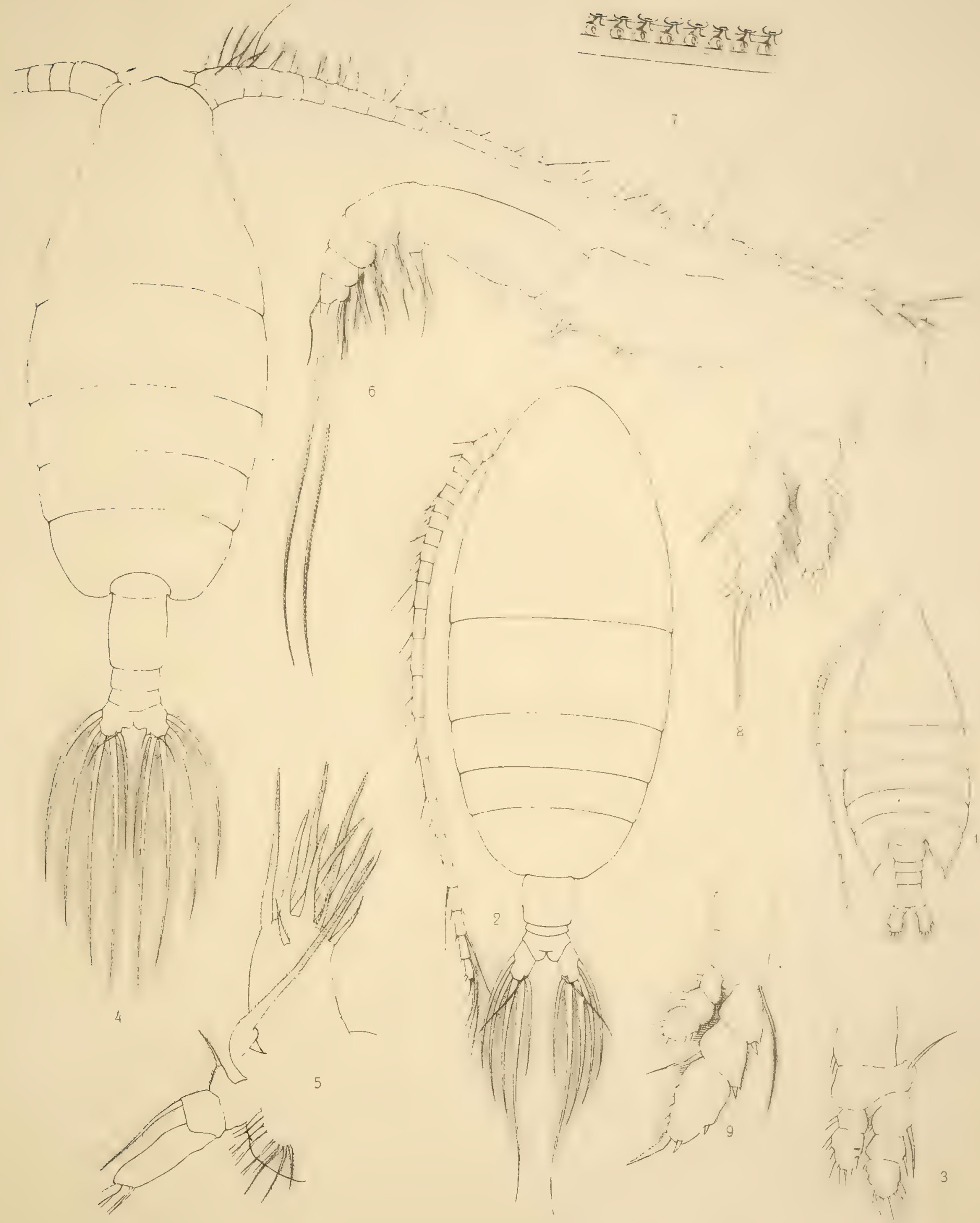




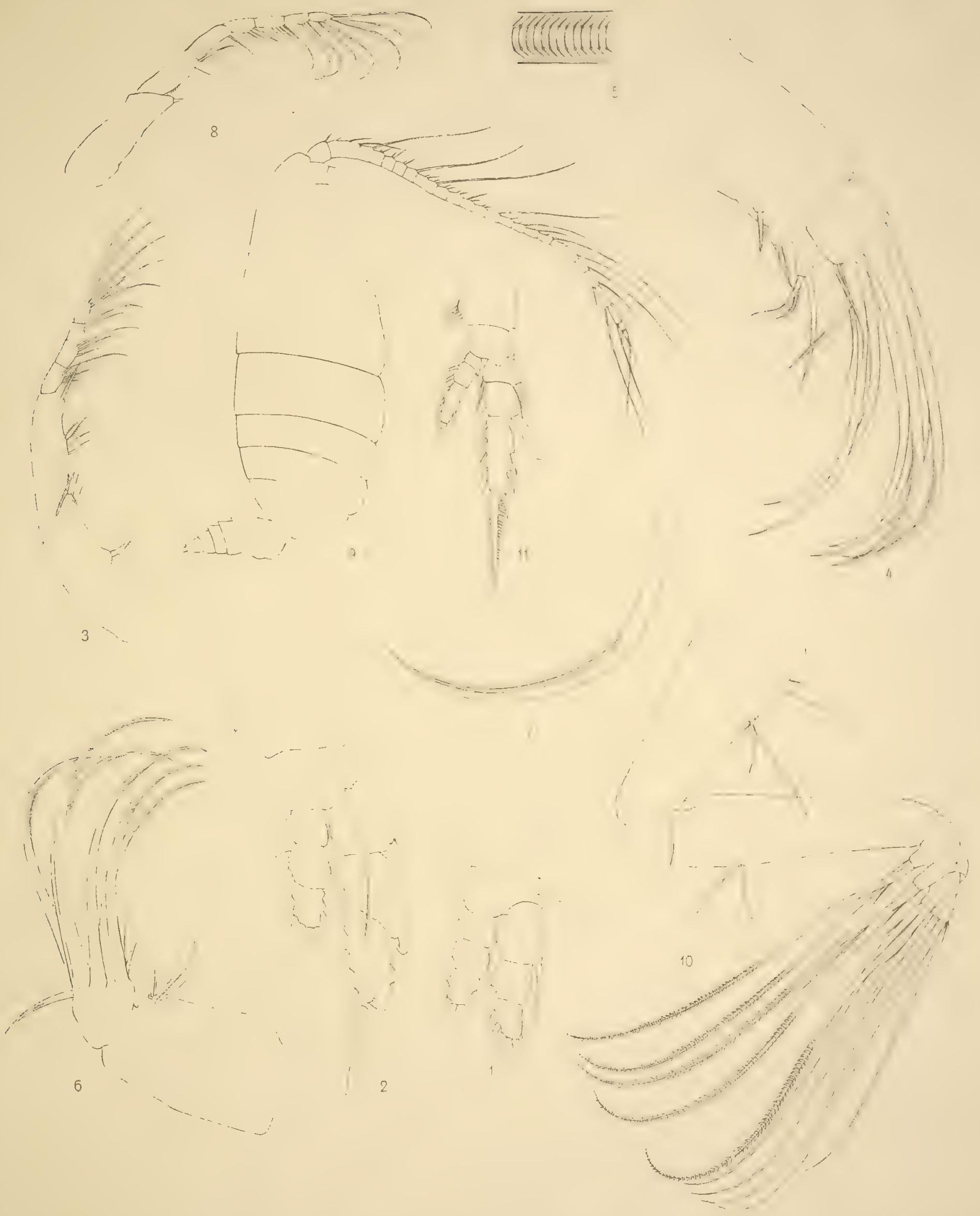

Marton tees de

1-2 Augaptilus facilis, $3-5$ Isocalanus major, $6-8$ Isocalanus minor, 9-10 Autanepsius minor, 11 Temoropsis simplex. 


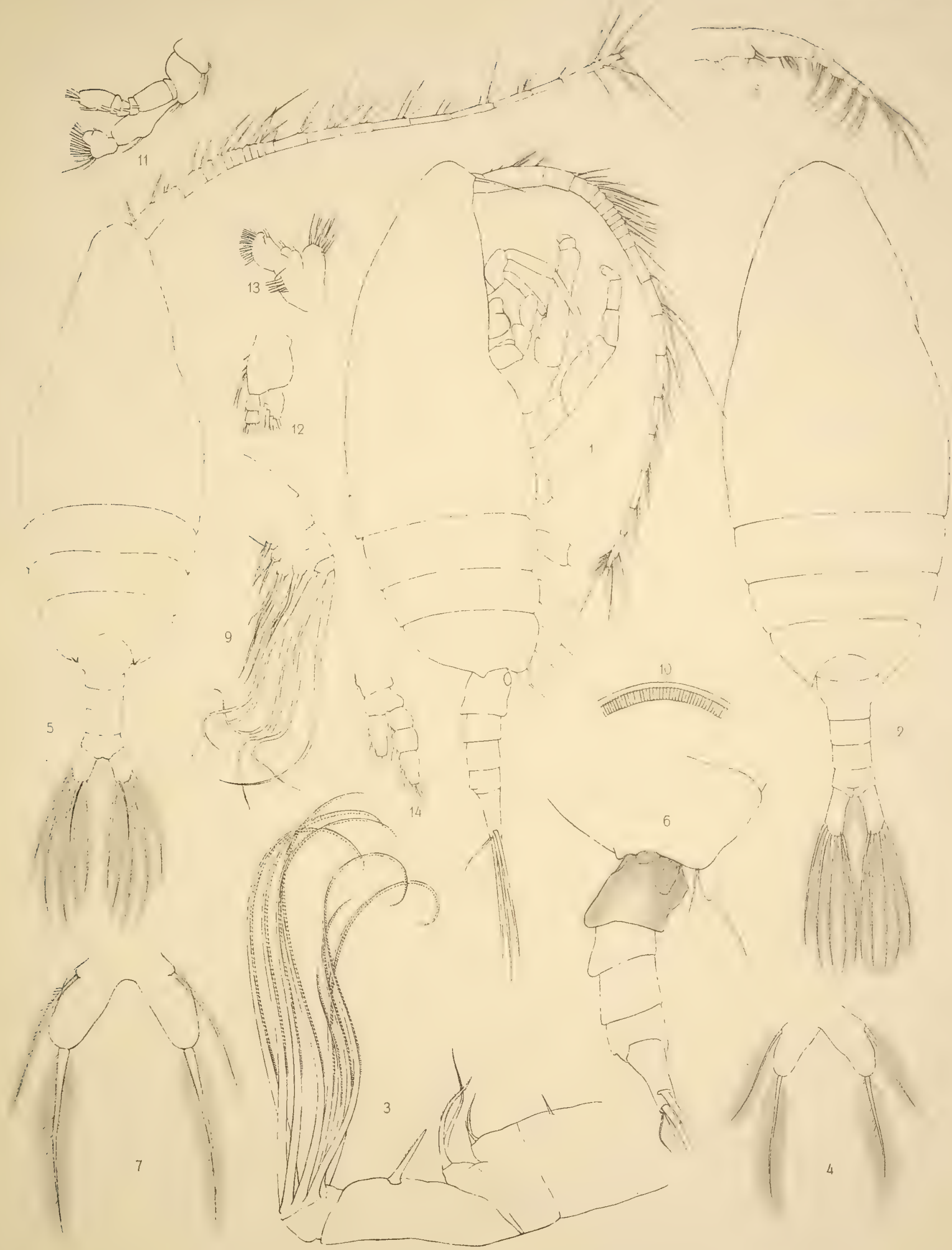



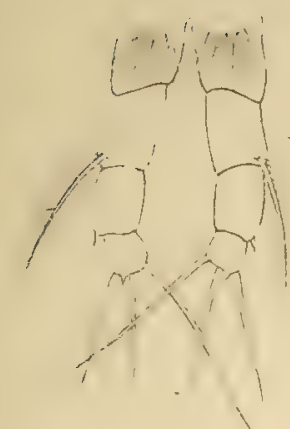

10

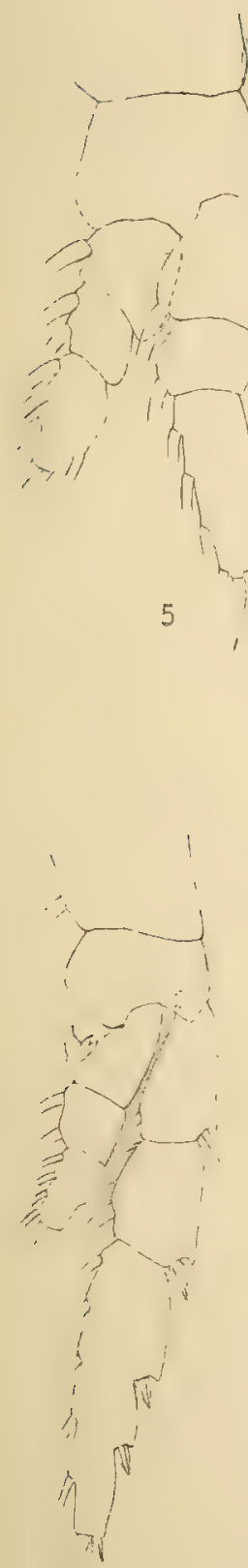

12
13
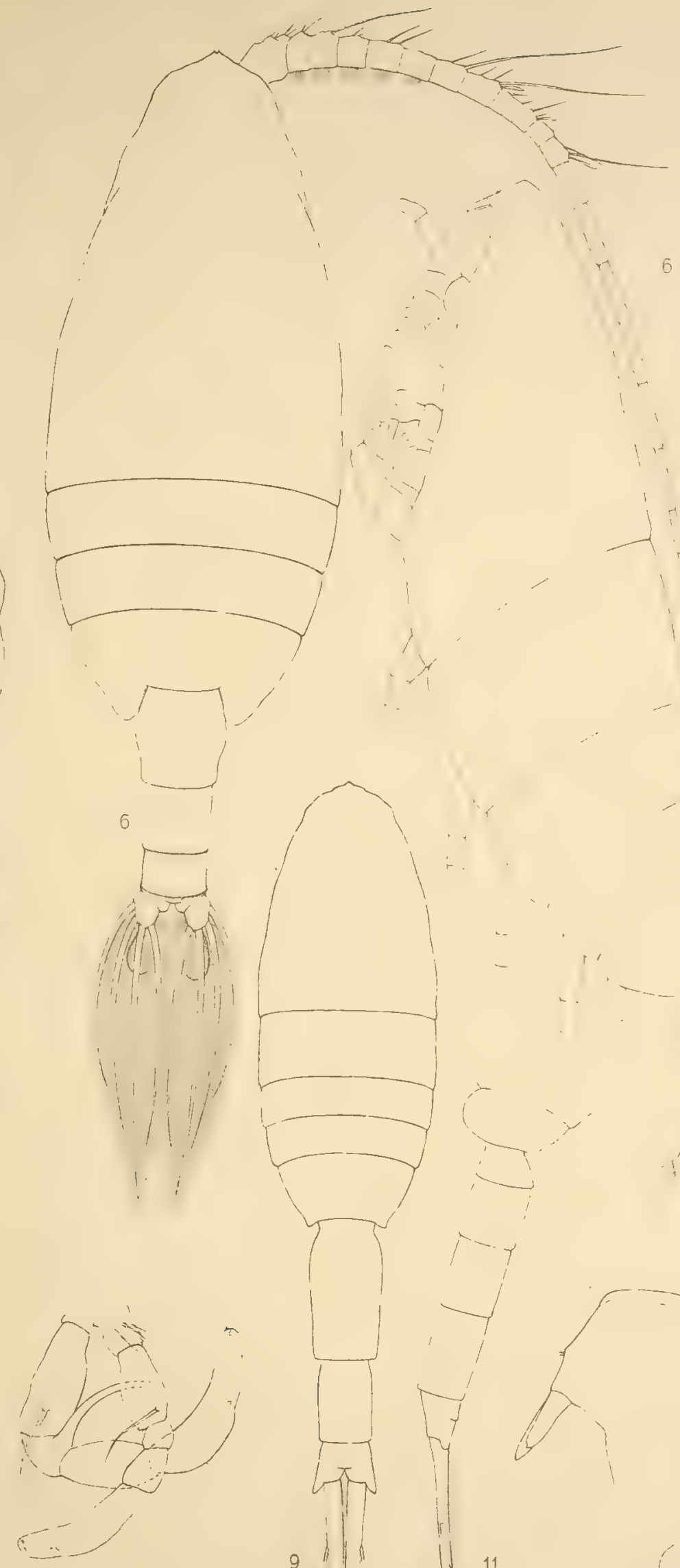

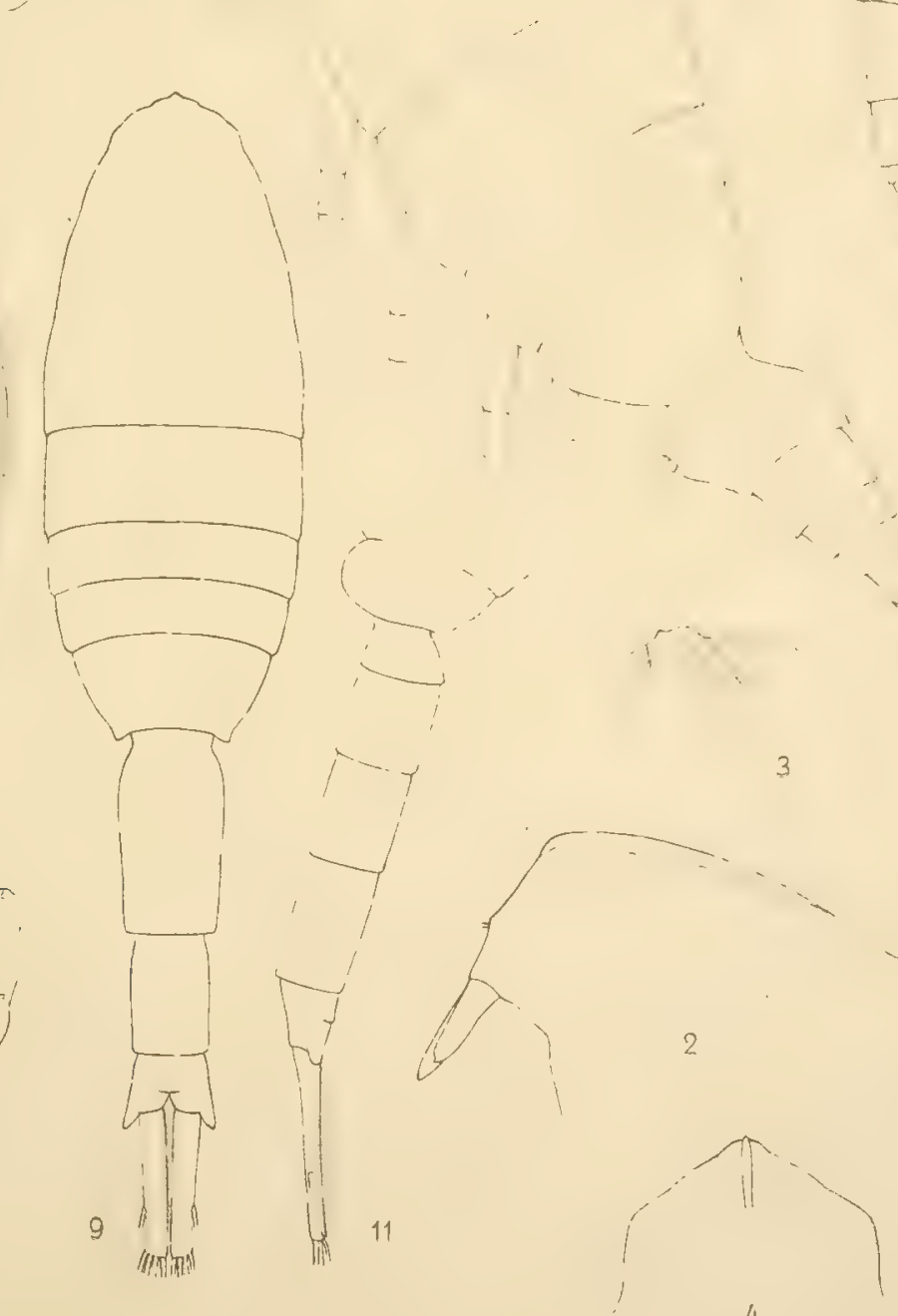

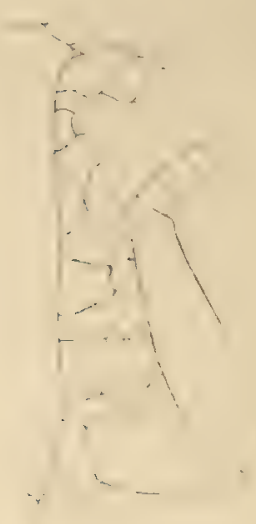
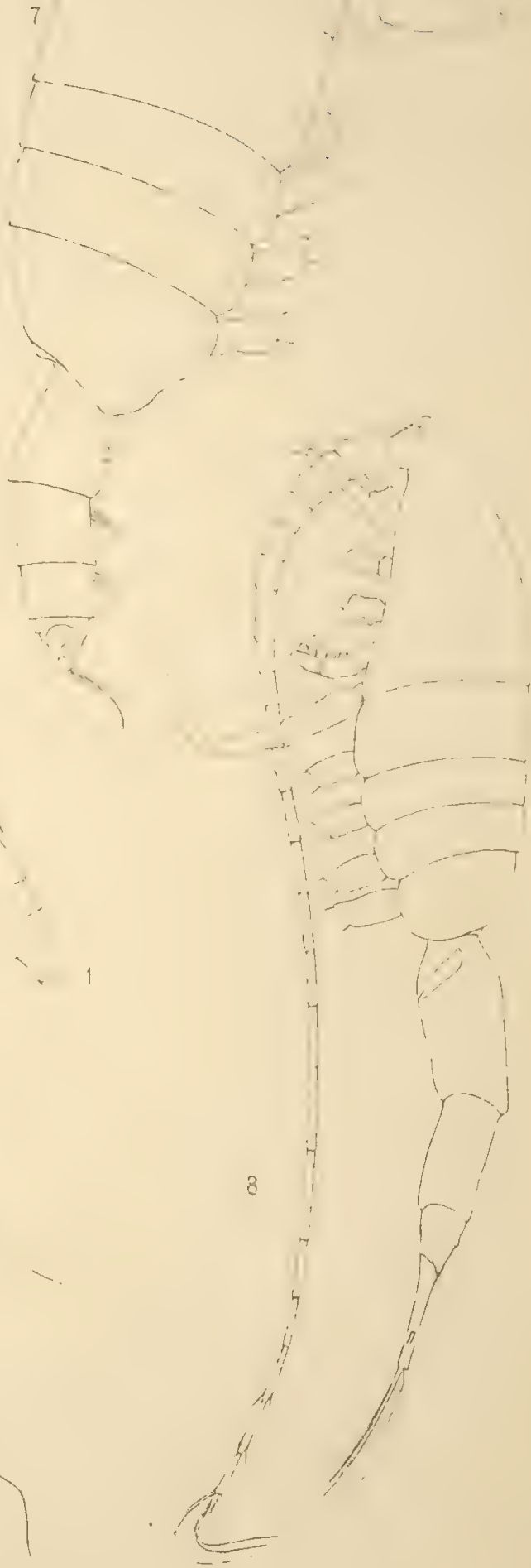

Marion Lees del. $1-5$ Heterocalanus medius, $6-7$ Valdiviella insignis, $8-13$ Metridia princeps.

Verlag von Georg Reimer in Be, n 

Deutsche Suidpolar-Expedition 1901-3.

Band XII Tafel XUT

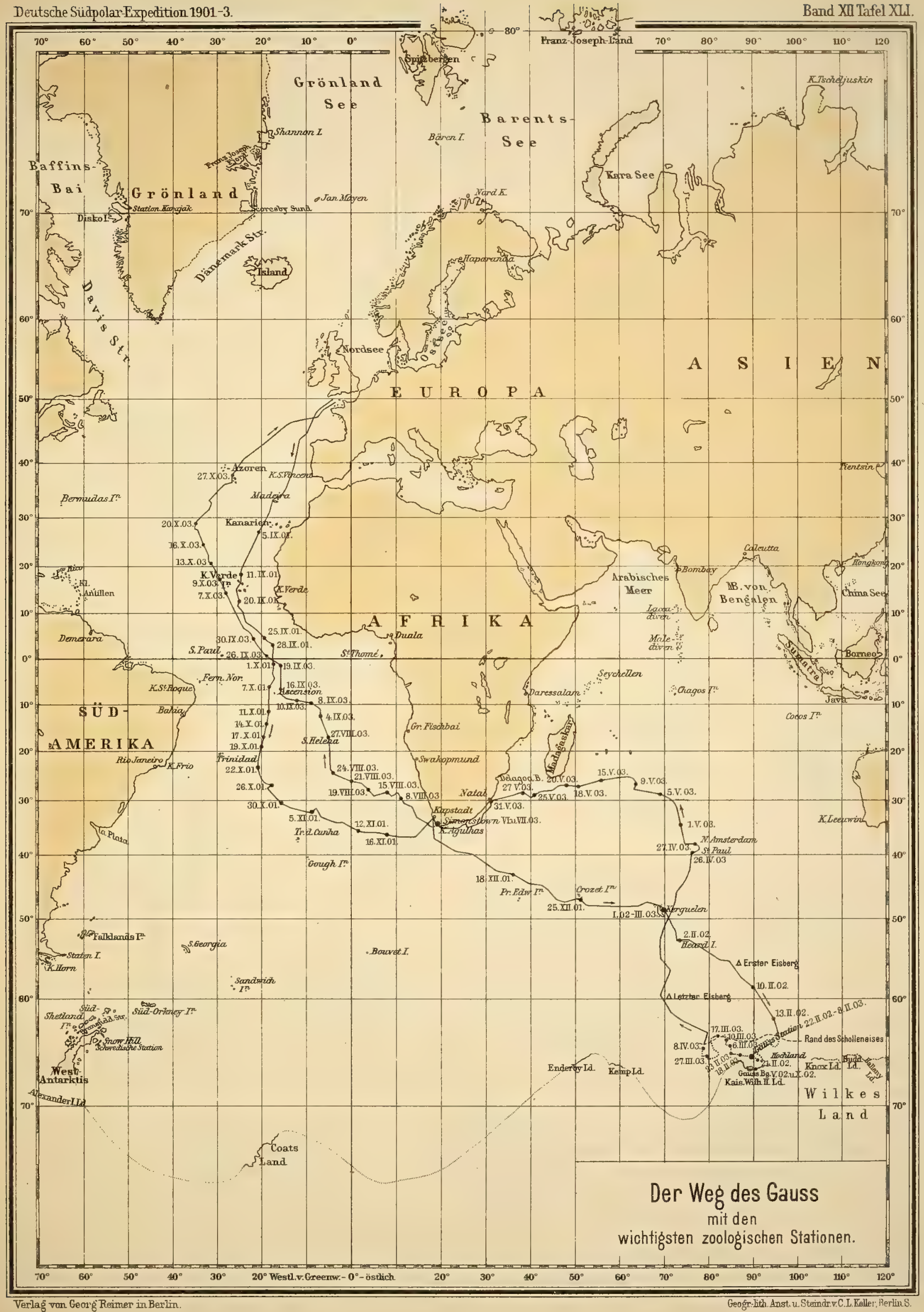

Verlag von Geos geimer in Berlin

Geofr-bith Aast u.Steindr.v. C.L. Kellier, Rerlin S 


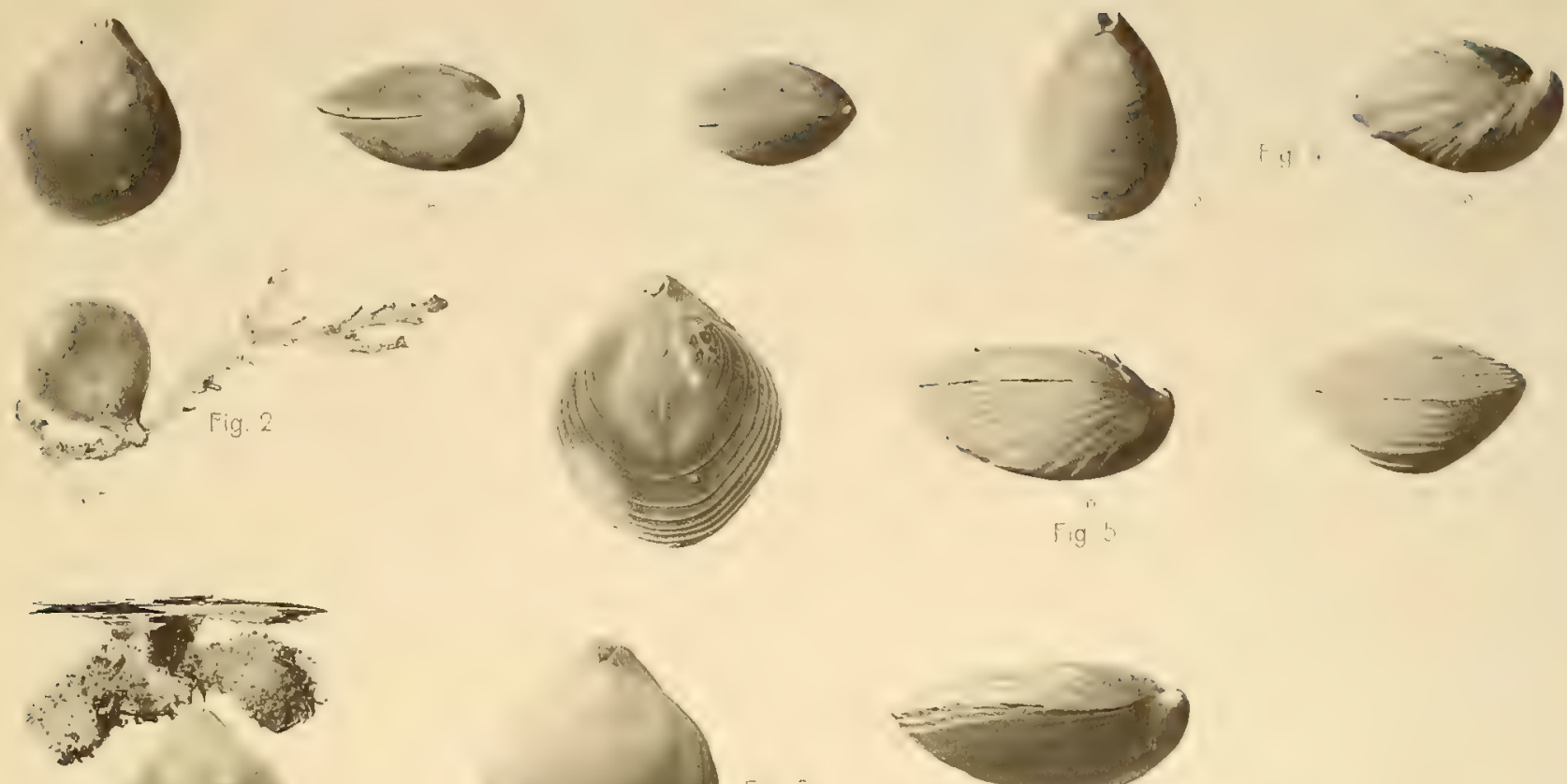
(n)
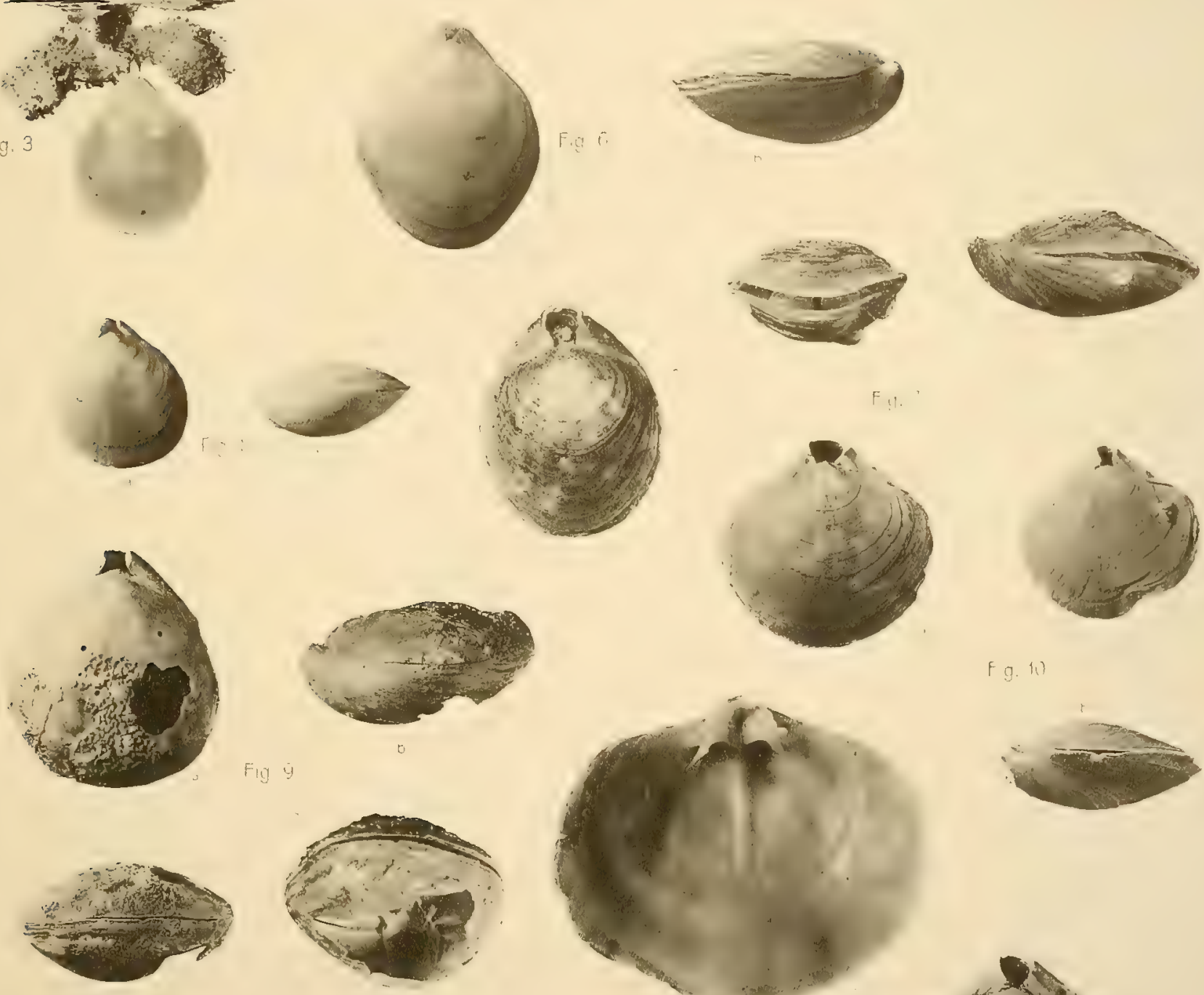

f g. 11$\}$

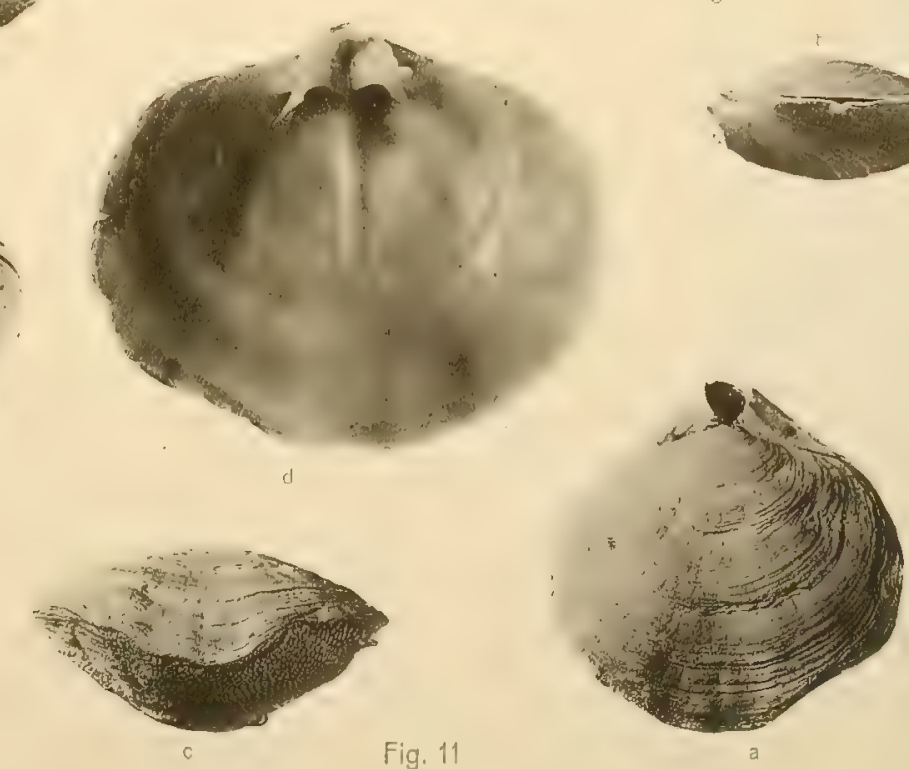




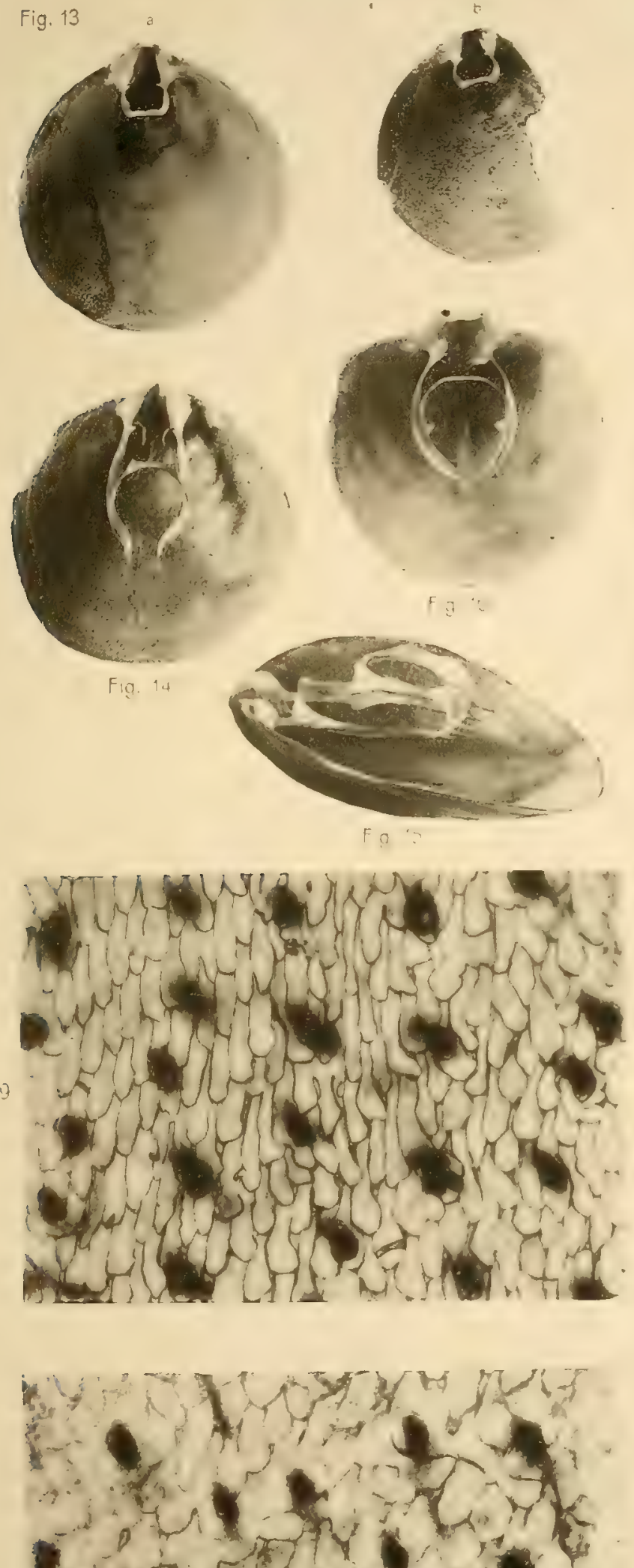

Fig. 20

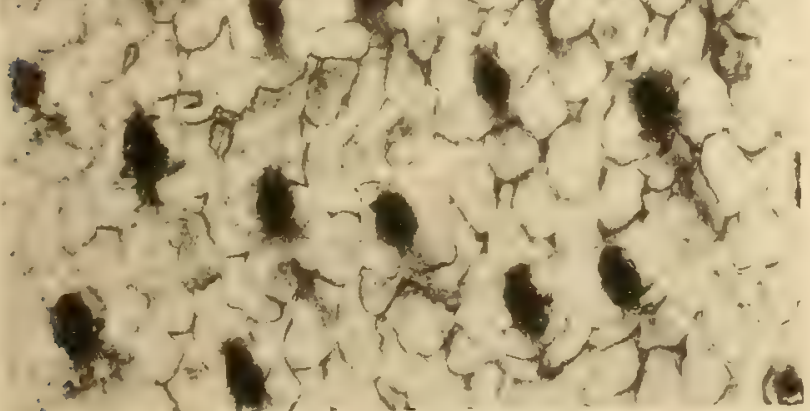

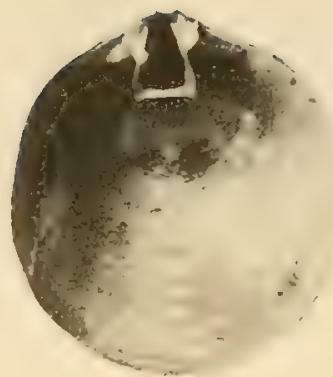
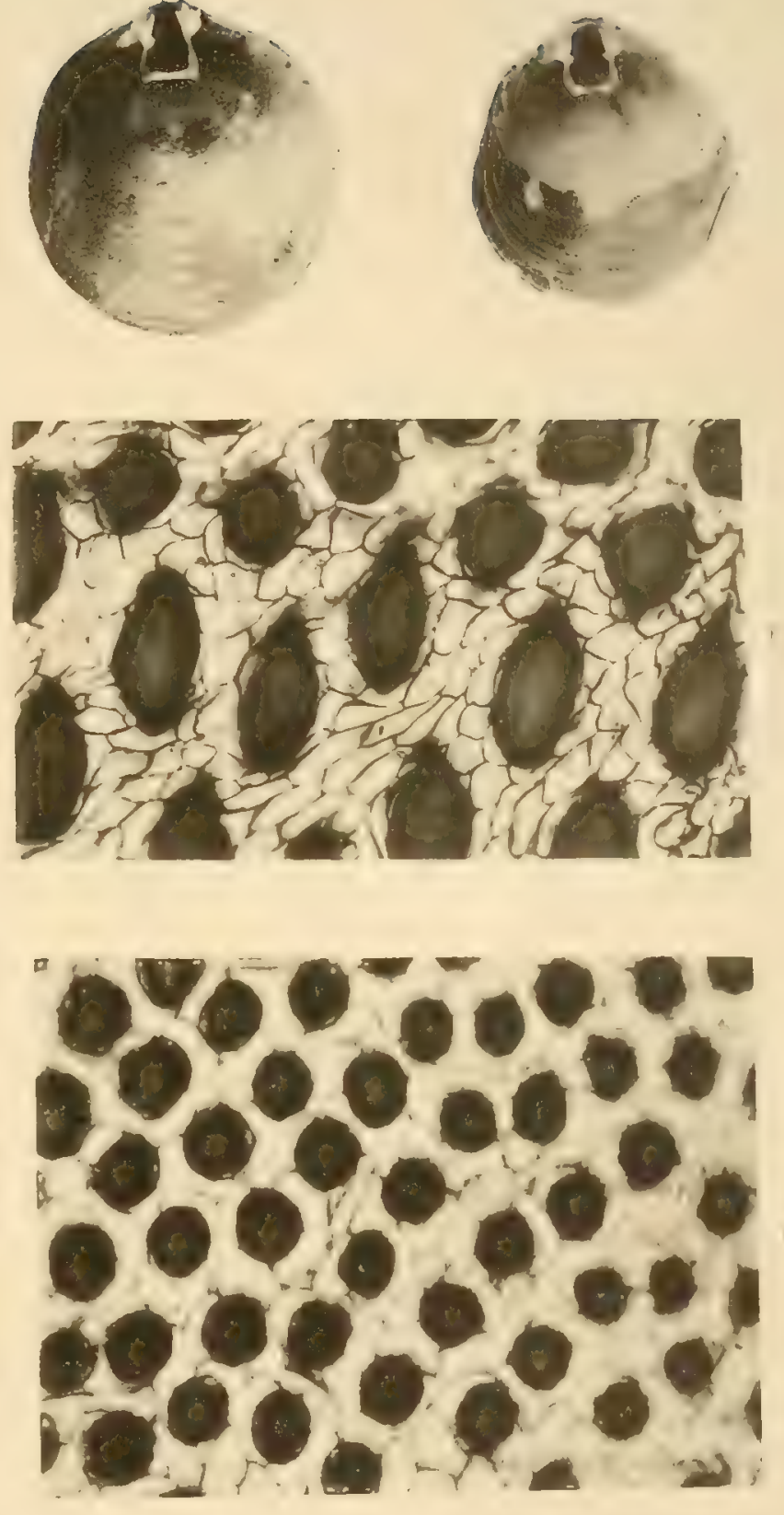

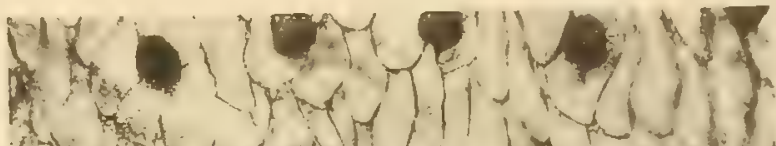

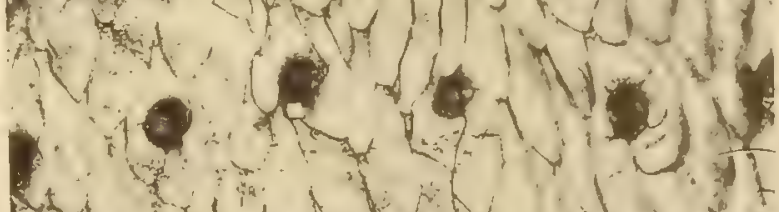
Wan -2 
WILSON COPEPOD LIBRARY

Snithsonian Institution

Invertebrate Zoology

(Crustacea) 

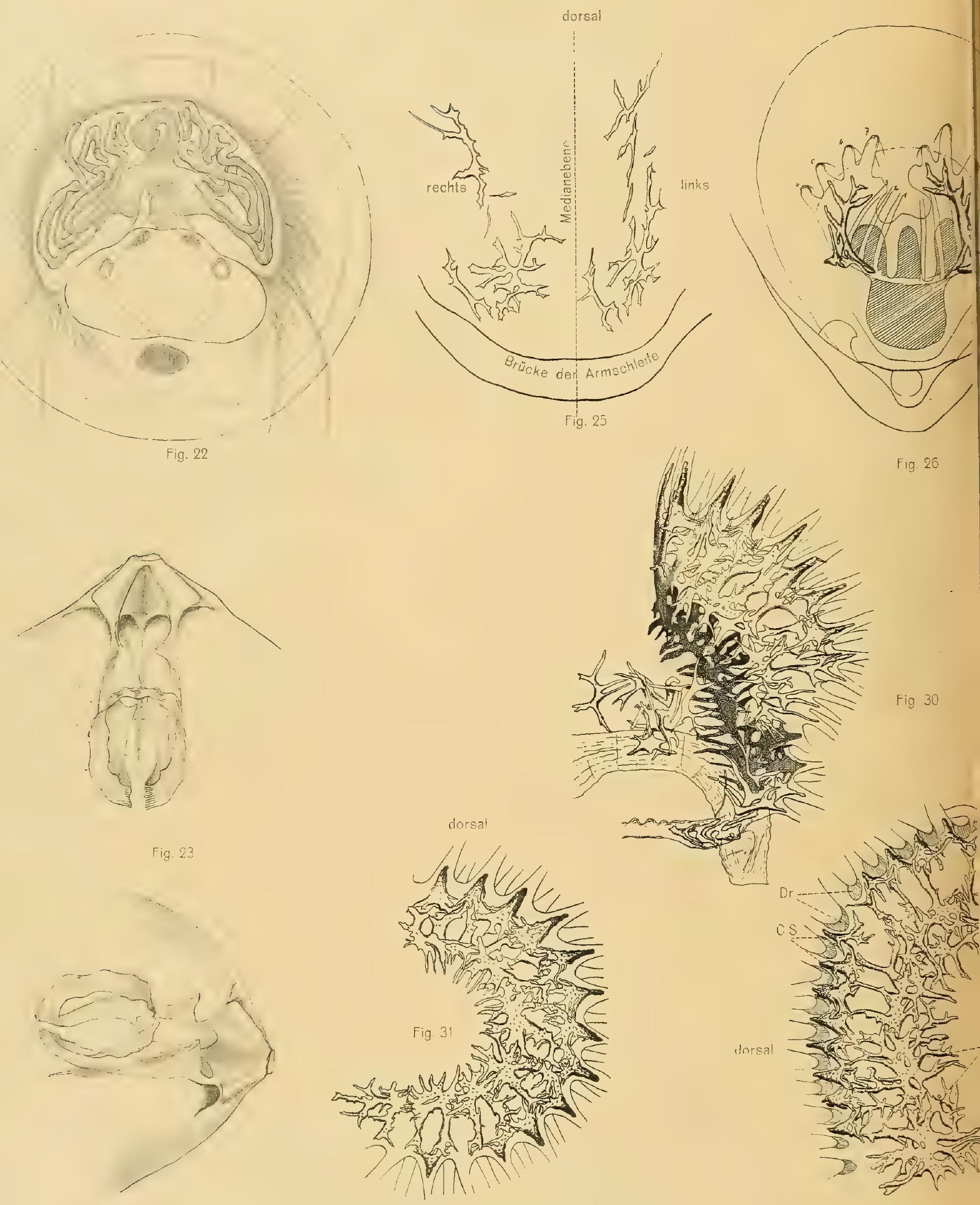

Fig 30
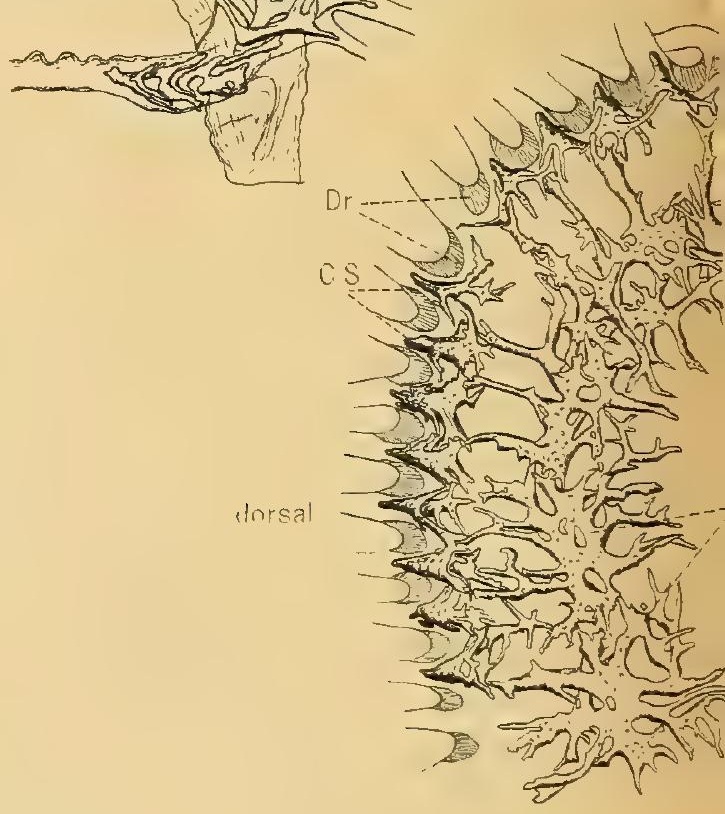


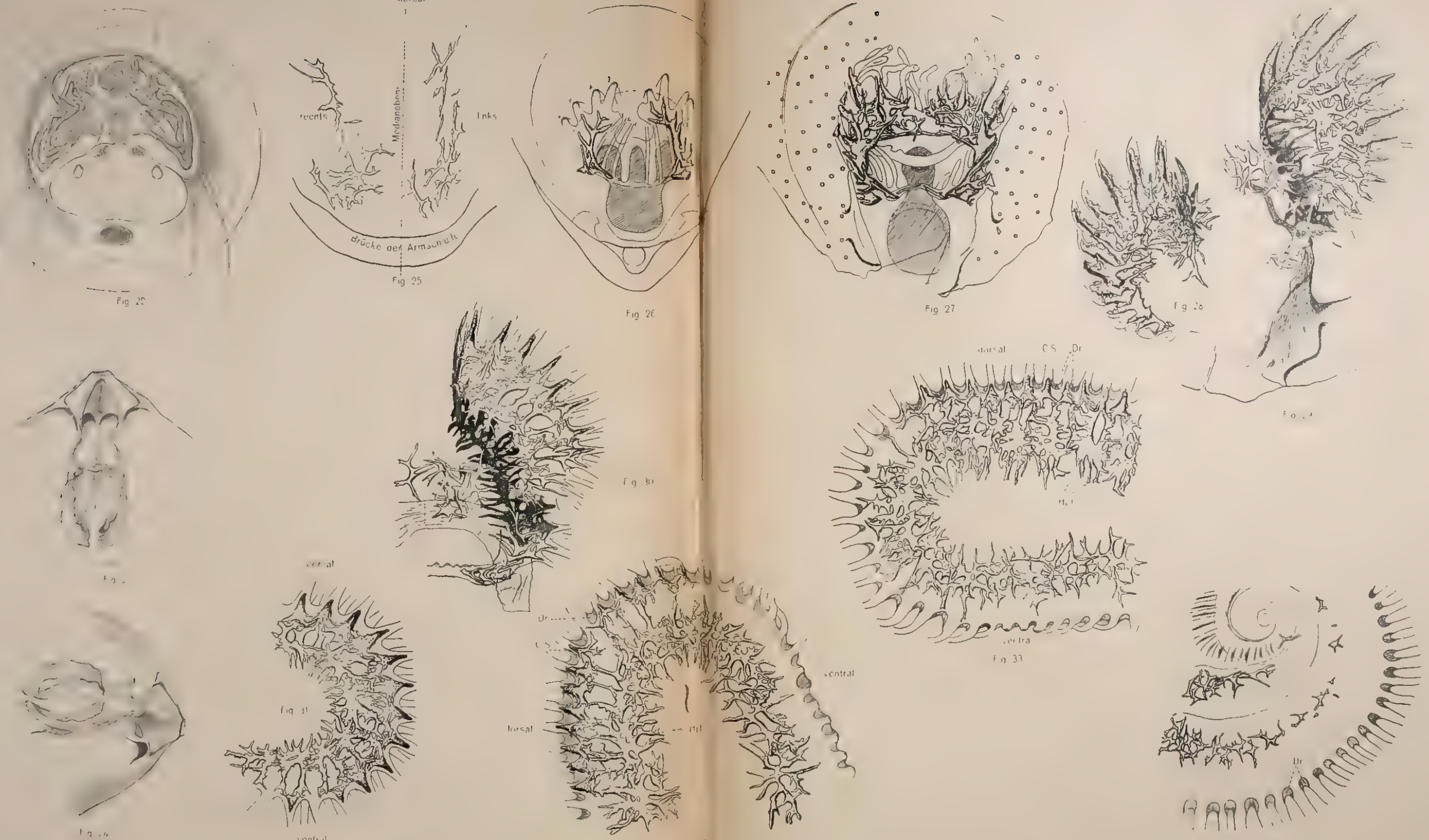





